Effect of Soil Replacement Option on Surface Deflections for Expansive Clay Profiles

by

Anushree Bharadwaj

A Dissertation Presented in Partial Fulfillment of the Requirements for the Degree

Doctor of Philosophy

Approved April 2013 by the Graduate Supervisory Committee:

Sandra Houston, Co-Chair

Bruno Welfert, Co-Chair

Claudia Zapata

ARIZONA STATE UNIVERSITY

May 2013 


\section{ABSTRACT}

Urbanization and infrastructure development often brings dramatic changes in the surface and groundwater regimes. These changes in moisture content may be particularly problematic when subsurface soils are moisture sensitive such as expansive soils. Residential foundations such as slab-on ground may be built on unsaturated expansive soils and therefore have to resist the deformations associated with change in moisture content (matric suction) in the soil. The problem is more pronounced in arid and semi arid regions with drying periods followed by wet season resulting in large changes in soil suction. Moisture content change causes volume change in expansive soil which causes serious damage to the structures. In order to mitigate these ill effects various mitigation are adopted. The most commonly adopted method in the US is the removal and replacement of upper soils in the profile. The remove and replace method, although heavily used, is not well understood with regard to its impact on the depth of soil wetting or near-surface differential soil movements. In this study the effectiveness of the remove and replace method is studied. A parametric study is done with various removal and replacement materials used and analyzed to obtain the optimal replacement depths and best material. The depth of wetting and heave caused in expansive soil profile under climatic conditions and common irrigation scenarios are studied for arid regions. Soil suction changes and associated soil deformations are analyzed using finite element codes for unsaturated flow and stress/deformation, SVFlux and SVSolid, respectively. The effectiveness and fundamental mechanisms at play in mitigation of expansive soils for remove and replace methods are studied, and include (1) its role in reducing the depth and degree of wetting, and (2) its effect in reducing the overall heave potential, and (3) the effectiveness of this method in pushing the seat of movement deeper within the soil profile to reduce differential soil 
surface movements. Various non-expansive replacement layers and different surface flux boundary conditions are analyzed, and the concept of optimal depth and soil is introduced. General observations are made concerning the efficacy of remove and replace as a mitigation method. 


\section{DEDICATION}

This thesis is dedicated to my dear husband Ajatshatru who showed great strength and support during all these years. 


\section{ACKNOWLEDGMENTS}

I express my deepest sense of gratitude and reverence towards Dr. Sandra L. Houston who introduced me to the importance of the subject of Unsaturated Soil Mechanics and gave valuable guidance and suggestions at all stages of the work embodied in the present thesis. She critically reviewed and evaluated the whole draft of the thesis and made valuable inputs in spite of her busy schedule. It was a rewarding and enlightening experience to have worked under her supervision at all levels in the fruitful culmination of this endeavor.

I would like to thank Dr. Bruno Welfert for helping me understand the mathematical implications of the unsaturated soil problem issues and adding value to my thesis by introducing the numerical aspects of the problem. He also provided his valuable inputs to this thesis document while reviewing it.

I wish to thank Dr. Claudia Zapata for serving on my committee and providing insightful suggestions and comments.

I also wish to thank Dr. Kenneth Walsh for providing helpful guidance in the times of need.

Special thanks to Rob Thode, and Murray Fredlund from SoilVision for their continuous support with the software.

Last but not the least, I owe a great debt of gratitude towards my parents, Mrs. Anjali and Dr. S.K. Bharadwaj, a rare blend of kindness, compassion and lofty virtues for their perseverance, forbearance and endurance during these years of my absence from home for the acquisition of this knowledge. I am grateful to my elder brother, Apoorva, who taught me the value of hard work and patience. I also would 
like to express my love to my younger brother, Anant, for keeping my spirits high during all these years.

There is a long list of my well wishers to whom I want to extend my sincere regards and appreciation for helping me learn and accomplish various tasks involved while working on this research.

A part of this study related to the stability and convergence issues for the unsaturated finite element solutions was supported by the National Science Foundation (NSF) under grant number CMMI-0825089. The opinions, conclusions, and interpretations expressed in this dissertation are those of the author, and not necessarily of NSF. 


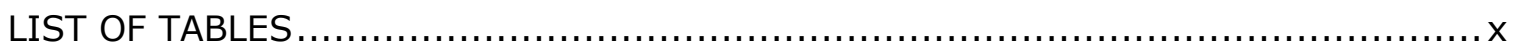

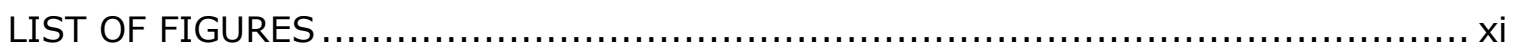

CHAPTER

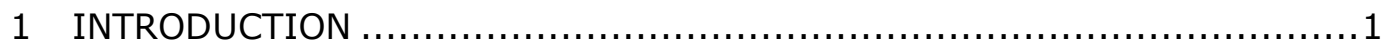

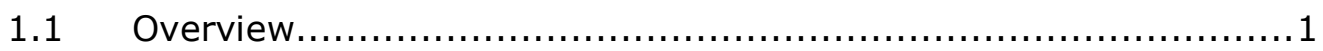

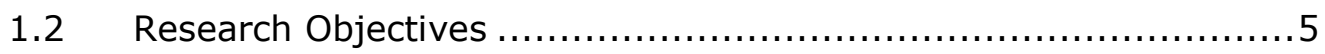

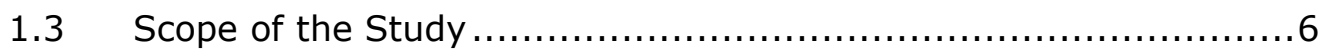

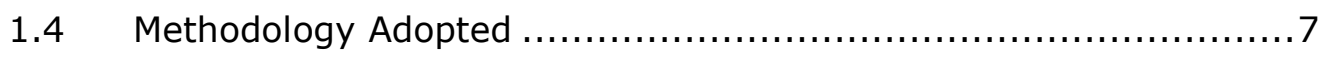

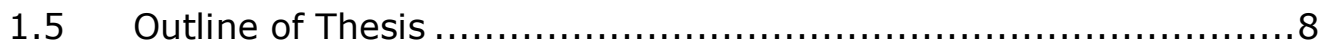

2 REMOVE AND REPLACE MITIGATION SOLUTIONS - A LITERATURE REVIEW

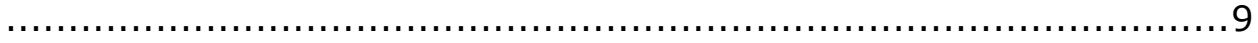

2.1 Remove and Replace Mitigation Technique ........................9

2.1.1 Depth of Wetting and Active Zone ......................... 18

2.2 Volume Change Dynamics of Soil and Lightly Loaded Structures Like Slab-On-Ground ............................................... 23

3 MOISTURE FLOW AND STRESS-DEFORMATION PDE'S $\ldots \ldots \ldots \ldots \ldots \ldots \ldots . \ldots \ldots$

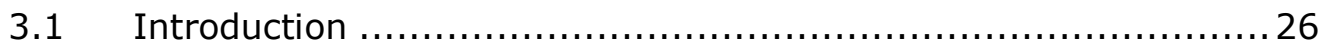

3.2 Moisture Flow in Unsaturated Soils ................................. 26

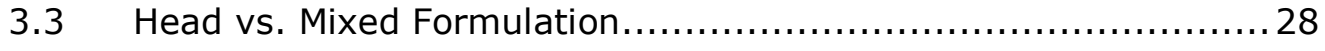

Soil Water Characteristic Curve .................................. 28 


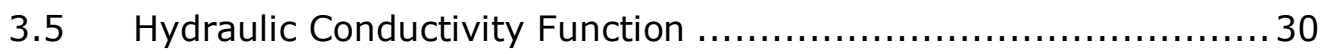

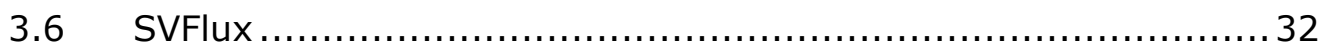

3.7 Volume Change in Unsaturated Expansive Soils .................... 34

3.8 Stress-Deformation PDE Solved in SVSolid $\ldots \ldots \ldots \ldots \ldots \ldots \ldots \ldots \ldots \ldots \ldots \ldots \ldots \ldots \ldots \ldots$

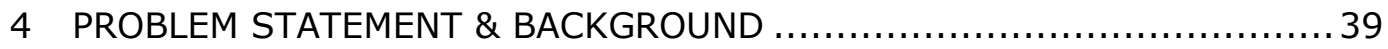

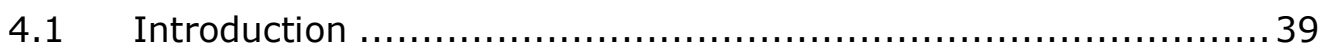

4.2 Boundary Value Problems.................................. 40

4.2.1 Procedure Adopted to Conduct the Remove \& Replace Stress Deformation Analyses of this Study ............................. 41

4.2.2 Coupling of SVFlux and SVSolid ...........................45

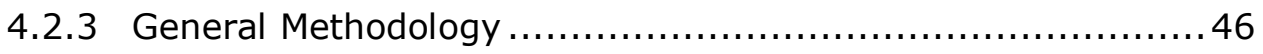

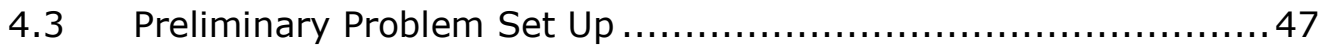

4.3.1 Mesh Size Selection .......................................... 49

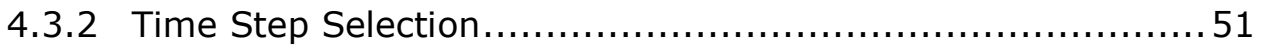

4.3.3 Selection of Position of Domain Boundaries .................. 53

4.4 Final Remove and Replace Problem Set Up ..................... 53

4.4.1 Initial and Final Condition for SVSolid Runs .................. 56

4.4.2 Mesh Size and Time Steps Used in Final Remove and Replace Study Analyses ................................................... 56

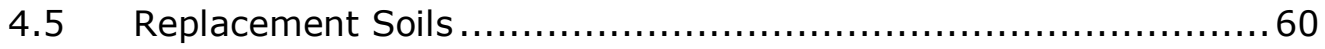


4.5.1 Replacement Layer SWCC and $\mathrm{K}_{\text {unsat }}$ Curves...................63

4.5.1.1 $\mathrm{K}_{\text {unsat }}$ Function Used ...............................64

4.5.2 Soil Properties ...........................................66

4.5.3 Degree of Saturation and Suction Values for Replacement Layer

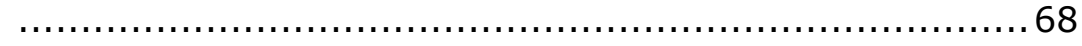

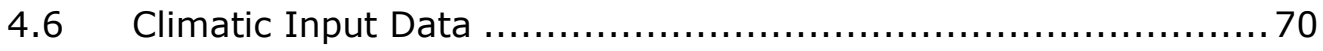

4.6.1 Actual Evaporation Analyses .............................. 78

4.7 Volume Change Properties in SVSolid .......................... 84

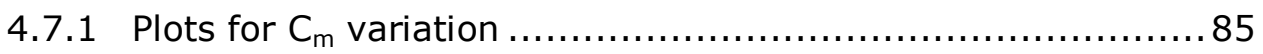

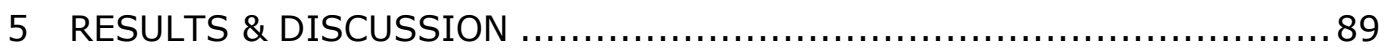

5.1 Presentation of Results and Discussion ........................... 89

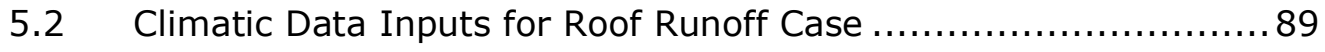

5.3 SVFlux and SVSolid Results for Roof Runoff Case ................. 92

5.3.1 $6^{\text {th }}$ Year Results for Lower $K_{\text {sat }}$ Replacement Layer Case..... .92

5.3.2 $6^{\text {th }}$ Year Results for Same $K_{\text {sat }}$ Replacement Layer Case ........ 99

5.3.3 $6^{\text {th }}$ Year Results for Higher $K_{\text {sat }}$ Replacement Layer Case..... 107

5.4 Climatic Data Inputs for Turf Landscape Case ................. 115

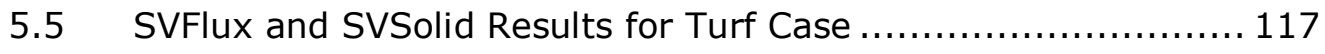

5.5.1 $6^{\text {th }}$ Yr Results for Lower $\mathrm{K}_{\text {sat }}$ Replacement Layer Case $\ldots \ldots \ldots 117$

5.5.2 $6^{\text {th }}$ Yr Results for $2 \mathrm{~m}$ Same $K_{\text {sat }}$ Replacement Layer Case.... 121 viii 
$5.6 \quad C_{m}$ Variation Results ...................................... 125

5.7 Piecewise Coupled Runs (Turf Case No Replacement Soil) ....... 129

5.8 Implications and Impact of Lateral Flow of Water $\ldots \ldots \ldots \ldots \ldots \ldots 132$

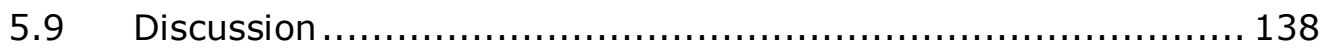

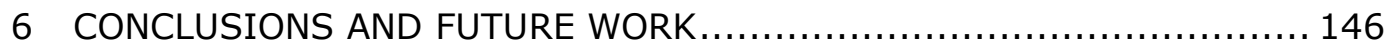

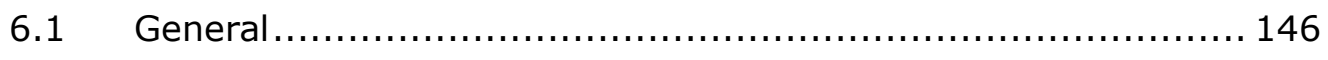

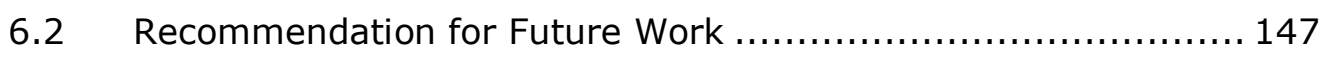

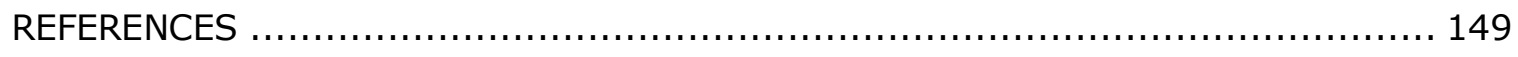

APPENDIX

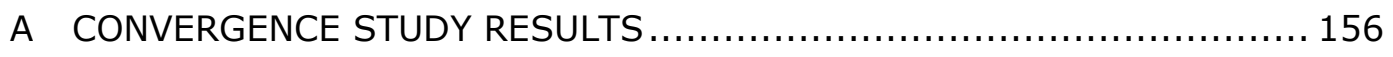

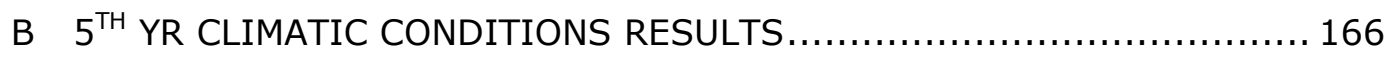

C IC AND FC SUCTION PROFILES FOR DIFFERENT DISTANCES FROM SLAB

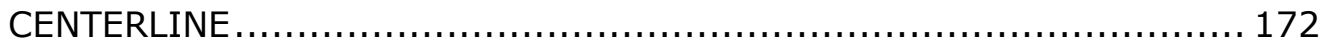

D $1^{\text {ST }}$ PANAM CONFERENCE: EFFECT OF SOIL REPLACEMENT OPTION ON SURFACE DEFLECTIONS FOR EXPANSIVE CLAY PROFILES $\ldots \ldots \ldots \ldots \ldots \ldots \ldots \ldots \ldots$ 


\section{LIST OF TABLES}

Table

Page

2.1. Reduction of heave for different cushions (Rao et.al, 2007) - CNS is cohesive non-expansive soil.

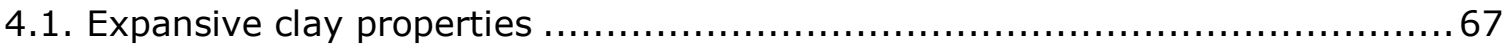

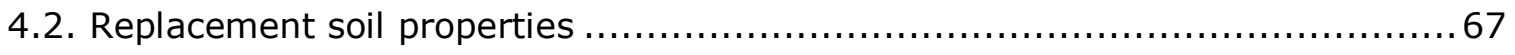

4.3. Placement saturation and suction values for the replacement layer soils ........69

4.4. Average Precipitation Data from Phoenix Airport Metrological Station (From

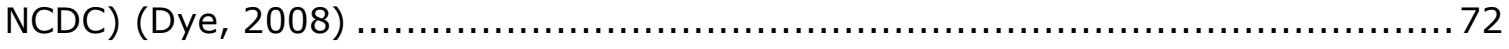

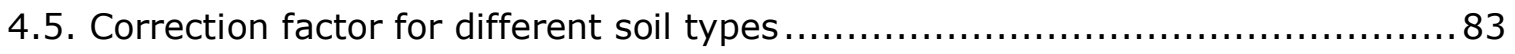

4.6. Typical values for the coefficients of lateral earth pressure (Lytton, 1994) ......85

4.7. Volume change Indices for Replacement soils ............................... 85

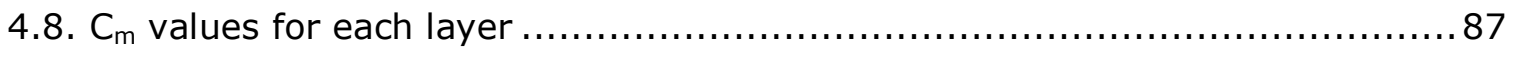

5.1. Heave reduction for different soil and depths of removal and replacement for

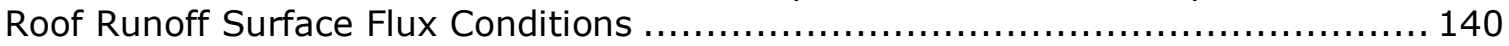

5.2. Heave reduction for different soil and depths of removal and replacement for Turf Surface Flux conditions. 


\section{LIST OF FIGURES}

Figure

Page

1.1. Occurrence and Distribution of Potentially Expansive Soil in the United States (US Army Corps of Engineers, TM 5-878-7, 1977)

2.1. Plot between swelling potential and thickness of fly ash cushion for different dry densities with $10 \%$ cement content (Rao, et al, 2007)

2.2. Heave -time plots for pavement slabs with cohesive soil cushion (Murthy and Praveen, 2008)

2.3. Vertical displacement measures of various depths of inert material at Fort Worth $\mathrm{N}$ loop (Lytton et.al, 2004) 14

2.4. Vertical Displacement Measures of various depths of inert material at Atlanta

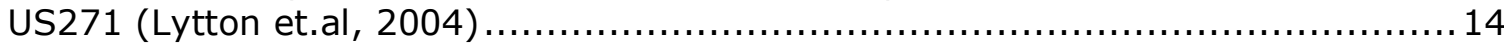

2.5. Structural distortion of structure resulting from over excavation (Maxwell, 2011)

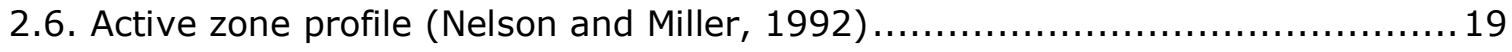

2.7. Heave occurring in the active zone (Nelson and Miller, 1992$) \ldots \ldots \ldots \ldots \ldots \ldots \ldots$

2.8. Example predevelopment and post development profiles of total suction and the

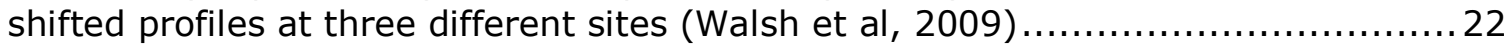

2.9. Illustration of the soil response to external loads and changes in matric suctions

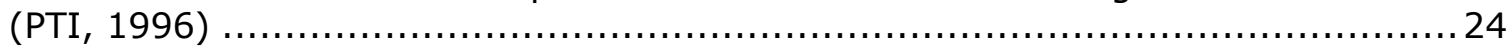

3.1. Typical SWCC curve (after Fredlund and Rahardjo, 1994) .................... 29

3.2. Relationships between water permeability and matric suction for different soils

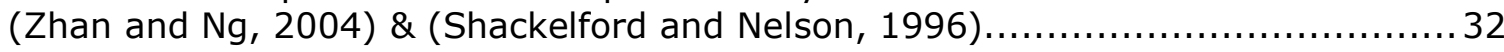

3.3. A typical void ratio constitutive surface plotted in semi logarithmic scale (Fredlund et al., 2001).....

3.4. The total suction is divided into increments and one load increment is applied (Vu and Fredlund, 2001).... 
Figure

4.1. Definition and meaning of a boundary value problem (Fredlund 2006)

4.2. $e_{m}$ and $y_{m}$ in slab-on-ground foundations

4.3. Steps to obtain final displacement in SVSolid

4.4. Initial problem setup

4.5. Suction variation at vertical section $X=10 \mathrm{~m}$ for various grid sizes (below slab edge)

4.7. Turf case boundary condition

4.8. Suction variation below slab edge after 5yr climatic condition run (Initial condition for the Final no replacement profile runs, blow up profile)....

4.9. 1-D suction variation for different size for no- replacement layer (blow up profile)

4.10. 1-D suction variation for different size for Lower $\mathrm{K}_{\text {sat }}$ replacement layer (blow up profile)....

4.11. 1-D suction variation for different size for Higher $\mathrm{K}_{\text {sat }}$ replacement layer (blow up profile)....

4.12. Suction Time-History plot at $1 \mathrm{~m}$ depth at various $\mathrm{X}$

4.13. Depth of replacement (cap) for lower conductivity soil

4.14. Depths for different replacement for same and higher conductivity soils

4.15. Matrix of runs.

4.16. SWCC for different soils

4.17. $K_{\text {unsat }}$ Curves for different soils 
4.18. Initial (IC) and Final condition (FC) suction variation at $X=10 \mathrm{~m}$, edge of slab ( $2 \mathrm{~m}$ same $\mathrm{K}_{\text {sat }}$ replacement case) for the roof run-off surface flux condition..........69

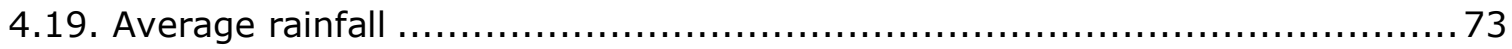

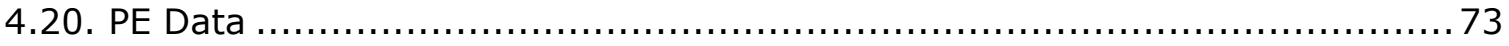

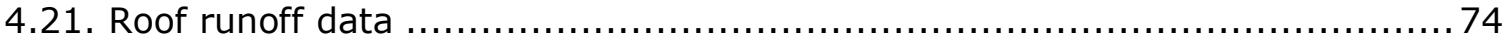

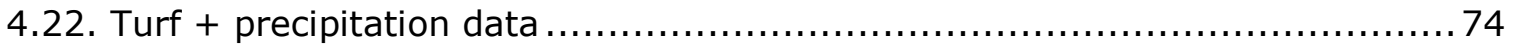

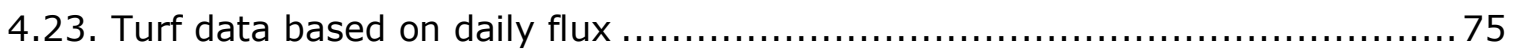

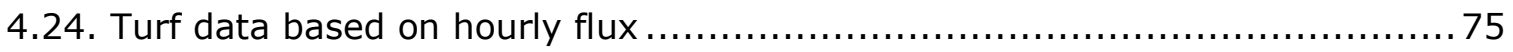

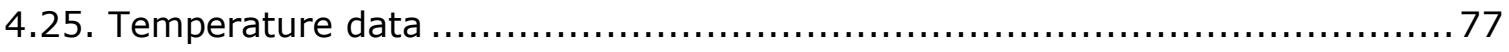

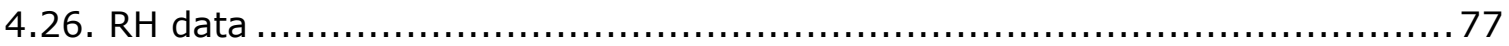

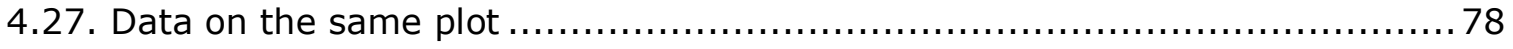

4.28. The ratio of AE to PE for different soils (Wilson et al. 1997) $\ldots \ldots \ldots \ldots \ldots \ldots \ldots \ldots . \ldots \ldots$

4.29. Ratio of AE/PE versus water availability (Holmes, 1961) ........................ 80

4.30. Relationship between relative humidity and total suction using Edlefsen and

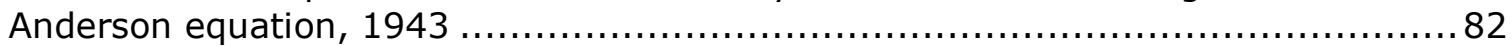

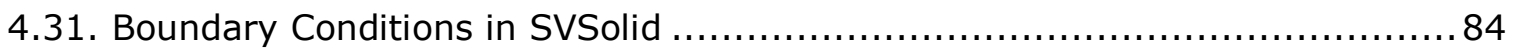

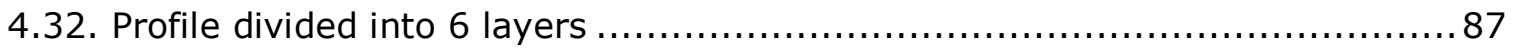

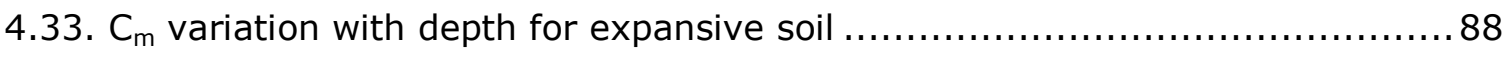

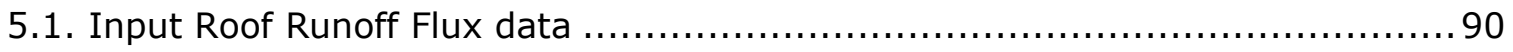

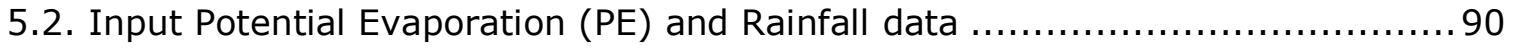


5.3.(a) Initial Condition (IC )and Final Condition (FC) suction profile right below slab edge (see Figure 5.4) - no replacement expansive clay case and roof runoff conditions.

5.3.(b) Initial Condition (IC ) and Final Condition (FC) suction profile right below slab edge (see Figure 5.4) - no replacement expansive clay case and roof runoff conditions.

5.5 (a) Initial Condition (IC ) and Final Condition (FC) suction profile right below slab edge (see Figure 5.4) - for $0.5 \mathrm{~m}$ lower $\mathrm{K}_{\text {sat }}$ replacement case and roof runoff conditions.

5.5 (b) Initial Condition (IC )and Final Condition (FC) suction profile right below slab edge (see Figure 5.4) - for $0.5 \mathrm{~m}$ lower $\mathrm{K}_{\text {sat }}$ replacement case and roof runoff conditions.

5.6.(a) End of $6^{\text {th }} y r$ suction variation profile below slab edge (see Figure 5.4) for no replacement expansive clay case and $0.5 \mathrm{~m}$ lower $\mathrm{K}_{\text {sat }}$ replacement material - roof runoff conditions.

5.6.(b) End of $6^{\text {th }} y r$ suction variation profile below slab edge (see Figure 5.4) for no replacement expansive clay case and $0.5 \mathrm{~m}$ lower $\mathrm{K}_{\text {sat }}$ replacement material - roof runoff conditions.

5.7. (a) Final Displacement results right below slab edge (see Figure 5.4) for no replacement expansive clay case and $0.5 \mathrm{~m}$ lower $\mathrm{K}_{\text {sat }}$ replacement material - roof runoff conditions.

5.7. (b) Final Displacement results right below slab edge (see Figure 5.4) for no replacement expansive clay case and $0.5 \mathrm{~m}$ lower $\mathrm{K}_{\text {sat }}$ replacement material - roof runoff conditions.

5.9. Final Displacement variation at the ground surface (see Figure 5.8) for no replacement expansive clay case and $0.5 \mathrm{~m}$ lower $\mathrm{K}_{\text {sat }}$ replacement material - roof runoff conditions.

5.10.(a) Initial Condition (IC )and Final Condition (FC) suction profile right below slab edge (see Figure 5.4) - 0.75m same $\mathrm{K}_{\text {sat }}$ replacement material and roof runoff conditions. 
5.10.(b) Initial Condition (IC )and Final Condition (FC) suction profile right below slab edge (see Figure 5.4) - 0.75m same $\mathrm{K}_{\text {sat }}$ replacement material and roof runoff conditions.

5.11.(a) Initial Condition (IC )and Final Condition (FC) suction profile right below slab edge (see Figure 5.4)- $2 \mathrm{~m}$ same $\mathrm{K}_{\text {sat }}$ replacement material and roof runoff conditions.

5.11.(b) Initial Condition (IC )and Final Condition (FC) suction profile right below slab edge (see Figure 5.4)- $2 \mathrm{~m}_{\text {same }} \mathrm{K}_{\text {sat }}$ replacement material and roof runoff conditions.

5.12.(a) Initial Condition (IC )and Final Condition (FC) suction profile right below slab edge (see Figure 5.4)- $4 \mathrm{~m}$ same $\mathrm{K}_{\text {sat }}$ replacement material and roof runoff conditions.

5.12.(b) Initial Condition (IC ) and Final Condition (FC) suction profile right below slab edge (see Figure 5.4)- $4 \mathrm{~m}$ same $\mathrm{K}_{\text {sat }}$ replacement material and roof runoff conditions.

5.13.(a) End of $6^{\text {th }}$ yr suction variation right below slab edge (see Figure 5.4) for no replacement expansive clay case and replacement cases - same $\mathrm{K}_{\text {sat }}$ replacement material and roof runoff conditions.

5.13.(b) End of $6^{\text {th }}$ yr suction variation right below slab edge (see Figure 5.4) for no replacement expansive clay case and replacement cases - same $\mathrm{K}_{\text {sat }}$ replacement material and roof runoff conditions.

5.14.(a) Final Displacement results right below slab edge for no replacement expansive clay case and replacement cases (see Figure 5.4) - same $\mathrm{K}_{\text {sat }}$ material and roof runoff conditions. 106

5.14.(b) Final Displacement results right below slab edge for no replacement expansive clay case and replacement cases (see Figure 5.4) - same $\mathrm{K}_{\text {sat }}$ material and roof runoff conditions.

5.15. Final Displacement variation at the ground surface (see Figure 5.8) for no replacement expansive clay case and replacement cases- same $\mathrm{K}_{\text {sat }}$ material and roof runoff conditions.

5.16.(a) Initial Condition (IC )and Final Condition (FC) suction profile right below slab edge (see Figure 5.4) $-0.75 \mathrm{~m}$ higher $\mathrm{K}_{\text {sat }}$ replacement case and roof runoff conditions. 108 
5.16.(b) Initial Condition (IC )and Final Condition (FC) suction profile right below slab edge (see Figure 5.4) - 0.75m higher $\mathrm{K}_{\text {sat }}$ replacement case and roof runoff conditions.

5.17.(a) Initial Condition (IC )and Final Condition (FC) suction profile right below slab edge (see Figure 5.4) - $2 \mathrm{~m}$ higher $\mathrm{K}_{\text {sat }}$ replacement material and roof runoff conditions.

5.17.(b) Initial Condition (IC )and Final Condition (FC) suction profile right below slab edge (see Figure 5.4) - $2 \mathrm{~m}_{\text {higher }} \mathrm{K}_{\mathrm{sat}}$ replacement material and roof runoff conditions.

5.18.(a) Initial Condition (IC )and Final Condition (FC) suction profile right below slab edge (see Figure 5.4) - 4m higher $\mathrm{K}_{\text {sat }}$ replacement material and roof runoff conditions

5.18.(b) Initial Condition (IC )and Final Condition (FC) suction profile right below slab edge (see Figure 5.4) - $4 \mathrm{~m}$ higher $\mathrm{K}_{\text {sat }}$ replacement material and roof runoff conditions

5.19.(a) End of $6^{\text {th }}$ yr suction variation right below slab edge (see Figure 5.4) for no replacement expansive clay and replacement cases - higher $\mathrm{K}_{\text {sat }}$ replacement material and roof runoff conditions.

5.19.(b) End of $6^{\text {th }}$ yr suction variation right below slab edge (see Figure 5.4) for no replacement expansive clay and replacement cases - higher $\mathrm{K}_{\text {sat }}$ replacement material and roof runoff conditions.

5.20.(a) Final Displacement results right below slab edge (see Figure 5.4) for no replacement expansive clay case and replacement cases - higher $\mathrm{K}_{\text {sat }}$ replacement material and roof runoff conditions.

5.20.(b) Final Displacement results right below slab edge (see Figure 5.4) for no replacement expansive clay case and replacement cases - higher $\mathrm{K}_{\text {sat }}$ replacement material and roof runoff conditions.

5.21. Final Displacement variation at the ground surface (see Figure 5.8) for no replacement expansive clay case and replacement cases - higher $\mathrm{K}_{\text {sat }}$ material and roof runoff conditions.... 
5.24.(a) Initial Condition (IC )and Final Condition (FC) suction profile right below slab edge (see Figure 5.4) - no replacement expansive clay case and turf conditions... 116

5.24.(b) Initial Condition (IC )and Final Condition (FC) suction profile right below slab edge (see Figure 5.4) - no replacement expansive clay case and turf conditions... 117

5.25.(a) Initial Condition (IC )and Final Condition (FC) suction profile right below slab edge (see Figure 5.4) - 0.5m lower $\mathrm{K}_{\text {sat }}$ replacement case and turf conditions..... 118

5.25.(b) Initial Condition (IC )and Final Condition (FC) suction profile right below slab edge (see Figure 5.4) - 0.5m lower $\mathrm{K}_{\text {sat }}$ replacement case and turf conditions...... 118

5.26.(a) End of $6^{\text {th }} \mathrm{yr}$ suction variation below slab edge (see Figure 5.4) for no replacement expansive clay and $0.5 \mathrm{~m}$ lower $\mathrm{K}_{\text {sat }}$ replacement material - turf conditions.

5.26.(b) End of $6^{\text {th }} \mathrm{yr}$ suction variation below slab edge (see Figure 5.4) for no replacement expansive clay and $0.5 \mathrm{~m}_{\text {lower }} \mathrm{K}_{\text {sat }}$ replacement material - turf conditions.

5.27.(a) Final Displacement results right below slab edge (see Figure 5.4) for no replacement expansive clay case and $0.5 \mathrm{~m}$ lower $\mathrm{K}_{\text {sat }}$ replacement material - turf conditions. . . . . . . .

5.27.(b) Final Displacement results right below slab edge (see Figure 5.4) for no replacement expansive clay case and $0.5 \mathrm{~m}$ lower $\mathrm{K}_{\text {sat }}$ replacement material - turf

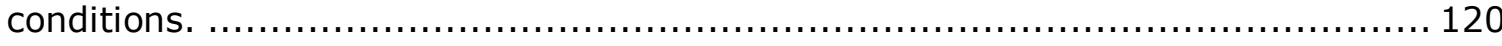

5.28. Final Displacement variation at the ground surface (see Figure 5.8) for no replacement expansive clay case and $0.5 \mathrm{~m}$ lower $\mathrm{K}_{\text {sat }}$ replacement material - turf conditions.

5.29.(a) Initial Condition (IC )and Final Condition (FC) suction profile right below slab edge (see Figure 5.4) - $2 \mathrm{~m}_{\text {same }} \mathrm{K}_{\text {sat }}$ replacement case and turf conditions........ 122

5.29.(b) Initial Condition (IC )and Final Condition (FC) suction profile right below slab edge (see Figure 5.4) - $2 \mathrm{~m}$ same $\mathrm{K}_{\text {sat }}$ replacement case and turf conditions........ 122

5.30.(a) End of $6^{\text {th }} \mathrm{yr}$ suction variation vertical profile right below slab edge (see Figure 5.4) - no replacement expansive clay and $2 \mathrm{~m}$ same $\mathrm{K}_{\text {sat }}$ replacement material and turf conditions. 
Figure

5.30.(b) End of $6^{\text {th }}$ yr suction variation vertical profile right below slab edge (see Figure 5.4) - no replacement expansive clay and $2 \mathrm{~m}$ same $\mathrm{K}_{\text {sat }}$ replacement material and turf conditions.

5.31.(a) Final Displacement results right below slab edge (see Figure 5.4) for no replacement expansive clay case and $2 \mathrm{~m}$ same $\mathrm{K}_{\text {sat }}$ replacement material - turf conditions.

5.31.(b) Final Displacement results right below slab edge (see Figure 5.4) for no replacement expansive clay case and $2 \mathrm{~m}$ same $\mathrm{K}_{\text {sat }}$ replacement material - turf conditions.

5.32. Final Displacement variation at the ground surface (see Figure 5.4) for no replacement expansive clay case and $2 \mathrm{~m}$ same $\mathrm{K}_{\text {sat }}$ replacement case - turf conditions.

5.33. $C_{m}$ variation with depth

5.34 . Final Displacement variation right below slab edge for no replacement case $\left(C_{m}\right.$ values shown are those at the top of the clay layer only - see Figure 5.33$) \ldots 126$

5.35 . Final Displacement variation at the ground surface for no replacement case $\left(C_{m}\right.$ values shown are maximum $\mathrm{cm}$ values at the ground surface only $-C_{m}$ varies with depth in all cases)

5.36 . Final Displacement variation right below slab edge (see Figure 5.4) for $0.5 \mathrm{~m}$ replacement case $\left(C_{m}\right.$ values shown are those at the top of the clay layer only - see

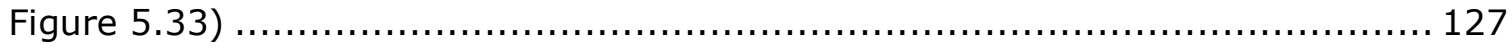

5.37. Final Displacement variation at the ground surface for $0.5 \mathrm{~m}$ replacement case $\left(C_{m}\right.$ values shown are the maximum $C_{m}$ values at the ground surface only) $\ldots \ldots \ldots 128$

5.38. Sequence of run to show piecewise coupled approach to obtain heave results.

5.39. Comparison of suction Variation below slab edge for uncoupled and piecewise coupled runs for $6^{\text {th }} \mathrm{yr}$ - no replacement and turf conditions. 130

5.40. Comparison of displacement variation below slab edge obtained from uncoupled and piecewise coupled runs - no replacement and turf conditions.... 
5.41. Comparison of displacement variation at the ground surface obtained from uncoupled and piecewise coupled runs - no replacement and turf conditions........ 132

5.42. Final Displacement vs. time plot for uncoupled and piecewise coupled runs for

$6^{\text {th }} \mathrm{yr}$ - no replacement and turf conditions.

5.43. Vertical profiles of wetting at $5 \mathrm{~m}, 10 \mathrm{~m}$ (slab edge), $19 \mathrm{~m}$, and $27 \mathrm{~m}$ from the slab centerline $-0.75 \mathrm{~m}$ same $\mathrm{K}_{\text {sat }}$ replacement material and roof runoff conditions (blow up profile).

5.44. Vertical profiles of wetting at $5 \mathrm{~m}, 10 \mathrm{~m}$ (slab edge), $19 \mathrm{~m}$, and $27 \mathrm{~m}$ from the slab centerline $-2 \mathrm{~m}$ same $\mathrm{K}_{\text {sat }}$ replacement material and roof runoff conditions (blow up profile).

5.45. Vertical profiles of wetting at $5 \mathrm{~m}, 10 \mathrm{~m}$ (slab edge), $19 \mathrm{~m}$, and $27 \mathrm{~m}$ from the slab centerline $-2 \mathrm{~m}$ higher $\mathrm{K}_{\text {sat }}$ replacement material and roof runoff conditions (blow up profile).

5.46. Bathtub effect

5.47. Vertical profiles of wetting at $5 \mathrm{~m}, 10 \mathrm{~m}$ (slab edge), $19 \mathrm{~m}$, and $27 \mathrm{~m}$ from the slab centerline $-0.5 \mathrm{~m}$ lower $\mathrm{K}_{\text {sat }}$ replacement material and turf conditions (blow up profile). 


\section{INTRODUCTION}

\subsection{Overview}

Expansive soils are present all over the world, including the United States. For decades engineering problems related to expansive soils in many parts of the world have been reported in the literature (Bao and $\mathrm{Ng}, 2000$ ), but are generally most serious in the arid and semi-arid regions. Australia, Britain, Canada, China, India, Mexico, Spain and United States are some of the countries which must cope with expansive clays (Fredlund, 1995). Damage to structures in the United States is commonly related to soil characteristics, with expansive (swell) soils generally causing the most severe problems. Severe or recurring damage can lower the value of a house or property. According to the American Society of Civil Engineers, about half of the houses built each year in the United States are situated on unstable soil, and about half of these will eventually suffer some soil related damage. According to Krohn and Slossom (1980), about $20 \%$ of the surface soils in United States exhibit shrink-swell behavior. According to Holtz and Hart (1978), $60 \%$ of 250,000 newly constructed homes built on expansive soils each year in United States experience minor damage and $10 \%$ experience significant damage, some beyond repair. Despite improvements in performance statistics for new houses built today, expansive soils remain a significant problem (Coduto, 1999). States like Arizona, California, Colorado and Texas have a significant extent of expansive soil and, due to the increasing maintenance costs, a reevaluation of construction and mitigation methods is needed (Hammerberg, 2006). Figure 1.1 shows the distribution of expansive soil in United States in 1977. 


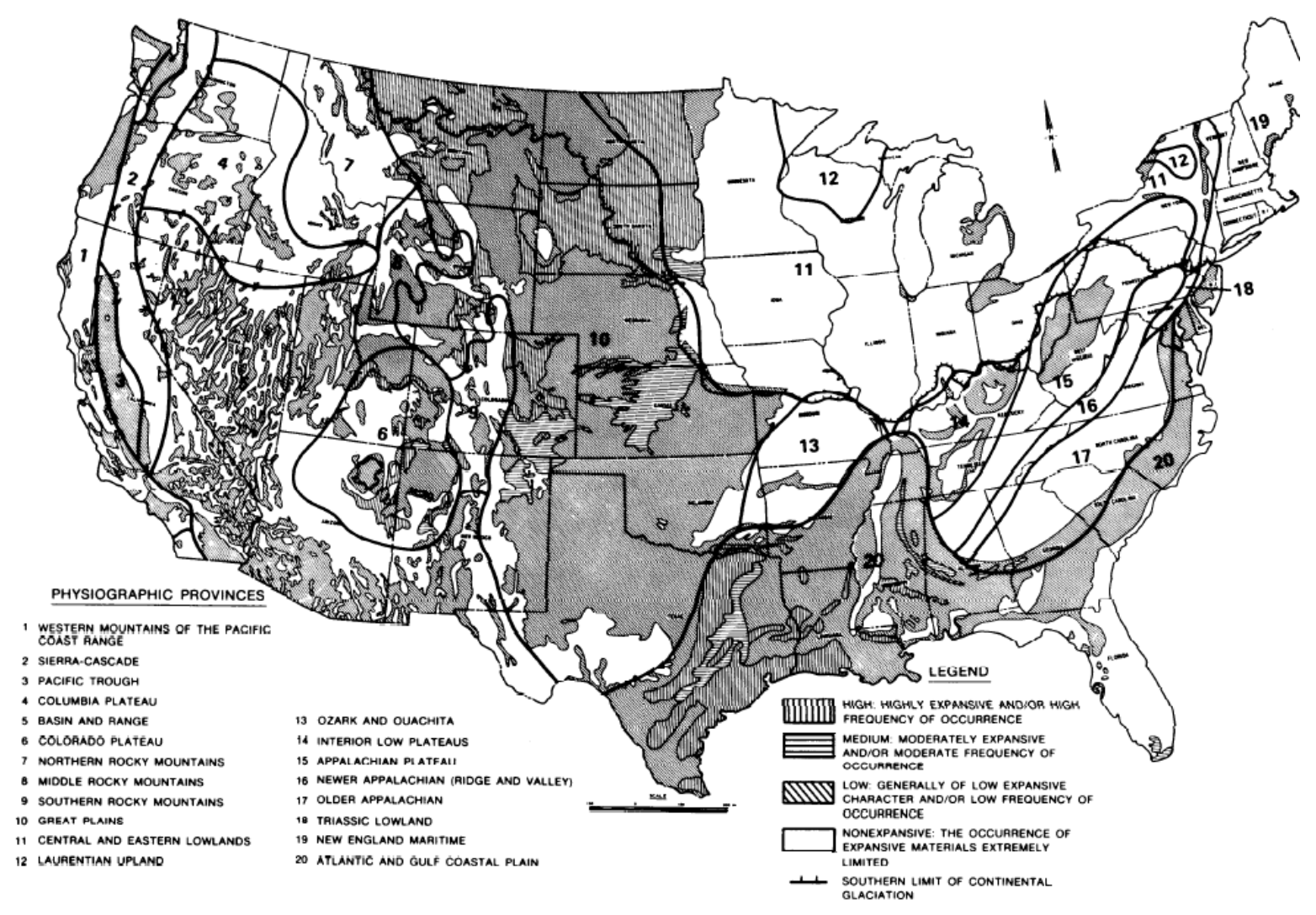

Figure 1.1. Occurrence and Distribution of Potentially Expansive Soil in the United States (US Army Corps of Engineers, TM 5-878-7, 1977) 
Local or regional maps showing even more expansive soils region have been constructed since then (Dye, et al, 2009).

The principal cause of expansive clays is the presence of clay mineral called Montmorillonite. The presence of Montmorillonite in clay imparts them high swellshrink potentials (Chen, 1988). These colloid-sized clay particles have a very large specific surface area per unit volume and carry negative charge on the surface and edge. These properties give expansive clays the capability to retain large amounts of water. Expansive soils are also called moisture sensitive soils because they undergo substantial volume changes associated with swelling process when subjected to wetting. As a result, many structures suffer severe damage and distress. The differential change in expansive soil's natural water content affects the engineering property of structures. Therefore, the biggest problem for all the constructed facilities built on expansive soil is the moisture content change that is associated with matric suction change.

Residential foundations such as slab-on ground are generally built on unsaturated soils including expansive soils and have to resist the deformations associated with change in matric suction in the soil. Matric suction change occurs due to excessive water exposure over a small area or in a localized fashion due to poor surface drainage, under pipe leakage or pipe break, heavy irrigation and infringement of a surface impoundment into joint or bedding features. The amount of heave occurring in an expansive soil can be represented in a differential form as a combination of relative changes in suction and net normal stress with appropriate factors called the volume change indices. Generally, during the swelling process, the net normal stress state variable remains constant while the matric suction stress state variable changes due to the wetting process. 
The hazard posed by expansive soils is greatest in regions with pronounced wet and dry seasons (Fredlund and Rahardjo, 1993). The swelling phenomenon is considered as one of the most serious challenges which the foundation engineer faces, because of the potential danger of unpredictable upward movements of structures founded on such soils (e.g. Seed et al., 1962; Komornik and David, 1969). Geotechnical engineering strategies for unsaturated soil zones often incorporate high degrees of conservatism resulting from assumption of saturated soil properties. On the other hand, assuming the soil dry throughout the life cycle of design would be unconservative. Such extreme assumptions in the degree of wetting during the lifetime of structure have negative implications for design, construction, functionality, safety and structural longevity (Houston, 2002).

There are various methods/techniques to reduce swelling in soils at the ground surface to prevent the damage caused to structures. Mitigation measures may be broadly defined as any actions or designs that lessen or solve moisture sensitive soil problems (Houston et.al, 2001). Mitigation measures for expansive soil have been summarized and described by several authors (Clemence and Finbarr, 1981; Chen 1988; Damon P Coppola, 2007; Fredlund and Rahardjo, 1993; Pengelly, et al., 1997; Nelson and Miller, 1992; Robert W Day, 1999). Among the various techniques of expansive soil mitigation, remove and replace technique has become prominent for lightly loaded structures and footings on expansive clays due to its effectiveness and adoptability. Removal of the upper expansive soil and replacing it with a non-expansive soil is one such method (IBC, 2006 \& IRC, 2006). To determine whether the option is economical or not, the depth of "active zone" is determined before the replacement process. However, determination of "active depth/zone" can be quite challenging, generally requiring some empirical correlations 
developed for a specific region, perhaps coupled with unsaturated flow analyses. Engineering practitioners still follow empirical approaches and local experience to handle the issues related to foundations over expansive clays (Fityus et al., 2004; Nelson and Miller, 1992; Lytton 1994; Wray 1997; Bratton 1991; Holland and Richards, 1984; Fredlund and Rahardjo, 1993).

Remove and Replace is widely used in construction practices and people have proved that it can be an effective technique. Further, several researchers have considered the mechanisms of remove and replace mitigation in the past. This study represents a unique investigation on the efficacy of remove and replace methods for mitigation of expansive soils in that the analyses are based on fundamental unsaturated flow and stress-deformation principles. These analyses provide a detailed look into the complexities of the mitigation mechanisms at play for remove and replace options.

The focus of the study is on the mitigation method of remove and replace and on the question of effective depth of wetting which will require coupled/uncoupled flow-deformation analyses using the finite element codes SVFlux and SVSolid using boundary flux conditions for arid region. This work includes a parametric study of the characteristics of the replacement (thickness and hydraulic conductivity) to assess the importance of the replacement soil characteristics on the optimal remove and replace solution.

\subsection{Research Objectives}

The intent of this study is to perform a parametric study using uncoupled flow-deformation analyses to evaluate the effectiveness of the remove and replace mitigation method for reducing surface deformations in moisture sensitive soils 
The primary objectives of this study for two different surface flux conditions (Roof Ponding \& Turf) are:

1. To evaluate effectiveness of remove and replace method for reducing differential heave at ground surface.

2. To study the relative effectiveness of the upper material properties and their thickness on the depth of wetting and reduction of surface heave of expansive soils.

3. To better understand best (optimal) replacement materials and depth of replacement for various surface flux conditions and replacement soil types.

\subsection{Scope of the Study}

The scope of this study is limited to providing an insight into the impact of subsurface wetting of expansive soils on surface-reflection deformation through the use of the finite element solvers SVFlux and SVSolid.

In brief, the scope of the study is:

1. To study the depth and extent of wetting for three different replacement soils and different replacement depths using SVFlux. Two different surface flux boundary conditions are considered: roof run-off ponded at the edge of the structure, and irrigated lawn (turf) conditions.

2. To use stress-deformation finite element analyses (SVSolid) to study the impact of remove and replace on differential surface heave for three different replacement soils and different depths using the soil suction changes obtained from the SVFlux analyses as input. 


\subsection{Methodology Adopted}

In order to achieve the objectives of this project, the response of a slab-onground is studied by using finite element software SVFlux for unsaturated flow analyses and SVSolid for stress-deformation analyses. Two-dimensional stress deformation analyses of a slab placed on an unsaturated swelling soil using SVFlux and SVSolid were performed, following the decoupled analysis approach proposed by Fredlund and Vu (2002). Deformation on the ground surface due to swelling in the soil was obtained for two different applied flux conditions (ponding of roof run-off water and irrigated lawn (turf) condition). The upper few meters of the swelling soil was subsequently replaced by non-expansive soil until a depth of replacement to study the impact of remove and replace on ground surface movements. SVSolid uses the soil suction results from SVFlux to determine deformations in soil. It is a decoupled approach, wherein the time-dependent part of the problem is done using SVFlux, and then the results are fed into SVSolid to obtain the stresses and deformations that occur between the initial and final soil suction conditions. In these analyses the net normal stresses (confining stresses) were held constant. Further, the slab-on-ground foundation was modeled simply as a flexible impermeable surface, which does not resist differential heave changes.

The three different replacement layer soil properties for this study were obtained from the SoilVision database which includes the SWCC and $\mathrm{K}_{\text {unsat }}$ data. The relevant volume change replacement soil properties are based on a literature review for expansive soils, and on properties determined by others on Arizona expansive clay (Dye, 2008). The replacement soils are all assumed and modeled to be nonmoisture sensitive (non-expansive), but feature three different saturated hydraulic conductivity values. Thus 3 different replacement soil types are considered, with (1) 
same, (2) lesser, and (3) greater saturated hydraulic conductivity compared to the underlying expansive clay saturated hydraulic conductivity.

\subsection{Outline of Thesis}

Chapter 1 includes the introduction of the research subject, objective and scope of the study and outline of the thesis.

Chapter 2 is focused on the literature review of remove and replace technique and its working mechanism. The theory of active zone and active depth is then explained, based on definitions presented by different authors in the literature. A short discussion is included on the volume change dynamics of soil and slab-onground.

Chapter 3 presents the PDE solved by SVFlux and SVSolid. A very brief summary of moisture flow and volume change in unsaturated soil is also included.

Chapter 4 is a discussion of this research, including the procedure adopted to conduct this study, coupling of the flow and stress-deformation software and the problem set up for the remove and replace cases analyzed. Later sections cover different replacement soil properties, boundary conditions and input fluxes used in the computer simulations.

Chapter 5 includes results and a discussion of the remove and replace cases analyzed in the research project, and is followed by conclusions and suggestions for future study in Chapter 6. 


\section{REMOVE AND REPLACE MITIGATION SOLUTIONS - A LITERATURE REVIEW}

It is a well-known fact that unsaturated expansive soil causes a lot of damage to earth supported structures due to their shrink/swell behavior in response to soil moisture (suction) changes. Lightly loaded structures are the worst affected because the stresses due to structural load do little to prevent heave. There are various remediation techniques available to mitigate the adverse effects of expansive soils. Non-structural solutions are aimed at bringing down the swelling potential and the volume changes in the expansive soil.

Removal of expansive soil and replacement with non-expansive soils is one method used to mitigate expansive soil foundation materials for slab-on-ground structures. The most appropriate type of replacement material and its thickness depend on the climatic factors for a particular region. This chapter includes a literature review of the remove and replace mitigation technique and its mechanism in mitigating expansion potential. A brief discussion on the interaction of lightly loaded structures like slab-on- ground is included at the end.

\subsection{Remove and Replace Mitigation Technique}

Mitigation of expansive soils can be accomplished in several ways. One of the ways to avoid the negative effects of expansive soils is to remove some thickness of expansive soil and replace it with non-expansive soil. Removal of expansive soils and replacement with non-expansive soils is one method to improve expansive soil profiles for support of structures (Nelson and Miller, 1992). In some cases, the expansive strata may be entirely removed. It becomes uneconomical to remove the entire depth of expansive soil when it extends to a great depth. It then becomes 
necessary to determine what depth of excavation and fill that is required to reduce total and differential movements to an acceptable level. Advantages of the remove and replace are discussed at the end of this section.

The non-expansive soil layer placed over the expansive soil after removal can provide increased confinement, and thus reduce swell for any expansive soil that does get wet. Katti (1979) found that if expansive soil layers are covered with a relatively thin layer of plastic non-expansive soil (clay soil) that the amount of heave is greatly reduced. He found a clay cap can reduce heave occurring below a depth of 1 to $1.2 \mathrm{~m}$. Furthermore, researchers found that if a layer of expansive soil is replaced with a soil which does not swell but exhibits some amount of plasticity, heave at greater depths is reduced. The remove and replace method, using a relatively thin placement of a clay cap, also reduces the differential heave at ground due to the reduced hydraulic conductivity of the cohesive soil. Satyanarayana (1969) and Aly Ahmed (2008) suggested that the entire depth of the expansive soil, or just a part of the expansive soil in the profile, may be removed and replaced with a "sand cushion" compacted to some particular dry density, moisture state, and thickness. However, the "sand cushion method" has several problems if the entire expansive soil layer is not removed. "The high permeability of sand creates conditions conducive to easy entry of water from the surface runoff" (Rao et. al, 2007). Rao et.al, 2007 do not recommend a sand for replacement soil. Figure 2.1 shows the swelling potential for an expansive soil profile with a fly ash cushion layer varied in thickness. Thicker replacement layers are more effective in reducing the swelling potential of the expansive soil (Figure 2.2). Table 2.1 presents the results of the experiments done by Rao et.al, (2007) comparing the efficacy of different "cushion" layers in counteracting heave in expansive soils. It was also reported that clay 
(plastic) replacement soils helps to stabilize expansive soil profiles (Murthy and Praveen, 2008). Moreover, they concluded that the replacement of upper expansive soil by cohesionless soils "breaks the cohesive bonds at the interface due to their different surface properties," resulting in reduced swell of the profile.

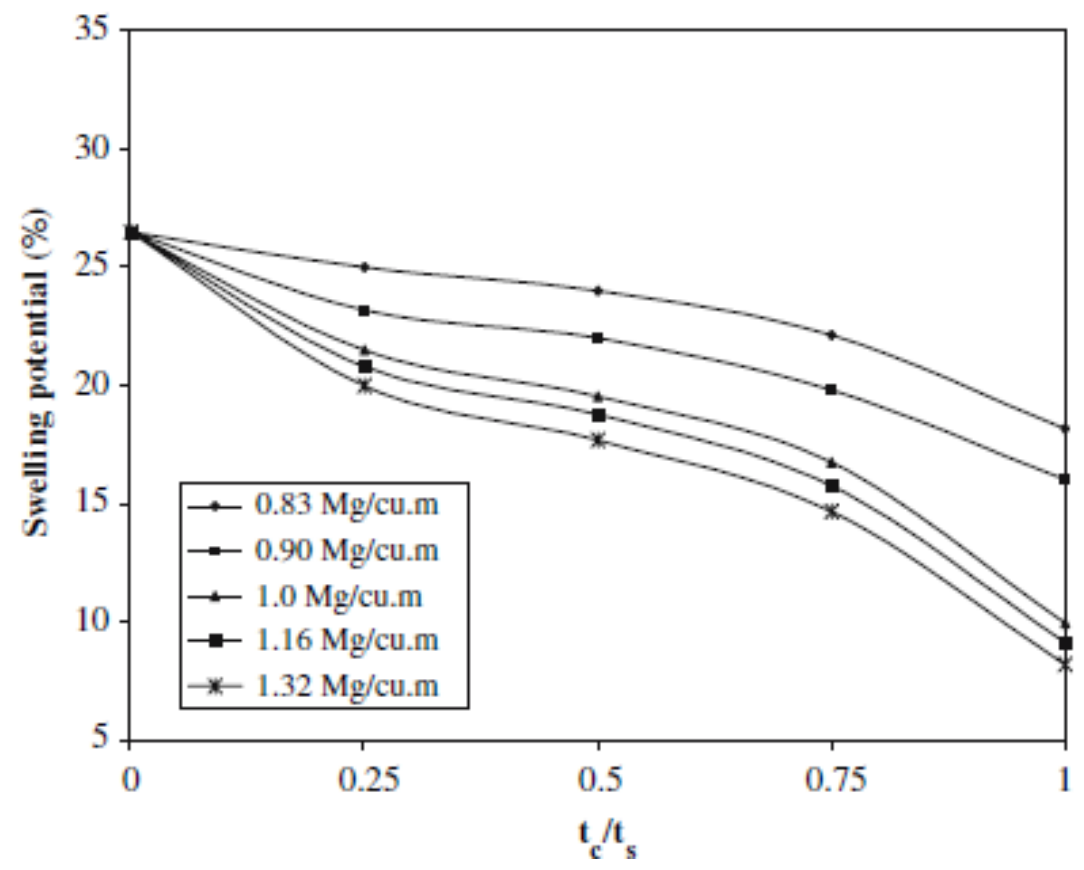

Figure 2.1. Plot between swelling potential and thickness of fly ash cushion for different dry densities with $10 \%$ cement content (Rao, et al, 2007) 


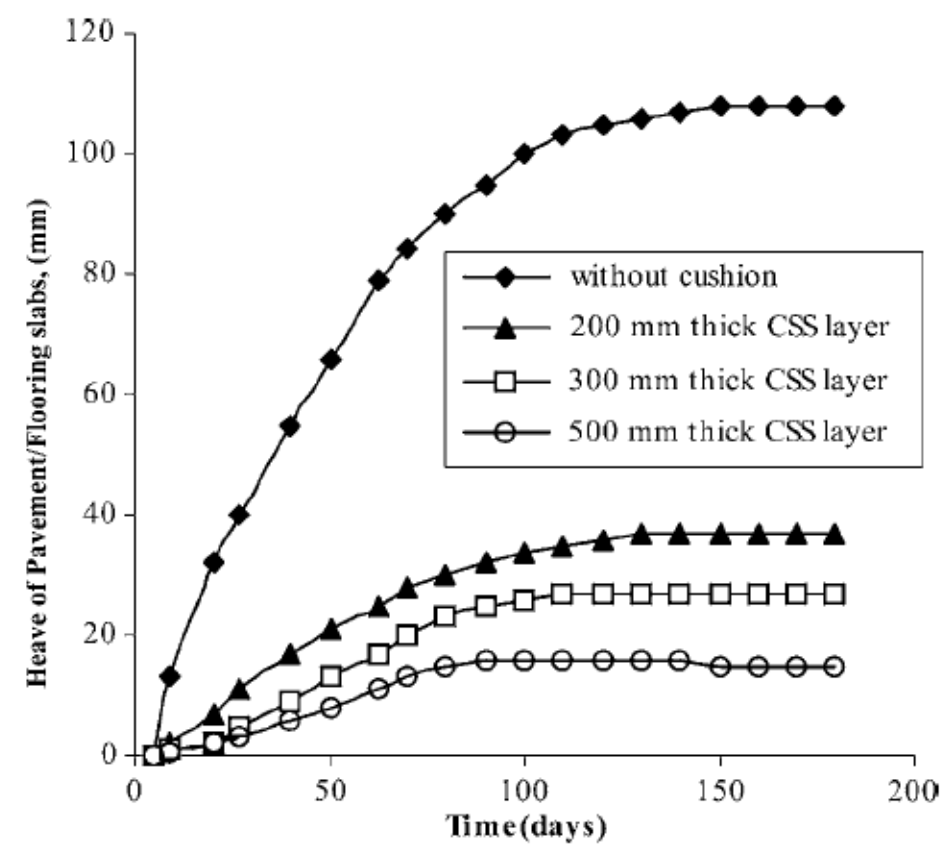

Figure 2.2. Heave -time plots for pavement slabs with cohesive soil cushion (Murthy and Praveen, 2008)

Table 2.1. Reduction of heave for different cushions (Rao et.al, 2007) - CNS is cohesive non-expansive soil.

\begin{tabular}{lrll}
\hline $\begin{array}{l}\text { Type of cushion } \\
\text { (thickness, } \\
\left.\mathrm{t}_{\mathrm{c}}=150 \mathrm{~mm}\right)\end{array}$ & $\begin{array}{l}\text { Heave } \\
(\mathrm{mm})\end{array}$ & $\begin{array}{l}\text { \% Reduction w.r.t } \\
\text { heave of un-cushioned } \\
\text { soil bed, } \mathrm{t}_{\mathrm{s}}\end{array}$ & $\begin{array}{l}\text { Heave } \\
\text { ratio } \mathrm{h}_{\mathrm{d}} / \mathrm{h}_{\mathrm{s}}\end{array}$ \\
\hline No cushion & 39.73 & - & 1.00 \\
Sand cushion & 17.36 & 56.3 & 0.43 \\
CNS cushion & 16.35 & 58.8 & 0.41 \\
Fly ash cushion & 9.93 & 75 & 0.24 \\
\hline
\end{tabular}

$h_{c}$, heave of cushioned soil; $h_{s}$, heave of un-cushioned soil 
Figure 2.2 shows the decrease in heave with time in the pavement slabs with different thickness of the cushion layer. It was found that the thickness of the cushion layer is an important factor influencing the degree of decrease of heave. It is evident from Figure 2.2 that as the cushion thickness is increased the total amount of heave is reduced.

Among other remedial techniques, the use of replacement soils below footings, pavements, linings, and other lightly loaded facilities has been recognized as an effective and economical approach (Burov, 1977; Katti and Katti, 1994). This method of mitigation for expansive soils is also mentioned in section 1805.8 of the International Building Code" (IBC)(2006) for design of foundations on expansive clay. The IBC document states that the removal of expansive soils should be done to a depth sufficient to ensure a constant moisture content in the remaining soil profile. IBC (2006) section R401.4.2 states that the top or subsoils should be removed to a depth and width sufficient to assure stable moisture content: "The soils removed may not be used as fill. Instead of a complete geotechnical evaluation, when top or subsoils are compressible or shifting, they shall be removed to a depth and width sufficient to assure stable moisture content in each active zone and shall not be used as fill or stabilized within each active zone by chemical, dewatering or presaturation".

Lytton et. al (2004) did research on the evaluation of effectiveness of various design/mitigation procedures for reducing swell and minimizing damage to pavements. The Lytton study was an evaluation of the effectiveness of replacement of in-situ subgrade soils with non-expansive soils. Lytton found that replacing the subgrade with inert (non-expansive) material is effective in reducing the pavement vertical movement. Figure 2.3 and Figure 2.4 shows how replacing the natural subgrade can reduce the vertical movement to a considerable degree. 


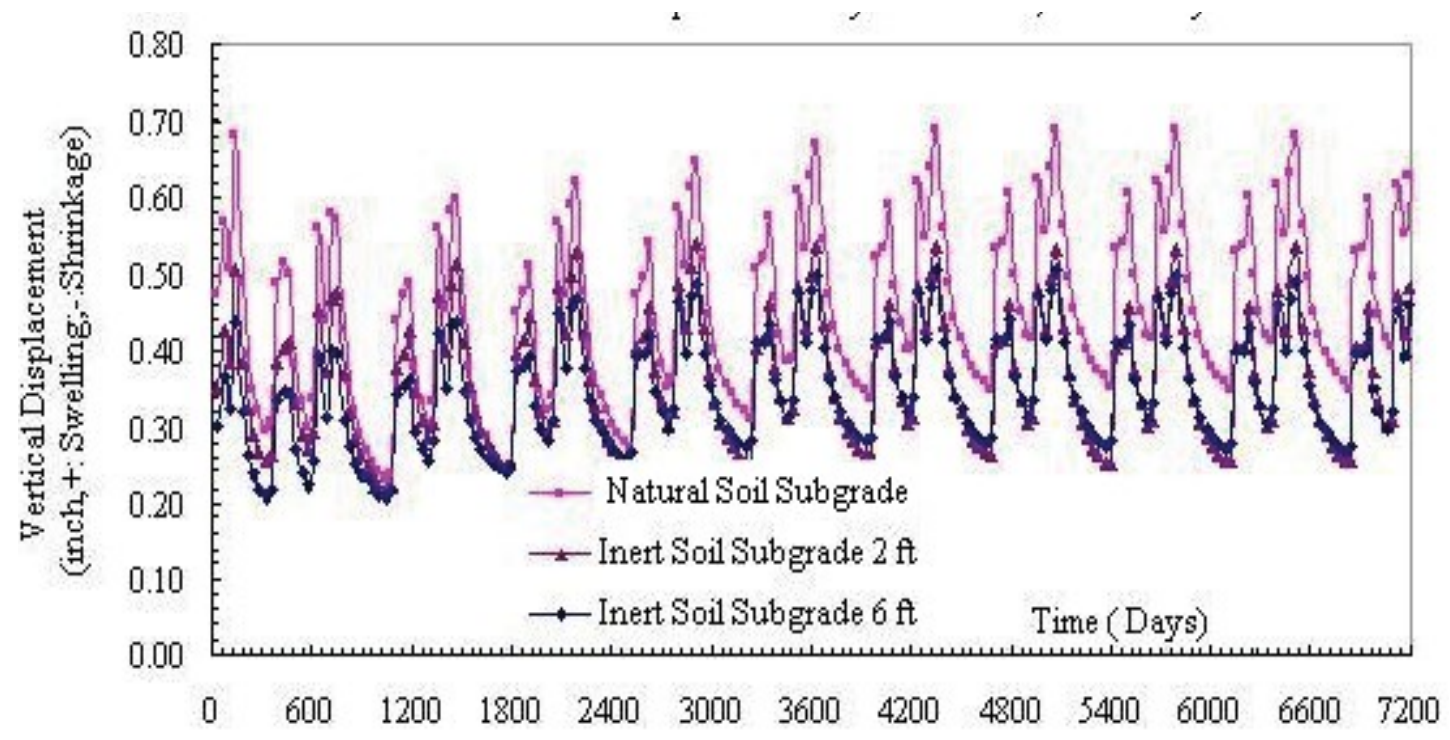

Figure 2.3. Vertical displacement measures of various depths of inert material at Fort Worth N loop (Lytton et.al, 2004)

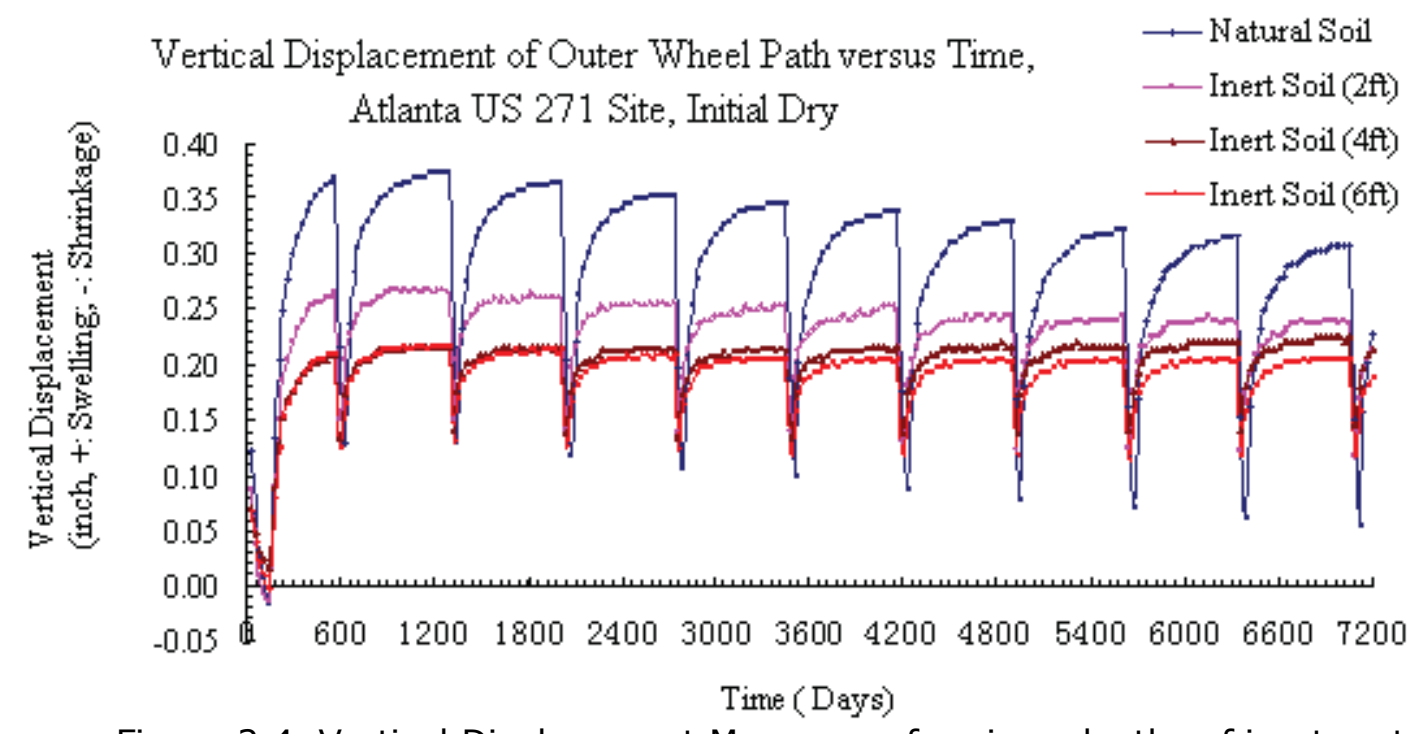

Figure 2.4. Vertical Displacement Measures of various depths of inert material at Atlanta US271 (Lytton et.al, 2004)

The remove and replace method has been used for mitigation of expansive soils in different states like California, Texas and Colorado (California residential code 2010, Texas industrialized building code council 2010, Benson and Associates PC 2005). Removal and replacement of expansive material have been successful in the 
repair of some hydraulic structures to reduce uplift pressures. Repairs were made on the Friant-Kearn canal (Holtz and Gibbs, 1956) and the Mohawk and Welton canals by over excavating the subgrade and replacing the expansive material with sand and lightly compacted gravel (Holtz, 1959). This remove and replace method also was also used to reduce expansion of clay by using a thick layer of the remove and replaced material to increase stress levels on underlying expansive clay. Hotlz (1959) noted that the differential movement was reduced by the presence of the replacement gravel layer.

Remove and replace techniques can reduce swelling in expansive soil by four different mechanisms.

1. First, replacing the upper layer of expansive soil with a lower conductivity soil will reduce the amount of water infiltrating the soil profile, thereby minimizing moisture content (suction) change within the profile. As the active zone is affected by climatic changes and is the region where swelling occurs in expansive soil, the main objective of this method is to stop water from entering the profile so that the moisture content remains unchanged due to the climatic variations.

2. Second, removing the expansive material in the region of wetting reduces the swelling below the foundation. If the clay exhibits a moderate to low expansion potential the reduced volume of expansive clay in upper, high moisture variation layer may be sufficient to prevent large movements at the surface. However," if there is a high potential for volume change in the underlying soil the reduced volume of expansive material may not adequately prevent surface heave or shrinkage " (Nelson and Miller, 1992). 
3. The third mechanism of the mitigating effect of remove and replace is that heave and differential heave are reduced by moving /pushing the seat of movement to a deeper depth in the soil profile.

4. Lastly (fourth), the volume change in expansive soil due to wetting gets reduced by the increased confinement provided by the non-expansive soil layer, if the thickness of the replacement layer is greater than the removed layer.

Nelson and Miller also mention the following advantages of the remove and replace technique:

1. Nonexpansive soils can be compacted at higher densities, yielding higher bearing capacities than can be produced by prewetting the expansive clay or compacting it at low densities.

2. The cost of soil replacement can be more economical that other stabilization procedures since it do not require special construction equipment such as discs, harrows, mixers or spreaders.

3. Removal and replacement require less delay to construction than some other procedures such as prewetting.

However, despite all the merits explained above, the remove and replace strategy can sometimes fail, either because of insufficient removal depth of the expansive soil or because the replacement soil is highly pervious and causes structural damage. Non-uniform depths of replacement underneath a structure can also cause differential movements and increase heave at the ground surface (see Figure 2.5), (Maxwell, 2011) 
It is known that pushing the "seat" of wetting deeper into the soil reduces the swelling feature on the surface (Walsh et.al, 2009). But the effect of remove and replace mitigation on the depth, degree and rate of wetting is less clear. One reason is that flow in unsaturated soils, including the determination of soil properties and characteristics, and their impact on soil deformation is a complex mechanism, which depends on local soil and climatic conditions.

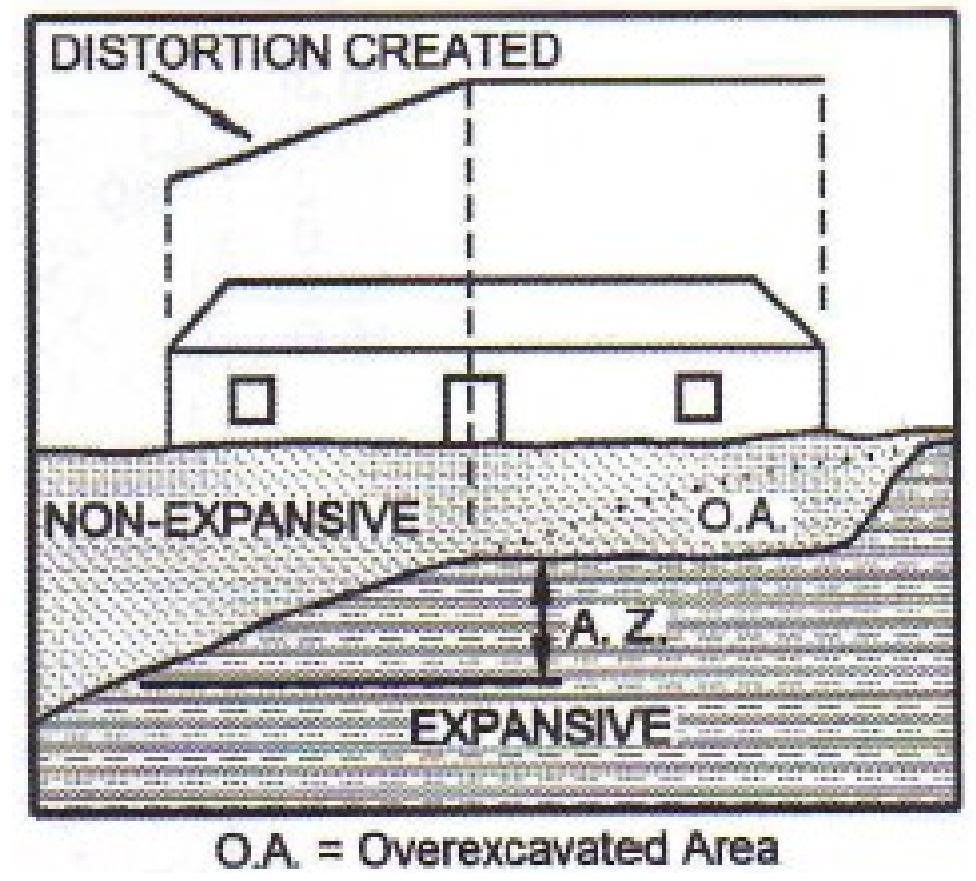

Figure 2.5. Structural distortion of structure resulting from over excavation (Maxwell, 2011)

Nelson and Miller (1992) state: "It is very important to recognize the effect of soil removal, replacement and application of a surcharge on soil microclimate" .When using granular/sandy soils as replacement layer caution should be exercised as these are highly permeable soils. Such soils provide access to water for seepage into lower 
underlying expansive soil layers which could result in heave. It is a general conception that very low permeability, nonexpansive soils are more satisfactory and works best as replacement layers. However, there should an optimal soil material depending on the region climate and other factors which could work as best to prevent heave."

\subsubsection{Depth of Wetting and Active Zone}

Expansive soils swells upon wetting. An important aspect of estimating heave in soils is the determination of the active depth of wetting. There are different views and concepts presented by various authors in the literature on depth of wetting (Walsh, et al, 2009, and associated Journal Discussions). In semi-arid areas evaporation exceeds the precipitation events or takes place simultaneously. This balancing process also limits the depth to which pore-water pressure changes can reasonably occur. The depth of wetting is defined by Nelson et al (2001) as "The depth to which water contents have increased due to the introduction of water from

external sources, or due to capillarity after the elimination of evapo-transpiration. The external sources include irrigation, seepage from ponds and others".

Figure 2.6 shows a general soil profile depicting the various climatic conditions and active depth. Figure 2.7 illustrates the active zone in an expansive soil and how heave affects the foundation. 


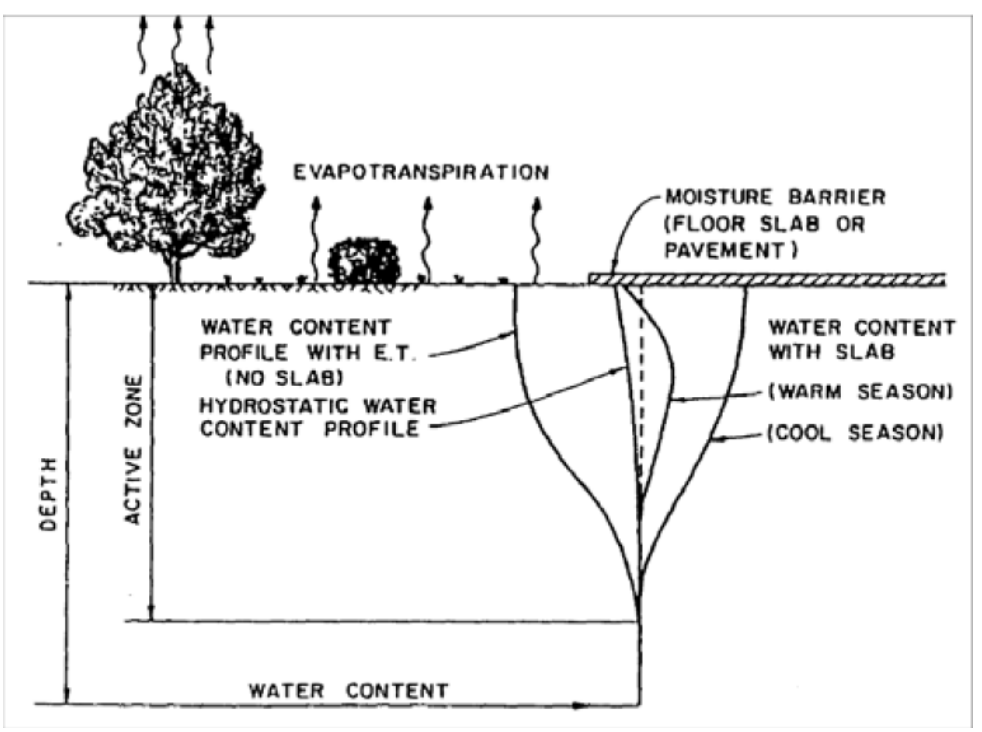

Figure 2.6. Active zone profile (Nelson and Miller, 1992)

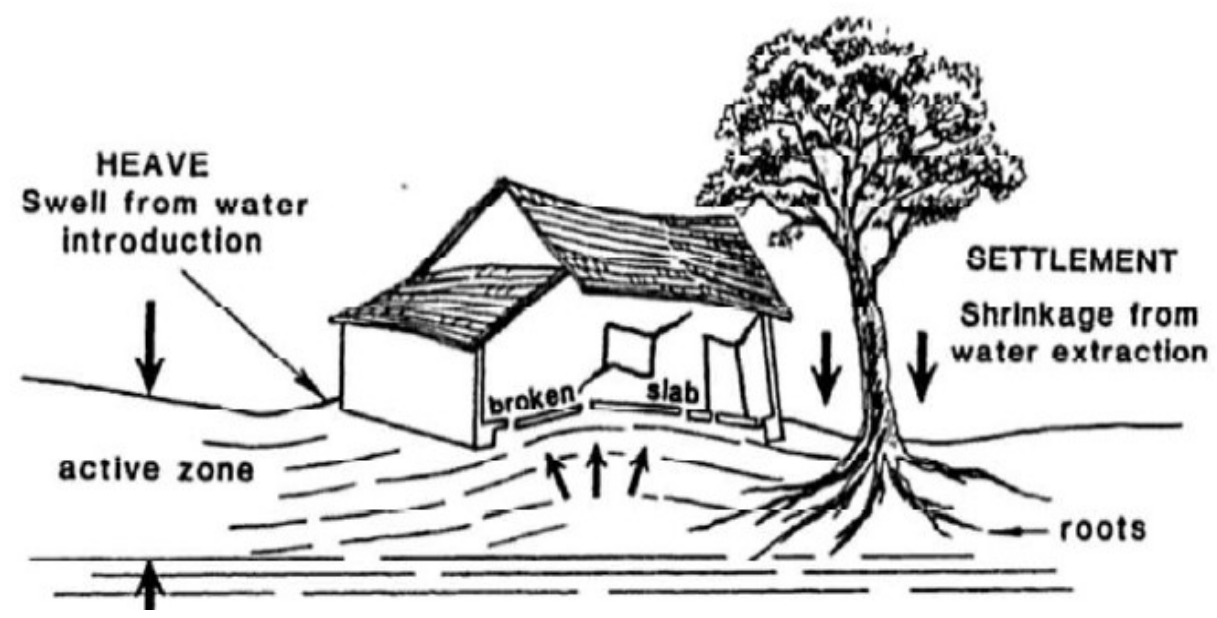

Figure 2.7. Heave occurring in the active zone (Nelson and Miller, 1992)

Active zone (depth of wetting within the region of the profile where the soil is expansive) could be only a 2 to $3 \mathrm{ft}(0.6$ or $0.9 \mathrm{~m})$ deep or could be $15 \mathrm{ft}(4.6 \mathrm{~m})$ or deeper, depending on the climate (Wray, 1995). The active zone thickness is influenced by the location of groundwater table. If the groundwater table is shallow (i.e., near the surface), it will tend to keep soil near the surface wetter that it would 
be if only the climate were influencing the surface soil moisture conditions (Wray, 1995). Conversely, if the groundwater table is deep, it will have a negligible effect on the active zone and the climate will govern the depth of the active zone. The active zone depth was found to vary between $1.2 \mathrm{~m}$ to $12 \mathrm{~m}$ (4 feet to 39 feet) depending on location (McKeen, 1980, 1981, 1985; O'Neill, 1980; O'Neill and Poormoayed, 1980; Thompson, 1992; Thompson and McKeen, 1995; Wray, 1989, 1997; Wray and Ellepola, 1991; Durkee, 2000, Chao et al., 2006, Walsh, et al 2009).

"In arid regions like Phoenix, it appears to be the prevailing opinion, that the top 1.2 to $1.5 \mathrm{~m}$ ( 4 to 5 feet) of soil are the most important for the slab design, with the active zone depth commonly assumed to be within the upper 1 to $3 \mathrm{~m}$ ( 3 to 9 feet) of the soil profile" (Houston et.al, 2011). The Colorado Association of Geotechnical Engineers (CAGE) has prescribed a depth of wetting of approximately 6 meters in their guidelines (CAGE, 1996). However, in addition to the findings from the theories described above, experience indicates that many sites exist where depth of wetting has greatly exceeded 6 meters (Overton, et al., 2006, and Chao, et al., 2006). Diewald (2003) evaluated post-construction data from 133 investigations and determined that the depth of wetting for 7-to-10-year-old residences is approximately 12 meters. Chen, 1988 recommends a minimum depth of 3 to $4 \mathrm{ft}$ for remove and replace. Usually sub excavation can be applied practically to a The active depth is the depth up to which changes in the pore-water pressure are likely to occur under given climatic conditions (Fredlund et al. 1993). Generally most of the heave occurs in near ground where maximum change in pore pressure occurs under no confinement. Precipitation or infiltration events cause a lowering of suction levels in the soils. However swelling soils have high clay content and as a result have low 
hydraulic conductivity which limits the ability of the soil to transfer excess water to lower depths.

Nelson et al (2001); Nelson, Durkee and Bonner(1998); Durkee (2000) define the active zone as the zone of soil that contributes to heave due to soil expansion at any particular time and it varies with time. Wetting depth due to climatic conditions is shown in Figure 2.6.

Walsh et al. (2009) developed a site specific approach for the Denver metropolitan area to assess the depth of wetting. In this method the average predevelopment suction trend line and post-development suction profile of the region is obtained first and then the trend line is shifted to obtain a best fit with the lower portion of the post-development profile. The depth of wetting is then defined as the depth to which the post-development suctions are significantly lower than the shifted suction profiles (Figure 2.8).

McOmber and Thompson (2000) method to estimate wetting depth is based on the difference between the post development and predevelopment suction profiles. Below that profile, an equilibrium suction exists. In the same study done in Denver region, the depth of wetting estimated by varies authors is different according to the approach adopted by them. McOmber and Thompson (2000) estimated a depth of wetting for that area around 6-9m, while of Nelson et al. (2001) estimated it to be about $15-28 \mathrm{~m}$.

Thompson (1997) and McKeen (2001) assume that an equilibrium suction profile exists below the depth of wetting. At the surface the suction fluctuates due to the climatic conditions. This approach has been used in their methods to evaluate heave below foundations. 


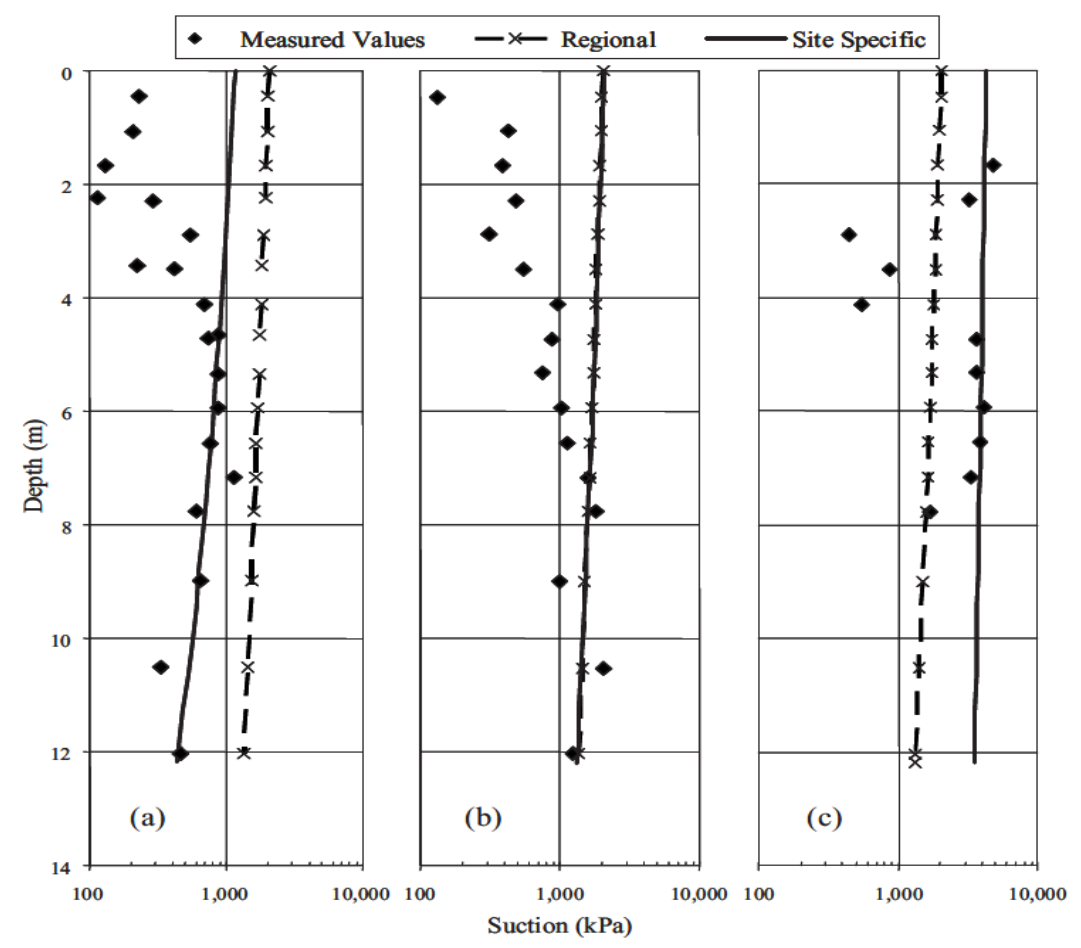

Figure 2.8. Example predevelopment and post development profiles of total suction and the shifted profiles at three different sites (Walsh et al, 2009)

Thompson (1997) developed two approaches, swell testing and suction measurement, to calculate potential future heave. McKeen (2001) mentioned that the plot of suction versus depth is the direct method to estimate the active zone depth which has been used in his method to calculate heave.

The climatic conditions of a region usually are the controlling factors of the active zone. In particular the maximum possible soil moisture seasonal changes impacts the suction profiles during wet and dry seasons. The expected swelling pressures as well as differential soil movement are dictated by these seasonal changes in suction or moisture content of the soil. Hence, for a geotechnical engineer dealing with expansive soil, it is very important to have knowledge of the soil suction distribution in the soil. Therefore, the engineering behavior (i.e., heave and 
shrinkage) of the soil is easier to manage if the seasonal soil suction distribution for a site with expansive soil is known. Consequently, there is a need for a proper basis to obtain an optimum replacement depth, based on flow-deformation analyses. Also, the actual wetting depth and active zone required in the design of slab-onground/foundations for lightly loaded structures should be identified and evaluated to avoid such failures.

\subsection{Volume Change Dynamics of Soil and Lightly Loaded Structures Like Slab-On-Ground}

The interaction between a slab-on-ground foundation and soil volume changes in expansive soil is quite complex. This whole system can be viewed as consisting of interactions between the soil and the structure.

The assessment of the variables, maximum ground surface movement in the absence of the slab, $y_{m}$, and horizontal distance of moisture movement beneath the slab, $e_{m}$ are commonly reported parameters used in structural design of slab-on-

ground foundation. A typical example of edge lift and center lift (edge drop) on a slab on ground under various climatic factors and external load is shown in Figure 2.9. 
Flexible impervious cover

or concrete slab

\section{Expansive soil}

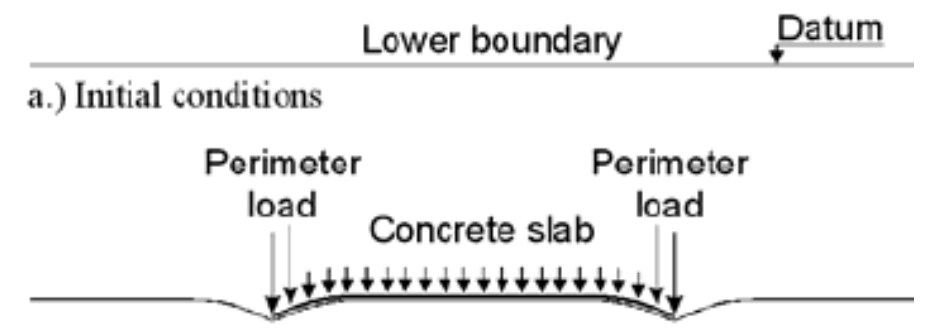

Datum

b.) Deformation due to external loads

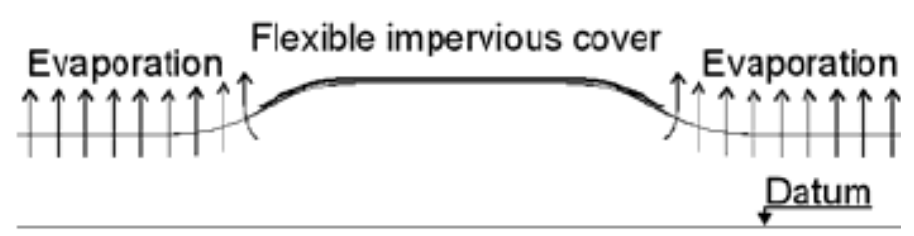

c.) Deformation due to drying (edge drop mode)

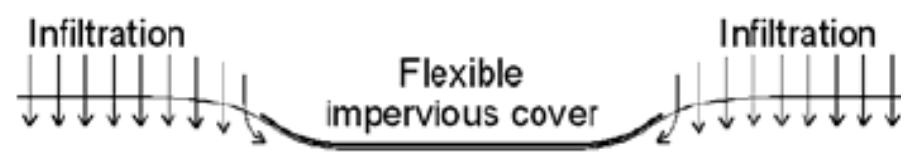

Datum

d.) Deformation due to wetting (edge lift mode)

Figure 2.9. Illustration of the soil response to external loads and changes in matric suctions (PTI, 1996)

Evaluation of slab on grade performance on expansive soils profiles can be studied using unsaturated flow and unsaturated soil stress- deformation analyses. Several finite element codes are available to solve the governing partial differential equations for flow/deformation, including SVFlux and SVSolid used in this study.

Remove and Replace technique is very commonly used in foundation and other construction practices. Several authors have reported in the literature about its 
effectiveness and adaptability. However, the efficacy of this method has not been analyzed extensively from a fundamental unsaturated soil moisture flow and stressdeformation perspective. This is an investigation on the remove and replacement method for mitigation of expansive soils in which the analyses are based on fundamental unsaturated flow and stress-deformation principles. Thus, this research represents a new and unique contribution to the state of knowledge on remove and replace methods. 


\section{MOISTURE FLOW AND STRESS-DEFORMATION PDE'S}

\subsection{Introduction}

This chapter presents a brief overview of the theory of moisture flow in unsaturated soil and the partial differential equation (PDE) solved in SVFlux. The next section includes a general theory on volume change in unsaturated expansive soil and the stress-deformation PDE solved by SVSolid for modeling suction and net normal stress induced deformation in unsaturated expansive soils.

\subsection{Moisture Flow in Unsaturated Soils}

As with the flow of water through saturated soils, flow of water through unsaturated soils is governed by gradients in total fluid potential (hydraulic head).

In general, the hydraulic head $h$ consists of three components: gravitational head, pressure head, and kinetic head. The total hydraulic head can be written

$$
h=y+\frac{u_{w}}{\gamma_{w}}+\frac{v_{w}^{2}}{2 g}
$$

where

$$
\begin{aligned}
& y=\text { elevation }[\mathrm{m}] \\
& u_{w}=\text { pore water pressure }[\mathrm{kPa}] \\
& v_{w}=\text { flow velocity }[\mathrm{m} / \mathrm{s}] \\
& \gamma_{w}=\text { specific weight of water }\left[\mathrm{kN} / \mathrm{m}^{3}\right] \\
& g=\text { acceleration due to gravity }\left[\mathrm{m} / \mathrm{s}^{2}\right]
\end{aligned}
$$


In the present study $v_{w}$ is small and only the first two components (elevation and pressure heads) are used.

The governing PDE for moisture flow through unsaturated soils for 2D unsaturated flow is given by Richard's equation (Equation 3.2)

$$
\frac{\partial}{\partial x}\left[\left(k_{x}^{w}(\theta)+k^{v d}(\theta)\right) \frac{\partial h}{\partial x}\right]+\frac{\partial}{\partial y}\left[\left(k_{y}^{w}(\theta)+k^{v d}(\theta)\right) \frac{\partial h}{\partial y}-k^{v d}(\theta)\right]=\frac{\partial \theta}{\partial t}
$$

where

$\mathrm{x}$ and $\mathrm{y}$ are the horizontal and vertical directions, respectively,

$\Theta$ is the volumetric water content [dimensionless],

$\mathrm{k}^{\mathrm{w}}(\Theta)$ is the two dimensional hydraulic conductivity function which provides the relationship between the hydraulic conductivity or volumetric water content and the matric suction [m/day]. The hydraulic conductivity is generally a function of the suction or, equivalently, the head.

Similarly $k^{v d}$ represents a scalar vapor conductivity function for the vapor phase. This term only contributes at relatively large suctions.

The dependent variable $\Theta$ is related to the suction $u_{a}-u_{w}$ difference between air and pore water pressures) via the soil water characteristic curve (SWCC), which depends on the soil characteristics. The suction $\mathrm{u}_{\mathrm{a}}-\mathrm{u}_{\mathrm{w}}$ is itself related to the head $\mathrm{H}$ via Equation 3.1.

Both SWCC and hydraulic conductivity functions are discussed in more detail below. 
The SWCC, hydraulic conductivity, and the vapor conductivity of soil tend to change with suction and therefore make the unsaturated flow equation nonlinear.

\subsection{Head vs. Mixed Formulation}

The moisture flow equation involves moisture content, total head and, implicitly, pore water pressure. Because these quantities are related to each other Richard's equation (Equation 3.2) can be written in terms of any single one of them exclusively. The head-based form is most commonly used but suffers poor mass balance in transient problems. This problem becomes even worse in problems with highly nonlinear soil water characteristic curves. For this study, the mixed form Equation 3.2 (Celia, 1990) involving both water content and pressure head is used. It has the advantage of improved mass-balance errors over head- based form.

\subsection{Soil Water Characteristic Curve}

One of the property functions required for unsaturated flow modeling is the soil water characteristic curve (SWCC), which describes the relationship between soil water content $(\theta)$ and soil suction $u_{a}-u_{w}$.

A typical SWCC is shown below in Figure 3.1. 


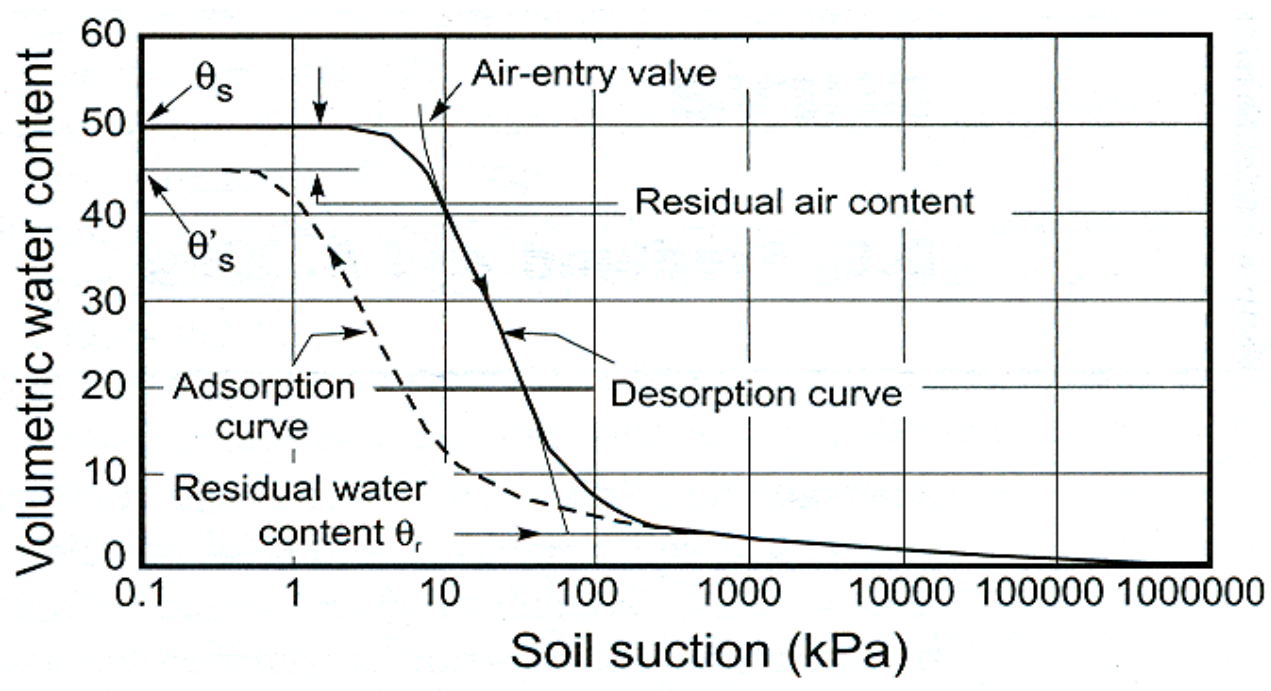

Figure 3.1. Typical SWCC curve (after Fredlund and Rahardjo, 1994)

The various material properties that affect the general shape of SWCC for various soils include pore size distribution, grain size distribution, density, organic material content, clay content and mineralogy.

The several defining features of the SWCC curves are shown in the

Figure 3.1 above. The most important of these are the saturated volumetric water content, air entry value (AEV), and residual water content. At zero suction the soil is fully saturated. As suction increases water content remains about constant until the air manages to penetrate the soil pores. So the corresponding suction value is the air entry value (AEV). As suction continues to increase the water content decreases until it reaches a residual value corresponding to a residual film surrounding soil particles. SVFlux provides different fits to estimate the SWCC for soils. For this study, the Fredlund and Xing (1994) fit was used for all soils. The fit is given by the equation 


$$
\theta_{w}=\theta_{s}\left[1-\frac{\ln \left(1+\mathrm{u}_{\mathrm{w}} / \mathrm{u}_{\mathrm{wr}}\right)}{\ln \left(1+10^{6} / u_{w r}\right)}\right]\left[\frac{1}{\left\{\ln \left[e+\left(\mathrm{u}_{\mathrm{w}} / a\right)^{n}\right]\right\}^{m}}\right]
$$

where

$\Theta_{w}=$ volumetric water content at any soil suction

$\Theta_{\mathrm{s}}=$ saturated volumetric water content

$a=a$ material parameter which is primarily a function of air entry value of the soil in $\mathrm{kPa}$

$\mathrm{n}=\mathrm{a}$ material parameter which is primarily a function of rate of water extraction from the soil once the air entry value has been exceeded

$\mathrm{m}=\mathrm{a}$ material parameter which is primarily a function of the residual water content

$\mathrm{u}_{\mathrm{w}}=\mathrm{u}_{\mathrm{a}}-\mathrm{u}_{\mathrm{w}}=$ soil suction

$\mathrm{u}_{\mathrm{wr}}=$ suction at which residual water content occurs $(\mathrm{kPa})$

When cycling through wetting and drying conditions possible hysteresis can occur but has not been considered in this study.

\subsection{Hydraulic Conductivity Function}

The other important soil property is its hydraulic conductivity which is also a function of either head, water content, pore water pressure, or suction. Saturated and unsaturated hydraulic conductivity are both related to the degree of resistance from soil particles when water flows in the soil pores. It is also a function of material variables describing pore structure i.e., void ratio and porosity; pore fluid properties i.e., density and viscosity. The hydraulic conductivity of an unsaturated soil can vary 
considerably during a transient process as a result of changes in the volume-mass properties.

A typical plot of unsaturated hydraulic conductivity for different soils as a function of suction is shown below in Figure 3.2. It can be observed that the hydraulic conductivities are different for different soils at the same volumetric water content. This difference is due to the differences in water configurations in individual soils.

Near saturation (at low suction) the coarse grained soils have higher conductivity than fine grained soil. However, when destaurated, the conductivity in the coarse grained soils decreases faster than in fine grained soil, resulting in a cross-over point. Beyond that point the hydraulic conductivity of the coarse grained soil remains lower than the fine grained soil. Such cross-over did in particular occur in our remove and replace strategy between the higher conductivity replacement soil and the original clay.

As the soil dries, there is less water in the voids and the hydraulic conductivity decreases. This effect also affects the rate of evaporation occurring across the soil surface. 


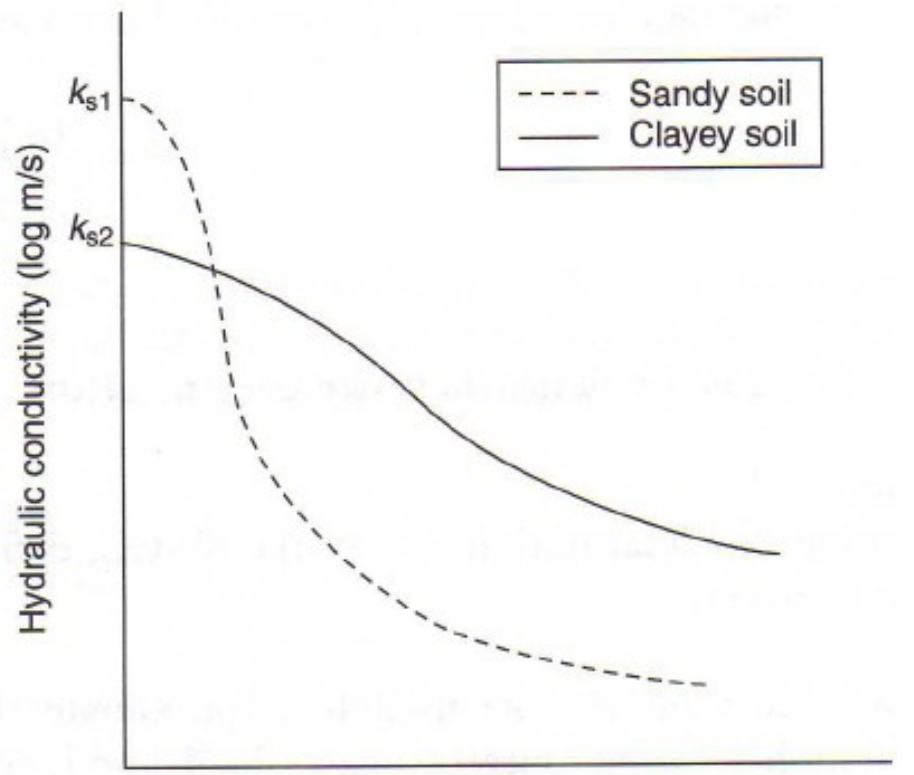

Matric suction $(\log \mathrm{kPa})$

Figure 3.2. Relationships between water permeability and matric suction for different soils (Zhan and Ng, 2004) \& (Shackelford and Nelson, 1996)

\subsection{SVFlux}

The commercial software package SVFlux was used for the analysis of the "remove and replace problem" considered in this study. SVFlux (Soil Vision Ltd.2009) is a seepage analysis package which is capable of solving $2 \mathrm{D}$ and $3 \mathrm{D}$ problems under either steady state or transient conditions. SVFlux implements both head based and mixed formulations of the Richard's equation (Equation 3.2).

SVFlux is based on the general purpose PDE solver FlexPDE, which can handle highly nonlinear PDE problem, such as water flow in unsaturated soils. FlexPDE allows piecewise linear or quadratic finite element spatial discretization. It has a feature for automatic mesh generation and adaptive grid refinement. 
Time integration of the time dependent Richard's Equation 3.2 is typically performed using an implicit scheme based on backward differentiation (BDF). This results in a system of nonlinear equations which are solved using a Newton-Krylov type iteration. The software also includes adaptive time stepping.

SVFlux allows application of both natural (Neumann/Flux) and essential (Dirichlet/Head) boundary conditions. Dye (2008) performed various sensitivity studies to evaluate the stability performance of solutions for fixed time steps and reported that tighter mesh spacing reduces the magnitude of oscillations induced in the results for applied Neumann boundary conditions (infiltration flux problems). Appropriate time steps and mesh sizes should be selected to obtain stable and converged solution. She also found that in case of problems involving runoff at the surface should be solved using tighter mesh sizes, as runoff induces oscillations in the simulations.

Dye also found that the numerical solutions are sensitive to the variability in the hydraulic conductivity functions in unsaturated soils. Therefore the hydraulic conductivity of soils, especially for lower conductivity soils, can have impacts on the stability and convergence of the problem solution. To ascertain convergence of the solution, global error parameters of the solver would be varied to check the sensitivity of the results to these variations. This is discussed in detail in Chapter 4 for the analyses performed in this research.

SVFlux offers various fits to estimate the $k_{\text {unsat }}$ curve for soils. The Leong and Rahardjo fit (1996) was used to define the $k_{\text {unsat }}$ curves for all the replacement soils in this study. 


\subsection{Volume Change in Unsaturated Expansive Soils}

Generally in a volume change analysis, both the net normal stress and matric suction must be considered." There are three primary factors that affect the total heave prediction, namely, the volume change indices and the present and the future stress state variables" (Fredlund, 1993). The amount of volume change in an expansive soil can be written as function of the difference between the present stress state and the future stress state and the volume change indices for the soil. Generally the net normal stress state variable remains constant while the matric suction stress state variable changes during the swelling or shrinkage process. For the different surface flux cases analyzed in this study, an uncoupled approach was used which involves the coupling between SVFlux and SVSolid. The details of how SVFlux and SVSolid are combined to obtain deformations resulting from unsaturated flow analyses for unsaturated expansive soils are discussed in Chapter 4.

\subsection{Stress-Deformation PDE Solved in SVSolid}

SVSolid Standard 6.0, used in this study, is a finite element package capable of solving stress-strain models for unsaturated soils (SVSolid manual, 2008). Like SVFlux, it also has the feature of automatic mesh generation to solve highly nonlinear problems. As in SVFlux, SVSolid also implements a Newton type iteration for solving the nonlinear PDE's for stress-deformation (SVSolid manual, 2008).

SVSolid offers different stress strain constitutive models like linear elastic model, anisotropic model, hyperbolic model and unsaturated model. SVSolid can perform both total stress and effective stress analysis depending upon the type of problem. 
The governing PDE relates the displacements $u$ and $v$ in the $x$ and $y$ direction respectively to the pore water $u_{a}-u_{w}$ obtained from SVFlux according to the isotropic, nonlinear elastic soil model (Vu and Fredlund, 2004):

$$
\begin{gathered}
\frac{\partial}{\partial x}\left(c_{11} \frac{\partial u}{\partial x}+c_{12} \frac{\partial v}{\partial y}\right)+c_{33} \frac{\partial}{\partial y}\left(\frac{\partial u}{\partial y}+\frac{\partial v}{\partial x}\right)-d_{s} \frac{\partial\left(u_{a}-u_{w}\right)}{\partial x}+b_{x}=0 \\
c_{33} \frac{\partial}{\partial x}\left(\frac{\partial u}{\partial y}+\frac{\partial v}{\partial x}\right)+\frac{\partial}{\partial y}\left(c_{12} \frac{\partial u}{\partial x}+c_{22} \frac{\partial v}{\partial y}\right)-d_{s} \frac{\partial\left(u_{a}-u_{w}\right)}{\partial y}+b_{y}=0
\end{gathered}
$$

where

$b_{x}$ and $b_{y}$ are body forces in $x$ and $y$ directions respectively

$b_{y}$ is the body load in vertical direction to incorporate the effect of gravity or overburden load

$b_{x}$ is the body force in horizontal direction and are calculated based on the coefficient of earth pressure at rest

$$
\begin{gathered}
c_{11}=c_{22}=\frac{(1-\mu) E}{(1+\mu)(1-2 \mu)} \\
c_{12}=\frac{\mu E}{(1+\mu)(1-2 \mu)} \\
c_{33}=\frac{E}{2(1+\mu)} \\
d_{s}=\frac{E}{(1-2 \mu) H}
\end{gathered}
$$

For a 2D plane strain case, Elasticity parameters are given by: 


$$
\begin{gathered}
E=\frac{4.605(1+\mu)(1-2 \mu)\left(1+e_{0}\right)}{C_{s}}\left(\sigma_{a v e}-u_{a}\right) \\
H=\frac{4.605(1+\mu)\left(1+e_{0}\right)}{C_{m}}\left(u_{a}-u_{w}\right)
\end{gathered}
$$

where

$\mathrm{E}$ is the elasticity parameter for the soil structure with respect to a change in net normal stress

$\mathrm{H}$ is an elasticity parameter for the soil structure with respect to a change in matric suction

$\mu$ is the Poisson's ratio for the soil structure and

$\mathrm{e}_{\mathrm{o}}$ is the initial void ratio

Equations 3.4 and 3.5 are used to compute the displacements in horizontal and vertical directions due to a change in matric suction obtained from SVFlux. $\mathrm{C}_{m}$ and $\mathrm{C}_{\mathrm{s}}$ are the swelling indices, i.e. the slopes of the void ration versus logarithm of net normal stress and logarithm matric suction respectively. Figure 3.3 shows the variation of $\mathrm{C}_{\mathrm{m}}$ and $\mathrm{C}_{\mathrm{s}}$ as used in SVSolid. 


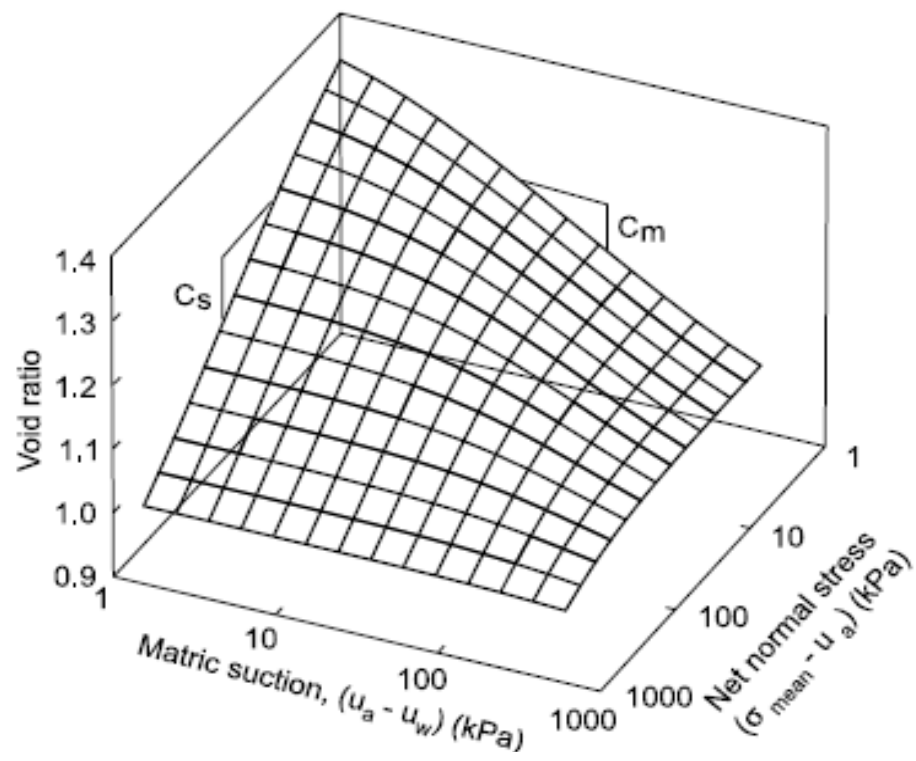

Figure 3.3. A typical void ratio constitutive surface plotted in semi logarithmic scale (Fredlund et al., 2001)

The elastic moduli $\mathrm{E}$ and $\mathrm{H}$ are calculated based on the $\mathrm{C}_{\mathrm{s}}$ and $\mathrm{C}_{\mathrm{m}}$. Lower $\mathrm{C}_{\mathrm{m}}$ values result in an increase of the elastic modulus $(\mathrm{H})$ with respect to suction, resulting in a reduction in final displacement value obtained from the PDE. In general, the $C_{m}$ value decreases with increasing confinement because increased confining stresses act to "hold the soil down" and reduce swell upon wetting.

The unsaturated model option in SVSolid is used in this study to solve for the problems involving stress-deformation analyses. An initial suction profile is obtained by running a transient simulation with SVFlux until the solution stabilizes. Next a final suction profile is obtained by another transient simulation using desired boundary conditions for a number of years ( 6 years for this study using climatic conditions). The initial and final suction profiles are provided directly to SVSolid. The software interpolates between these two profiles at a number of stages (see Figure 3.4) from which it obtains small variations in suction profiles. Corresponding 
incremental deformations are then obtained from Equations 3.4 and 3.5. "During each incremental step, the elastic moduli are assumed to be unchanged" ( Vu and Fredlund, 2001). Then, "new moduli are selected at the beginning of each new incremental step depending upon the stress level and the displacements from each incremental step are accumulated to give total displacement" (Vu and Fredlund, 2001). The overall strategy can be interpreted as continuation technique via linearization and accumulation of incremental deformations.

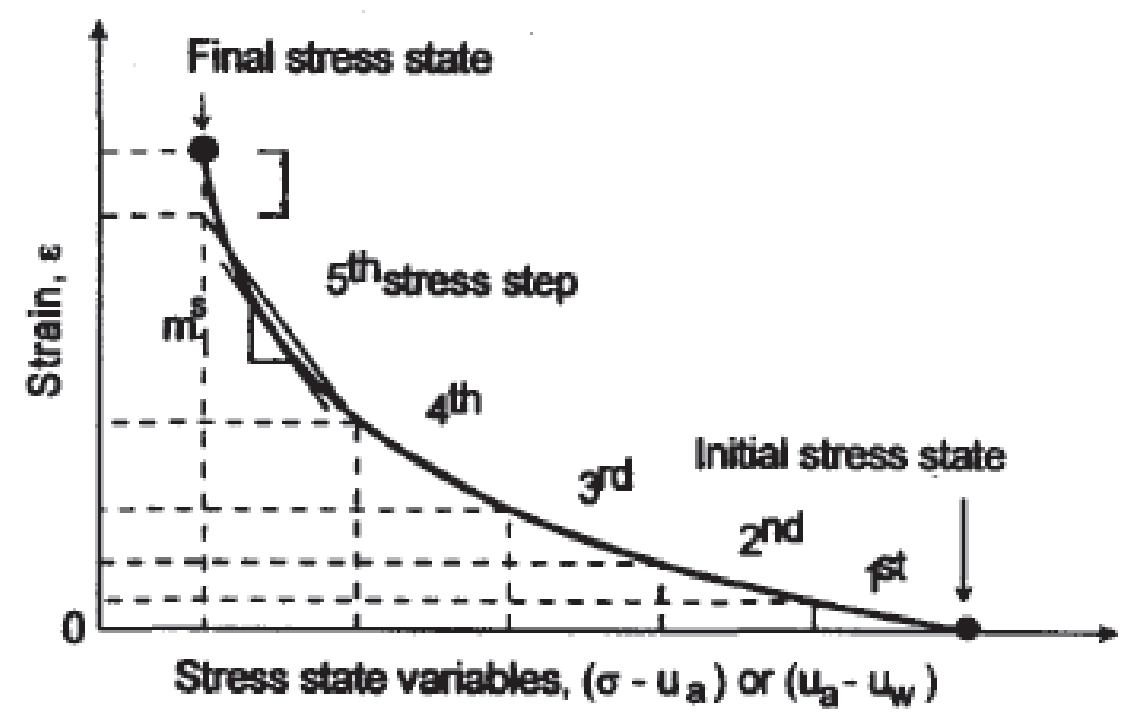

Figure 3.4. The total suction is divided into increments and one load increment is applied (Vu and Fredlund, 2001) 


\section{PROBLEM STATEMENT \& BACKGROUND}

\subsection{Introduction}

The objective of the research is to study the effect of remove and replace options for mitigation of expansive soil profiles for shallow foundation structures. Removal of expansive soils and replacement with non-expansive soils is one method to reduce expansion potential of a clay profile. In some cases, the expansive strata may be entirely removed. It becomes uneconomical to remove the entire depth of expansive soil when it extends to a great depth. It then becomes necessary to determine the optimal depth of excavation and fill required to reduce heave to an acceptable level. The details of different remove and replace cases, whose strategies were outlined in chapter 2, are presented in Section 4.5 of this chapter. The study of optimal replacement depth and material is accomplished using two commercial softwares, SVFlux and SVSolid (SVOffice 2009). Dye (2008) performed a detailed study on moisture flow through expansive soil, including a study of the effect of time and space discretization on the numerical stability and convergence of the problem of infiltration into expansive clays. Since the Dye study, several revisions have been added to the SVOffice software to improve the stability of numerical solutions in particular for stiff problems. In this study, the solutions presented for the remove and replace problem were evaluated for stability and convergence, and iterations on discretization in time and space were done for 1D models in obtaining and appropriate finite element solutions; then these discretizations were checked for the 2-D case. Only the final stable and converged solutions are presented in the body of this dissertation, although several iterations on discretization were required to obtain satisfactory solutions. The 2D problem analyzed is described in the sections below, including initial conditions, and various boundary conditions considered. The Soil- 
Water Characteristic Curve (SWCC) and $\mathrm{K}_{\text {unsat }}$ functions used for the expansive and replacement soils are also presented and discussed. Overall this chapter describes the problem setup and the various soil properties considered for the replacement soil layers, as well as properties selected to represent the natural expansive clay profile to be mitigated.

\subsection{Boundary Value Problems}

The finite element analysis for swelling problems in unsaturated soil mechanics is done by solving stress-strain partial differential equations (PDE's) for soil equilibrium using unsaturated flow PDE's (Richards Equation) solutions. This may be done in a coupled or uncoupled manner. The governing partial differential equations used in this study for both fluid flow and stress deformation are based on the general theory of unsaturated soils using two independent stress-strain variables (Vu and Fredlund 2002). As discussed by Fredlund (2006), the solution to the flow and stress-deformation equations for specific site conditions can be viewed as a boundary value problem, as shown in Figure 4.1. When a head value is specified for flow type problems it is called a Dirichlet boundary condition. The specification of flow rate across a boundary results in Neuman type boundary condition. Both types of boundary conditions must be considered in the study of expansive soils for fieldappropriate conditions.

The volume changes associated with expansive clays can be predicted as the solution of a stress-deformation analysis using the fluid flow analyses for determination of soil suction changes (Vu and Fredlund 2002). In the analysis proposed by Vu and Fredlund for expansive soils, and used in the SVSolid software, the soil properties are generally nonlinear but are converted to equivalent, 
incremental elastic parameters. The swelling index is converted to an equivalent variable elasticity function for the unsaturated soil (Vu and Fredlund, 2002). For expansive soils, the volume change occurs in response to changes in soil suction, typically for constant, or essentially constant, net normal stress conditions.

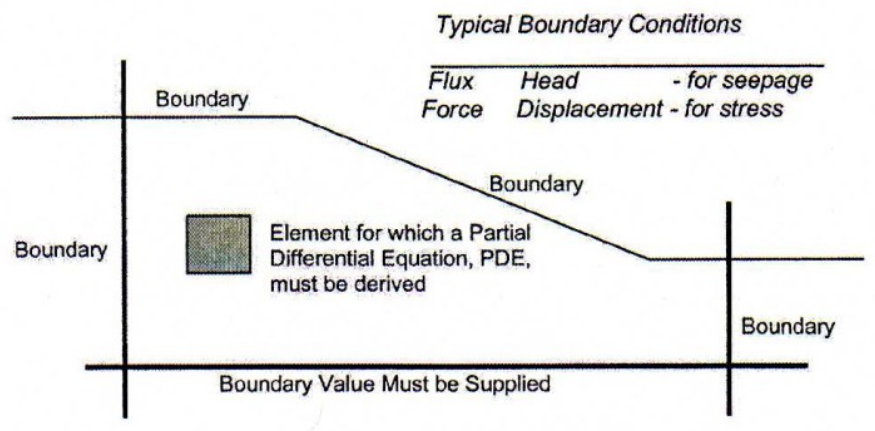

Figure 4.1. Definition and meaning of a boundary value problem (Fredlund 2006)

\subsubsection{Procedure Adopted to Conduct the Remove \& Replace Stress Deformation Analyses of this Study}

The methodology adopted in this study is summarized as below:

1. A decoupled analysis is performed, wherein the unsaturated flow analysis is first solved and then used as input to the stress-deformation analysis of the expansive clay. In the SVSolid software there is a piecewise one-way coupling such that the changes in soil suction associated with the fluid flow analysis are used to compute deformations that result in changes in net normal stress. The changes in net normal stress are not used to compute changes in soil suction. 
2. The conditions for climate conditions plus development-induced flow (e.g. irrigation, roof run-off, etc) on the unmitigated expansive soil profile condition, in the absence of removal and replacement, are evaluated to establish a baseline condition for comparison to remove and replace options.

An unsaturated fluid flow analysis model (i.e., SVFlux) is prepared for the expansive clay soil profile to obtain the pore water pressure (soil suction) conditions for natural climatic conditions. To establish the initial conditions the soil profile is subjected to 5 years of natural climatic conditions, which was found to provide essentially pseudo-steady-state conditions for the profile (steady other than seasonal fluctuations). These analyses establish the initial condition for the no replacement case. Next, transient (e.g. irrigated lawn conditions, or roof runoff ponding conditions) are analyzed to establish the final boundary condition for the deformation analyses (SVSolid) for the no replacement case. The stress-deformation model using SVSolid provides deformations associated with the changes in matric suction. The soil profile is divided into different layers to incorporate the variation of matric suction volume change index, $C_{m}$, with depth (see Figure 4.33 ). The soil properties for the native clay are for an actual expansive soil, although the variation of $C_{m}$ with depth is estimated based on experience and literature values. $C_{m}$ is the slope of the void ratio vs. suction plot on a semi logarithmic scale (see Figure 3.3). The entire deformation pattern is determined in the finite element analyses, but deformation below the slab edge and ground surface is captured for plotting in this study for comparison of the efficacy of various remove \& replacement depths, as described briefly in Chapter 3 and discussed in detail in the subsequent sections of this chapter. 
3. After the soil deformation pattern is obtained for the natural, unmitigated soil profile, the fluid flow model is rerun but with the top layer of the expansive soil profile removed and replaced with non-expansive soils. For each run, the replacement layer for this study consists of one of three different artificial non-expansive soils with varying hydraulic conductivities compared to that native clay - higher than, lower than, or equal to the native clay conductivity. For the non-expansive soils, reasonable volume change properties are estimated based on the literature values on compacted soils. Details are provided in subsequent sections of this chapter. The unsaturated flow analysis (SVFlux) is performed for the two layered soil model with the top layer of the natural clay profile replaced with various non-expansive soils. The flow analyses conducted using SVFlux are followed by a 2D deformation analyses using SVSolid for each remove and replace case.

The soil suction variation and changes in degree of saturation are obtained from the unsaturated analysis (SVFlux). Time history plots for saturation and suction are captured and saved for subsequent evaluation at various defined points along the $x$ and $y$ axes within the domain of the soil profile. These points lie on a grid and are spaced at a distance equal to the grid size, concentrated mostly in the region near to the surface where suction changes occur. The grid points are distanced more sparsely as the depth below ground surface increases. Also, plots for suction and saturation are obtained for various depths below the slab edge for subsequent evaluation of the model results. Thus, horizontal and vertical profiles of soil suction and degree of saturation may be plotted for comparison between the various remove and replace options and for the two selected surface boundary conditions (roof run-off or turf (lawn). 
Finally, results are plotted in terms of vertical profiles of displacement below slab edge, horizontal profiles of displacement on the ground surface to estimate the differential settlement occurring across the slab. The slab itself is not modeled, except to serve as a flexible impermeable member. Thus, the displacements represent soil movements and do not consider soil-structure interaction effects.

4. Comparisons are made between the various remove and replace options. A matrix showing all of the conditions considered and compared in this study is shown in Figure 4.15, later in this chapter.

5. Finally displacement (primarily heave) results are interpreted in terms edge moisture distance $\left(e_{m}\right)$ and differential movement $\left(y_{m}\right)$ for slab (see Figure 4.2). The magnitude of $y_{m}$ refers to soil movements that would occur in the absence of the slab. The edge moisture variation distance refers to the distance inward from the edge of the slab that the soil moisture content can be expected to vary. 


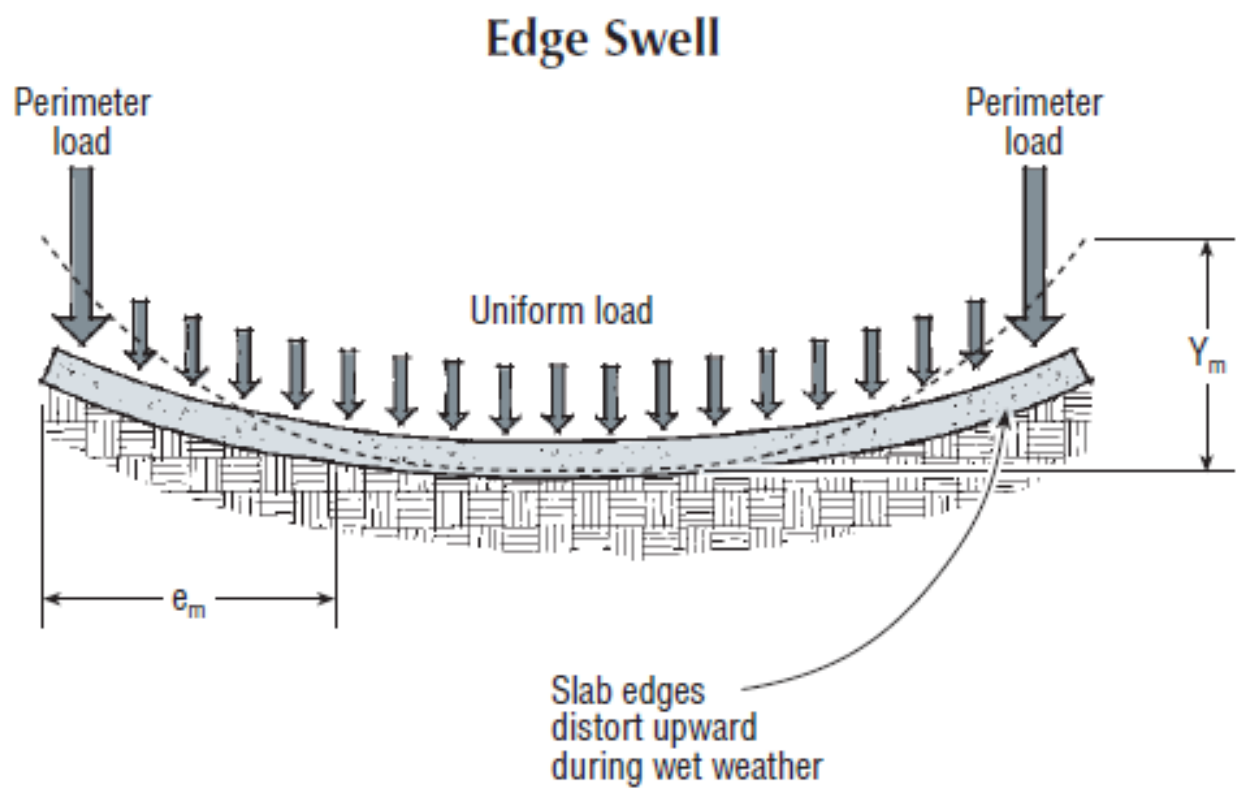

Figure 4.2. $e_{m}$ and $y_{m}$ in slab-on-ground foundations

\subsubsection{Coupling of SVFlux and SVSolid}

The primary cause of volume change in the current problem is the change in soil suction. The fluid flow analysis is the initial and most important step to determining the overall volume change. The initial and final conditions (from SVFlux analyses) are selected each time manually for input into SVSolid depending at what time the final displacement value is needed. The manual iteration method involves steps (explained below) to arrive at the final displacement using SVFlux and SVSolid software packages. These software packages utilize the FlexPDE generic finite element solver to solve the partial differential equations for flow and stressdeformation. The steps are described as below:

1. Initial SVFlux seepage analysis

2. Final SVFlux transient seepage analysis

3. SVSolid Stress/deformation analysis 
The purpose of the initial seepage analysis in SVFlux is to get 2 outputs:

1. A head profile to use as initial conditions for the final transient seepage analysis

2. To obtain a suction profile to use as initial conditions for the SVSolid analysis.

The Final Transient SVFlux analysis provides an output of suction variation within the profile at a given time, which becomes the final condition input into SVSolid. SVSolid then uses these initial and final suction profiles to compute the deformations induced due the change in suction.

The flow chart (Figure 4.3) below explains the process to obtain the final displacement values for the moisture change problems.

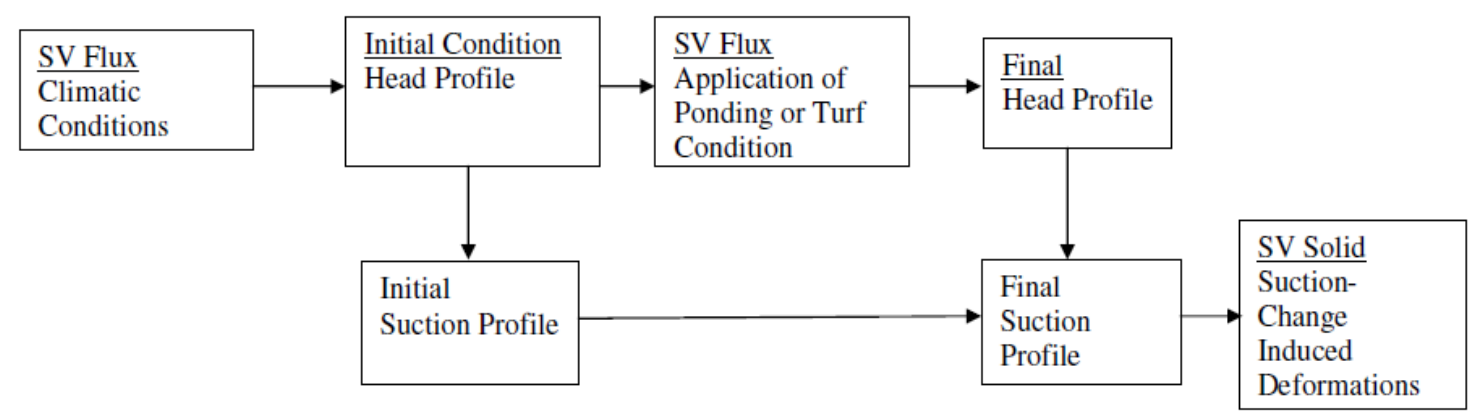

Figure 4.3. Steps to obtain final displacement in SVSolid

\subsubsection{General Methodology}

In order to achieve the objectives of this project the response of a slab-onground by using SVFlux for seepage analysis and SVSolid for stress-deformation analyses is studied. A two dimensional stress deformation analysis of a slab placed on an unsaturated swelling soil is performed using SVFlux and SVSolid packages is done which follows the decoupled analysis approach proposed by Fredlund and Vu 
(2002). Deformation on the ground surface due to swelling and/or shrinkage in the natural, unmitigated soil was obtained for two different applied surface flux conditions, roof run-off ponded at the slab edge or turf (lawn) landscape conditions. Then the upper few meters of the swelling soil was replaced by non-expansive soil to a given depth of replacement, to determine the impact of the remove and replace mitigation scheme. SVSolid uses the seepage analysis results from SVFlux to determine stress and deformation in soil. It is a decoupled approach where the time dependent part of the problem is done using SVFlux and then the initial and final soil suction results are fed into SVSolid to obtain the stresses and deformations after a particular time (final condition).

The three different replacement layer soil properties for this study were obtained from the SoilVision database. This database includes the SWCC and $\mathrm{K}_{\mathrm{unsat}}$ data for various soils. The relevant replacement soil volume change properties are based on a literature review. The volume change index with respect to suction, $C_{m}$, varies with depth for the expansive clay layer, and the variation with depth was estimated primarily from oedometer test results on compacted soils presented by Miller, 1992) (see Figure 4.33).

\subsection{Preliminary Problem Set Up}

A preliminary study was conducted to obtain optimal space and time discretization values and to study appropriate placement of edge and base boundaries so as to not affect the solution in the zone of interest around the slab. The preliminary problem consisted of a 2D soil profile 7 meters deep and $20 \mathrm{~m}$ wide. The initial condition for the problem was a head of $-153 \mathrm{~m}$ applied over the entire soil profile. The initial condition head value used in the analyses is based on the desert 
region suction values typical of the Phoenix, Arizona region, as reported by Dye (2008). With this initial condition, steady state analysis was done in SVFlux for the problem to obtain a hydrostatic head profile and a suction profile. The head profile obtained from this run was used as an initial condition for the subsequent transient analysis in SVFlux. The subsequent transient run in SVFlux is done with roof runoff data applied on the top boundary of the soil profile (over a region of $1 \mathrm{~m}$ ), allowing for approximately 5 inches of ponding to occur, with the remainder run off. This transient SVFlux run also generates a suction profile. The suction profile obtained from the steady state run was used as the initial condition for the SVSolid analysis and the final condition for SVSolid is obtained from the subsequent transient SVFlux run. For the transient analysis in SVFlux, the boundary value consists of a head $153 \mathrm{~m}$ applied at the bottom boundary of the domain, and a zero (no) flux condition is applied on both lateral sides. On the top boundary, a slab-on-ground covers half the boundary length and a flux consisting of average yearly roof runoff data (Figure 4.21) was applied over a concentrated area of length of 1 meter as shown in the Figure 4.4 below. The details of the climatic data are given in Section 4.6. For the preliminary stability and convergence studies an average flux was used, although for the final analyses hourly flux steps were used to obtain a more accurate description of the surface flow conditions as averaging of surface flux has been found to overestimate depth and extent of wetting (Dye, et al., 2008)

Once the change between initial and final suction is obtained for the soil profile, it is used to obtain the data required for plots of the vertical movement (or the amount of swelling at the surface) and profiles of suction below slab edge using SVSolid. The coupling between the two softwares is explained in Section 4.2.2. 


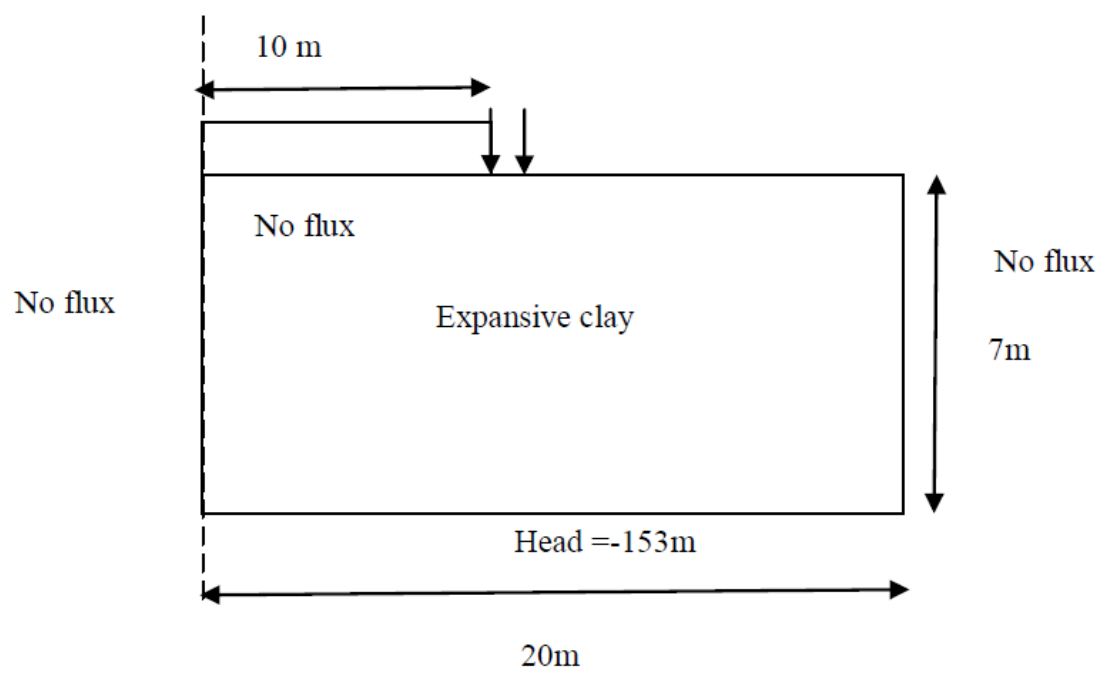

Figure 4.4. Initial problem setup

The problem set up presented in this study is geometrically axisymmetric and therefore only half of the soil profile was analyzed.

\subsubsection{Mesh Size Selection}

Boundary flux modeling with different flux conditions is complex and challenging from numerical and convergence perspectives. Therefore an optimum mesh size is necessary in order to obtain stable solutions that run in a reasonable length of time. The number of nodes/mesh density, and $\Delta \mathrm{t}$ (time), was varied using different mesh spacing in SVFlux so as to compare the results and check for convergence. "In a given numerical problem the number, shape and density of elements used effects the computational expense and accuracy of solution" ( Vu, 2002). The accuracy of finite element solution depends on the choice of the finite element mesh. As the size of the finite element mesh gets smaller, in general, the accuracy of the solution increases. Because a finer mesh size adds to the solution times of the problem, the selection of mesh size and time discretization is an important part in the optimization process. For the initial problem set up, different 
mesh sizes were used on the "no replacement" expansive soil profile in order to obtain stable results in SVFlux. A separate convergence study was done to find out the appropriate $\Delta \mathrm{x}$ and $\Delta \mathrm{t}$ for the expansive clay profile runs. A result for suction variation for a vertical profile at the edge of the slab, for various different grid sizes, is shown below in Figure 4.5. Additional saturation and suction results for different grid size are included in Appendix A. The software code gives the option to the user to manually control the mesh density or use the regrid option. If the regrid option is chosen the PDE solver implements adaptive mesh refinement. The solver automatically refines the mesh (produces more nodes) in the region where the specified error limit is exceeded. This process allows a specified accuracy to be achieved. This option can be turned off and a fixed mesh can be chosen. In this section the effect of the adaptive mesh and fixed mesh on the suction results are discussed.

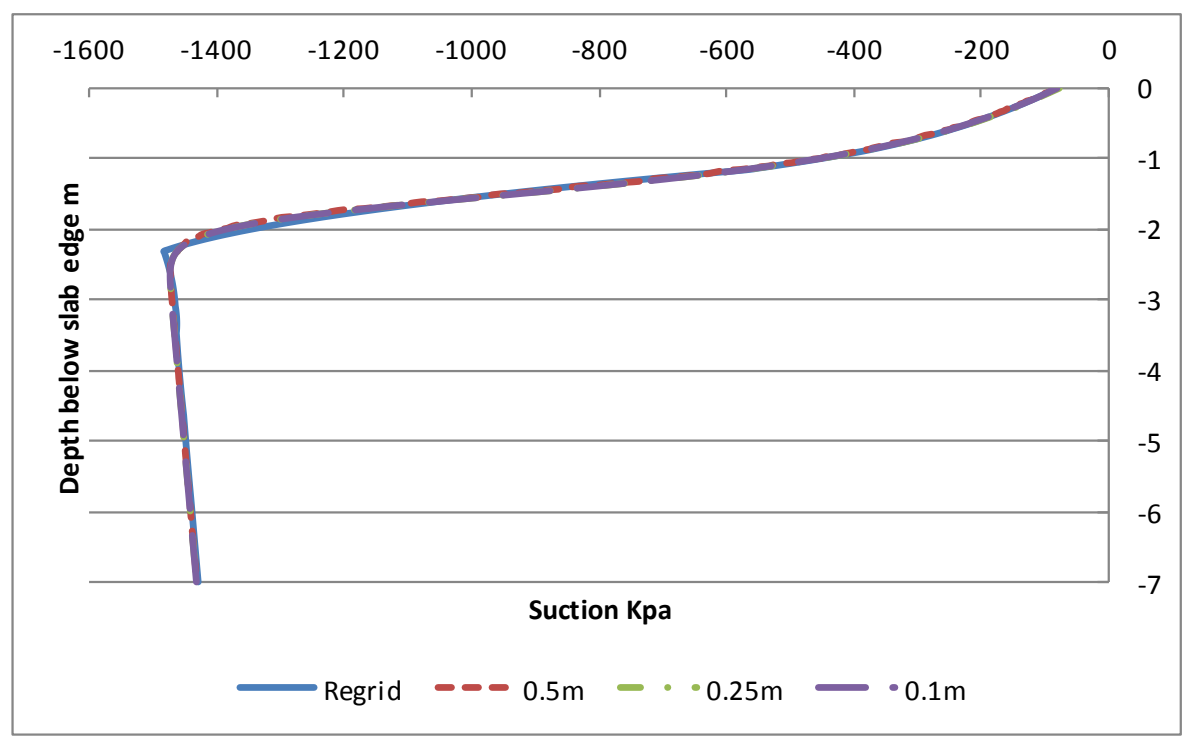

Figure 4.5. Suction variation at vertical section $X=10 \mathrm{~m}$ for various grid sizes (below slab edge) 
In the case of final remove and replacement runs analyzed in this research, a finer mesh size was used in the top regions where maximum moisture activity occurs, and a coarser mesh size was used in the remainder of the domain. In Section 4.4.2 additional details about the mesh size used in the replaced soil layers are provided.

\subsubsection{Time Step Selection}

The solution accuracy and solution stability is sensitive to the size of time steps. To select the time steps for the remove and replace study, a small convergence/stability study was undertaken by varying $\Delta t$ to find out its effect on output results. The smallest time steps were not chosen, as bigger time steps gave satisfactory results with shorter run times. However, $\Delta$ t was selected for which convergence and stability were demonstrated. Tables and figures of the analyses performed in the selection of $\Delta t$ are included in Appendix A.

In the convergence study where average roof runoff data was applied, a fixed $\Delta t$ could not be used, because the step error obtained was too large for the given required accuracy. Reducing the fixed $\Delta t$ did not resolve the problem, a sign that the software needed to take extremely small steps at some point during the computation (discontinuity or large variation in the solution). Therefore the $(\Delta t)_{\max }$ was varied along with the grid size to obtain an optimum solution (run time and grid space). It was observed that as the time step and grid space decreases the run time increases, and the run times can become prohibitive if very small discretization of space and time is selected. Based on these studies, $\Delta t=0.5$ day and $\Delta x=0.25 \mathrm{~m}$ were chosen for initial/trial set of runs as the runtime was the least and gave the same result as that of smaller time step and grid size. Although adaptive grid refinement is designed to 
address local spatial oscillations and instabilities in the solution, using the option in our run did not resolve apparent oscillations in the output of the pore water pressure (pwp) /suction as evident in the plots included in Appendix A (Figure A.1 to A.4).

In another exercise, the global error parameter, ERRLIM, was also changed for different grid size to check if the results show any sensitivity to this change. ERRLIM is the primary accuracy control in the finite element code. It is an estimate of the relative error in the dependent variables. Since the solution is not guaranteed to lie within this error a finer mesh density was applied other than regrid in order to make sure that a converged solution is achieved. The spatial accuracy and temporal controls are set to the ERRLIM values by default in the software. But the output results did not change, which is further evidence of a converged solution for the discretization selected. Finally, a default ERRLIM value of 0.002 was used for the runs.

In SVFlux, the maximum $\Delta t$ increment cannot be greater than $20 \%$ of a day when using climate boundary conditions because the irrigation and rainy periods must be represented in a fairly accurate manner to obtain accurate subsurface suction profiles (Dye. et al., 2008). However, when the value of $\Delta$ t was changed to 0.5 day directly in the FlexPDE code, the results obtained were the same, demonstrating that the $\Delta \mathrm{t}$ of 0.2 days was more than adequate. Another exercise was done on a layered (replacement layer) 1D model to obtain an appropriate $\Delta \mathrm{x}$ and $\Delta \mathrm{t}$ for the "Final Remove and replacement" problem. This study was performed in addition to the single layer study discussed above because of the discontinuity resulting from the replacement layer, which could affect convergence/stability results. Details of the 2-layer 1D model are included in the Section 4.4.2 below. 


\subsubsection{Selection of Position of Domain Boundaries}

An initial 2-D soil profile set up was chosen to be $20 \mathrm{~m}$ wide and $7 \mathrm{~m}$ deep for this exercise consisting of no replacement expansive clay, as discussed above. The soil modeled is expansive clay classified as a $\mathrm{CH}$. The size of the problem domain was determined by an iterative process, wherein the bottom and right boundaries were moved in and out from the slab location. Bottom and right domain boundaries were moved one at a time. The output suction result from each iteration was compared to make sure that the boundaries do not significantly affect the final result. A final domain size was selected to be $35 \mathrm{~m}$ wide $\times 30 \mathrm{~m}$ deep, for which the final suction results in the region of interest were found satisfactory. The horizontal and vertical extension of the soil profile must be evaluated in order to cover the entire active zone.

All the different remove and replace scenarios were analyzed for a $35 \mathrm{~m}$ wide and $30 \mathrm{~m}$ deep domain. As a preliminary study, the roof runoff was averaged over the entire year and applied next to the slab edge; a set of runs was done for different depths of higher $\mathrm{K}_{\text {sat }}$ replacement soil. The details of the study are included in Appendix D.

\subsection{Final Remove and Replace Problem Set Up}

For the final set of runs used to assess the impact of remove and replace on expansive soil deformation, the "no replacement" expansive soil profile was treated as a layered system. The $30 \mathrm{~m}$ deep profile was divided into six different layers, each $5 \mathrm{~m}$ deep. Each layer has soil properties for the selected natural expansive clay, with decreasing expansion index with depth. The layered profile allows incorporating the 
values of volume change index as a function of depth when doing the stressdeformation analyses.

Final runs for the "no removal and replacement" and "remove and replaced" soil profiles were performed for two different surface flux conditions, as discussed above and in Chapter 2. The schematic of the profile for the two different boundary conditions applied at the top surface are shown in Figure 4.6 and Figure 4.7 below. The flux boundary conditions are discussed in more detail under the climatic data section below.

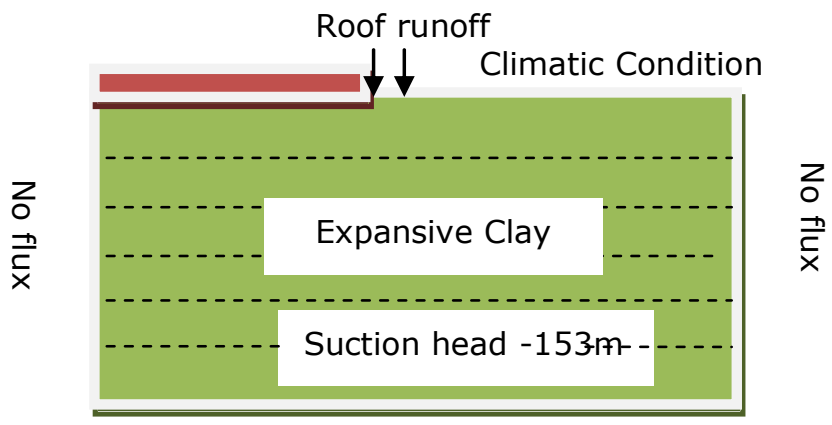

Figure 4.6. Roof runoff case boundary condition

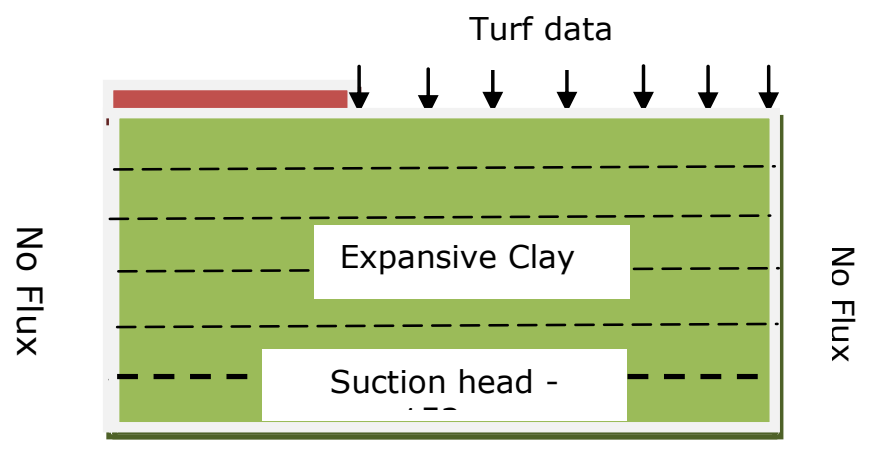

Figure 4.7. Turf case boundary condition 
For the final set of remove and replace runs, a more realistic initial condition was used for the head profile. A run in SVFlux was done for climatic surface boundary conditions for 5 years. The suction profile at the end of 5 years of analyses was judged to be a good approximation of the pseudo-equilibrium condition in the field. A no replacement expansive soil profile problem was run in SVFlux under Phoenix-region climatic conditions until "steady state" suction profile was reached, which occurred after the first five years. This provided a more appropriate initial condition for the problem to be analyzed further. The results for the 5 year expansive clay, climatic surface flux condition runs are included in the Appendix B, and these results were used for initial conditions on all subsequent runs for evaluation of the remove and replace option.

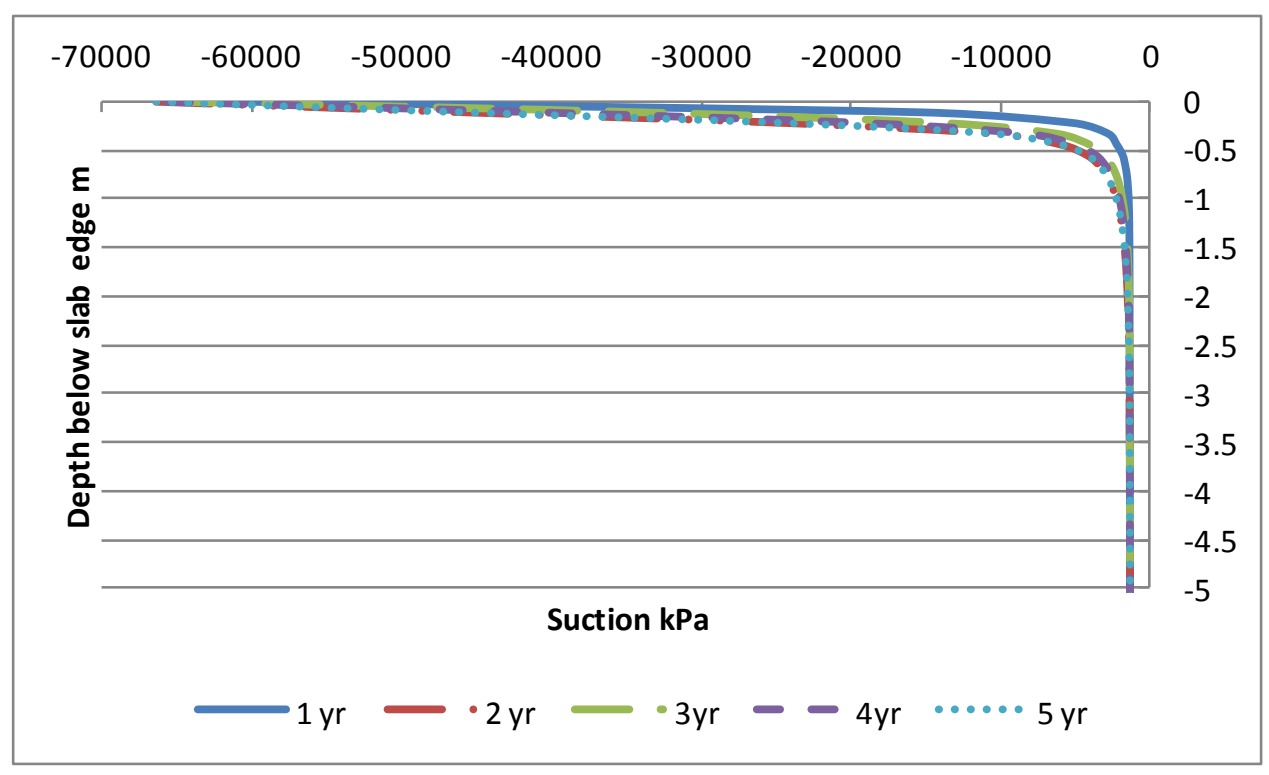

Figure 4.8. Suction variation below slab edge after 5yr climatic condition run (Initial condition for the Final no replacement profile runs, blow up profile)

The final set of transient runs for different replacement depths were done with initial condition input as the head profile from the 5 year equilibrium profile. The 
replacement layer however, was placed at a different suction head, as discussed in Section 4.5.3. Where removal and replacement conditions were run, the upper portion of the steady-state suction profile was "scalped" to the removal depth, and the suction profile in the upper region was replaced with suction conditions consistent with field compaction practices (i.e., suction values consistent with placement at approximately optimum moisture content).

These analyses for the remove and replace options and the non-replacement layer options were run for 6 years, for roof runoff and turf landscape flux data surface flux conditions, and suction conditions at the end of the 6 year period were used as the final suction condition for the SVSolid analysis.

\subsubsection{Initial and Final Condition for SVSolid Runs}

To obtain the final displacement that occurs in an expansive soil due to suction variation, an initial suction and a final suction profile is required. When doing the stress-deformation analyses, the changes in suction values with time is needed to obtain the displacement that occurs in the soil. These suction profiles are obtained from the seepage analyses done using SVFlux. For these final runs, the initial suction condition in the native clay is obtained from the 5 year climatic data (Phoenix area) run, as discussed above. The final condition suction profile was obtained from the final set of SVFlux runs under roof runoff and turf boundary conditions - at the end of 6 years, as discussed above.

\subsubsection{Mesh Size and Time Steps Used in Final Remove and Replace Study Analyses}

Before starting the final condition transient runs for different replacement depths, a 1D no replacement expansive clay model and replaced layer model was 
analyzed with a 1 yr climatic boundary condition at the top under different mesh sizes to obtain convergence. This was necessary as the set of final runs had more complicated suction conditions at the interface of replacement layer, compared to the initial runs performed to study convergence and stability issues. A finer mesh was used in the upper region of the remove and replace soil profile as maximum suction gradient occurs in this region. For no replacement case a mesh size of $0.25 \mathrm{~m}$ was used as shown in Figure 4.9. A mesh size of $0.125 \mathrm{~m}$ was finally used in the upper replacement region for higher and same $\mathrm{K}_{\text {sat }}$ replacement case (see Figure 4.10). A finer mesh size of $0.083 \mathrm{~m}$ was used for the lower $\mathrm{K}_{\text {sat }}$ case. For the remaining profile, a mesh size of $0.25 \mathrm{~m}$ was used (Figure 4.11). Figure 4.9, Figure 4.10 and Figure 4.11 show the results of $1-\mathrm{D}$ analyses for no replacement, lower $\mathrm{K}_{\text {sat }}$ and higher $\mathrm{K}_{\text {sat }}$ replacement layer.

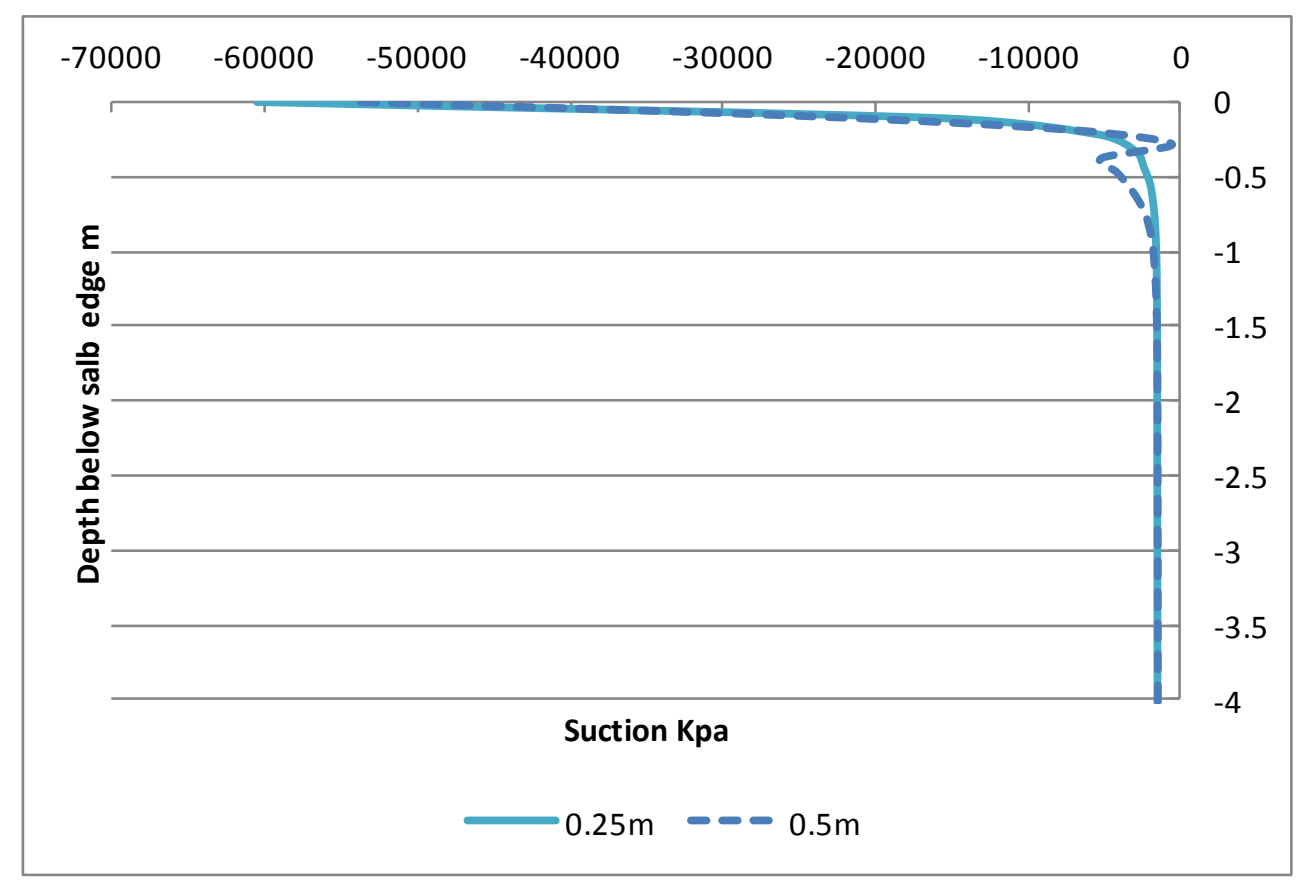

Figure 4.9. 1-D suction variation for different size for no- replacement layer (blow up profile) 


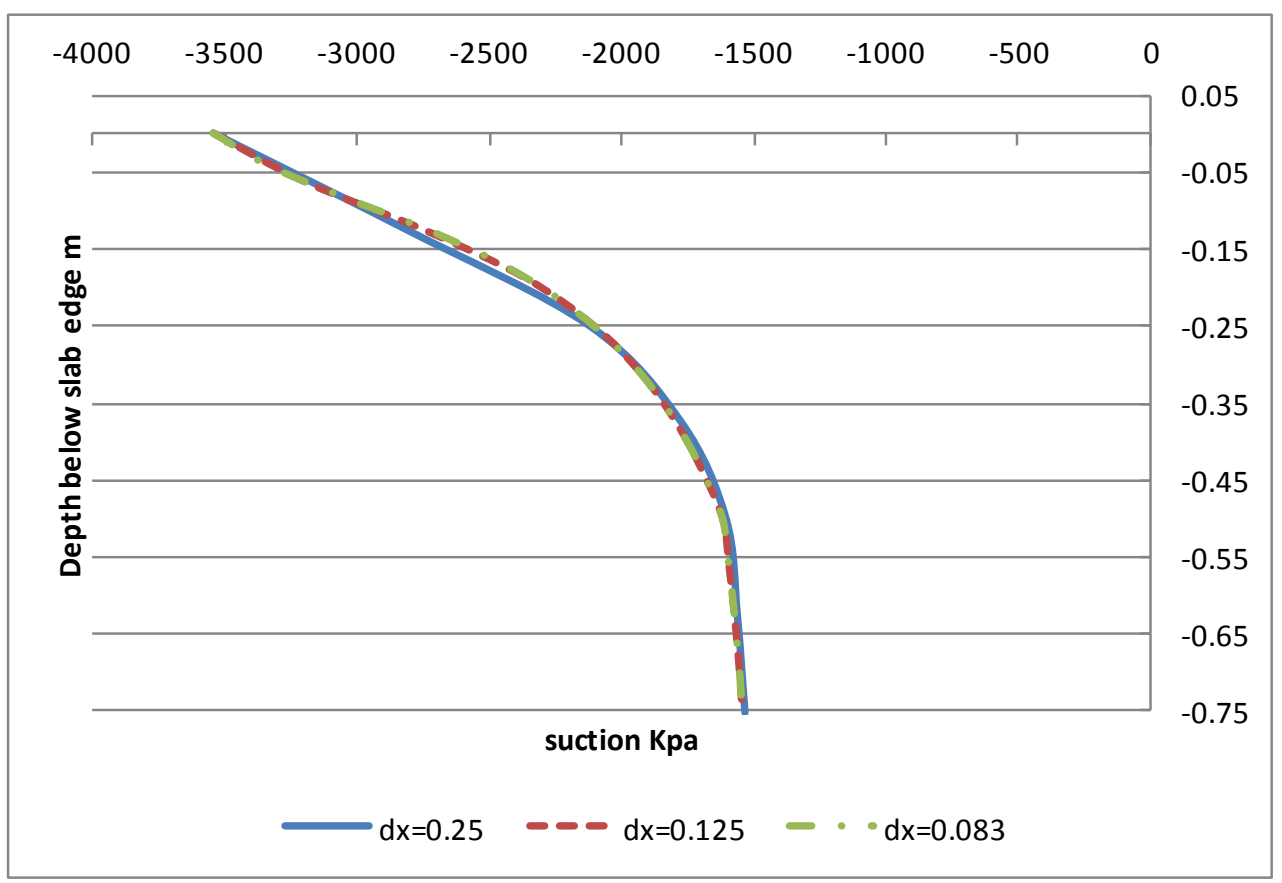

Figure 4.10. 1-D suction variation for different size for Lower $\mathrm{K}_{\text {sat }}$ replacement layer (blow up profile)

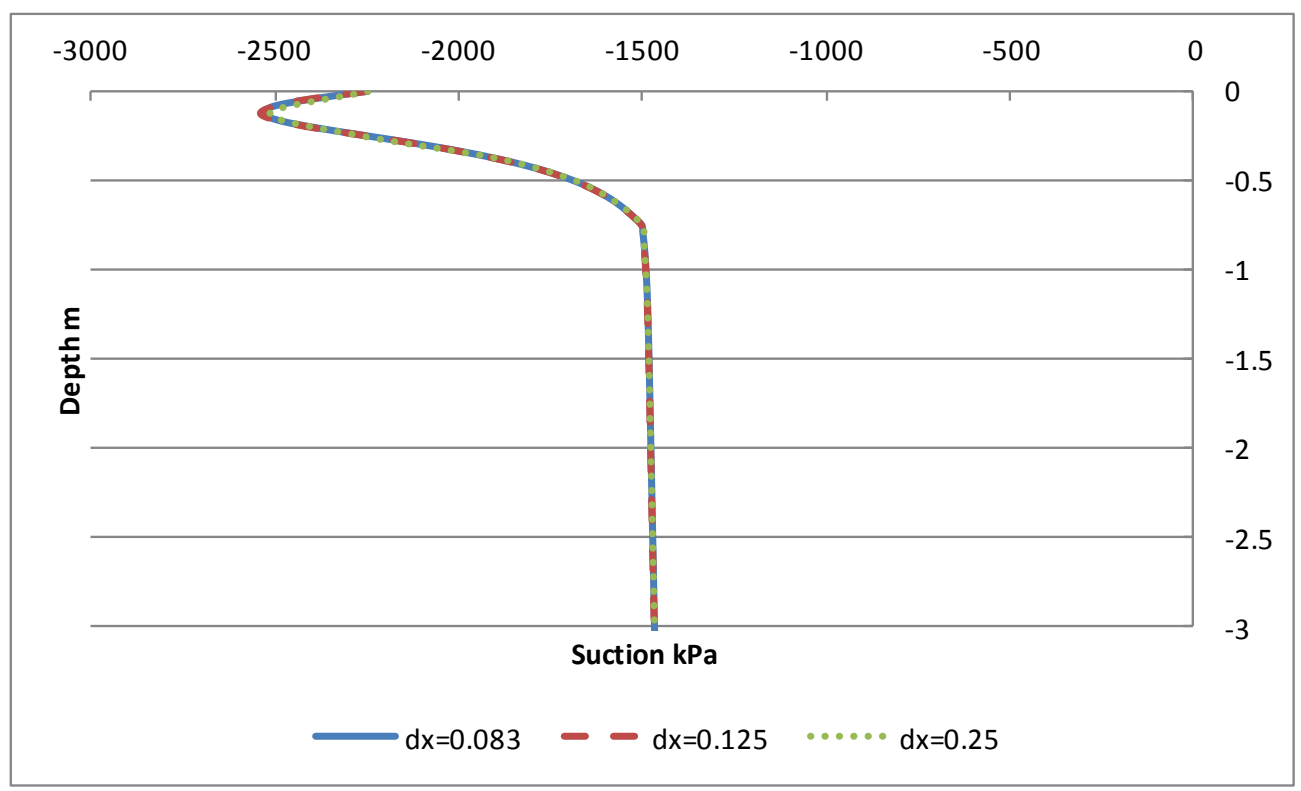

Figure 4.11. 1-D suction variation for different size for Higher $\mathrm{K}_{\text {sat }}$ replacement layer (blow up profile) 
For the final 2-D runs a total of 78329 nodes were formed for the no replacement expansive clay profile run. A maximum of 182596 nodes were created for the lower conductivity $\mathrm{K}_{\text {sat }}$ replacement case as the mesh spacing used for the top two layers was smallest in this case. Figure 4.12 shows the time-history of suction plot for a horizontal section at a depth of $1 \mathrm{~m}(\mathrm{Y}=1 \mathrm{~m})$ after the $5 \mathrm{yr}$ climatic run for "no replacement" case. Suction time-history plots for other depths are included in the Appendix B.

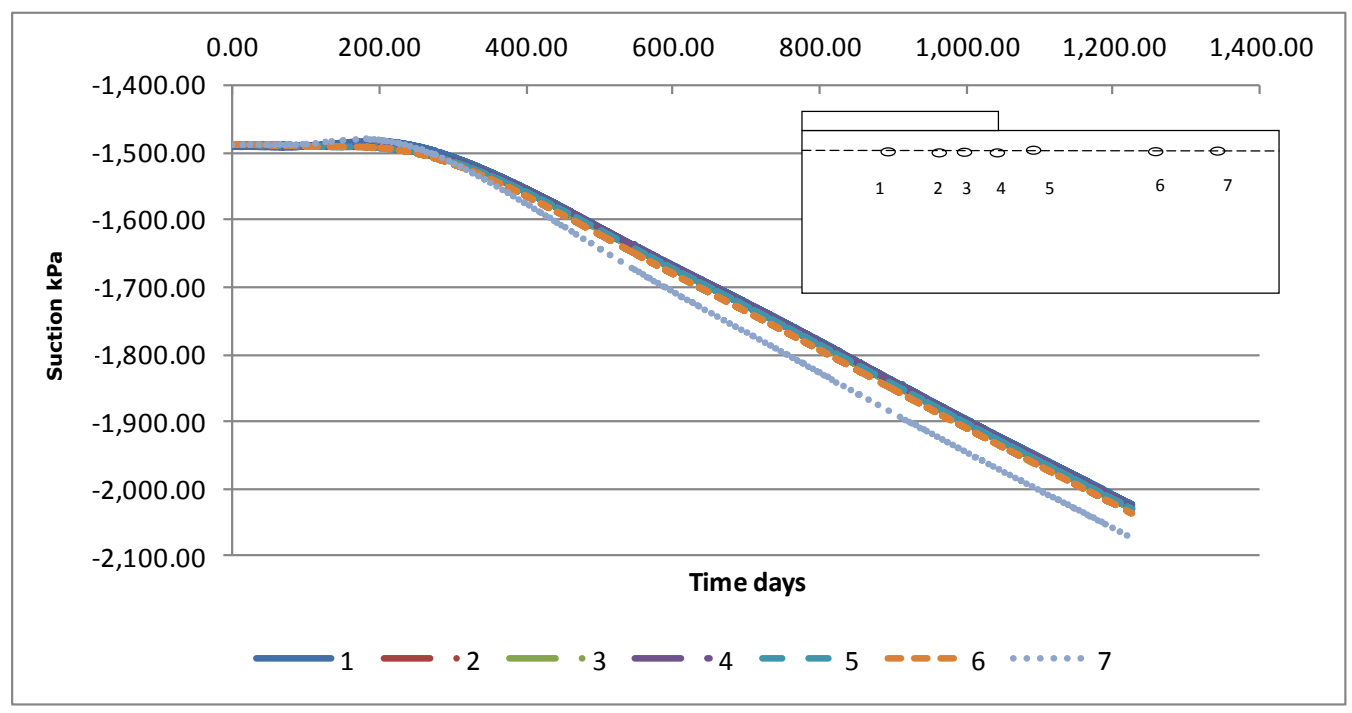

Figure 4.12. Suction Time-History plot at $1 \mathrm{~m}$ depth at various $X$

Points 1 through 7 are the points located at different distance from the center of the slab (see figure above). Point 1 is located at $5 \mathrm{~m}$ away from the center of the slab, point 2 is at $8 \mathrm{~m}$ away from the center of slab, point 3 is at $9 \mathrm{~m}$ away from the center of slab, point 4 is at $10 \mathrm{~m}$ away from the center, point 5 is at $11 \mathrm{~m}$ away from the center of slab, point 6 is at $19 \mathrm{~m}$ away from the center of slab, point 7 is at $27 \mathrm{~m}$ away from the center of slab. 
A smaller $\Delta t$ of 0.2 day was used for all the final runs. As compared to the initial (preliminary) runs (coarser mesh size of $0.5 \mathrm{~m}$ ) these runs were longer run times. The longer run times are a result of the finer grid/mesh size in the upper regions and the smaller $\Delta \mathrm{t}$. The lower $\mathrm{K}_{\text {sat }}$ replacement soil case took the longest, about 149 days to complete!

\subsection{Replacement Soils}

As mentioned in Chapter 1, three different depths of replacement for higher and same conductivity soil were used for the final runs for the roof runoff climatic conditions case. For the lower conductivity case, only the upper $0.5 \mathrm{~m}$ of the expansive clay was removed and then lower conductivity $0.5 \mathrm{~m}$ clay cap of replacement soil was considered (see Figure 4.13 below). For the replacement soils with same and higher conductivity, three different depths of replacement were chosen based on the literature review and knowledge of commonly used replacement depths.

Figure 4.14 shows the various depths of removal and replacement for the same $\mathrm{K}_{\text {sat }}$ and higher $\mathrm{K}_{\text {sat }}$ replacement soil. The matrix of total runs can be seen in Figure 4.15 . 


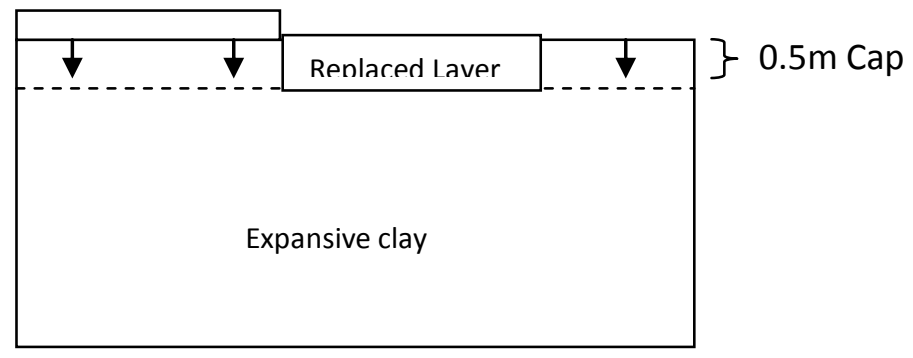

Figure 4.13. Depth of replacement (cap) for lower conductivity soil

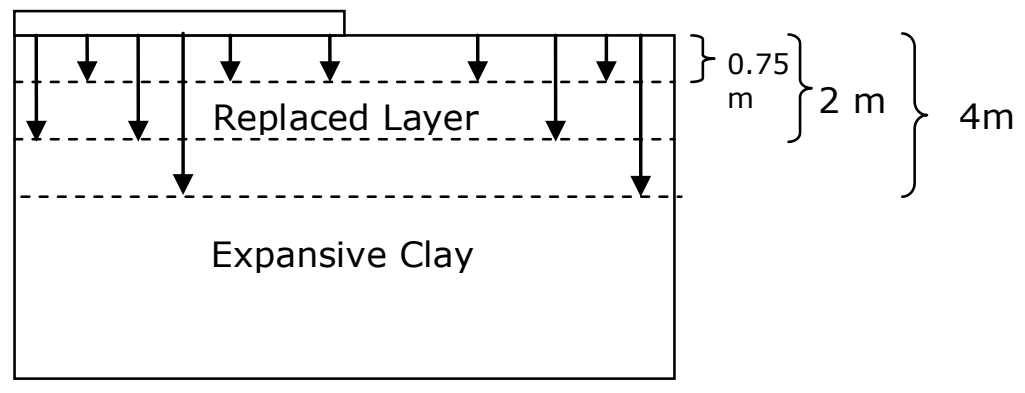

Figure 4.14. Depths for different replacement for same and higher conductivity soils

In case of turf landscape conditions only two different depths of removal and replacement were analyzed. 


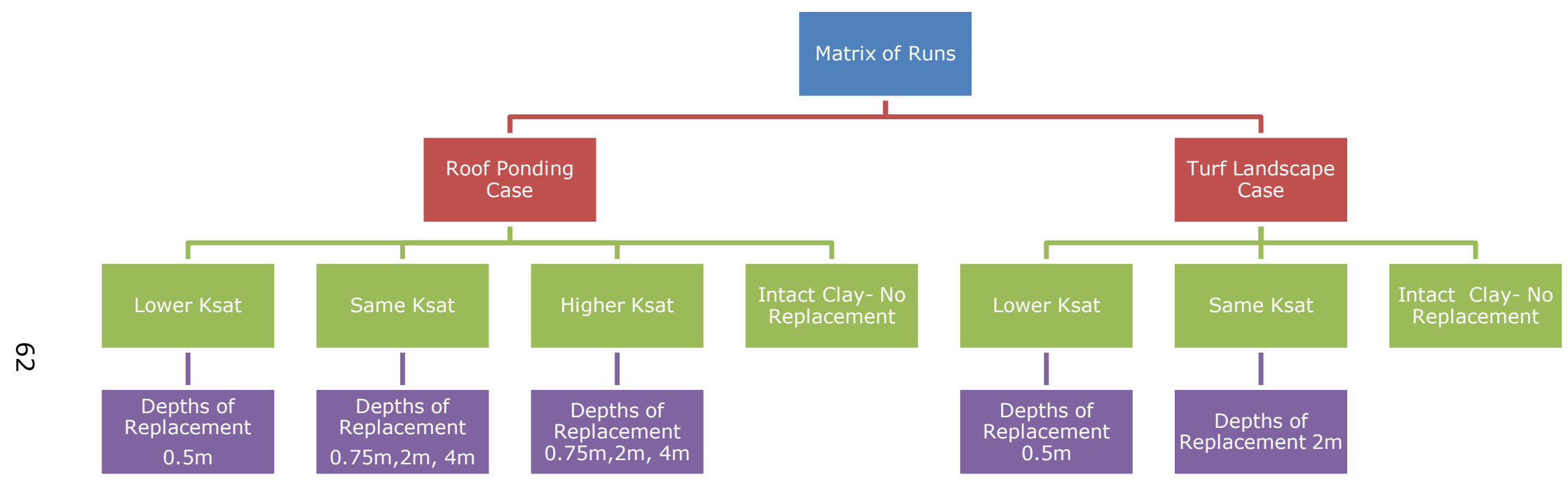

Figure 4.15. Matrix of runs 


\subsubsection{Replacement Layer SWCC and $K_{\text {unsat }}$ Curves}

The three different conductivity soils, and associated properties, were obtained from the SoilVision data source to represent the replacement layer soils. The soils were chosen primarily on the basis of the saturated hydraulic conductivity property. The first soil chosen was a lower conductivity soil with saturated hydraulic conductivity one order of magnitude lower than the expansive soil. The second replacement soil has saturated hydraulic conductivity nearly the same as the expansive soil. The third replacement soil has saturated hydraulic conductivity of nearly two orders of magnitude higher than the expansive soil.

\subsubsection{SWCC Fit}

The soil water characteristic curve for the expansive clay and replacement soils are plotted together in Figure 4.16. The SWCC for the soil in this problem is defined by using the Fredlund and Xing fit (1994) which is given by Equation 4.1 below:

$$
\theta_{w}=\theta_{s}\left[1-\frac{\ln \left(1+\mathrm{u}_{\mathrm{w}} / \mathrm{u}_{\mathrm{wr}}\right)}{\ln \left(1+10^{6} / u_{w r}\right)}\right]\left[\frac{1}{\left\{\ln \left[e+\left(\mathrm{u}_{\mathrm{w} / a}\right)^{n}\right]\right\}^{m}}\right]
$$

where

$\Theta_{\mathrm{w}}=$ volumetric water content at any soil suction

$\Theta_{\mathrm{s}}=$ saturated volumetric water content

$a=a$ material parameter which is primarily a function of air entry value of the soil in $\mathrm{kPa}$ 
$\mathrm{n}=$ a material parameter which is primarily a function of rate of water extraction from the soil once the air entry value has been exceeded

$\mathrm{m}=\mathrm{a}$ material parameter which is primarily a function of the residual water content

$\mathrm{u}_{\mathrm{w}}=\mathrm{u}_{\mathrm{a}}-\mathrm{u}_{\mathrm{w}}=$ soil suction

$\mathrm{u}_{\mathrm{wr}}=$ suction at which residual water content occurs ( $\left.\mathrm{kPa}\right)$

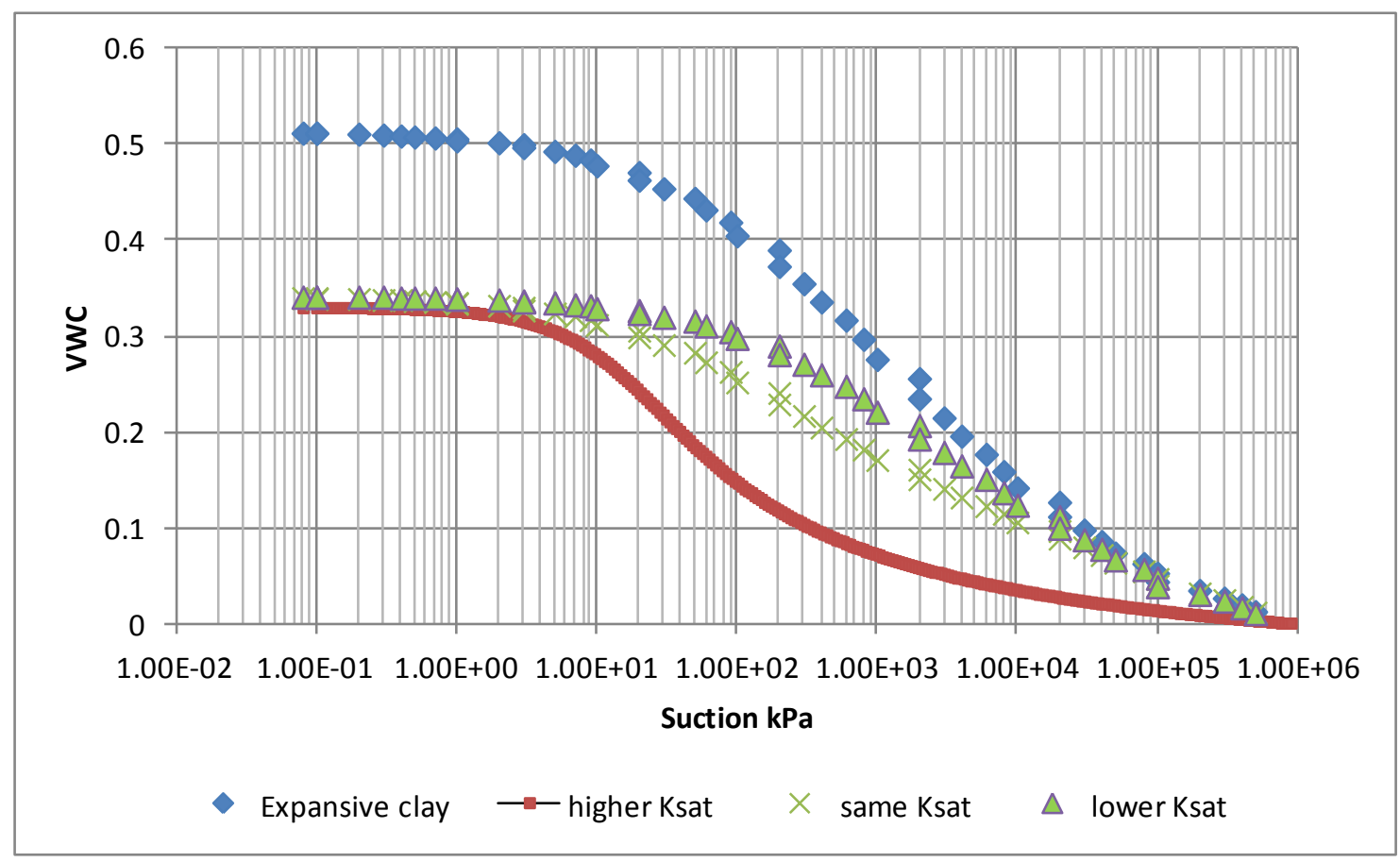

Figure 4.16. SWCC for different soils

\subsubsection{1 $\mathrm{K}_{\text {unsat }}$ Function Used}

Leong and Rahardjo fit (1997) is used to describe the unsaturated hydraulic conductivity for this problem. The fit is given by Equation 4.2.

$$
\mathrm{k}_{\left(\mathrm{u}_{\mathrm{a}}-\mathrm{u}_{\mathrm{w}}\right)}=k_{s}\left[\ln \left(e+\left(\frac{u_{a}-u_{w}}{a}\right)^{n}\right)\right]^{-p m}
$$


where

$\mathrm{n}=$ controls the slope at the inflection point, and

$\mathrm{m}=$ residual water content in the soil.

$\mathrm{p}=$ different constant soil parameters

$\mathrm{k}_{\mathrm{s}}=$ saturated hydraulic conductivity

As explained in Section 3.3.2, coarser grained soils have a cross-over on the hydraulic conductivity curves when compared to fine grained soil. The higher conductivity replacement soil also has a cross over with expansive soil and lower conductivity soil. Coarse grained soils have higher conductivity than fine grained soil at low suctions near saturation. However, the unsaturated conductivity curves cross at a particular suction value and beyond that point the hydraulic conductivity of fine grained soil remains higher than the coarse grained soil. The $K_{\text {unsat }}$ curves for all the soils are plotted in Figure 4.17. 


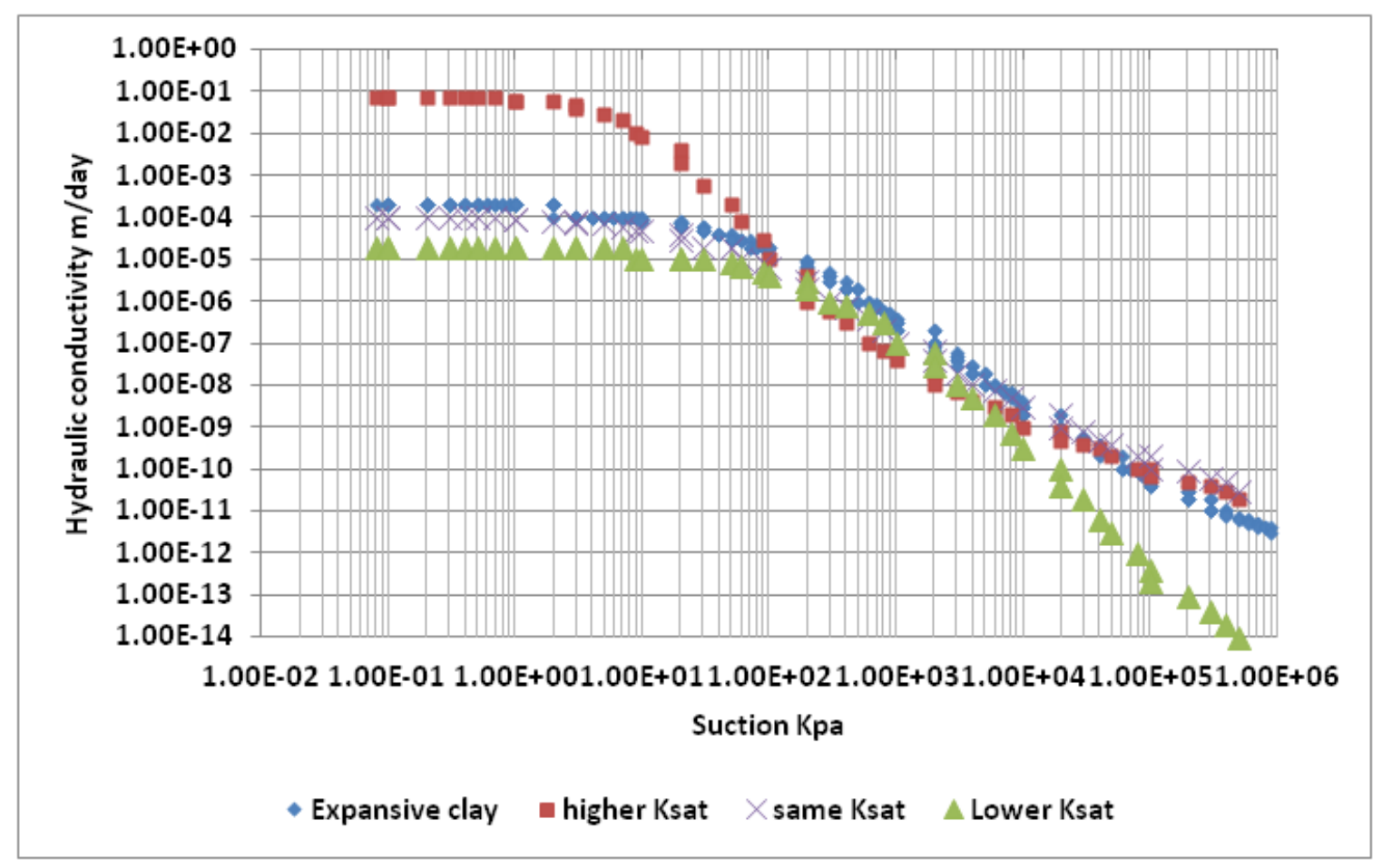

Figure 4.17. $\mathrm{K}_{\text {unsat }}$ Curves for different soils

\subsubsection{Soil Properties}

The Expansive soil properties are shown in Table 4.1. The replacement soil properties are tabulated in Table 4.2. The expansive soil is a $\mathrm{CH}$ soil, highly expansive in nature. The higher conductivity soil is a sandy loam which is categorized as SM-ML soil with low plasticity index (less than 10 ). The lower $\mathrm{K}_{\text {sat }}$ replacement soils can be described as clay loam and is classified as CL soil. The same $\mathrm{K}_{\text {sat }}$ replacement soil can be classified as CL-ML soil. The replacement layer is well compacted and homogenized and laid at optimum moisture content.

These replacement soils are insensitive to moisture change (i.e. they do not change volume significantly when soil suction is changed). Thus, as mentioned 
Chapter 1 , the replacement soils are non-expansive in nature. The volume change properties for the replacement soils are included in the following sections.

Table 4.1. Expansive clay properties

\begin{tabular}{|c|c|}
\hline LL & 85 \\
\hline $\mathrm{PI}$ & 53 \\
\hline $\mathrm{G}_{\mathrm{s}}$ & 2.79 \\
\hline$\rho_{\mathrm{d}}$ & $1.36 \mathrm{~g} / \mathrm{cm}^{3}$ \\
\hline Fredlund \& Xing, $\mathrm{a}$ & 140 \\
\hline $\mathrm{n}$ & 0.6 \\
\hline $\mathrm{m}$ & 0.9 \\
\hline $\mathrm{h}$ & 2000 \\
\hline$\theta_{\mathrm{w}}$ & 0.512 \\
\hline $\mathrm{K}_{\mathrm{sat}}$ & $2.42 \times 10^{-9} \mathrm{~m} / \mathrm{s}$ \\
& $2.09 \times 10^{-4} \mathrm{~m} / \mathrm{day}$ \\
\hline $\mathrm{P}$ & 12 \\
\hline
\end{tabular}

Table 4.2. Replacement soil properties

\begin{tabular}{|c|c|c|c|}
\hline Soil Density & Higher $\mathbf{K}_{\text {sat }}$ & Lower $\mathbf{K}_{\text {sat }}$ & Same $\mathbf{K}_{\text {sat }}$ \\
\hline Dry density & $1770 \mathrm{Kg} / \mathrm{m}^{3}$ & $1799 \mathrm{Kg} / \mathrm{m}^{3}$ & $1803 \mathrm{Kg} / \mathrm{m}^{3}$ \\
\hline Total unit weight & $20.6 \mathrm{KN} / \mathrm{m}^{3}$ & $20.99 \mathrm{KN} / \mathrm{m}^{3}$ & $21.01 \mathrm{KN} / \mathrm{m}^{3}$ \\
\hline Sat. VWC & 0.33 & 0.34 & 0.34 \\
\hline $\mathrm{K}_{\text {sat }}$ & $7.2 \times 10^{-2}$ & $2.09 \times 10^{-5}$ & $1.11 \times 10^{-4}$ \\
& $\mathrm{~m} / \mathrm{day}$ & $\mathrm{m} / \mathrm{day}$ & $\mathrm{m} / \mathrm{day}$ \\
\hline AEV & $15 \mathrm{kPa}$ & $60 \mathrm{kPa}$ & $22 \mathrm{kPa}$ \\
\hline Leong \& & 11 & 12 & 10 \\
Rahardjo P & & & \\
\hline
\end{tabular}




\subsubsection{Degree of Saturation and Suction Values for Replacement Layer}

The degree of saturation of the replacement layer was based on typical values for compacted soil presented by Benson (1995) for 13 different compacted soils. He reports values for optimum dry density and water content for different compactive efforts. For soils which are close in properties to the lower $\mathrm{K}_{\text {sat }}$ replacement layer, the saturation at optimum is in the range of $78 \%$ and for some it is even as low as $42 \%$. Based on this, a value of $75 \%$ was chosen to be a good estimate (within the range) for lower $\mathrm{K}_{\text {sat }}$ replacement layer. Also for the higher $\mathrm{K}_{\text {sat }}$ replacement layer, Maud (1960) has reported values as low as $51.8 \%$ for sandy loams. This provided a reasonable estimate for the higher $\mathrm{K}_{\text {sat }}$ replacement soil. A non-expansive soil is usually considered to be a soil that has a plasticity index less than 20 .

The suction values were estimated from the SWCC curves of the replacement soils based on their respective saturation values. The goal in selection of replacement layer soil properties was to have reasonable properties as well as consistency in properties for a given soil type.

Table 4.3 below shows the values of suction and optimum saturation $\left(\mathrm{S}_{\mathrm{opt}}\right)$ used for the different replacement layer runs. 
Table 4.3. Placement saturation and suction values for the replacement layer soils

\begin{tabular}{|c|c|c|c|c|}
\hline $\begin{array}{c}\text { Replacement } \\
\text { Soil }\end{array}$ & PI & $\begin{array}{c}\text { P200, \% } \\
\text { fines }\end{array}$ & Sopt & Suction \\
\hline Higher $\mathrm{K}_{\text {sat }}$ & 5 & 30 & $51.8 \%$ & $70 \mathrm{kPa}$ \\
\hline Same $\mathrm{K}_{\text {sat }}$ & 11 & 62 & $65.9 \%$ & $300 \mathrm{kPa}$ \\
\hline${\text { Lower } \mathrm{K}_{\text {sat }}}$ & 18 & 74 & $74.8 \%$ & $490 \mathrm{kPa}$ \\
\hline
\end{tabular}

Figure 4.18 shows the initial and final condition suction curves for $2 \mathrm{~m}$ same Ksat replacement case. The initial condition curve is obtained from the $5 \mathrm{yr}$ climatic equilibrium run with the top $2 \mathrm{~m}$ depth scalped and replaced with same $\mathrm{K}_{\text {sat }}$ soil and placed at $-300 \mathrm{kPa}$ suction. The final condition suction profile is obtained from the end of the 6yr transient run for the roof-run off surface flux case.

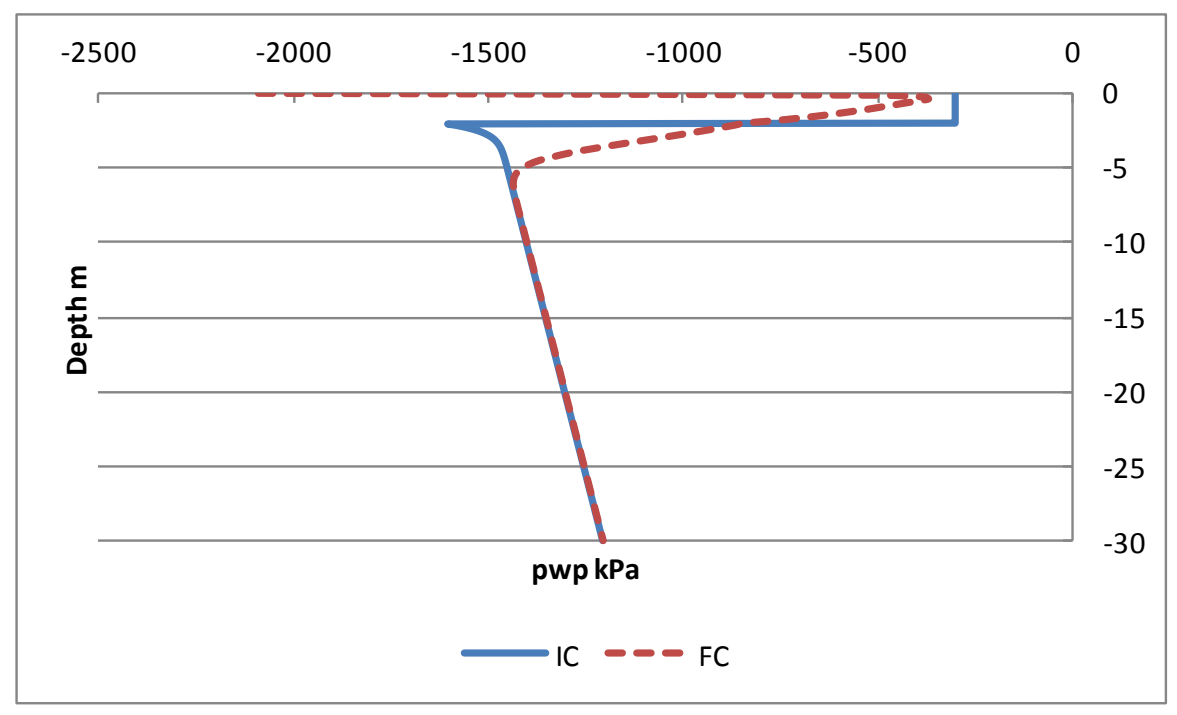

Figure 4.18. Initial (IC) and Final condition (FC) suction variation at $X=10 \mathrm{~m}$, edge of slab ( $2 \mathrm{~m}$ same $\mathrm{K}_{\text {sat }}$ replacement case) for the roof run-off surface flux condition 
The initial and final condition suction profiles for other replacement cases for the roof run-off runs and turf runs are included in Chapter 5, with an emphasis on vertical profiles beneath the slab edge. The initial and final condition suction profiles at various distances beneath and outside of the slab edge, for both roof runoff and turf cases are included in Appendix C.

\subsection{Climatic Input Data}

The average precipitation data applied as the climatic boundary conditions for establishment of initial condition ( 5 yr run) was obtained from Phoenix airport metrological station (Dye, 2008). Statistical analyses show that Phoenix receives an average of $8.04 \mathrm{in} / \mathrm{yr}(0.2 \mathrm{~m} / \mathrm{yr})$ rainfall with a standard deviation of $3 \mathrm{in} / \mathrm{yr}$. Table 4.4 shows the precipitation input flux and the potential evaporation for each month in the Phoenix region. Potential evaporation is applied using daily time steps with higher evaporation rates during summer months and lower evaporation rates during winters.

Dye (2008) did a study of how the yearly average precipitation flux and daily steps scheme precipitation flux affects the final suction results computed from unsaturated flow analyses. It was found that for the Phoenix region the amount of precipitation flux is small enough that all rainfall tends to infiltrate into the soil and therefore averaging the rainfall flux does not affect the final output suction variation. The actual scheme consisted of rainfall application only on the number of rainy days. Therefore an average precipitation flux was used for the analyses (Figure 4.19) for the open surface outside of the roof run-off ponded region. Figure 4.20 shows the potential evaporation applied each day of the month. 
A simulation of slab-on-ground problem was performed to access the impact of ponded roof runoff drainage conditions on moisture flow through unsaturated soil in 2D domain for three different replacement soil types, namely SM-ML and CL-ML and expansive soil. The amount of roof runoff was calculated based on assumed 10 meter wide total roof area (Dye, 2008). Figure 4.21 shows the variation of applied roof runoff flux. The spikes in the roof runoff flux data show that it is applied only on those days of each month when rainfall occurs. The runoff data is applied at the start of rainy day each month and ends at the last day of precipitation. A pond $0.13 \mathrm{~m}$ deep is allowed to occur, and any excess is run-off. Eventually, when rain stops, the pond water either evaporates or infiltrates. Another 2D simulation was done with the turf landscape irrigation data as the boundary condition. Dye (2008) did a study to find out the typical irrigation pattern in the Phoenix, AZ region for the turf landscape. It was determined that the most common irrigation pattern is to water each day throughout the year. There are two different irrigation seasons namely summer and winter irrigation and therefore the flux applied to the turf landscape also varies. More water is needed to irrigate the landscape during summer season and less is needed during the winter season. The summer irrigation season begins from May and ends in October. The magnitude of flux applied is $0.4 \mathrm{in} / \mathrm{hr}$ for $1 \mathrm{hr}$ every day. The winter irrigation month is from November to April and the magnitude of applied flux is $0.2 \mathrm{in} / \mathrm{hr}$ for $0.5 \mathrm{hr}$ every day.

For analyses purpose the hourly flux was simply converted to daily flux. It was then applied on a daily basis for each day of the month.

Figure 4.22 shows the applied irrigation turf flux + precipitation data. The runoff function was invoked in SVFlux in order to let the excess water flow off. 
Figure 4.25 and Figure 4.26 shows the applied temperature and relative humidity data for a year. Figure 4.27 shows all the applied flux data on the same plot.

Table 4.4. Average Precipitation Data from Phoenix Airport Metrological Station (From NCDC) (Dye, 2008)

\begin{tabular}{|c|c|c|c|c|c|c|}
\hline \multirow{3}{*}{ Month } & \multirow{3}{*}{$\begin{array}{c}\begin{array}{c}\text { Average } \\
\text { Precipitation }\end{array} \\
{[\text { in/mo }]}\end{array}$} & \multirow{2}{*}{\multicolumn{2}{|c|}{$\begin{array}{c}\text { Average } \\
\text { Number of } \\
\text { Rainy }\end{array}$}} & \multicolumn{3}{|c|}{ Desert Input $[\mathrm{m} / \mathrm{h}]$} \\
\hline & & & & \multicolumn{2}{|c|}{$\begin{array}{c}\text { Precipitation applied } \\
\text { as per }\end{array}$} & \multirow{2}{*}{ PE } \\
\hline & & Days & Hours & $\begin{array}{c}\text { Prec. } \\
\text { Scheme }\end{array}$ & $\begin{array}{l}\text { Ave. flux } \\
\text { per mo. }\end{array}$ & \\
\hline 1 & 0.98 & 6 & 7 & $7.20 \mathrm{E}-04$ & $4.00 \mathrm{E}-05$ & $-1.16 \mathrm{E}-04$ \\
\hline 2 & 0.90 & 6 & 8 & $6.40 \mathrm{E}-04$ & $4.44 \mathrm{E}-05$ & $-1.46 \mathrm{E}-04$ \\
\hline 3 & 1.10 & 7 & 8 & $7.30 \mathrm{E}-04$ & $5.45 \mathrm{E}-05$ & $-2.26 \mathrm{E}-04$ \\
\hline 4 & 0.32 & 4 & 5 & $7.00 \mathrm{E}-04$ & $1.98 \mathrm{E}-05$ & $-3.07 E-04$ \\
\hline 5 & 0.15 & 3 & 1 & $1.65 E-03$ & $6.73 E-06$ & $-4.00 \mathrm{E}-04$ \\
\hline 6 & 0.03 & 2 & 1 & $7.80 \mathrm{E}-04$ & $2.23 \mathrm{E}-06$ & $-4.20 \mathrm{E}-04$ \\
\hline 7 & 1.02 & 8 & 5 & $1.06 \mathrm{E}-03$ & $5.82 \mathrm{E}-05$ & $-4.35 E-04$ \\
\hline 8 & 0.82 & 9 & 2 & $1.45 \mathrm{E}-03$ & $3.67 E-05$ & $-3.62 E-04$ \\
\hline 9 & 0.70 & 5 & 3 & $1.49 \mathrm{E}-03$ & $3.11 \mathrm{E}-05$ & $-3.06 \mathrm{E}-04$ \\
\hline 10 & 0.58 & 4 & 4 & $1.17 \mathrm{E}-03$ & $2.48 \mathrm{E}-05$ & $-2.32 \mathrm{E}-04$ \\
\hline 11 & 0.69 & 4 & 6 & $9.00 \mathrm{E}-04$ & $2.93 \mathrm{E}-05$ & $-1.50 \mathrm{E}-04$ \\
\hline 12 & 0.78 & 5 & 6 & 7.70E-04 & $3.06 \mathrm{E}-05$ & $-9.80 \mathrm{E}-05$ \\
\hline
\end{tabular}




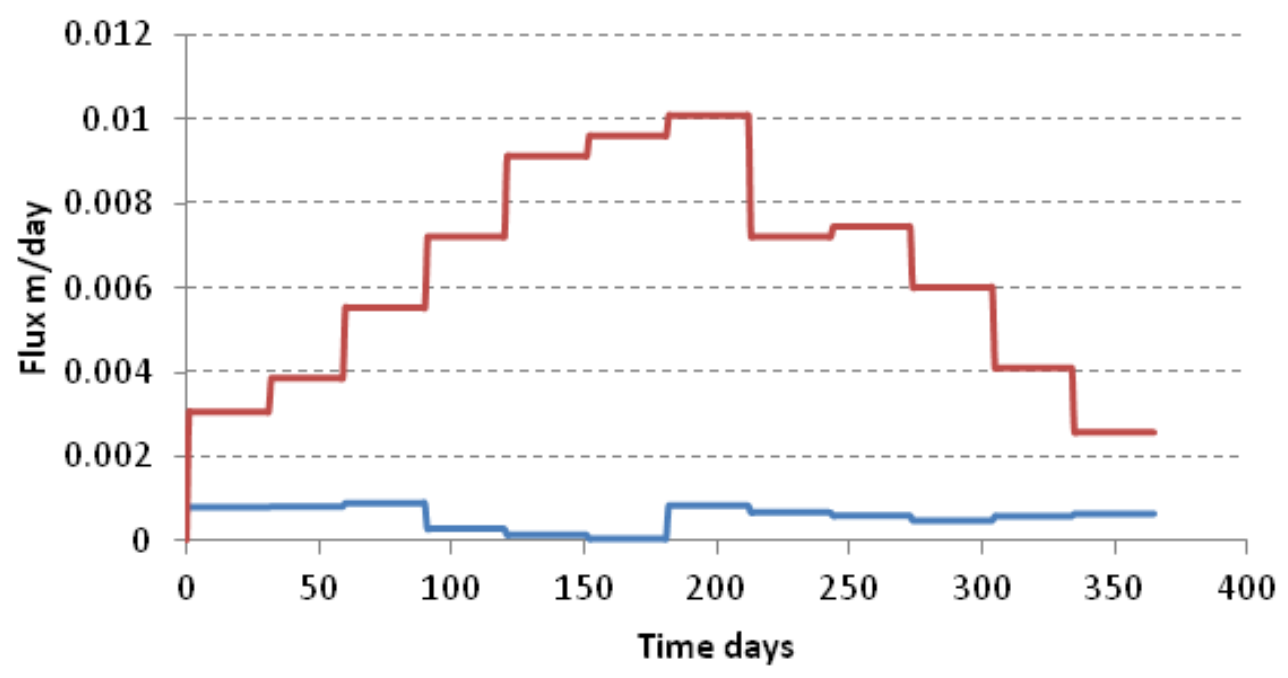

$\longrightarrow$ Rainfall $\longrightarrow$ PE

Figure 4.19. Average rainfall

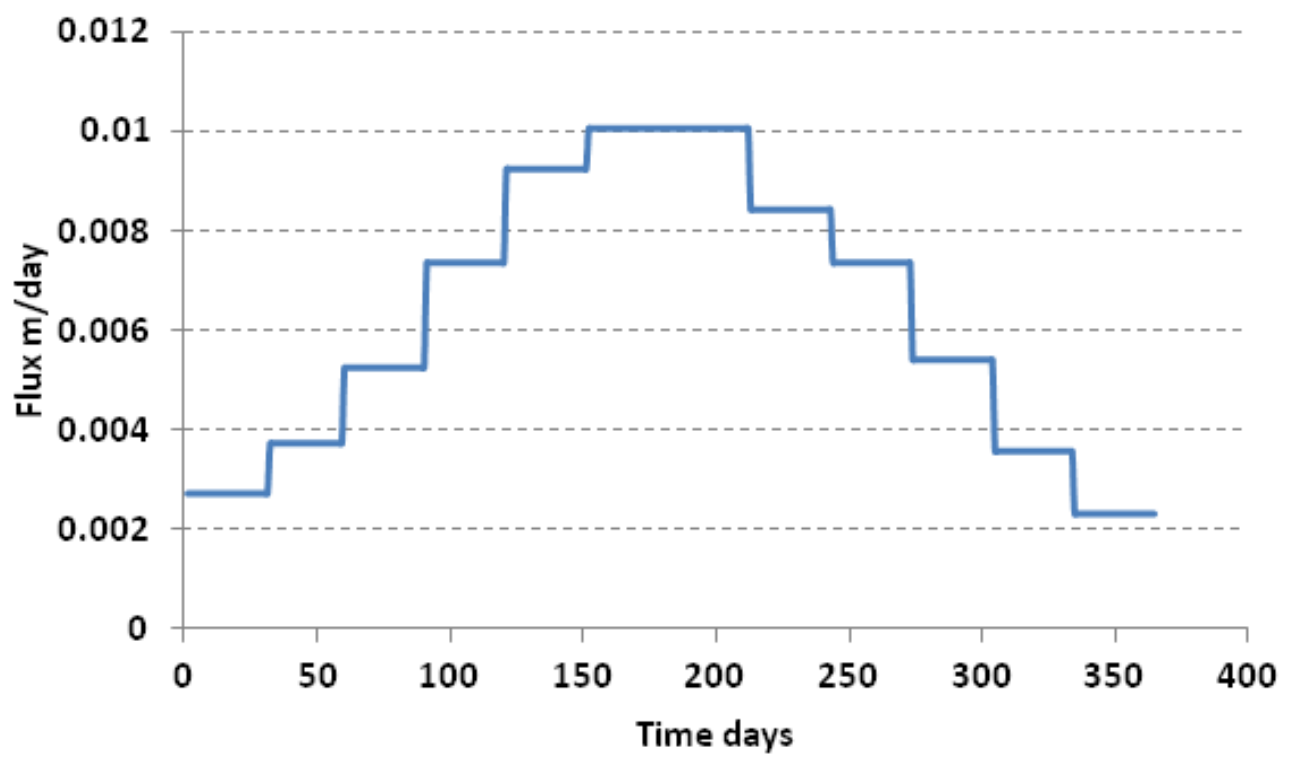

Figure 4.20. PE Data 


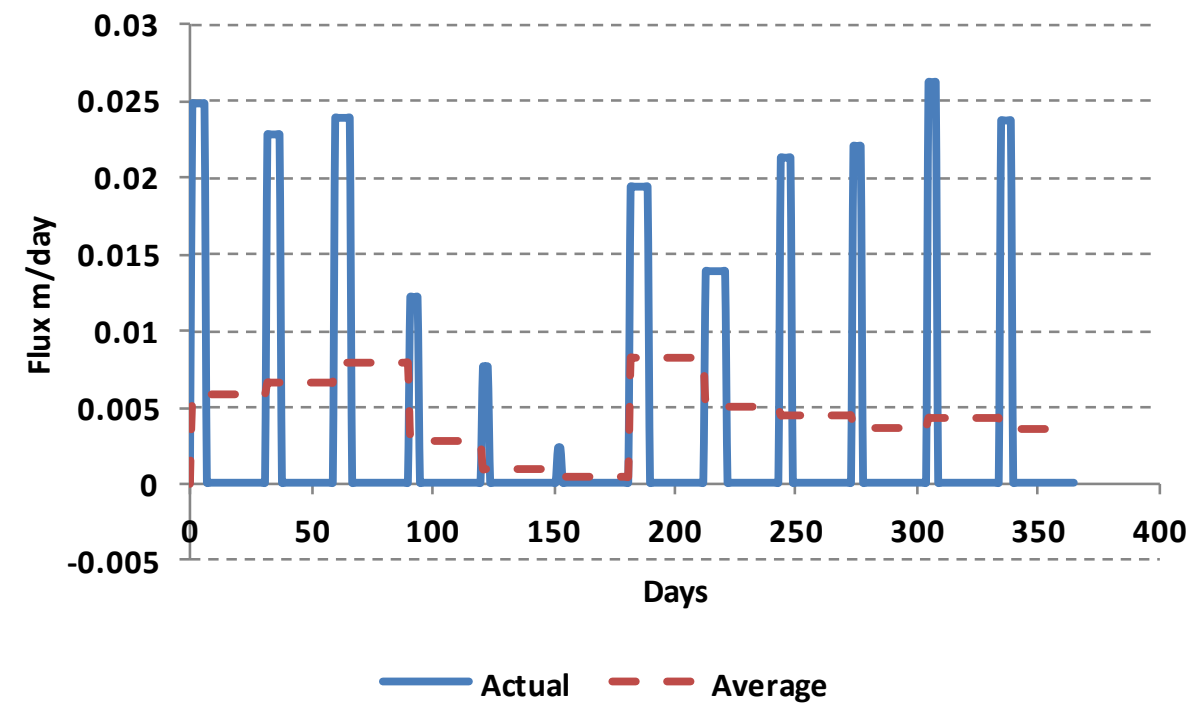

Figure 4.21. Roof runoff data

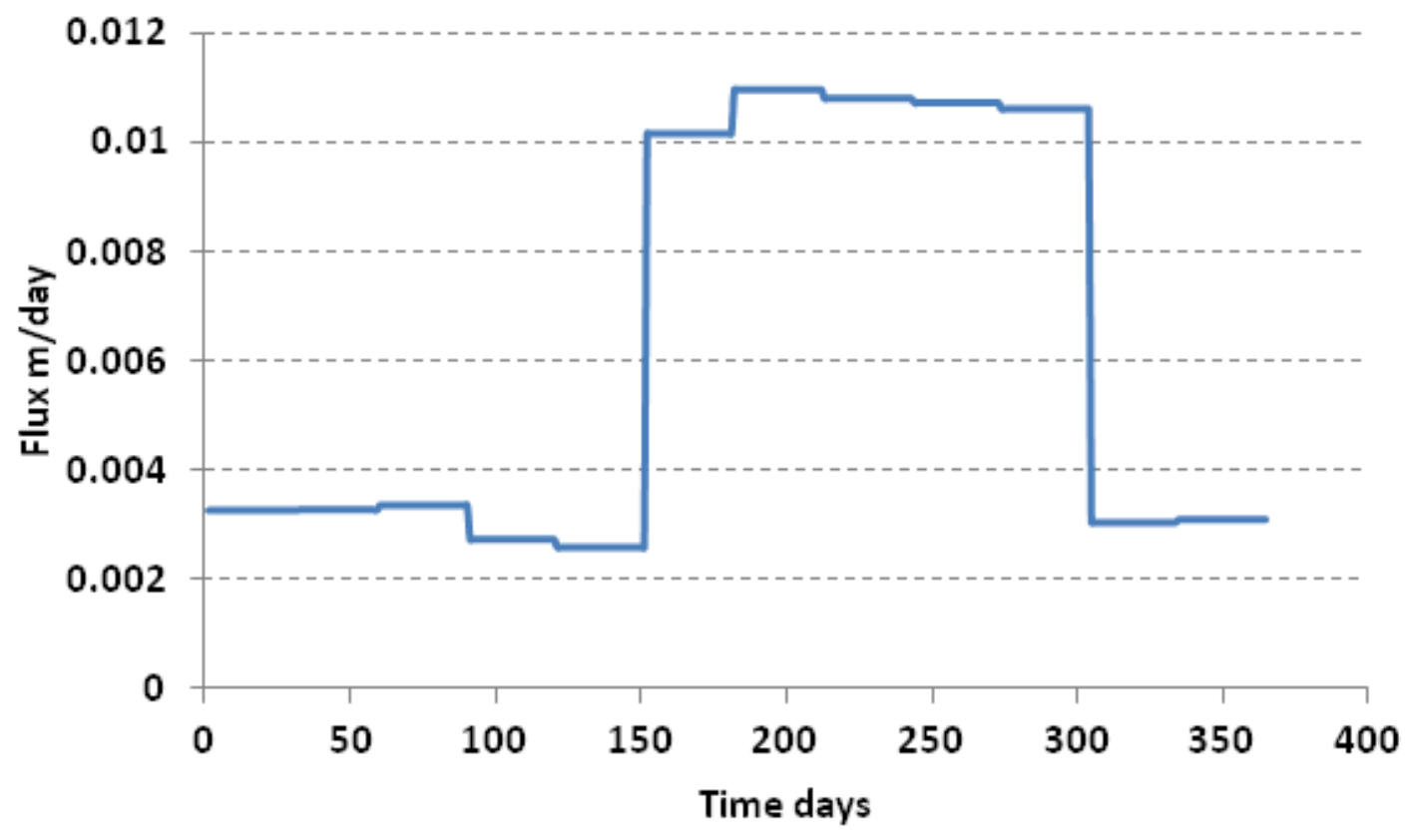

Figure 4.22. Turf + precipitation data 


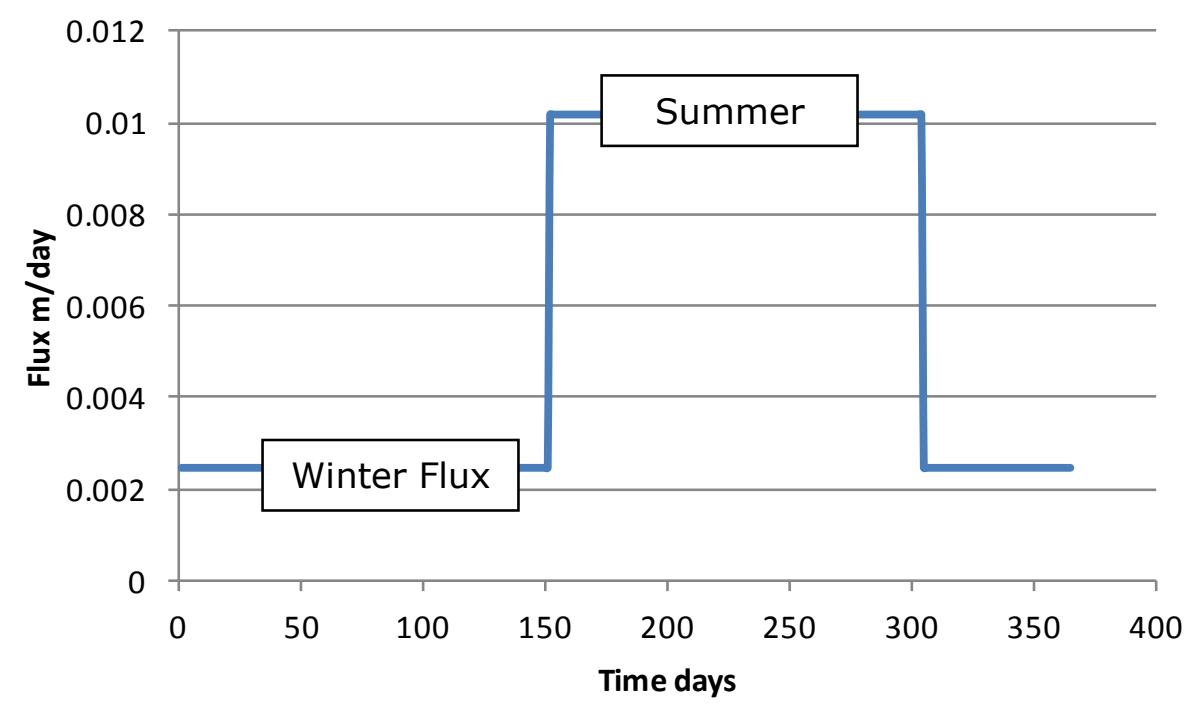

Figure 4.23. Turf data based on daily flux

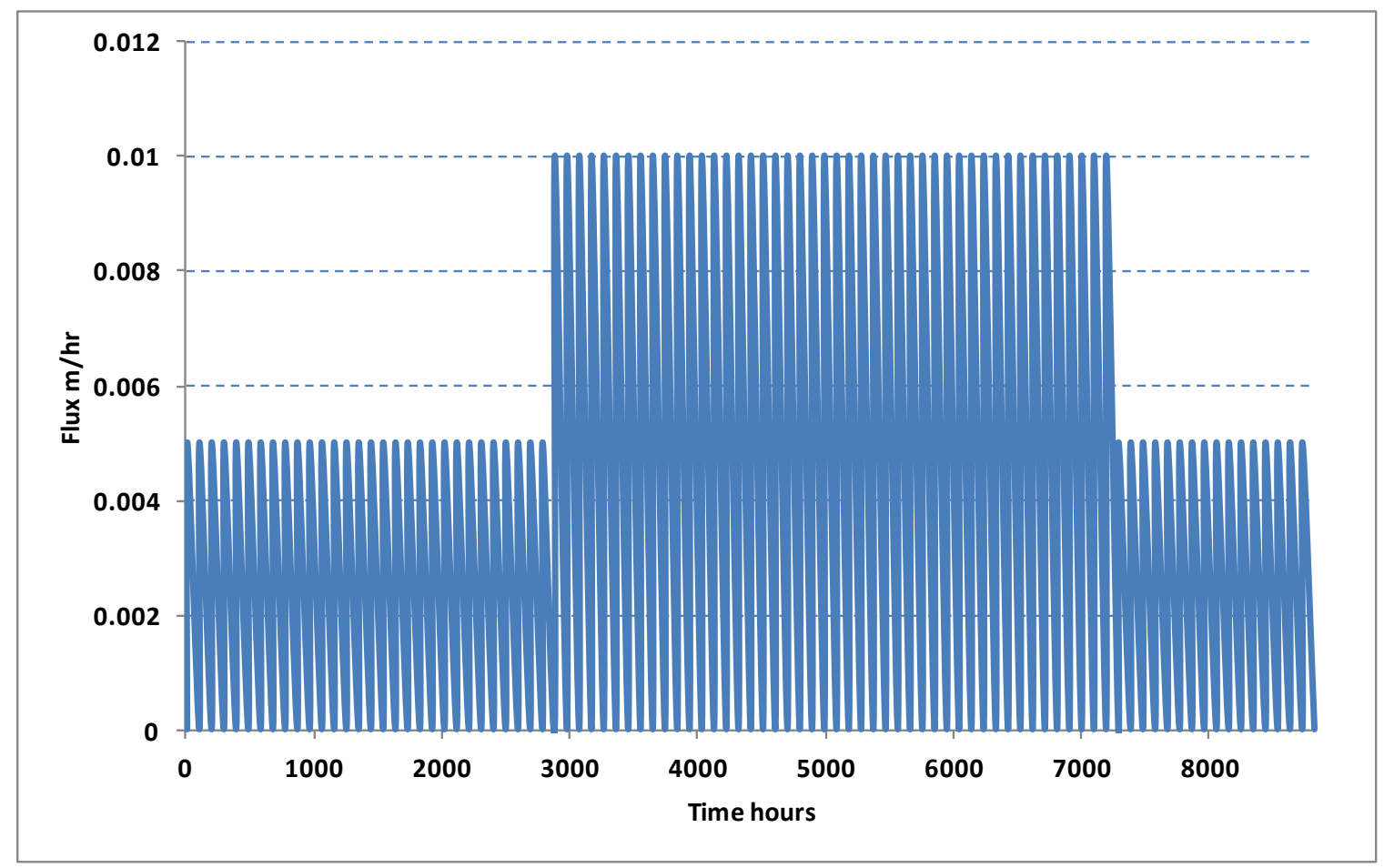

Figure 4.24. Turf data based on hourly flux 
Figure 4.23 and Figure 4.24 shows the daily and hourly turf flux variation.

It should be noted that, although the amount of water applied to soil is the same in both the cases, all of the applied water infiltrates into the soil profile when the amount of water applied during irrigation is spread out over the entire day. Therefore, spreading out the irrigation over the entire day provides a reasonable simulation for poorly sloped ground surface conditions wherein all of the applied water is forced to infiltrate into the soil profile. Hourly flux, when used together with the run-off simulator in SVFlux, allows for simulation of a good drainage condition. This is because any water that cannot infiltrate during the actual irrigation time period of approximately 1 hour is forced to run-off rather than to infiltrate into the soil profile. In case of hourly flux, evaporation occurs from the ground surface during non-irrigation periods when there is no rainfall (a common case in arid climatic conditions).

Turf flux when applied on a daily basis does not produce the amount of runoff as compared to hourly flux and thus simulates a poor drainage condition. Since the flux is concentrated for each day instead of hours, the soil is not allowed to drain off the actual amount of water that it should otherwise. There is more water being forced into the soil than the actual infiltration rate. Due to this, the results of daily flux are expected to show somewhat higher depth of wetting as compared to hourly results (Heather et.al, 2008). The turf cases analyzed in this study are more relevant to a condition with poor drainage conditions. 


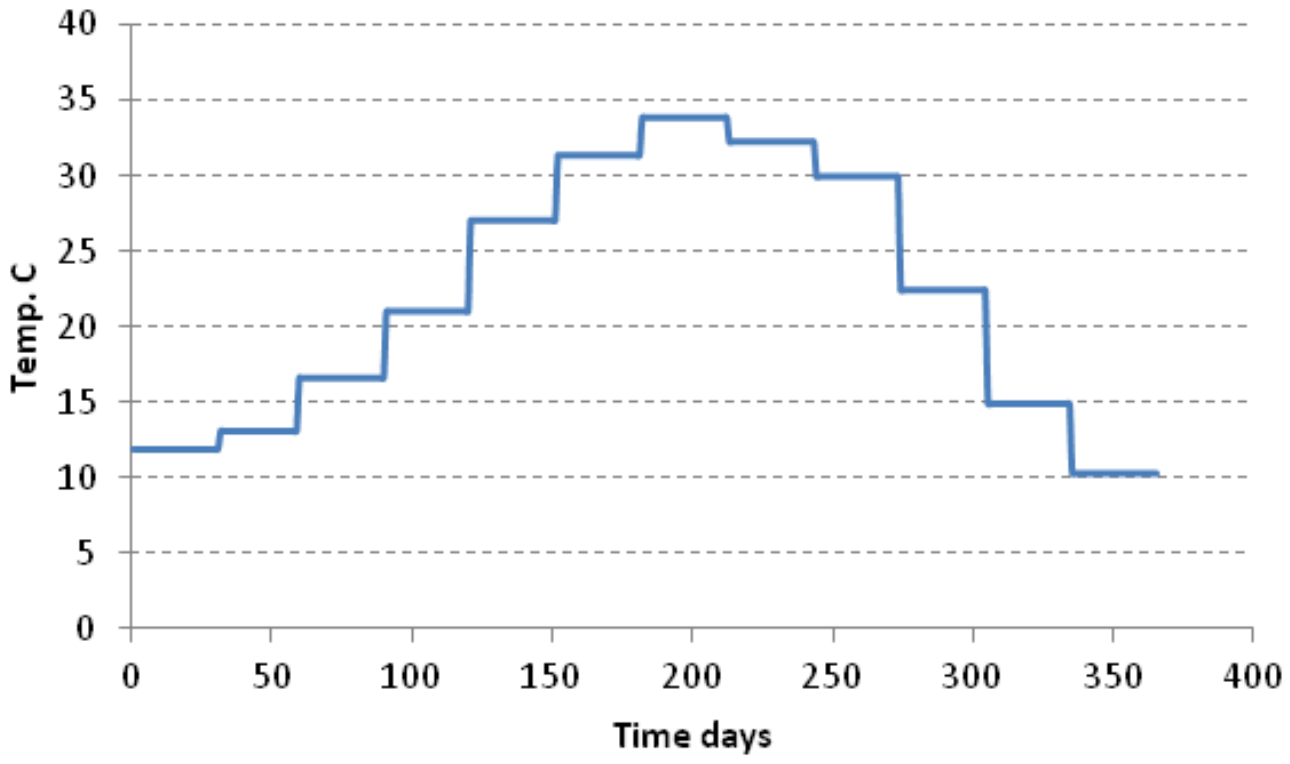

Figure 4.25. Temperature data

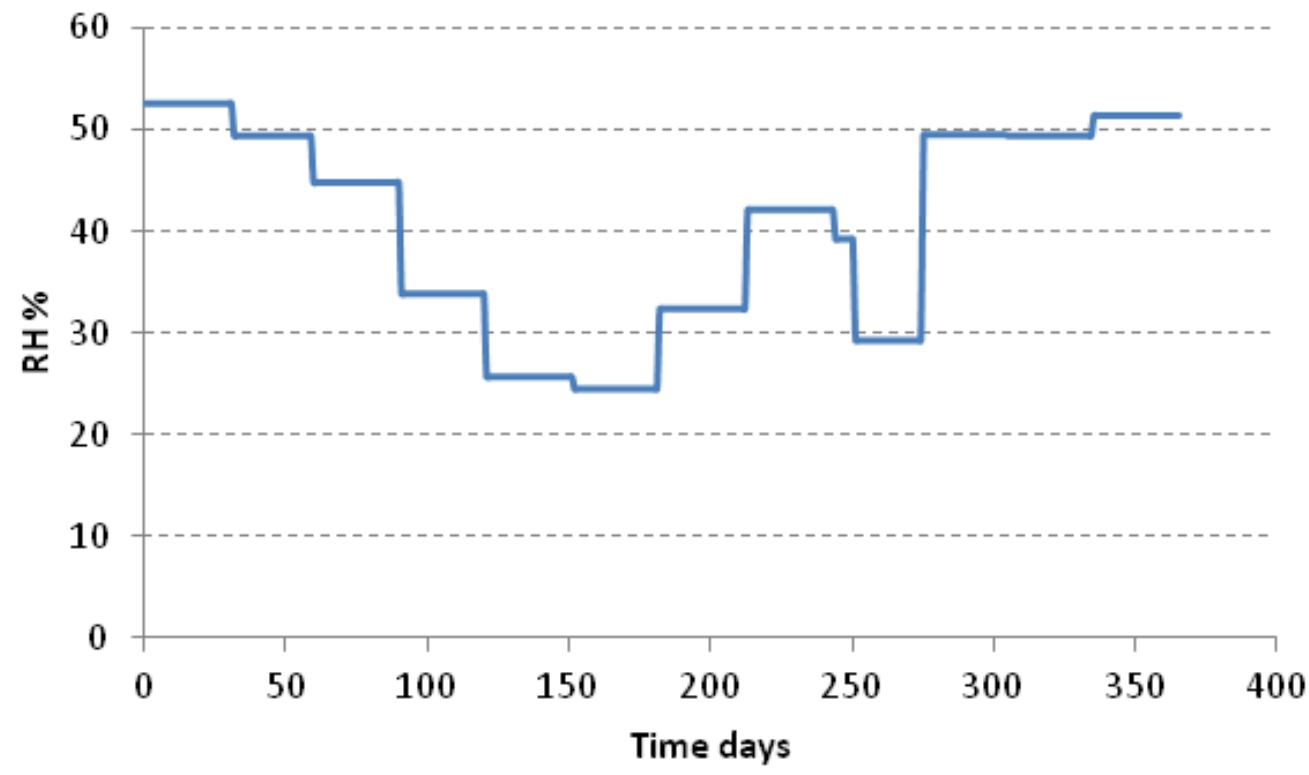

Figure 4.26. RH data 


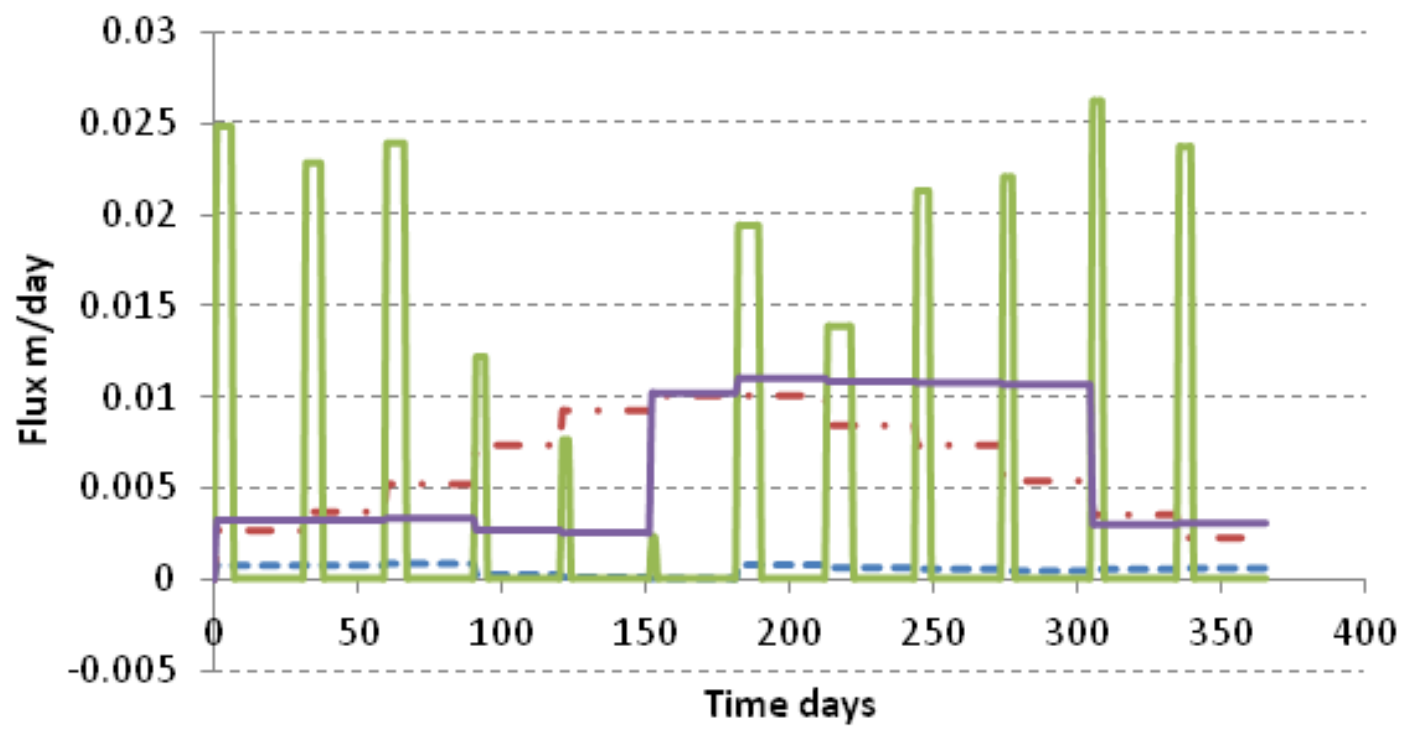

---- Rainfall $-\cdot-\mathrm{PE} \longrightarrow$ Roof Runoff $\longrightarrow$ Turf+ppt

Figure 4.27. Data on the same plot

\subsubsection{Actual Evaporation Analyses}

It is difficult to measure actual evaporation directly. Various procedures can be found in the literature to estimate the actual evaporative flux (Wilson-Penman 1994, Wilson et al. 1994). SVFlux implements several methods to evaluate the actual evaporation values based on potential evaporation values. The "limiting function" proposed by Wilson et al. (1997) is used for the seepage analysis done for the problems in this study.

The boundary condition for moisture flow can be defined as

$$
q_{v}=P-A E-R_{o f f}
$$

where

$q_{v}$ is the downward moisture flow rate at the soil surface [m/day] 
$P$ is the precipitation flux $[\mathrm{m} /$ day $]$

$R_{\text {off }}$ is the water runoff $[\mathrm{m} / \mathrm{day}]$

$\mathrm{AE}$ is the actual evaporation [m/day]

Actual evaporation $\mathrm{AE}$ is obtained from potential evaporation PE using a limiting factor:

$$
A E=P E\left[\frac{u_{v}^{\text {soil }}-u_{v}^{\text {air }}}{u_{v o}^{\text {soil }}-u_{v}^{\text {air }}}\right]
$$

where

$A E$ is the actual evaporative flux [m/day]

$\mathrm{PE}$ is the Potential evaporation [m/day]

$u_{v}^{\text {soil }}$ is the actual vapor pressure at the soil surface $[\mathrm{kPa}]$

$u_{v o}^{\text {soil }}$ is the saturated vapor pressure in the soil at the ground surface [kPa]

$u_{v}^{\text {air }}$ is the vapor pressure in the air above the soil surface $[\mathrm{KPa}]\left(<u_{v 0}^{\text {soil }}, u_{v}^{\text {soil }}\right)$

The above equation is based on the assumption that temperature of air and soil are the same in the entire domain. Also, actual soil evaporation is approximately equal to the potential rate of evaporation until the value of matric suction reaches approximately $3000 \mathrm{kPa}$. AE then declines with increasing value of suction shown in Figure 4.28. 


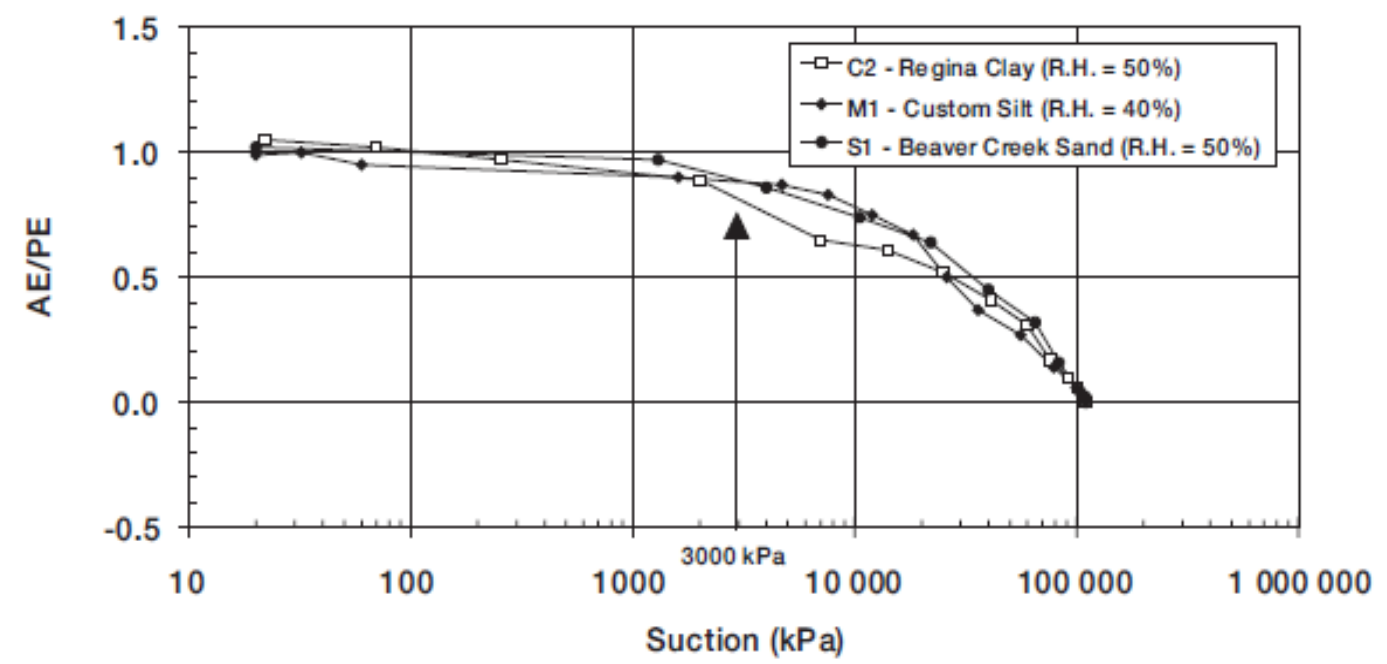

Figure 4.28. The ratio of AE to PE for different soils (Wilson et al. 1997)

Holmes (1961) suggested that the actual evaporation rate as a ratio of potential evaporation is a function of soil moisture availability. Figure 4.29 shows the ratio of $A E / P E$ as a function of moisture availability for a typical sand and clay. Figure 4.28 and Figure 4.29 are related through SWCC.

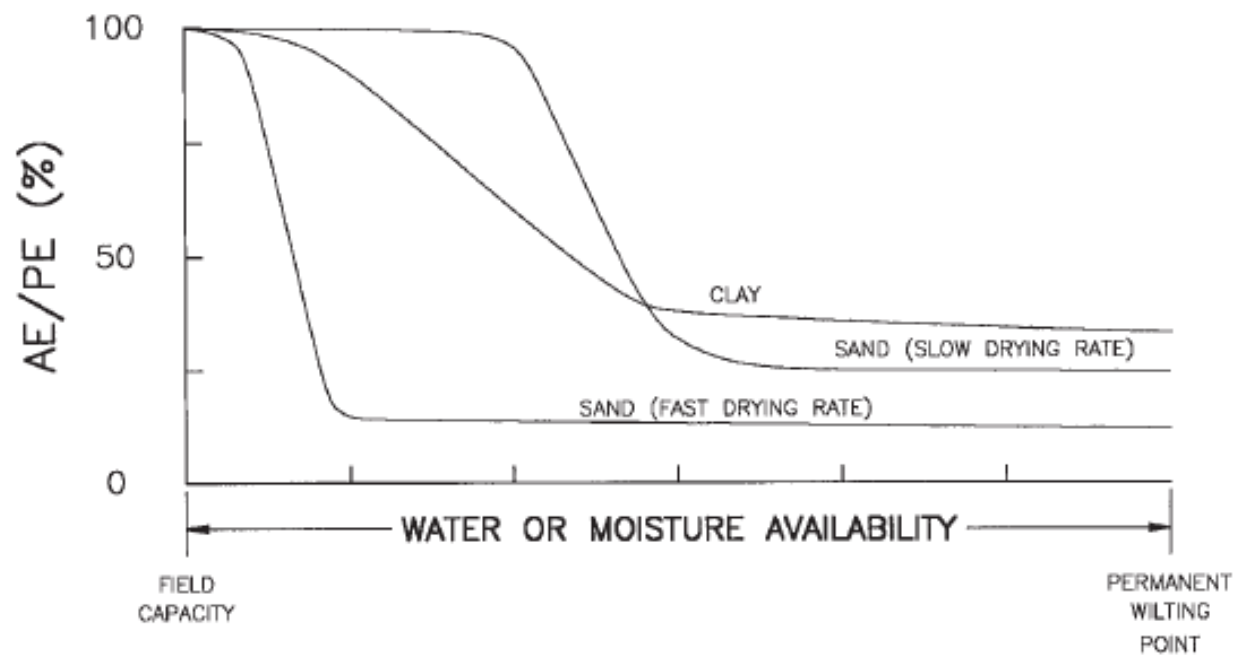

Figure 4.29. Ratio of AE/PE versus water availability (Holmes, 1961) 
The air temperature and relative humidity inputs are required to calculate vapor diffusion near the surface of the soil. The actual evaporation is the amount of moisture that will evaporate from a bare soil. It is required to calculate infiltration and runoff for atmospheric models.

In order to improve the accuracy and stability of evaporative and atmospheric modeling, SVFlux provides three options based on the method to calculate the actual evaporation. A suction correction factor is applied based on the type of soil being modeled. The following values are suggested for different soil types in conjunction with Wilson's "limiting equation" (Equation 4.4).

The option of surface suction correction is recommended. The following is general suggestion for the value of correction factor:

1. For sand: correction factor $=-1.8$

2. For silt: correction factor $=-1.0$

3. For clay correction factor $=0$

Figure 4.30 shows the values of corresponding correction factors for different types of soils. 


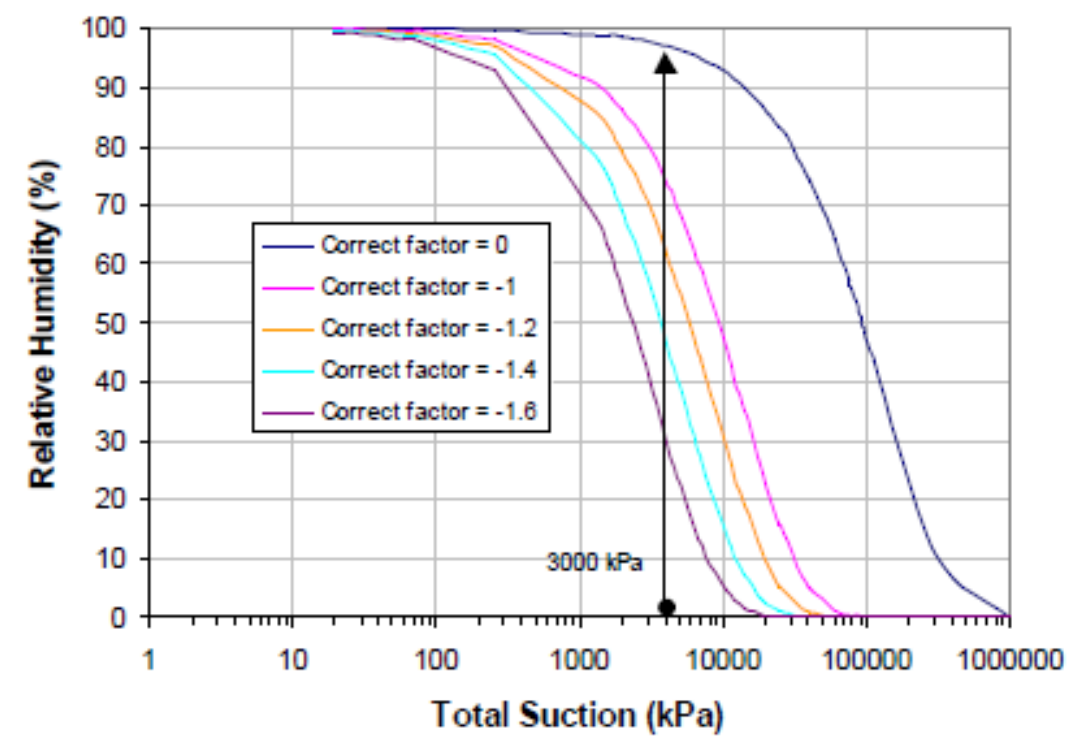

Figure 4.30. Relationship between relative humidity and total suction using Edlefsen and Anderson equation, 1943

Using this option invokes an empirical correction factor (Alvenas and Jansson, 1997) to adjust the total suction used to calculate the humidity at the soil surface.

The Relative humidity at soil surface is modified with following expression:

$$
h_{s}=\frac{u_{v}^{\text {soil }}}{u_{w}^{\text {soil }}}=\exp \left(\frac{-g w_{v} \delta_{\text {corr }}}{\gamma_{w} R\left(273.15+T_{s}\right)}\right)
$$

where

$\Psi=\left(u_{a}-u_{w}\right)+\Pi$

$\Psi=$ total suction $[\mathrm{kPa}]$

$\mathrm{W}_{\mathrm{v}}=$ molecular weight of water $[0.018 \mathrm{~kg} / \mathrm{mol}]$

$\mathrm{Y}_{\mathrm{w}}=$ unit weight of water $\left[9.807 \mathrm{KN} / \mathrm{m}^{3}\right]$

$\mathrm{g}=$ gravity acceleration $\left[\mathrm{m} / \mathrm{s}^{2}\right]$ 
$\mathrm{R}=$ universal gas constant $[8.314 \mathrm{~J} /(\mathrm{mol} . \mathrm{K})]$

$\mathrm{T}_{\mathrm{s}}=$ soil surface temperature $\left[{ }^{\circ} \mathrm{C}\right]$

$\mathrm{T}_{\mathrm{a}}=$ air temperature obtained from weather station $\left[{ }^{\circ} \mathrm{C}\right]$

$\mathrm{U}_{\mathrm{a}}=$ the pore-air pressure $[\mathrm{kPa}]$

$\mathrm{U}_{\mathrm{w}}=$ the pore-water pressure $[\mathrm{kPa}]$

$\Pi=$ osmotic pressure $[\mathrm{kPa}]$

$\delta_{\text {corr }}=10^{- \text {(fcorr) }}=$ correction factor of soil surface suction which varies from 1 to 100

$f_{\text {corr }}=$ empirical number changing from 0 to -2 , default $f_{\text {corrr }}=-1.2$

Figure 4.30 has different curves for various soils and a correction factor value associated with it. Based on it a soil type close to the replacement layer was chosen and a value was then assumed. The following values were used for the replacement layer soils:

Table 4.5. Correction factor for different soil types

\begin{tabular}{|c|c|}
\hline Soil Type & F $_{\text {corr }}$ \\
\hline Expansive & 0 \\
\hline Higher conductivity & -1.4 \\
\hline Same conductivity & -1.2 \\
\hline Lower Conductivity & -1.2 \\
\hline
\end{tabular}




\subsection{Volume Change Properties in SVSolid}

The boundary conditions for the problem in SVSolid are shown in the Figure 4.31 below.

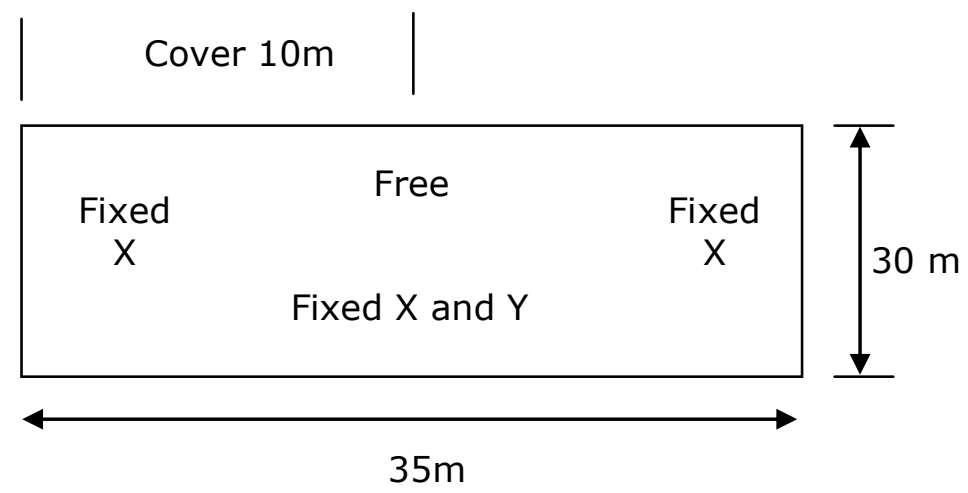

Figure 4.31. Boundary Conditions in SVSolid

Table 4.6 shows the coefficients of lateral earth pressure suggested by Lytton (1994) for different soil conditions. The $\mathrm{K}_{0}$ used for the soils in this case was assumed to be 0.5 . A Poisson's ration value of 0.35 was used for the different soils in all the runs.

Table 4.7 summarizes the some key properties used for analyzing the different replacement soil models. 
Table 4.6. Typical values for the coefficients of lateral earth pressure (Lytton, 1994)

\begin{tabular}{|c|c|}
\hline $\mathbf{K}_{\mathbf{o}}$ & Field Condition \\
\hline 0 & When soil is dry and cracked \\
\hline 0.333 & When soil is dry and cracks are opening \\
\hline 0.5 & $\begin{array}{l}\text { When cracks are closed and suction is in steady state } \\
\text { condition }\end{array}$ \\
\hline 0.667 & When cracks are closed and soil is wetting \\
\hline 1 & When soil is wetting and in hydrostatic stress condition \\
\hline $2-3$ & Passive earth pressure \\
\hline
\end{tabular}

Table 4.7. Volume change Indices for Replacement soils

\begin{tabular}{|c|c|c|c|}
\hline Soil & $\begin{array}{c}\text { Poisson's } \\
\text { ratio }\end{array}$ & $\mathbf{C}_{\mathbf{m}}$ & $\mathbf{e}_{\mathbf{o}}$ \\
\hline Lower K $_{\text {sat }}$ & 0.35 & 0.0001 & 0.52 \\
\hline Same $_{\text {sat }}$ & 0.35 & 0.0003 & 0.51 \\
\hline Higher K & & 0.0005 & 0.49 \\
\hline Expansive clay & 0.35 & 0.3 & 1 \\
\hline
\end{tabular}

A non-expansive soil should be such that it has negligible volume change properties $(\approx 0)$. The final remove and replacement soil runs were done using the revised values of $C_{m}$. (see Table 4.7)

\subsubsection{Plots for $C_{m}$ variation}

The Expansive soil profile is shown below (Figure 4.32). The whole profile was divided into 6 layers, $5 \mathrm{~m}$ each and the overburden is calculated at the centre of each 
layer. The swelling pressure is assumed based on the values reported by Heather (2008) for high plasticity clays.

The Volume change index with respect to suction is a function of net normal stress. As the overburden increases the $C_{m}$ goes down. For the problems analyzed, the $C_{m}$ is input as a function of depth. $C_{m}$ is not a constant but a linear function approximated as constant within a layer (Figure 4.33).

Nelson and Miller (1992) suggested a general equation to obtain heave based on oedometer test. Equation 4.6 was used to obtain the variation of $C_{m}$ for different depths. The corrected $C_{m}$ for each layer is a percentage of the top layer which is calculated based on the ratio of overburden and selling pressure.

$$
\rho=\sum_{1}^{n}\left[\frac{C_{\rho} z_{i}}{\left(1+e_{o}\right)_{i}} \log \left(\frac{\sigma_{f}^{\prime}}{\sigma_{s}^{\prime}}\right)_{i}\right]
$$

where

$\rho=$ free-field heave $[\mathrm{m}]$

$\mathrm{C}_{\rho}=$ heave index

$\mathrm{z}_{\mathrm{i}}=$ layer thickness $[\mathrm{m}]$

$\mathrm{e}_{0}=$ initial void ratio

$\sigma_{f}^{\prime}=$ final effective stress state $[\mathrm{kPa}]$

$\sigma_{s}^{\prime}=$ swelling pressure from the constant-volume oedometer test [kPa]

Corrected $C_{m}=C_{m}\left(\sigma_{c v}-\sigma_{v}\right) / \sigma_{c v}, \quad \sigma_{c v}=$ swelling pressure of the expansive soil $(700 \mathrm{KPa}), \sigma_{v}=$ overburden at the center of each layer. 


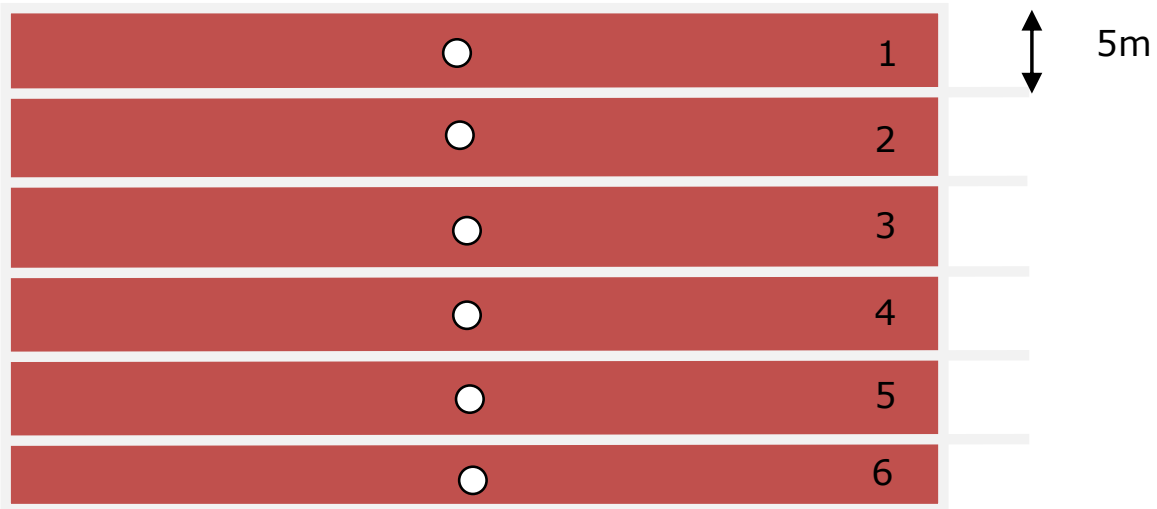

Figure 4.32. Profile divided into 6 layers

Table 4.8. $C_{m}$ values for each layer

\begin{tabular}{|c|c|}
\hline Layer no. & $\begin{array}{c}\text { Corrected } \\
\mathbf{C}_{\mathbf{m}}\end{array}$ \\
\hline 1 & 0.30 \\
\hline 2 & 0.24 \\
\hline 3 & 0.20 \\
\hline 4 & 0.16 \\
\hline 5 & 0.12 \\
\hline 6 & 0.08 \\
\hline
\end{tabular}




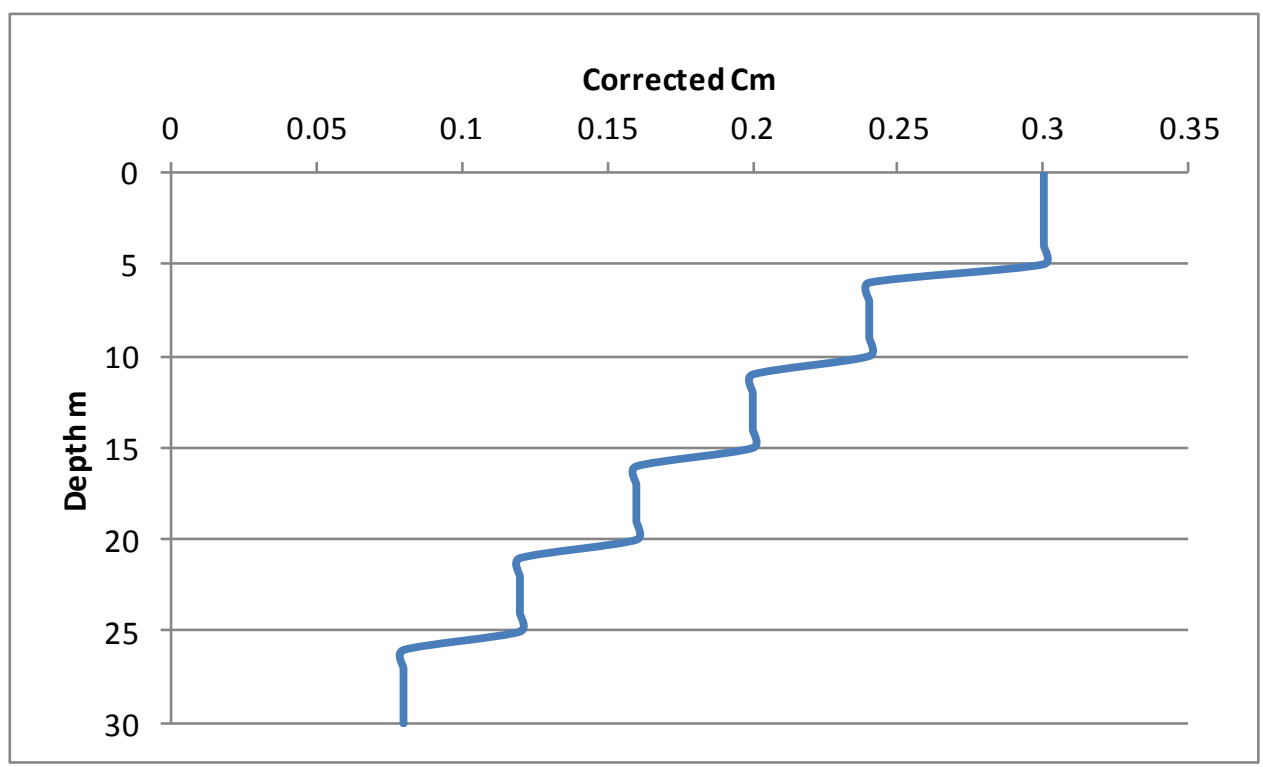

Figure 4.33. $C_{m}$ variation with depth for expansive soil 


\section{RESULTS \& DISCUSSION}

\subsection{Presentation of Results and Discussion}

The final SVFlux results for the analyses of this study of the remove and replace option for mitigation of expansive soils are presented in this chapter. Selected profiles of matric suction versus depth are provided to illustrate the performance of the various removal and replacement scenarios described in Chapter 4. The final SVSolid results are presented in terms of displacement/heave at the ground surface, from which total heave and differential heave can be compared for the various remove and replace options studied. Comparisons are made between the various remove and replace options on the basis of extent and degree of wetting as well as on ground surface total and differential movements. The efficacy of remove and replace as a mitigation alternative for expansive soil is discussed in view of the numerical results, and observations and recommendations on selection of depth and replacement soil type (the same, more, or less permeable than underlying expansive clay) are presented in the context of unsaturated flow and stress/deformation principles.

\subsection{Climatic Data Inputs for Roof Runoff Case}

The roof runoff input flux for the runs is presented below in Figure 5.1. Figure 5.2 shows the rainfall and evaporation input for these set of runs. Additional details on the selection of surface flux condition were provided in Chapter 4. Figure 5.3 shows the initial and final condition suction variation for the no replacement case. The variation is shown for the vertical profile located immediately below slab edge. 


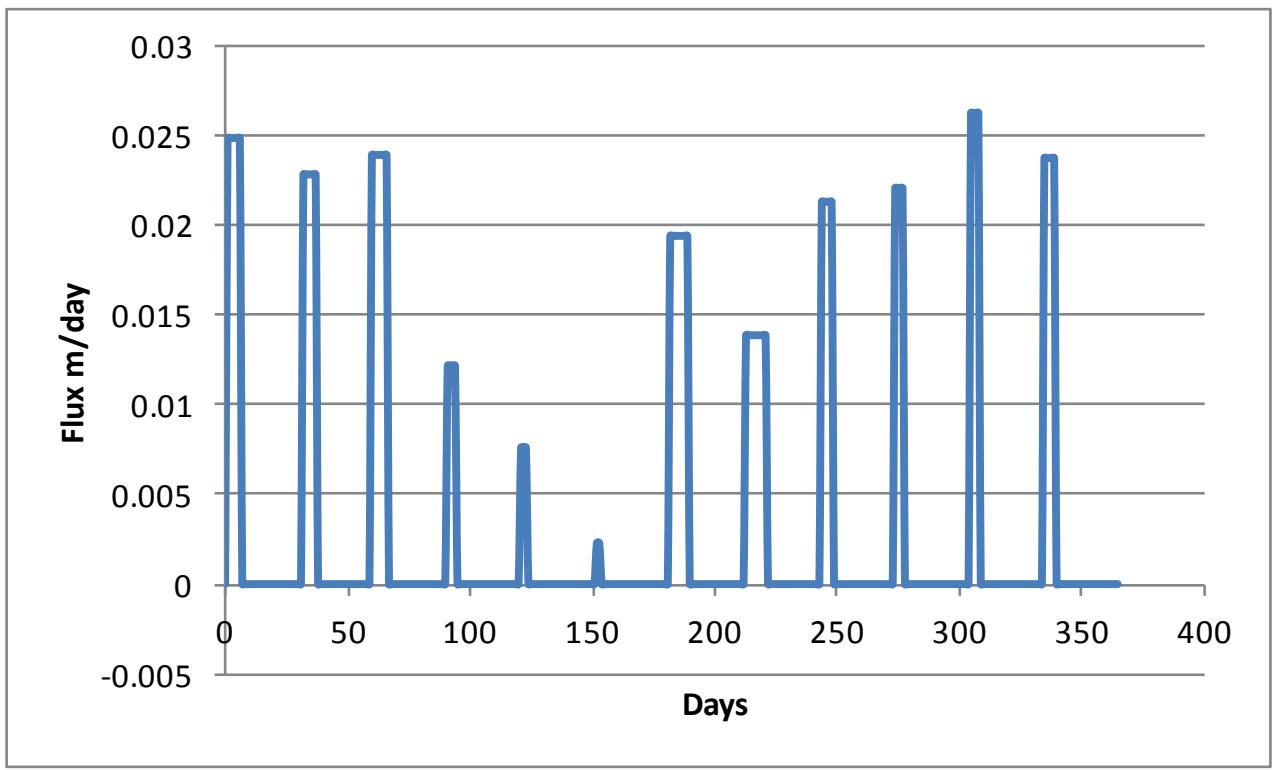

Figure 5.1. Input Roof Runoff Flux data

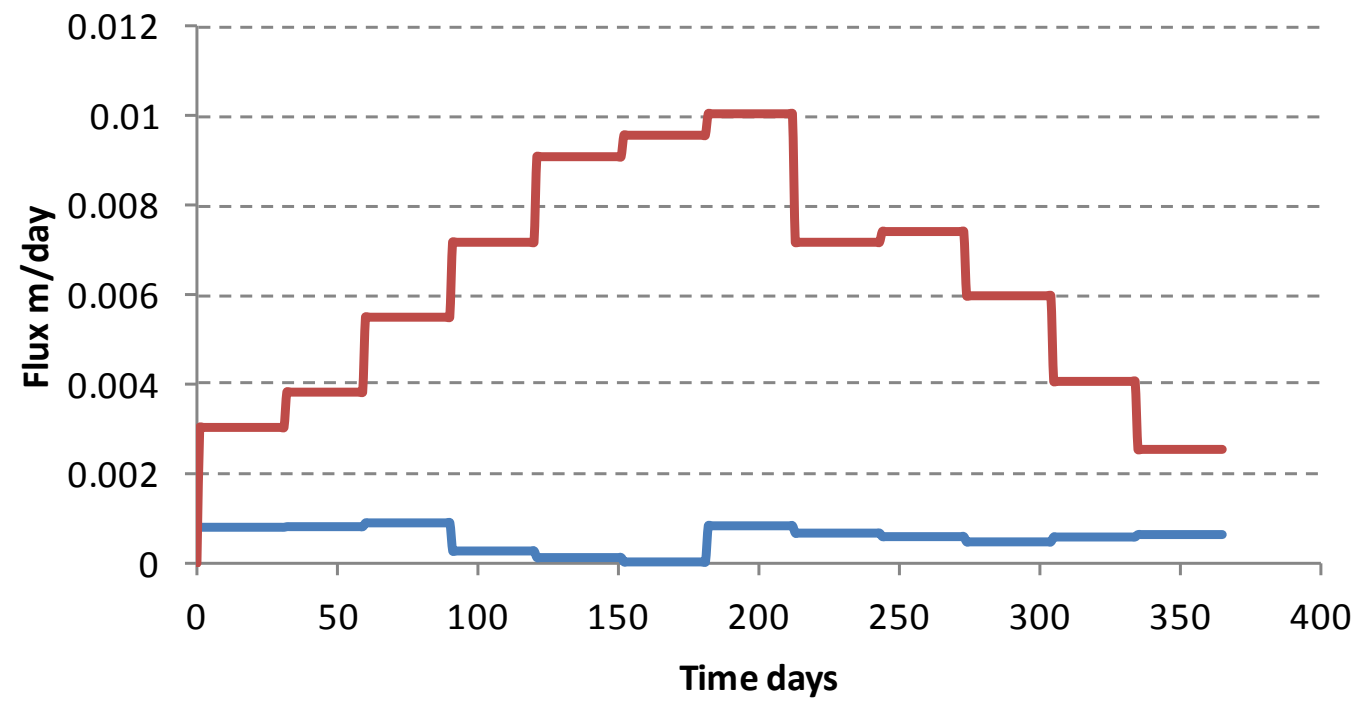

Rainfall $\longrightarrow P E$

Figure 5.2. Input Potential Evaporation (PE) and Rainfall data 


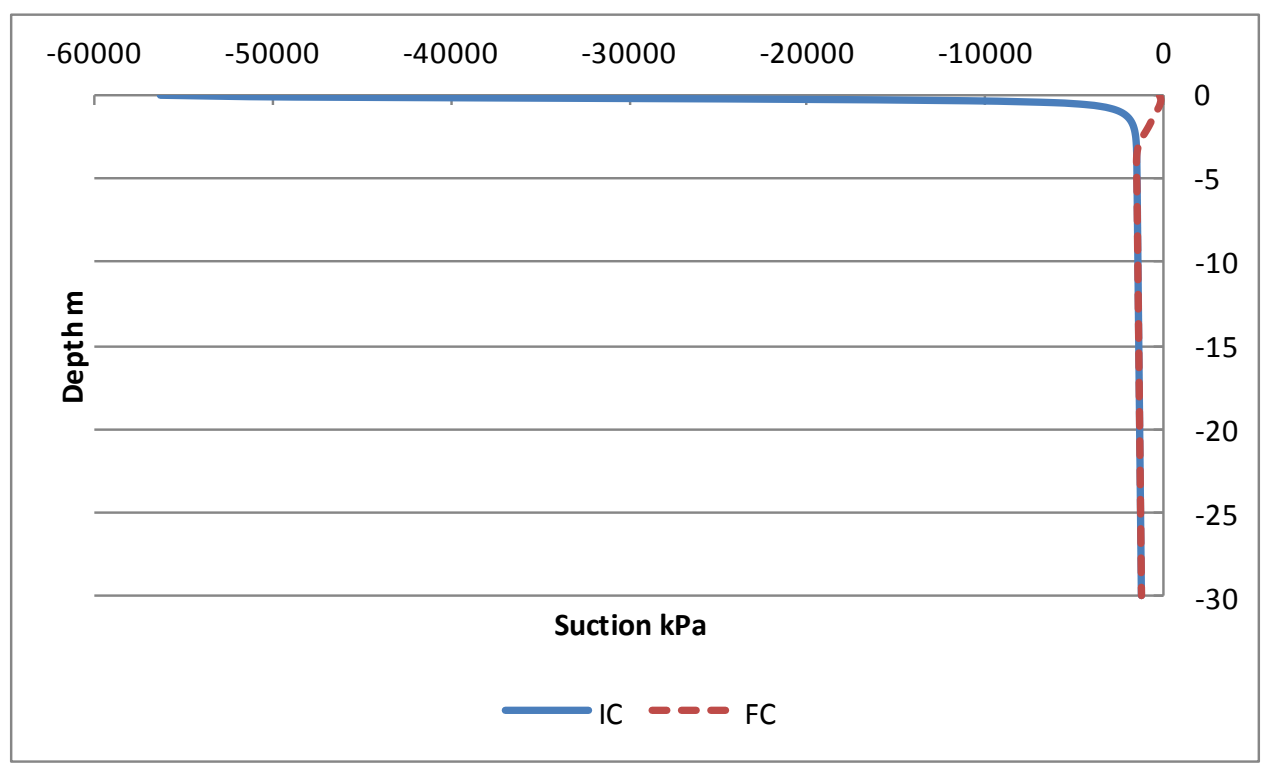

Figure 5.3.(a) Initial Condition (IC )and Final Condition (FC) suction profile right below slab edge (see Figure 5.4) - no replacement expansive clay case and roof runoff conditions.

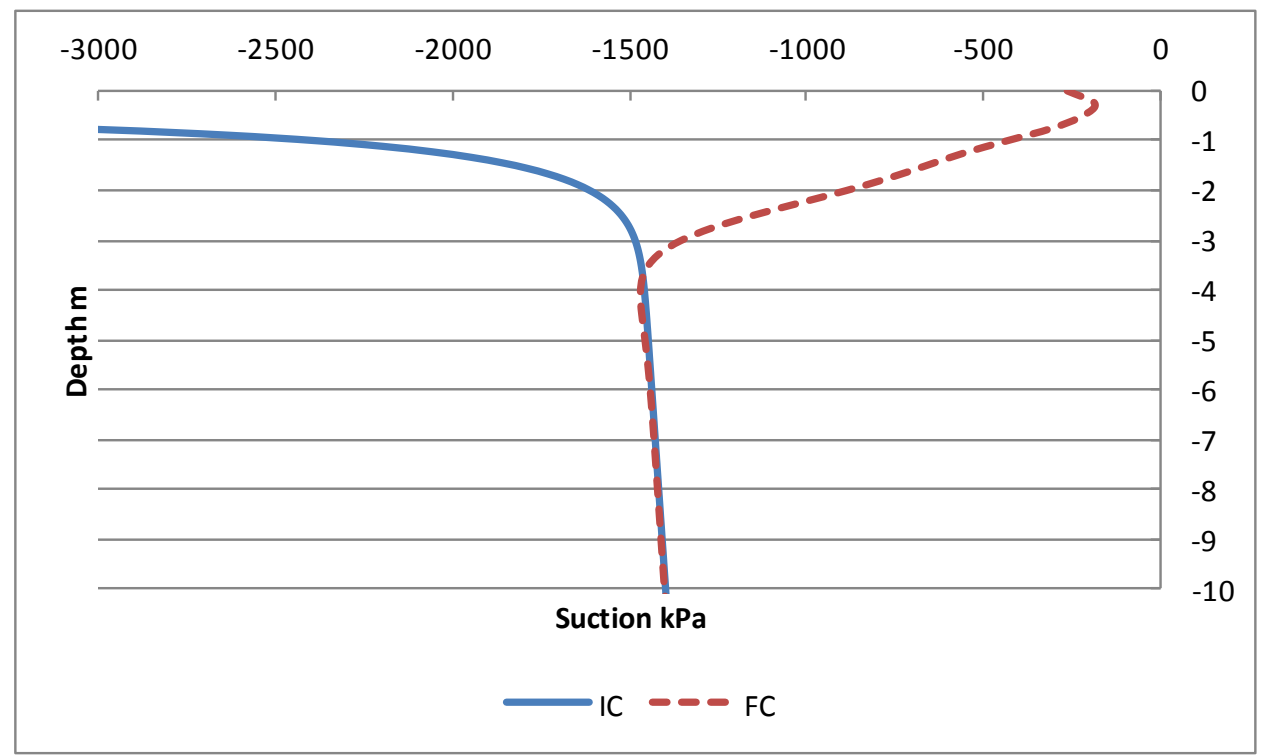

Figure 5.3.(b) Initial Condition (IC )and Final Condition (FC) suction profile right below slab edge - no replacement expansive clay case and roof runoff conditions (blow up profile). 


\subsection{SVFlux and SVSolid Results for Roof Runoff Case}

All the results of the unsaturated flow and deformation analyses for all the different replacement depths and replacement material types are presented in the following sections one by one.

\subsection{1 $6^{\text {th }}$ Year Results for Lower $K_{\text {sat }}$ Replacement Layer Case}

Presented below are the $6^{\text {th }} \mathrm{yr}$ results of the roof runoff runs for the lower $\mathrm{K}_{\text {sat }}$ replacement depth case. This section includes the results obtained from SVFlux and SVSolid analyses. Although the soil suction variations within the entire domain are computed from the finite element unsaturated flow analyses, for comparison of various cases, plots of soil suction and degree of saturation are presented for a vertical profile located immediately below the slab edge, as shown in Figure 5.4. Figure 5.5 shows the initial and final condition suction variation (below slab edge) for $0.5 \mathrm{~m}$ lower $\mathrm{K}_{\text {sat }}$ case.

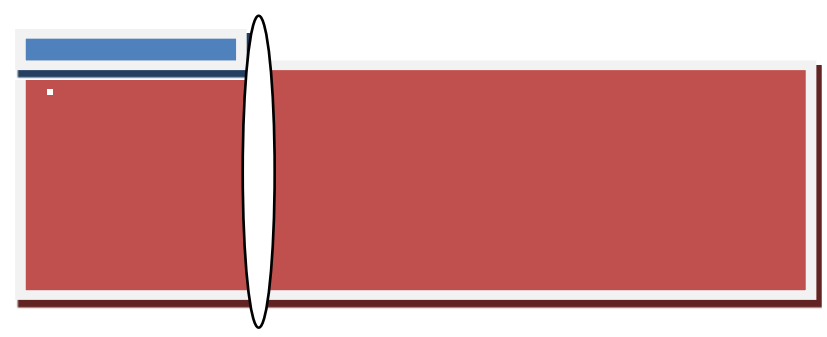

Figure 5.4. Section below slab edge 


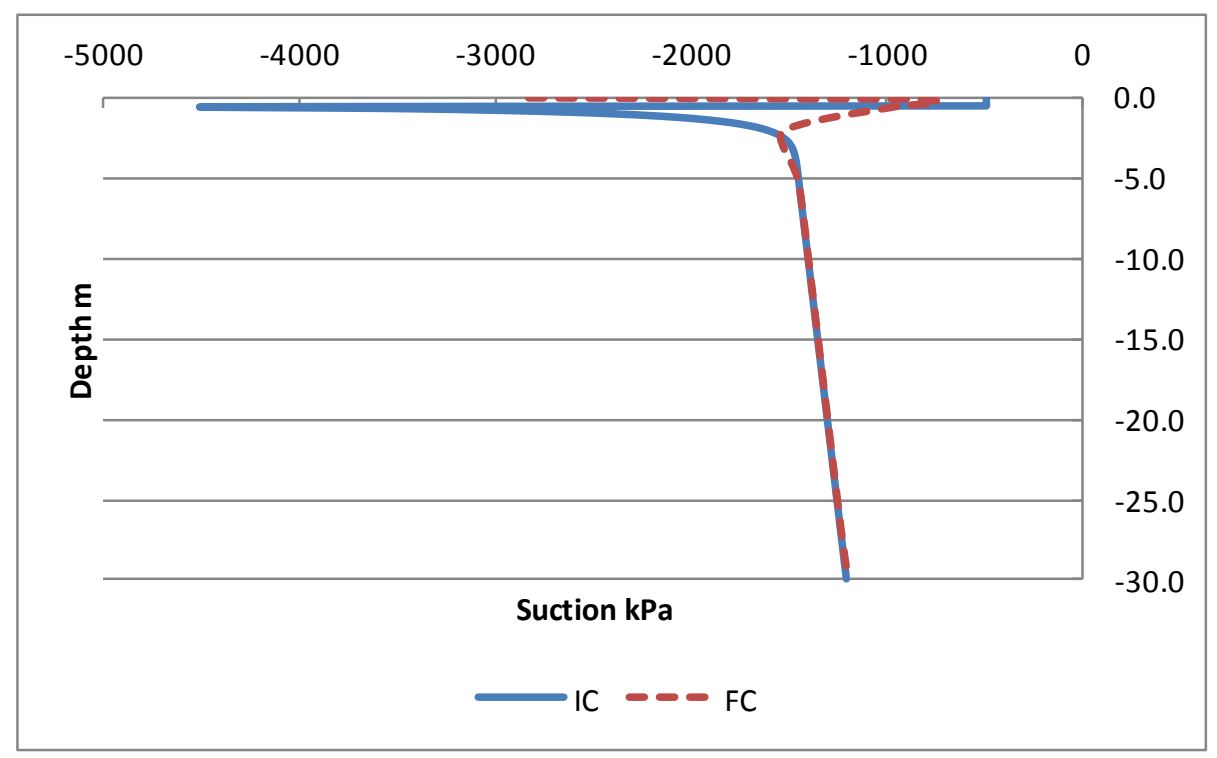

Figure 5.5 (a) Initial Condition (IC )and Final Condition (FC) suction profile right below slab edge (see Figure 5.4 ) - for $0.5 \mathrm{~m}$ lower $\mathrm{K}_{\text {sat }}$ replacement case and roof runoff conditions.

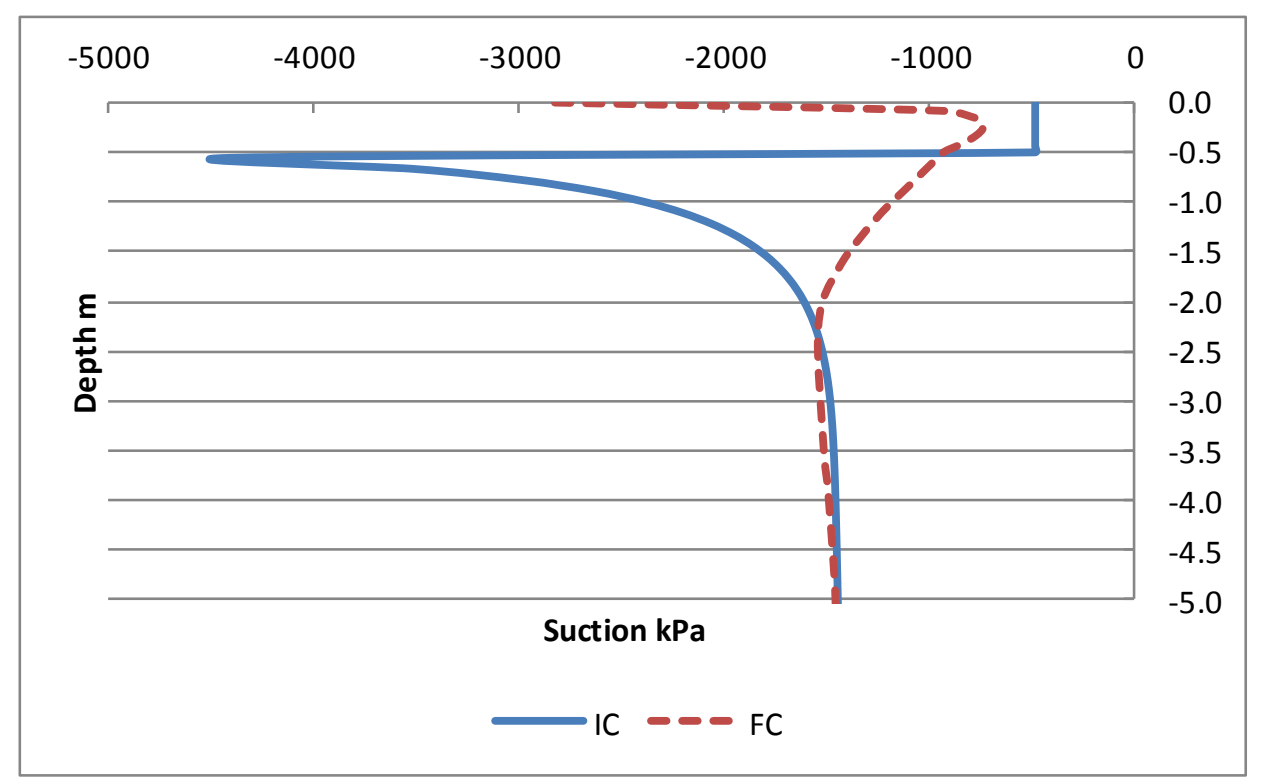

Figure 5.5.(b) Initial Condition (IC )and Final Condition (FC) suction profile right below slab edge - for $0.5 \mathrm{~m}$ lower $\mathrm{K}_{\text {sat }}$ replacement case and roof runoff conditions (blow up profile). 
The initial and final condition (IC and FC) suction plots (Figure 5.5) show that the water does not go deeper than about $2 \mathrm{~m}$ for the clay cap option and roof runoff surface flux conditions. Figure 5.6 below shows a plot which compares the $6^{\text {th }} \mathrm{yr}$ suction results for no replacement and $0.5 \mathrm{~m}$ cap case. The $0.5 \mathrm{~m}$ cap results in less wetting of the soil in the upper 5 meters, compared to the no replacement case, as expected.

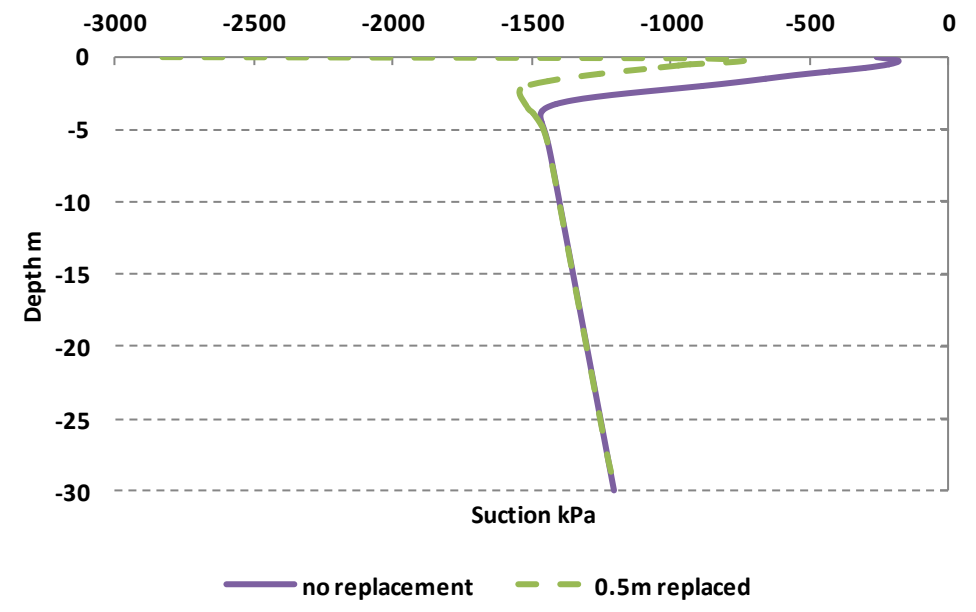

Figure 5.6.(a) End of $6^{\text {th }}$ yr suction variation profile below slab edge (see Figure 5.4) for no replacement expansive clay case and $0.5 \mathrm{~m}$ lower $\mathrm{K}_{\text {sat }}$ replacement material - roof runoff conditions. 


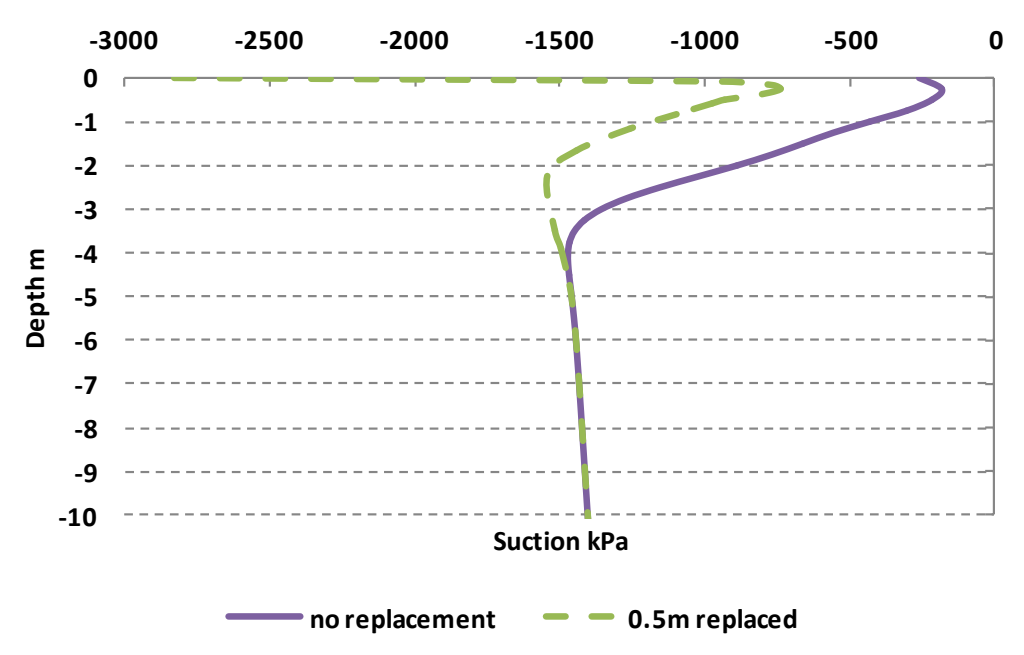

Figure 5.6.(b) End of $6^{\text {th }} \mathrm{yr}$ suction variation profile below slab edge for no replacement expansive clay case and $0.5 \mathrm{~m}$ lower $\mathrm{K}_{\text {sat }}$ replacement material - roof runoff conditions (blow up profile).

Figure 5.7 show the displacement profile obtained from SVSolid for the $0.5 \mathrm{~m}$ clay cap case and the no replacement expansive clay case for roof runoff surface flux conditions. The presence of the clay cap dramatically reduced heave. 


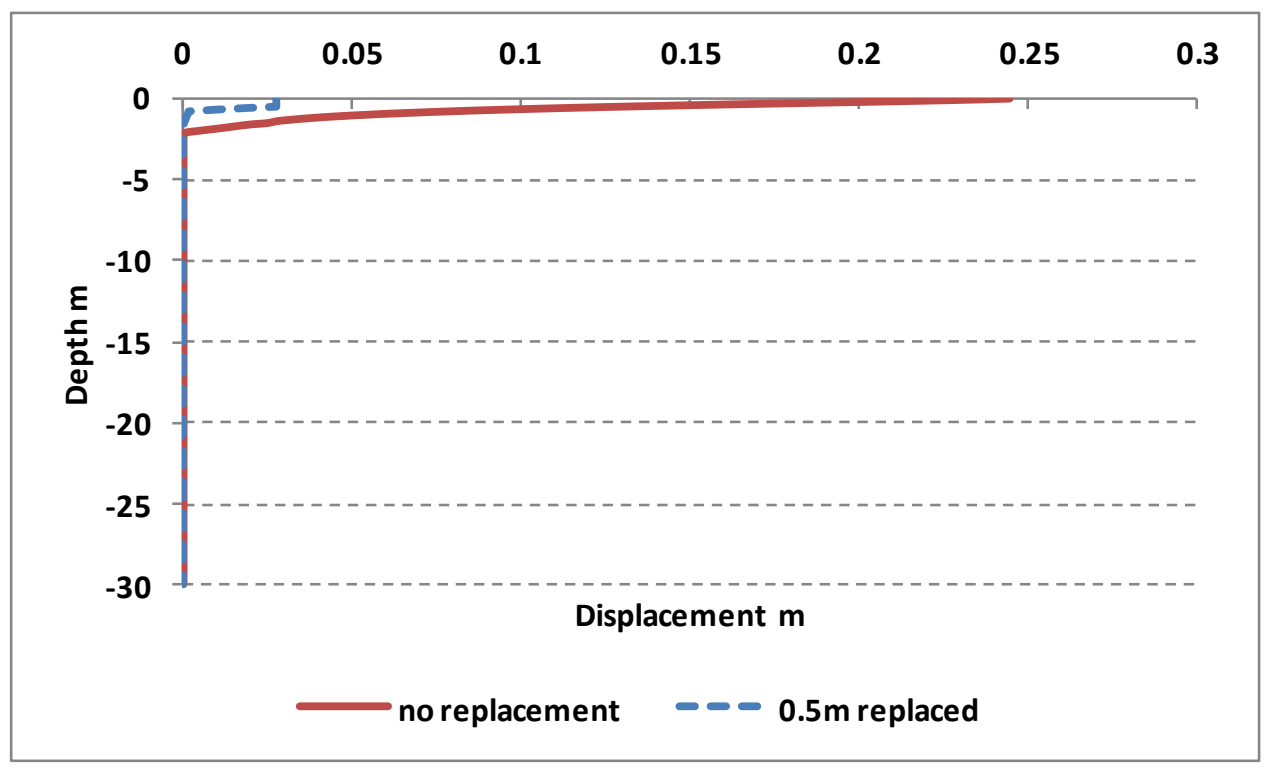

Figure 5.7. (a) Final Displacement results right below slab edge (see Figure 5.4) for no replacement expansive clay case and $0.5 \mathrm{~m}$ lower $\mathrm{K}_{\text {sat }}$ replacement material - roof runoff conditions.

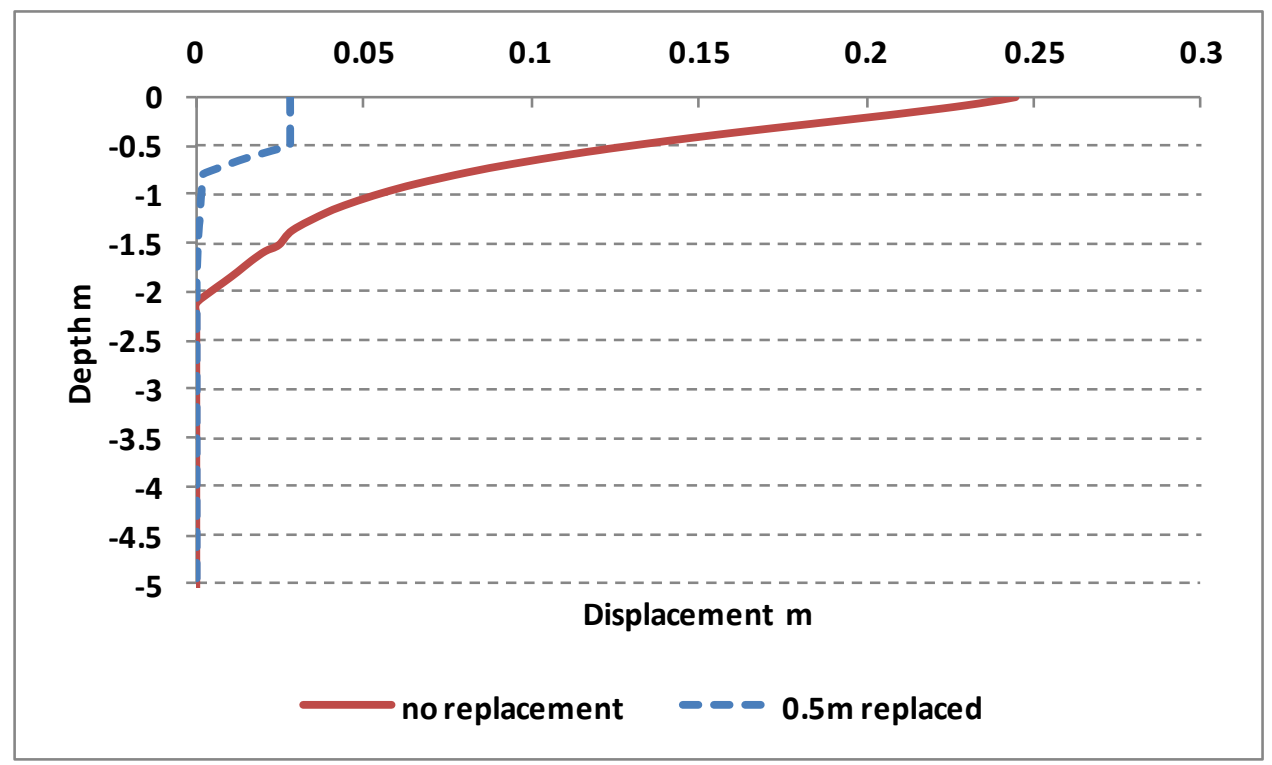

Figure 5.7.(b) Final Displacement results right below slab edge for no replacement expansive clay case and $0.5 \mathrm{~m}$ lower $\mathrm{K}_{\text {sat }}$ replacement material - roof runoff conditions (blow up profile). 
The ground surface movements obtained for all the cases at section shown below in Figure 5.8. Ground surface movements are plotted from the center of the slab to a distance $35 \mathrm{~m}$ away from the center of the slab (the RHS domain boundary). The edge of the slab is located $10 \mathrm{~m}$ from the center of the slab.

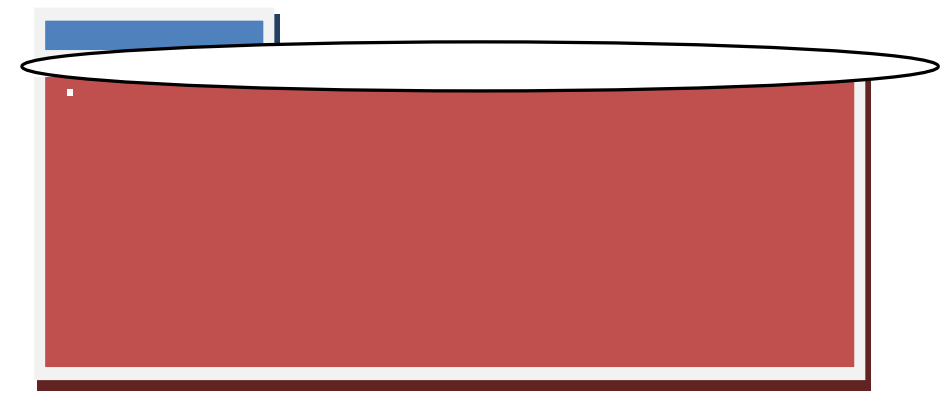

Figure 5.8. Section at the Ground Surface

Figure 5.9 shows the soil movements at the ground surface for the 0.5 clay cap case and the no replacement case for roof runoff conditions. Because arid-region climatic conditions are applied outside of the slab, other than in the ponded region, the expansive clay actually dries in this region due to evaporation. The clay cap of $0.5 \mathrm{~m}$ minimizes both wetting and drying of the underlying expansive clay, greatly reducing the ground surface total and differential movements.

The peak swell (heave) on the ground for the no replacement case occurs, as expected, right below the slab edge where the water is ponded. When a replacement layer of $0.5 \mathrm{~m}$ lower conductivity soil is used, the peak movement (total heave) is greatly reduced. Figure 5.9 also shows that the differential movements at the ground surface are greatly reduced by placement of the clay cap. The clay cap, at suction value corresponding to placement at optimum moisture conditions (490 kPa), has a lower conductivity than the relatively drier underlying native expansive clay. The lower conductivity of the clay cap serves to reduce the infiltration of roof runoff 
water, and also reduces the amount of evaporation that can occur outside of the slab and ponded water region. The net effect is a dramatic decrease in both total and differential heave compared to the no replacement case. It can also be seen from Figure 5.9 that the presence of the clay cap results is zero ground surface deformation for distances greater than $10 \mathrm{~m}$ from the slab edge (20 $\mathrm{m}$ from slab center). This is because the clay cap controls the amount of infiltration into the soil profile to the extent that lateral spreading of water beneath the slab is minimal and essentially no subsurface wetting occurs beyond about $20 \mathrm{~m}$ away from the slab edge when the cap is present. Additional discussion on the impacts of lateral flow of water is presented in Section 5.8 below.

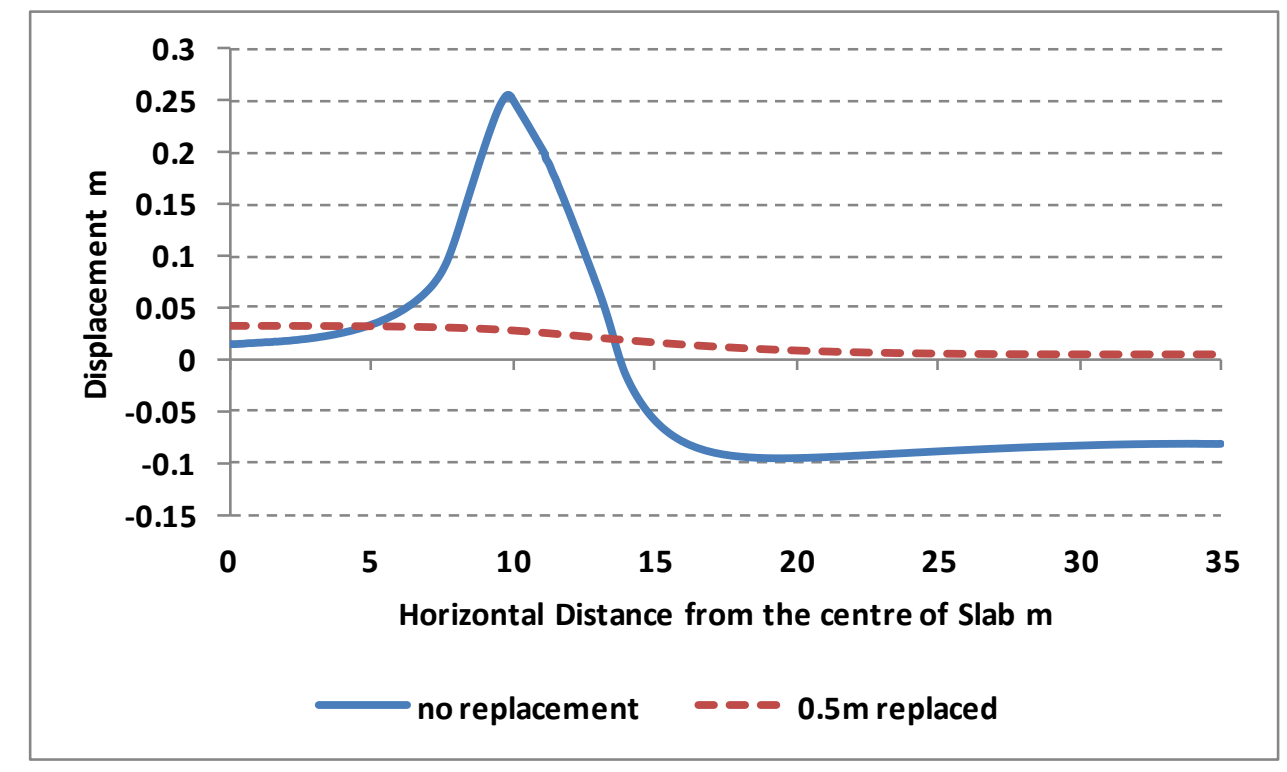

Figure 5.9. Final Displacement variation at the ground surface (see Figure 5.8) for no replacement expansive clay case and $0.5 \mathrm{~m}$ lower $\mathrm{K}_{\text {sat }}$ replacement material - roof runoff conditions. 


\subsection{2 $6^{\text {th }}$ Year Results for Same $K_{\text {sat }}$ Replacement Layer Case}

The analyses for the same $\mathrm{K}_{\text {sat }}$ replacement material types are presented below. Several depths of removal and replacement were considered. In Figure 5.10, the suction profiles results for the $0.75 \mathrm{~m}$ depth replacement, same $\mathrm{K}_{\text {sat }}$ material are shown for a vertical profile immediately below the slab edge. Figure 5.11 and Figure 5.12 show results for the $2 \mathrm{~m}$ and $4 \mathrm{~m}$ replacement depths for same $\mathrm{K}_{\text {sat }}$ material and roof runoff surface flux conditions.

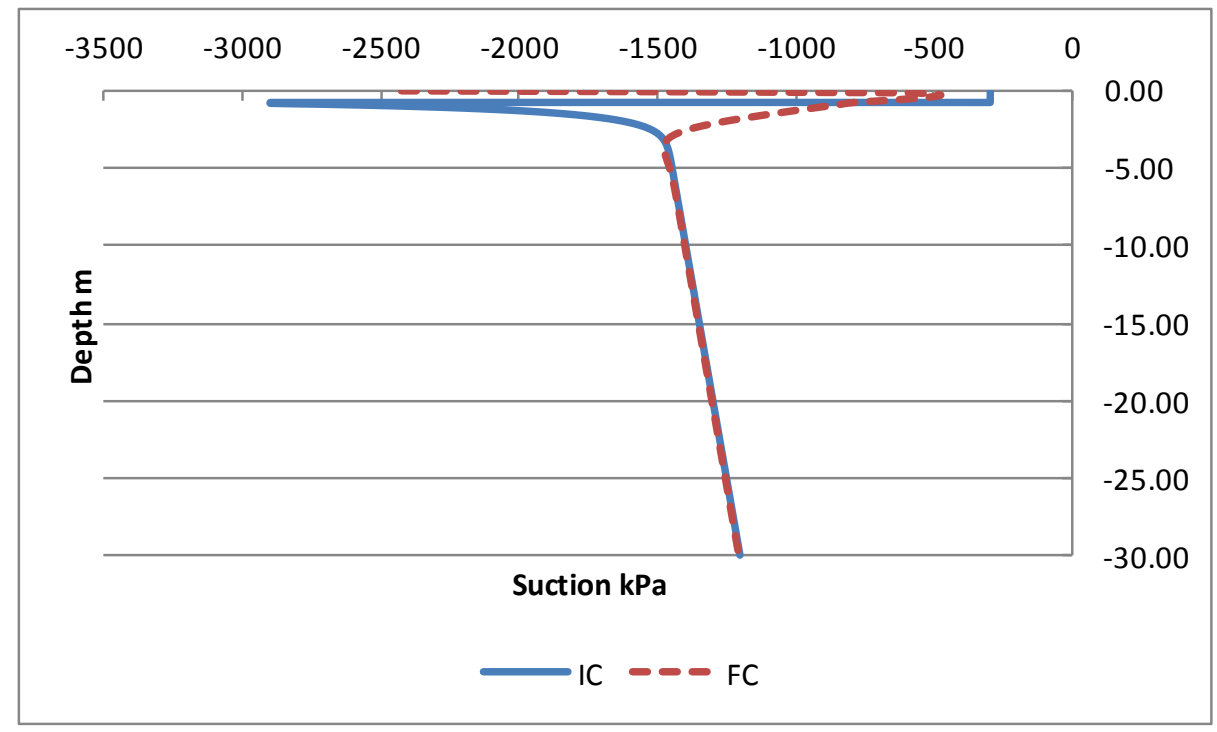

Figure 5.10.(a) Initial Condition (IC )and Final Condition (FC) suction profile right below slab edge (see Figure 5.4 ) - 0.75m same $\mathrm{K}_{\text {sat }}$ replacement material and roof runoff conditions. 


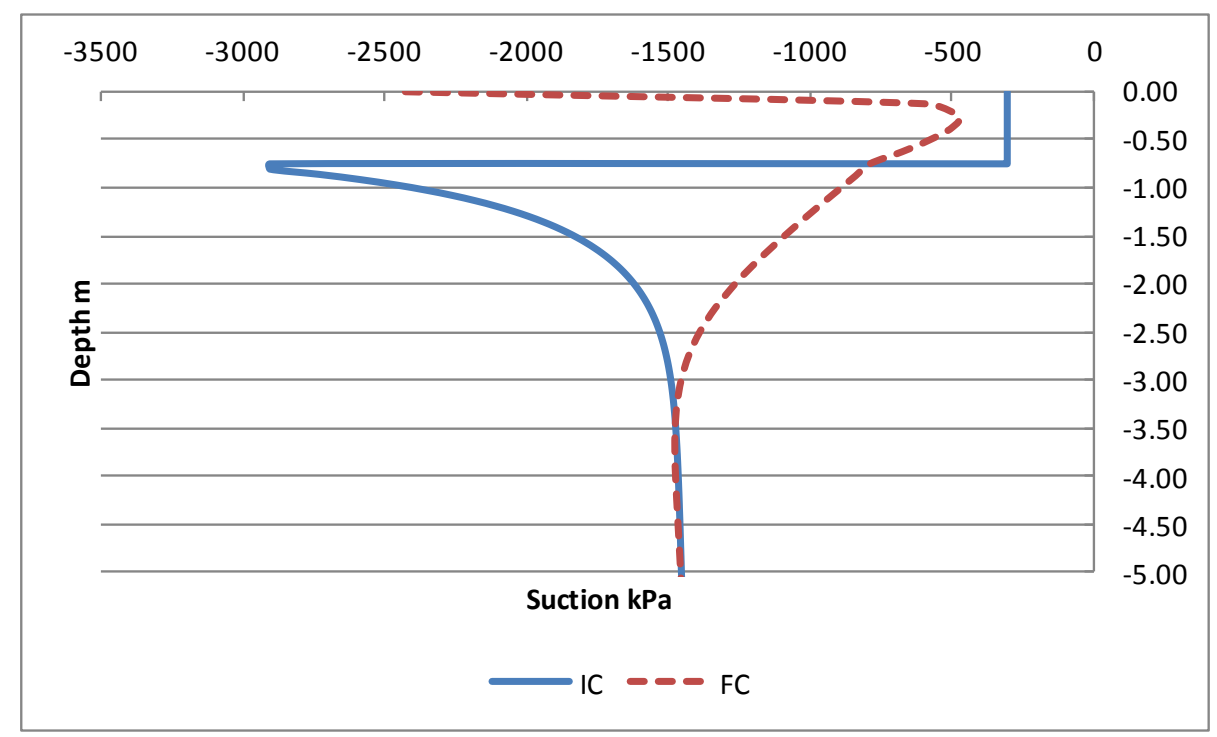

Figure 5.10.(b) Initial Condition (IC )and Final Condition (FC) suction profile right below slab edge $-0.75 \mathrm{~m}$ same $\mathrm{K}_{\text {sat }}$ replacement material and roof runoff conditions (blow up profile).

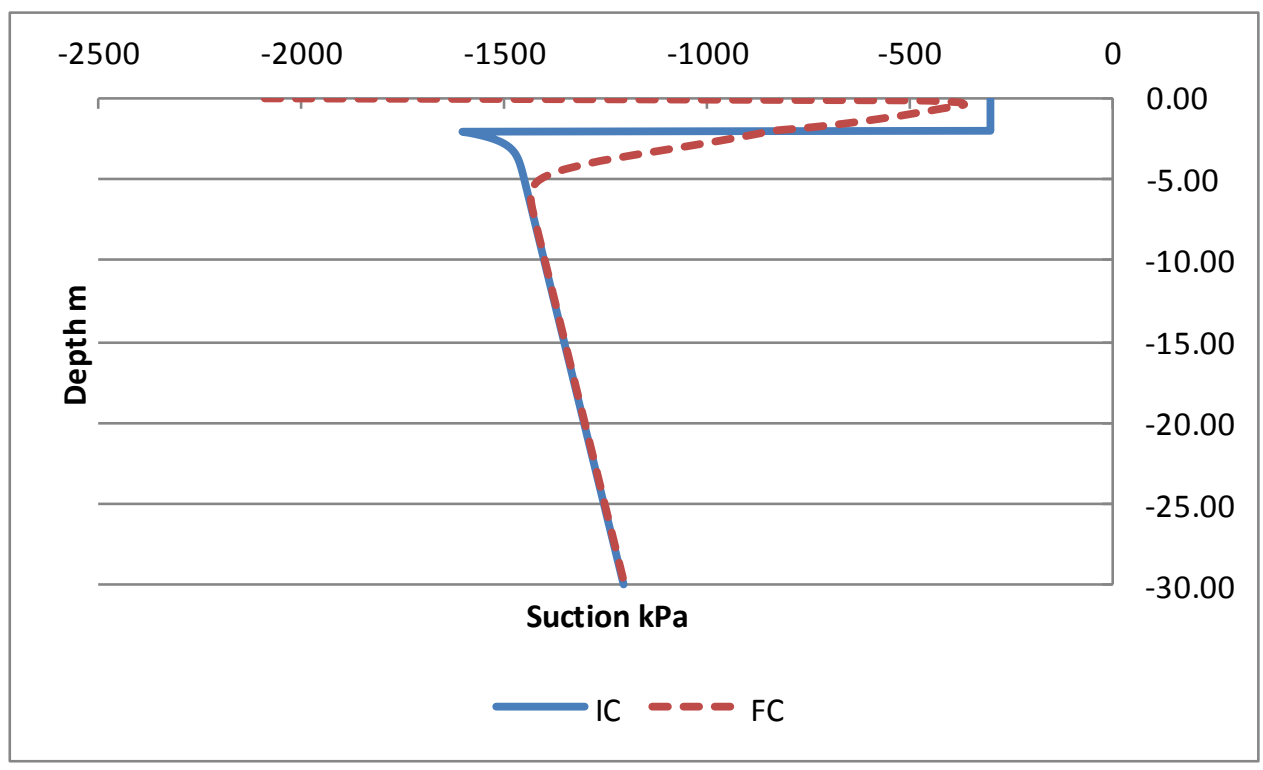

Figure 5.11.(a) Initial Condition (IC )and Final Condition (FC) suction profile right below slab edge (see Figure 5.4 )- $2 \mathrm{~m}$ same $\mathrm{K}_{\text {sat }}$ replacement material and roof runoff conditions. 


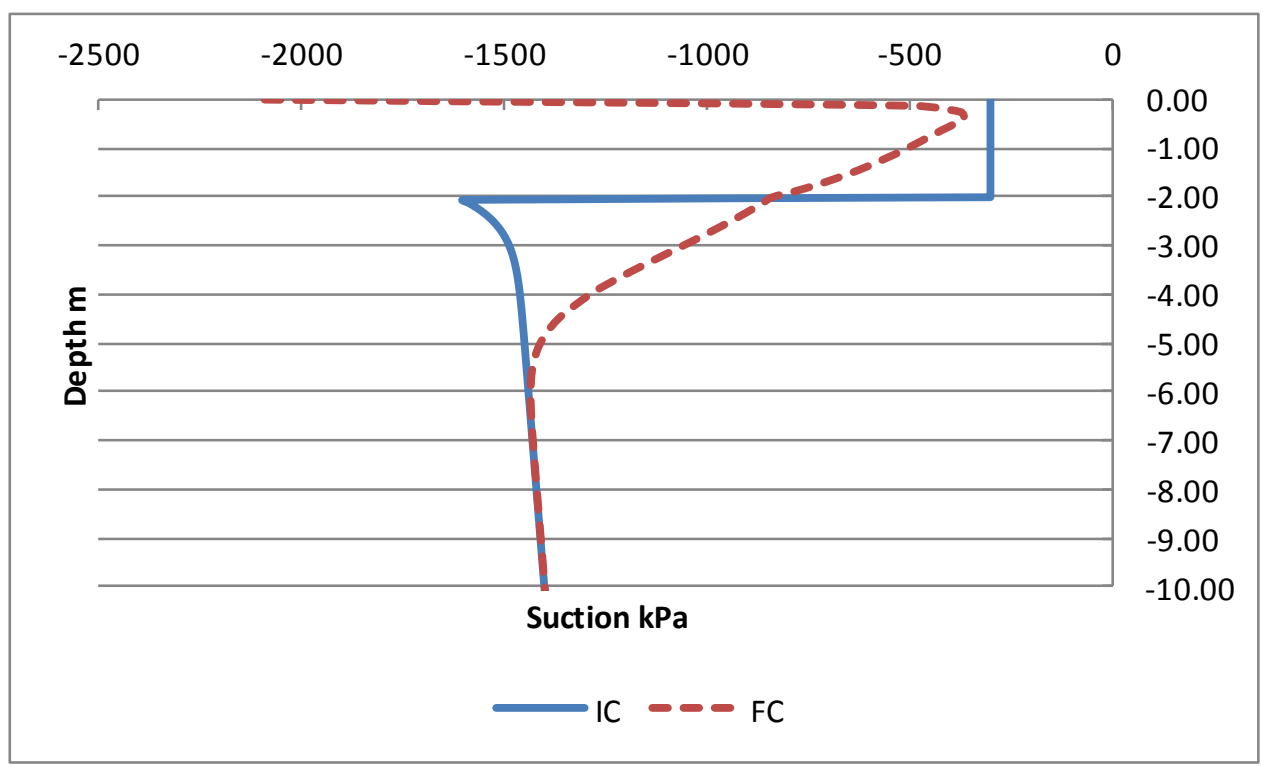

Figure 5.11.(b) Initial Condition (IC )and Final Condition (FC) suction profile right below slab edge $-2 \mathrm{~m}$ same $\mathrm{K}_{\text {sat }}$ replacement material and roof runoff conditions (blow up profile).

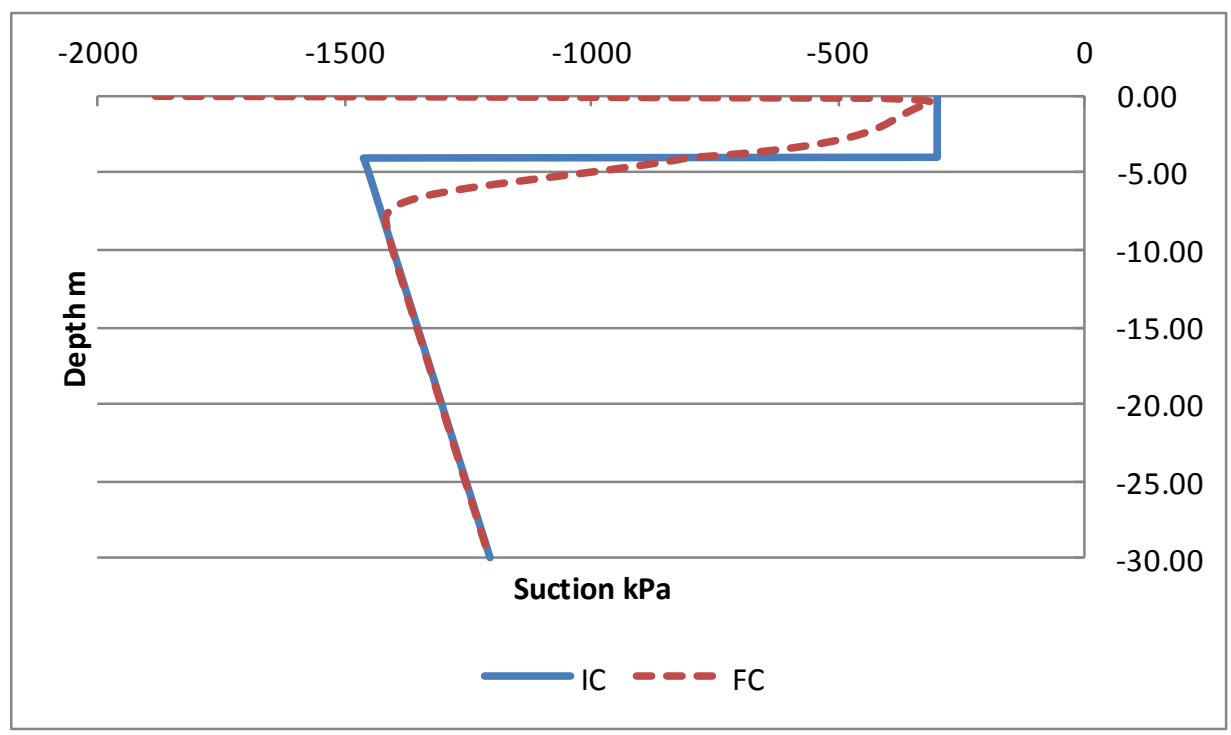

Figure 5.12.(a) Initial Condition (IC )and Final Condition (FC) suction profile right below slab edge (see Figure 5.4 )- $4 \mathrm{~m}_{\text {same }} \mathrm{K}_{\text {sat }}$ replacement material and roof runoff conditions. 


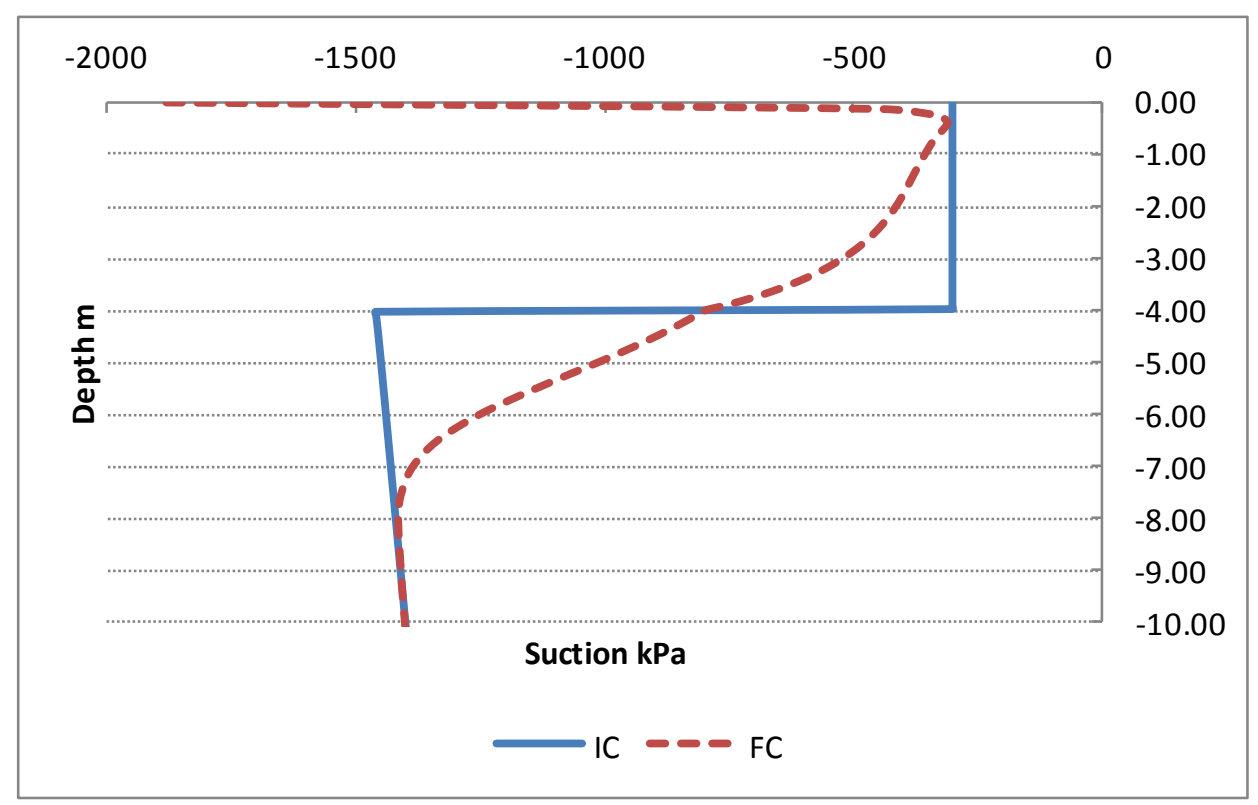

Figure 5.12.(b) Initial Condition (IC )and Final Condition (FC) suction profile right below slab edge $-4 \mathrm{~m}$ same $\mathrm{K}_{\text {sat }}$ replacement material and roof runoff conditions (blow up profile).

Presented below are results at the end of $6^{\text {th }} \mathrm{yr}$ for the roof runoff runs all the same $\mathrm{K}_{\text {sat }}$ replacement depth cases. This section includes the results obtained from SVFlux and SVSolid analyses. The no replacement case is also shown for comparison. As shown in Figure 5.13, the water infiltrates deeper for $2 \mathrm{~m}$ and $4 \mathrm{~m}$ replacement cases compared to the $0.75 \mathrm{~m}$ replacement depth for the same $\mathrm{K}_{\text {sat }}$ replacement material and roof runoff conditions. Further, the $0.75 \mathrm{~m}$ option results in a reduced depth of wetting compared to the no replacement case, in spite of this replacement material having a higher conductivity at its optimum water content placement moisture condition ( $300 \mathrm{kPa}$ ) when compared to the relatively drier underlying native clay. The reason that the $0.75 \mathrm{~m}$ option minimizes the depth of wetting is that it is serving as a store and release layer, functioning similarly to evapo-transpirative covers used in waste containment systems. Often this is referred to as a "sponge 
effect" because the water enters the upper soil layer where it is stored until a nonrain period during which evaporation acts to pull the soil moisture upward. Because the conductivity of the underlying expansive clay is lower than the conductivity of the replacement layer, water tends to stay in the upper replacement layer longer rather than moving quickly into the underlying expansive clay material (i.e. a pseudoperching of water occurs on top of the expansive clay layer). The deeper wetting for the $2 \mathrm{~m}$ and $4 \mathrm{~m}$ replacement with same $\mathrm{K}_{\text {sat }}$ material is due to this replacement soil (as placed at optimum water content) having a relatively higher hydraulic conductivity than the native expansive clays. In the case of the $2 \mathrm{~m}$ and $4 \mathrm{~m}$ replacement layer the infiltrating roof runoff water goes deeper into the profile, compared to the shallower $0.75 \mathrm{~m}$ replacement case, where it cannot be as readily evaporated during dry days.

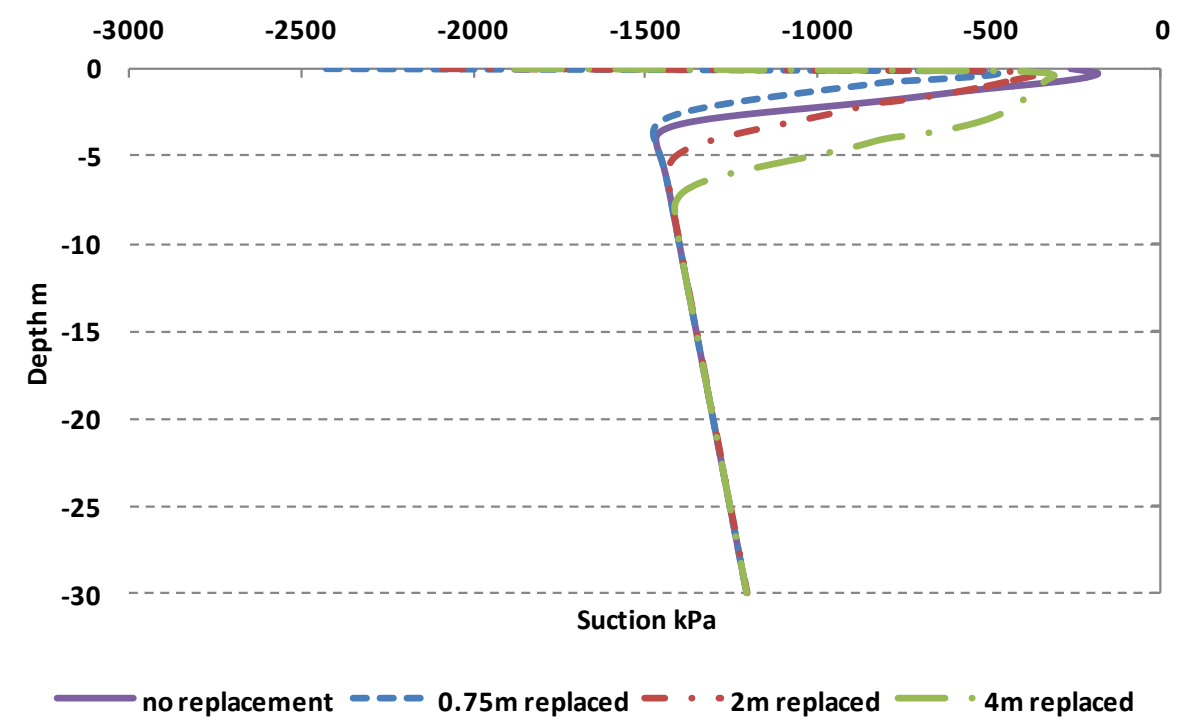

Figure 5.13.(a) End of $6^{\text {th }} \mathrm{yr}$ suction variation right below slab edge (see Figure 5.4) for no replacement expansive clay case and replacement cases - same $\mathrm{K}_{\text {sat }}$ replacement material and roof runoff conditions. 


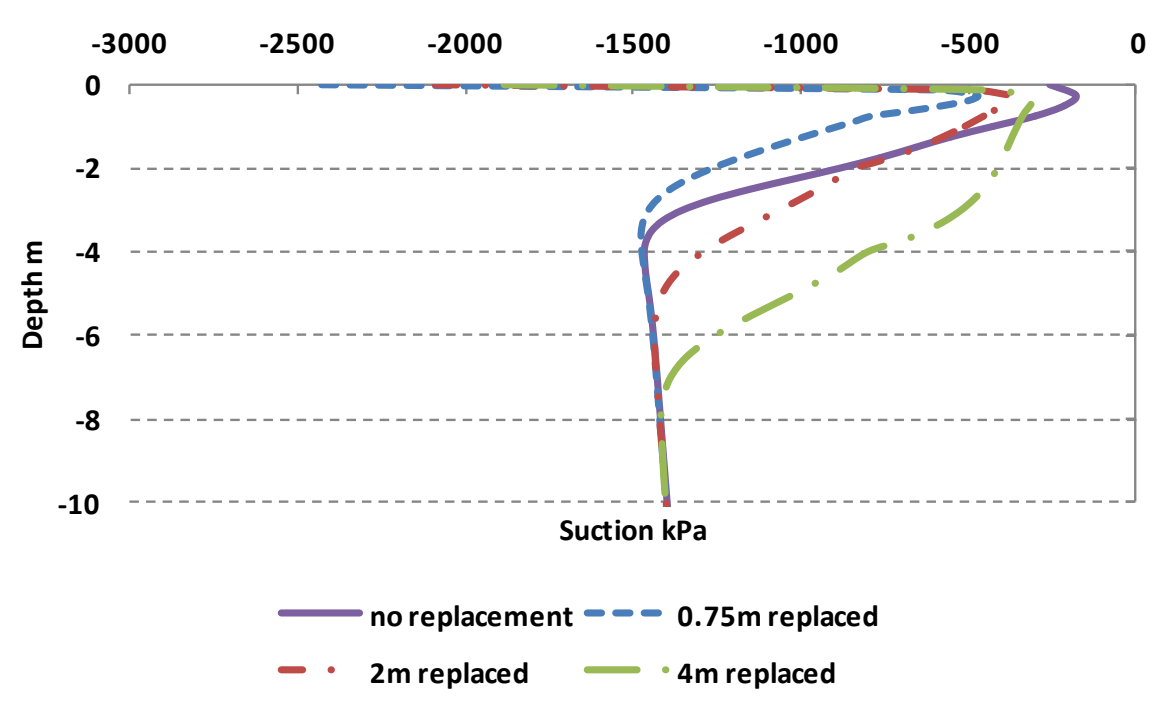

Figure 5.13.(b) End of $6^{\text {th }} \mathrm{yr}$ suction variation right below slab edge for no replacement expansive clay case and replacement cases - same $\mathrm{K}_{\text {sat }}$ replacement material and roof runoff conditions (blow up profile).

Figure 5.14 shows a vertical profile beneath the slab edge which compares the $6^{\text {th }} \mathrm{yr}$ deformation results obtained from SVSolid for the roof runoff case and same $\mathrm{K}_{\text {sat }}$ replacement material case, together with the no replacement case. Figure 5.15 shows the ground surface deformations for the same $\mathrm{K}_{\text {sat }}$ analyses for roof runoff, along with the ground surface deformations for the no replacement case. The $0.75 \mathrm{~m}$ same $\mathrm{K}_{\text {sat }}$ replacement depth has a significant effect on the surface heave. There is about $75 \%$ reduction in the maximum vertical displacement near the slab edge point for the $0.75 \mathrm{~m}$ replacement option. The $2 \mathrm{~m}$ and $4 \mathrm{~m}$ replacement depths have almost the same effect on reducing the vertical heave. However, the differential movement is least in case of higher depths of replacement. The differential movements are reduced in spite of the greater depths of wetting for the $2 \mathrm{~m}$ and $4 \mathrm{~m}$ replacement cases because the seat of movement is pushed deeper within the soil profile, dramatically affecting the differential heave at the ground surface. In 
addition, the $2 \mathrm{~m}$ and $4 \mathrm{~m}$ replacement depth result in removal of a greater depth of native expansive clay, and the remaining clay at higher confinement also has a reduced $C_{m}$ value. The net effect is that both total and differential movements are reduced for the $2 \mathrm{~m}$ and $4 \mathrm{~m}$ replacement options compared to the no replacement condition. However, for these surface flux boundary conditions, the $4 \mathrm{~m}$ replacement option does not result in much improvement in either total movement or differential movement at the ground surface compared to the $2 \mathrm{~m}$ replacement option.

It can also be observed from Figure 5.15 and Figure 5.21 that the same $\mathrm{K}_{\text {sat }}$ and higher $\mathrm{K}_{\text {sat }}$ replacement options do not reduce the surface deformation to zero even at $25 \mathrm{~m}$ distant from the slab edge (35m from slab centerline). The deformations at $25 \mathrm{~m}$ from the slab edge are small (about $0.05 \mathrm{~m}$ ), but not zero, as a result of lateral movement of water through the relatively higher conductivity replacement layer that allows for some subsurface wetting of the underlying expansive clay. This phenomenon is discussed in greater detail in a subsequent section of this chapter, Section 5.8 . 


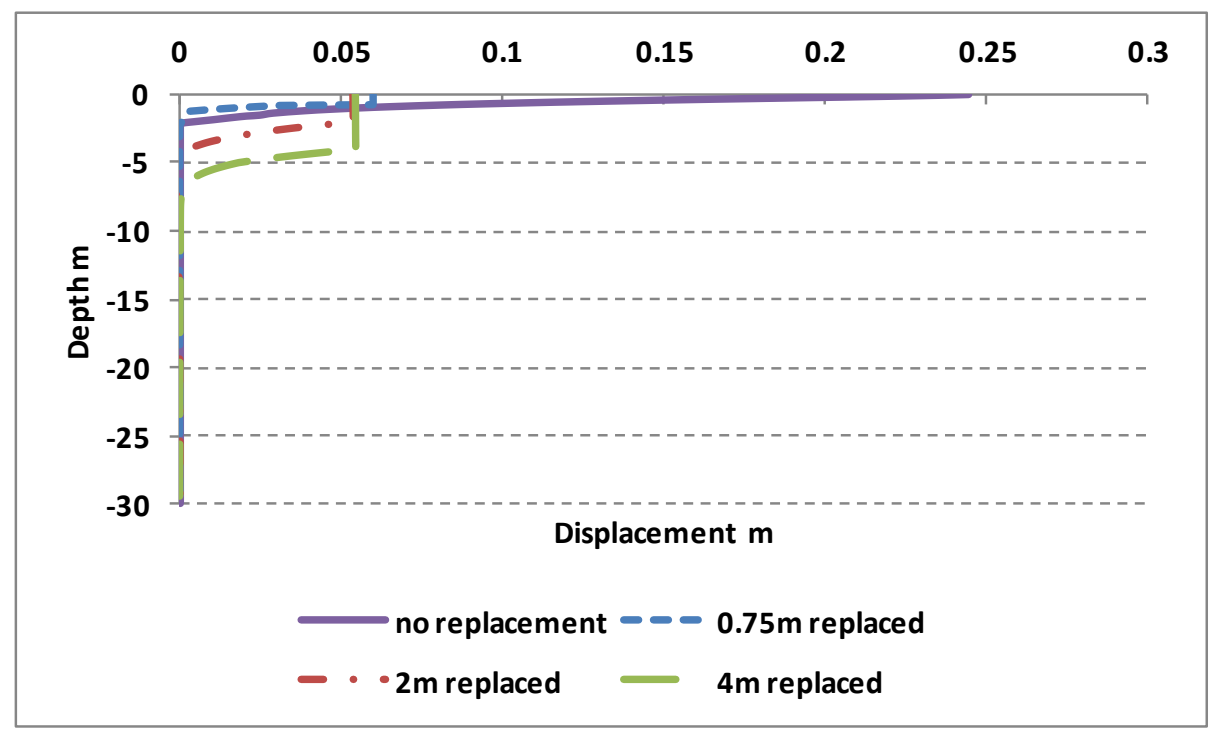

Figure 5.14.(a) Final Displacement results right below slab edge for no replacement expansive clay case and replacement cases (see Figure 5.4 ) - same $\mathrm{K}_{\text {sat }}$ material and roof runoff conditions.

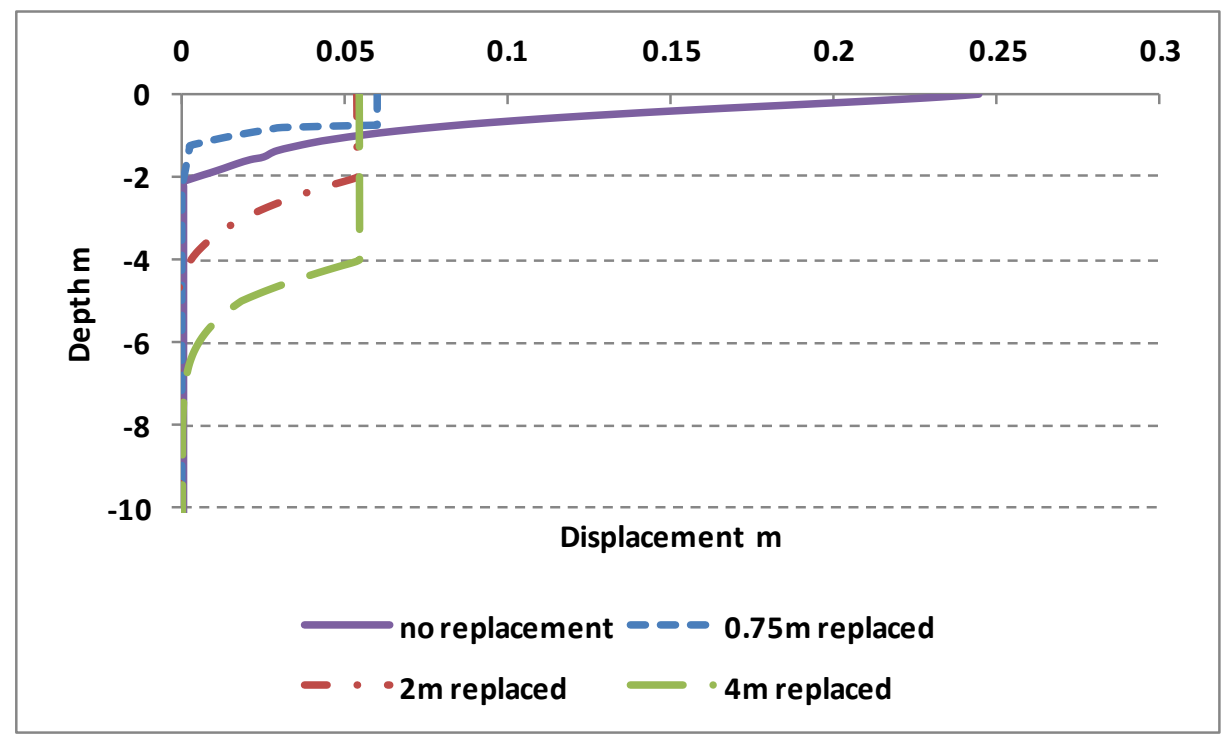

Figure 5.14.(b) Final Displacement results right below slab edge for no replacement expansive clay case and replacement cases - same $\mathrm{K}_{\text {sat }}$ material and roof runoff conditions (blow up profile). 


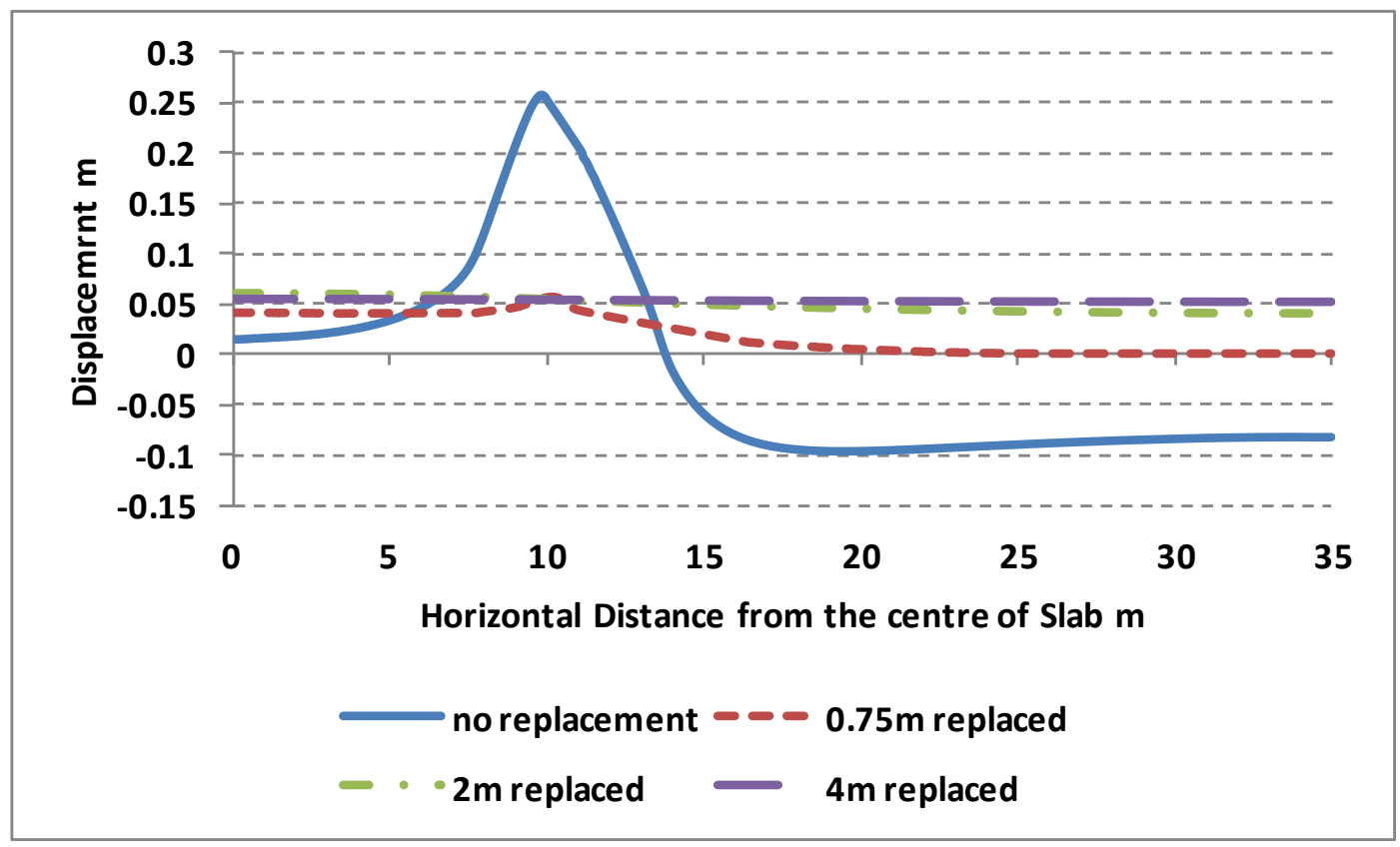

Figure 5.15. Final Displacement variation at the ground surface (see Figure 5.8) for no replacement expansive clay case and replacement cases- same $\mathrm{K}_{\text {sat }}$ material and roof runoff conditions.

\subsection{3 $6^{\text {th }}$ Year Results for Higher $K_{\text {sat }}$ Replacement Layer Case}

Presented below are the $6^{\text {th }} \mathrm{yr}$ results of the roof runoff runs for all the higher $\mathrm{K}_{\text {sat }}$ replacement depth cases. This section includes the results obtained from SVFlux and SVSolid analyses. 


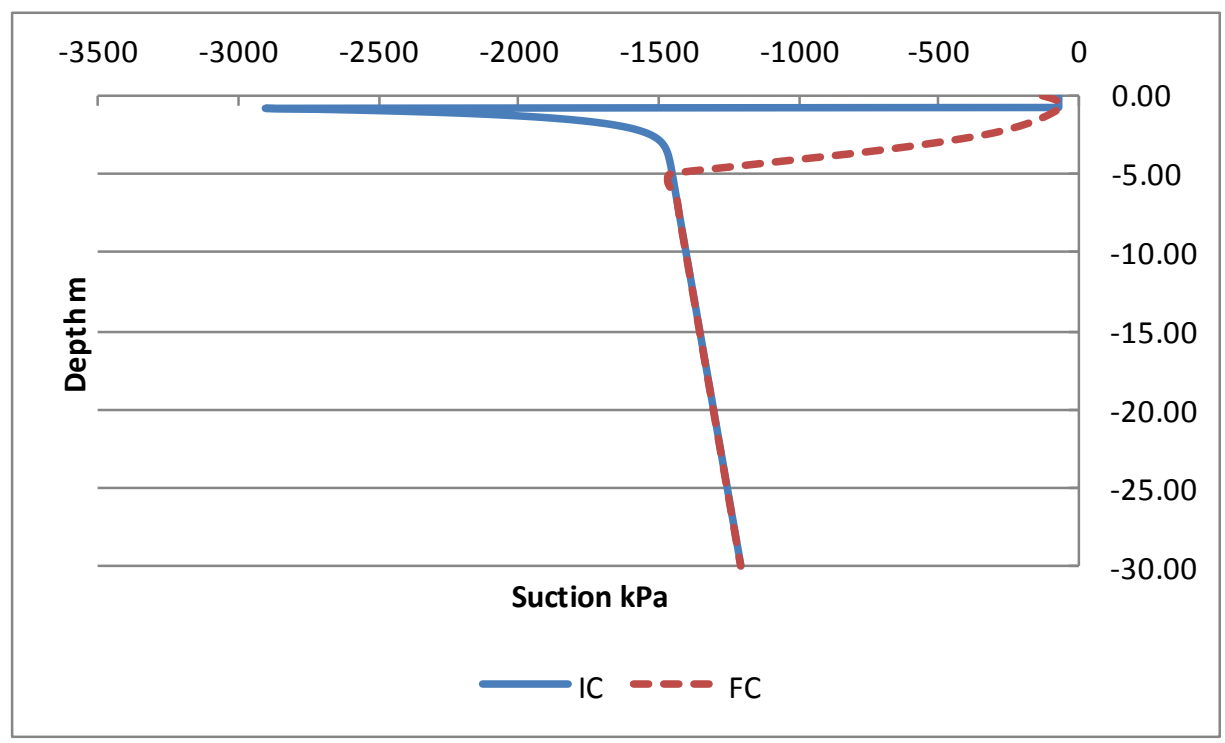

Figure 5.16.(a) Initial Condition (IC )and Final Condition (FC) suction profile right below slab edge (see Figure 5.4 ) $-0.75 \mathrm{~m}$ higher $\mathrm{K}_{\text {sat }}$ replacement case and roof runoff conditions.

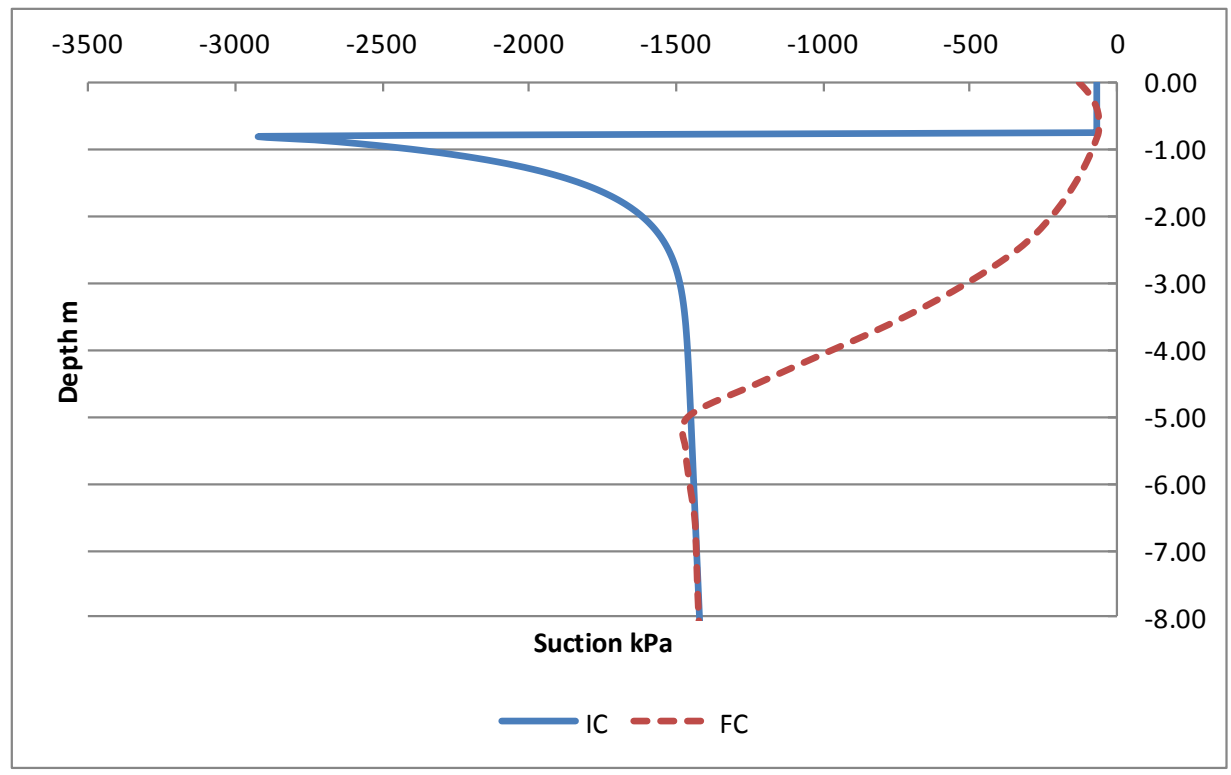

Figure 5.16.(b) Initial Condition (IC )and Final Condition (FC) suction profile right below slab edge $-0.75 \mathrm{~m}$ higher $\mathrm{K}_{\text {sat }}$ replacement material and roof runoff conditions (blow up profile). 
Figure 5.17 shows the initial and final condition suction variation (below slab edge) for the $2 \mathrm{~m}$ higher $\mathrm{K}_{\text {sat }}$ case for roof runoff conditions.

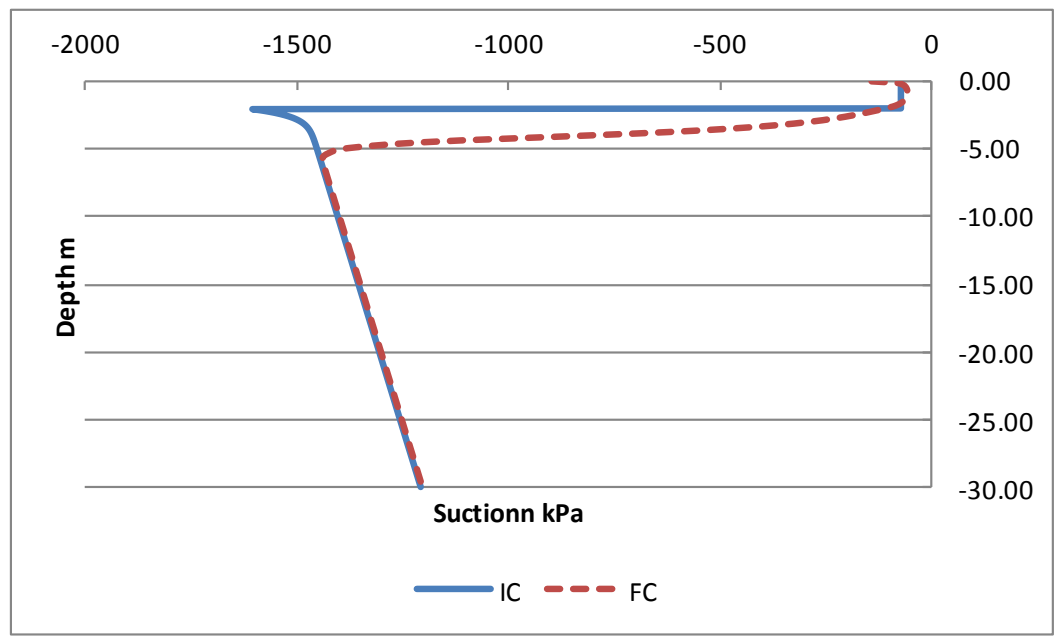

Figure 5.17.(a) Initial Condition (IC )and Final Condition (FC) suction profile right below slab edge (see Figure 5.4 ) $-2 \mathrm{~m}$ higher $\mathrm{K}_{\text {sat }}$ replacement material and roof runoff conditions.

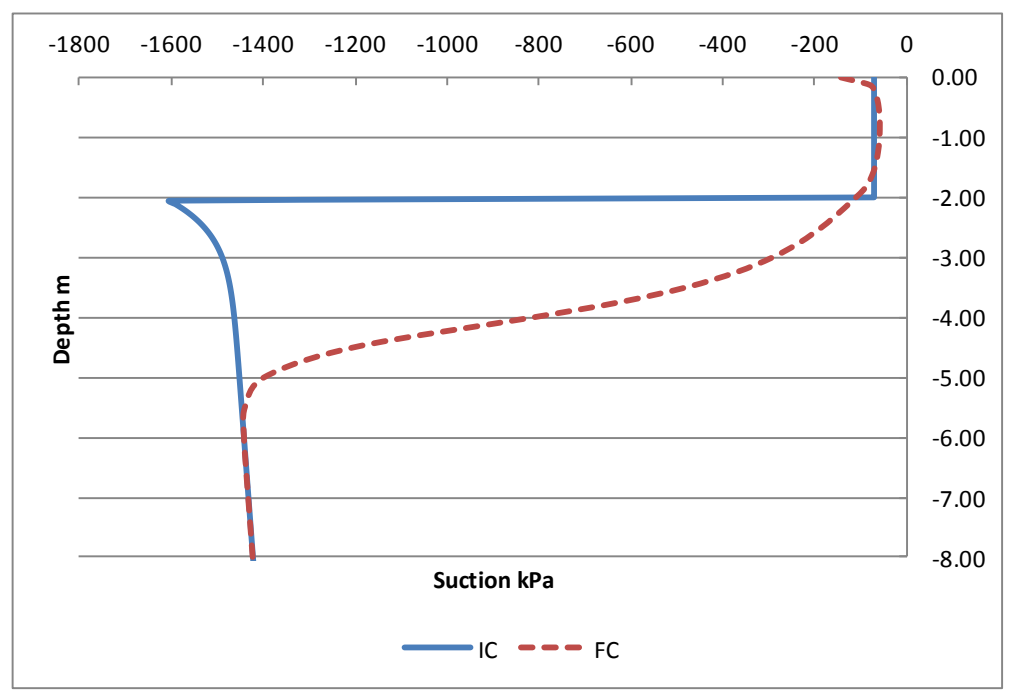

Figure 5.17.(b) Initial Condition (IC )and Final Condition (FC) suction profile right below slab edge $-2 \mathrm{~m}$ higher $\mathrm{K}_{\text {sat }}$ replacement material and roof runoff conditions (blow up profile). 
Figure 5.18 shows the initial and final condition suction variation (below slab edge) for the $4 \mathrm{~m}$ higher $\mathrm{K}_{\text {sat }}$ case.

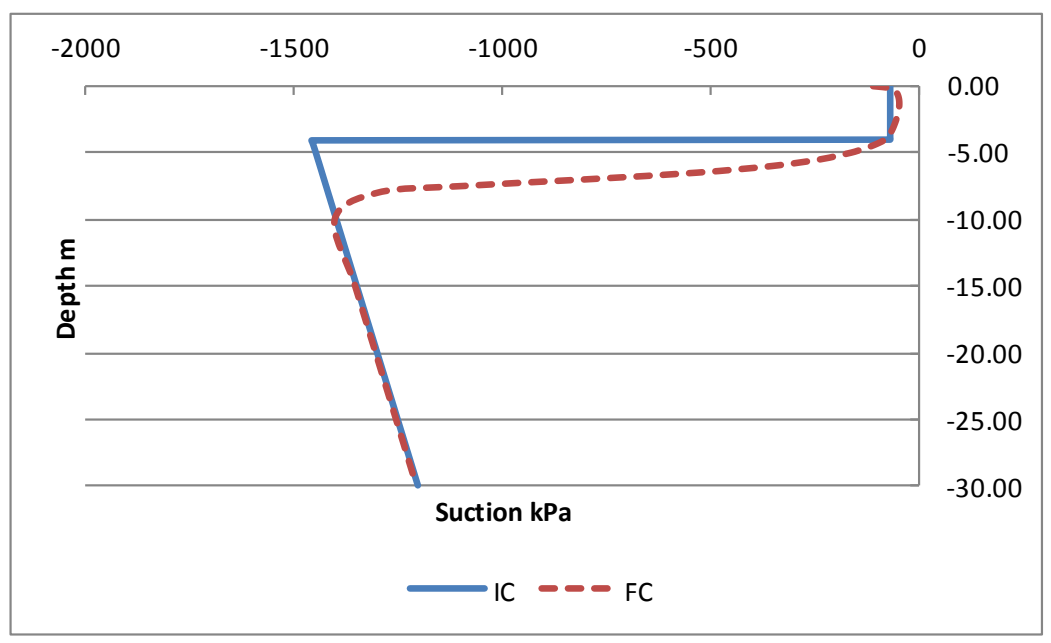

Figure 5.18.(a) Initial Condition (IC )and Final Condition (FC) suction profile right below slab edge (see Figure 5.4 ) $-4 m$ higher $\mathrm{K}_{\text {sat }}$ replacement material and roof runoff conditions

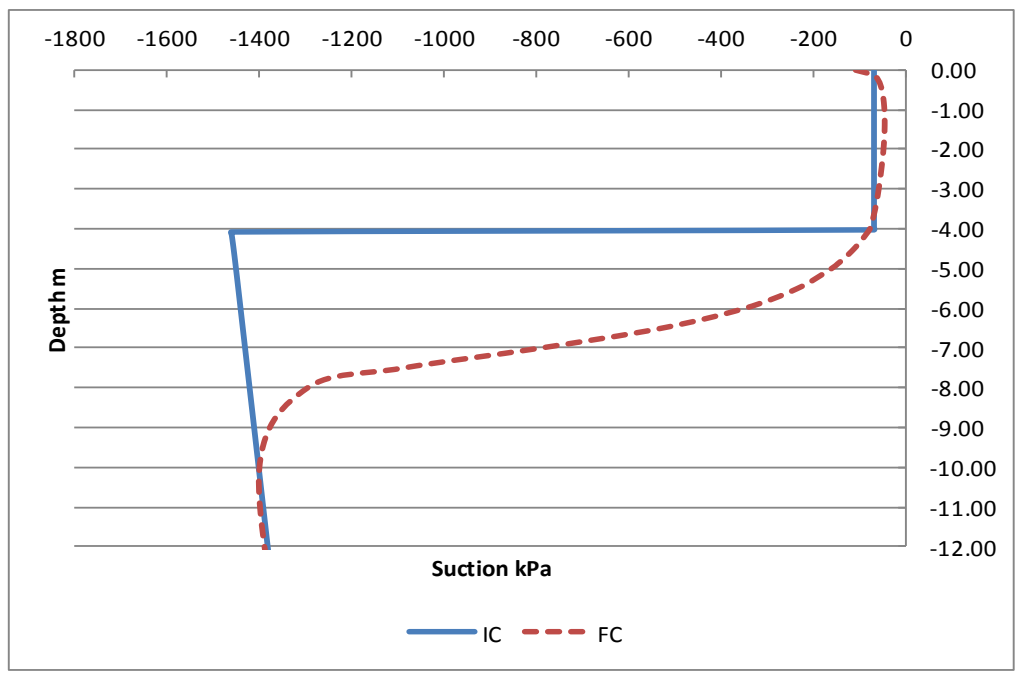

Figure 5.18.(b) Initial Condition (IC )and Final Condition (FC) suction profile right below slab edge $-4 \mathrm{~m}$ higher $\mathrm{K}_{\text {sat }}$ replacement material and roof runoff conditions (blow up profile). 
A summary of the suction profiles beneath slab edge for the roof runoff case and higher $\mathrm{K}_{\text {sat }}$ replacement material is show in Figure 5.19. Because the replacement layer has significantly higher hydraulic conductivity than the underlying native clay, placement of this higher conductivity material type results in substantially greater depth and degree of wetting compared to the no replacement case. The ponded water at the edge of the slab easily enters the replacement layer material and the storage capacity of this soil is inadequate to provide any "sponge effect" like that observed for the same $\mathrm{K}_{\text {sat }}$ replacement material at $0.75 \mathrm{~m}$ depth of replacement.

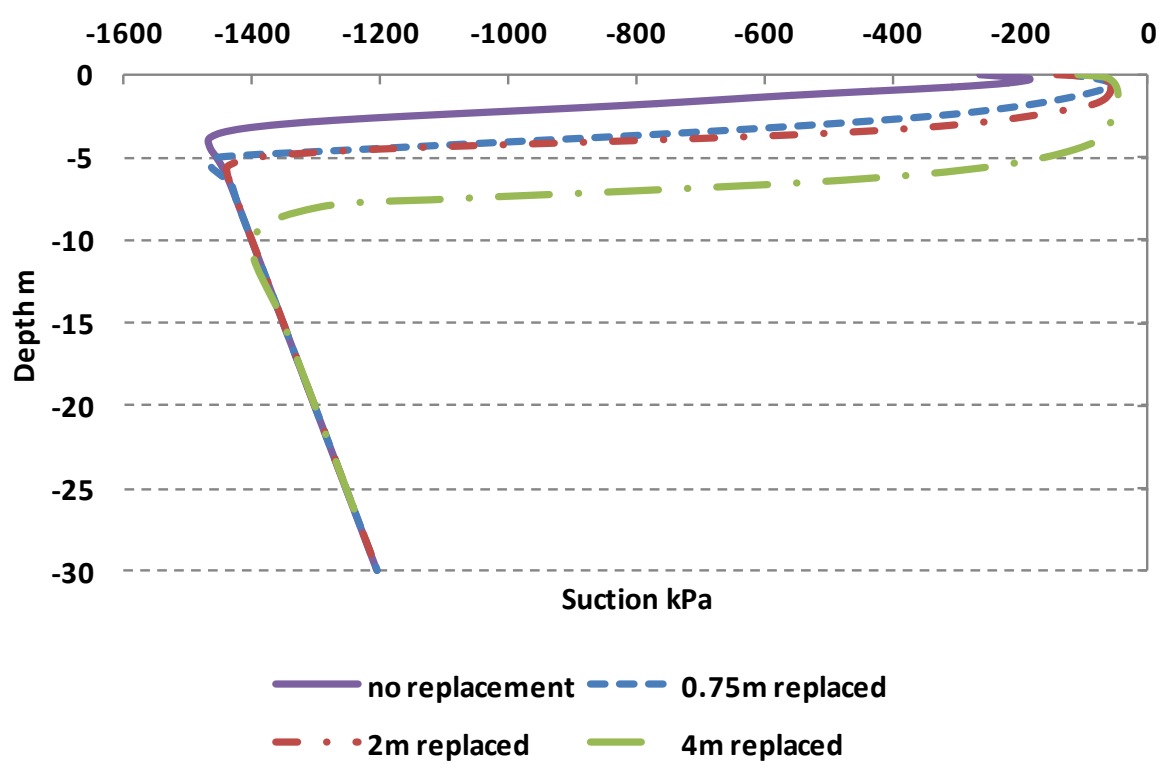

Figure 5.19.(a) End of $6^{\text {th }} \mathrm{yr}$ suction variation right below slab edge (see Figure 5.4) for no replacement expansive clay and replacement cases - higher $\mathrm{K}_{\text {sat }}$ replacement material and roof runoff conditions. 


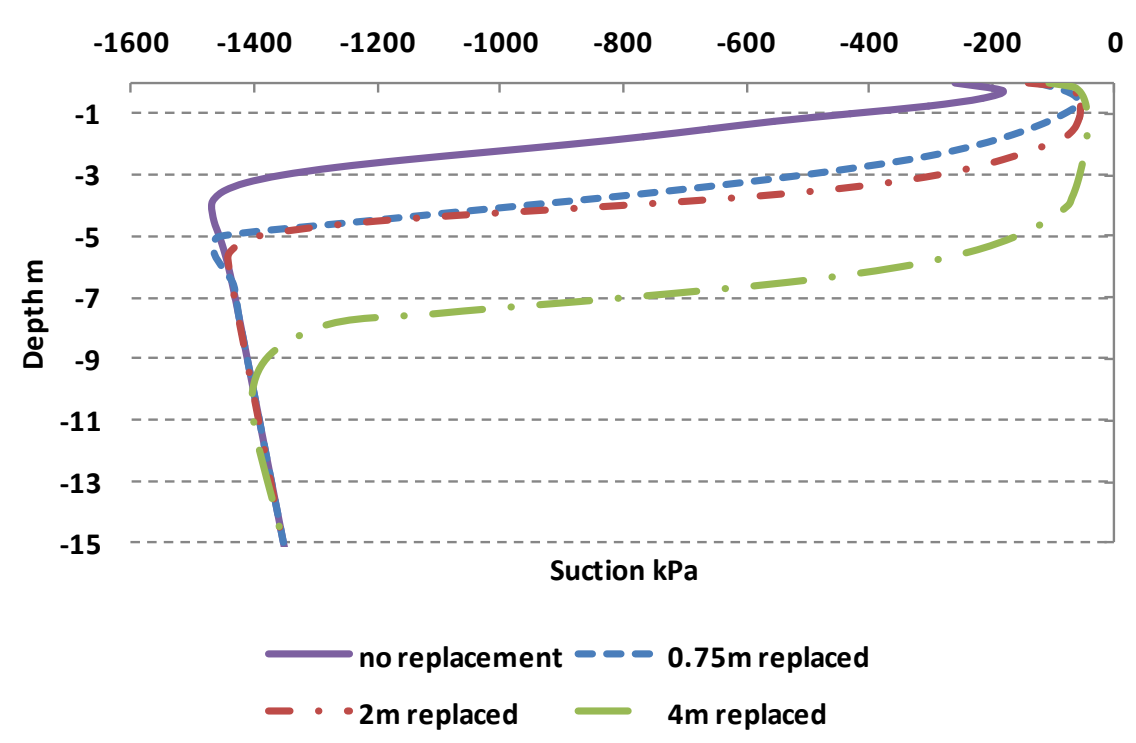

Figure 5.19.(b) End of $6^{\text {th }} \mathrm{yr}$ suction variation right below slab edge for no replacement expansive clay and replacement cases - higher $\mathrm{K}_{\text {sat }}$ replacement material and roof runoff conditions (blow up profile).

The SVSolid analyses for the higher $\mathrm{K}_{\text {sat }}$ replacement, roof runoff case are summarized in Figure 5.20 and Figure 5.21below. While the remove and replace option results in some mitigation of total and differential heave, due to the deeper wetting and higher degree of wetting that occurs, the higher $\mathrm{K}_{\text {sat }}$ material is not as effective in mitigating the expansive soil movements as the same $\mathrm{K}_{\text {sat }}$ or lower $\mathrm{K}_{\text {sat }}$ replacement materials. The water easily enters the higher $\mathrm{K}_{\text {sat }}$ material and the replacement layer serves more or less as a "bathtub" for collecting water as a source for deeper wetting within the native expansive clay below. The primary mitigation mechanisms for replacement with higher $\mathrm{K}_{\text {sat }}$ material are pushing the seat of movement deeper within the soil profile and removal of expansive soil material (replacing with non-expansive material). However, higher $\mathrm{K}_{\text {sat }}$ replacement materials do not decrease the degree and depth of wetting, and thus a very important 
mechanism of mitigation for removal and replacement is lacking when higher conductivity soils are used as replacement material.

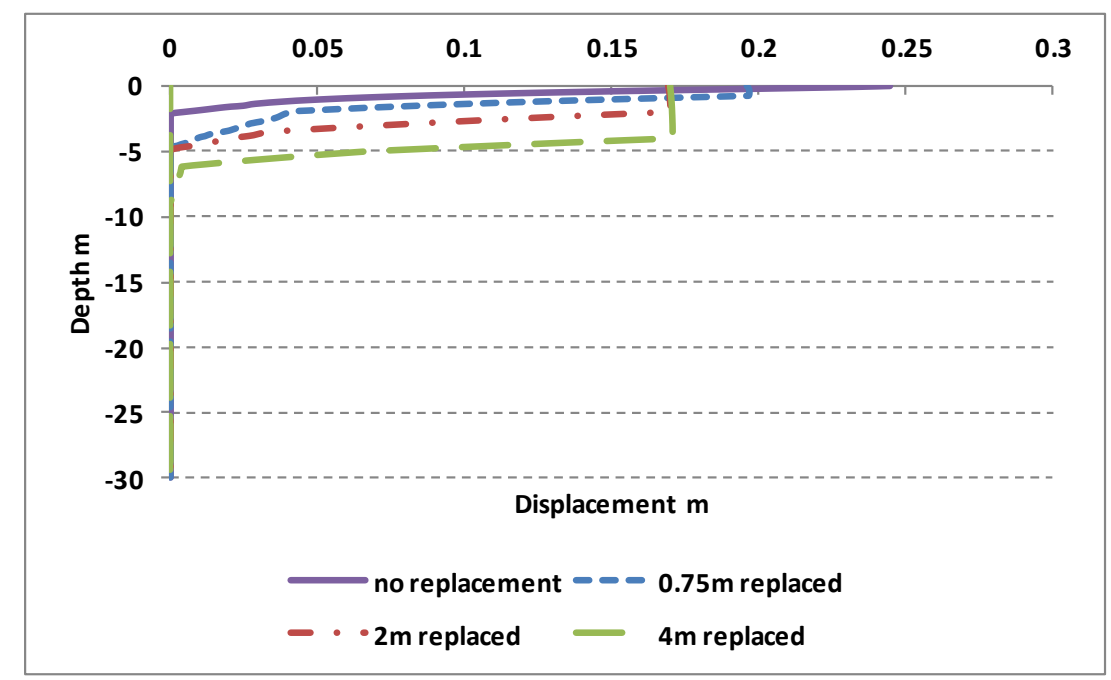

Figure 5.20.(a) Final Displacement results right below slab edge (see Figure 5.4) for no replacement expansive clay case and replacement cases - higher $\mathrm{K}_{\mathrm{sat}}$ replacement material and roof runoff conditions.

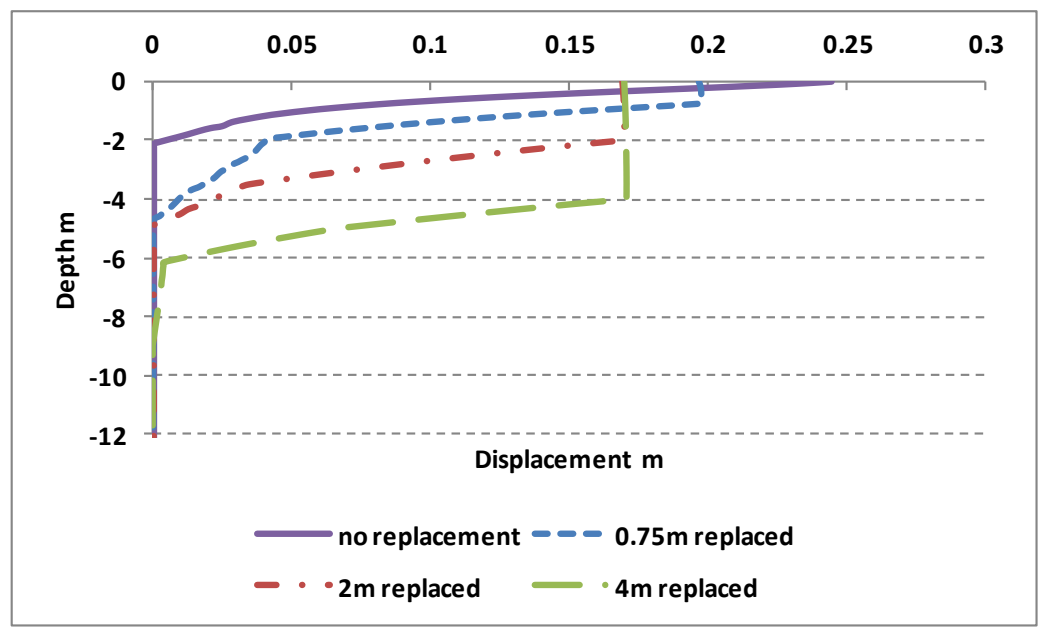

Figure 5.20.(b) Final Displacement results right below slab edge for no replacement expansive clay case and replacement cases - higher $\mathrm{K}_{\text {sat }}$ replacement material and roof runoff conditions (blow up profile). 


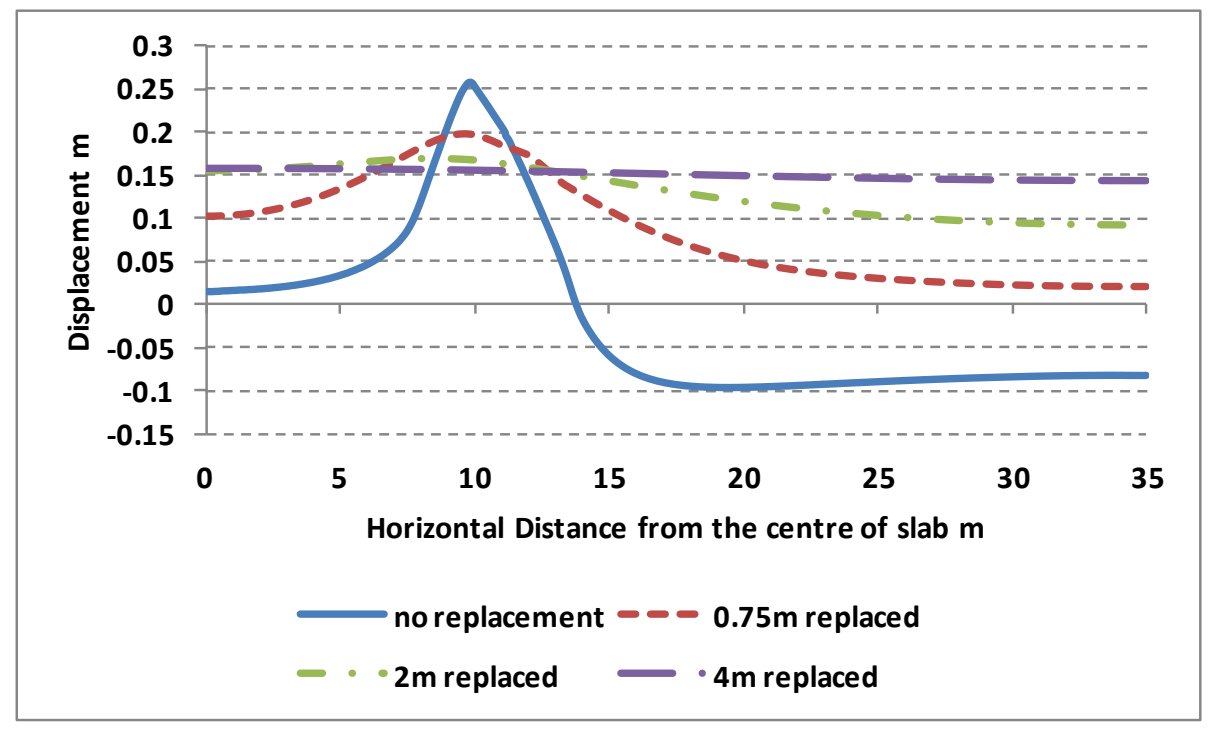

Figure 5.21. Final Displacement variation at the ground surface (see Figure 5.8) for no replacement expansive clay case and replacement cases - higher $\mathrm{K}_{\text {sat }}$ material and roof runoff conditions.

Figure 5.20 and Figure 5.21 shows the variation of heave below slab edge and at the ground surface. It is evident from Figure 5.20 that there is a reduction in vertical heave right below the slab edge. Also, the differential heave is reduced at the ground surface in all the different cases of higher $\mathrm{K}_{\text {sat }}$ replacement case (Figure 5.21). The higher conductivity case is analyzed to simulate the sand cushions commonly used in pavement and foundation constructions on expansive soil. The higher $\mathrm{K}_{\text {sat }}$ replacement soil used for these runs has a saturated conductivity two orders of magnitude higher than the expansive clay. Due to its property, it lets the water infiltrate easily into the profile. The percentage reduction is much lower as compared to the other replacement soil type cases. A maximum reduction of only $38.4 \%$ occurs for the $4 \mathrm{~m}$ replacement case. 


\subsection{Climatic Data Inputs for Turf Landscape Case}

The turf input flux for the runs is presented below in Figure 5.22. Figure 5.23 shows the rainfall and evaporation input for these set of runs. Additional details on the selection of surface flux condition were provided in Chapter 4 . The turf surface flux boundary condition simulates an over-irrigated lawn for a site with poor drainage conditions. Figure 5.24 shows the initial and final condition suction variation for no replacement case. The variation is for the section located right below slab edge.

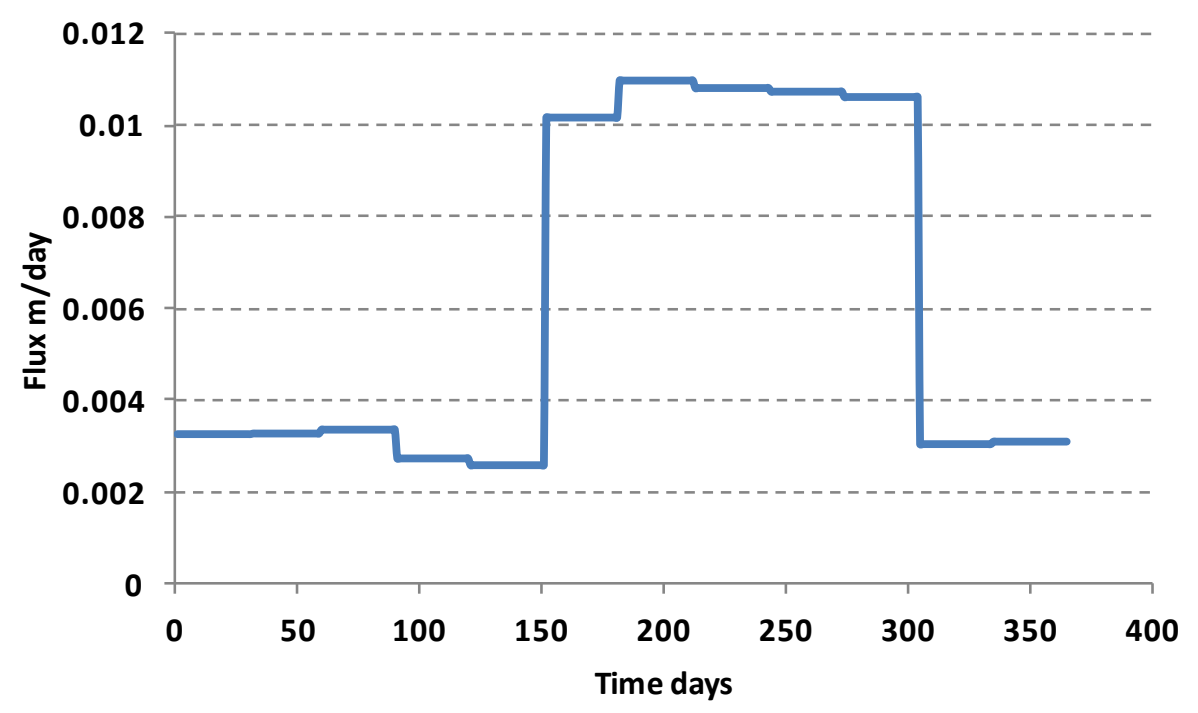

Figure 5.22. Input Roof Runoff Flux data 

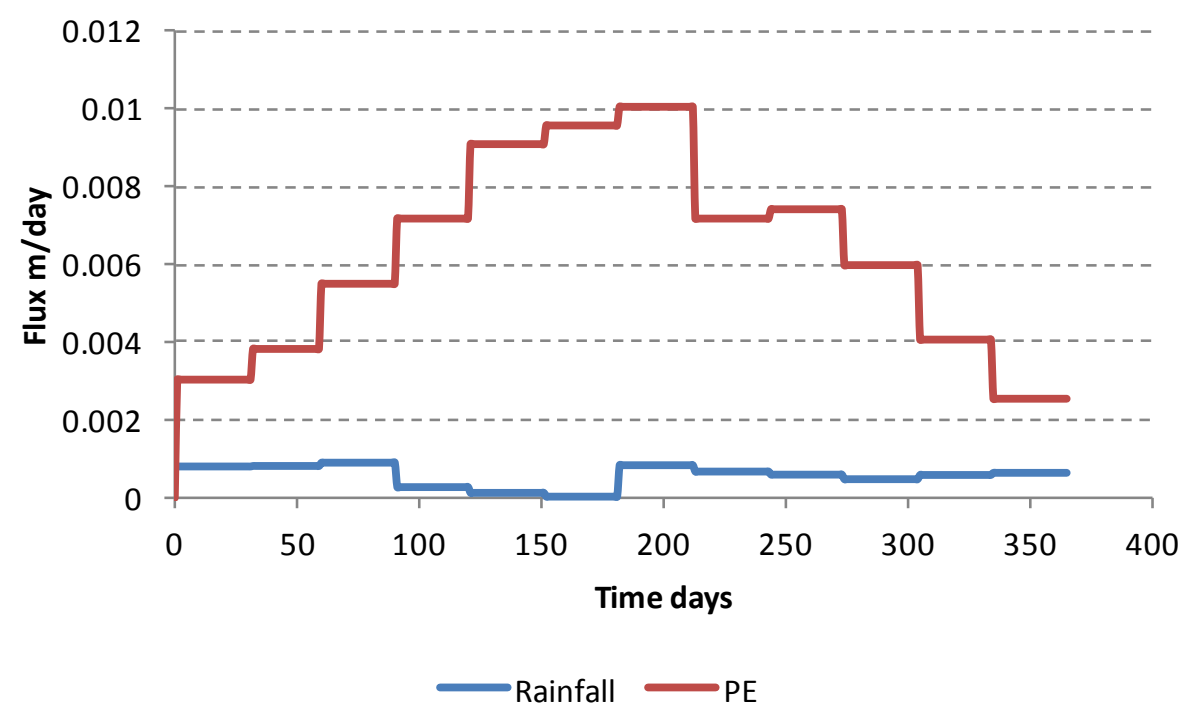

Figure 5.23. Input Potential Evaporation and Rainfall data

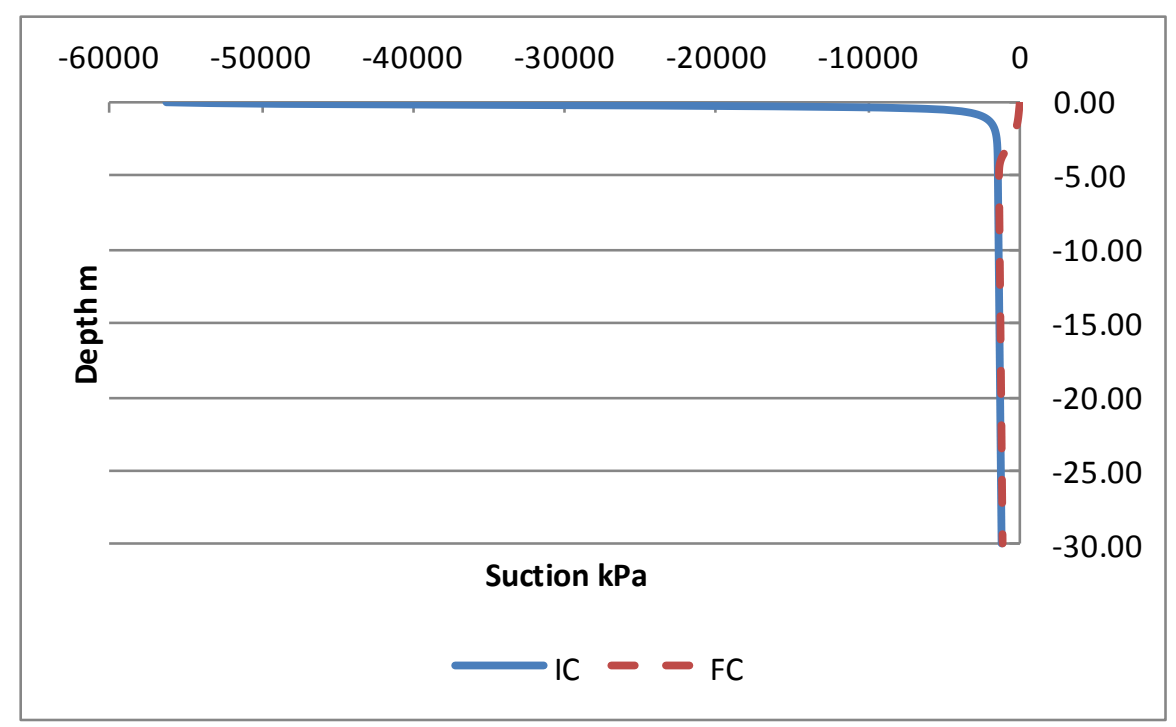

Figure 5.24.(a) Initial Condition (IC )and Final Condition (FC) suction profile right below slab edge (see Figure 5.4) - no replacement expansive clay case and turf conditions. 


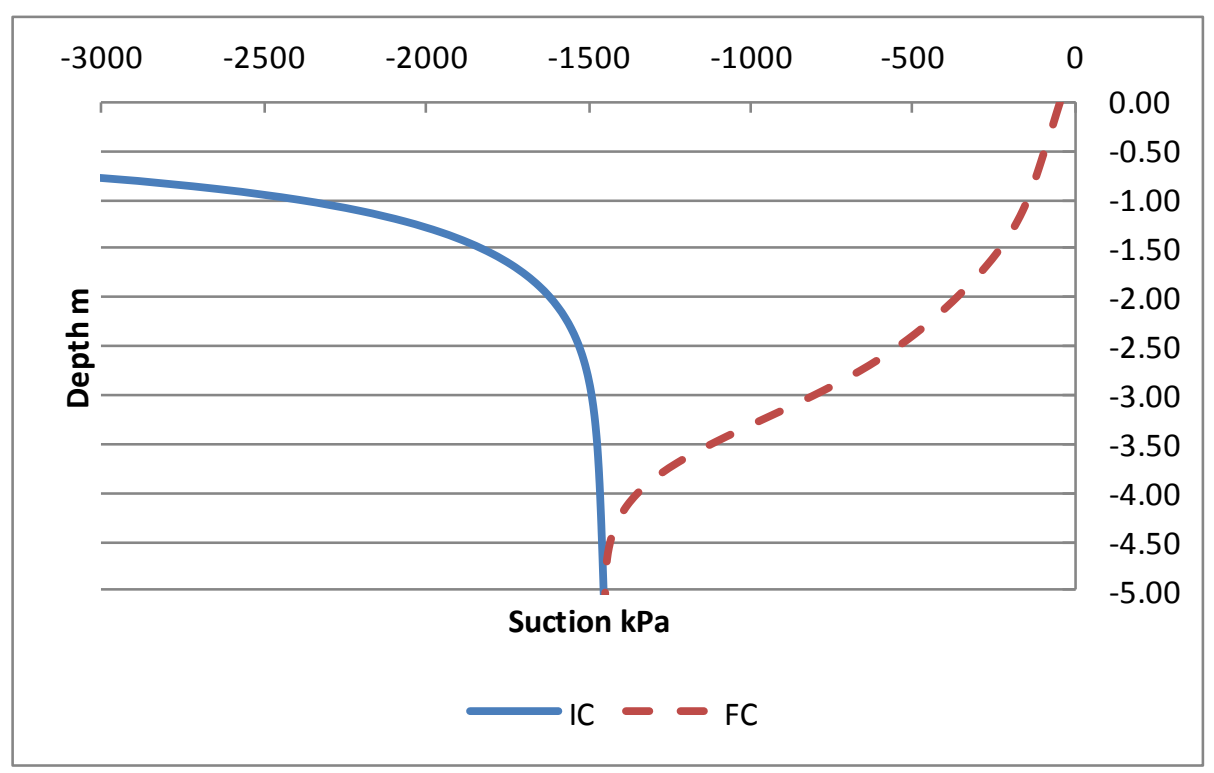

Figure 5.24.(b). Initial Condition (IC )and Final Condition (FC) suction profile right below slab edge - no replacement expansive clay case and turf conditions (blow up profile).

\subsection{SVFlux and SVSolid Results for Turf Case}

All the results of the unsaturated flow and deformation analyses for all the different replacement depths are presented in the following sections one by one.

\subsection{1 $6^{\text {th }}$ Yr Results for Lower $K_{\text {sat }}$ Replacement Layer Case}

Presented below are the $6^{\text {th }} \mathrm{yr}$ results of the turf runs for the lower $\mathrm{K}_{\text {sat }}$ replacement depth case. This section includes the results obtained from SVFlux and SVSolid analyses. Although the soil suction variations within the entire domain are computed from the finite element unsaturated flow analyses, for comparison of various cases, plots of soil suction are presented for a vertical profile located immediately below the slab edge, as shown in Figure 5.4. 


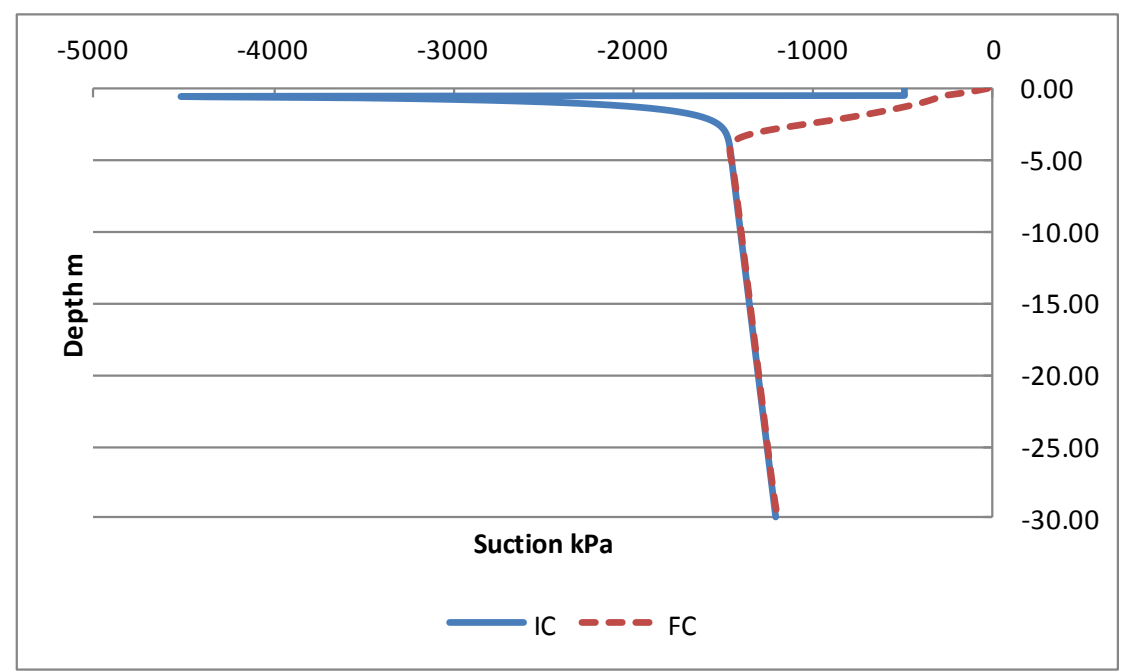

Figure 5.25.(a) Initial Condition (IC )and Final Condition (FC) suction profile right below slab edge (see Figure 5.4) - 0.5m lower $\mathrm{K}_{\text {sat }}$ replacement case and turf conditions.

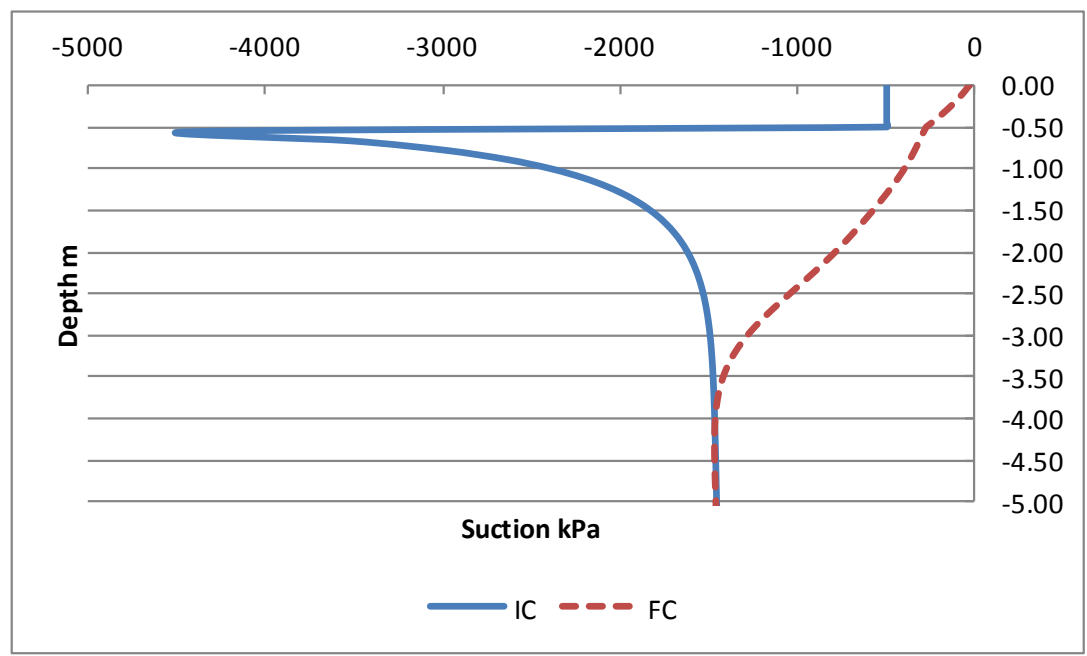

Figure 5.25.(b) Initial Condition (IC )and Final Condition (FC) suction profile right below slab edge $-0.5 \mathrm{~m}$ lower $\mathrm{K}_{\text {sat }}$ replacement case and turf conditions (blow up profile).

Figure 5.25 shows the initial and final condition suction variation (below slab edge) for $0.5 \mathrm{~m}$ lower $\mathrm{K}_{\text {sat }}$ case. The infiltration depth in this case is about $3.5 \mathrm{~m}$ deep. 118 
Figure 5.26 shows a plot which compares the $6^{\text {th }} \mathrm{yr}$ suction results for no replacement and $0.5 \mathrm{~m}$ cap case.

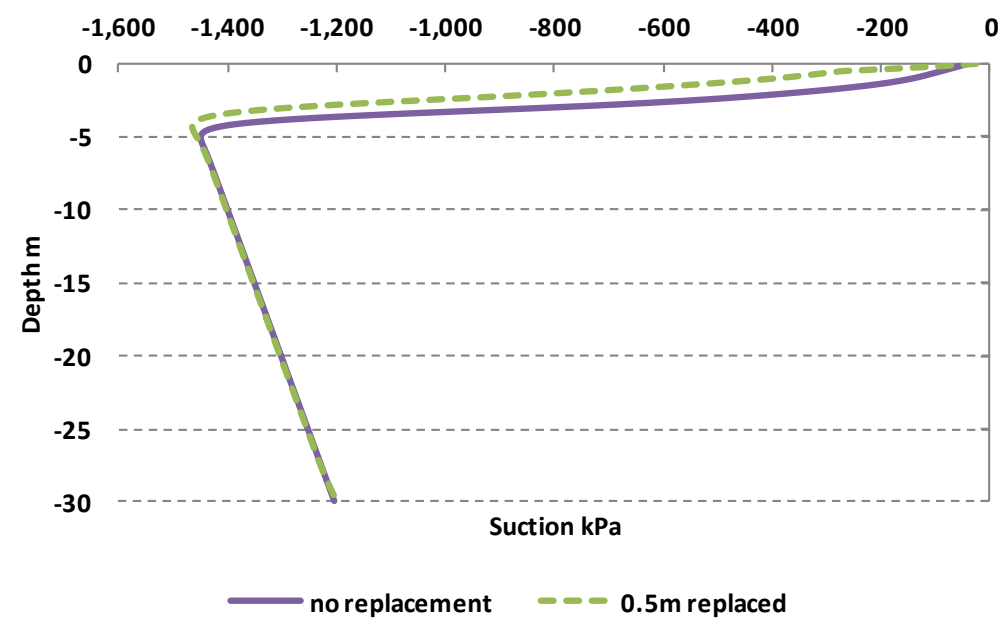

Figure 5.26.(a) End of $6^{\text {th }} \mathrm{yr}$ suction variation below slab edge (see Figure 5.4) for no replacement expansive clay and $0.5 \mathrm{~m}$ lower $\mathrm{K}_{\text {sat }}$ replacement material turf conditions.

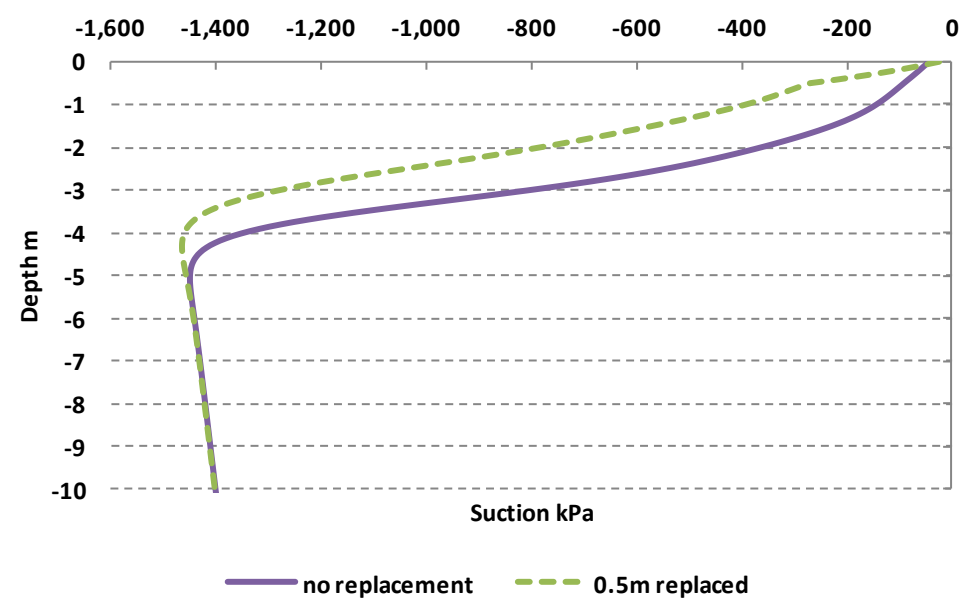

Figure 5.26.(b) End of $6^{\text {th }}$ yr suction variation below slab edge for no replacement expansive clay and $0.5 \mathrm{~m}$ lower $\mathrm{K}_{\text {sat }}$ replacement material - turf conditions (blow up profile). 


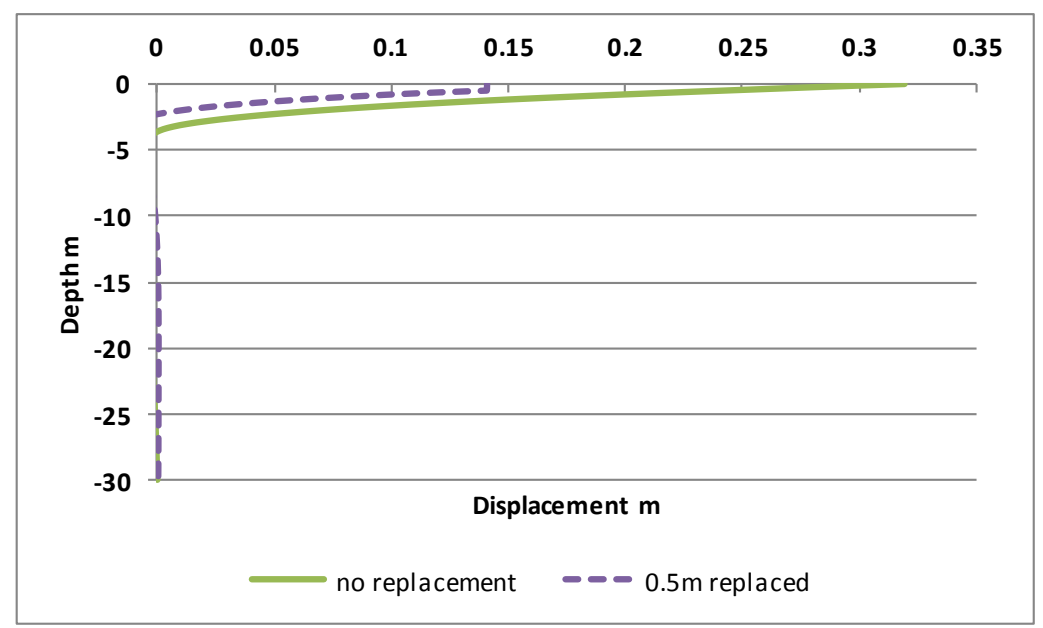

Figure 5.27.(a) Final Displacement results right below slab edge (see Figure 5.4) for no replacement expansive clay case and $0.5 \mathrm{~m}$ lower $\mathrm{K}_{\text {sat }}$ replacement material - turf conditions.

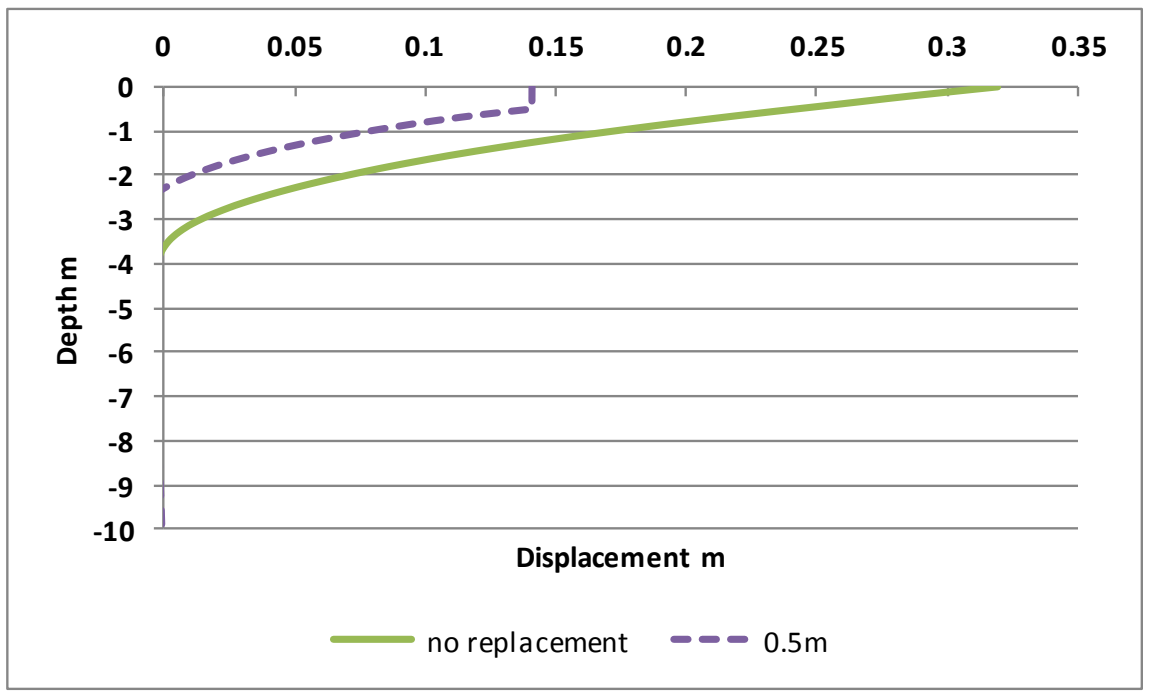

Figure 5.27.(b) Final Displacement results right below slab edge for no replacement expansive clay case and $0.5 \mathrm{~m}$ lower $\mathrm{K}_{\text {sat }}$ replacement material - turf conditions (blow up profile). 


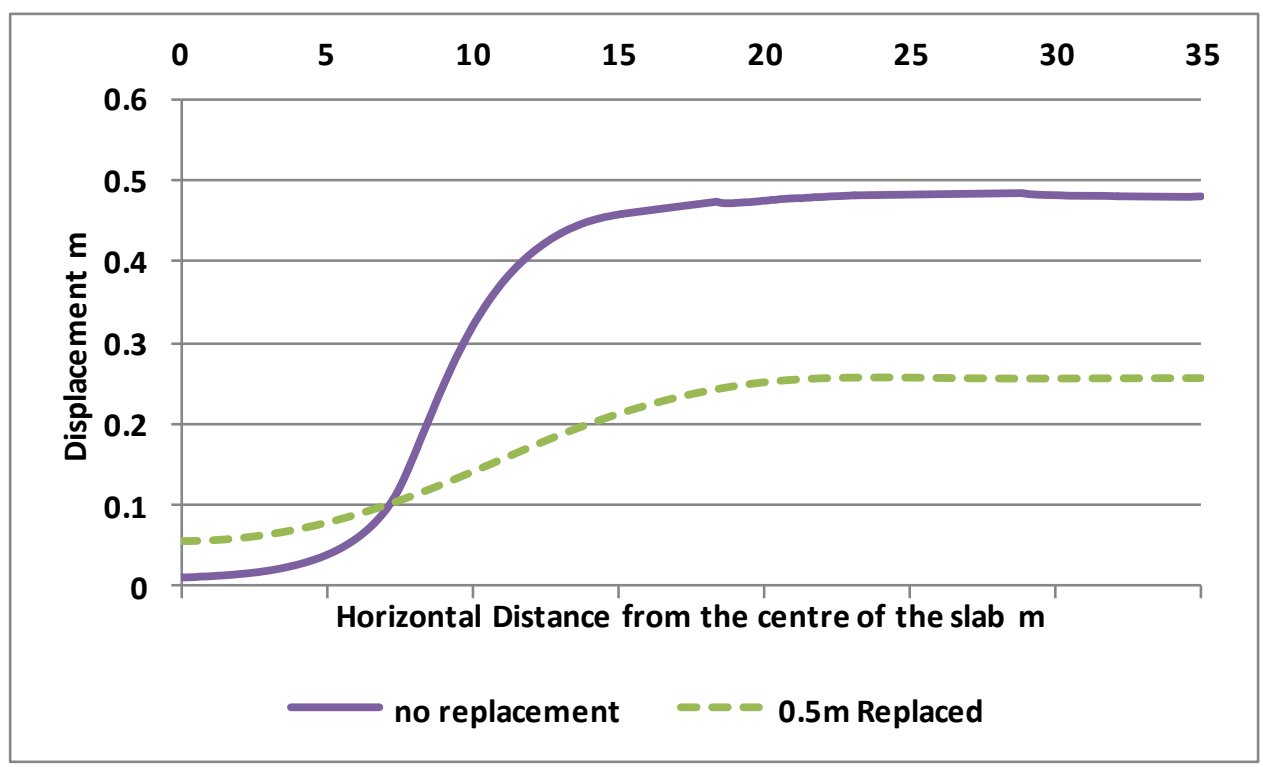

Figure 5.28. Final Displacement variation at the ground surface (see Figure 5.8) for no replacement expansive clay case and $0.5 \mathrm{~m}$ lower $\mathrm{K}_{\text {sat }}$ replacement material - turf conditions.

\subsection{2 $6^{\text {th }}$ Yr Results for $2 \mathrm{~m}$ Same $K_{\text {sat }}$ Replacement Layer Case}

Presented below are the $6^{\text {th }} \mathrm{yr}$ results of the turf runs for the same $\mathrm{K}_{\text {sat }}$ replacement depth case. This section includes the results obtained from SVFlux and SVSolid analyses. Figure 5.29 shows the initial and final condition suction variation (below slab edge) for $2 \mathrm{~m}$ same $\mathrm{K}_{\text {sat }}$ case. Figure 5.30 shows a plot which compares the $6^{\text {th }} \mathrm{yr}$ suction results for no replacement with the $2 \mathrm{~m}$ cap case. 


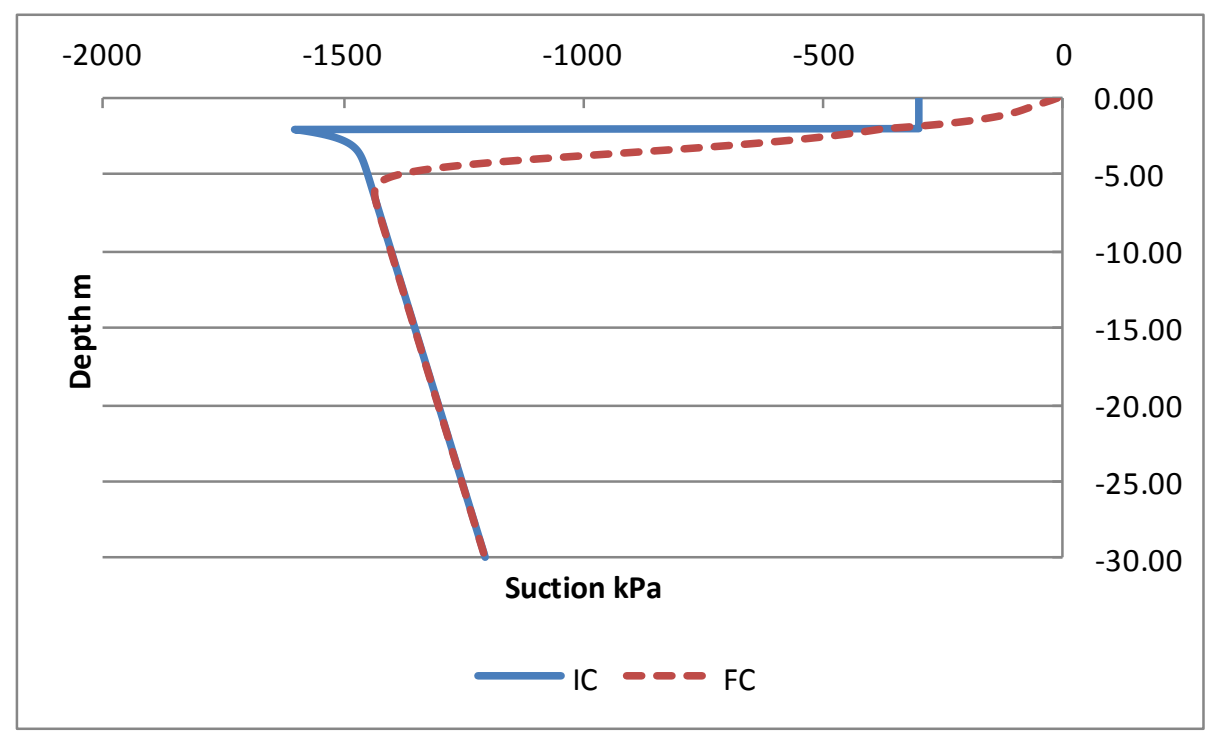

Figure 5.29.(a) Initial Condition (IC )and Final Condition (FC) suction profile right below slab edge (see Figure 5.4 ) - $2 \mathrm{~m}$ same $\mathrm{K}_{\text {sat }}$ replacement case and turf conditions.

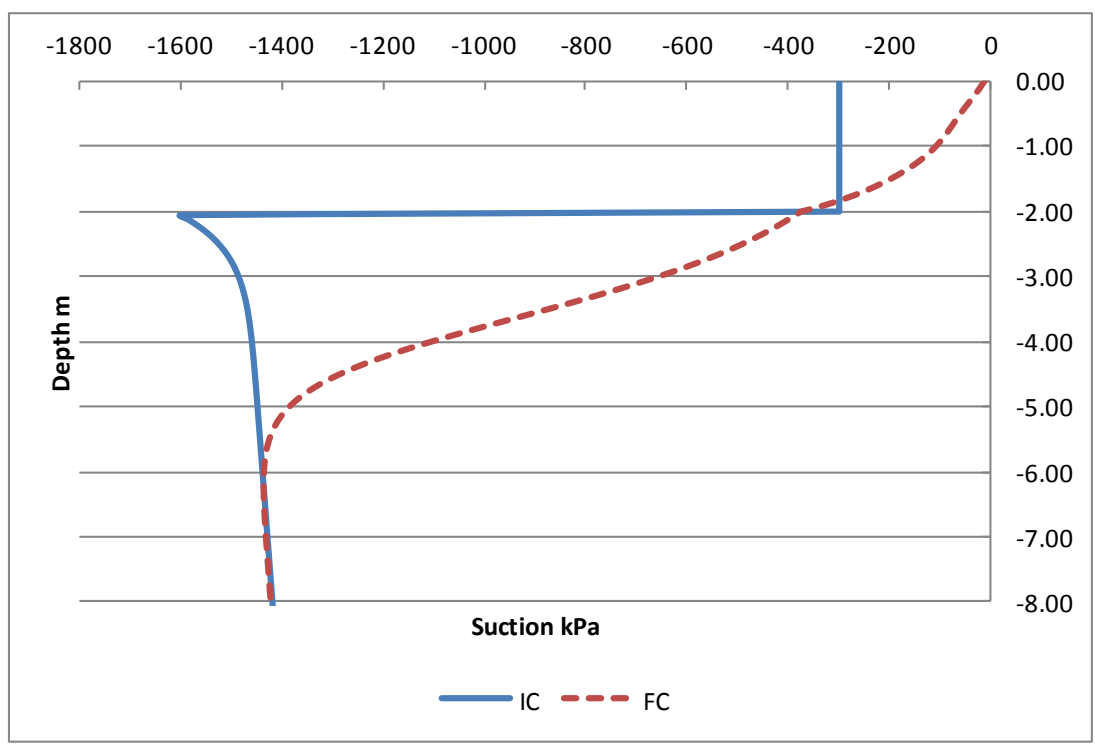

Figure 5.29.(b) Initial Condition (IC )and Final Condition (FC) suction profile right below slab edge $-2 \mathrm{~m}$ same $\mathrm{K}_{\text {sat }}$ replacement case and turf conditions (blow up profile). 


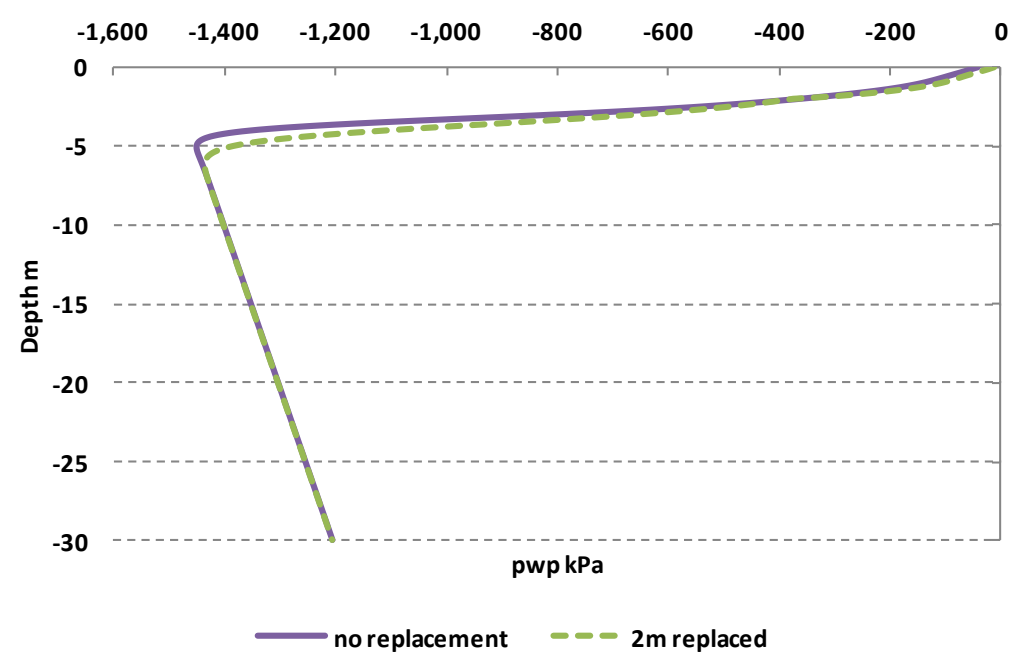

Figure 5.30.(a) End of $6^{\text {th }}$ yr suction variation vertical profile right below slab edge (see Figure 5.4) - no replacement expansive clay and $2 \mathrm{~m}$ same $\mathrm{K}_{\text {sat }}$ replacement material and turf conditions.

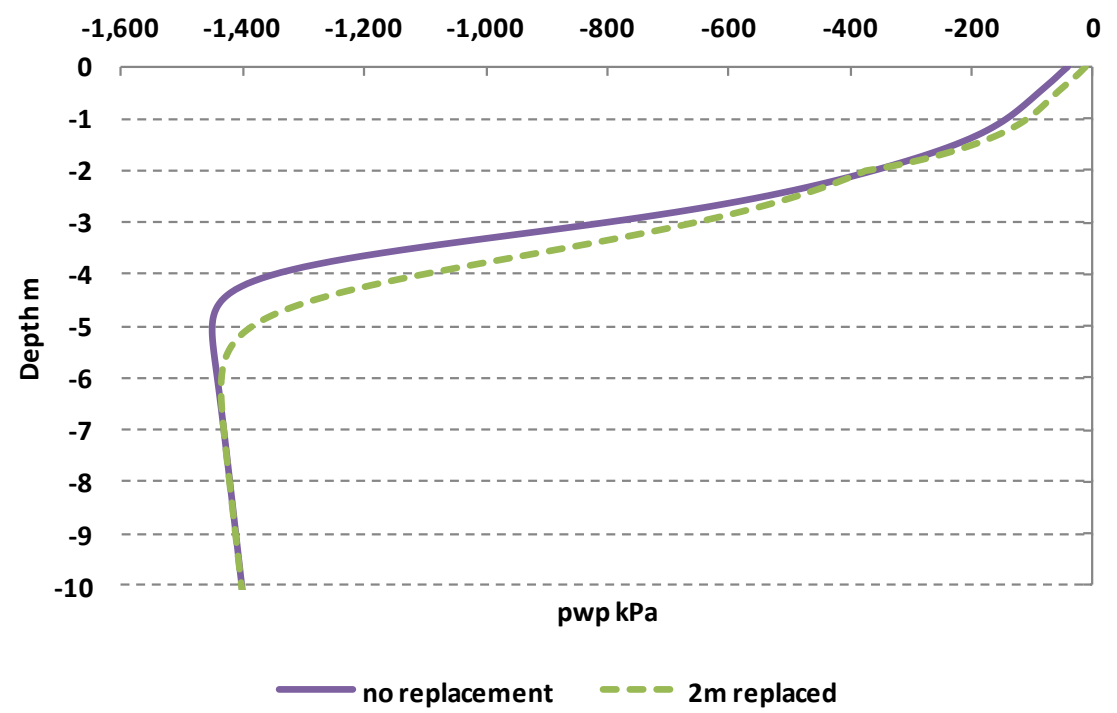

Figure 5.30.(b) End of $6^{\text {th }} \mathrm{yr}$ suction variation vertical profile right below slab edge - no replacement expansive clay and $2 \mathrm{~m}$ same $\mathrm{K}_{\text {sat }}$ replacement material and turf conditions (blow up profile). 


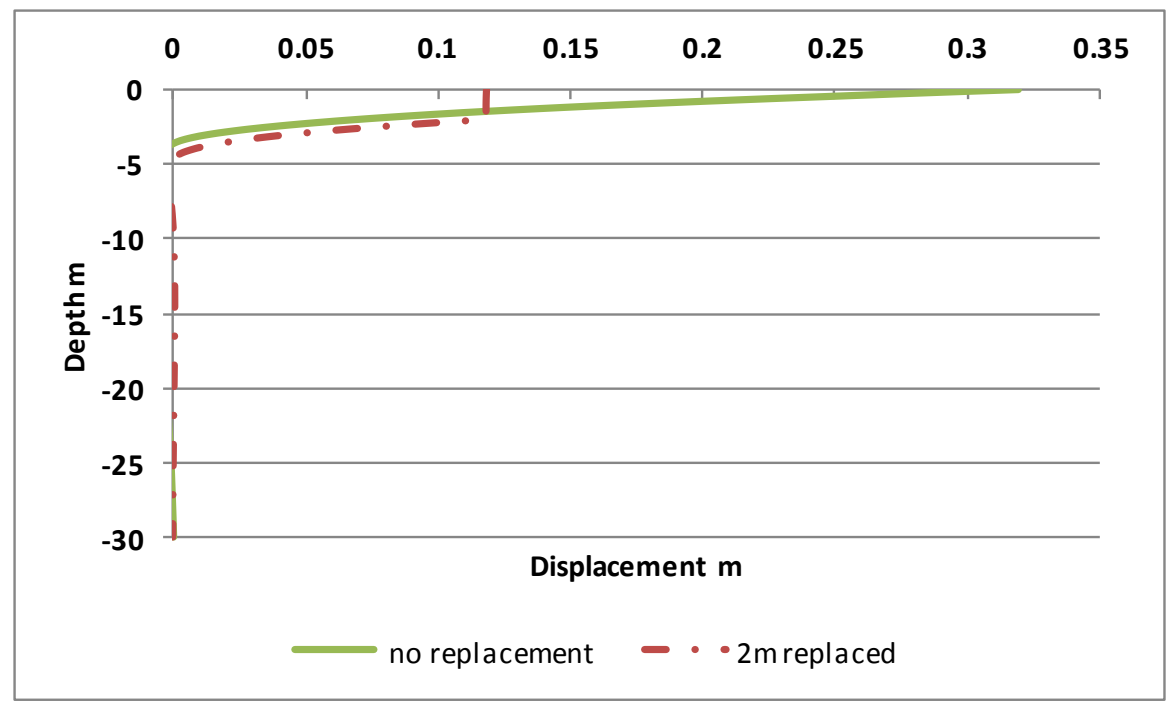

Figure 5.31.(a) Final Displacement results right below slab edge (see Figure 5.4) for no replacement expansive clay case and $2 m$ same $K_{\text {sat }}$ replacement material - turf conditions.

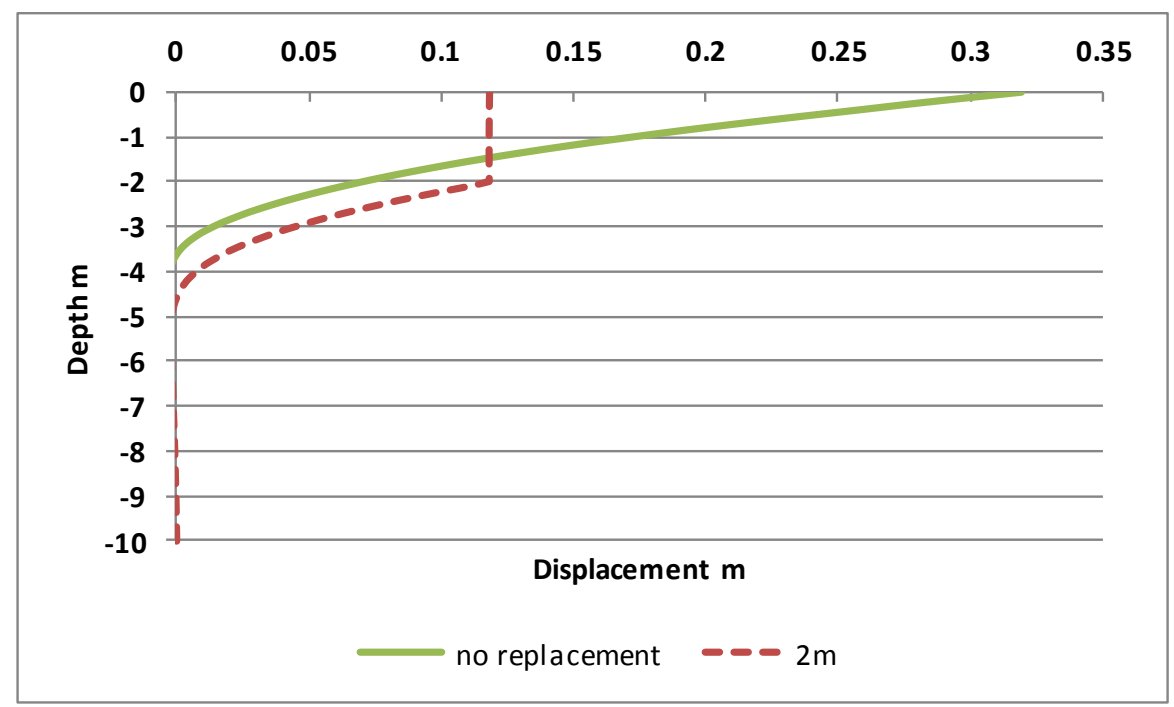

Figure 5.31.(b) Final Displacement results right below slab edge for no replacement expansive clay case and $2 \mathrm{~m}$ same $\mathrm{K}_{\text {sat }}$ replacement material - turf conditions (blow up profile). 


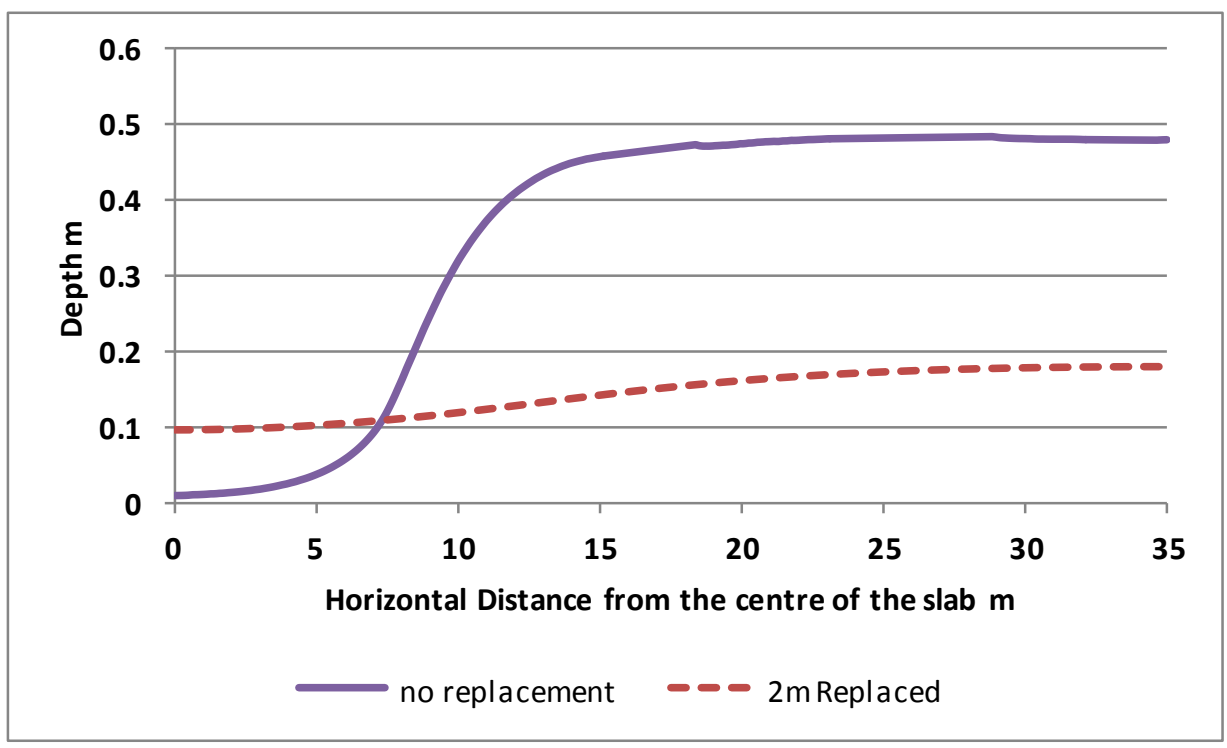

Figure 5.32. Final Displacement variation at the ground surface (see Figure 5.4) for no replacement expansive clay case and $2 \mathrm{~m}$ same $\mathrm{K}_{\text {sat }}$ replacement case turf conditions.

\section{6 $C_{m}$ Variation Results}

Another investigation was done in which $\mathrm{C}_{\mathrm{m}}$ function was varied for the expansive (native) soil profile and two cases were run; the no replacement case and $0.5 \mathrm{~m}$ cap case with Turf boundary condition on the top. The three different $C_{m}$ value profiles were used with the maximum values at the top of the layer of native clay being $0.3,0.15$ and 0.1 to do the above mentioned runs. The plots of varying $C_{m}$ with depth are shown below (Figure 5.33). 


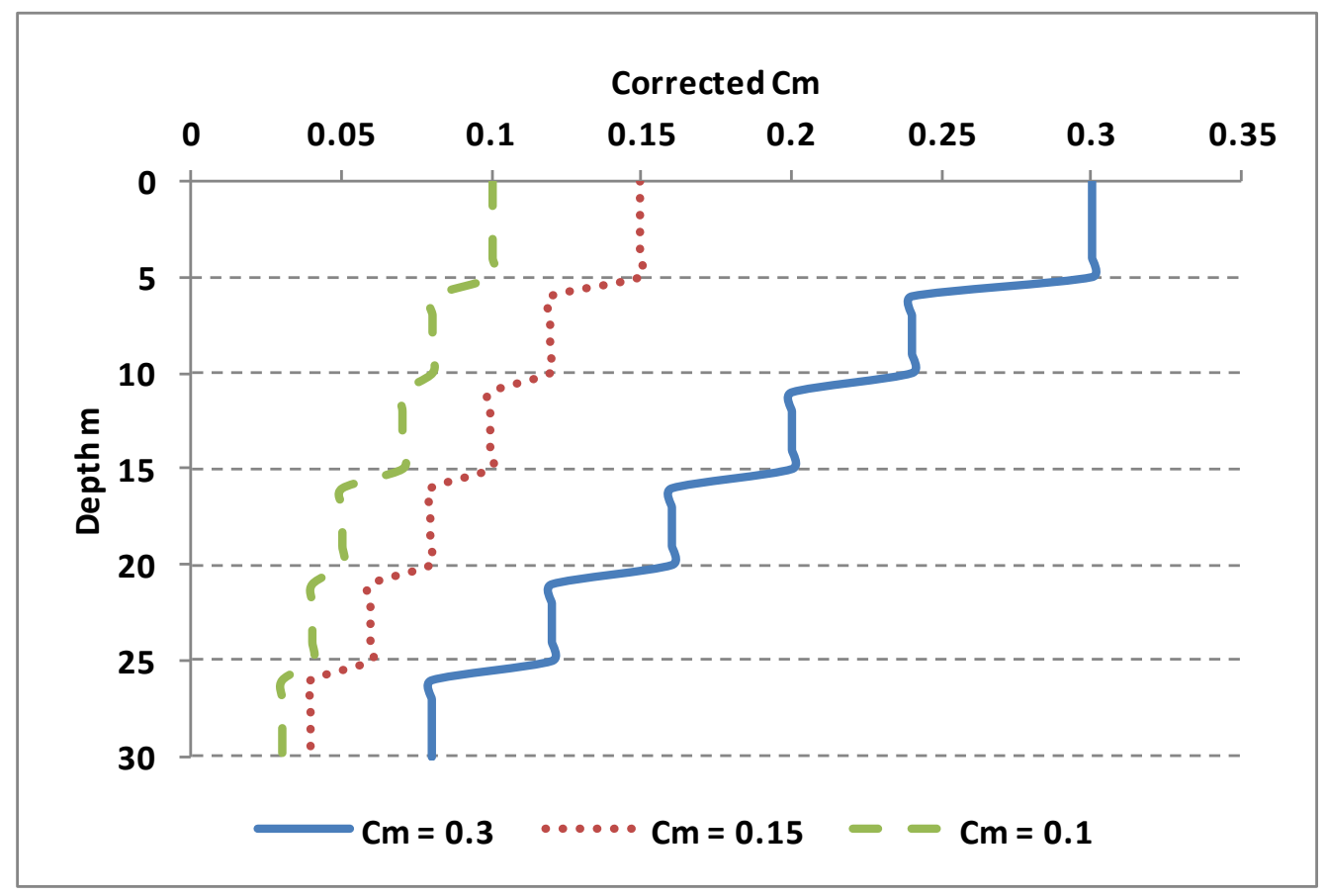

Figure 5.33. $\mathrm{C}_{\mathrm{m}}$ variation with depth.

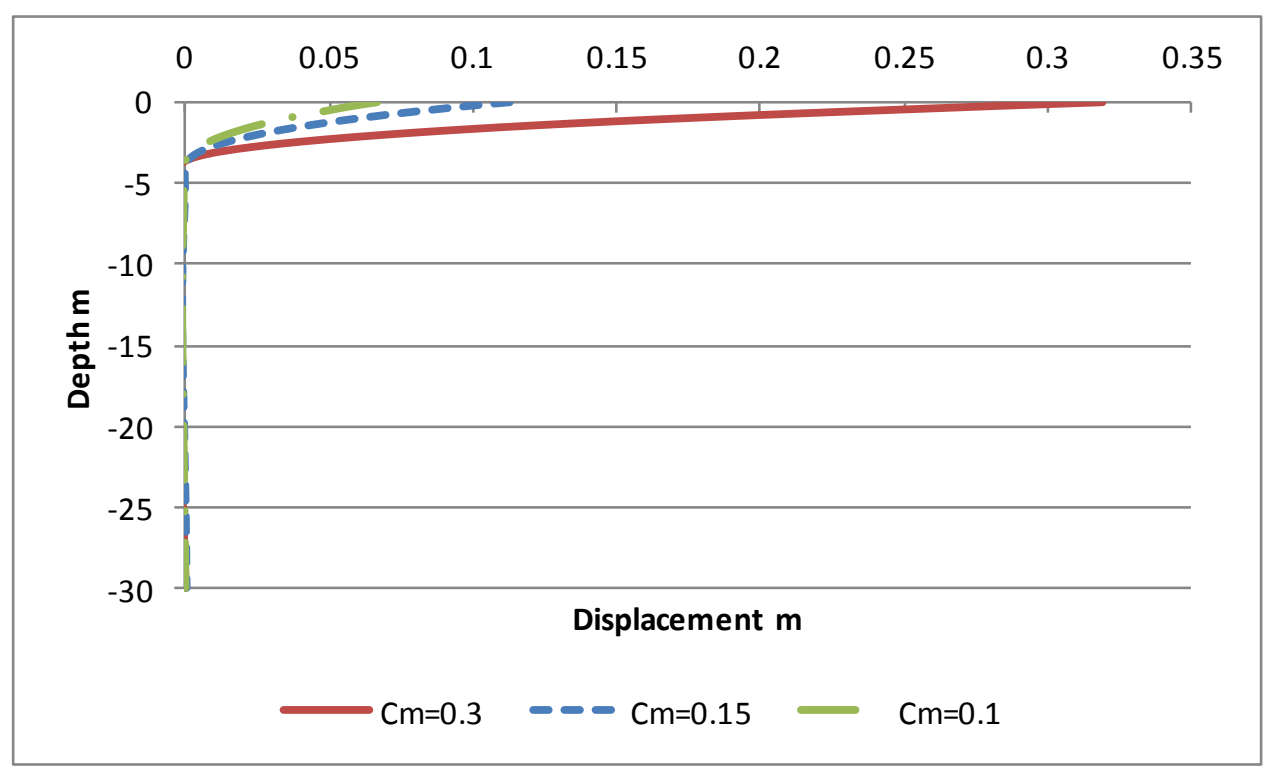

Figure 5.34. Final Displacement variation right below slab edge for no replacement case $\left(C_{m}\right.$ values shown are those at the top of the clay layer only - see Figure 5.33) 


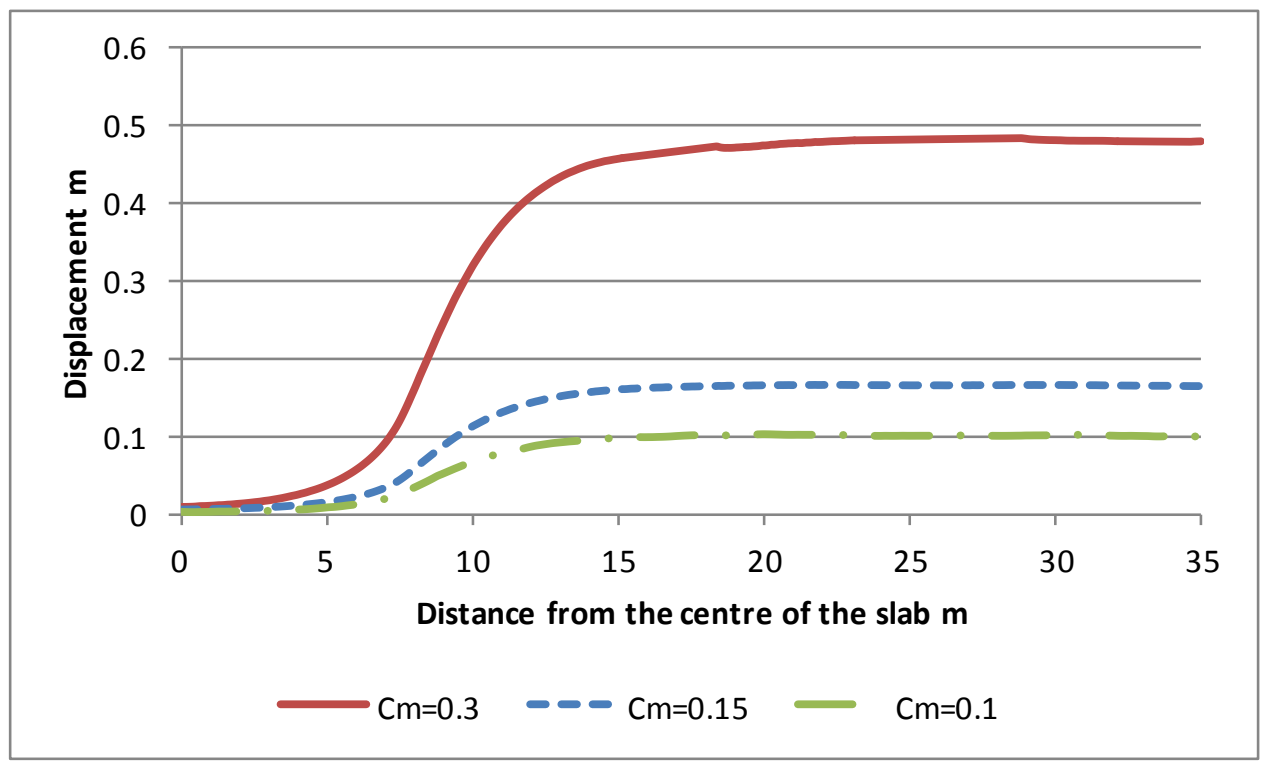

Figure 5.35. Final Displacement variation at the ground surface for no replacement case $\left(\mathrm{C}_{\mathrm{m}}\right.$ values shown are maximum $\mathrm{cm}$ values at the ground surface only $-\mathrm{C}_{\mathrm{m}}$ varies with depth in all cases)

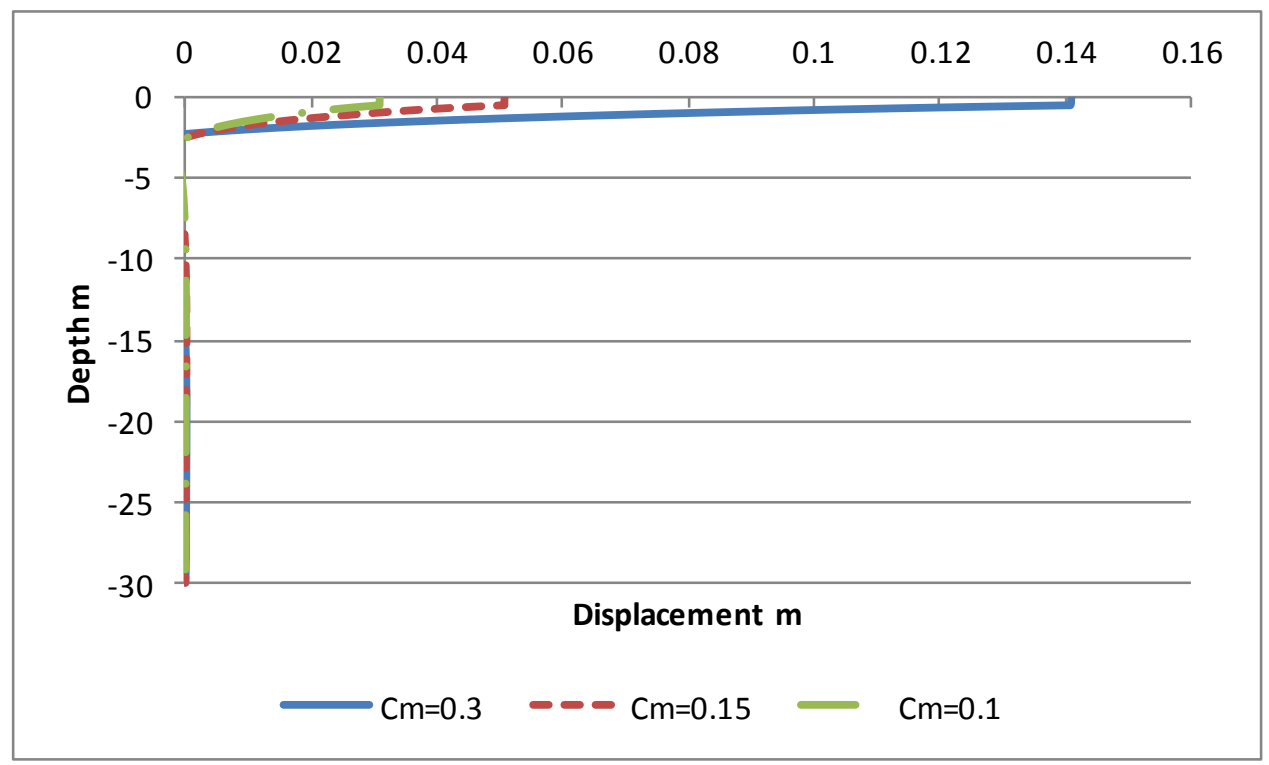

Figure 5.36. Final Displacement variation right below slab edge (see Figure 5.4) for $0.5 m$ replacement case $\left(C_{m}\right.$ values shown are those at the top of the clay layer only - see Figure 5.33) 


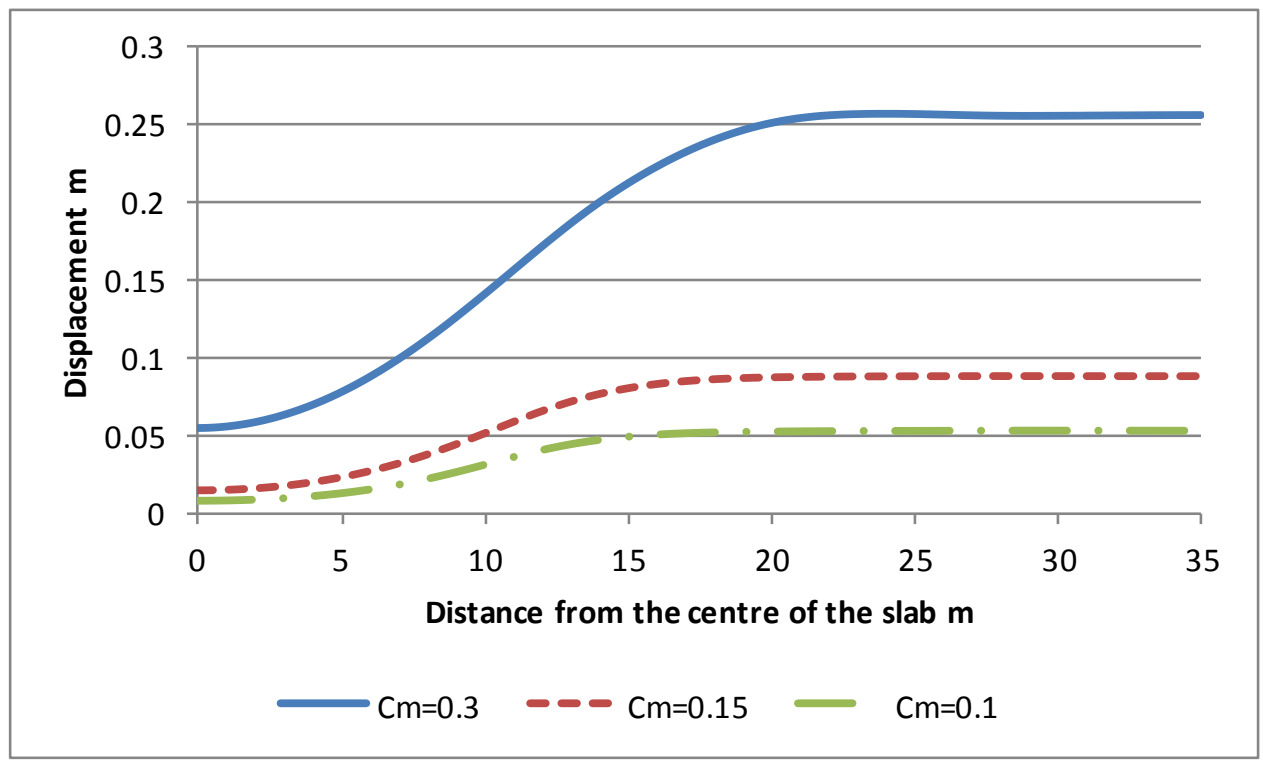

Figure 5.37. Final Displacement variation at the ground surface for $0.5 \mathrm{~m}$ replacement case $\left(C_{m}\right.$ values shown are the maximum $C_{m}$ values at the ground surface only).

Figure 5.34 and Figure 5.35 shows the attenuating effect on surface heave as $C_{m}$ is reduced for native clay. The curve with smallest magnitude of vertical heave below slab edge is the one representing the smallest $C_{m}$ in Figure 5.34 . The lowest displacement curve corresponds to the lowest value of $C_{m}$ in Figure 5.35, as expected.

Similar trend can be observed for $0.5 \mathrm{~m}$ cap in Figure 5.36 and Figure 5.37. The reduced swell potential of the lower layers due to a relatively lower $C_{m}$ results in diminished heave. Because the unsaturated flow analyses were not modified for the study of varying $C_{m}$ values of the native clay layer, the reduction in ground surface movements is directly proportional to the ratio of the $C_{m}$ values in the zone of wetting, as expected. Clearly, when the underlying soil is less expansive, a given change in soil suction results in less differential movement. 
The results indicate that as the value of $C_{m}$ is lowered for a soil, the heave value decreases as well at the ground surface and at sections below slab edge. In this study of effect of $C_{m}$, the unsaturated flow results were not altered, which is the same as keeping the $\mathrm{K}_{\text {sat }}$ value the same, regardless of the magnitude of heave index. This is therefore not entirely realistic. In fact, the decrease in heave, when conductivity values are not adjusted, is exactly proportional to the ratio of the $C_{m}$ values in the zone of wetting.

\subsection{Piecewise Coupled Runs (Turf Case No Replacement Soil)}

As a part of this study piecewise-coupled analysis was done for no replacement turf case in order to compare the heave results from piecewise coupled analysis to uncoupled analysis. For piecewise coupled analysis, SVFlux runs were made in sequence of 6 different stages. First a 1year run was made with Turf condition on the top (See Figure 5.38). The head obtained after $1^{\text {st }}$ year run was used to do second year run and so forth. Then heave is obtained in SVSolid at different times (1st year, 2nd year, 3rd year etc.). See Figure 5.39 below. The initial condition to start these is also obtained from the 5-year climatic conditions run as done for all other cases. 


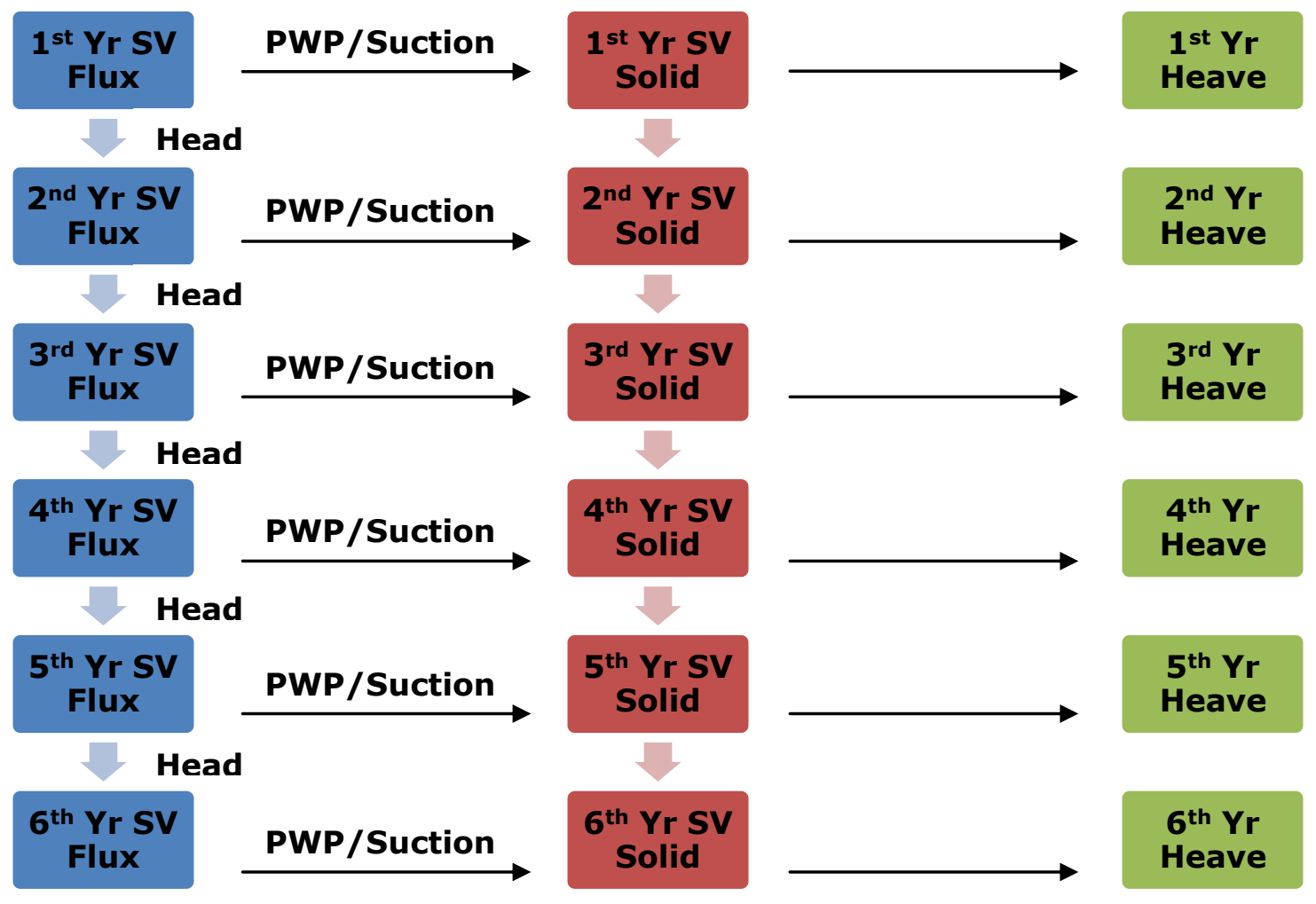

Figure 5.38. Sequence of run to show piecewise coupled approach to obtain heave results.

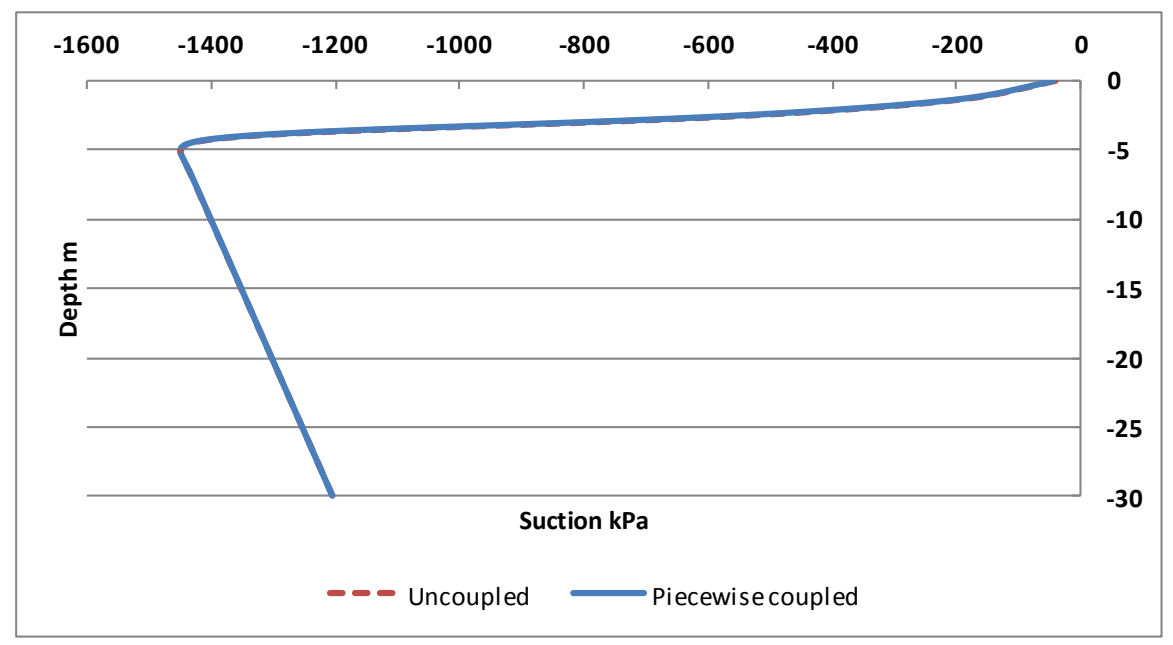

Figure 5.39. Comparison of suction Variation below slab edge for uncoupled and piecewise coupled runs for $6^{\text {th }} \mathrm{yr}$ - no replacement and turf conditions. 


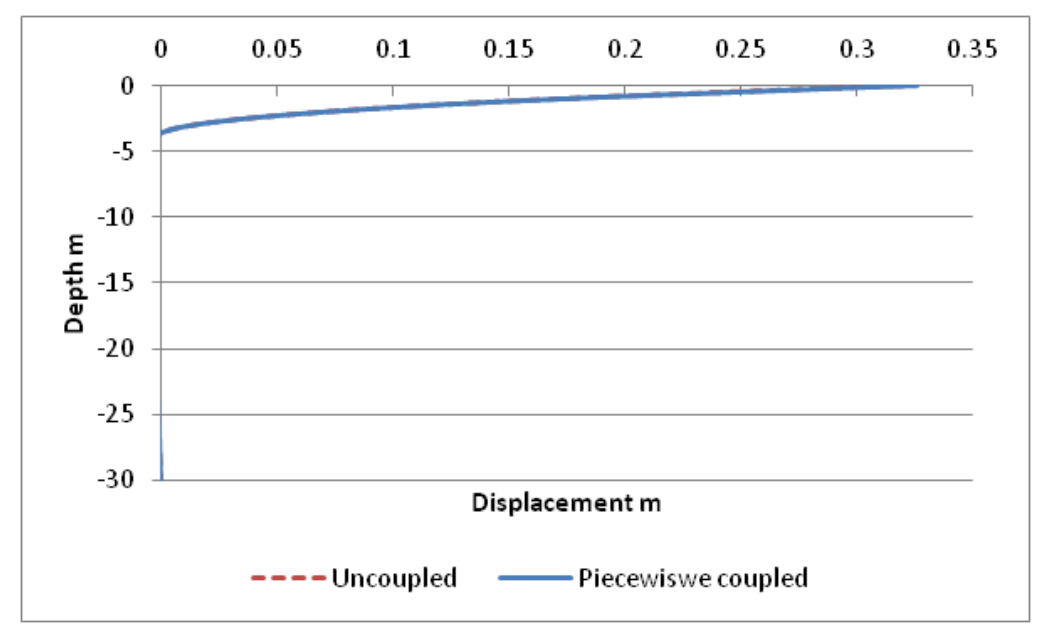

Figure 5.40. Comparison of displacement variation below slab edge obtained from uncoupled and piecewise coupled runs - no replacement and turf conditions.

Figure 5.39 shows a comparison of the $6^{\text {th }} \mathrm{yr}$ suction variation below slab edge obtained by the two types of coupling. Figure 5.40 and

Figure 5.41Figure 5.41 is a comparison plot of displacement below slab edge and at the ground surface obtained by the two approaches.

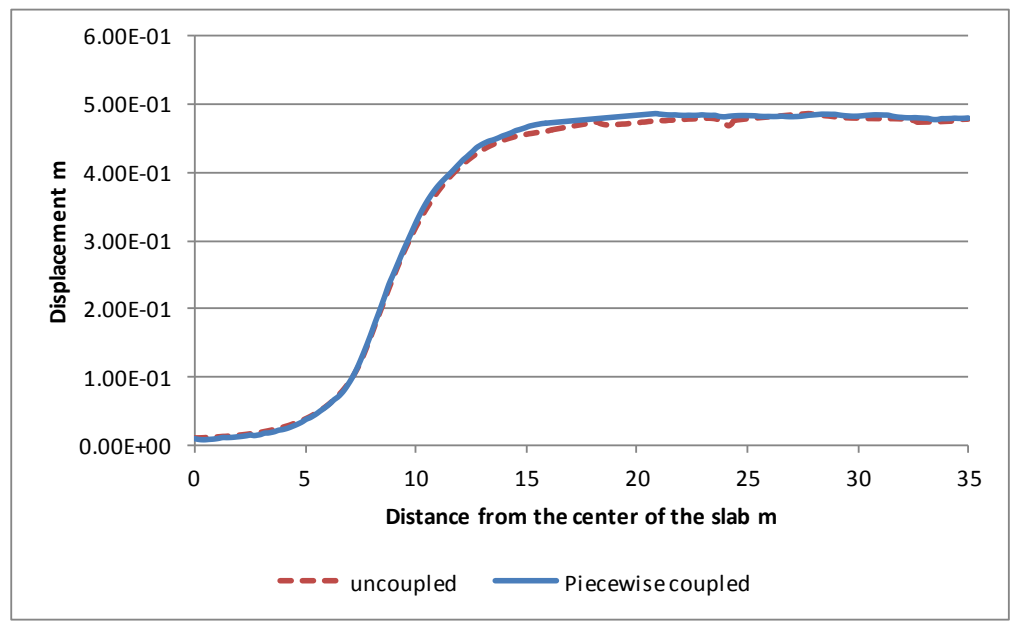


Figure 5.41. Comparison of displacement variation at the ground surface obtained from uncoupled and piecewise coupled runs - no replacement and turf conditions.

The piecewise coupled and uncoupled displacement results show comparable results. The uncoupled analyses were used throughout this research.

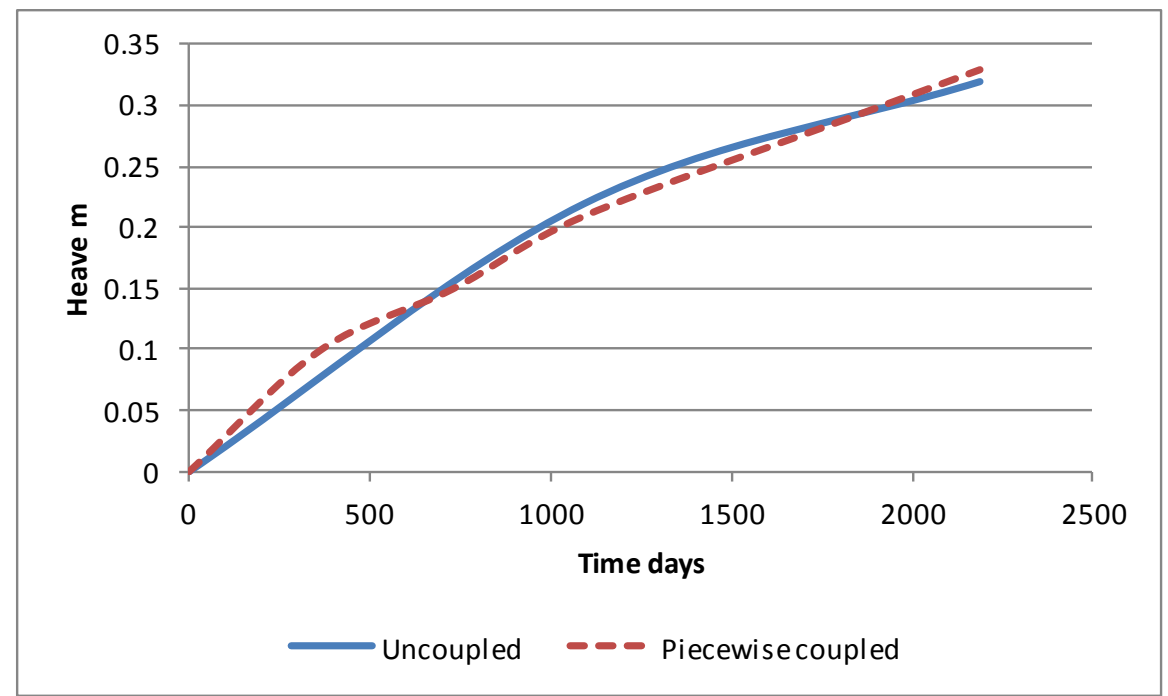

Figure 5.42. Final Displacement vs. time plot for uncoupled and piecewise coupled runs for $6^{\text {th }} \mathrm{yr}$ - no replacement and turf conditions.

Figure 5.42 shows heave vs. time plot for uncoupled and piecewise coupled runs. The displacement curve obtained by using both approaches compares well.

\subsection{Implications and Impact of Lateral Flow of Water}

The performance of a given remove and replace option is affected by the lateral movement of water within the surface, which is itself affected by the thickness and type of replacement material as well as the surface flux boundary conditions. Consider Figure 5.15 showing the ground surface deformation patterns for the roof 
runoff condition and same $\mathrm{K}_{\text {sat }}$ replacement material type. The $0.75 \mathrm{~m}$ replacement layer arrests ground surface movement entirely $10 \mathrm{~m}$ away from the slab edge (20m from slab center), whereas the $2 \mathrm{~m}$ replacement layer results in some surface displacement $(0.05 \mathrm{~m})$ at $10 \mathrm{~m}$ and $25 \mathrm{~m}$ away from the slab edge. The surface heave observed away from the slab, in the open climate region of the domain, is a result of water moving laterally through the soil profile, primarily through the wetter (and therefore higher conductivity) replacement soil layer. However, the $0.75 \mathrm{~m}$ replacement layer and the $2 \mathrm{~m}$ replacement layer cases, for the same $\mathrm{K}_{\text {sat }}$ replacement material, behave differently with respect to surface heave because the depth and degree of wetting within the different thickness replacement layers differs both vertically and laterally.

Figure 5.43 shows vertical profiles of wetting for the $0.75 \mathrm{~m}$ same $\mathrm{K}_{\text {sat }}$ replacement layer for roof runoff conditions at 5m, 10m (slab edge), 19m, and 27m from the slab centerline. For the $0.75 \mathrm{~m}$ same $\mathrm{K}_{\text {sat }}$ replacement case, ponding of roof runoff at the slab edge results in some wetting of the expansive clay soil beneath the slab and out to about $10 \mathrm{~m}$ beyond the slab edge, but the suction profile $17 \mathrm{~m}$ from the slab edge ( $27 \mathrm{~m}$ from slab centerline) shows that the replacement layer does not transmit water laterally to this distance, and this is largely a result of the store and release (sponge effect) discussed previously. Figure 5.44 shows vertical profiles of suction for the $2 \mathrm{~m}$ same $\mathrm{K}_{\text {sat }}$ replacement soil case, roof runoff conditions, at $5 \mathrm{~m}$, $10 \mathrm{~m}, 19 \mathrm{~m}$, and $27 \mathrm{~m}$ from the slab centerline. 


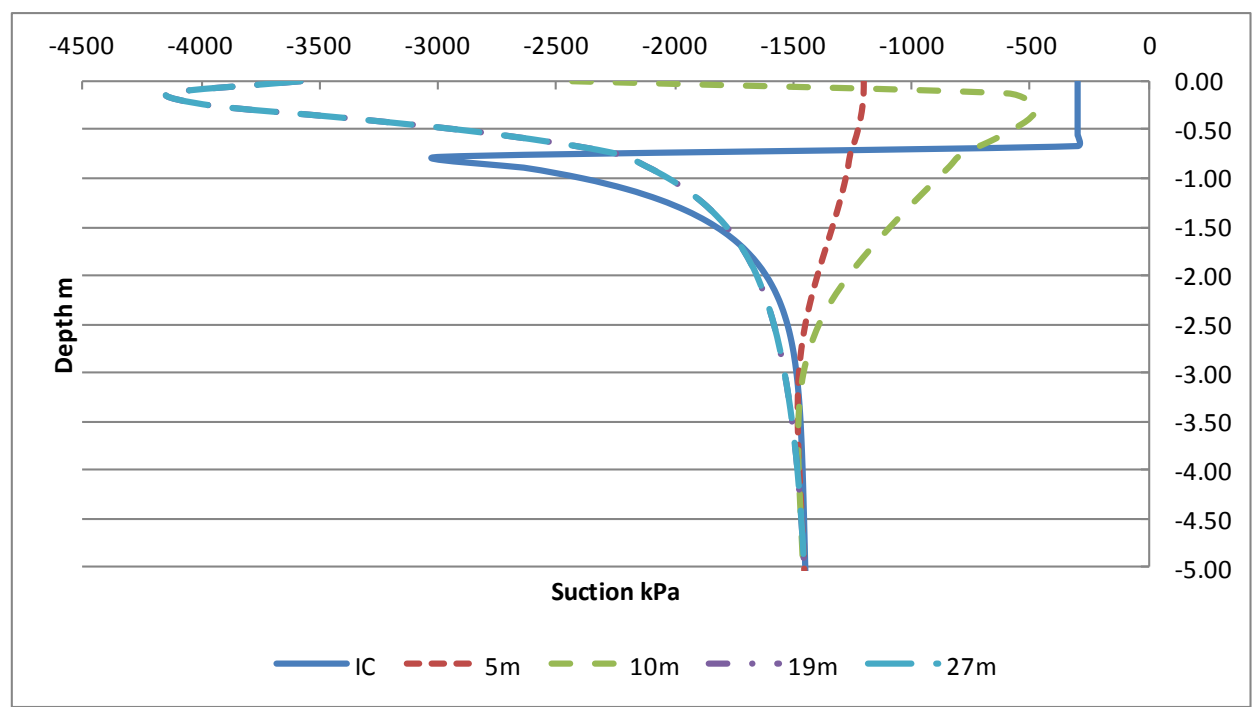

Figure 5.43. Vertical profiles of wetting at $5 \mathrm{~m}, 10 \mathrm{~m}$ (slab edge), 19m, and $27 \mathrm{~m}$ from the slab centerline $-0.75 \mathrm{~m}$ same $\mathrm{K}_{\text {sat }}$ replacement material and roof runoff conditions (blow up profile).

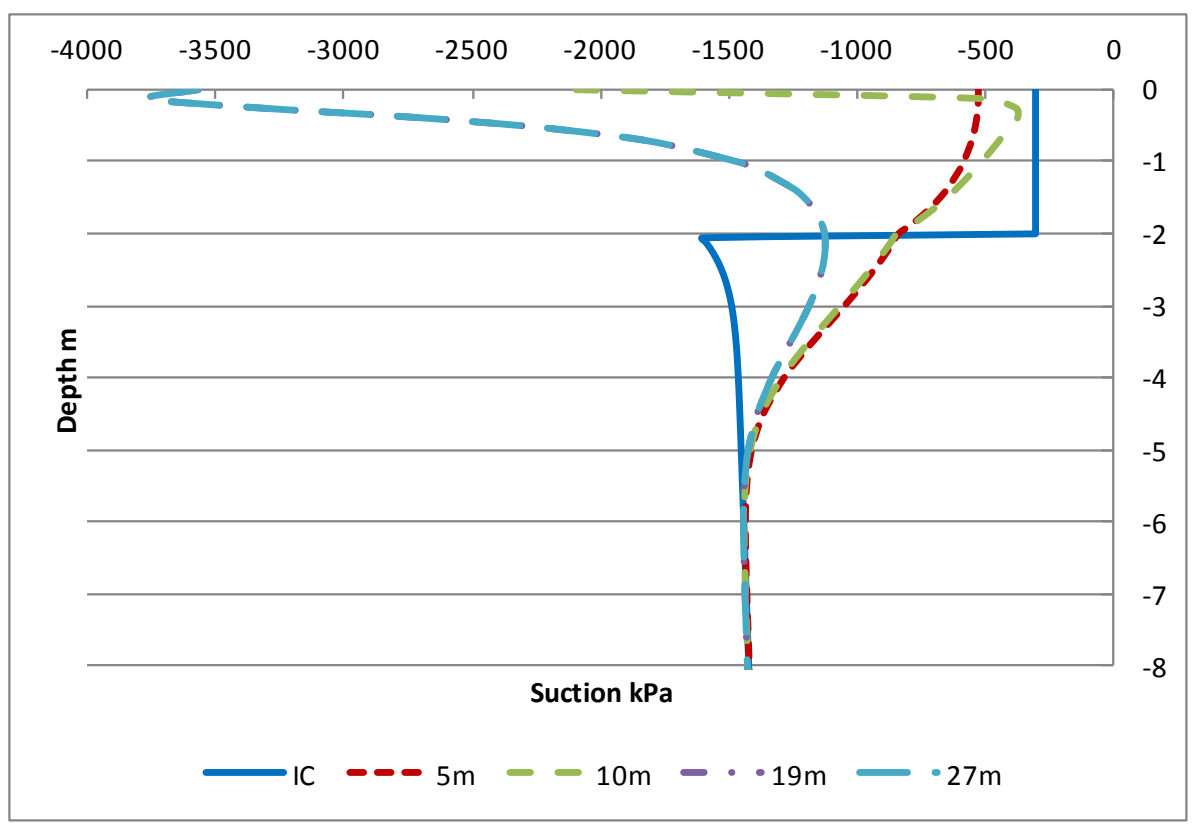

Figure 5.44. Vertical profiles of wetting at $5 \mathrm{~m}, 10 \mathrm{~m}$ (slab edge), 19m, and $27 \mathrm{~m}$ from the slab centerline - $2 \mathrm{~m}$ same $\mathrm{K}_{\text {sat }}$ replacement material and roof runoff conditions (blow up profile). 
It can be seen that lateral flow through the relatively wetter same $\mathrm{K}_{\text {sat }}$ replacement soil material provides a source of water ("bathtub" of water) that moves downward into the expansive clay soil. The evaporative flux is ineffective in removing much of the water that enters into this deeper replacement soil layer (i.e. any sponge effect is minimal).

Figure 5.21 shows the ground surface displacement for the roof runoff condition and higher $\mathrm{K}_{\text {sat }}$ replacement soil. For this case, the $2 \mathrm{~m}$ replacement thickness results in about $0.1 \mathrm{~m}$ surface displacement even $25 \mathrm{~m}$ away from the slab edge ( $35 \mathrm{~m}$ from slab center). Figure 5.45 shows the vertical profiles of suction for the $2 \mathrm{~m}$ replacement and higher $\mathrm{K}_{\text {sat }}$ replacement material for roof runoff conditions at $5 \mathrm{~m}, 10 \mathrm{~m}, 19 \mathrm{~m}$, and $27 \mathrm{~m}$ from the slab centerline. Comparing this plot to the $2 \mathrm{~m}$ replacement layer with same $\mathrm{K}_{\text {sat }}$ soil, it can be seen that the higher conductivity replacement material results is higher degree and extent of wetting both vertically and laterally, and the replacement layer provides a source of water that moves deeper into the expansive soil layer. This is the classic "bathtub" effect wherein higher conductivity replacement soils result is deeper wetting of the moisture sensitive soil compared to even the no replacement case. A schematic drawing of the bathtub effect is provided in Figure 5.46. 


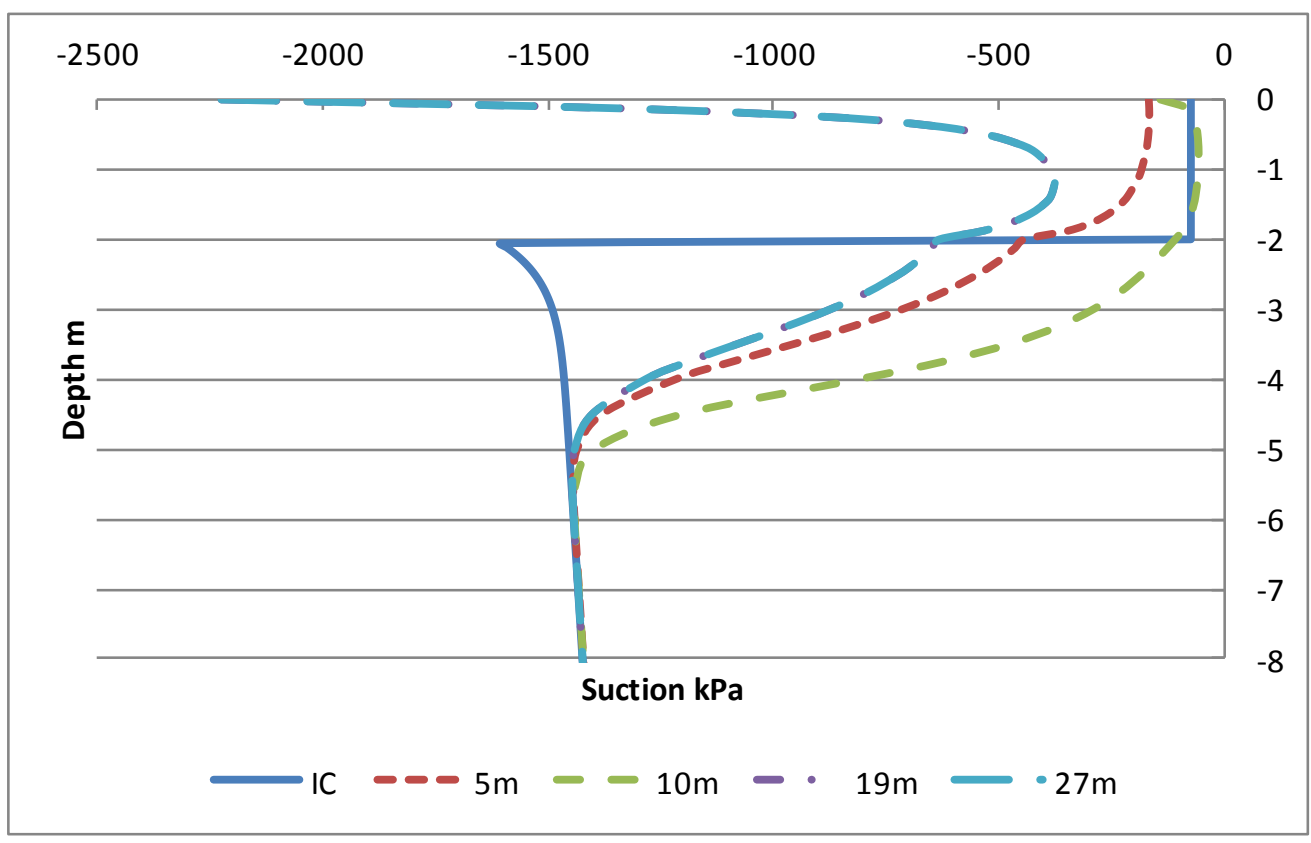

Figure 5.45. Vertical profiles of wetting at 5m,10m (slab edge), 19m, and $27 m$ from the slab centerline $-2 m$ higher $K_{\text {sat }}$ replacement material and roof runoff conditions (blow up profile).

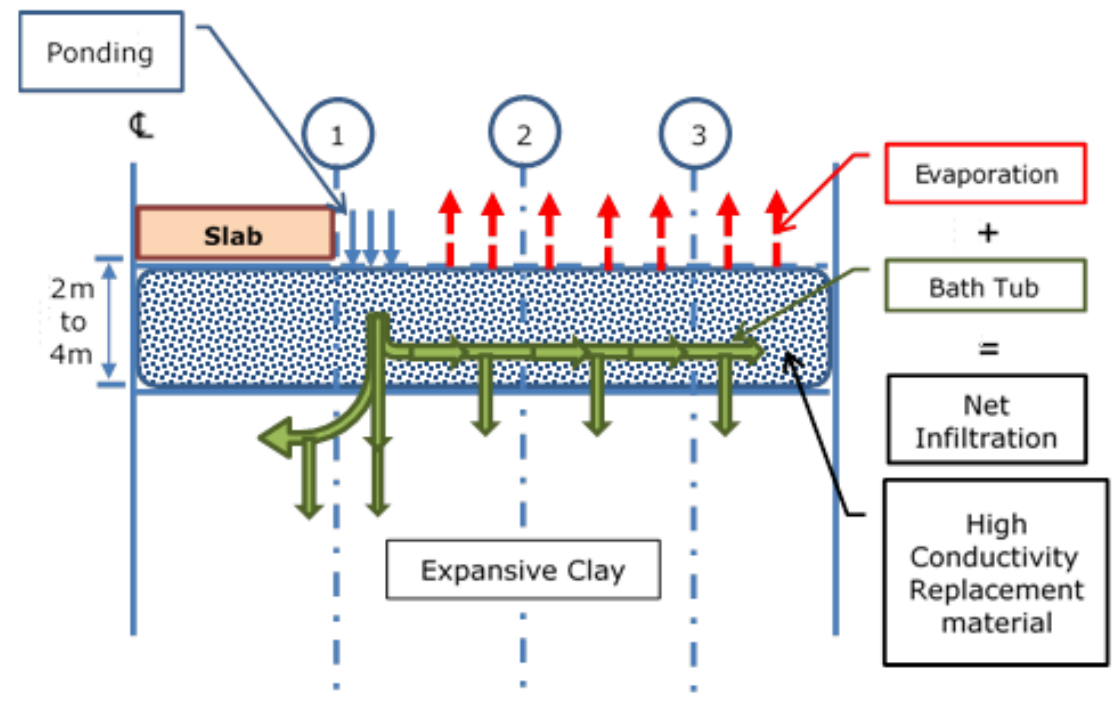

Figure 5.46. Bathtub effect 
Finally, Figure 5.28, which shows the ground surface displacement for the turf flux boundary condition and for lower $\mathrm{K}_{\text {sat }} 0.5 \mathrm{~m}$ replacement layer (clay cap case), reveals that $0.28 \mathrm{~m}$ of surface deflection exists even up to $25 \mathrm{~m}$ away from the slab edge. Although the clay cap retards infiltration into the underlying expansive clay compared to the no replacement case, given the extensive irrigation watering that keeps the ground surface wet outside of the slab region, some significant depth and degree of wetting occurs throughout the clay profile. The water that enters the profile in this case is more a result of downward infiltration rather than lateral migration, as can be seen from the Figure 5.47 vertical profiles of suction at $5 \mathrm{~m}$, $10 \mathrm{~m}, 19 \mathrm{~m}$, and $27 \mathrm{~m}$ from the slab centerline for turf conditions and $0.5 \mathrm{~m}$ lower $\mathrm{K}_{\text {sat }}$ replacement material.

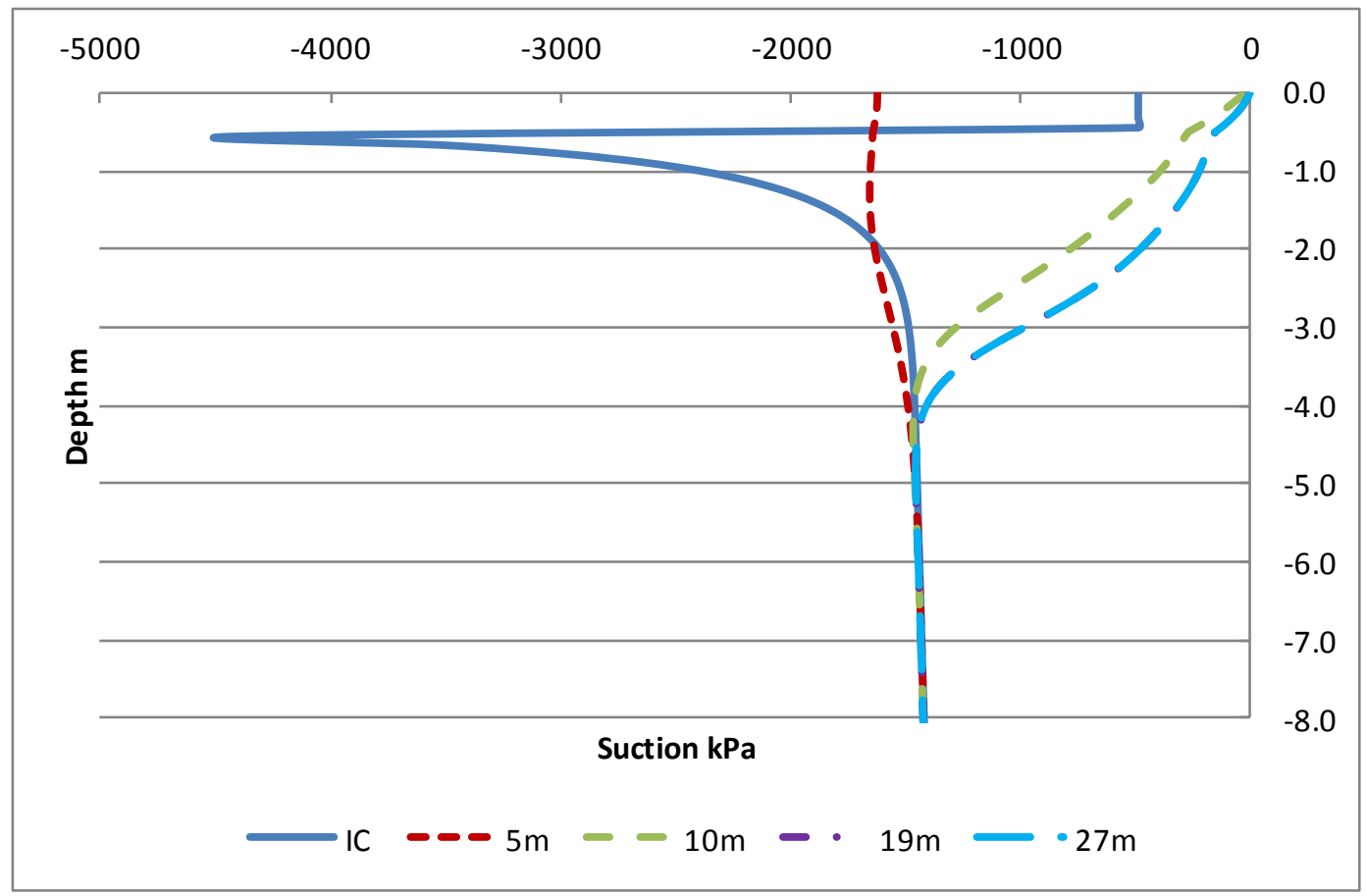

Figure 5.47. Vertical profiles of wetting at $5 \mathrm{~m}, 10 \mathrm{~m}$ (slab edge), 19m, and $27 \mathrm{~m}$ from the slab centerline $-0.5 \mathrm{~m}$ lower $\mathrm{K}_{\text {sat }}$ replacement material and turf conditions (blow up profile). 


\subsection{Discussion}

This study represents a unique investigation on the efficacy of remove and replacement methods for mitigation of expansive soils in that the analyses are based on fundamental unsaturated flow and stress-deformation principles. These analyses provide a detailed look into the complexities of the mitigation mechanisms at play for remove and replace options. The unsaturated flow/deformation analyses performed show that the remove and replace technique can be very effective in mitigating both total and differential deformation resulting from suction changes within expansive soil profiles. However, the processes by which the remove and replace method serves to mitigate expansive soil movements are complex and inter-related, and it is clearly possible, based on findings from this study, for a user of this mitigation method to select a remove and replace option that worsens the expansive soil problem (e.g. high conductivity replacement soils can result in deep and high degree of wetting). On the other hand, for many scenarios of removal and replacement and surface flux conditions, the remove and replace method can be highly successful in mitigating total and differential heave, which likely explains why this method has been widely used in practice.

There are several aspects of the remove and replace method that must be considered: (1) The effect of removal and replacement on depth and degree of wetting within the soil profile, which is a function of both the replacement material type and the depth (thickness) of the replacement layer. In addition, the performance of the replacement material depends on the placement conditions because placement moisture condition affects the conductivity of the layer. In the end, depending on the replacement option selected, it is possible to increase or decrease the depth and degree of wetting within the underlying clay profile. (2) To 
the extent that the replacement soil is non-expansive (non-moisture sensitive or "inert") the remove and replace method gets rid of shrink/swell materials immediately below the foundation. For a given depth and degree of wetting, removal of expansive clay decreases total wetting-induced heave. In addition, because the seat of movement is pushed deeper within the soil profile, differential heave is reduced. However, the depth and degree of wetting cannot be guaranteed to decrease (or even remain the same) when using the remove and replace method, and thus the effect of the replacement of expansive soil with inert material has highly variable impact on total and differential heave depending on the replacement depth and replacement soil conductivity characteristics. Further, even if there is a reduction in total and differential heave, the amount of reduction may not be adequate to ensure good performance of the structure. (3) If the thickness of the replacement layer is greater than the removed layer the confining pressure within the underlying expansive soil layer will be increased, which decreases the swell potential of clay. Although this is a known effect, this mechanism of increased confinement was not studied in this research.

The impact of pushing the "seat" of wetting deeper into the soil reduces the swelling feature on the surface (Walsh et.al, 2009). But the effect of remove and replace mitigation on the depth, degree and rate of wetting is less clear. This study sheds some light on the complexity of the unsaturated flow aspects of the remove and replace mitigation technique. The complexities are primarily due to the highly nonlinear nature of the unsaturated soil storage function (SWCC) and hydraulic conductivity function. The hydraulic conductivity of an unsaturated soil varies over several orders of magnitude, depending on the value of soil suction. Further, the unsaturated hydraulic conductivity of granular soils can be lower than the 
unsaturated hydraulic conductivity of a fine-grained soil, depending on the value of soil suction. The net result is that the impact of various remove and replace options is not always intuitive. Following are the key findings from this research study on remove and replace mitigation wherein two very different surface flux conditions were considered for various replacement depths and use of three differing hydraulic conductivity function replacement materials were studied. The findings are based on sound unsaturated soil principles incorporated into 2-D unsaturated flow and unsaturated soil stress-deformation finite element code. Table 5.1 and Table 5.2 provide a summary of the various scenarios considered in this study. Table 5.1 includes the results obtained for the roof runoff surface flux condition and Table 5.2 includes the results obtained for the turf surface flux conditions.

Table 5.1. Heave reduction for different soil and depths of removal and replacement for Roof Runoff Surface Flux Conditions

\begin{tabular}{|c|c|c|c|c|}
\hline $\begin{array}{c}\text { Replacement Soil } \\
\text { Type }\end{array}$ & $\begin{array}{c}\text { Max.Depth of } \\
\text { Replacement } \mathbf{m}\end{array}$ & $\begin{array}{c}\text { Max. Total } \\
\text { Heave m }\end{array}$ & $\begin{array}{c}\text { \% Reduction } \\
\text { in Heave at } \\
\text { surface } \\
\mathbf{( X = 1 0 m )}\end{array}$ & $\begin{array}{c}\text { Differential } \\
\text { Heave } \\
\text { m }\end{array}$ \\
\hline Lower $\mathbf{K}_{\text {sat }}$ & 0.5 & 0.028 & 89 & 0.03 \\
\hline \multirow{3}{*}{ Same $\mathbf{K}_{\text {sat }}$} & 0.75 & 0.063 & 75 & 0.01 \\
\cline { 2 - 5 } & 2 & 0.058 & 77 & $\approx 0$ \\
\hline \multirow{3}{*}{ Higher $\mathbf{K}_{\text {sat }}$} & 4 & 0.055 & 78 & $\approx 0$ \\
\cline { 2 - 5 } & 0.75 & 0.195 & 22 & 0.1 \\
\hline No Replacement & 2 & 0.165 & 34 & 0.01 \\
\hline
\end{tabular}

The heave pattern obtained for turf flux conditions is different from the roof runoff case. Unlike the roof runoff case the flux is evenly applied all over the top exposed region of the profile. As a result of this the heave pattern is uniform below and beyond the slab edge. However, the heave values are higher in turf as the final suction values are much smaller in this as compared to the roof runoff. This is a 
direct result of application of a surface flux condition consistent with poorly graded surface conditions that do not provide for runoff of excess irrigation water. There is a net wetting effect of the soil in this case. However, the removal and replacement results follow the same trend in terms of reduction of wetting and reduction of heave as for the roof runoff case. In all cases, removal and replacement of the upper expansive soils shows a reduction in heave. However, it can be seen that there is likely some optimal (i.e. most cost-effective) remove and replace option.

The $2 \mathrm{~m}$ same $\mathrm{K}_{\text {sat }}$ replacement case works as well as the $0.5 \mathrm{~m}$ cap to reduce subsurface wetting and ground surface heave. The vertical heave reduction is only slightly better in $2 \mathrm{~m}$ same $\mathrm{K}_{\text {sat }}$ case. The initial and final suction and saturation variation plot for $2 \mathrm{~m}$ same $\mathrm{K}_{\text {sat }}$ shows the top region reaches to condition close to saturation after 6 years.

A comparison between two replacement soils and depth for turf case is presented in Table 5.2.

Table 5.2. Heave reduction for different soil and depths of removal and replacement for Turf Surface Flux conditions.

\begin{tabular}{|c|c|c|c|c|}
\hline $\begin{array}{c}\text { Replacement } \\
\text { Soil Type }\end{array}$ & $\begin{array}{c}\text { Max.Depth of } \\
\text { Replacement } \mathbf{m}\end{array}$ & $\begin{array}{c}\text { Max. Total } \\
\text { Heave at } \\
\text { surface } \\
\mathbf{m}(\mathbf{X}=\mathbf{1 0 m})\end{array}$ & $\begin{array}{c}\text { Depth of } \\
\text { wetting\% } \\
\text { Reduction in } \\
\text { Heave at } \\
\text { surface } \\
(\mathbf{X = 1 0 m})\end{array}$ & $\begin{array}{c}\text { Differential } \\
\text { heave } \\
\mathbf{m}\end{array}$ \\
\hline Lower $\mathbf{K}_{\text {sat }}$ & 0.5 & 0.145 & 56 & 0.07 \\
\hline Same $\mathbf{K}_{\text {sat }}$ & 2 & 0.119 & 64 & $\approx 0$ \\
\hline No Replacement & - & 0.33 & - & 0.32 \\
\hline
\end{tabular}

There has to be a tradeoff between the depth up to which the seat of movement is pushed down and depth of removal and replacement. For example, when replacing the expansive soil with higher conductivity replacement soil a caution 
should be exercised since the water tends to push down into the expansive clay region due to its higher conductivity.

It can be observed that after a certain depth of removal there is no significant decrease in the heave at the ground. Therefore it is very important to understand that getting rid of the expansive soil in the entire depth of wetting might not be the best solution economically. When removing the few upper meters of expansive soil results are as effective in reducing heave as removing and replacing greater depths with non-expansive soil, the opportunity for cost-saving/optimal design is available.

It is evident from the results of the cases analyzed in this study that pushing the seat of wetting/movement deeper into the soil curbs the heave/shrinkage movements and differential movements at the ground surface. The best choice however, for replacement materials is expected to be site-specific, and dependent on climatic and irrigation conditions, as a minimum.

Following is a brief summary of conclusions from this study:

1. The remove and replace option can be an effective technique for reducing suction-change induced total and differential movements associated with expansive soil profiles.

2. Placement of a low conductivity "clay cap" is effective in reducing the depth and degree of wetting as well as total and differential movements resulting from suction changes in expansive clay soils. The clay cap serves to retard downward infiltration and upward evaporation from the soil profile, thus reducing differential movements at the ground surface by providing for more uniform subsurface moisture conditions. In this study the clay cap was assumed to remain uncracked even during drying. Methods to minimize 
cracking of a clay cap, such as covering with a relatively impermeable layer of pavement, should be considered for field applications of the clay cap option. While deeper layers of low conductivity clay would further reduce depth and degree of moisture content change and serve to push the seat of movement deeper within the soil profile, for practical applications there is a limit to the thickness of clay replacement layer that can be used.

3. There is, conceptually, an optimal depth of removal and replacement that will provide for acceptable total and differential movements. The optimal thickness of replacement is a function of the surface flux boundary conditions and the hydraulic conductivity characteristics and storage characteristics of the replacement material. For example, when significant evaporation occurs between wetting events, intermediate conductivity materials (such as silt and low plasticity clays, perhaps) may provide a "sponge-type" effect wherein water enters the replacement layer where it tends to be stored on top of the higher conductivity expansive soil layer until an evaporation event removes most of the applied water from the profile. If the removed layer thickness becomes too great, however, infiltrating water may reach a depth such that evaporation from the ground surface is not effective in removing the water so that the water continues into the underlying expansive clay over time.

4. In this study, as with actual field conditions, the expansion potential of the expansive clay was reduced with depth as confinement due to overburden pressures increased. In addition, presence of the replacement layer serves to push the seat of movement deeper into the profile. However, if the underlying clay layer is deep and deep wetting occurs, movements may still be intolerable. 
5. In this study it was shown that higher conductivity replacement layers result in deeper wetting within the soil profile and therefore high conductivity replacement soils, such as granular soils (sand cushions) are not a good option, in general. In addition, higher conductivity replacement layer allow greater lateral movement of water which can result in wetting of the expansive clay and ground surface heave considerable distances away from the source of wetting. The deeper wetting associated with lateral movement of water also suggests that any sources of water that could move laterally through the soil profile (either on-site or off-site) should be taken into consideration in selection of the mitigation solution. In this study, the source of wetting was restricted to downward infiltration only from on-site sources.

6. Given the tendency to compact replacement materials at or wet of optimum (at relatively low suction values), the fact that hydraulic conductivity of soil increases with decreasing suction must be considered in the evaluation of the performance of a given replacement material type. For example, in this study replacement material having the same saturated hydraulic conductivity as the underlying expansive clay was found to have a sufficiently high hydraulic conductivity at optimum moisture content placement conditions to allow substantial lateral movement of water and rather deep wetting into the underlying relatively dry expansive clay. This means that if a replacement soil is placed very wet, it may, for certain surface flux conditions where evaporation is minimal, perform similarly to a higher conductivity replacement soil with regard to resulting depth, degree, and extent of wetting.

7. Given the complexities of the processes involved in remove and replace mitigation solutions, it is difficult to intuitively know what is the optimal solution for a given surface flux condition. Still, certain generalizations can be 
made from the findings of this study. While it is difficult to know the optimal replacement depth for any given surface flux or replacement layer thickness, it is clear that extremely large replacement depths (e.g. the $4 \mathrm{~m}$ replacement considered here) are unlikely to be optimal as one reaches a point of diminishing return on total and differential ground surface movements. Also, there are certain designs that are not expected to work well, such as use of high conductivity replacement material type because of the tendency towards deeper and greater degree of wetting when water enters the high conductivity replacement material. The higher conductivity material placed on top of the expansive clay can serve as a "bathtub" to collect water which then penetrates to considerable depth within the underlying clay layer. 


\section{CONCLUSIONS AND FUTURE WORK}

\subsection{General}

It has been long established that mitigation techniques are very important for construction on expansive soils. The remove and replace technique is a very good alternative when compared to other expensive mitigation methods. Although the remove and replace option has been studied by several researchers in the past, there is no comprehensive analytical study available to evaluate a reasonable replacement material type and depth of removal and replacement when foundation is constructed on expansive soil. The depth is removed and replaced either based on past experience or some empirical data set. This study represents a unique investigation on the efficacy of remove and replaces methods for mitigation of expansive soils in that the analyses are based on fundamental unsaturated flow and stress-deformation principles. These analyses provide a detailed look into the complexities of the mitigation mechanisms at play for remove and replace options, and demonstrate that the most appropriate and cost-effective depth of replacement and replacement material type are not intuitively obvious. The results of this study show that the remove and replace method can be highly successful in mitigating total and differential heave, which likely explains why this method has been widely used in practice. However, the processes involved are complex and inter-related, resulting in the possibility of selection of a remove and replace option that worsens the expansive soil problem (e.g. high conductivity replacement soils can result in deep and high degree of wetting). 
The study sets the stage for sound application of remove and replace mitigation methods. However, in consideration of the complexities involved, and in consideration of the wide-spread use of remove and replace methods in practice, further study is warranted.

\subsection{Recommendation for Future Work}

This study provides a significant contribution to the understanding of remove and replace methods for mitigation of moisture sensitive soil profiles such as expansive clays and collapsible soil. However, there remain research questions that should be addressed by future studies. Following is recommended for future work:

1. Longer simulations of remove and replace cases should be run in order to assess the efficacy of removal depths and material under long term wetting.

2. Actual replacement soils and their volume change properties should be tested in the laboratory and used in the unsaturated flow/deformation analyses. In this study the replacement material properties were assumed such that the replacement material had very low volume change in response to suction changes.

3. Hypothetical cases were used in this study. To the extent possible, the findings from this work should be validated for actual field case histories. This is particularly important given the complex interactions at play in this mitigation method.

4. The impact of distributed load on the slab should be studied to know how much it helps to prevent heave, and the slab stiffness and soil-structure interaction effects should be studied. 
5. Three-dimensional volume change problems should be analyzed in future when 3D modeling becomes less challenging.

6. Other surface flux boundary conditions should be studied, including in particular, the study of turf conditions for a well-graded site where excess irrigation water is run-off rather than allowed to infiltrate into the profile. 


\section{REFERENCES}

Ahmed, A. 2009. Evaluation of Drying and Wetting Cycles with Soil Cushion to Mitigate the Potential of Expansive Soil in Upper Egypt. Department of Civil Engineering, Beni-Suef University, Beni-Suef, Egypt

Bao, C. G., and Ng, C. W. W. 2000. Keynote lecture: Some thoughts and studies on the prediction of slope stability in expansive soils. Proceedings of $2^{\text {nd }}$ int. conf. on unsaturated soils and slope stability for expansive soils Vol (2):71-98.

Benson, C. H. and, Trast, J. M. 1995. Hydraulic Conductivity of Thirteen Compacted Clays, STS Consultants Ltd., Clay and Clay Minerals Society Vol. 43, no.6:669-681.

Bratton, Wesley L. Slab-On-Ground Foundations Constructed Over Expansive Clay: Parameters to Predict Volume Change Potential by Dissertation In Civil Engineering, Submitted to the Graduate Faculty of Texas Tech University. 1991

Burov, E. S. 1977. Using compensating cushions in the construction of structures on expansive soils. Proc., 1st National Symp. on Expansive Soils:166-169. Harcourt-Butler Technological Institute, Kanpur, India.

California Building Standards and Codes for Residential Structures. 2010.

Celia, M. A., and Bouloutas, E. T. July 1990. A General Mass- Conservative Numerical Solution for the Unsaturated Flow Equation. Water Resources Research Vol. 26(7):1483-1496. Elsevier.

Chen, F. H. 1988. Foundations on Expansive Soils, $2^{\text {nd }}$ ed.: 463. Amsterdam:

Chen, F. H. 1988. Foundations on Expansive Soils. Development in Geotechnical Engineering 54. Elsevier Science Publishers B. V.

Clemence, S. and Finbarr, A. 1981. Design Considerations for Collapsible Soils. Journal of Geotechnical Engineering, ASCE 107(3): 305-318.

Coduto, P.D. 1999. Foundation Design - Principles and Practices. $54^{\text {th }}$ edition. New Jersey: Prentice Hall.

Coppola, D. G. 2007. Introduction to International Disaster Management Amsterdam: Elsevier Publication. 
Day, R. W. June 2, 2006. Expansive Soils: Recent Advances in Characterization and Treatment $1^{\text {st }}$ edition, Taylor \& Francis.

Dye, H. 2008. Moisture Movement through Expansive Soil and Impact on Performance of Residential Structures, PhD Dissertation, Arizona State University.

Dye, H.B., Houston, S.L., and Houston, W.N. July 2-4, 2008. Surface flux boundary simplifications for flow through clay under landscaped conditions. Unsaturated Soils: Advances in Geo-Engineering. Proceedings of the First European Conference on Unsaturated Soils, E-Unsat.: 805-810. Durham, UK. (ed. Toll, D.G., Augarde, C.E., Gallipoli, D. \& Wheeler,S.J.), Leiden: CRC Press/Balkema.

Edlefsen, N. E., and Anderson, A. B. C. 1943. Thermodynamics of Soil Moisture 15:31- 298. Hilgardi.

Fredlund, D. G, 2006. Unsaturated Soil Mechanics in Engineering Practice. Journal of Geotechnical and Geotechnical Engineering 132(3):286-321.

Fredlund, D. G, Hung, Vu, Fredlund, M., and Thode, R. Oct $1^{\text {st }}, 2004$. Modeling soil-structure interaction of slabs on expansive soils, Soilvision Systems Ltd.

Fredlund, D. G. 1979. Second Canadian Geotechnical Colloquium: Appropriate Concepts and Technology for Unsaturated Soils. Canadian Geotechnical Journal Vol.16, no.1:121-139.

Fredlund, D. G. May 18-19, 2000. Historical Developments and Milestones in unsaturated Soils, UNSAT ASIA, Keynote Address: 53-68. Singapore.

Fredlund, D. G., and Rahardjo, H. 1993. Soil Mechanics for Unsaturated soils. New York: John Wiley \& Sons.

Fredlund, D. G., and Rahardjo, H. 1994. Equations for the Soil-Water Characteristic Curve. Canadian Geotechnical Journal 31(3):521-532.

Fredlund, D. G. August 22-23, 1995. The Prediction of Heave in Expansive Soils - Canada-Kenya Symposium on Unsaturated Soil Behaviour and Applications: 105-119. University of Nairobi, Nairobi, Kenya.

Fredlund, D. G., and Xing, A. 1994. Equations for the Soil Water Characteristic Curve. Canadian Geotechnical Journal Vol.31:521-532. 
Goode, J. C., Hamberg, D. J., and Nelson, J. D. 1984. Moisture Content and Heave beneath Slabs on Grade. Fifth International Conference on Expansive Soils 1984:Preprints of Papers International Conference on Expansive Soils. Adelaide, S. Australia.

Hamberg, D. J. 1985. A Simplified Method for Predicting Heave in Expansive Soils. M.Sc. thesis: 275, Colorado State Univ., Fort Collins.

Hamberg, D. J., and Nelson, J. D. 1984. Prediction of Floor Slab Heave. Proc. $5^{\text {th }}$ Int. Conf. Expansive Soils: 137-140. Adelaide, Australia.

Hammel, J. E., Papendick, R. I., and Campbell, G. S. 1981. Fallow Tillage Effects on Evaporation and Seedzone Water Content in a Dry Summer Climate. Soil Science Society of America Journal 45:1016-1022.

Holland, J. E., and Richards, J. 1984. The Practical design of foundations for light structures on expansive clays. Proceedings, 5th Int. Conf. on Expansive Soils, $A C T$. Institution of Engineers, Australia.

Ho, D. Y. F., Fredlund, D. G., and Rahardjo, H. 1992. Volume Change Indices during loading and unloading of an unsaturated soil. Canadian Geotechnical Journal Vol.29, No.2:195-207.

Holmes, R. M., 1961. Estimation of Soil Moisture Content Using Evaporation Data. Proceedings of Hydrology Symposium, No. 2 Evaporation: 184-196. Ottawa: Queen's Printer.

Holtz, R. D., and Kovacs, W. D. 1981. An Introduction to Geotechnical Engineering. Prentice-Hall, Inc.

Holtz, W. G., and Gibbs, G. J. 1956. Engineering Properties of Expansive Clays. Trans. Am. Soc. Civ. Engrs. 121:641-677.

Holtz, W. G., and Hart, S. S. 1978. Home Construction On Shrinking And Swelling Soils. American Society of Civil Engineers. Denver : Colorado Geological Survey

Horton, R. E. 1940. An approach towards a physical interpretation of infiltration capacity, Soil Sci. Soc. Am.Proc. 5:399-417.

Houston, S. L. 1996. Foundations and pavements on unsaturated soils - Part one: Collapsible soils. Proceedings of the $1^{\text {st }}$ International Conference on Unsaturated Soils, UNSAT'95. 14211440. Paris, France. 
Houston, S. L., Dye, H. B., Zapata, C. E., Walsh, K. D., and Houston, W. N. February 1, 2011. Study of Expansive Soils and Residential Foundations on Expansive Soils in Arizona. Journal of Performance of Constructed Facilities Vol. 25: No. 1.

Houston, S. L., Houston, W. N., Zapata, C. E., and Lawrence, C. 2001, Geotechnical engineering practice for collapsible soils. Department of Civil and Environmental Engineering, Arizona State University, Tempe, Arizona, 85287-5306.

Hung, Q. Vu, and Fredlund, D.G. 2000. Implementation of soil Property Functions in Volume Change Analysis in Unsaturated Soils.

Hung, Q. Vu, and Fredlund, D.G. 2004. The prediction of one, two and three dimensional heave in expansive soils, Canadian Geotechnical Journal Vol.41:713737.

Hung, Q. Vu. Uncoupled and Coupled Solutions of Volume Change Problems in Expansive Soils, Ph D. Dissertation: 319. Department of Civil Engineering, University of Saskatchewan, Saskatoon, Saskatchewan, Canada.

International Building Code (IBC) 2006 \& International Residential Code (IRC), 2006.

Katti, R. K. 1979. Search for solutions to problems in black cotton soils. First Indian Geotechnical Society Annual Lecture, Indian Geotechnical Journal 9-1:1-88.

Kerrane, J. P. What are Expansive Soils? Benson \& Associates PC.

Komornick, A. K., and David D. 1969. Prediction of Swelling Pressure of Clays. Proceedings ASCE, Journal of soil mechanics and Foundation Engineering Division Vol.25, No. SM1:209-225. New York.

Komornik, A., Wiseman, G., and Ben-Yaacob, Y. 1969. Studies of In-Situ Moisture and Swelling Potential Profiles. Proc. $2^{\text {nd }}$ Int. Conf. Unsaturated Expansive Soils: 348-361. Texas.

Krohn, J. P., and Slosson, J. E. 1980. Assessment of Expansive Soils in the United States. Proceedings of 4th International Conference on Expansive Soils:596608. Denver, Colorado.

Lytton, R. 1994. Prediction of movement of expansive clay: Proceeding of vertical and horizontal deformation of foundations and embankments. Geotechnical Special Publication 2:1827-1845. 
Lytton, R. L. 1977. Foundation on Expansive Soils. Desai, C. S., and Christian, J. T. (Editors), Numerical Methods in Geotechnical Engineering: 427-458. New York: McGraw-Hill.

Lytton, R. L. 1977. The Characterization of Expansive Soils in Engineering Soils in Engineering, Presentation at the Symposium on Water Movement and Equilibrum in Swelling Soils. American Geophysical Union. San Francisco, CA.

Lytton, R., Aubeny, C., and Bulut, R. 2004. Design procedures for pavements on expansive soils (Project Number 0-4518) Report 0-4518-1 Vol 1.

McKeen, R. G. 1992. A model for predicting expansive soil behavior. Proceedings of the $7^{\text {th }}$ International Conference on Expansive Soils: 1-6. Dallas, Texas.

McKeen, R. G. 2001. Investigating field behavior of expansive clay soils. Proc., Expansive Clay Soils and Vegetative Influence on Shallow Foundations, ASCE 82-94. Reston, VA.

McKeen, R. G., and Johnson, L. D. 1990. Climate-controlled soil design parameters for mat foundations. Journal of Geotechnical Engineering 116-7:10731094.

McOmber, R. M., and Thompson R.W. 2000. Verification of Depth of Wetting for Potential Heave Calculations. Advances in Unsaturated Geotechnics, ed. Shackelford et al., ASCE Geotechnical Special Publication no. 99:409-422.

McWhorter, D. B, and Nelson, J. D, Nov. 1979. Unsaturated Flow Beneath Tailings Impoundments, Journal of Geotechnical engineering Division, ASCE Vol (105), No. GT11:1317-1334.

Murthy, V. R., and Praveen, G. V. 2008. Use of chemically stabilized soil as cushion material below light weight structures founded on expansive soil. Journal of materials in civil and materials, ASCE 0899-1561(2008)20:5(392).

NAVFAC. 1971. Soil Mechanics, Foundation and Earth Structures, Design Manual, NAVFACDM-7, Naval Facilities Engineering Command. Department of the Navy, Bureau of Yards and Docks, Washington, DC.

Nelson, J. D., Overton, D., and Durkee, D. B. 2001. Depth of wetting and active zone. Proceedings of Geo-Institute Shallow Foundation and Soil Properties Committee: 95-109. 
Nelson, J. D. and Miller, D. J. 1992. Expansive Soils: Problems and Practice in Foundation and Pavement Engineering. New York: John Wiley \& Sons.

O'Neill, M. W., and Poormoayed, N. 1980. Methodology for foundations on expansive clays. ASCE Journal of Geotechnical Engineering Division: 1345-1364.

Richards, L. A. 1931. Capillary Conduction of Liquids through Porous Mediums 1:318-333. Physics, NY.

Rollins, K. and Rogers, G. W., 1994. Mitigation Measures for Small Structures on Collapsible Alluvial Soils, Journal Geotechnical Engineering, ASCE 120 (9).

Seed, H. B., Woodward, R. K., and Lundgren, R. 1962. Prediction if swelling Potential for compacted Clays. Journal of Soil Mechanics division, ASCE Vol.88, SM3: 53-87.

Shackelford, C. D., Chiu, T. F., Young, R. N., and Thomas, H. R. 1997. The influence of the capillary barrier effect on the use of sand under drains in waste disposal practice. Geoenvironmental engineering, contaminated ground: Fate of pollutants and remediation: 357-364. London: Thomas Telford.

SK.

SoilVision Systems Ltd. 2008. SVFlux \& SVSolid User's Manual. Saskatoon,

SoilVision Systems Ltd. 2009. SVOffice User's Manual. Saskatoon, SK.

Thompson, R. W, 1997. Evaluation Protocol for Repair of Residences Damaged by Expansive Soils. Proceedings of Sessions on Unsaturated Soils at GeoLogan, The Geo-Institute, Special Publication No. 68, ASCE. Logan, Utah.

Vu, H. Q. 2000. Finite Element Method for The Prediction of Volume Change in Expansive Soils. M.Sc. Thesis: 314. Department of Civil Engineering, University of Saskatchewan, Saskatoon, Sask. Canada.

Walsh, K. D, Colby, C. A, Houston, W. N., and Houston, S. L. 2009. Method for evaluation of depth of wetting in residential areas, Journal of Geotechnical and Geoenvironmental Engineering Vol.135 (2):169-176.

Walsh, K. D, Houston, S. L., Houston, W. N., and Harraz, A. M. Nov, 2009. Finite Element Evaluation of Deep-Seated Swell. Proceedings of $4^{\text {th }}$ Asia-Pacific Conference on unsaturated Soils 23-25. Newcastle, Australia.

Warren, W. 1995. So your home is built on expansive soil. ASCE. 
Wilson, G. W., Fredlund, D. G., and Barbour, S. L. 1994. Coupled Soil Atmosphere Modeling For Soil Evaporation. Canadian Geotechnical Journal 31: 151161.

Wray, W. K, and Meyer, K. T. 2004. Expansive Clay Soil-A Widespread and Costly Geohazard. Geo-Strata, ASCE Geo Institute 24-28.

www.azgs.az.gov/HomeOwners-OCR/HG4_problemsoils.pdf.

Zhan, L. T., and Ng, C. W. W. 2004. Analytical Analysis of Rainfall Infiltration Mechanism in Unsaturated Soils. International Journal of Geomechanics, ASCE. Vol. 4, No.4:273-284. 
APPENDIX A

CONVERGENCE STUDY RESULTS 
Table A1. Convergence study for the Initial trial Runs

\begin{tabular}{|c|c|c|c|c|}
\hline Max Increment & Grid size & Avg. Dt & Nodes & Runtime (SV Flux) \\
\hline 0.5 & Regrid & 0.44045 & 520 & $1: 54$ \\
\hline & $0.5 \mathrm{~m}$ & 0.44669 & 2685 & $18: 20$ \\
\hline & $0.25 \mathrm{~m}$ & 0.41132 & 10545 & $58: 47$ \\
\hline & $0.1 \mathrm{~m}$ & 0.44668 & 62273 & $2: 21: 45$ \\
\hline
\end{tabular}

\begin{tabular}{|c|c|c|c|c|}
\hline Max Increment & Grid size & Avg. Dt & Nodes & Runtime (SV Flux) \\
\hline 0.2 & Regrid & 0.17123 & 512 & $4: 12$ \\
\hline & $0.5 \mathrm{~m}$ & 0.17783 & 2685 & $21: 14$ \\
\hline & $0.25 \mathrm{~m}$ & 0.17783 & 10545 & $1: 22: 08$ \\
\hline & $0.1 \mathrm{~m}$ & 0.17783 & 62273 & $3: 45: 12$ \\
\hline
\end{tabular}

\begin{tabular}{|c|c|c|c|c|}
\hline Max Increment & Grid size & Avg. Dt & Nodes & Runtime (SV Flux) \\
\hline 0.1 & Regrid & 0.0895 & 550 & $20: 41$ \\
\hline & $0.5 \mathrm{~m}$ & 0.08887 & 2685 & $3: 51: 40$ \\
\hline & $0.25 \mathrm{~m}$ & 0.08887 & 10545 & $8: 55: 36$ \\
\hline & $0.1 \mathrm{~m}$ & 0.08887 & 62273 & $12: 37: 52$ \\
\hline
\end{tabular}

\begin{tabular}{|c|c|c|c|c|}
\hline Max Increment & Grid size & Avg. Dt & Nodes & Runtime (SV Flux) \\
\hline 0.01 & Regrid & 0.00869 & 550 & $45: 36$ \\
\hline & $0.5 \mathrm{~m}$ & 0.00889 & 2685 & $6: 57: 30$ \\
\hline & $0.25 \mathrm{~m}$ & 0.00889 & 10545 & $18: 34: 55$ \\
\hline & $0.1 \mathrm{~m}$ & 0.00889 & 62273 & $25: 34: 45$ \\
\hline
\end{tabular}

\begin{tabular}{|c|c|c|c|c|}
\hline 0.001 & Regrid & 0.00869 & 550 & $8: 45: 37$ \\
\hline & $0.5 \mathrm{~m}$ & 0.00889 & 2685 & $38: 47: 50$ \\
\hline & $0.25 \mathrm{~m}$ & 0.00889 & 10545 & $55: 30: 16$ \\
\hline & $0.1 \mathrm{~m}$ & 0.00889 & 62273 & - \\
\hline
\end{tabular}




\section{A.1 Suction Results for Different $\Delta x$ and Constant $\Delta t$ (Initial Preliminary/Trial Runs)}

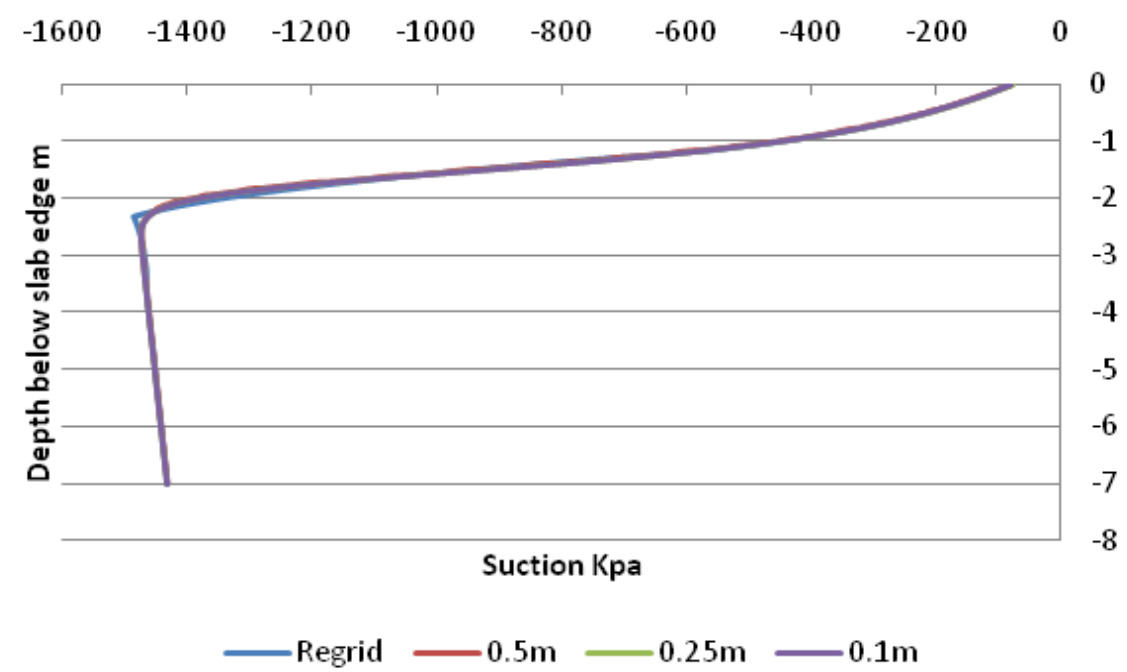

Figure A.1. Suction variation below slab edge $(X=10 \mathrm{~m})$ for $\Delta t=0.01$

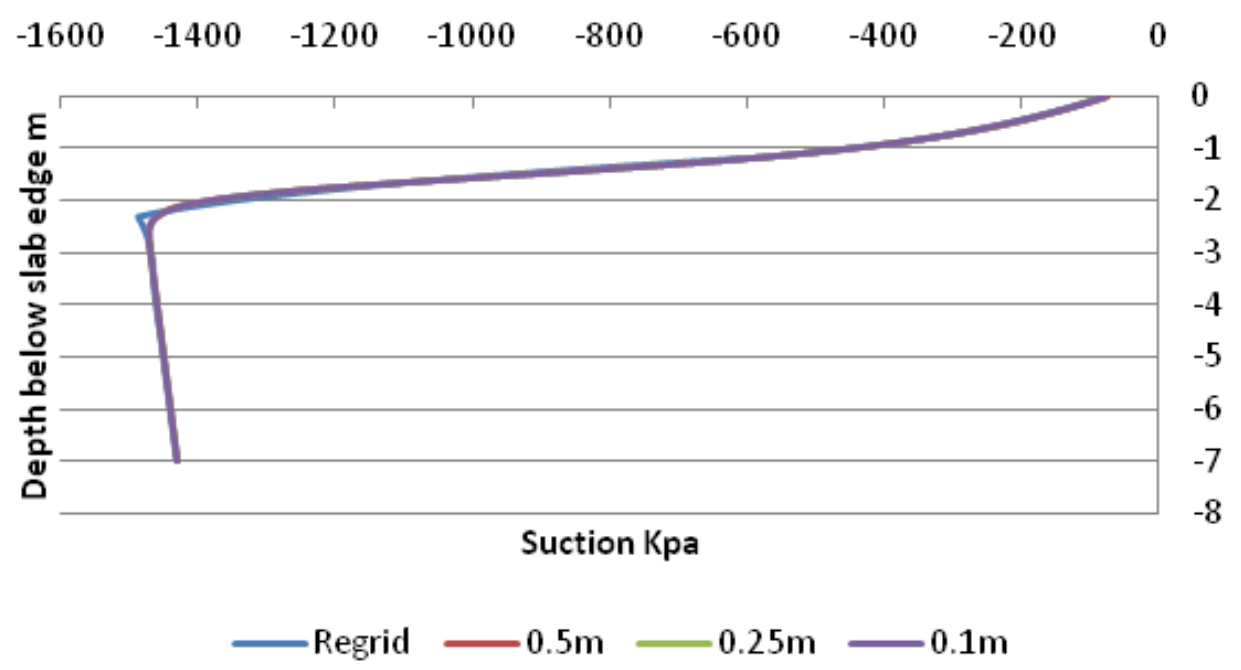

Figure A.2. Suction variation below slab edge $(X=10 \mathrm{~m})$ for $\Delta t=0.1$ 


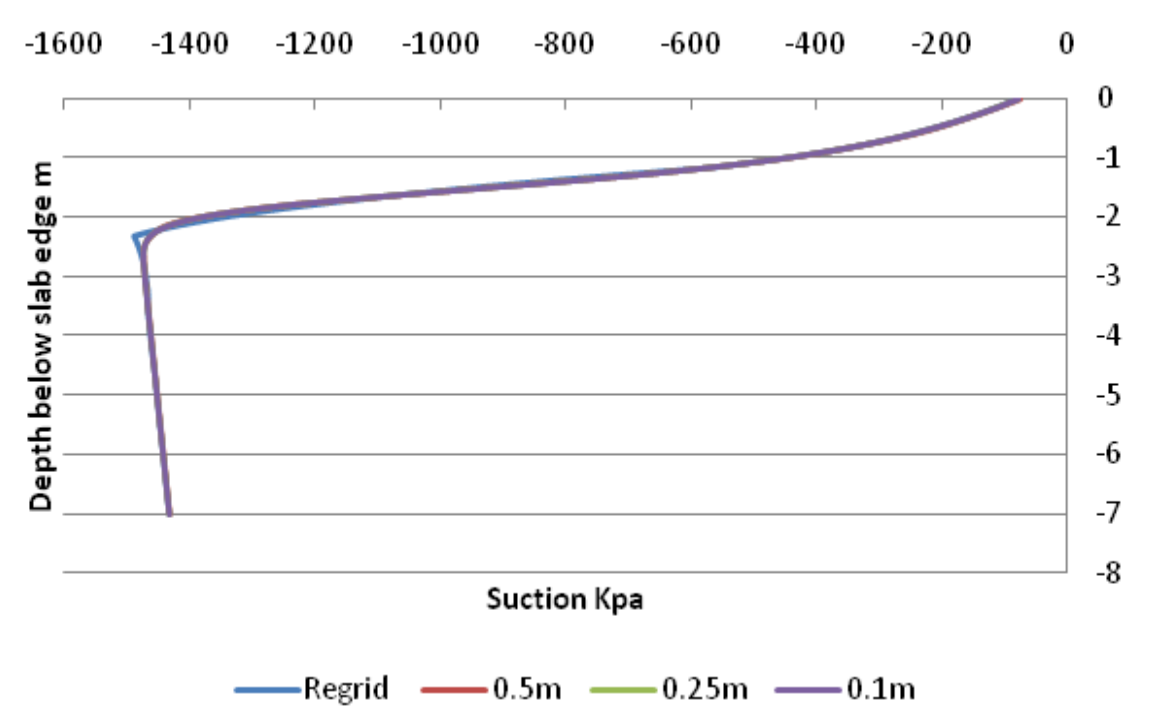

Figure A.3. Suction variation below slab edge $(X=10 \mathrm{~m})$ for $\Delta t=0.2$

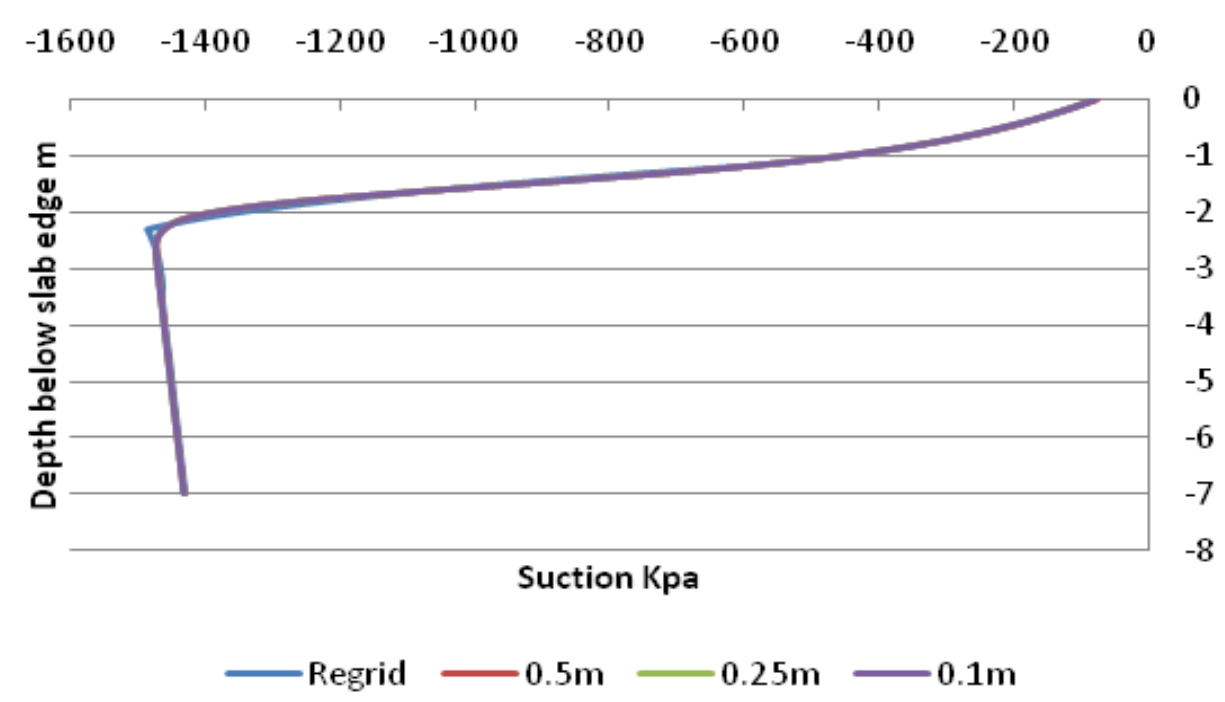

Figure A.4. Suction variation below slab edge $(X=10 \mathrm{~m})$ for $\Delta t=0.5$ 


\section{A. 2 Suction Results Different $\Delta t$ and Constant $\Delta x$ (Initial Trial Runs)}

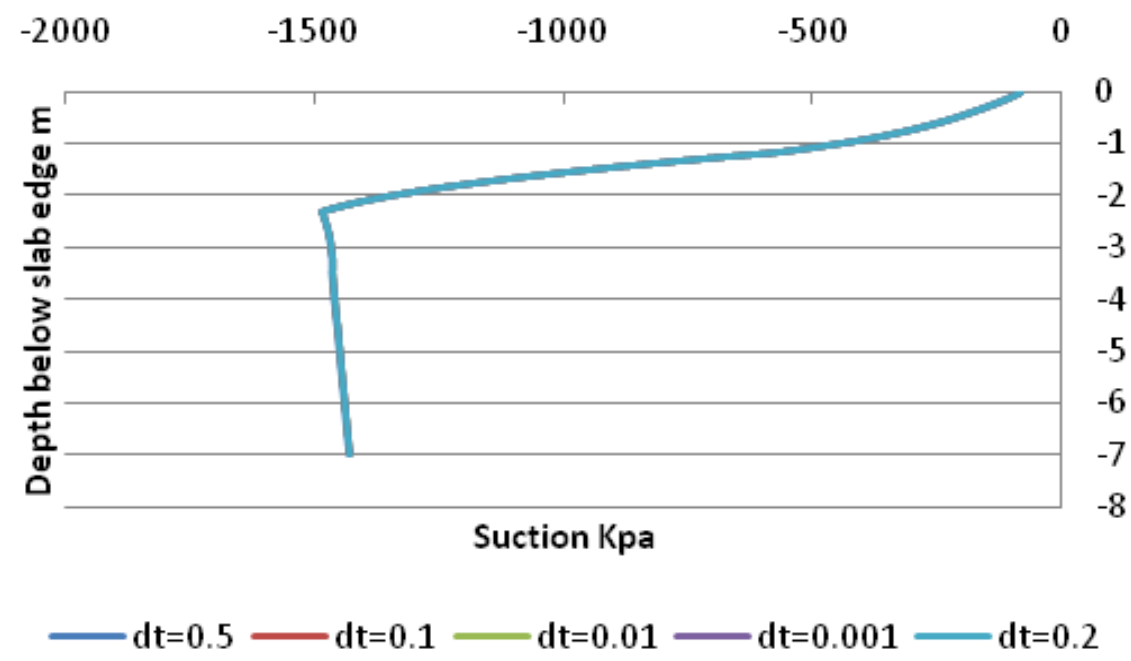

Figure A.5. Suction variation below slab edge $(X=10 \mathrm{~m})$ for Regrid

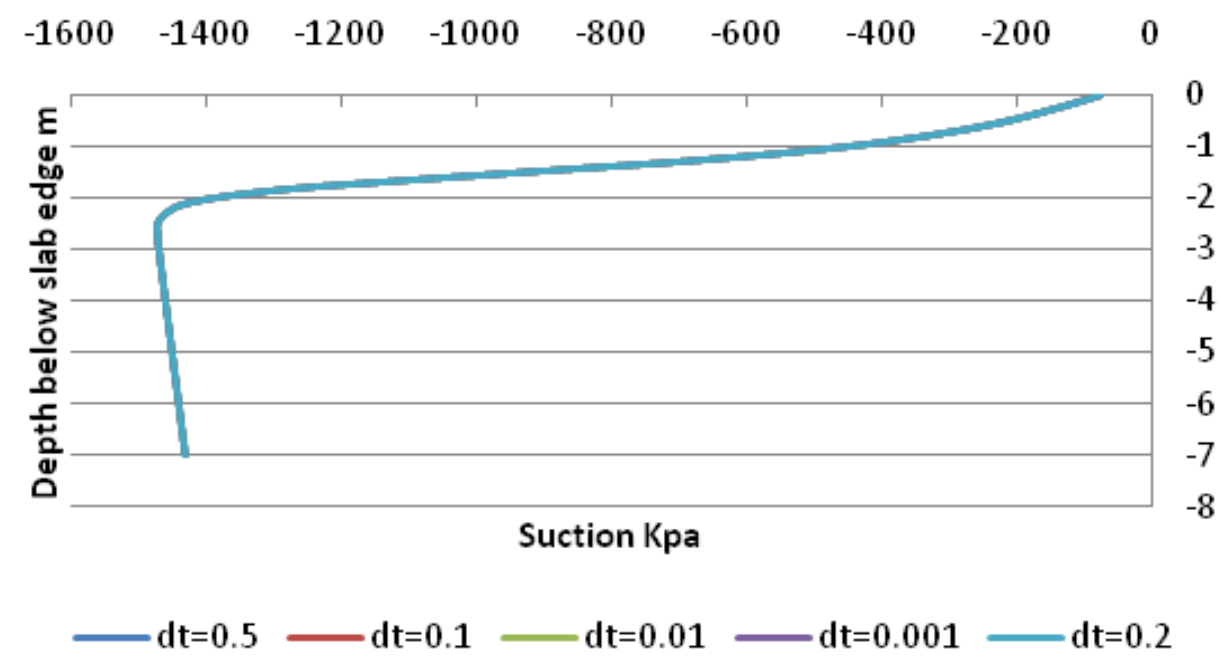

Figure A.6. Suction variation below slab edge $(X=10 \mathrm{~m})$ for $\Delta x=0.5 \mathrm{~m}$ 


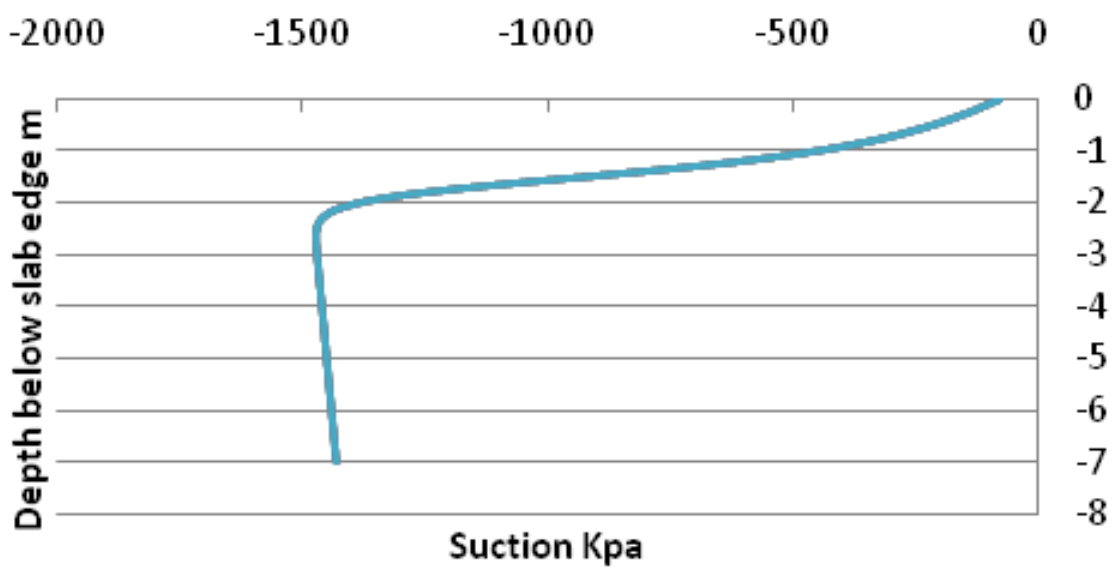

$\mathrm{dt}=0.5 \longrightarrow \mathrm{dt}=0.1 \longrightarrow \mathrm{dt}=0.01 \longrightarrow \mathrm{dt}=0.001 \longrightarrow \mathrm{dt}=0.2$

Figure A.7. Suction variation below slab edge $(X=10 \mathrm{~m})$ for $\Delta x=0.25 \mathrm{~m}$

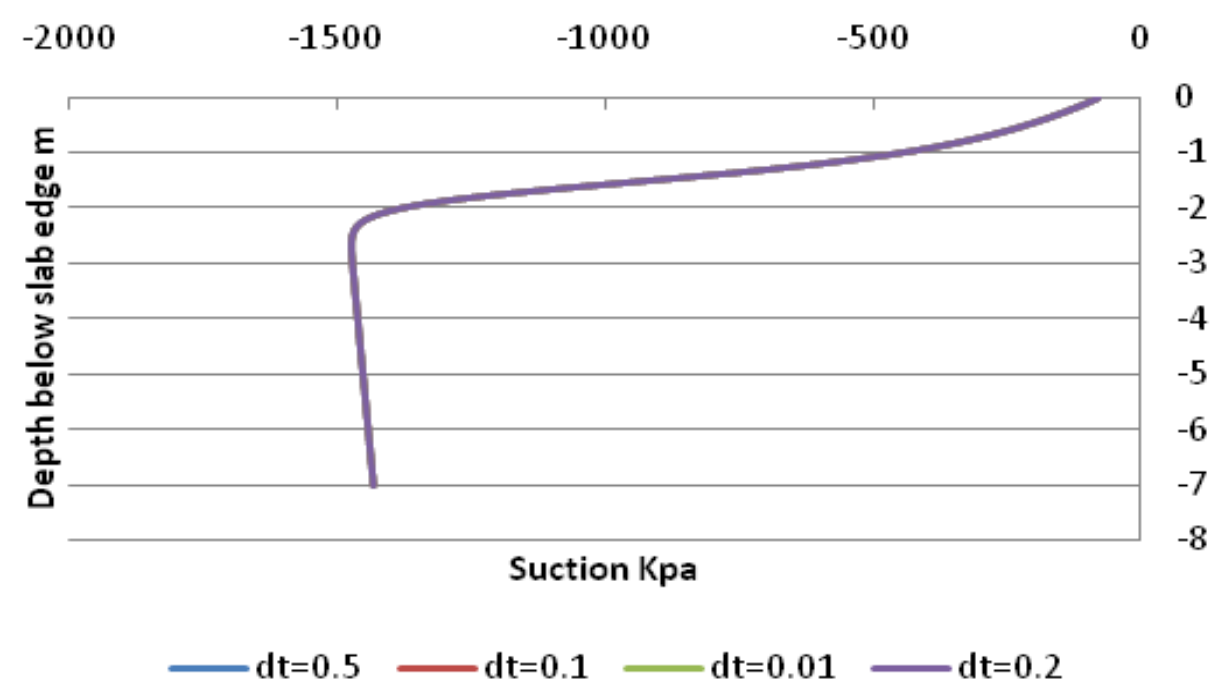

Figure A.8. Suction variation below slab edge $(X=10 \mathrm{~m})$ for $\Delta x=0.1 \mathrm{~m}$ 


\section{A.3 Saturation Results for Different $\Delta x$ and Constant $\Delta t$ (Initial Trial Runs)}

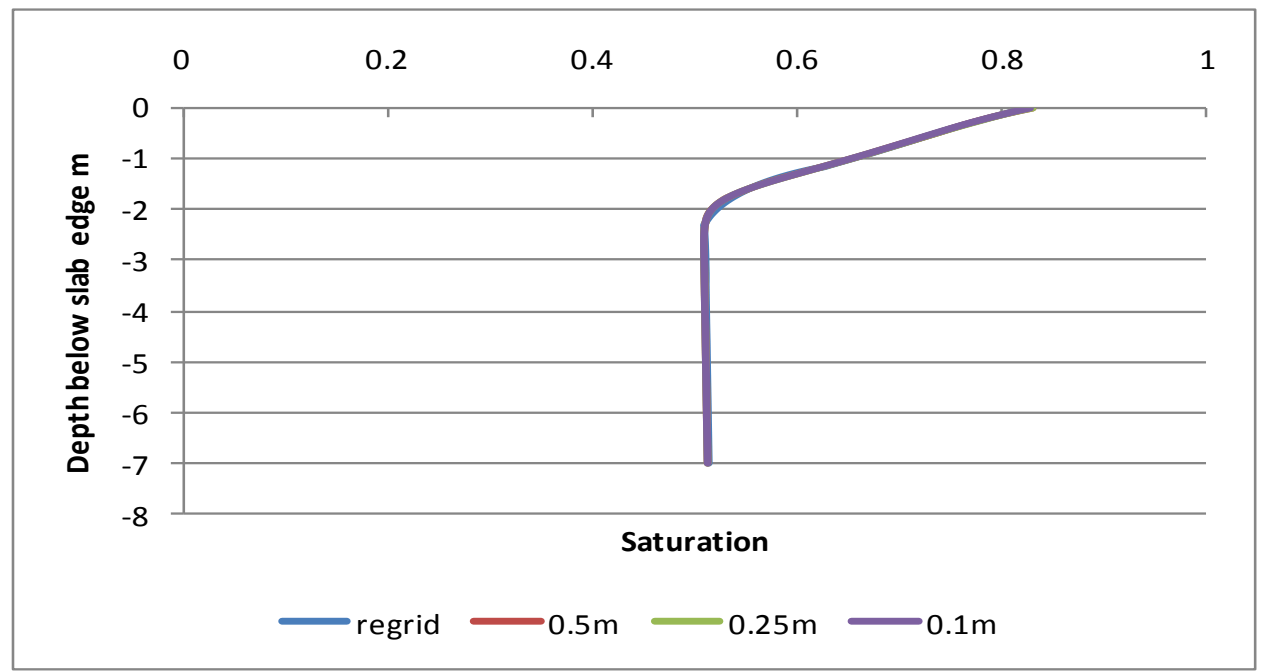

Figure A.9.Saturation variation below slab edge $(X=10 \mathrm{~m})$ for $\Delta t=0.01 \mathrm{~m}$

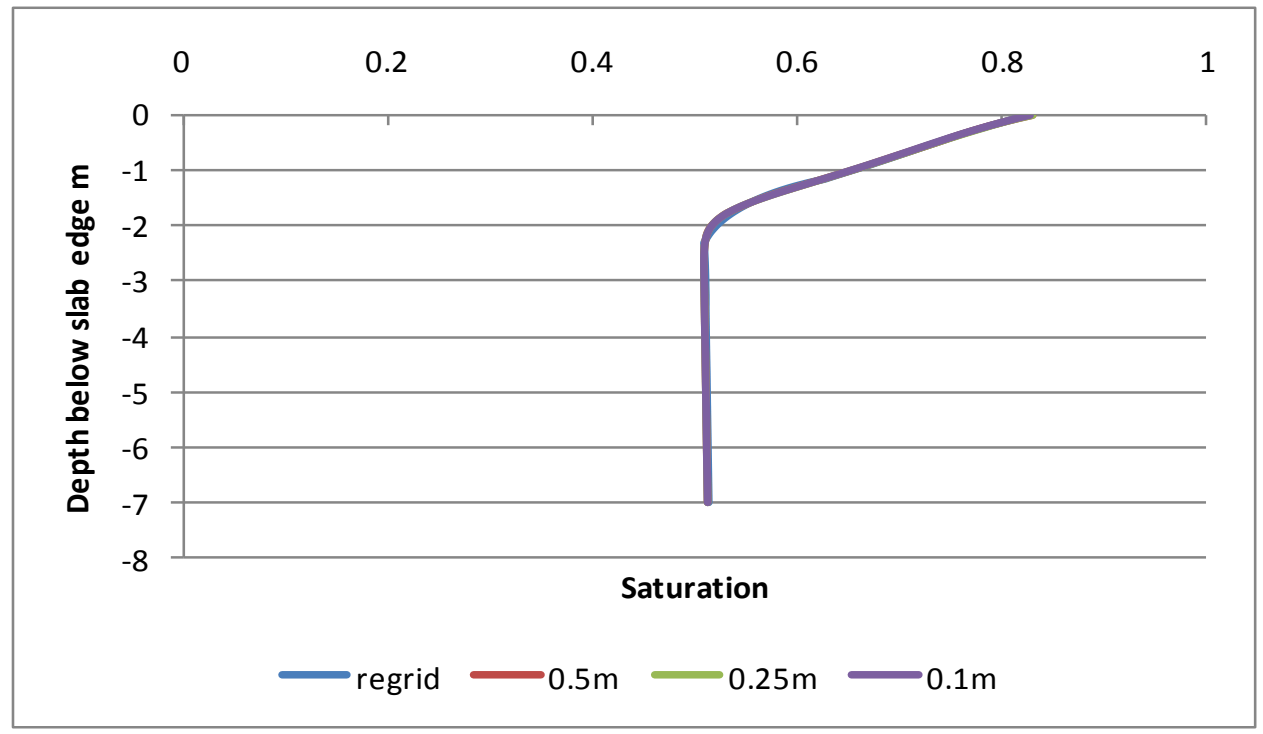

Figure A.10. Saturation variation below slab edge $(X=10 \mathrm{~m})$ for $\Delta t=0.1 \mathrm{~m}$ 


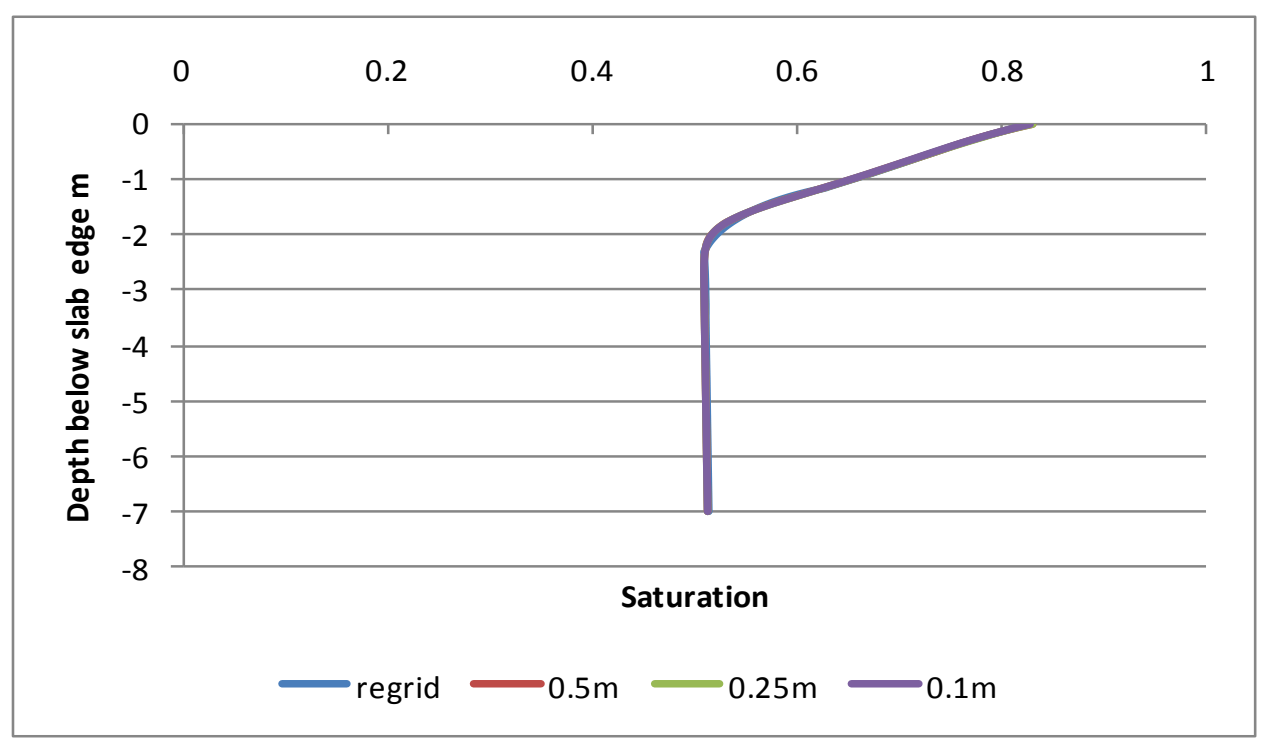

Figure A.11. Saturation variation below slab edge $(X=10 \mathrm{~m})$ for $\Delta t=0.2 \mathrm{~m}$
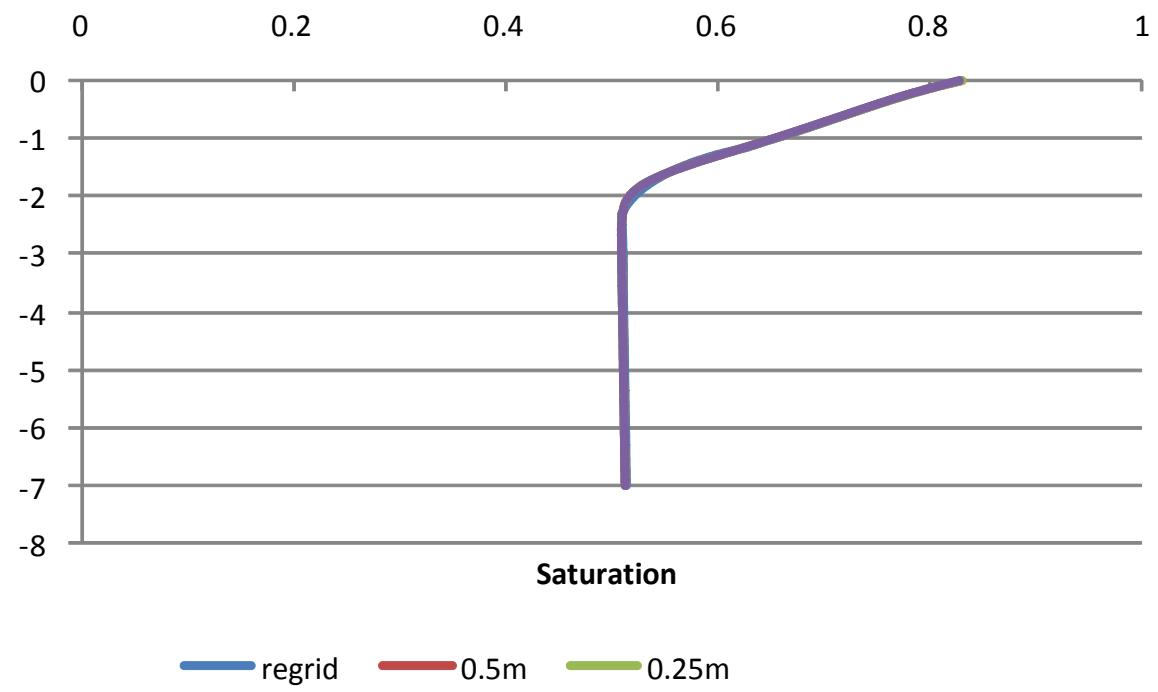

Figure A.12. Saturation variation below slab edge $(X=10 \mathrm{~m})$ for $\Delta t=0.5 \mathrm{~m}$ 


\section{A.4 Saturation Results for Different $\Delta t$ and Constant $\Delta x$ (Initial Trial Runs)}

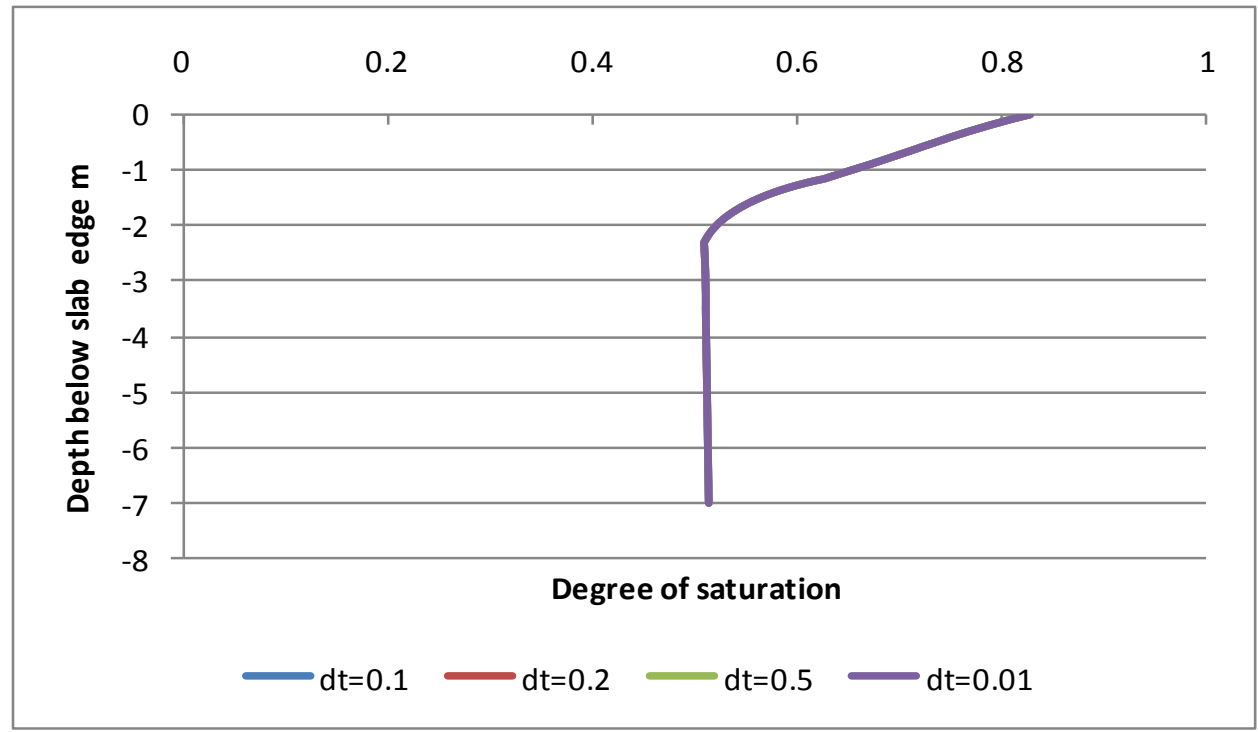

Figure A.13. Saturation variation below slab edge $(X=10 \mathrm{~m})$ for Regrid

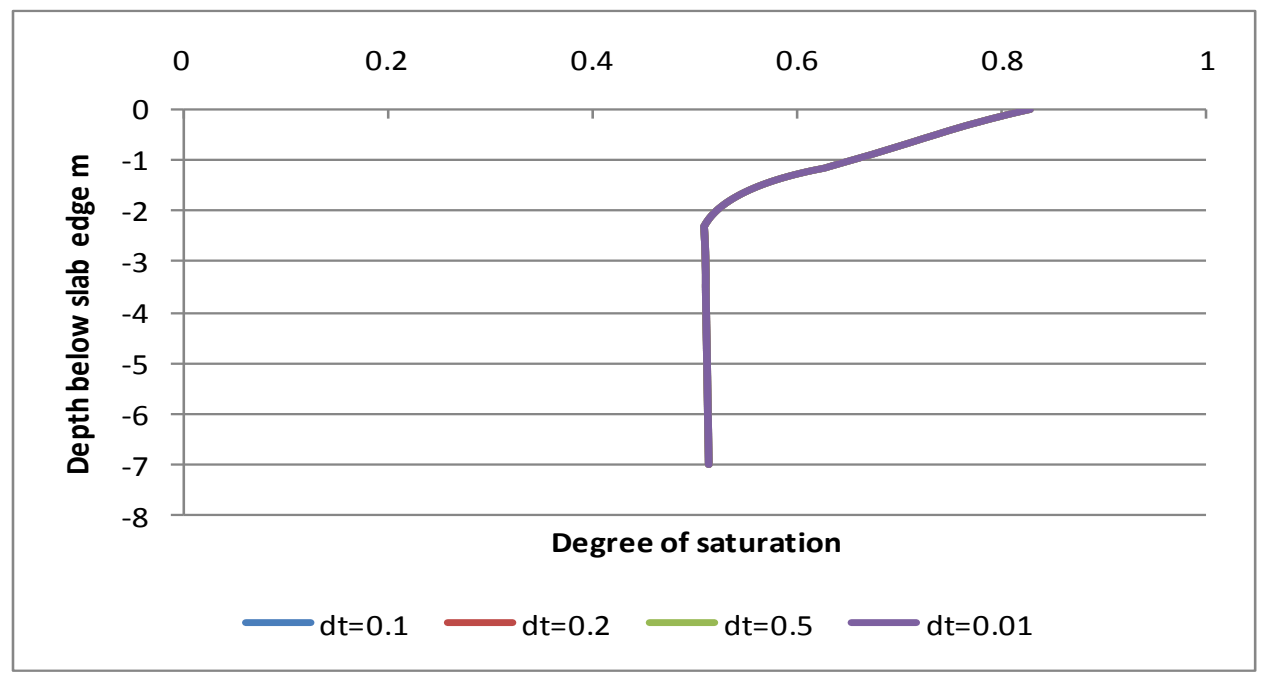

Figure A.14. Saturation variation below slab edge $(X=10 \mathrm{~m})$ for $\Delta x=0.5 \mathrm{~m}$ 


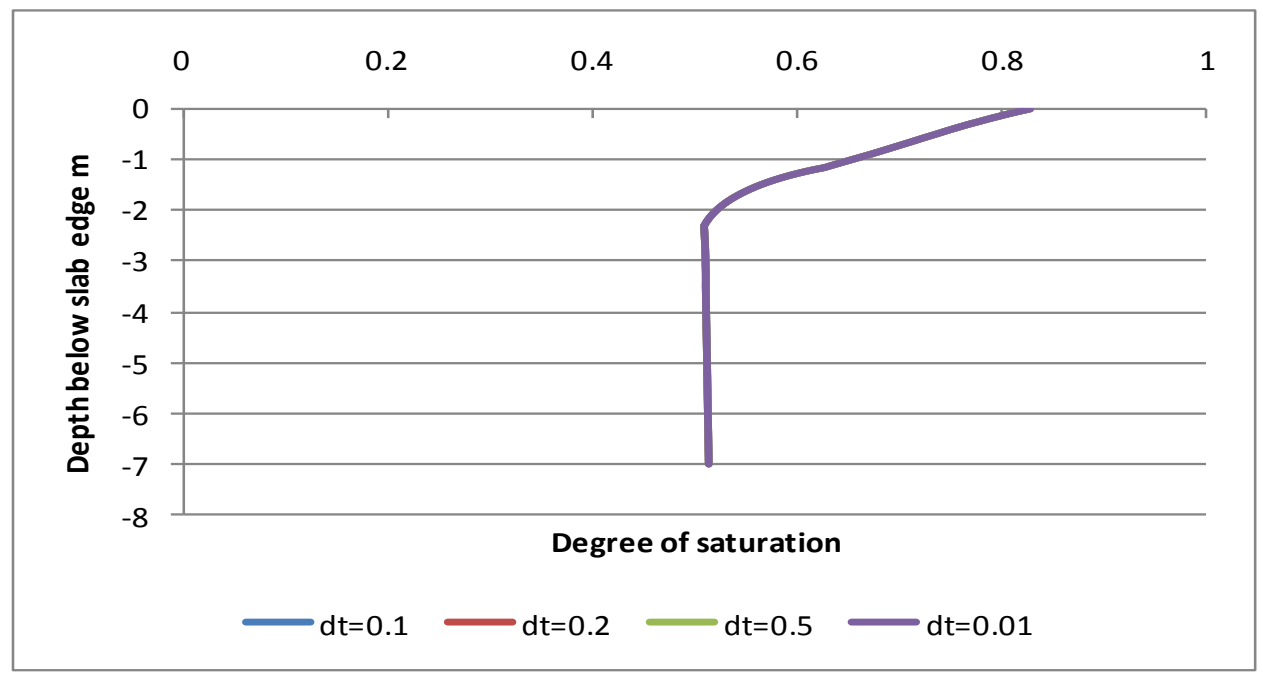

Figure A.15. Saturation variation below slab edge $(X=10 \mathrm{~m})$ for $\Delta x=0.25 \mathrm{~m}$

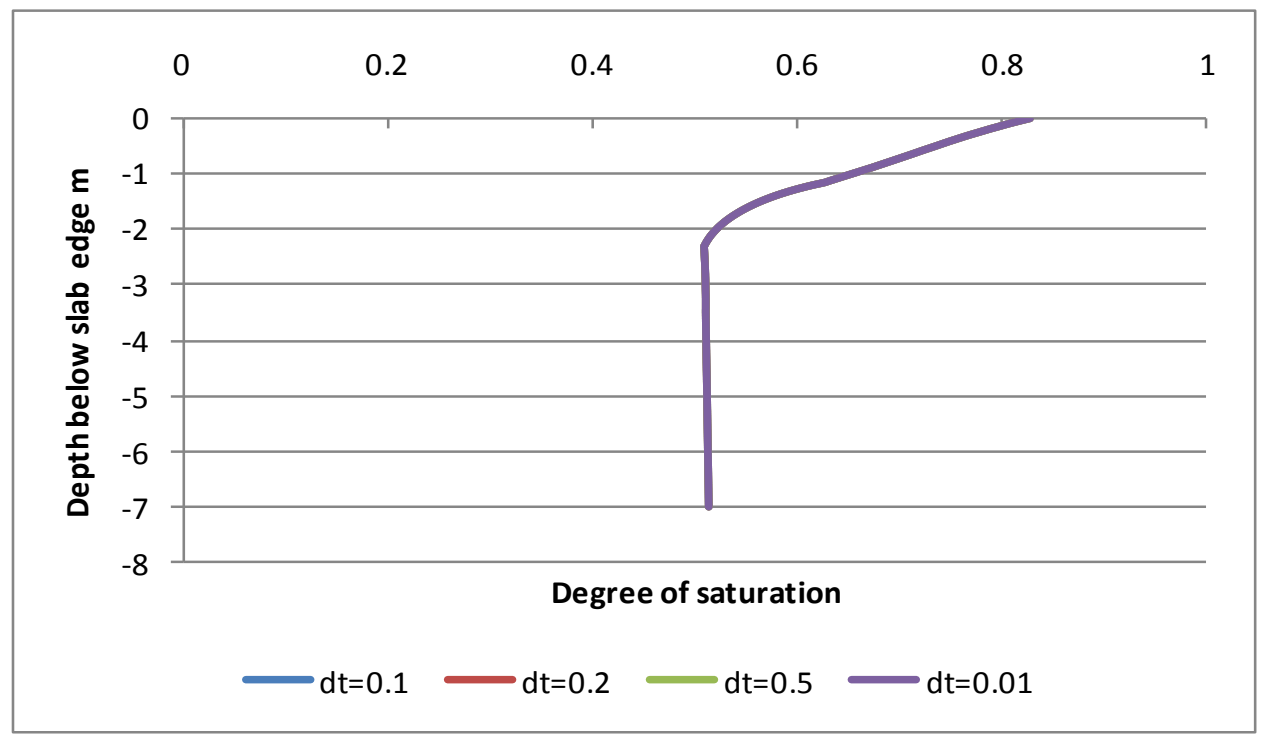

Figure A.16. Saturation variation below slab edge $(X=10 \mathrm{~m})$ for $\Delta x=0.1 \mathrm{~m}$ 
APPENDIX B

$5^{\text {TH }}$ YR CLIMATIC CONDITIONS RESULTS 


\section{B.1 5 Yr Climatic Condition Runs for Intact Soil (Initial Condition for Final}

Remove and Replacement SV Flux Runs)

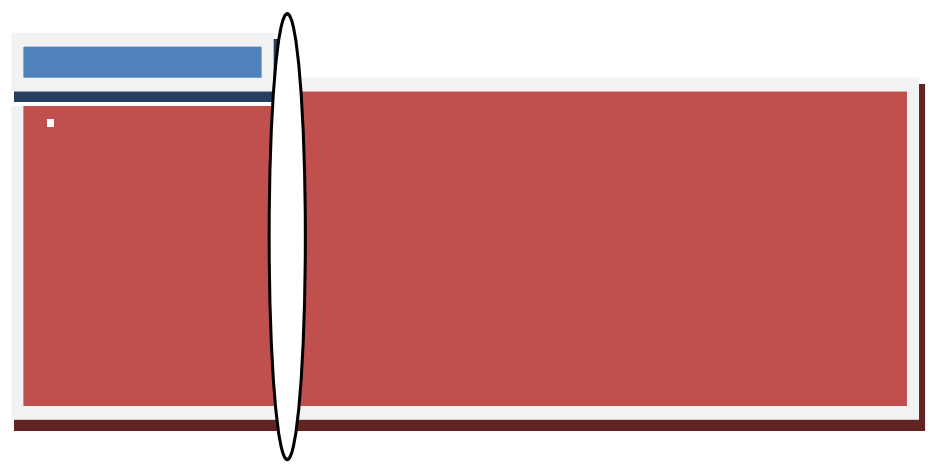

Figure B.1. Section below slab edge

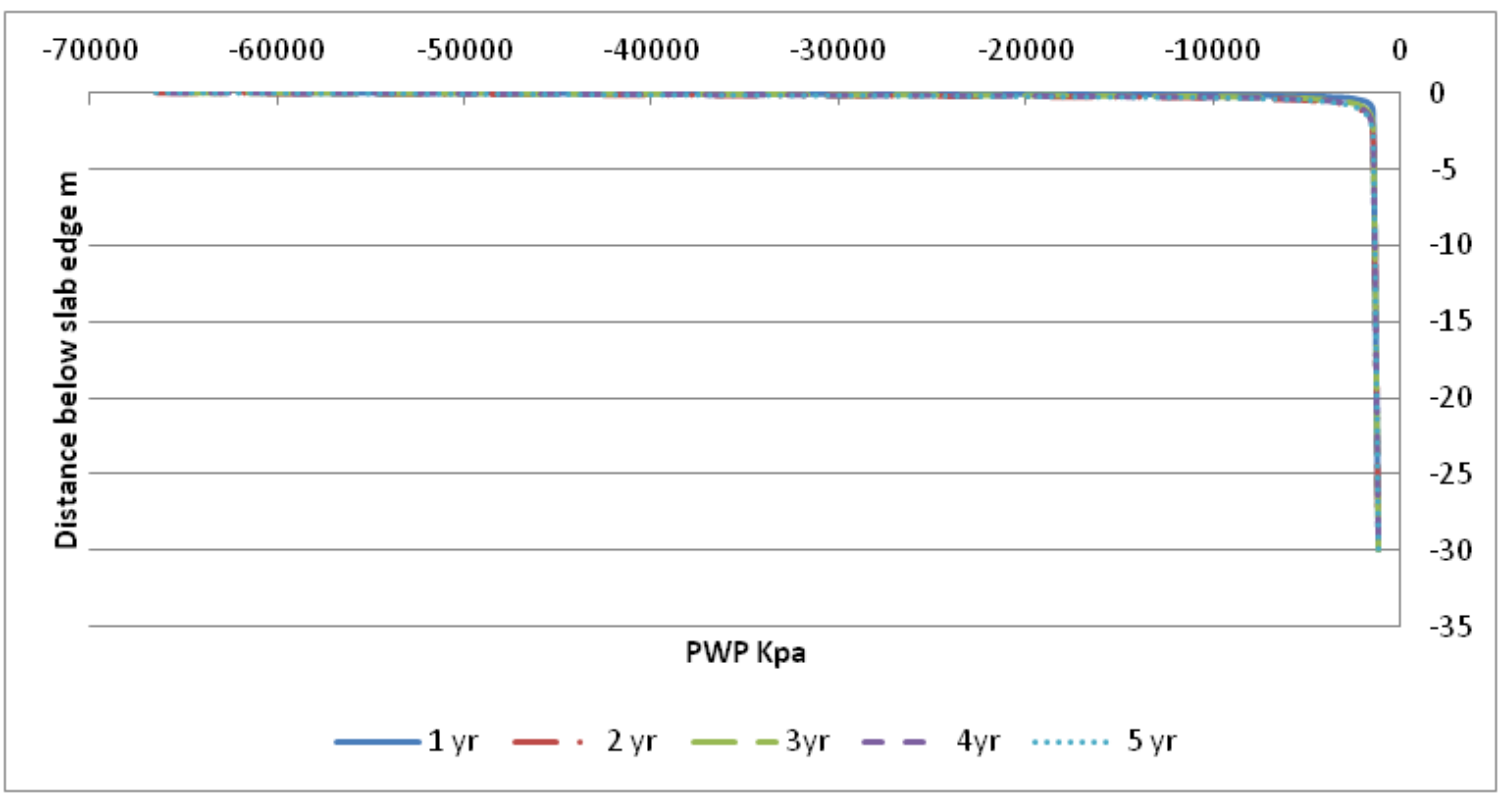

Figure B.2. Vertical profile below slab edge (see Figure B.1) 


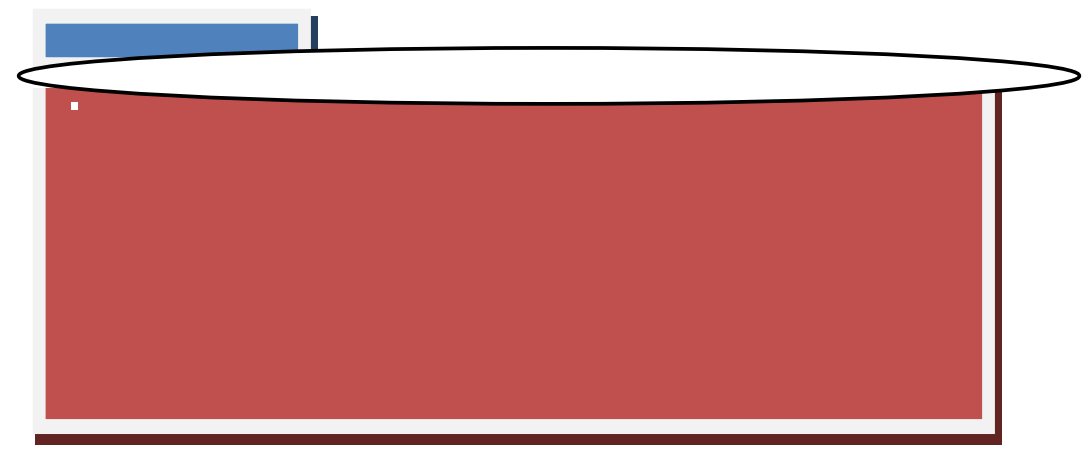

Figure B.3. Horizontal section at the ground surface

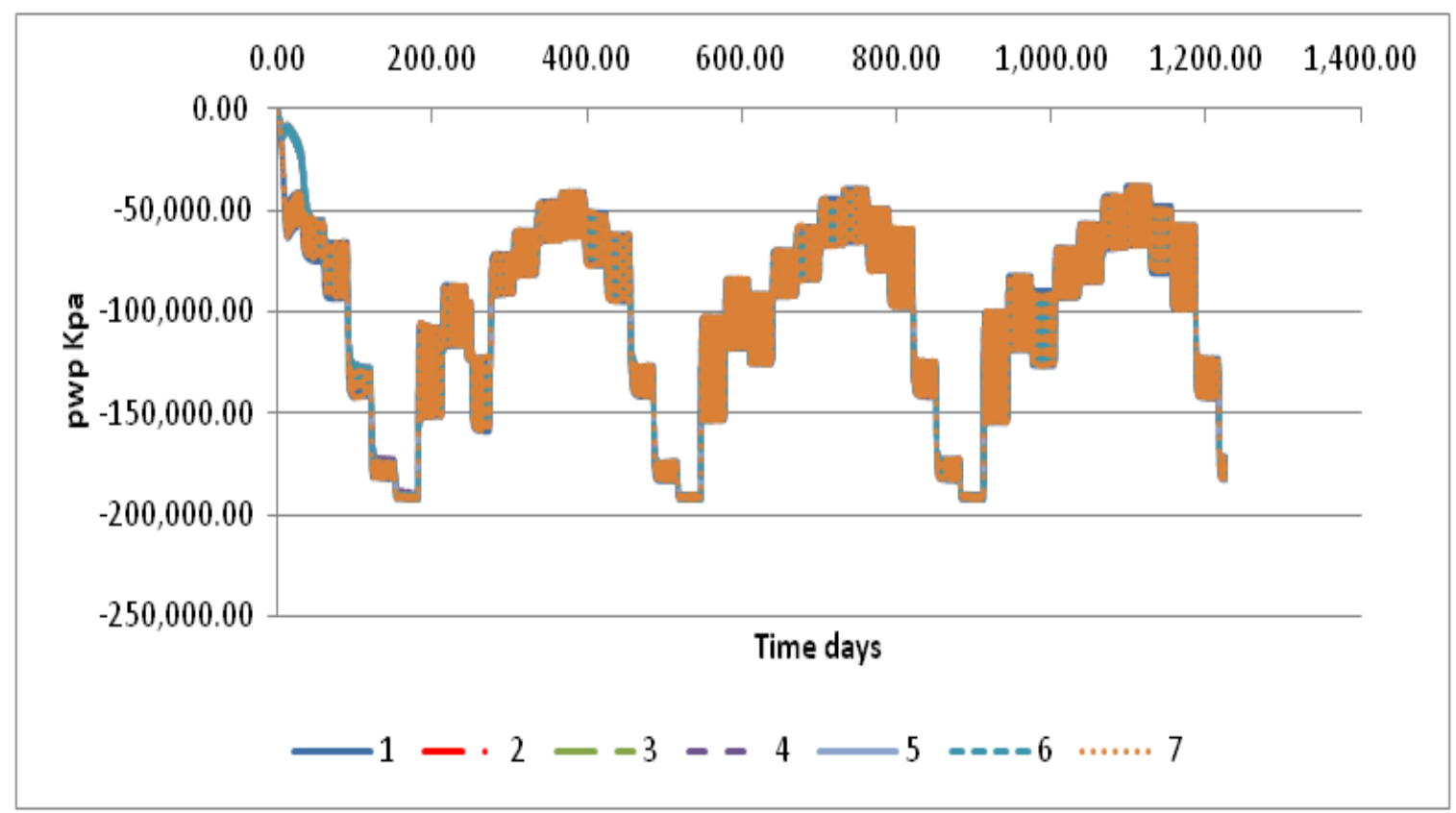

Figure B.4. History pwp plot at the ground surface (see Figure B.3) 


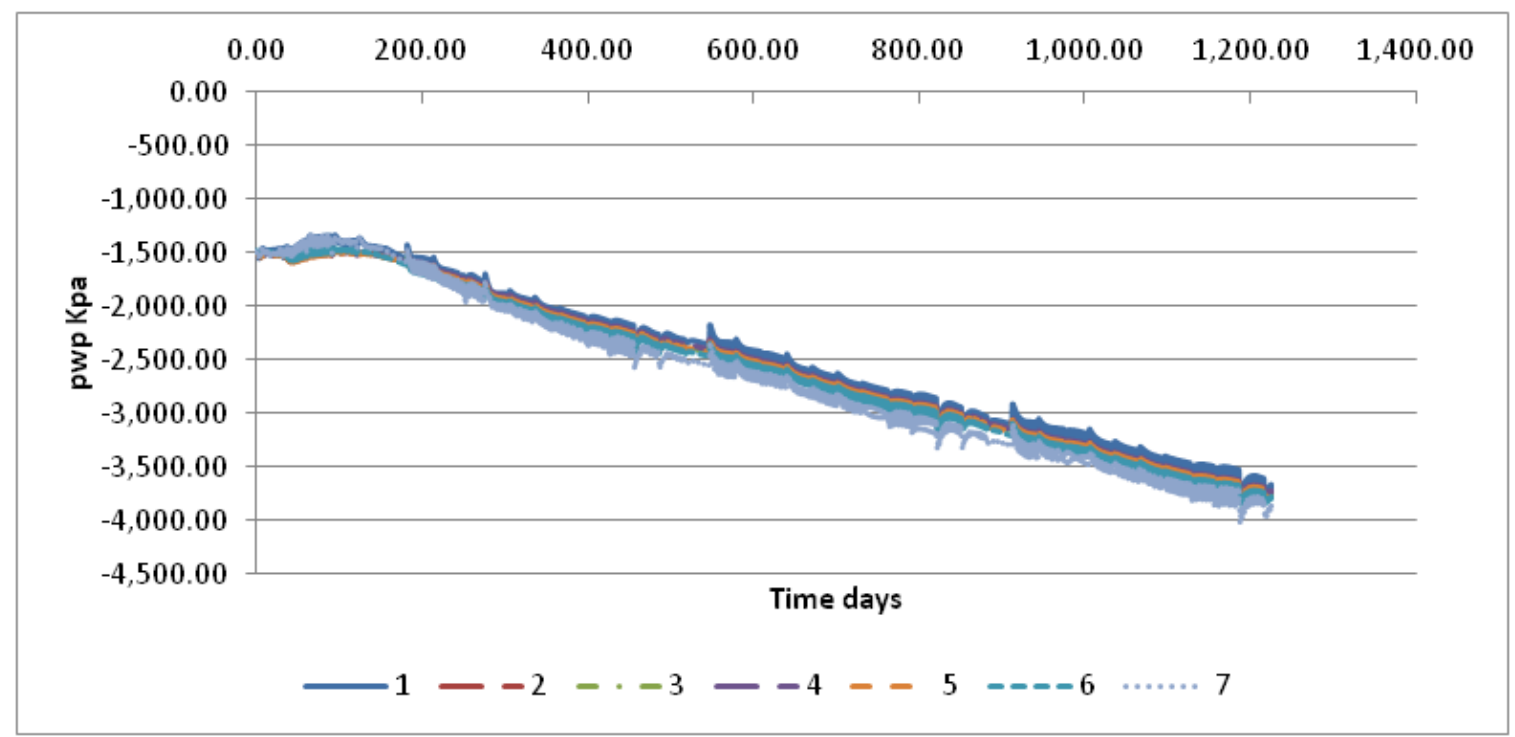

Figure B.5. History pwp plot at the $\mathrm{Y}=0.25 \mathrm{~m}$ below surface

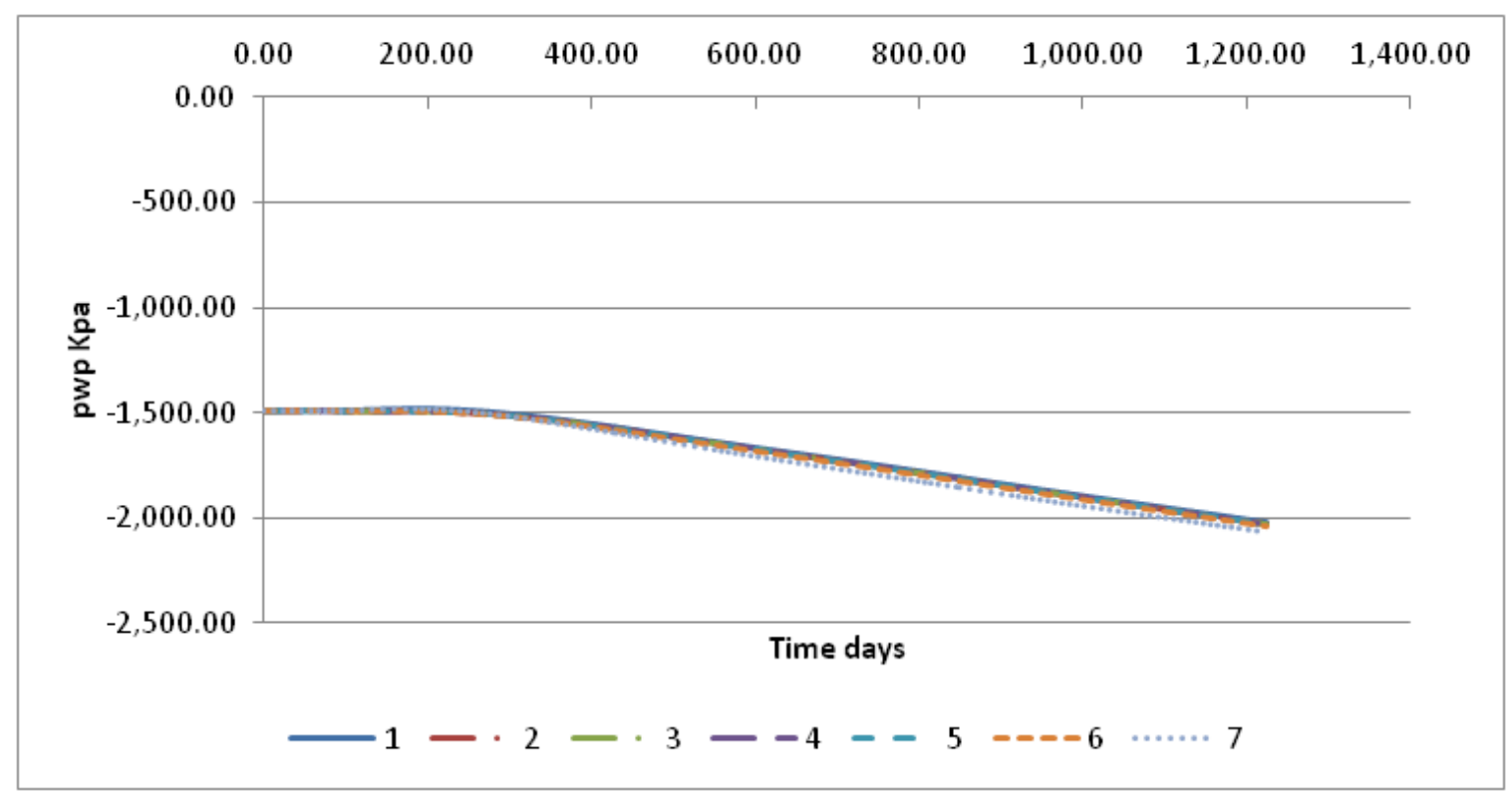

Figure B.6. History pwp plot at the $Y=0.5 \mathrm{~m}$ below surface 


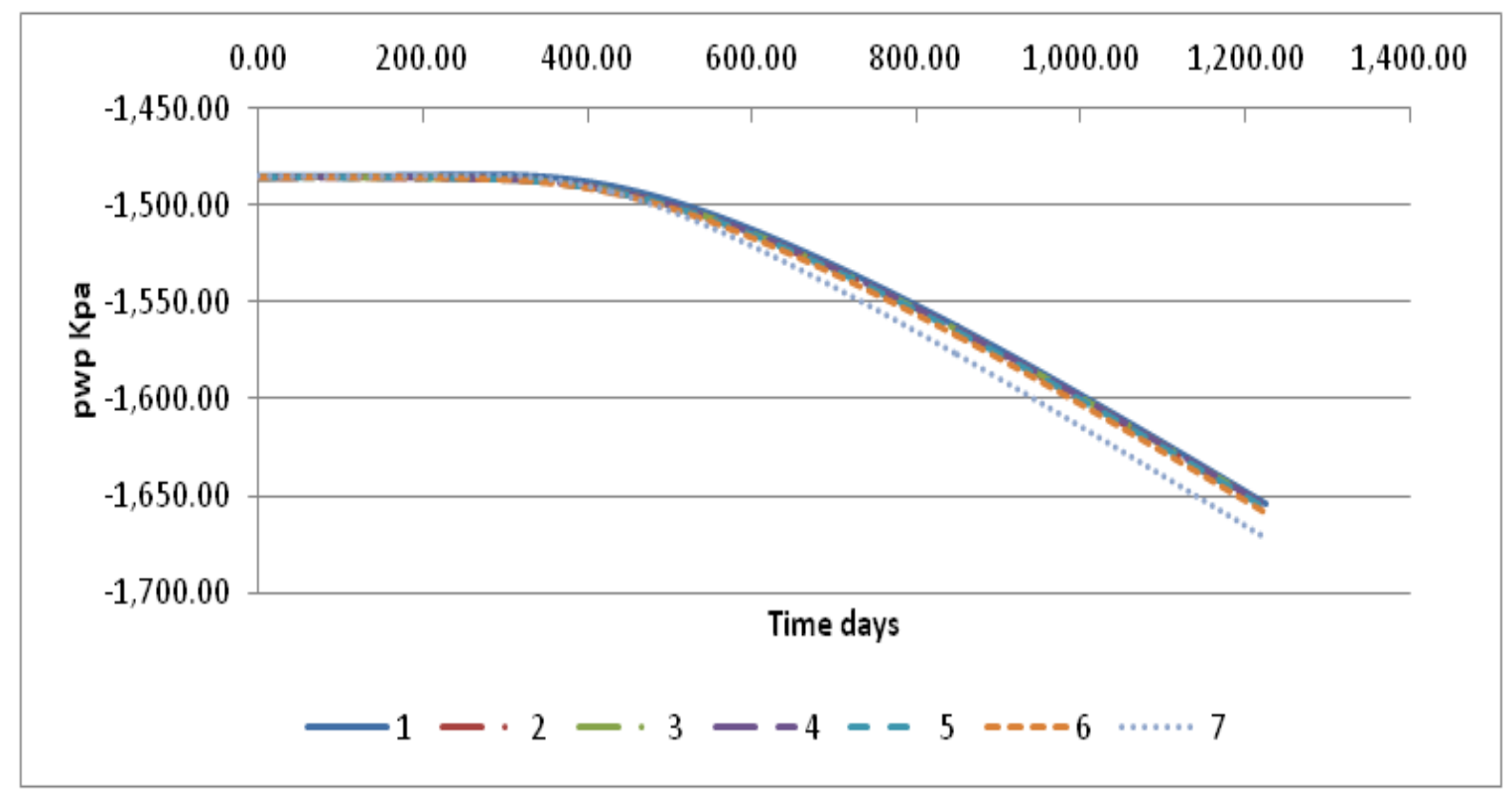

Figure B.7. History pwp plot at $Y=1 \mathrm{~m}$ below ground surface

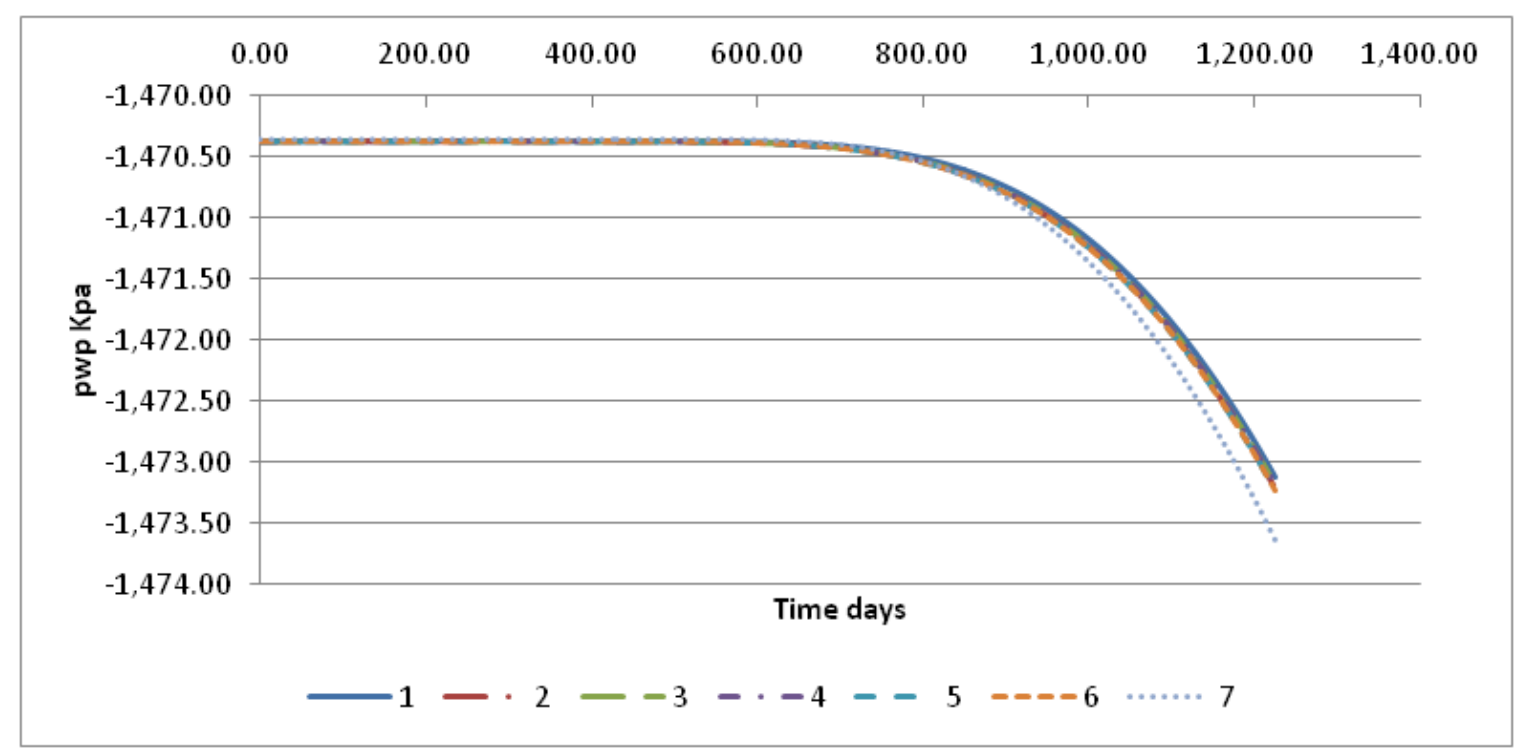

Figure B.8. History pwp plot at $Y=1.5 \mathrm{~m}$ below ground surface 


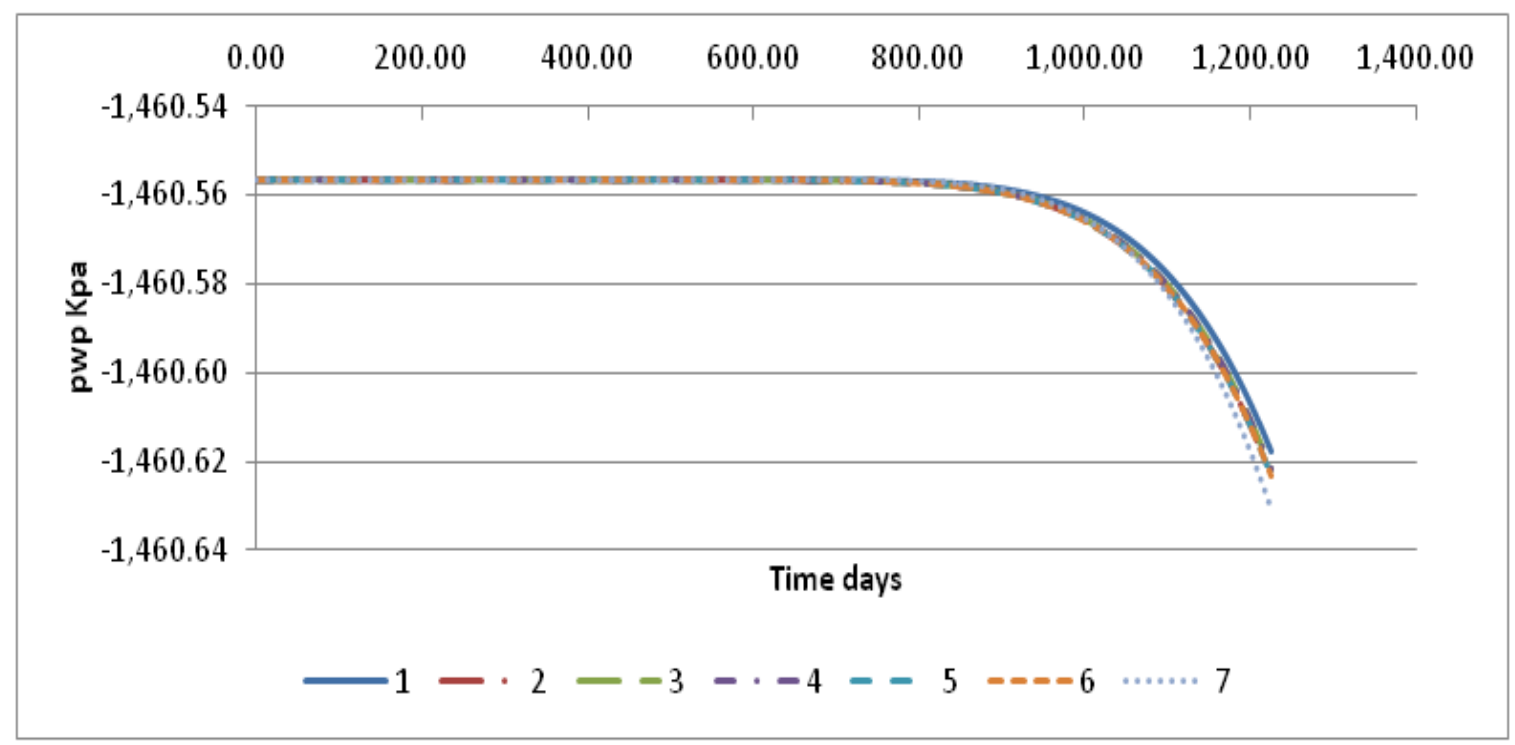

Figure B.9. History pwp plot at $\mathrm{Y}=2 \mathrm{~m}$ below ground surface 
APPENDIX C

IC AND FC SUCTION PROFILES FOR DIFFERENT DISTANCES FROM SLAB CENTERLINE 


\section{C.1 Roof Runoff Boundary Conditions Case}

The suction plots included in this section are for the vertical sections of the soil profile as shown in the sketch below. The plots shown below are for all the replacement cases and no replacement case.

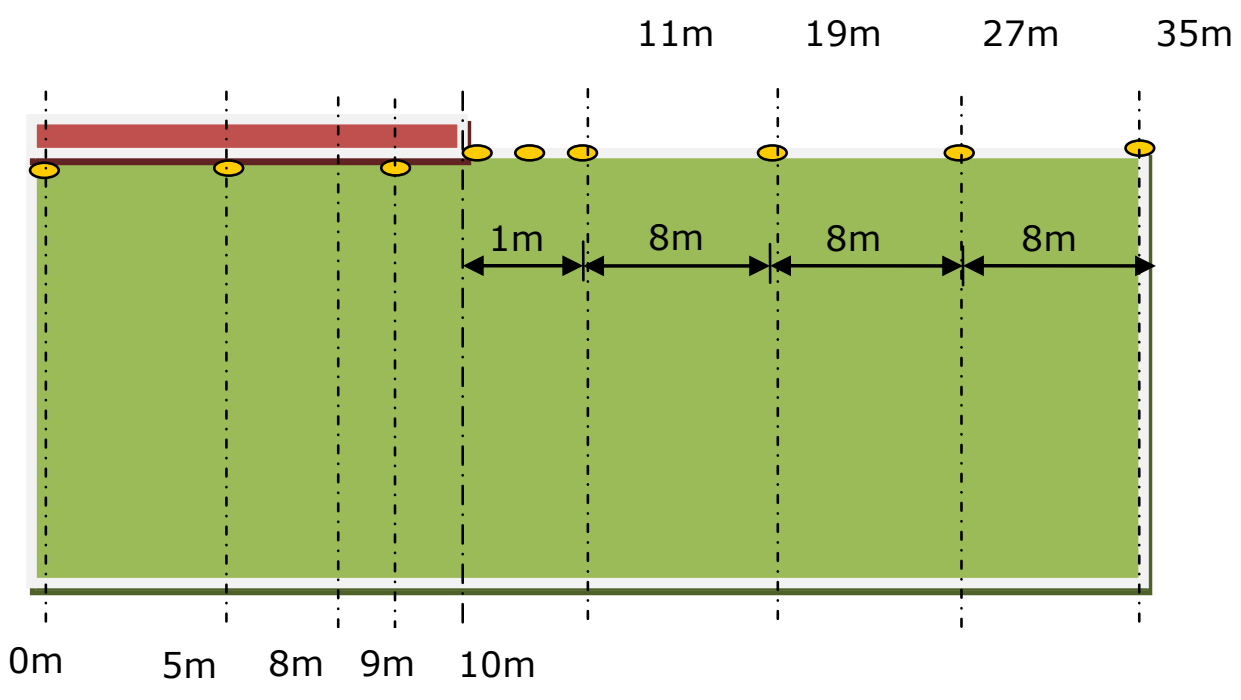




\section{C.1.1 IC and FC Suction Plots for No Replacement Expansive Clay Case}

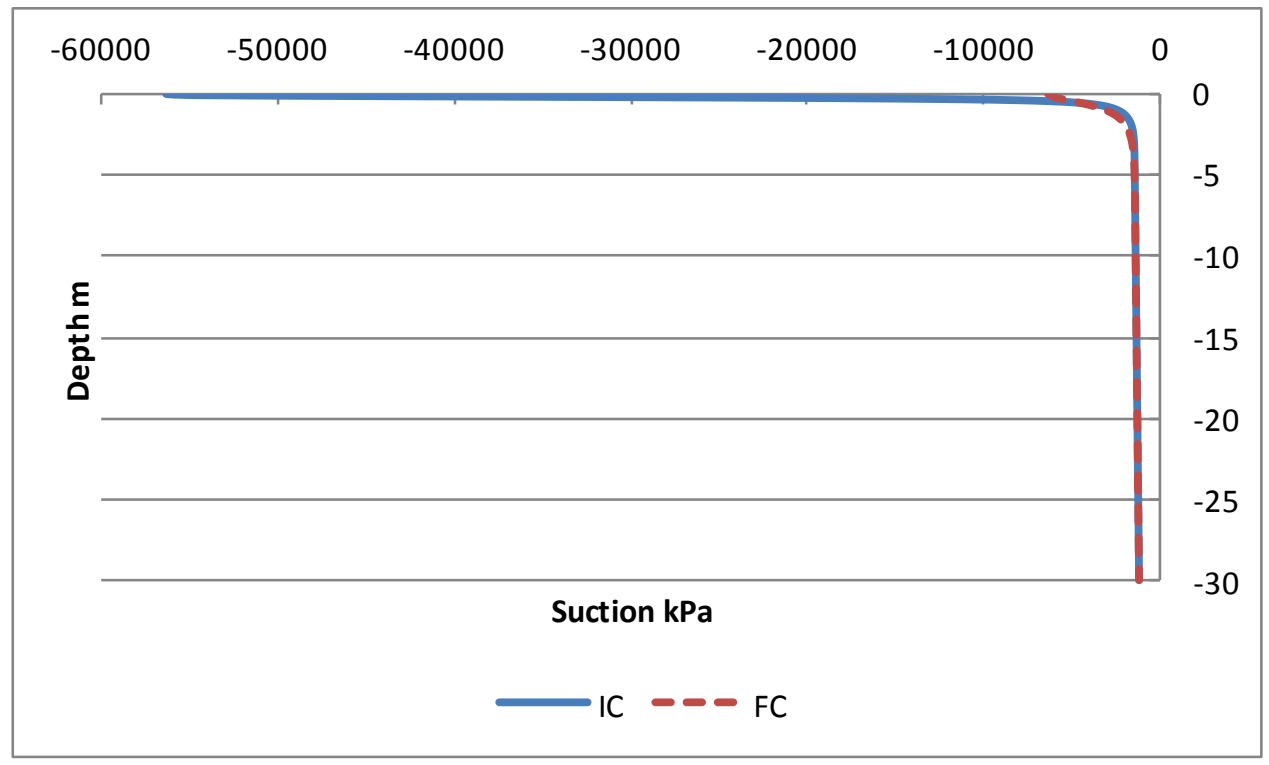

Figure C.1. - Vertical suction profile at $0 \mathrm{~m}$

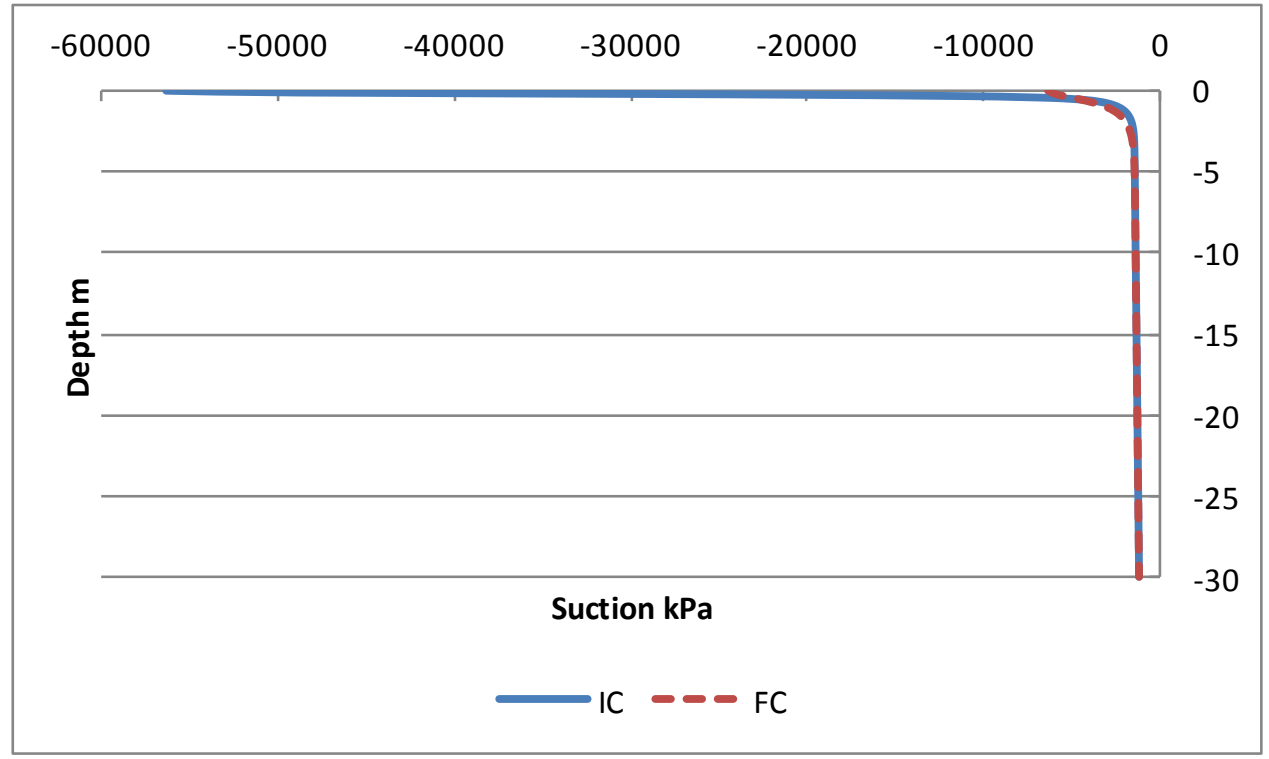

Figure C.2. Vertical suction profile at $5 \mathrm{~m}$ 


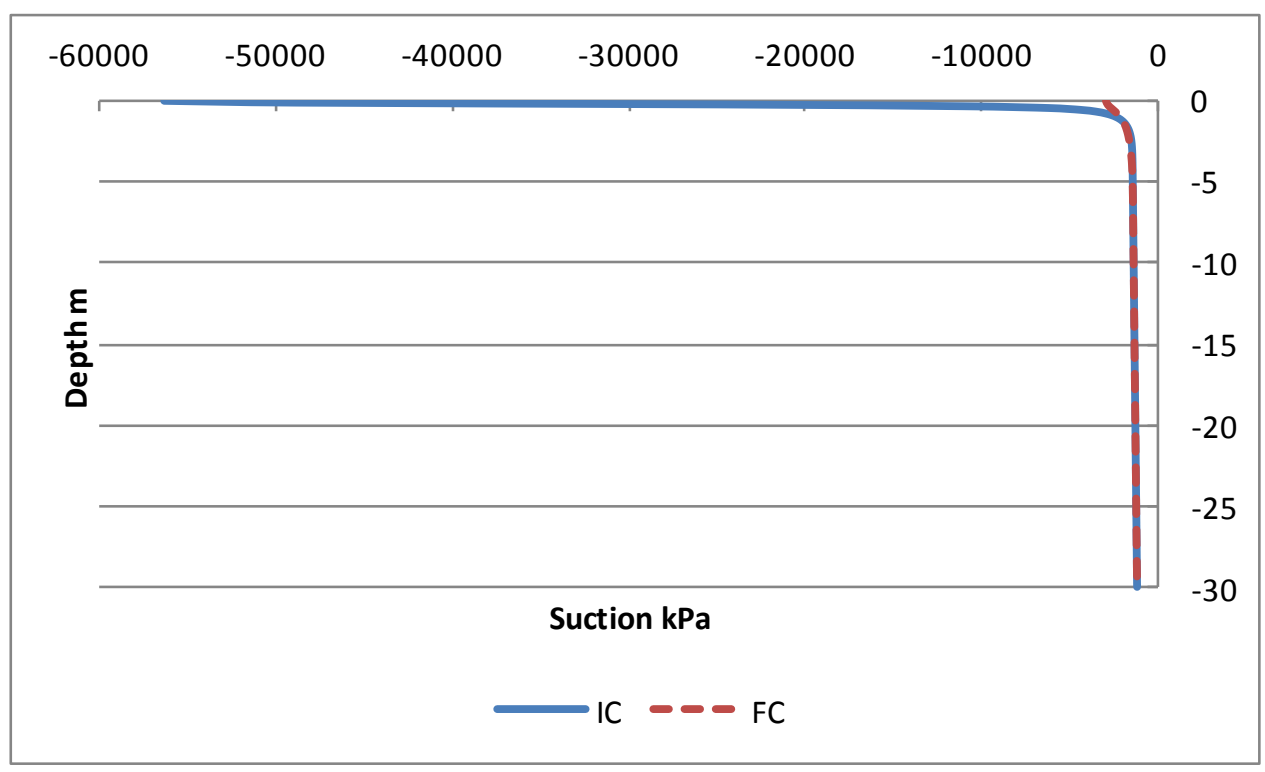

Figure C.3. Vertical suction profile at $8 \mathrm{~m}$

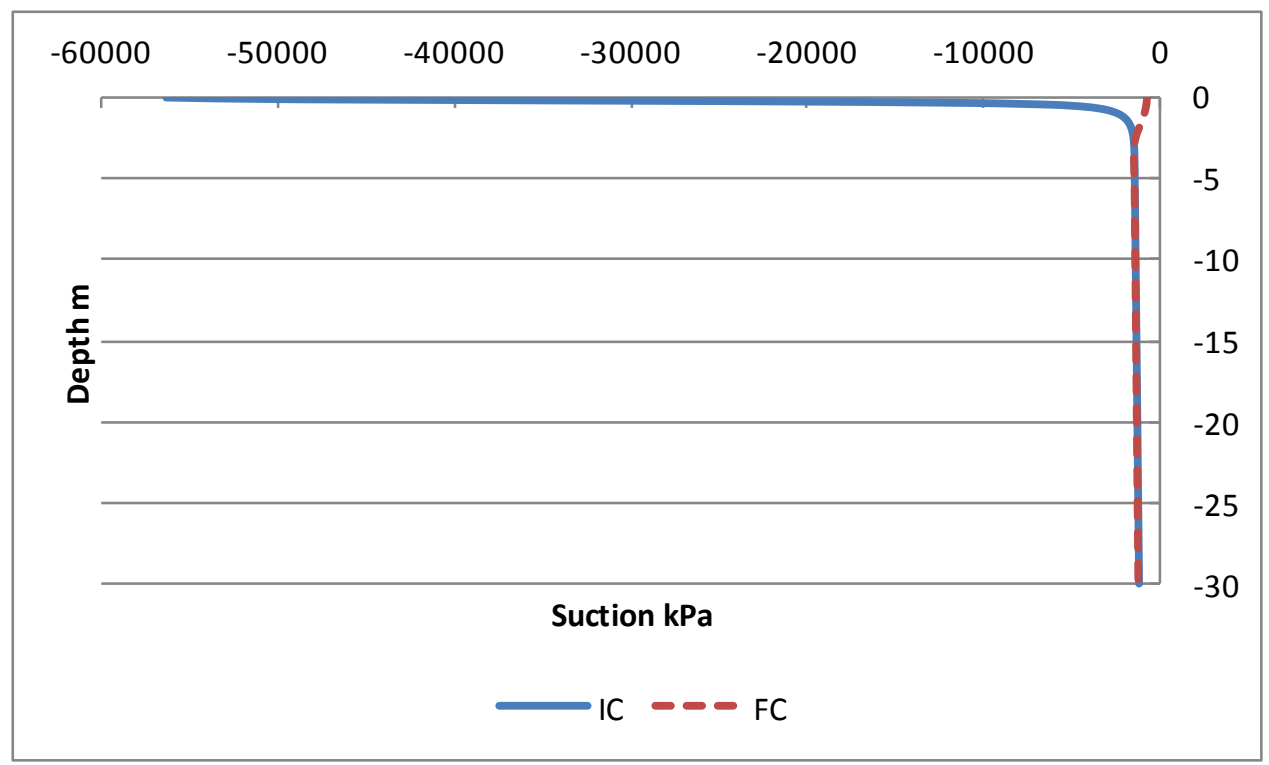

Figure C.4. Vertical suction profile at $9 \mathrm{~m}$ 


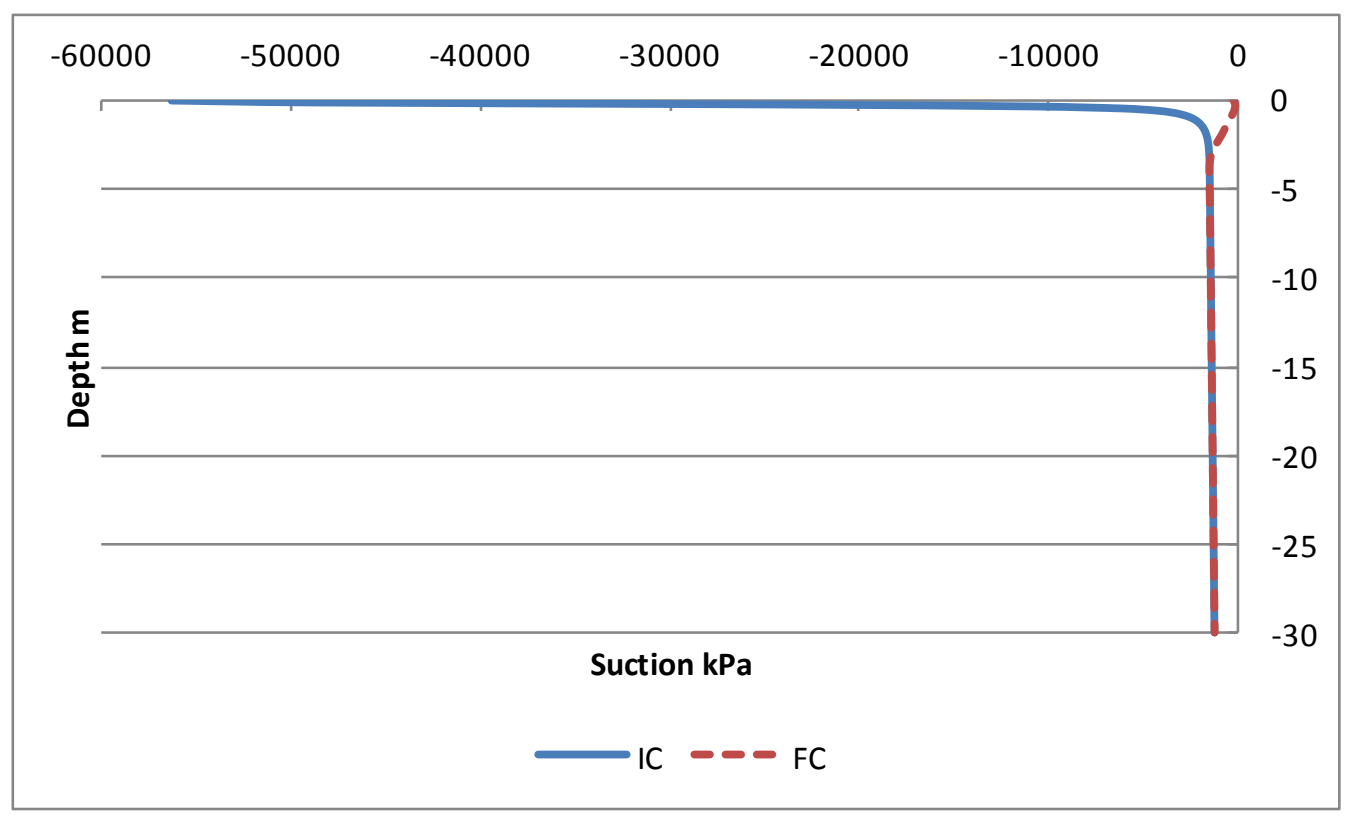

Figure C.5. Vertical suction profile at $10 \mathrm{~m}$

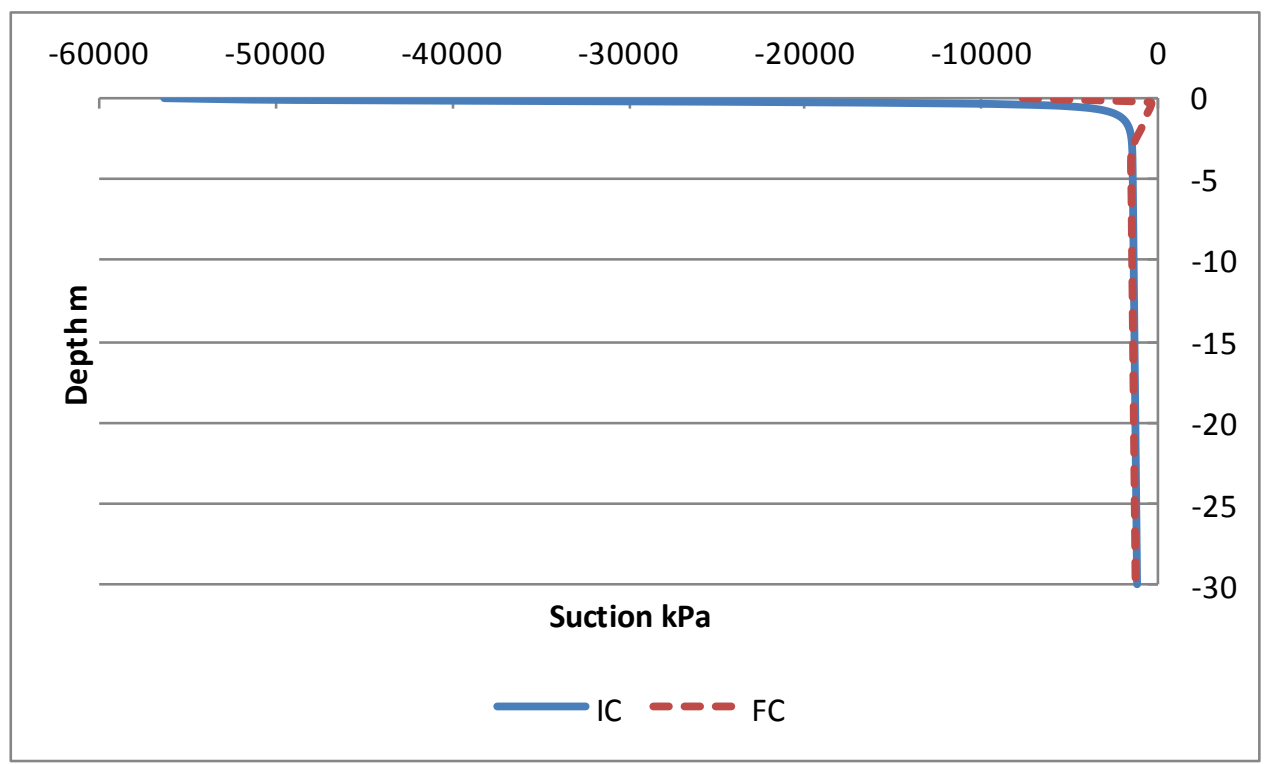

Figure C.6. Vertical suction profile at $11 \mathrm{~m}$ 


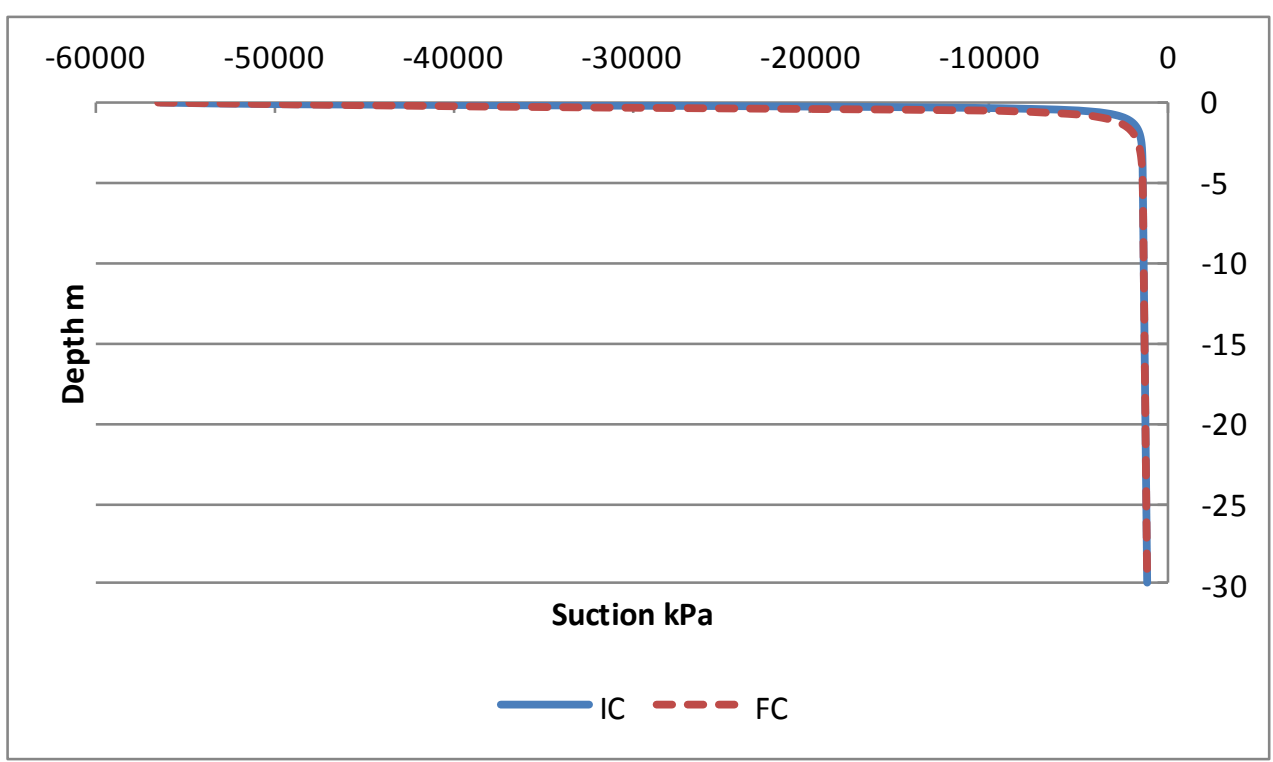

Figure C.7. Vertical suction profile at $19 \mathrm{~m}$

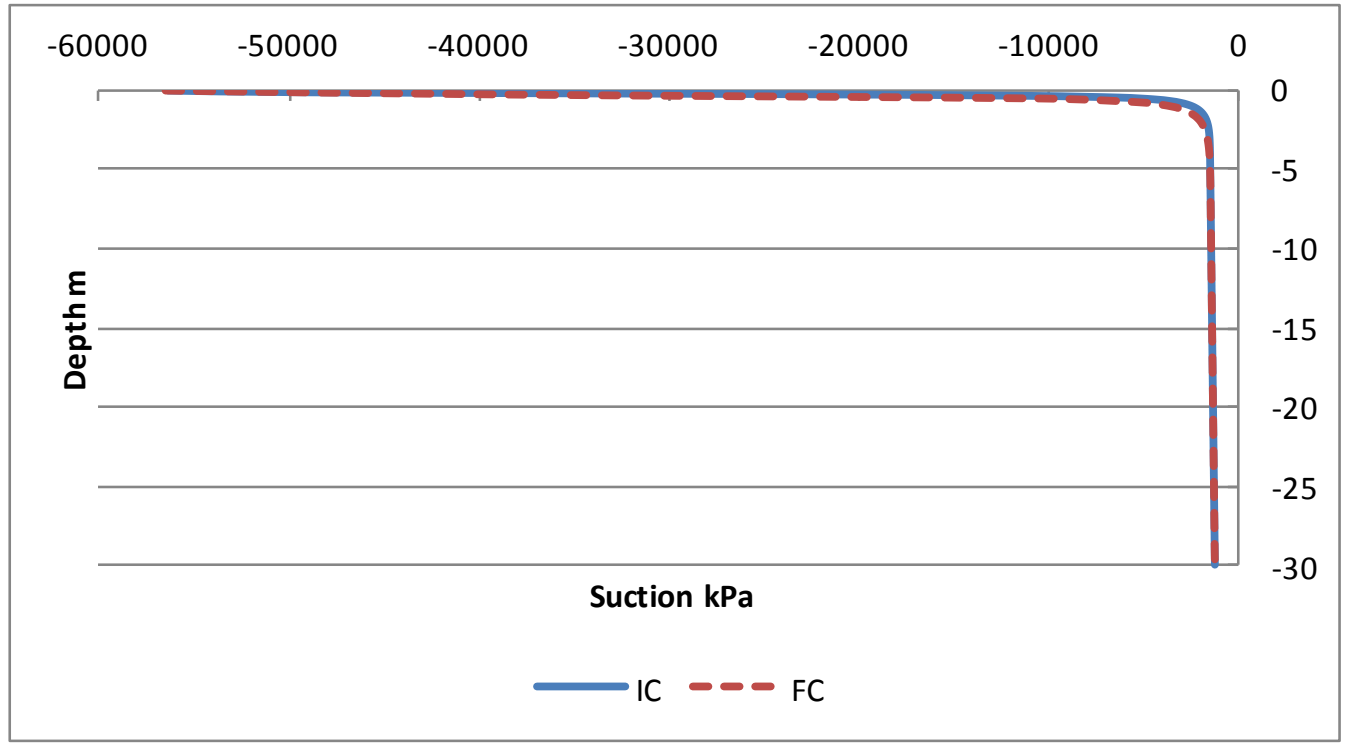

Figure C.8. Vertical suction profile at $27 \mathrm{~m}$ 


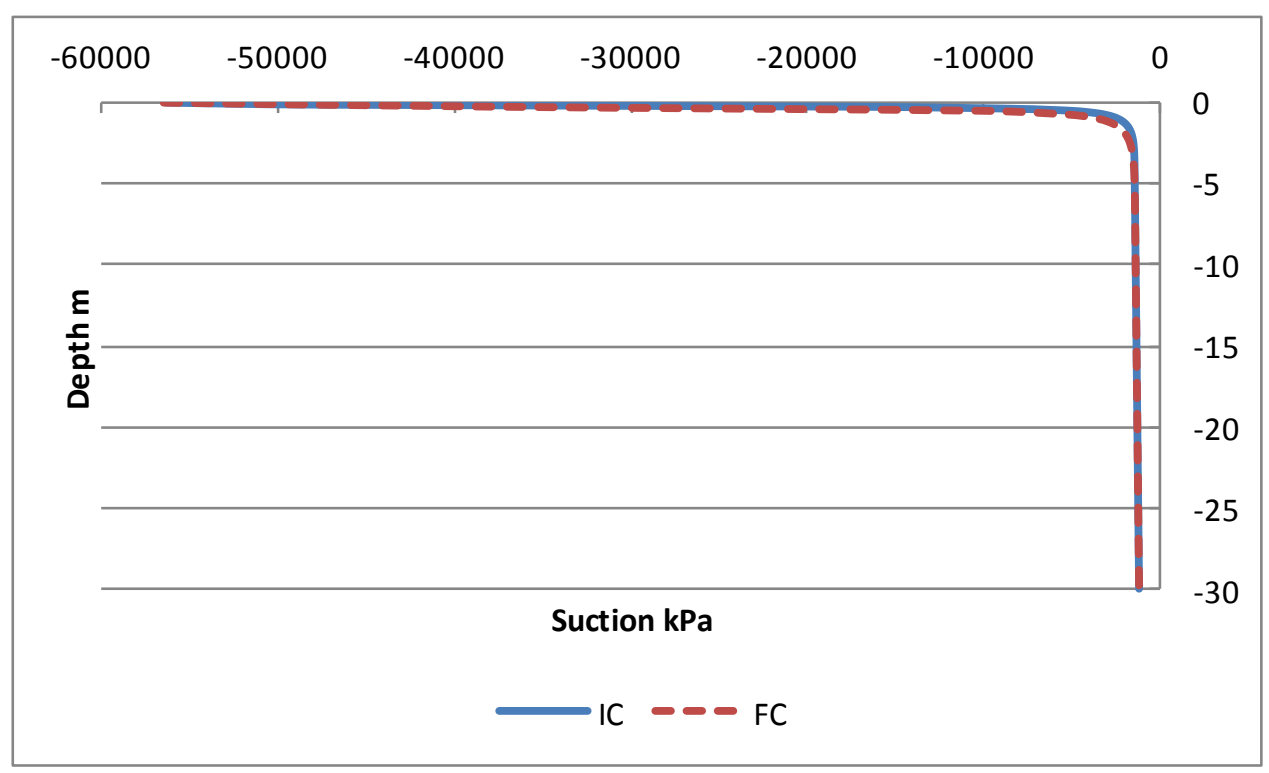

Figure C.9. Vertical suction profile at $35 \mathrm{~m}$

\section{C.1.2 IC and FC Suction Plots for $\mathbf{0 . 5 m}$ Lower $\mathrm{K}_{\text {sat }}$ Replacement Layer Case}

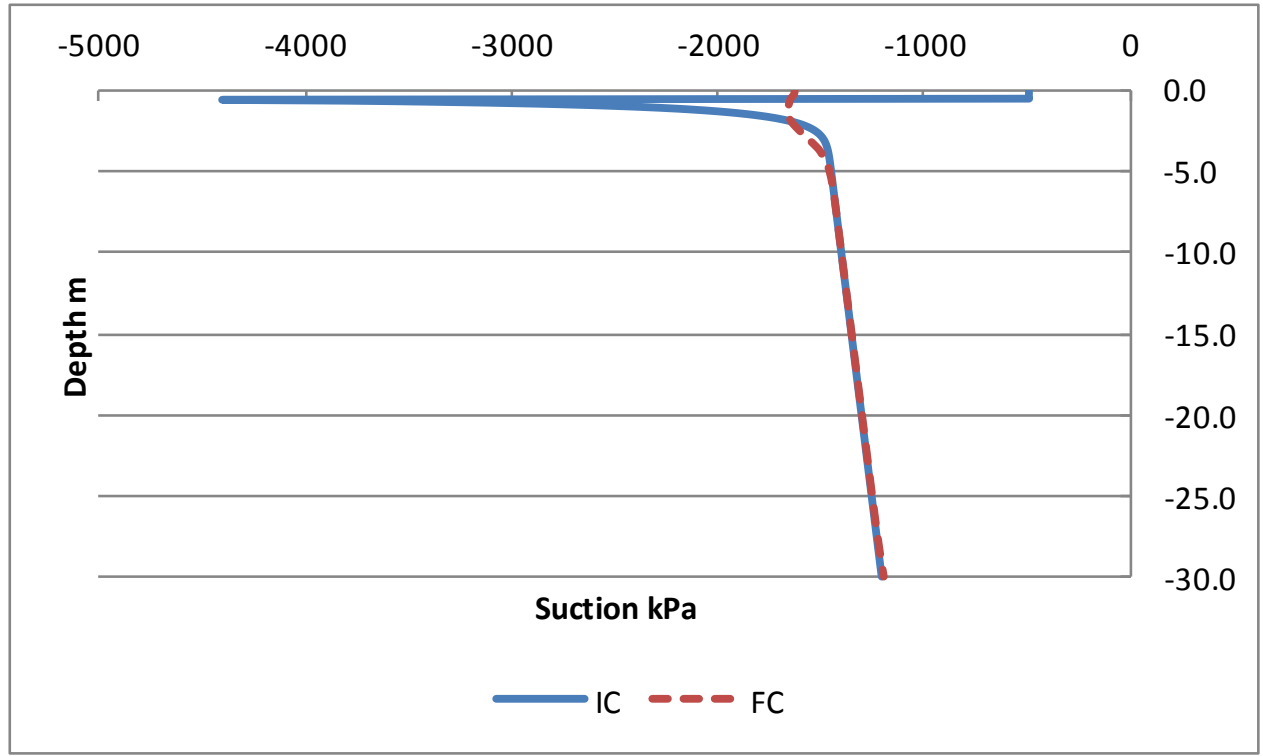

Figure C.10. Vertical suction profile at $0 \mathrm{~m}$ 


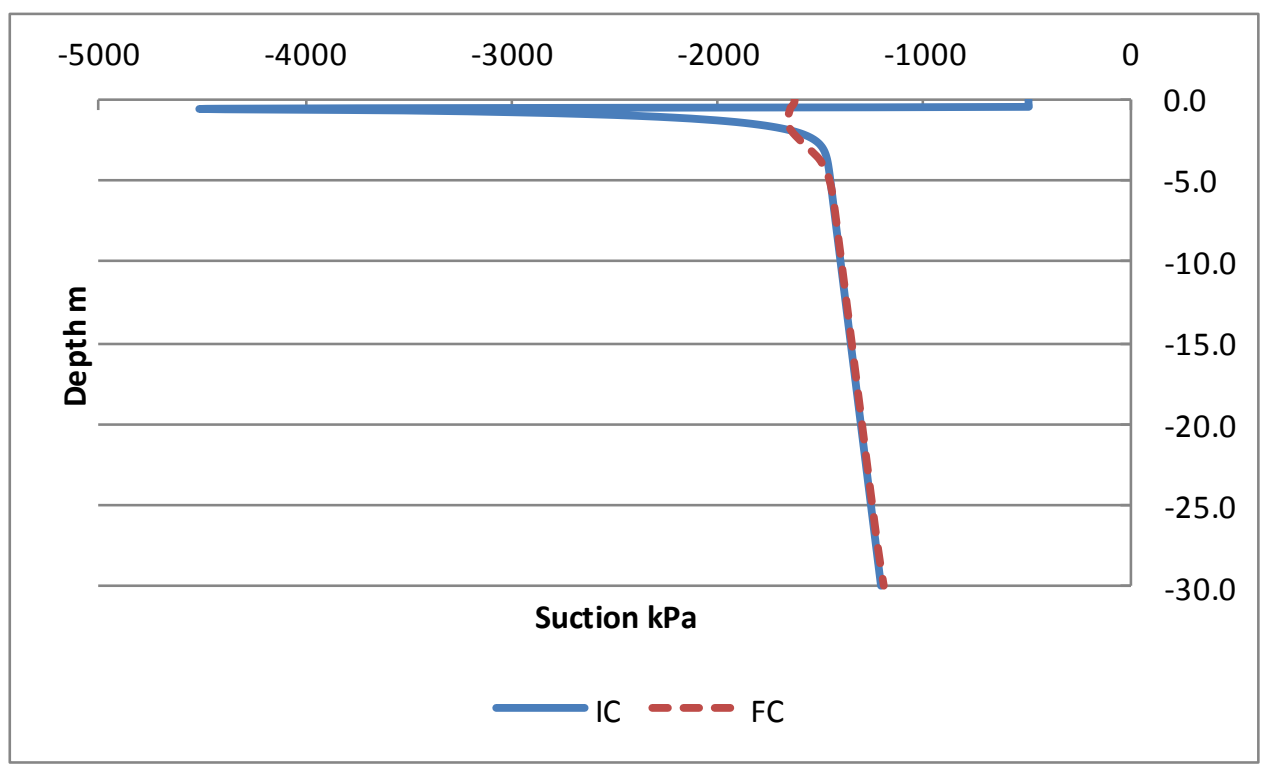

Figure C.11. Vertical suction profile at $5 \mathrm{~m}$

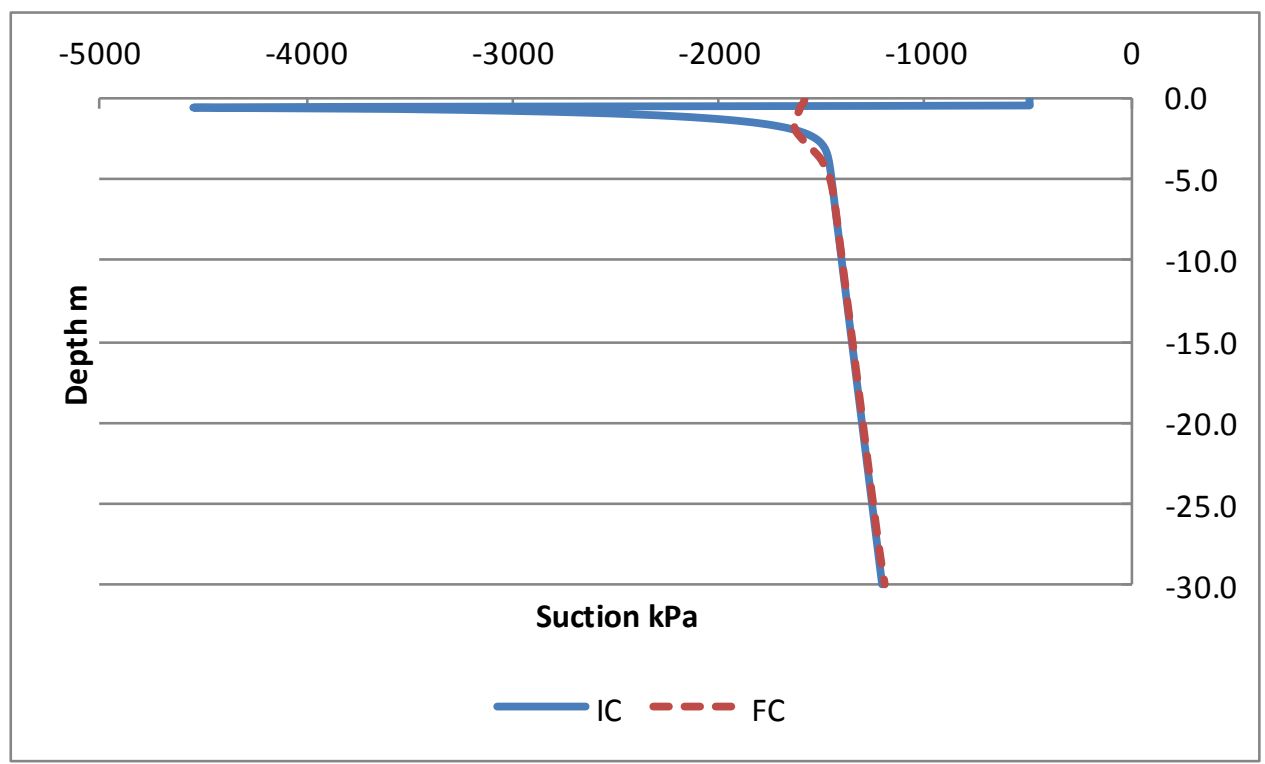

Figure C.12. Vertical suction profile at $8 \mathrm{~m}$ 


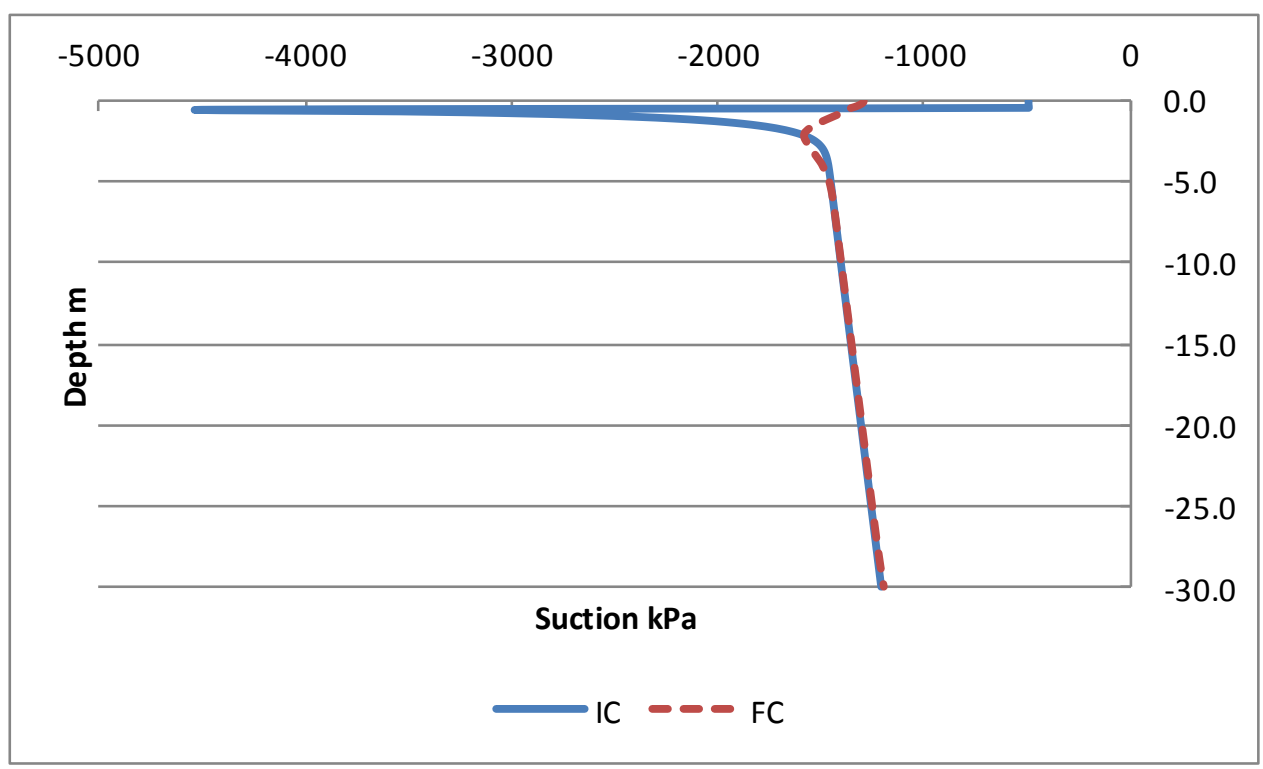

Figure C.13. Vertical suction profile at $9 \mathrm{~m}$

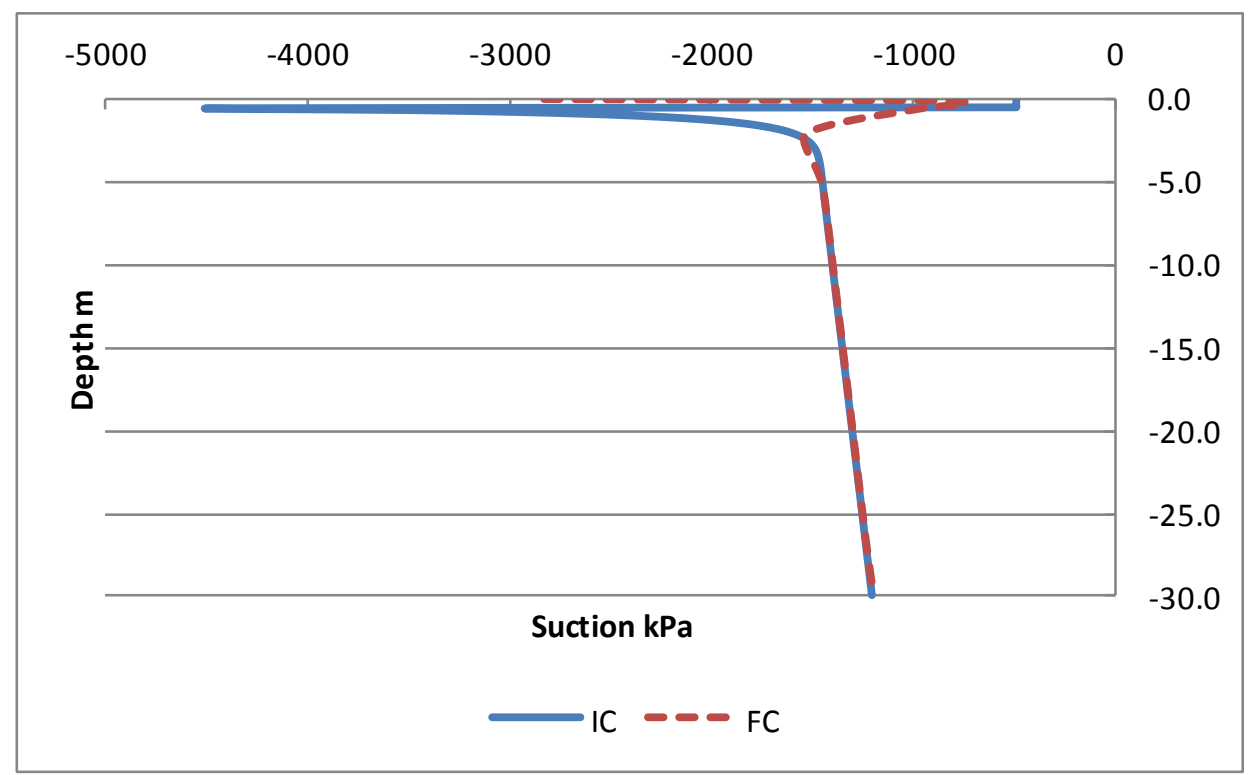

Figure C.14. Vertical suction profile at $10 \mathrm{~m}$ 


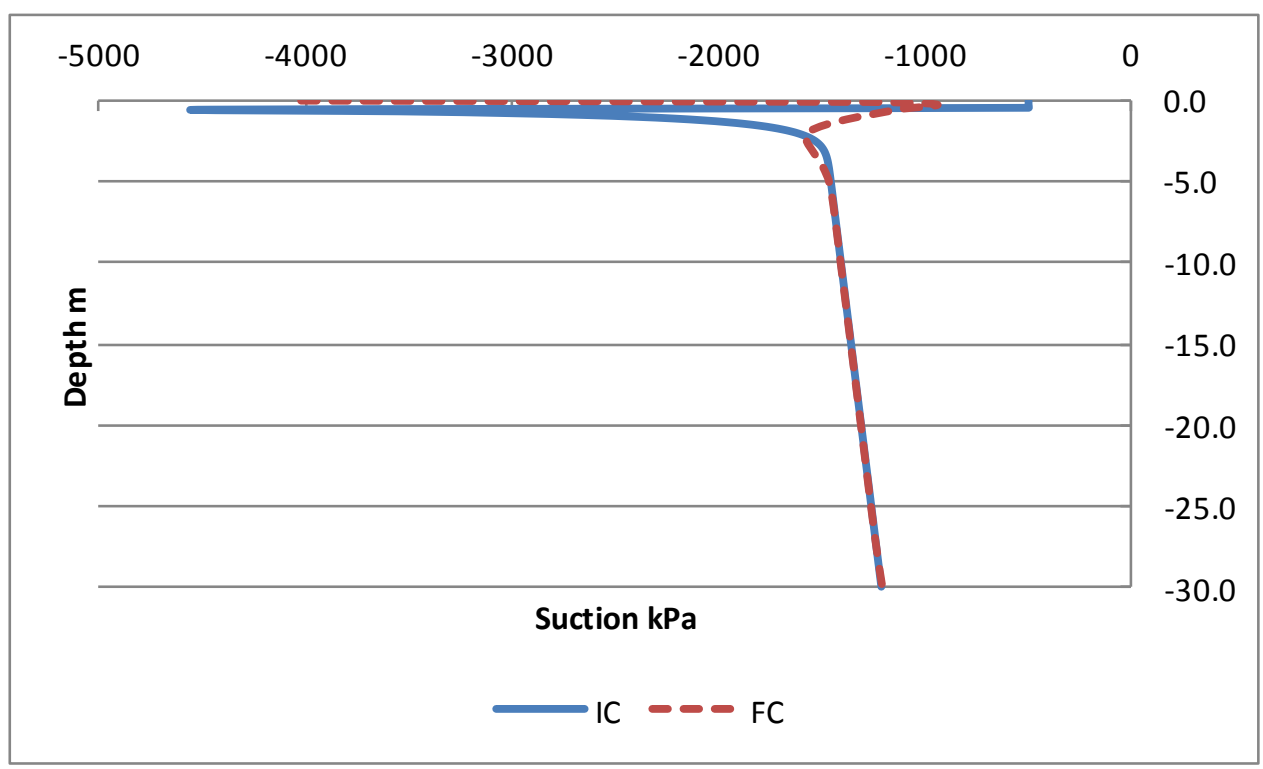

Figure C.15. Vertical suction profile at $11 \mathrm{~m}$

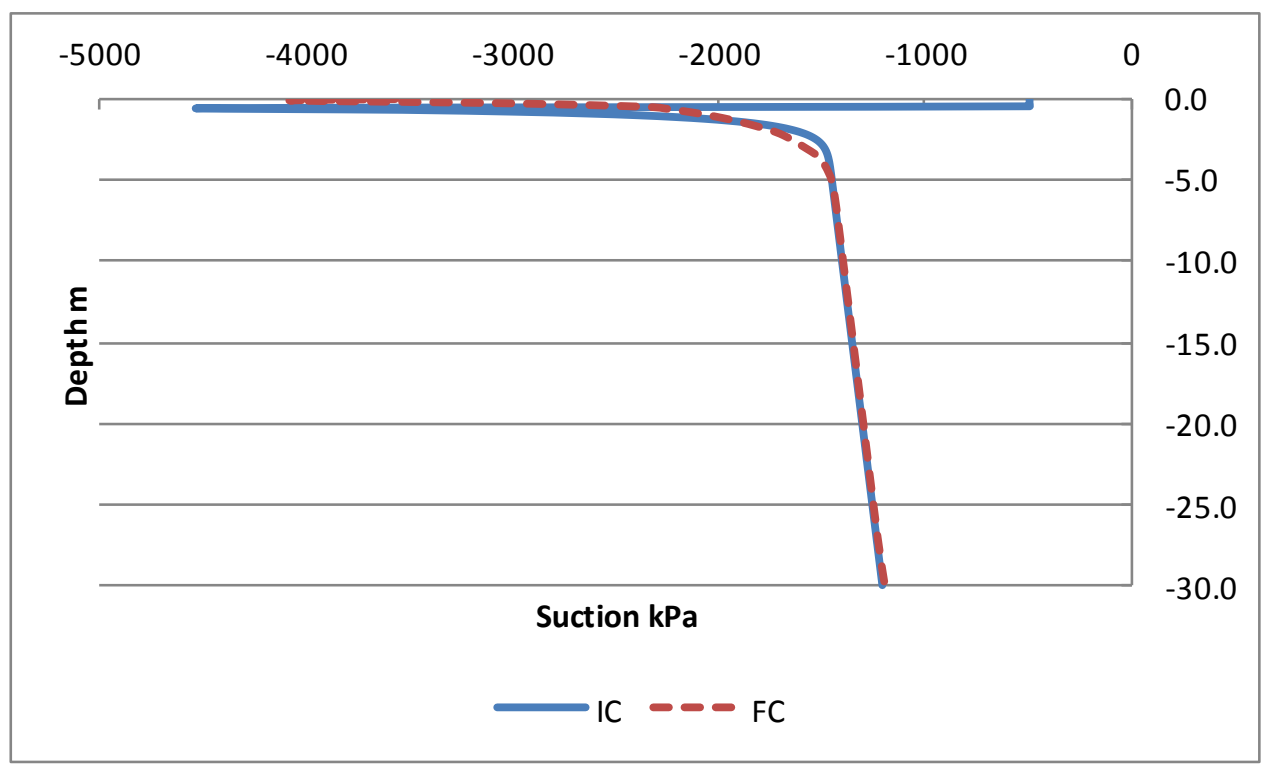

Figure C.16. Vertical suction profile at $19 \mathrm{~m}$ 


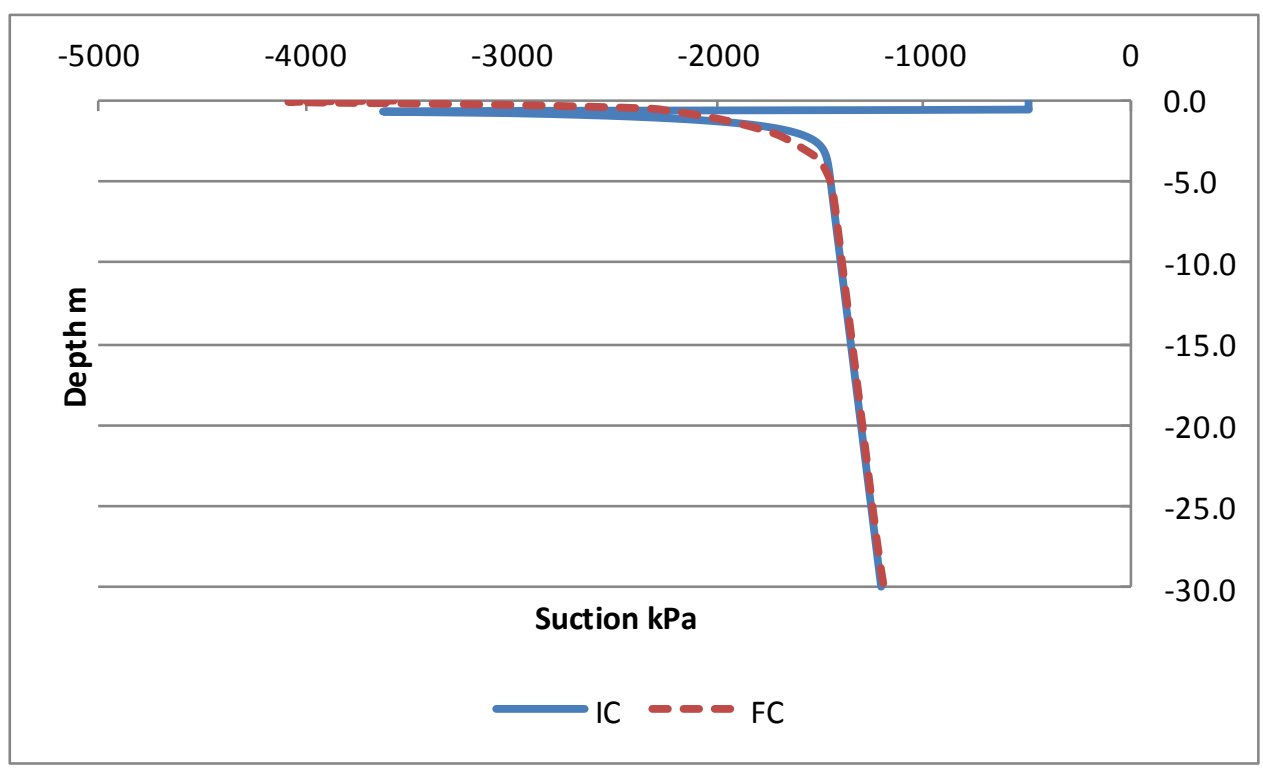

Figure C.17. Vertical suction profile at $27 \mathrm{~m}$

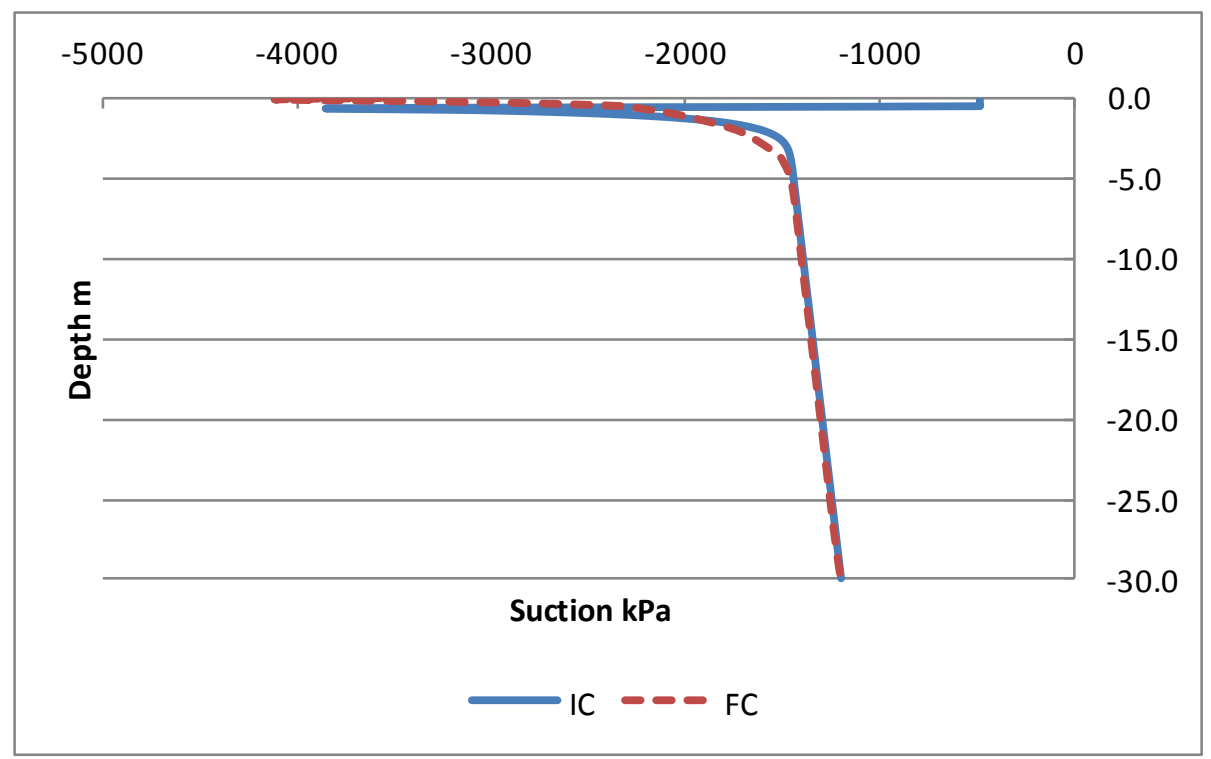

Figure C.18. Vertical suction profile at $35 \mathrm{~m}$ 


\section{C.1.3 IC and FC Suction Plots for 0.75m Same $K_{\text {sat }}$ Replacement Case}

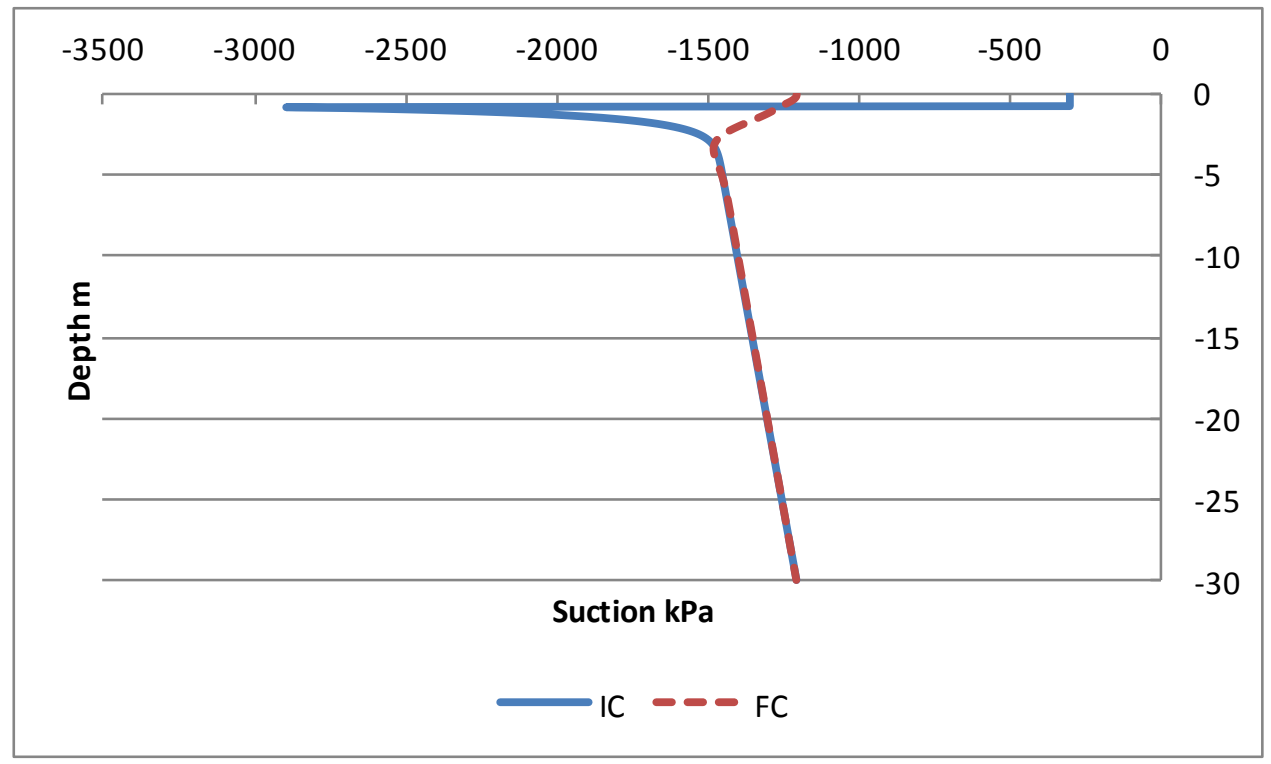

Figure C.19. Vertical suction profile at $0 \mathrm{~m}$ section

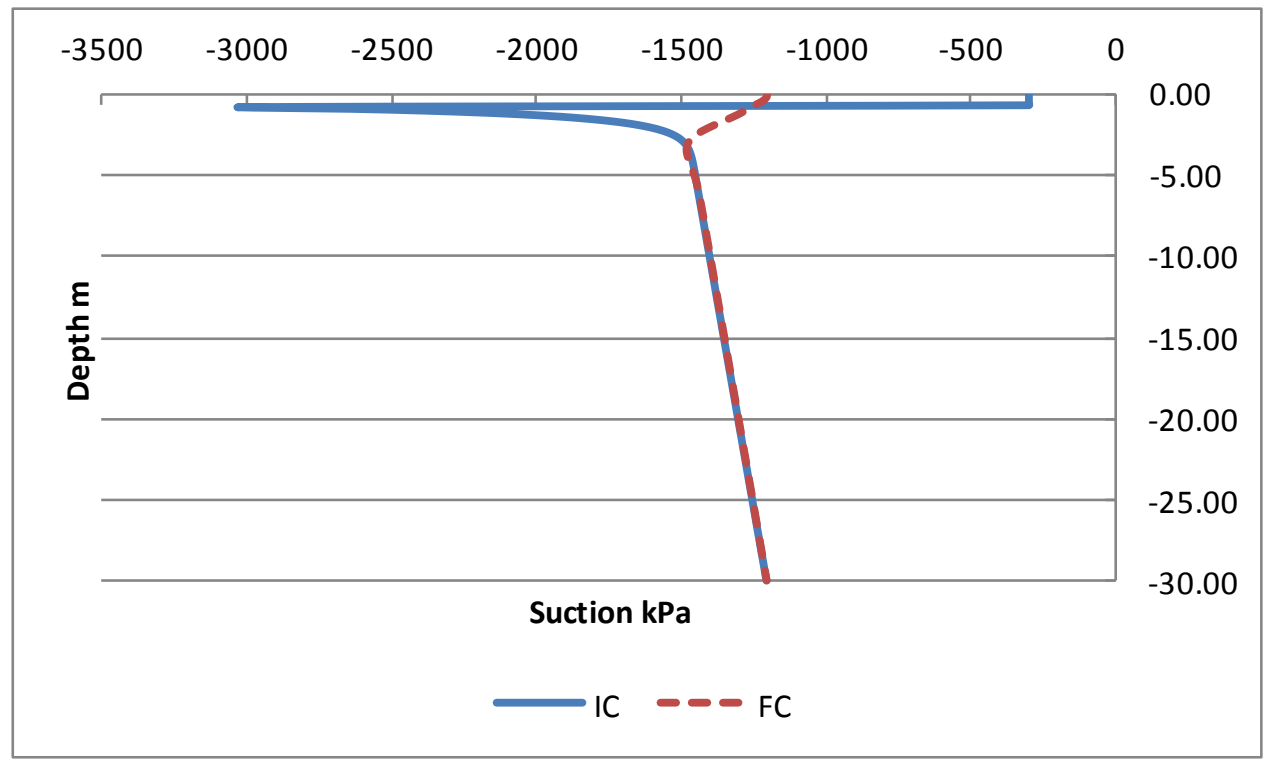

Figure C.20. Vertical suction profile at $5 \mathrm{~m}$ section 


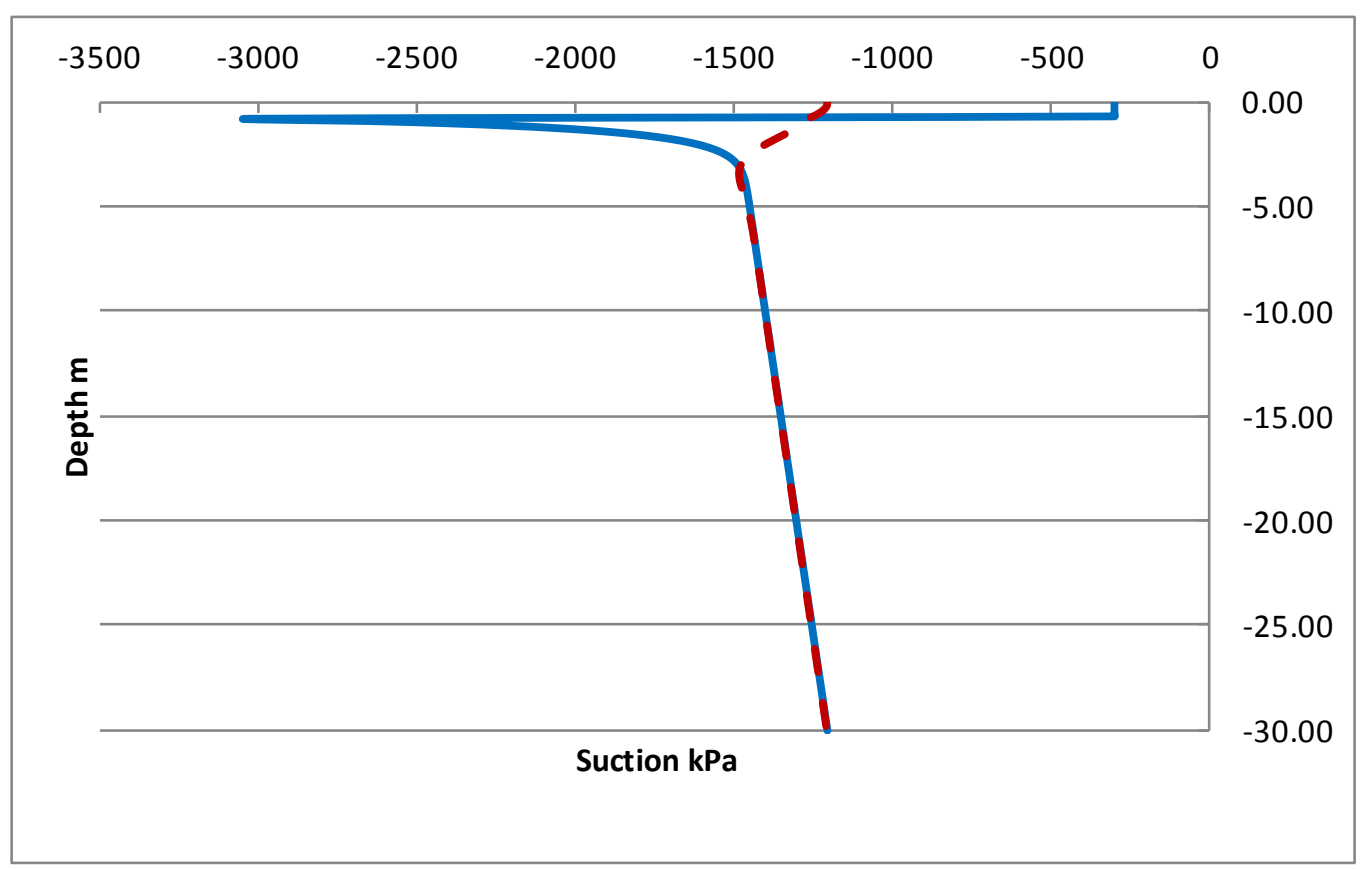

Figure C.21. Vertical suction profile at $8 \mathrm{~m}$ section

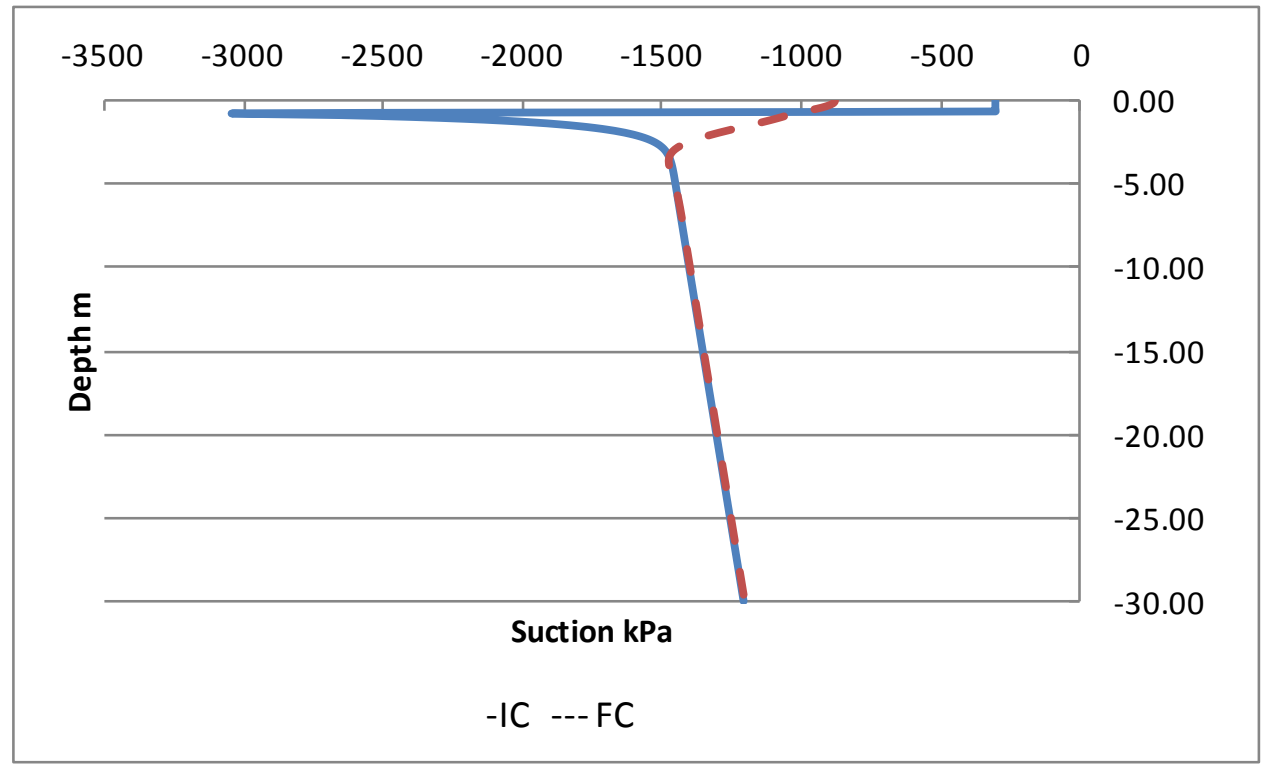

Figure C.22. Vertical suction profile at $9 \mathrm{~m}$ section 


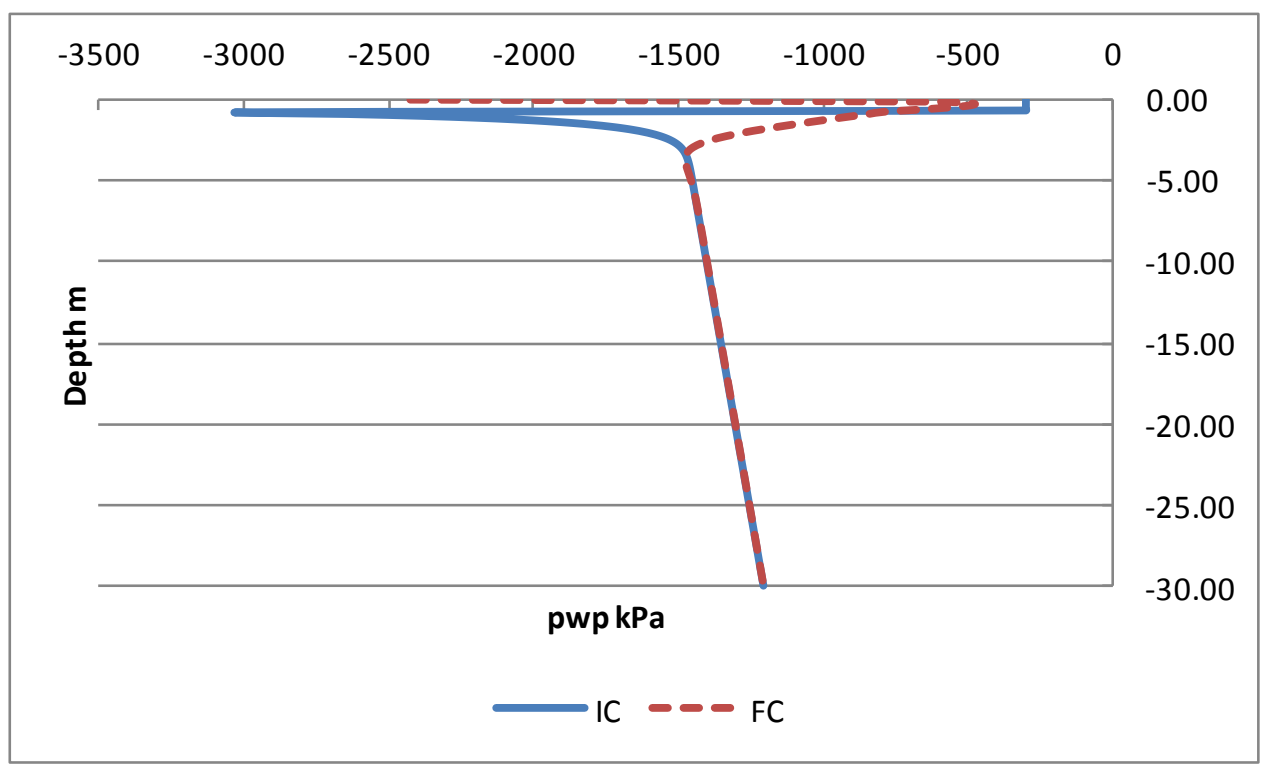

Figure C.23. Vertical suction profile at $10 \mathrm{~m}$ section

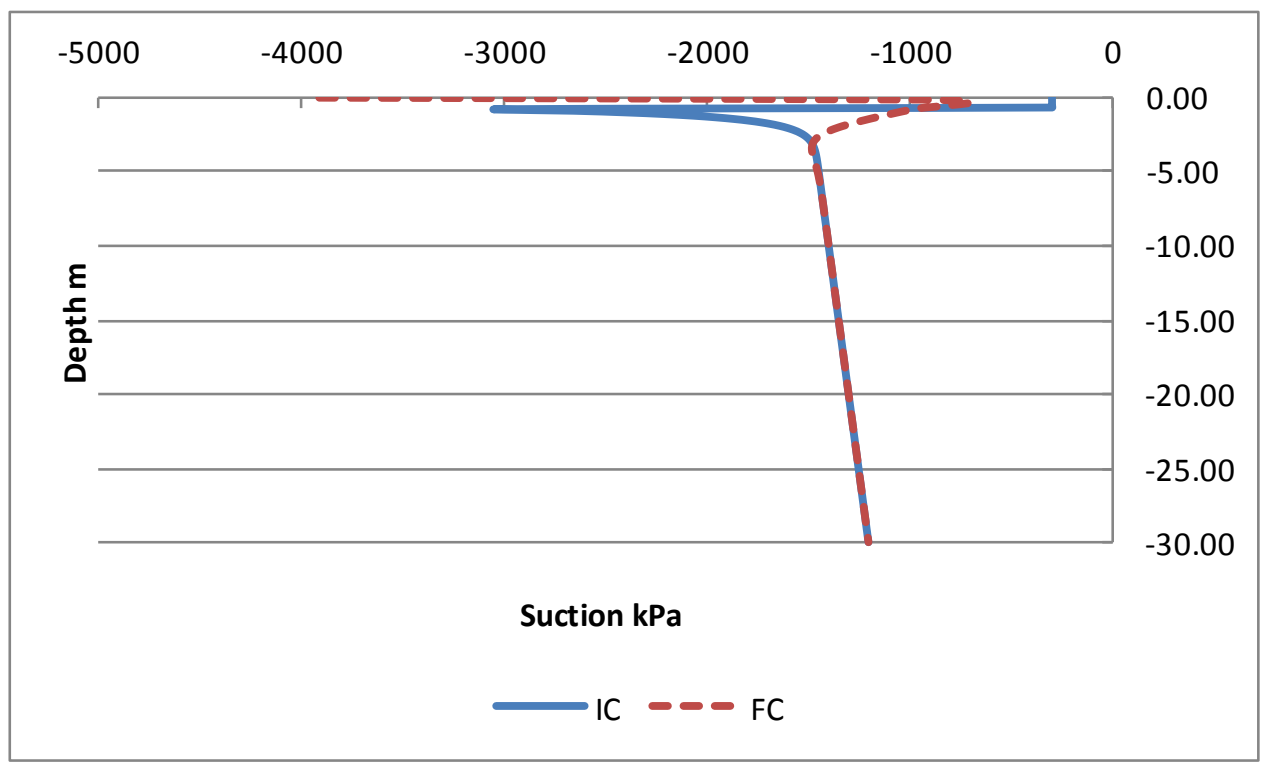

Figure C.24. Vertical suction profile at $11 \mathrm{~m}$ section 


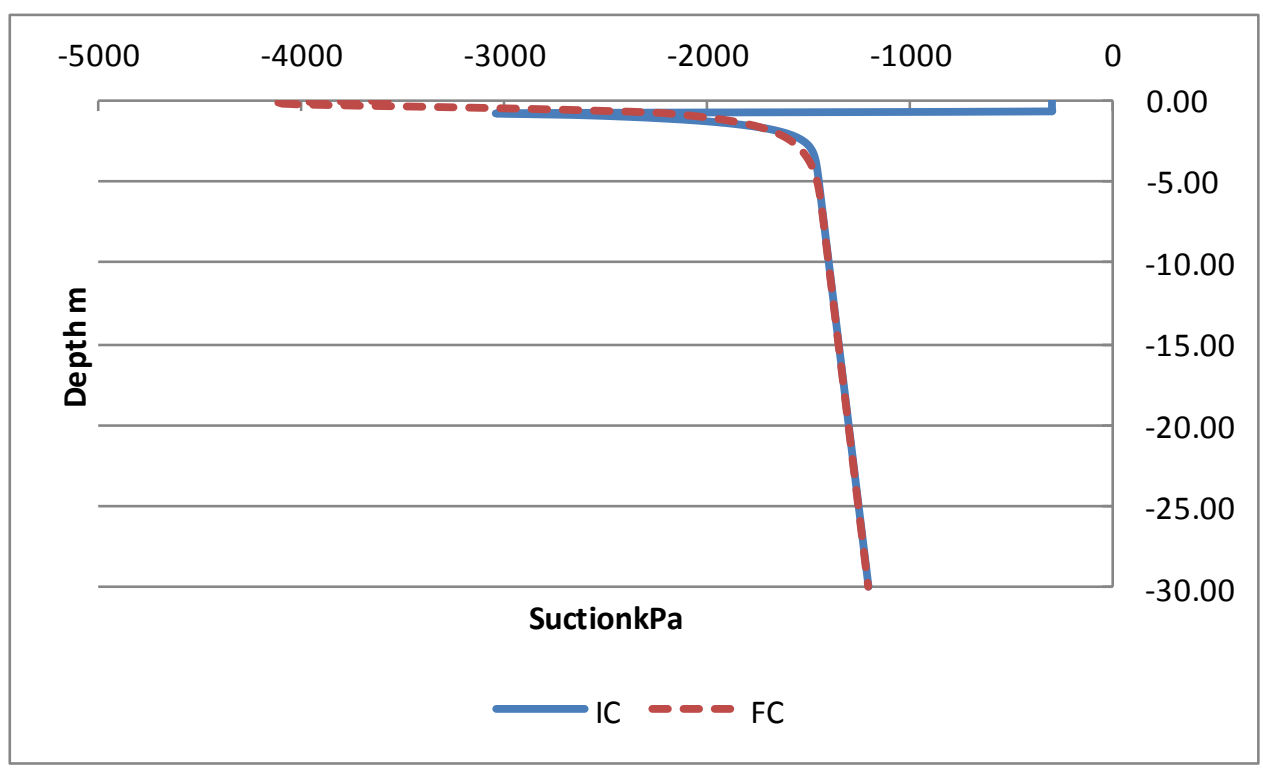

Figure C.25. Vertical suction profile at $19 \mathrm{~m}$ section

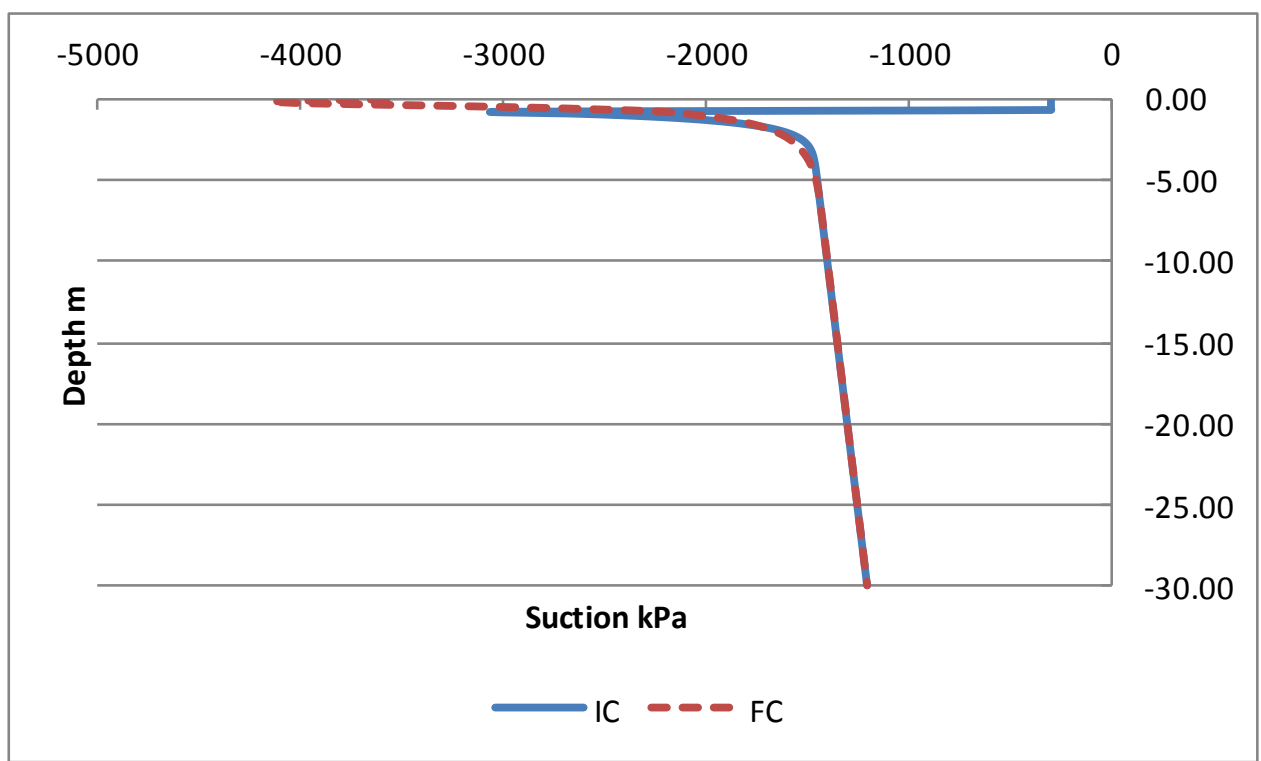

Figure C.26. Vertical suction profile at $27 \mathrm{~m}$ section 


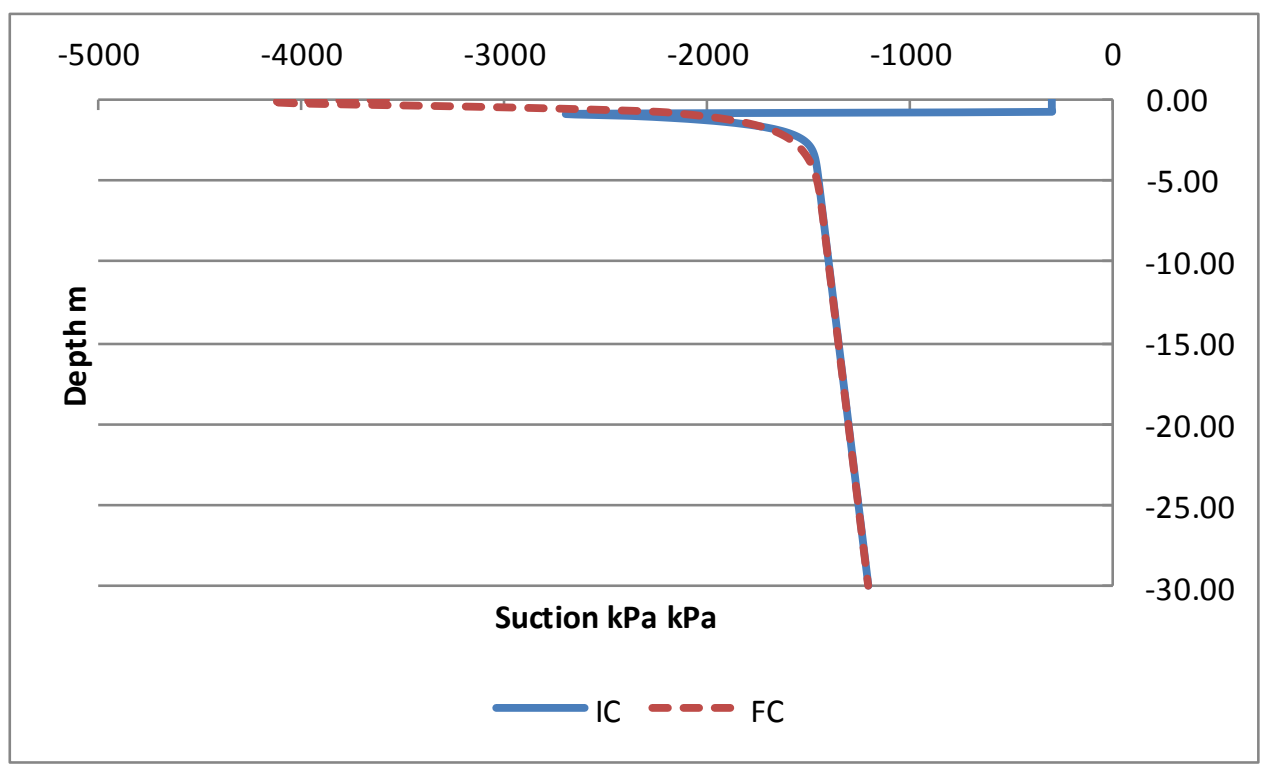

Figure C.27. Vertical suction profile at $35 \mathrm{~m}$ section

\section{C.1.4 IC and FC Suction Plots for $2 \mathrm{~m}$ Same $K_{\text {sat }}$ Replacement Layer Case}

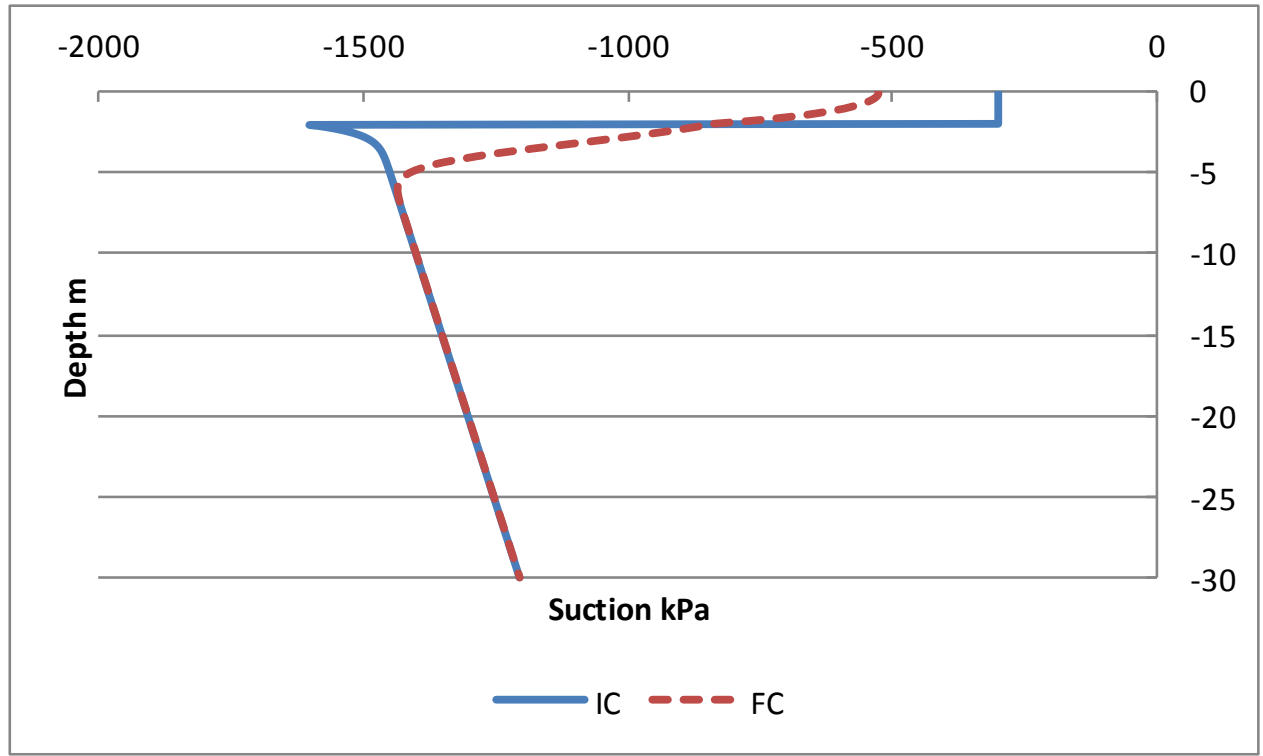

Figure C.28. Vertical suction profile at $0 \mathrm{~m}$ 


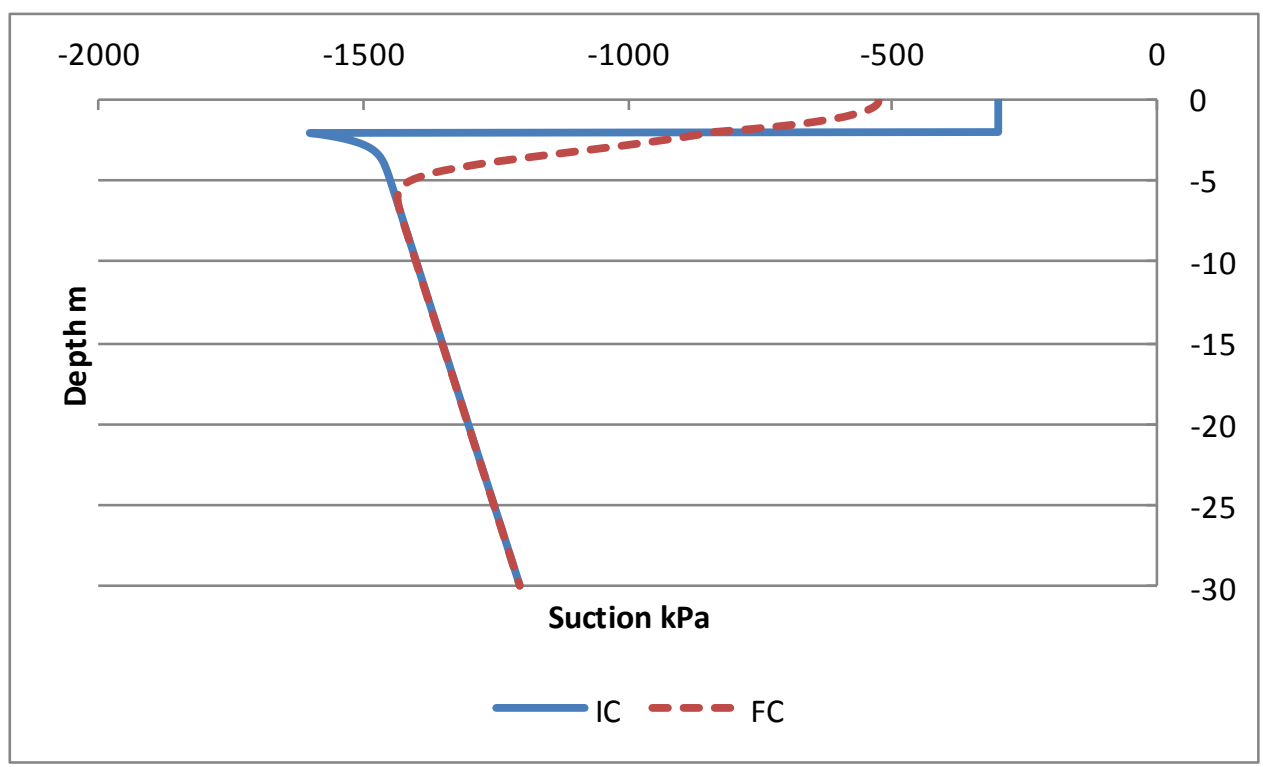

Figure C.29. Vertical suction profile at $5 \mathrm{~m}$

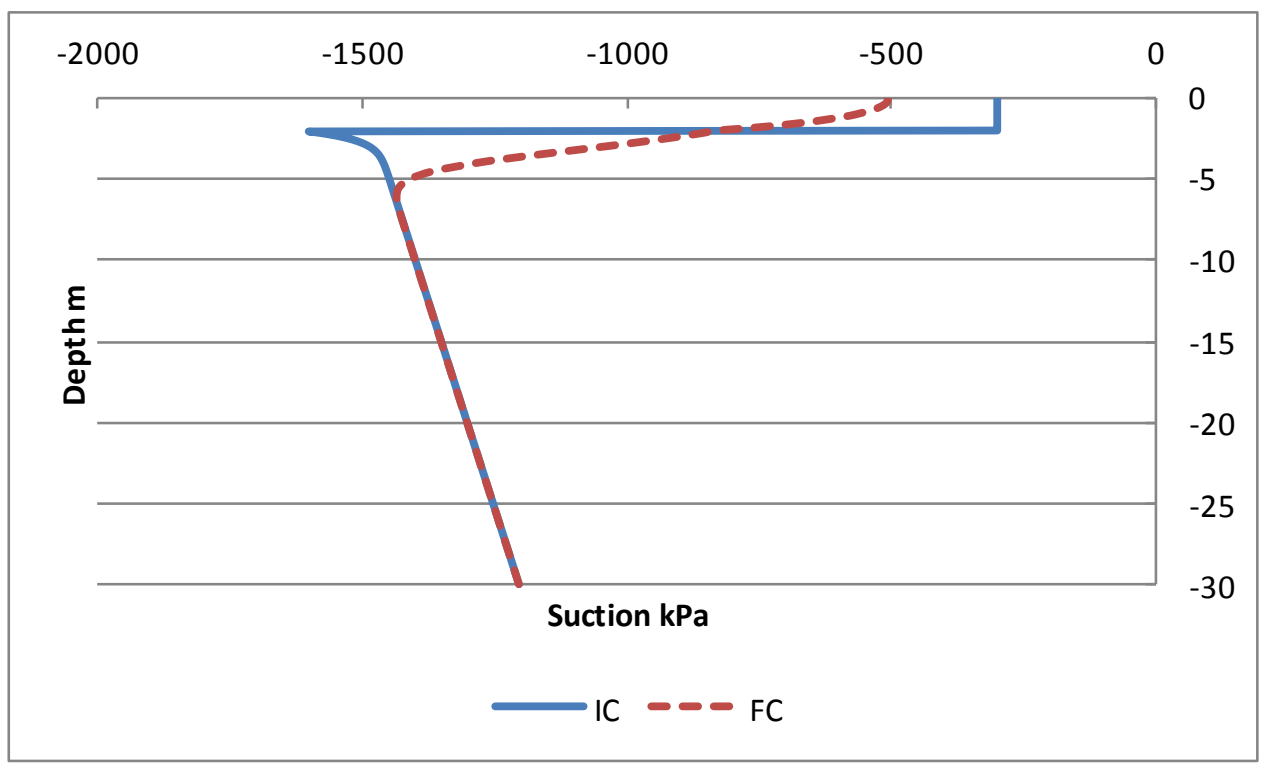

Figure C.30. Vertical suction profile at $8 \mathrm{~m}$ 


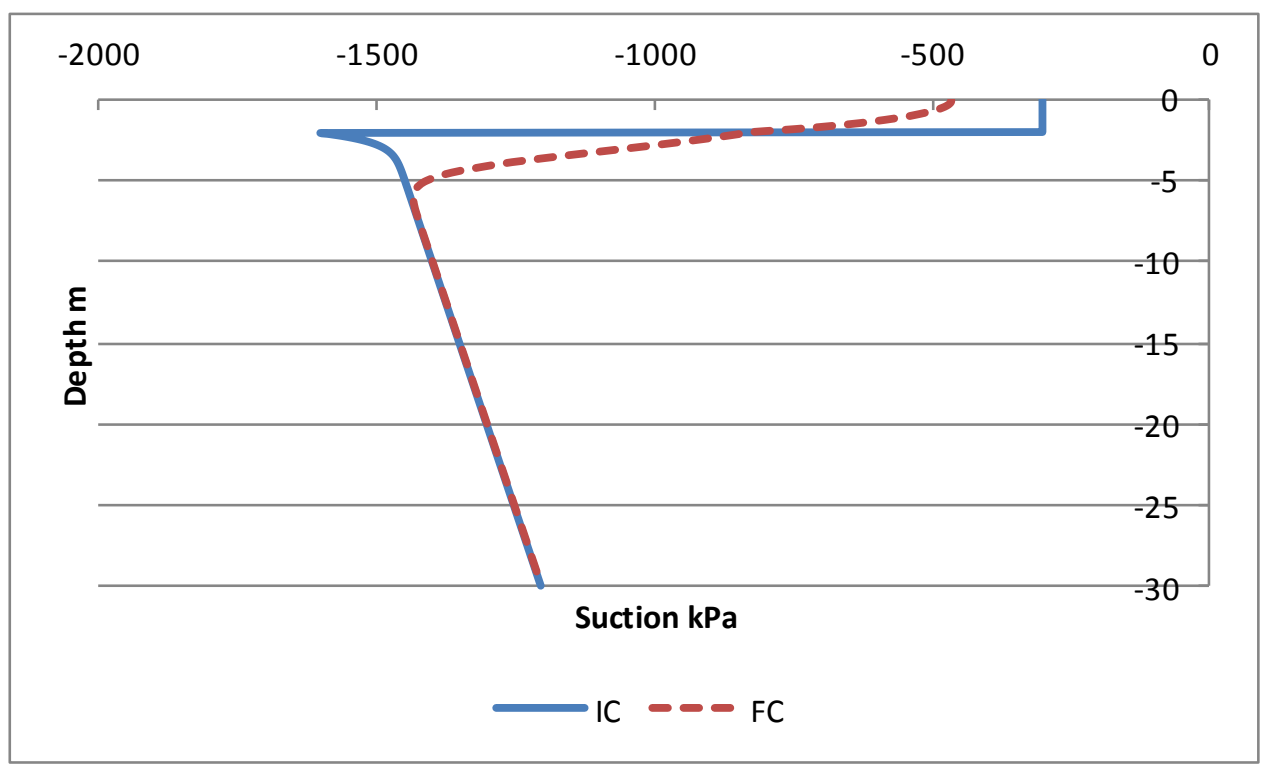

Figure C.31. Vertical suction profile at $9 \mathrm{~m}$

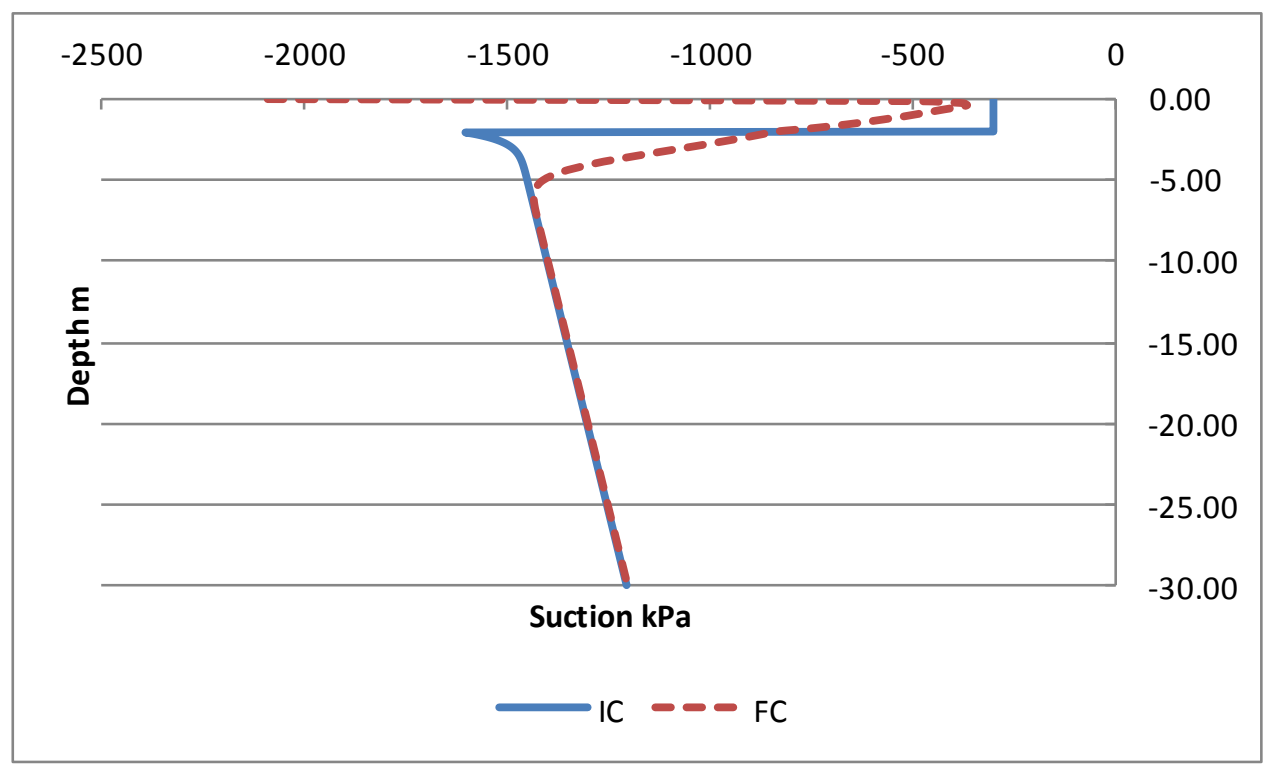

Figure C.32. Vertical suction profile at $10 \mathrm{~m}$ 


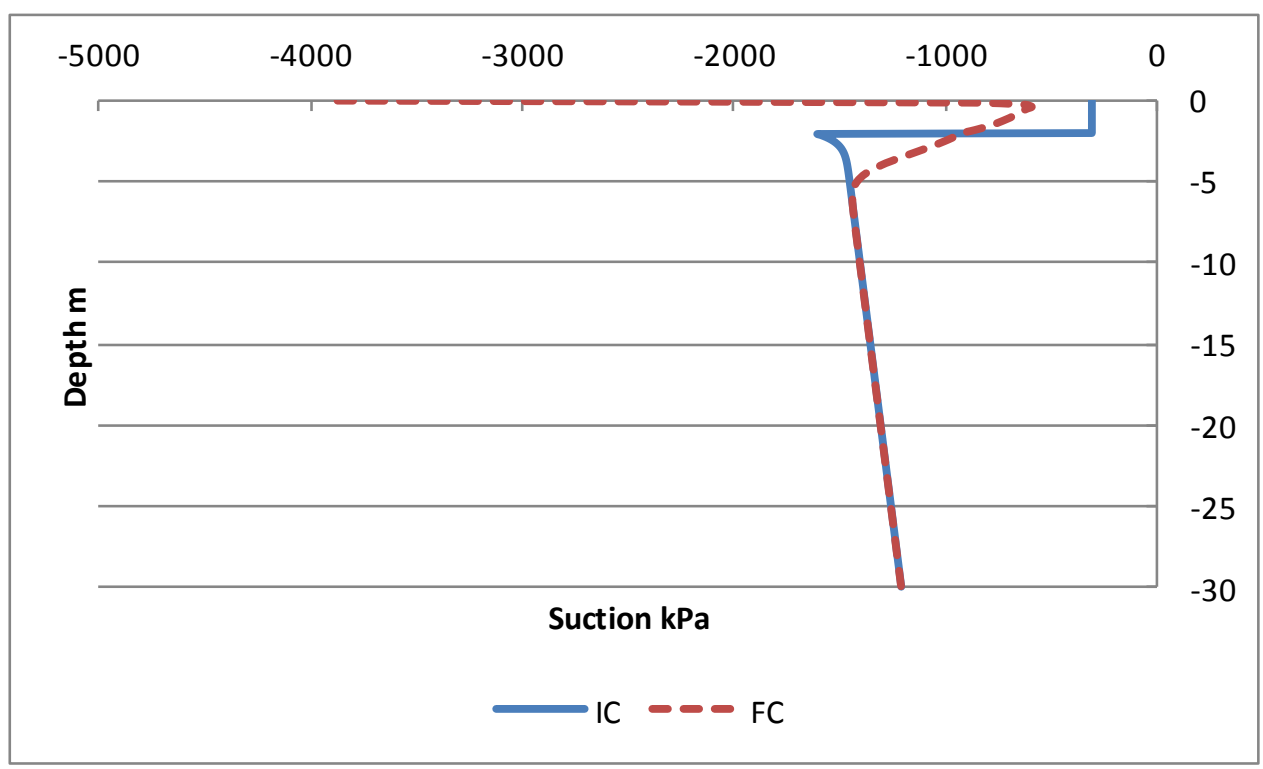

Figure C.33. Vertical suction profile at $11 \mathrm{~m}$

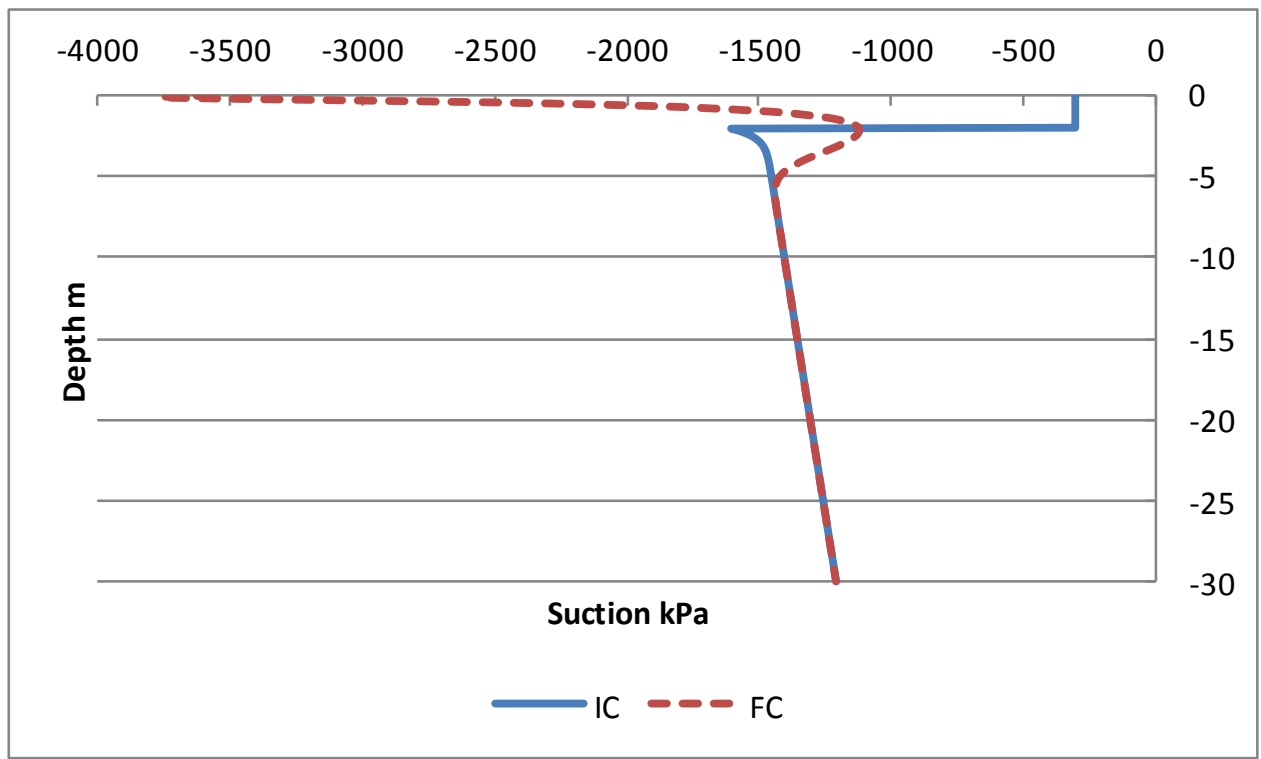

Figure C.34. Vertical suction profile at $19 \mathrm{~m}$ 


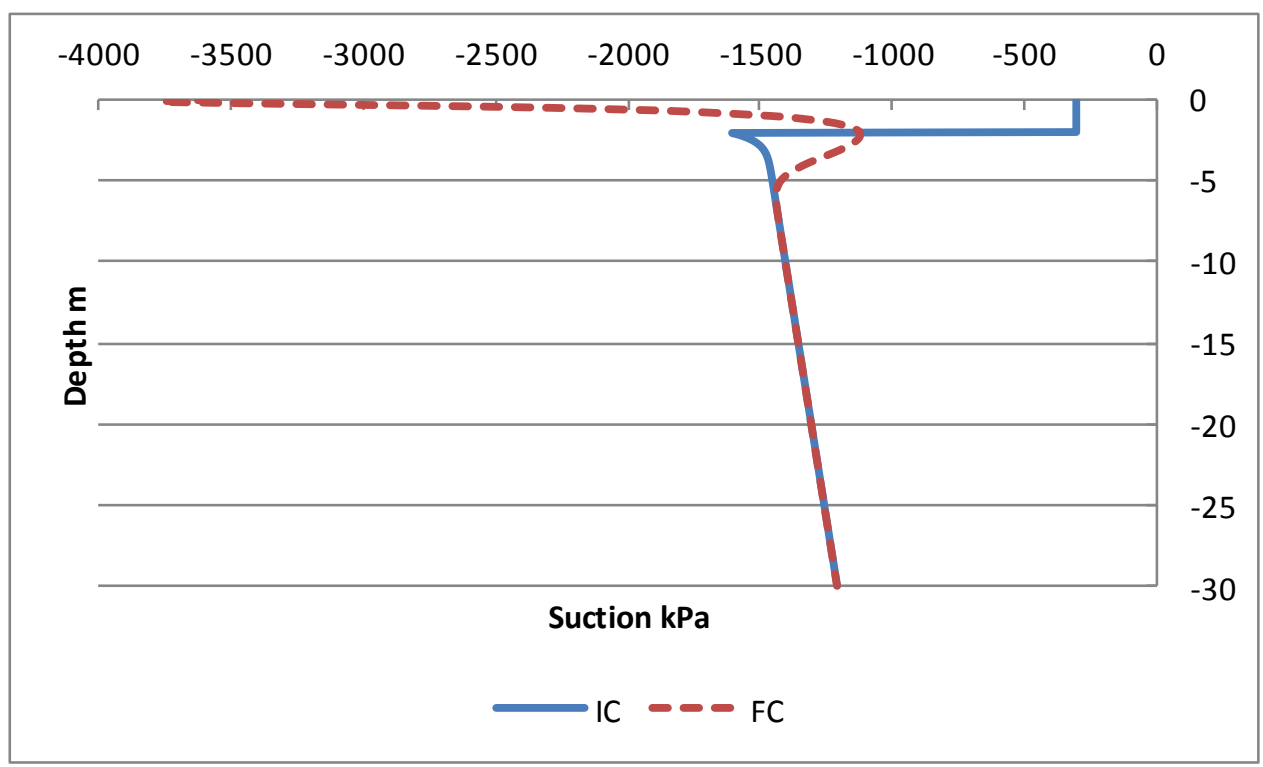

Figure C.35. Vertical suction profile at $27 \mathrm{~m}$

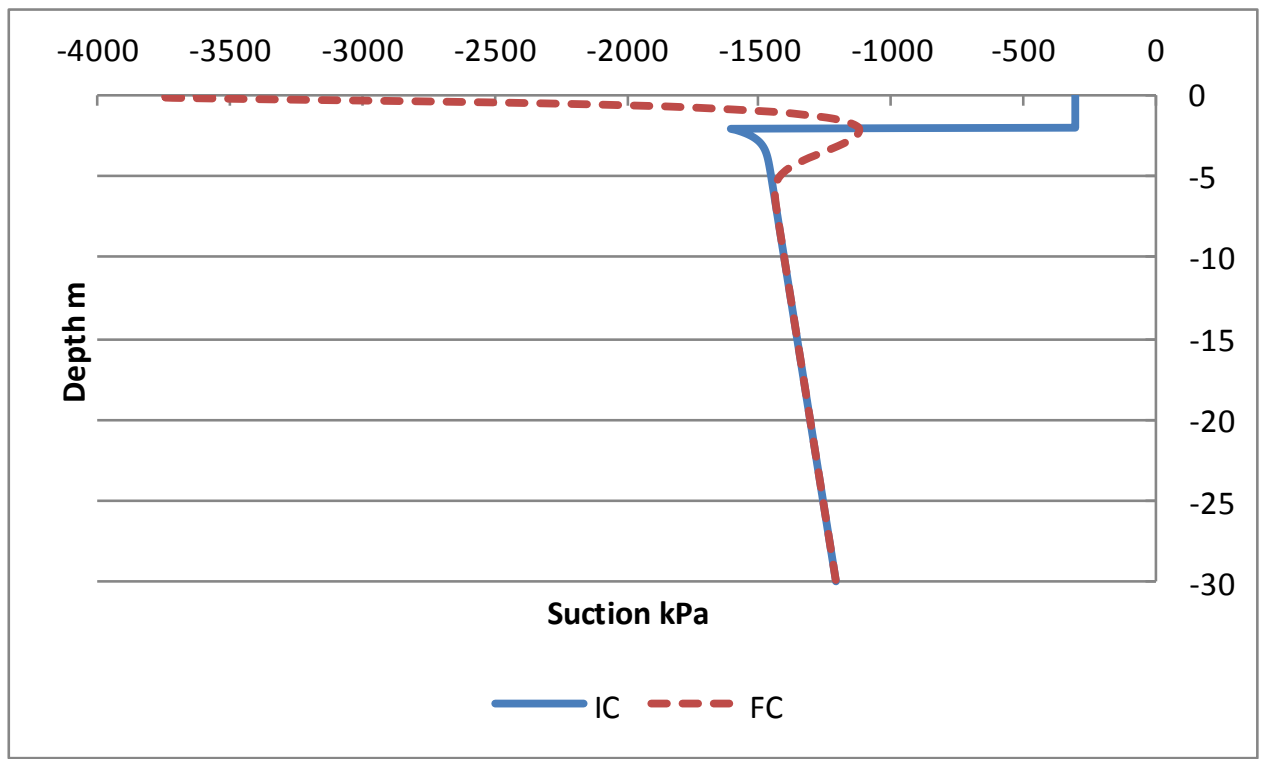

Figure C.36. Vertical suction profile at $35 \mathrm{~m}$ 


\section{C.1.5 IC and FC Suction Plots for $4 \mathrm{~m}$ Same $K_{\text {sat }}$ Replacement Layer Case}

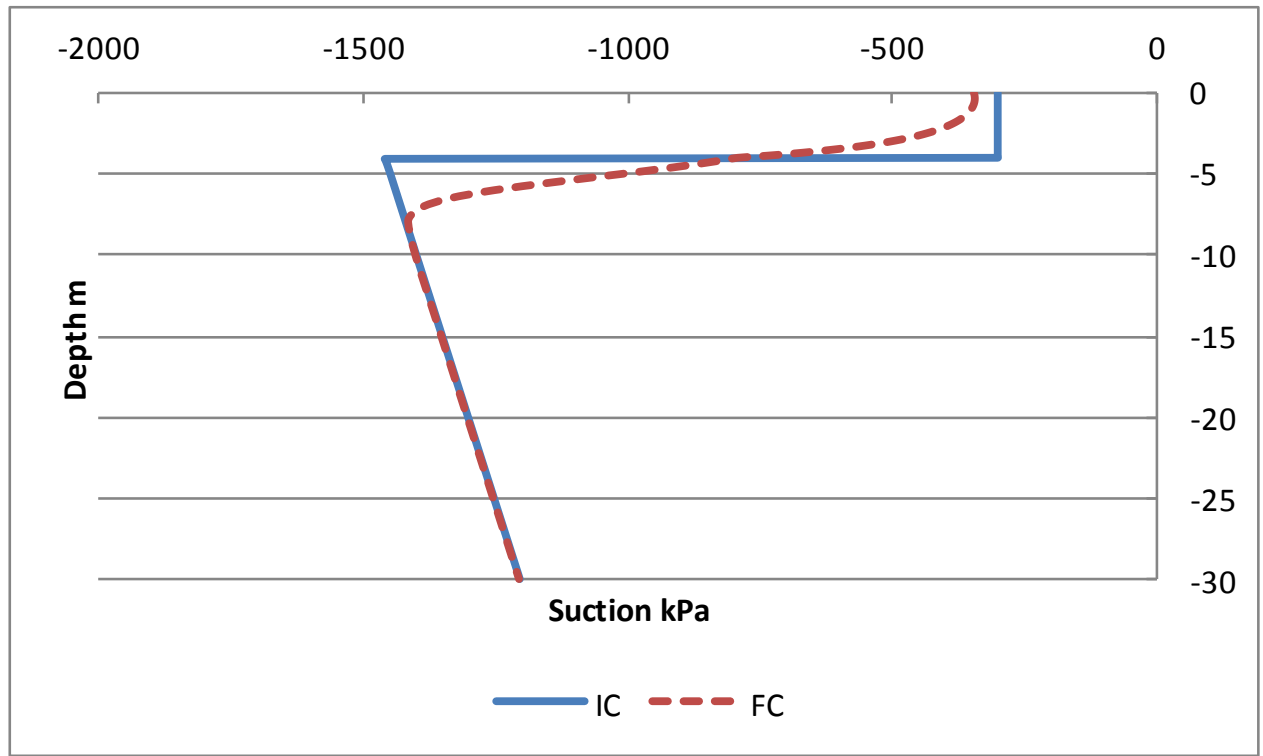

Figure C.37. Vertical suction profile at $0 \mathrm{~m}$

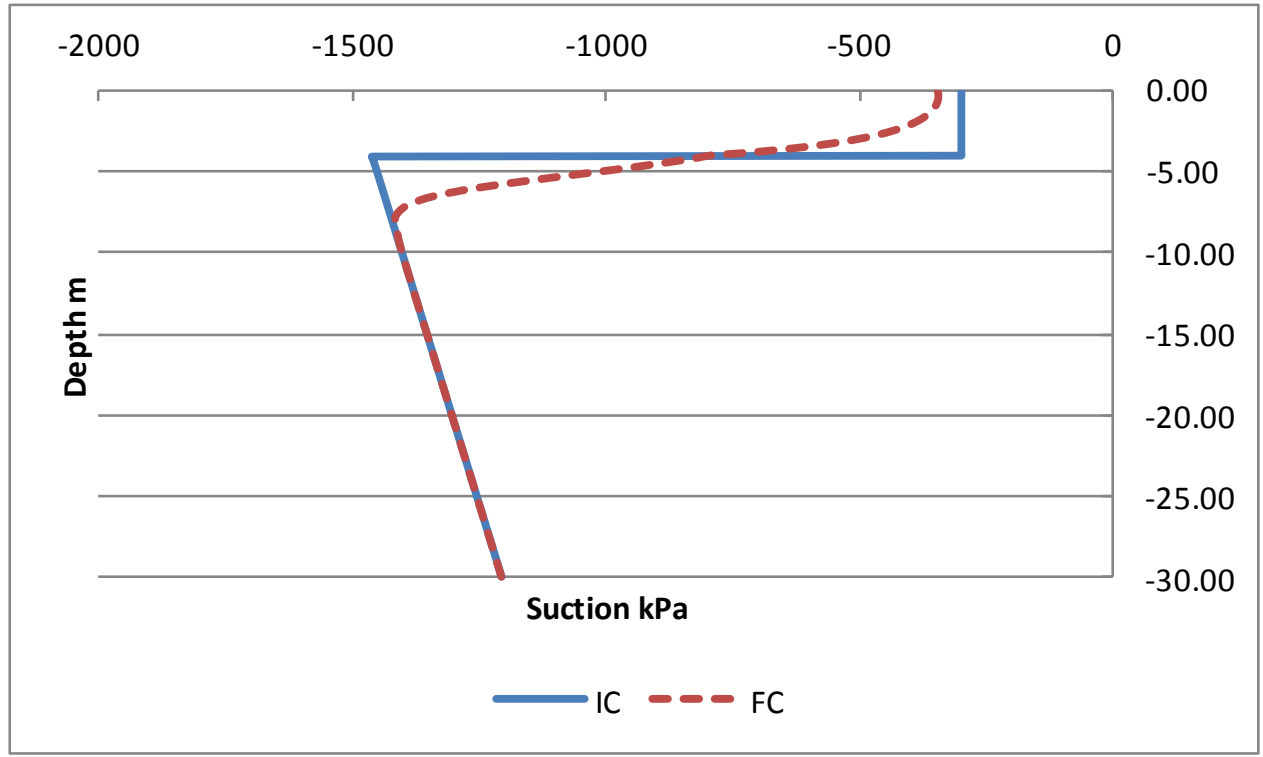

Figure C.38. Vertical suction profile at $5 \mathrm{~m}$ 


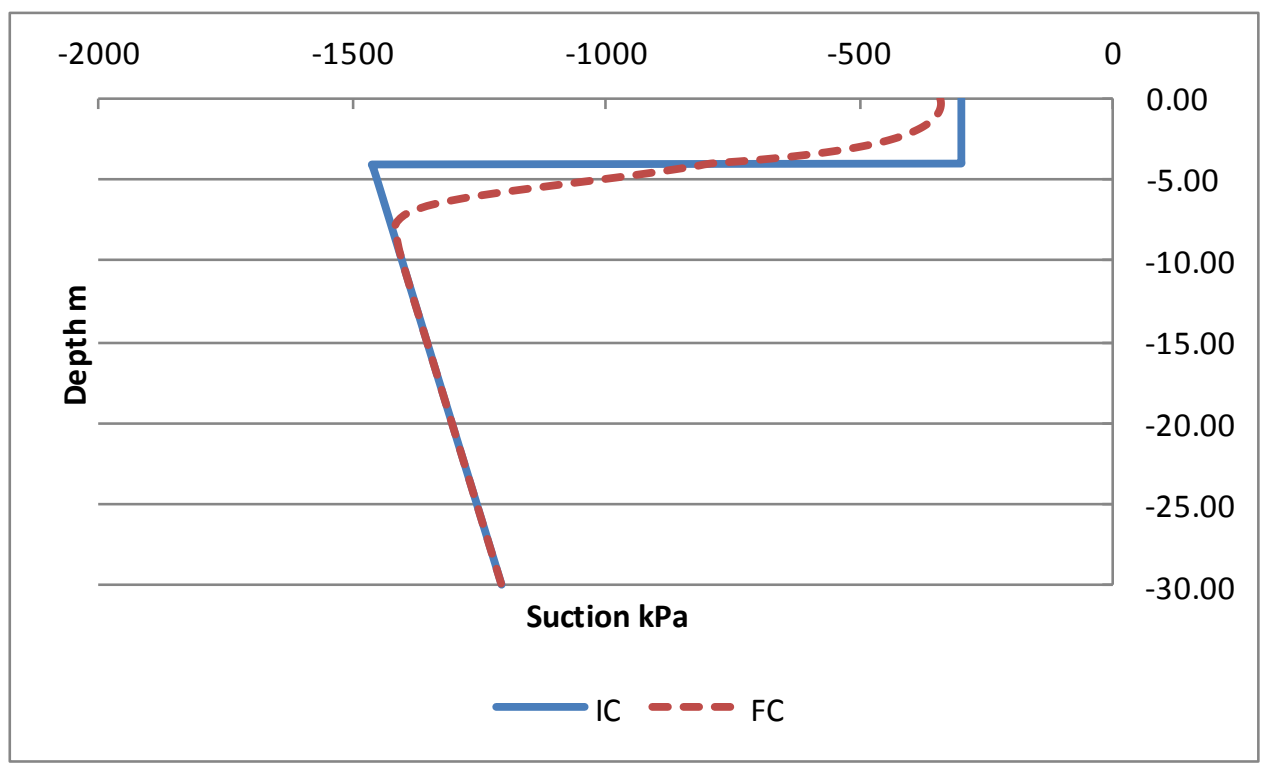

Figure C.39. Vertical suction profile at $8 \mathrm{~m}$

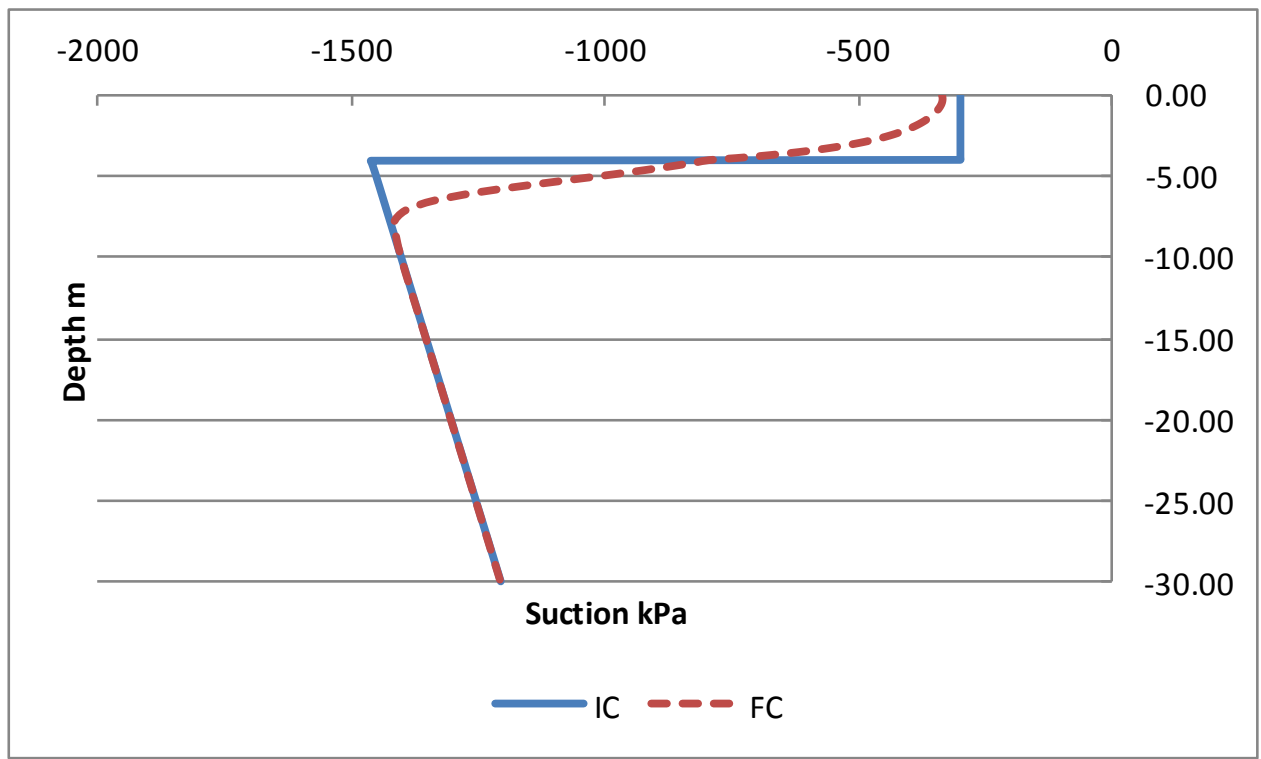

Figure C.40. Vertical suction profile at $9 \mathrm{~m}$ 


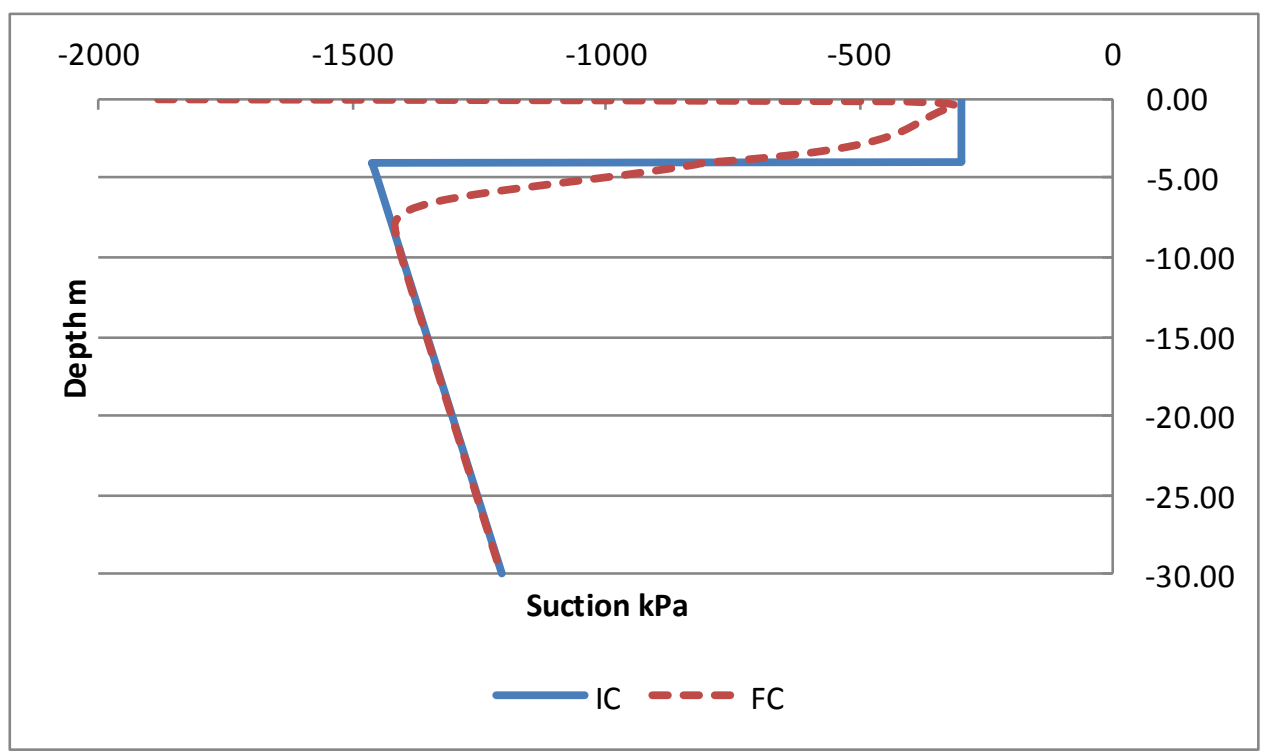

Figure C.41. Vertical suction profile at $10 \mathrm{~m}$

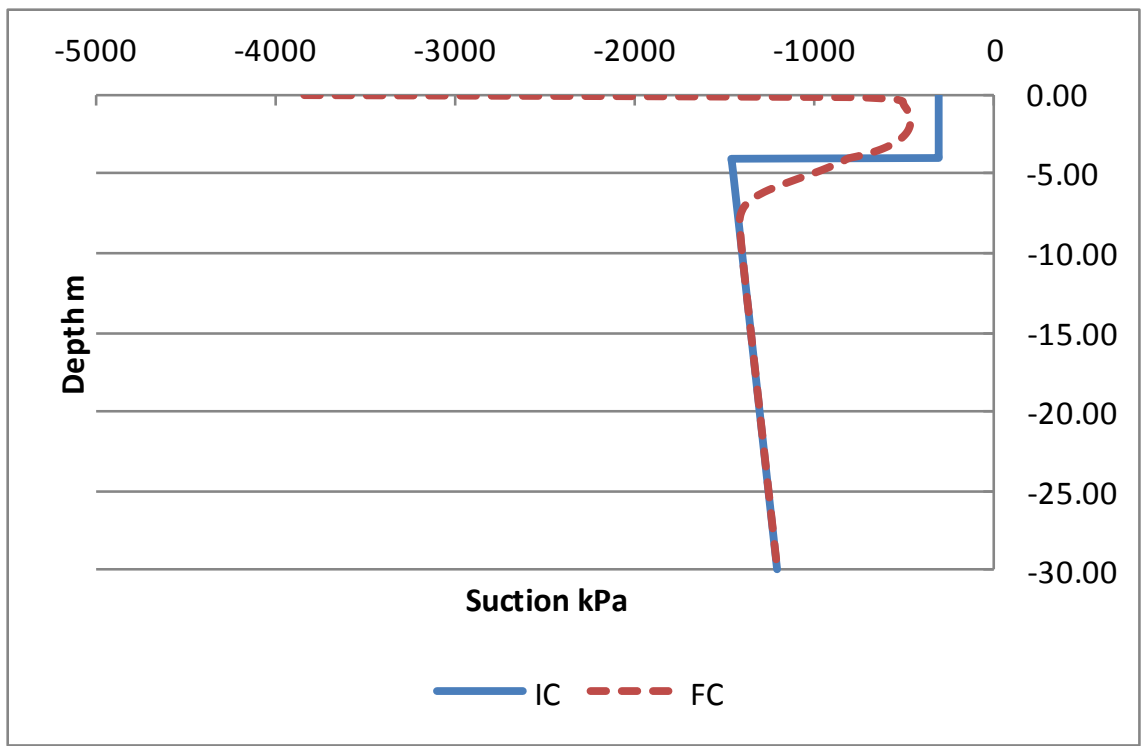

Figure C.42. Vertical suction profile at $11 \mathrm{~m}$ 


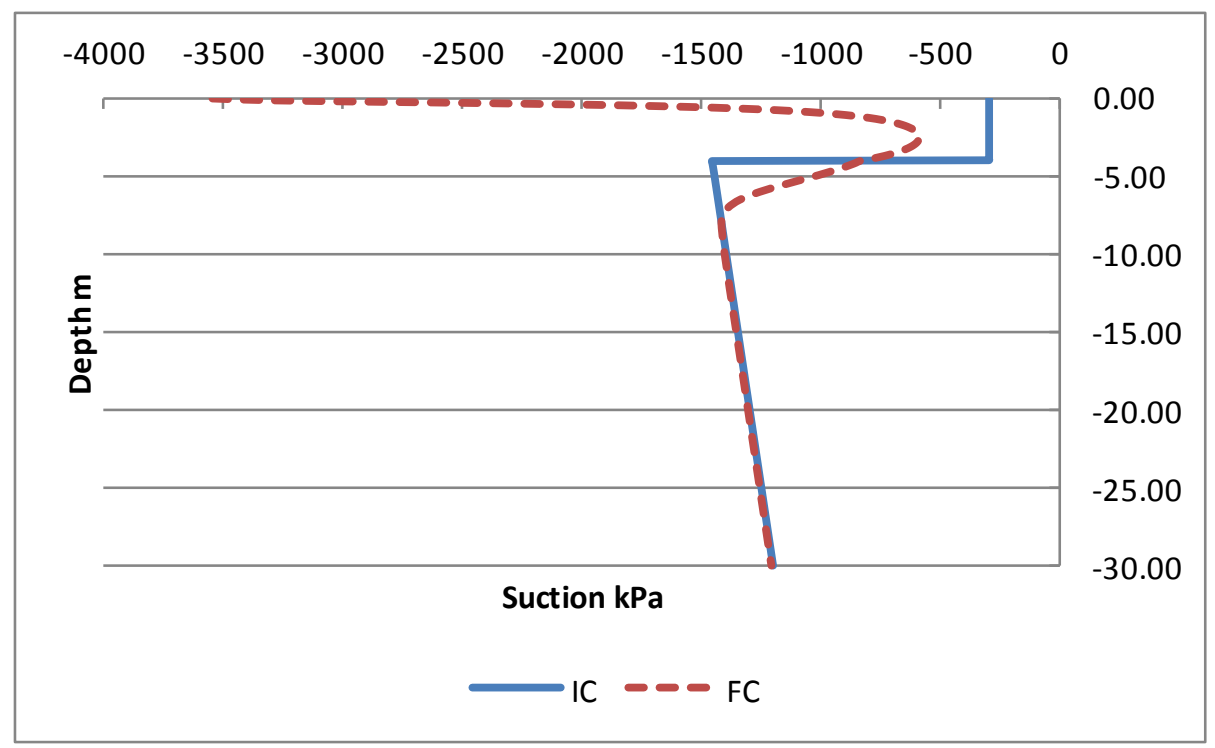

Figure C.43. Vertical suction profile at $19 \mathrm{~m}$

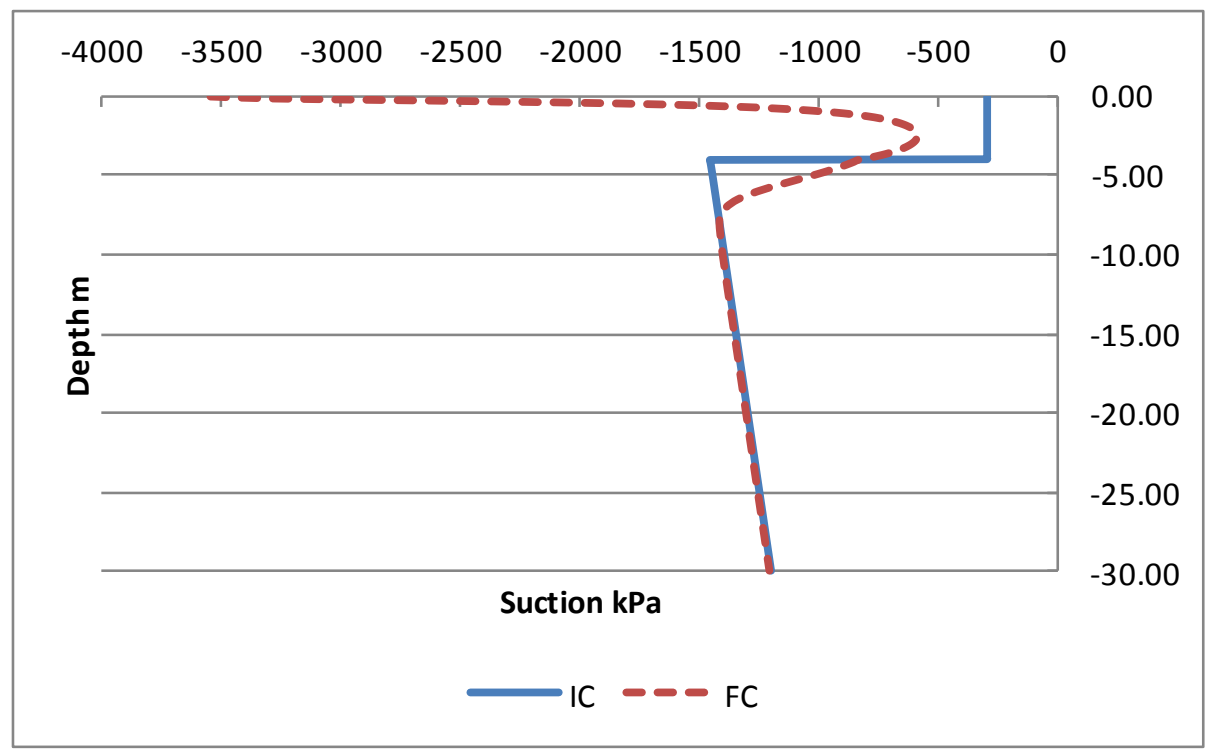

Figure C.44. Vertical suction profile at $27 \mathrm{~m}$ 


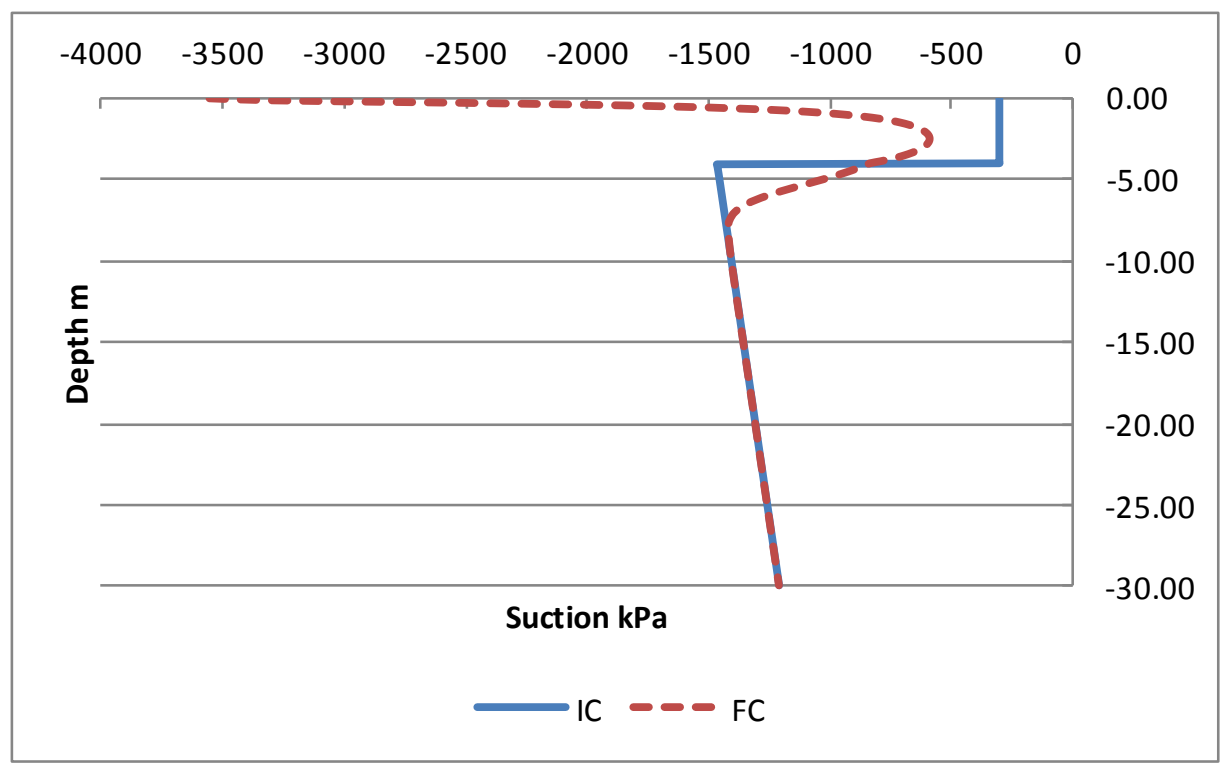

Figure C.45. Vertical suction profile at $35 \mathrm{~m}$

\section{E.1.6 IC and FC Suction Plots for $0.75 \mathrm{~m}$ Higher $\mathrm{K}_{\text {sat }}$ Replacement Case}

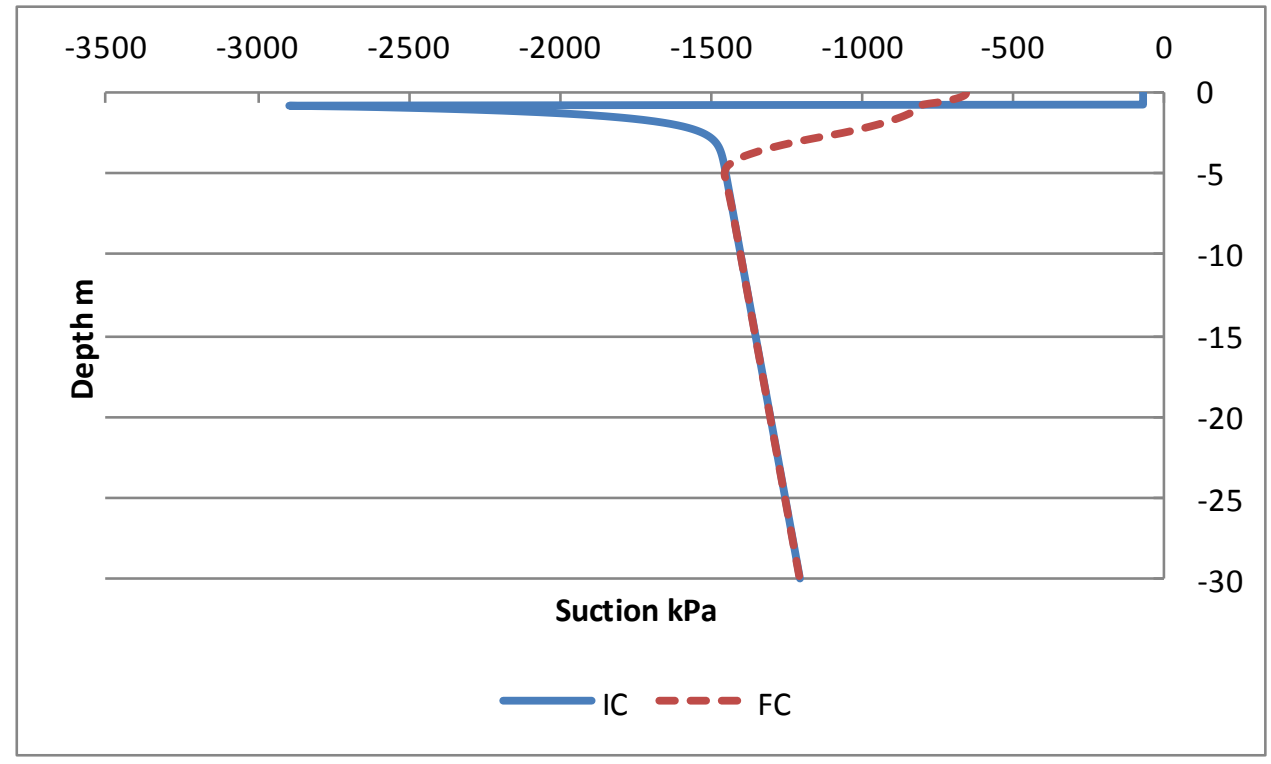

Figure C.46. Vertical suction profile at $0 \mathrm{~m}$ 


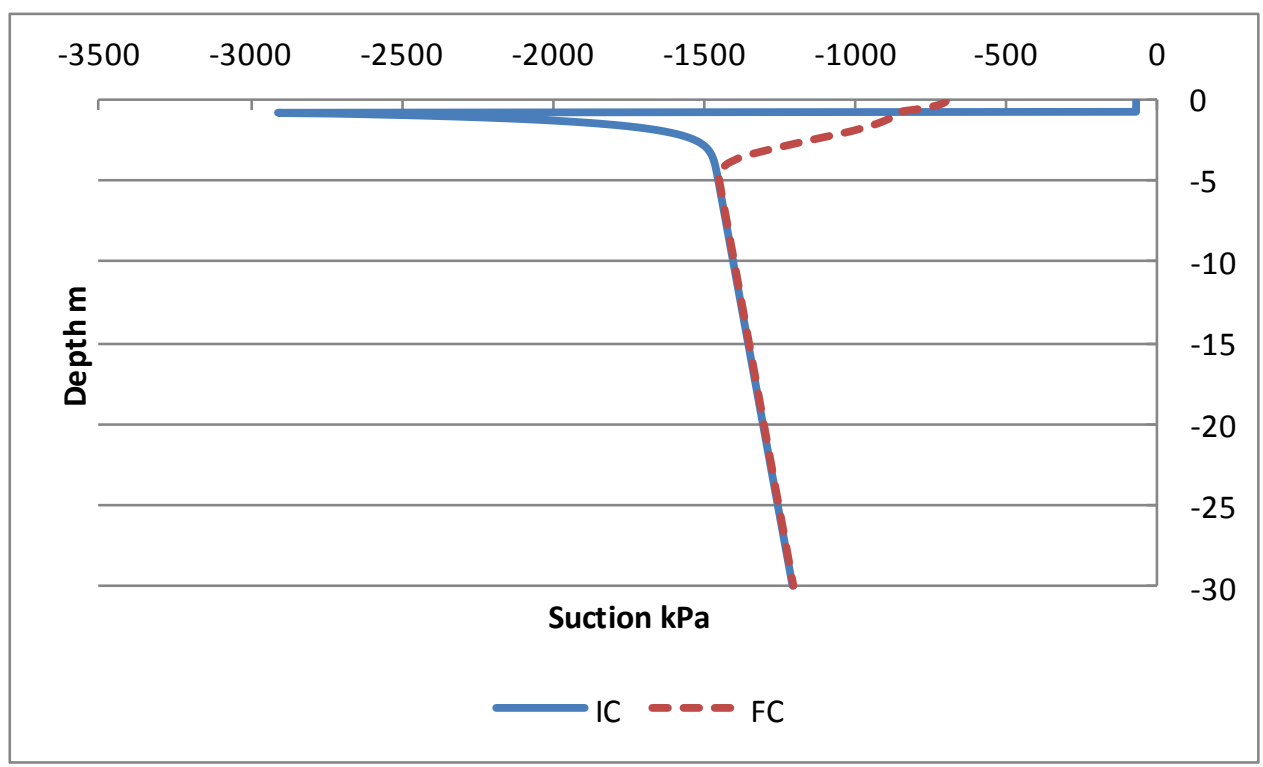

Figure C.47. Vertical suction profile at $5 \mathrm{~m}$

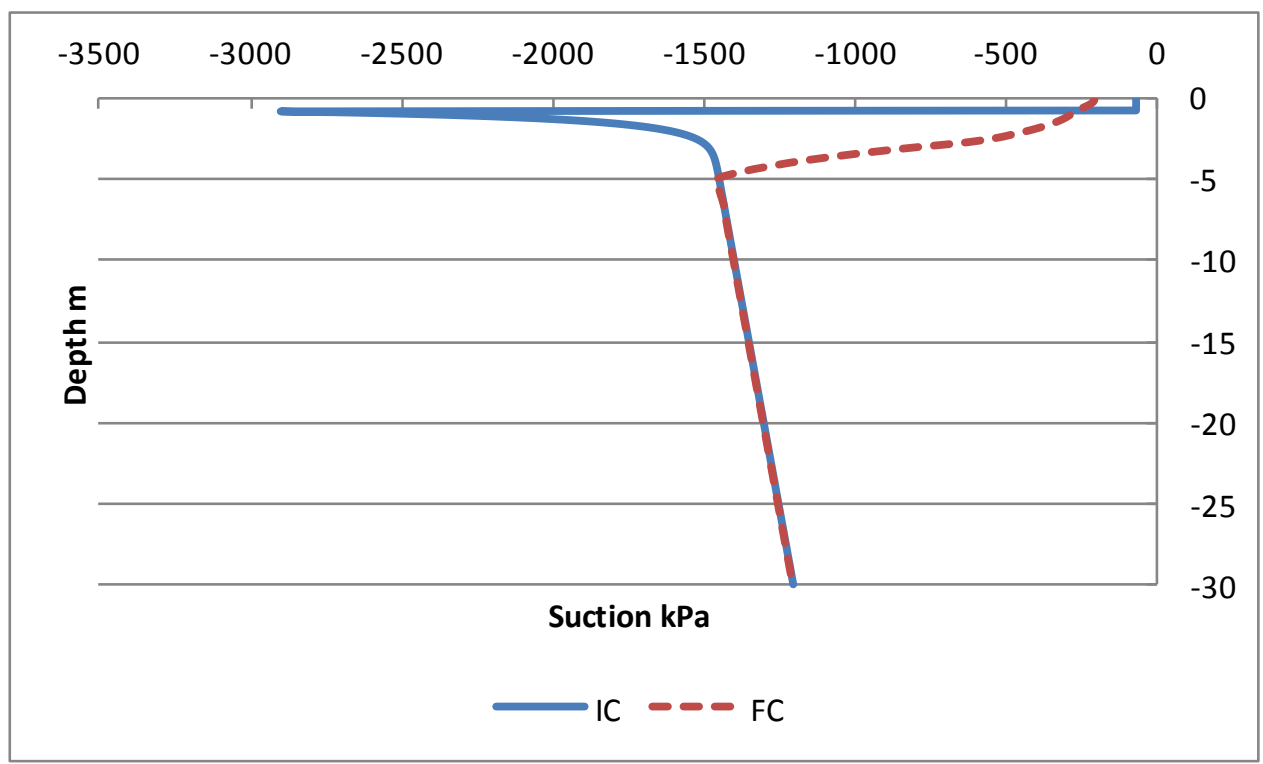

Figure C.48. Vertical suction profile at $8 \mathrm{~m}$ 


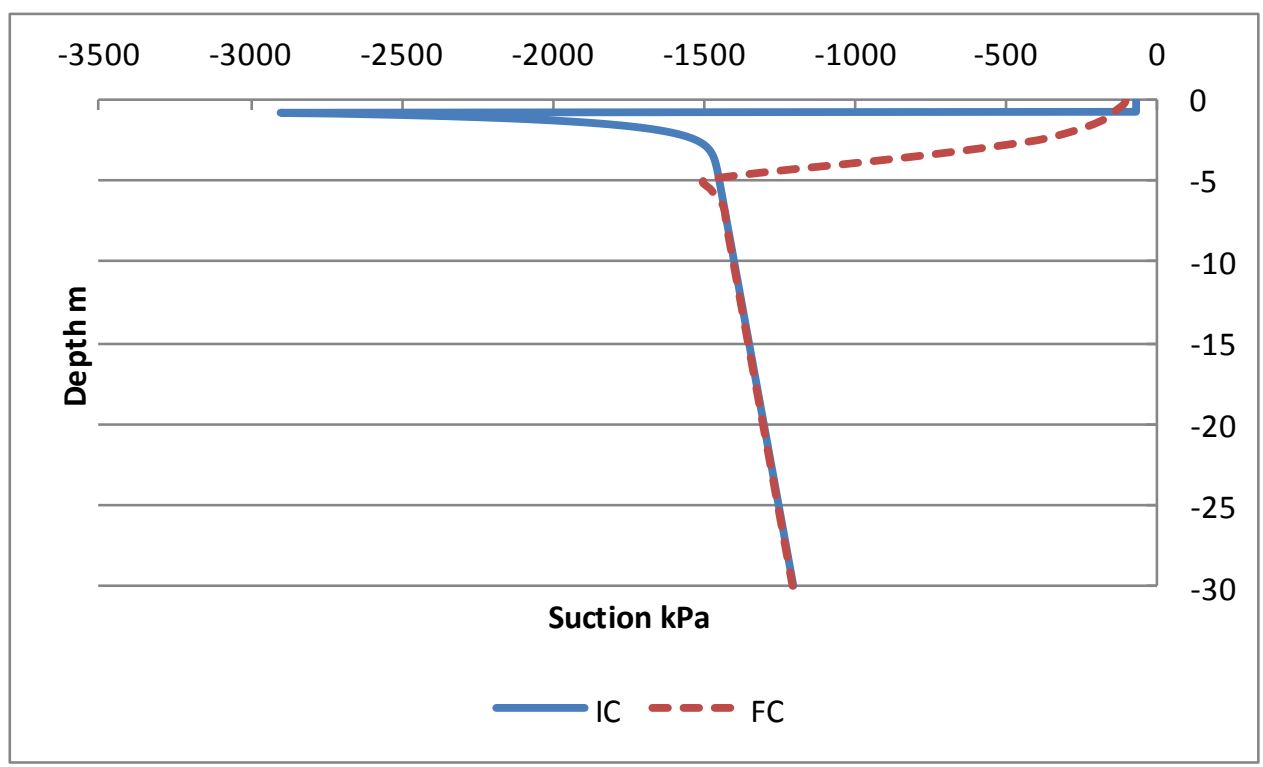

Figure C.49.Vertical suction profile at $9 \mathrm{~m}$

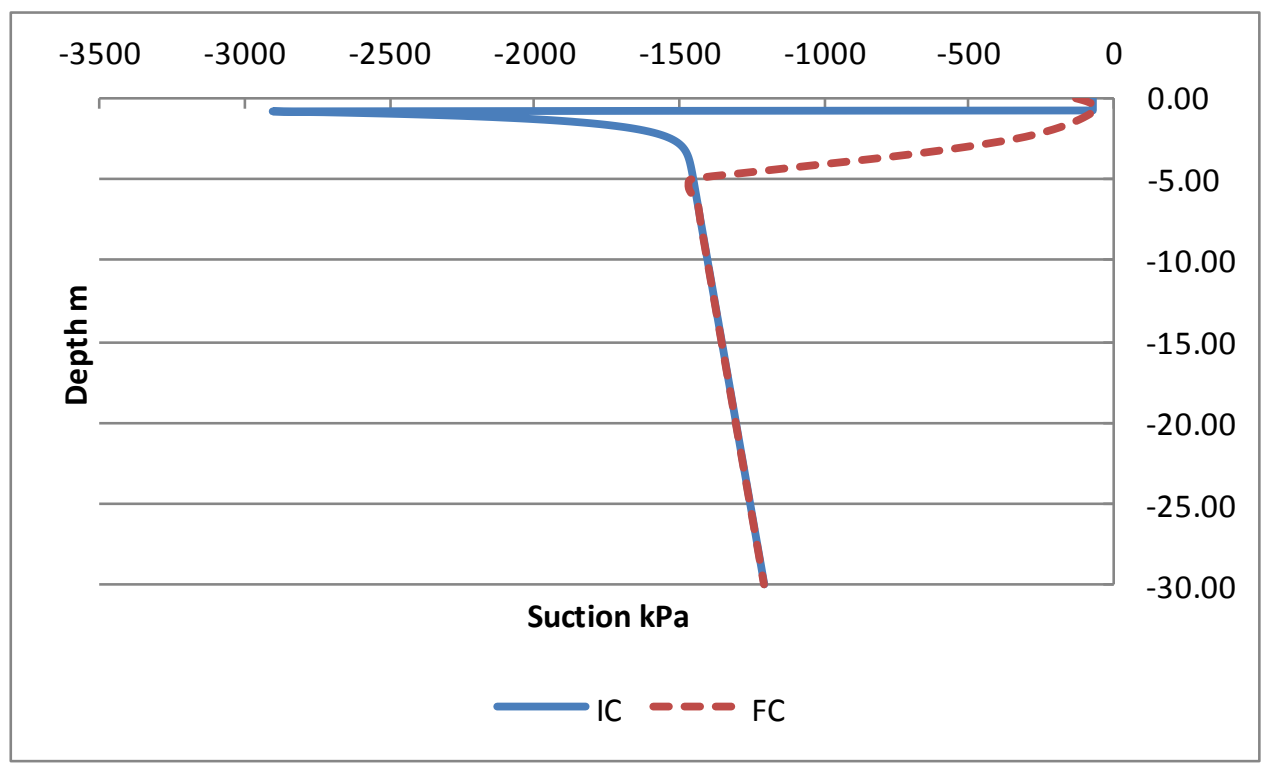

Figure C.50. Vertical suction profile at $10 \mathrm{~m}$ 


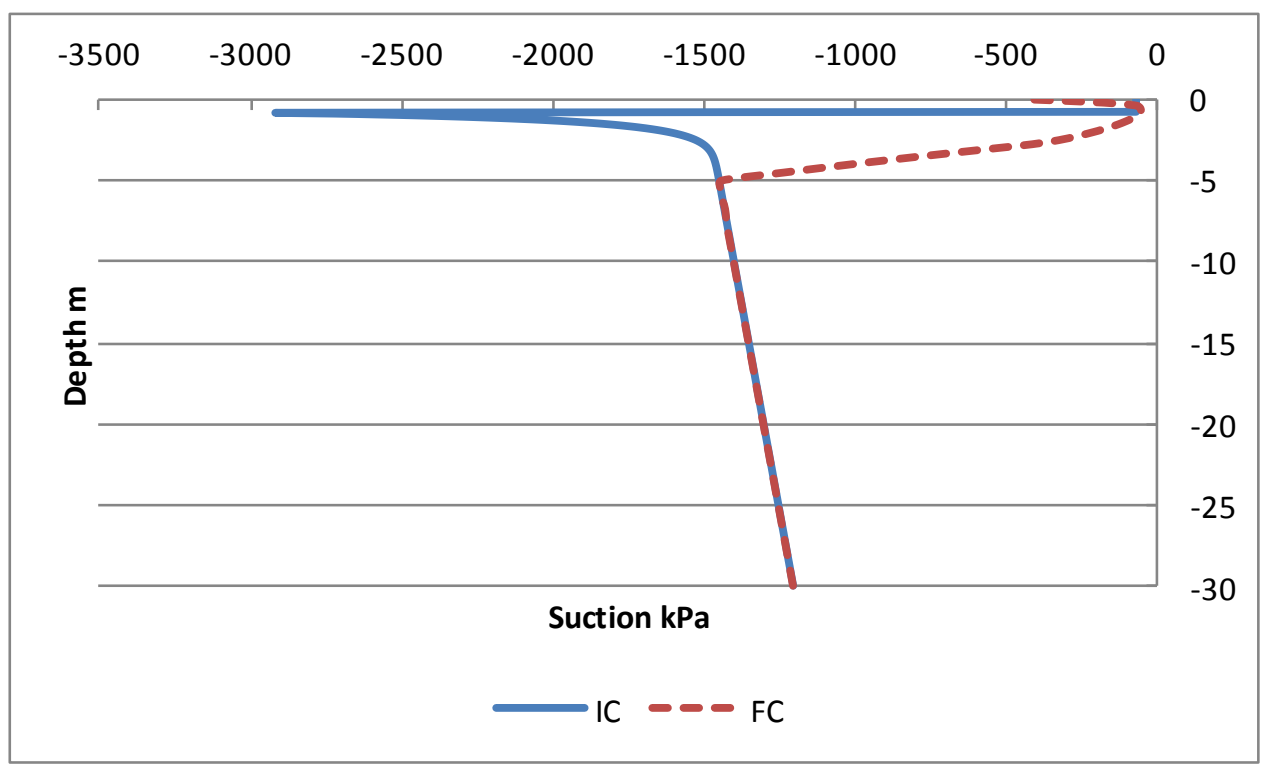

Figure C.51. Vertical suction profile at $11 \mathrm{~m}$

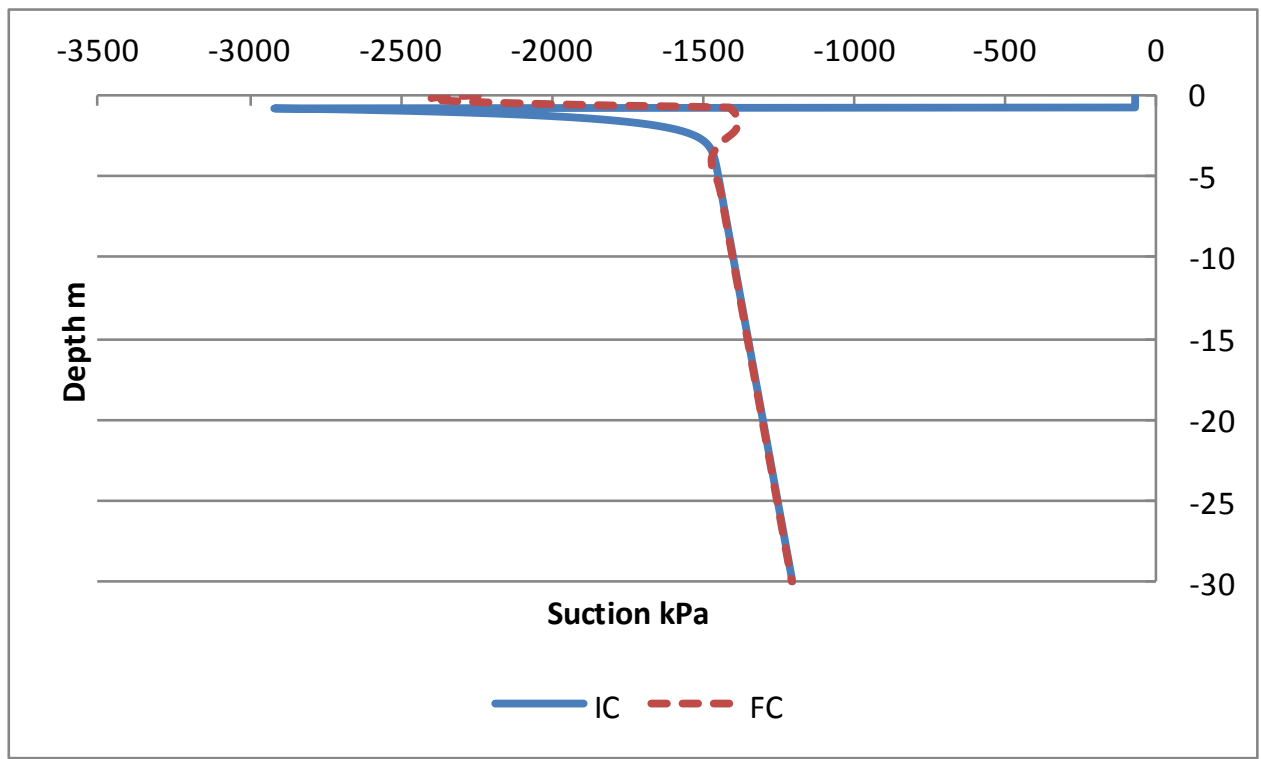

Figure C.52. Vertical suction profile at $19 \mathrm{~m}$ 


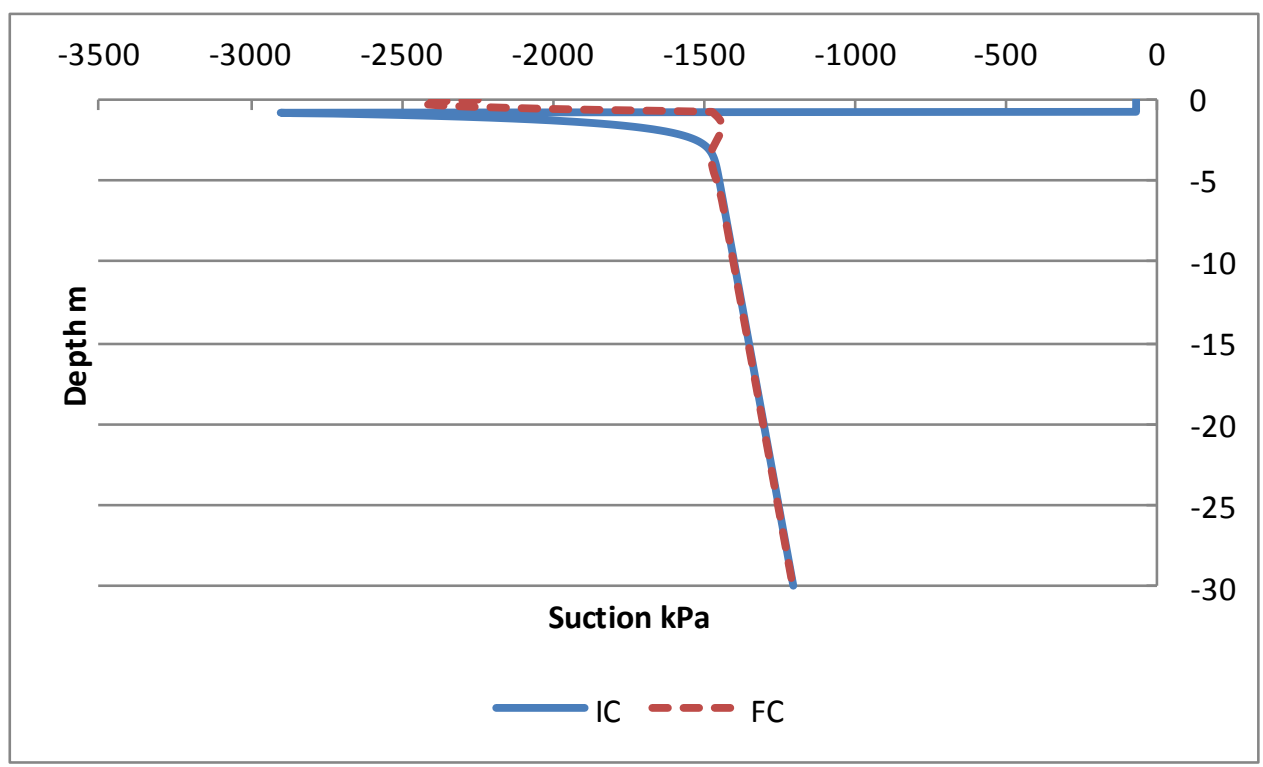

Figure C.53. Vertical suction profile at $27 \mathrm{~m}$

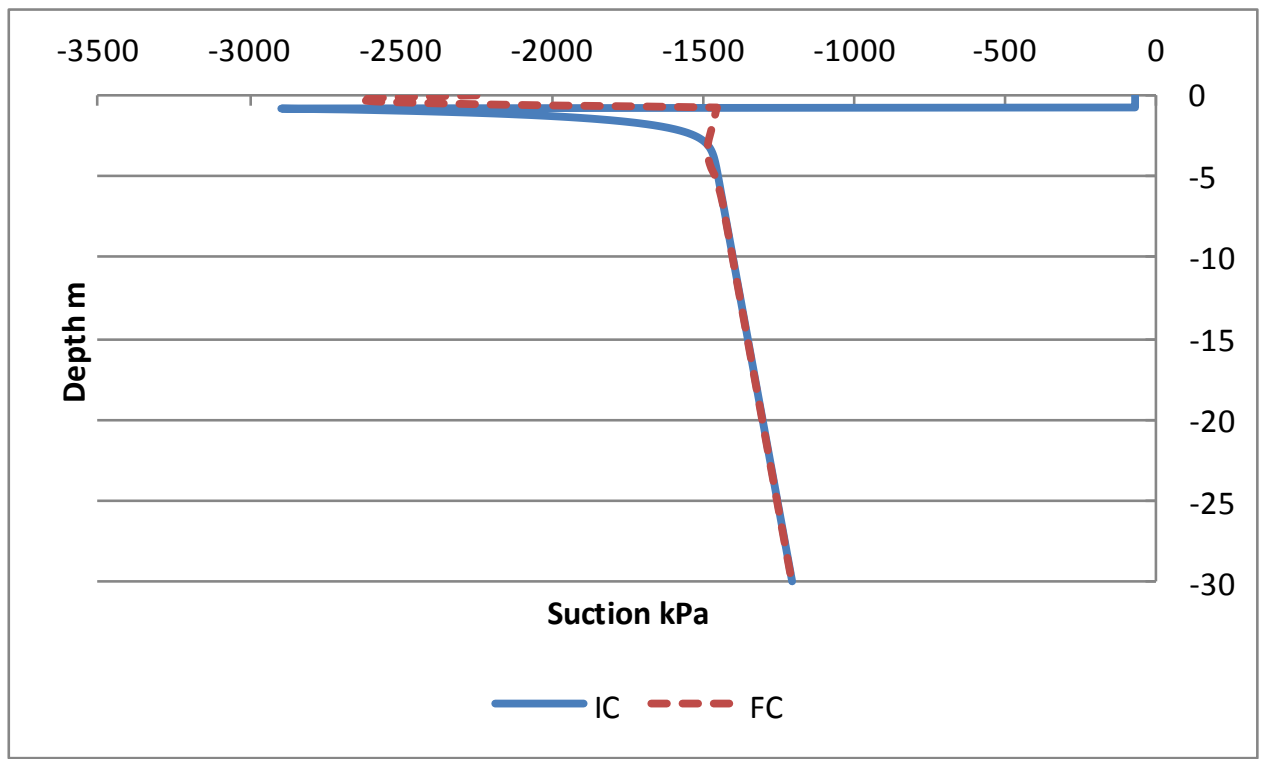

Figure C.54. Vertical suction profile at $35 \mathrm{~m}$ 


\section{C.1.7 IC and FC Suction Plots for $\mathbf{2 m}$ Higher $\mathbf{K}_{\text {sat }}$ Replacement Case}

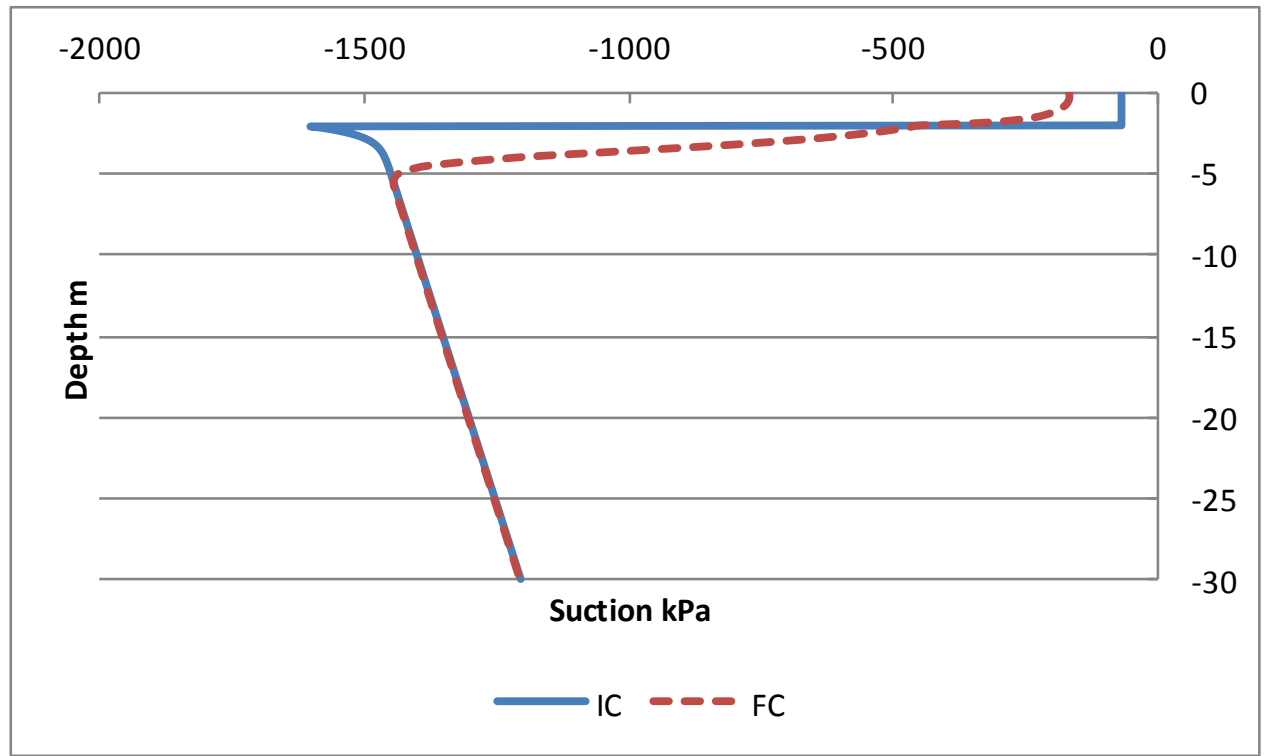

Figure C.55. Vertical suction profile at $0 \mathrm{~m}$

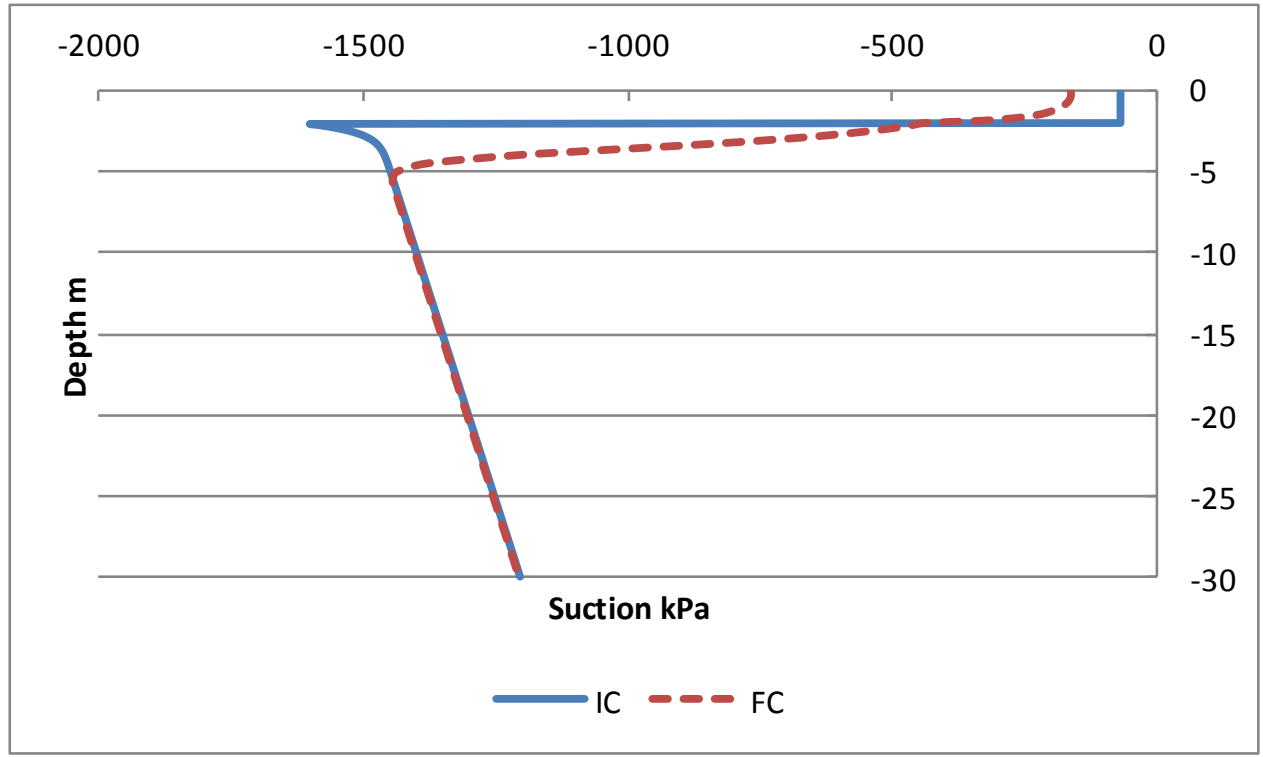

Figure C.56. Vertical suction profile at $5 \mathrm{~m}$ 


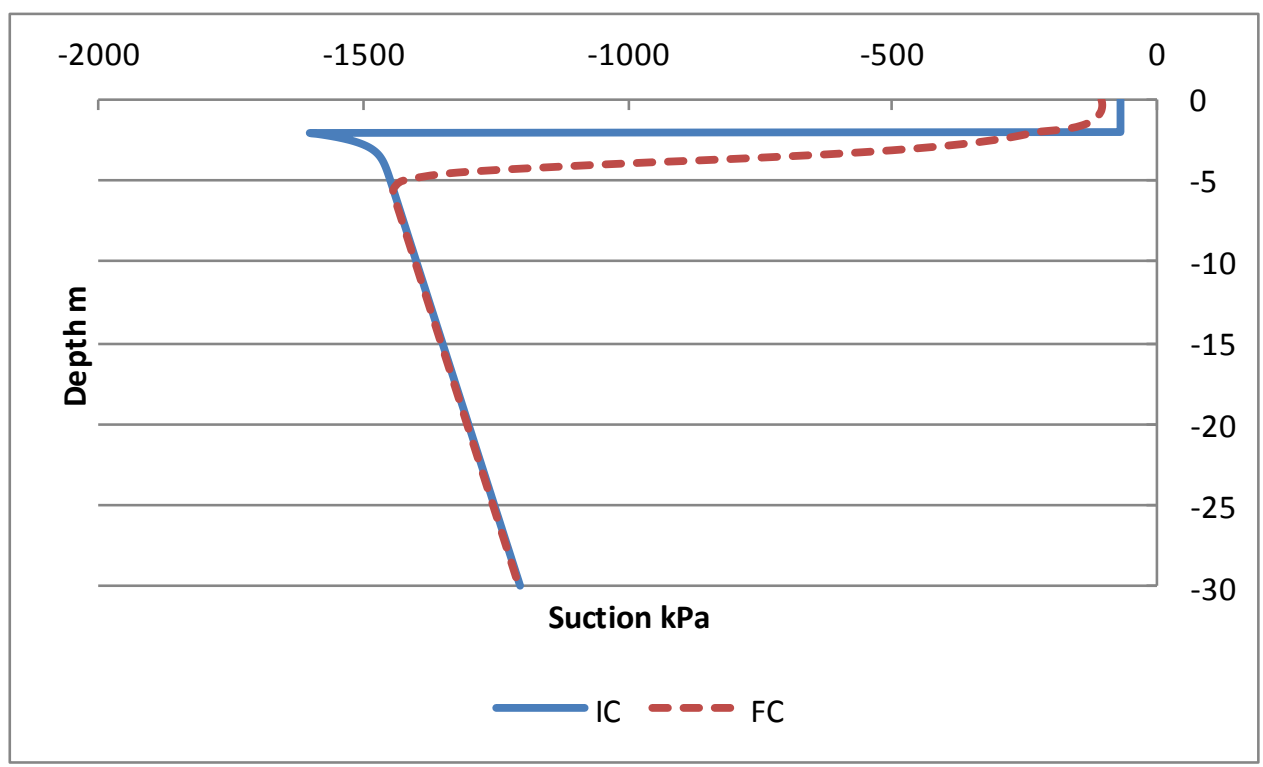

Figure C.57. Vertical suction profile at $8 \mathrm{~m}$

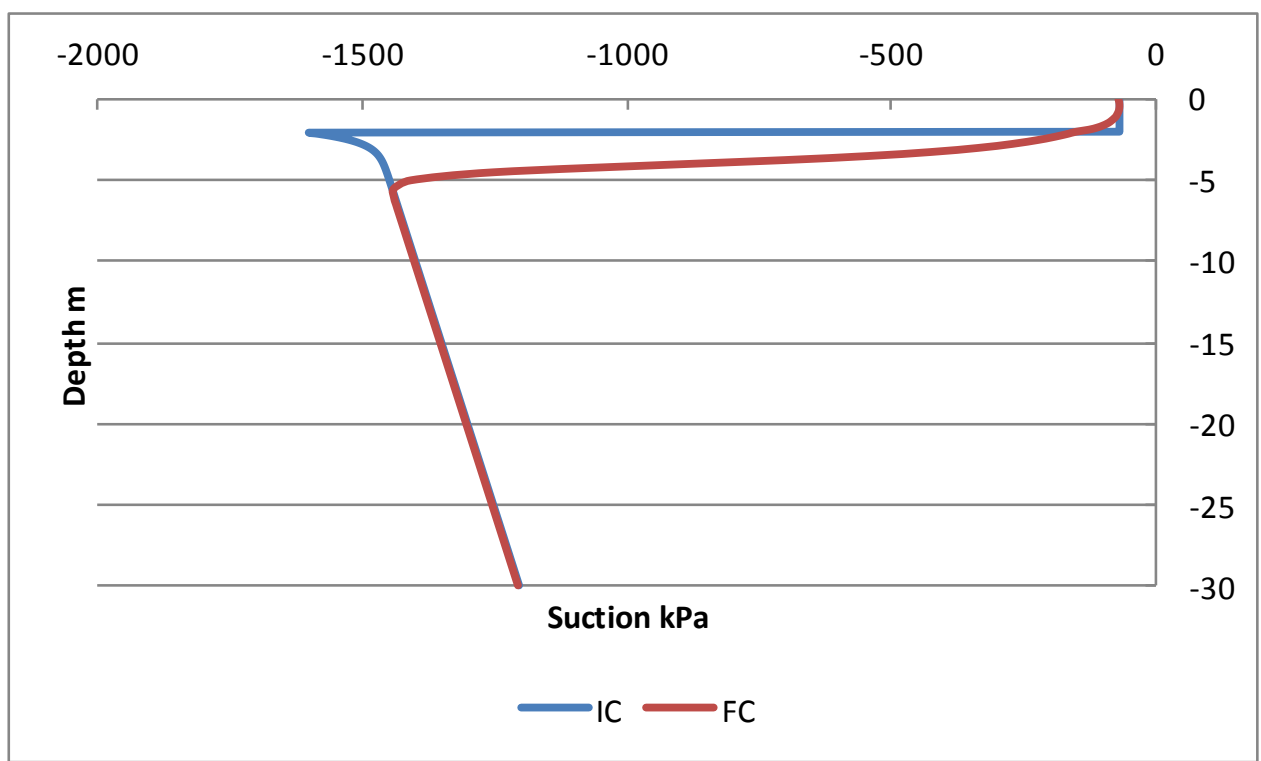

Figure C.58. Vertical suction profile at $9 \mathrm{~m}$ 


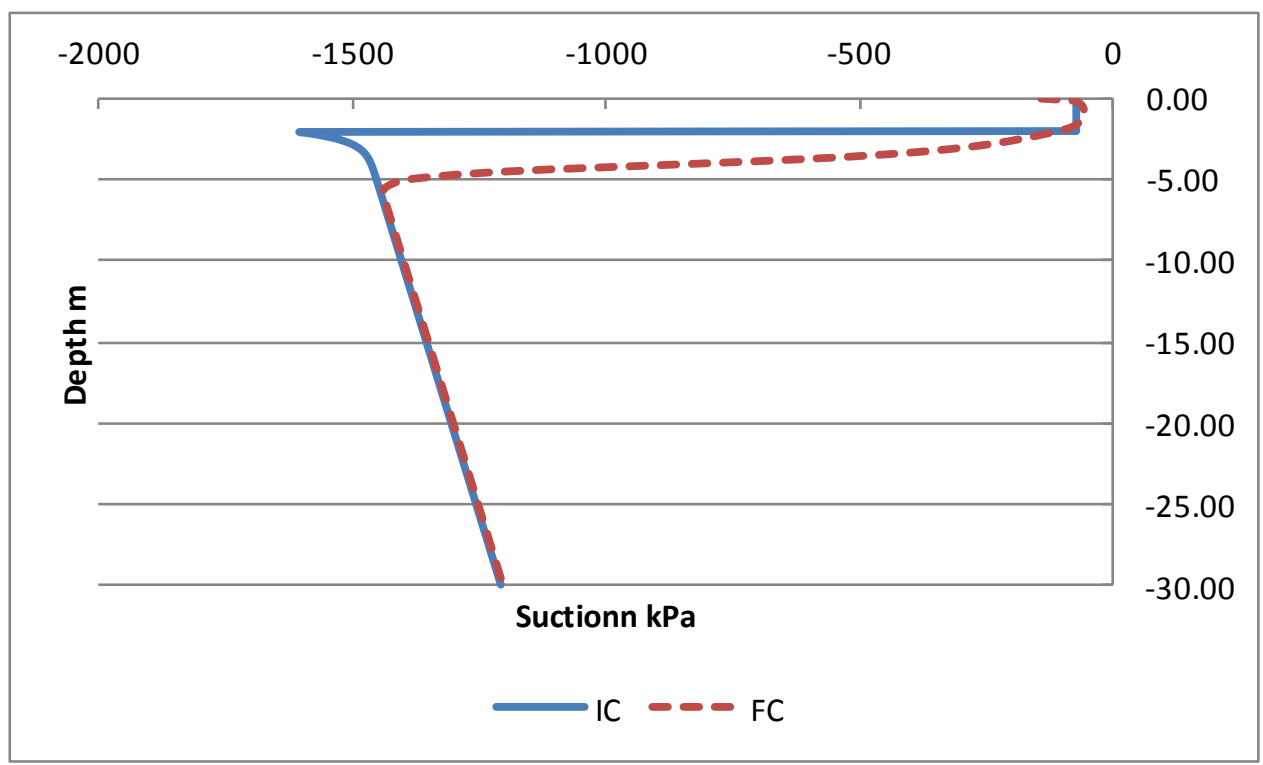

Figure C.59. Vertical suction profile at $10 \mathrm{~m}$

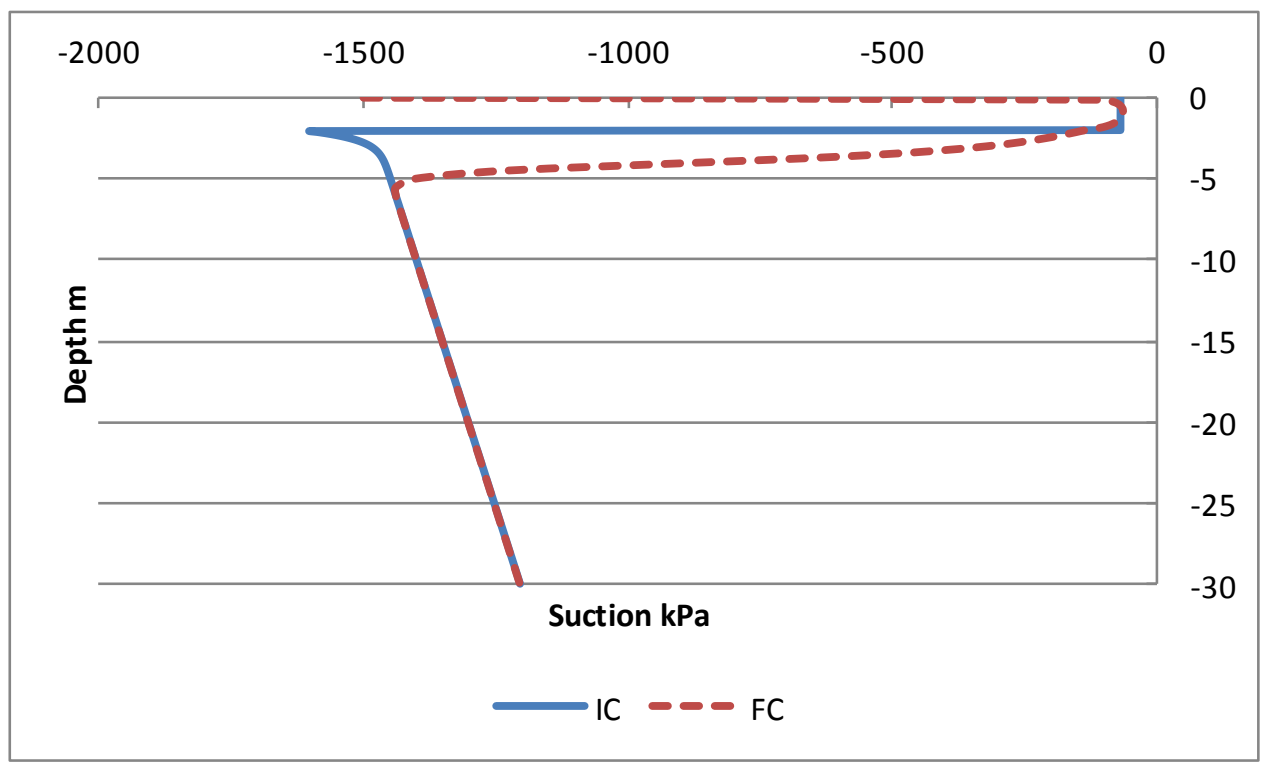

Figure C.60. Vertical suction profile at $11 \mathrm{~m}$ 


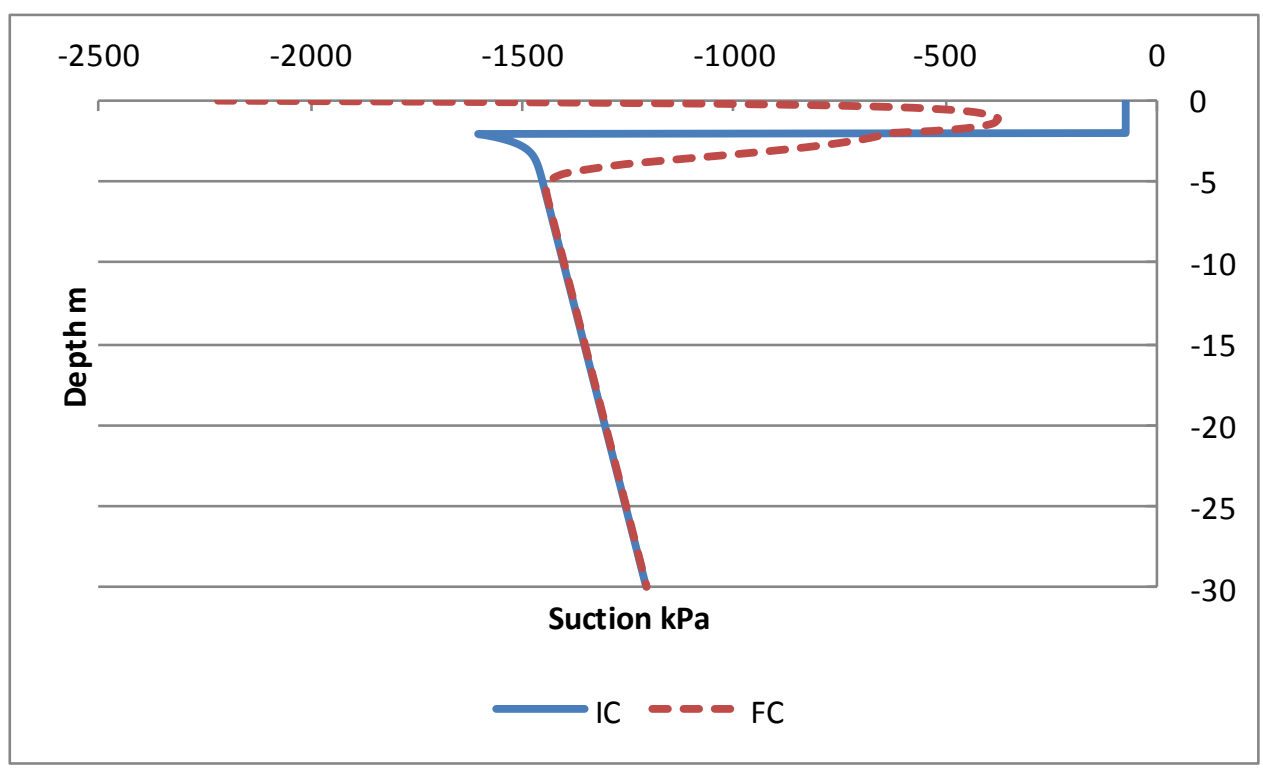

Figure C.61. Vertical suction profile at $19 \mathrm{~m}$

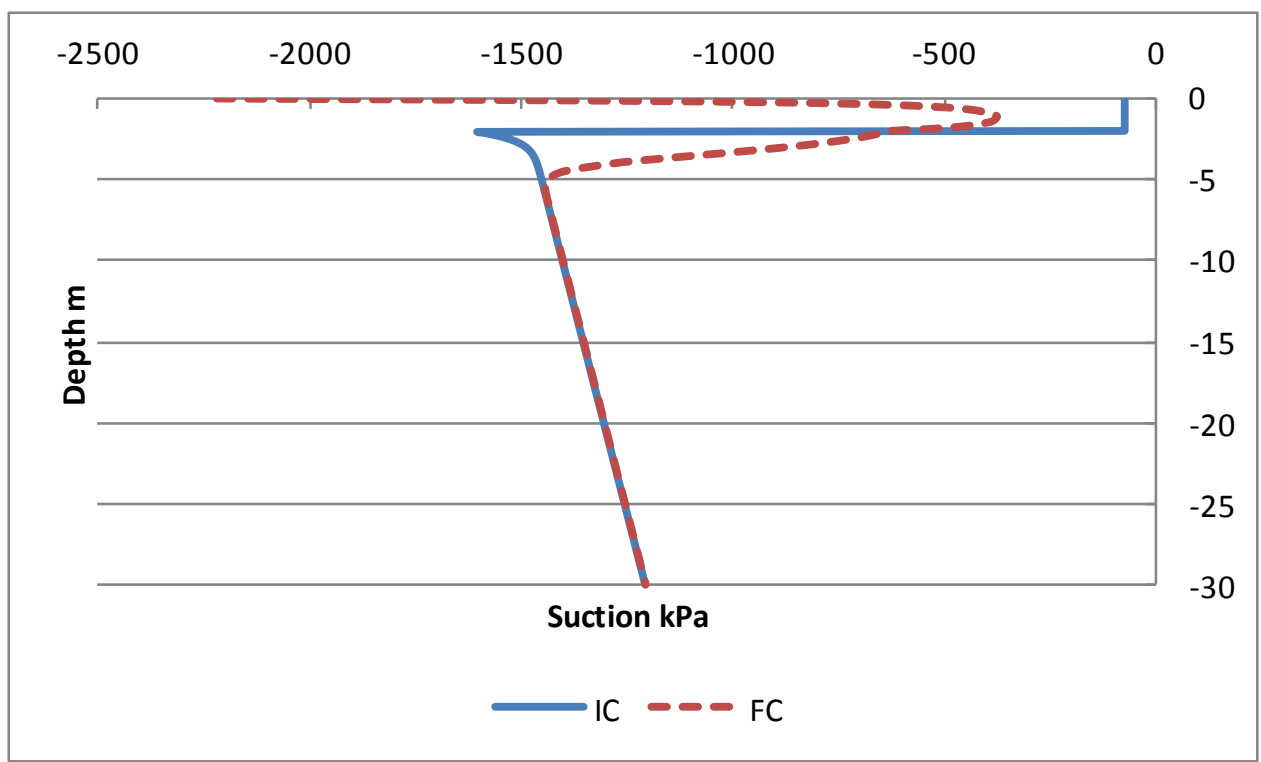

Figure C.62. Vertical suction profile at $27 \mathrm{~m}$ 


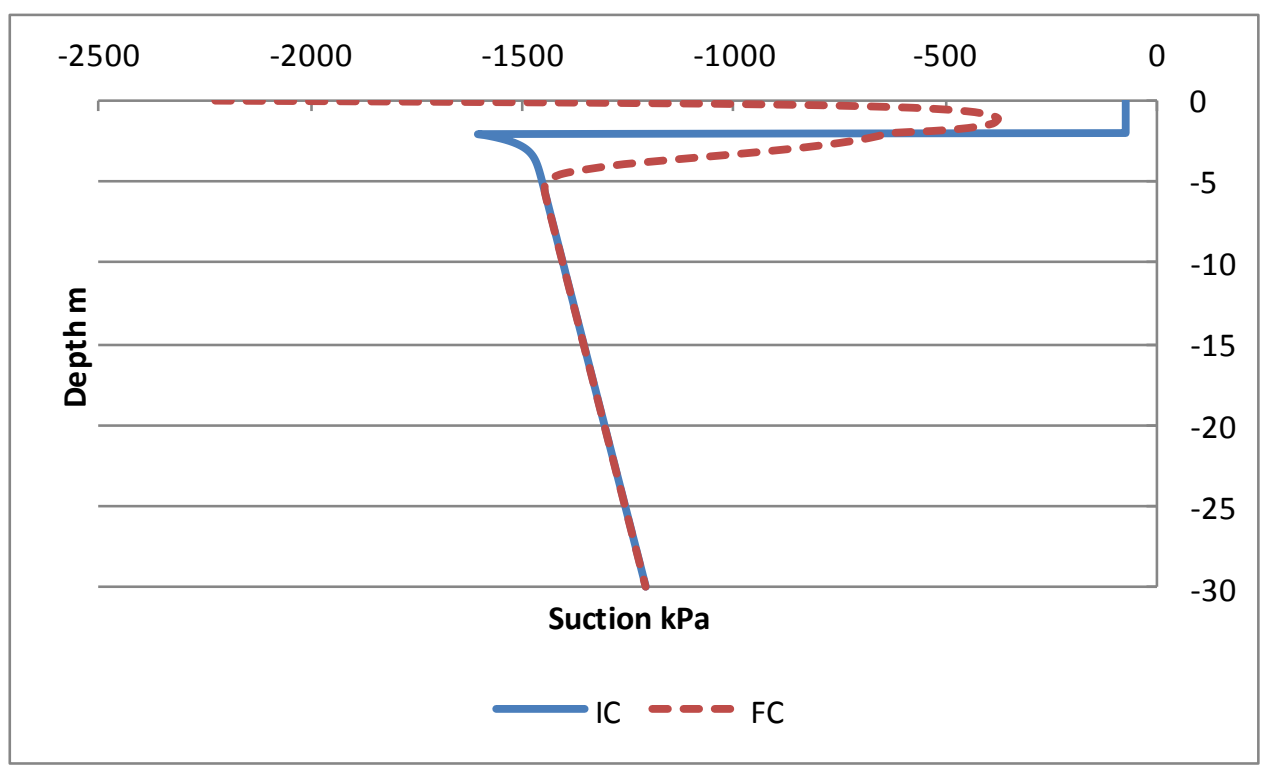

Figure C.63. Vertical suction profile at $35 \mathrm{~m}$

\section{C.1.8 IC and FC Suction Plots for $\mathbf{4 m}$ higher $\mathrm{K}_{\text {sat }}$ Replacement Layer Case}

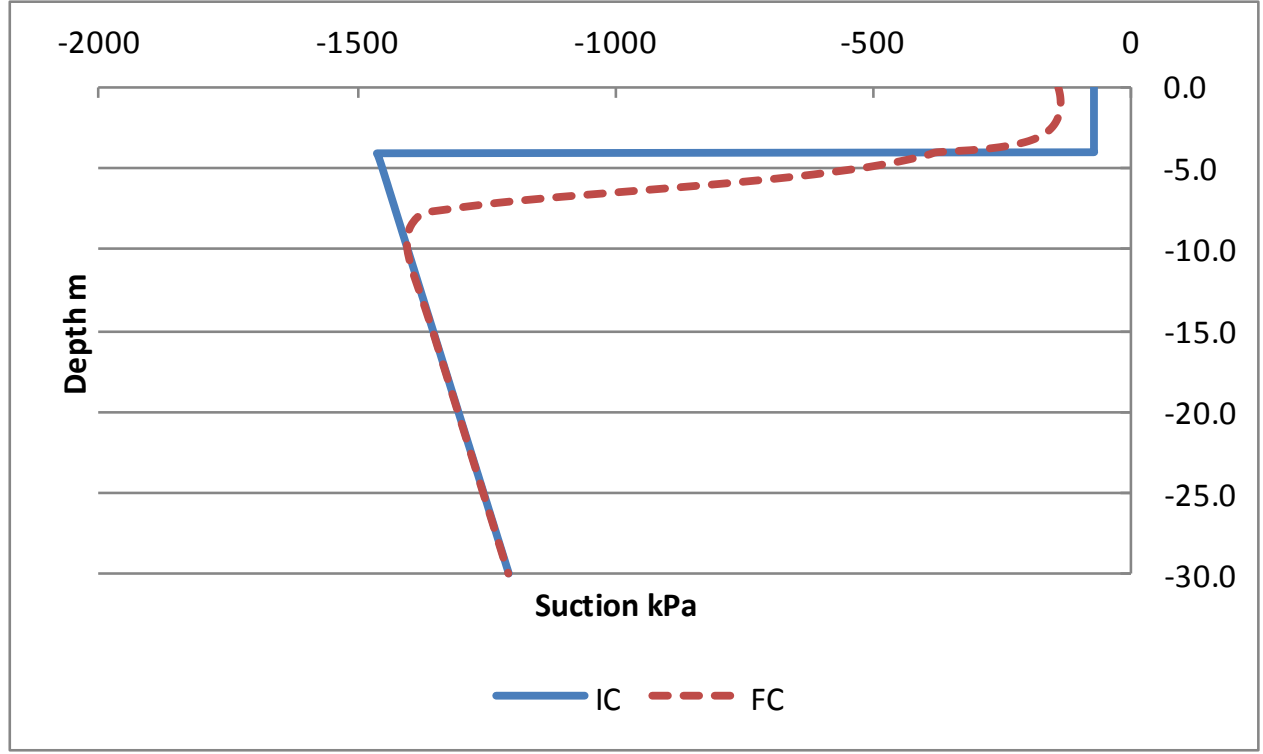

Figure C.64. Vertical suction profile at $0 \mathrm{~m}$ 


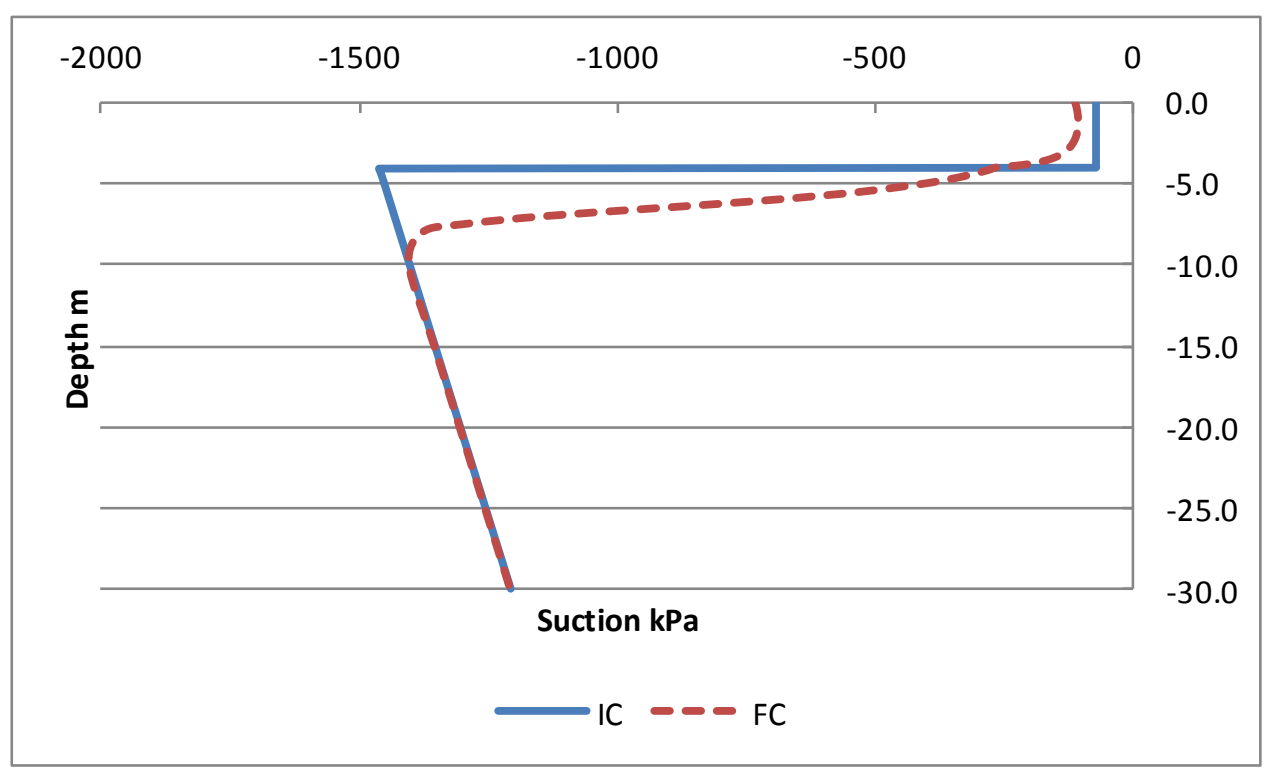

Figure C.65. Vertical suction profile at $5 \mathrm{~m}$

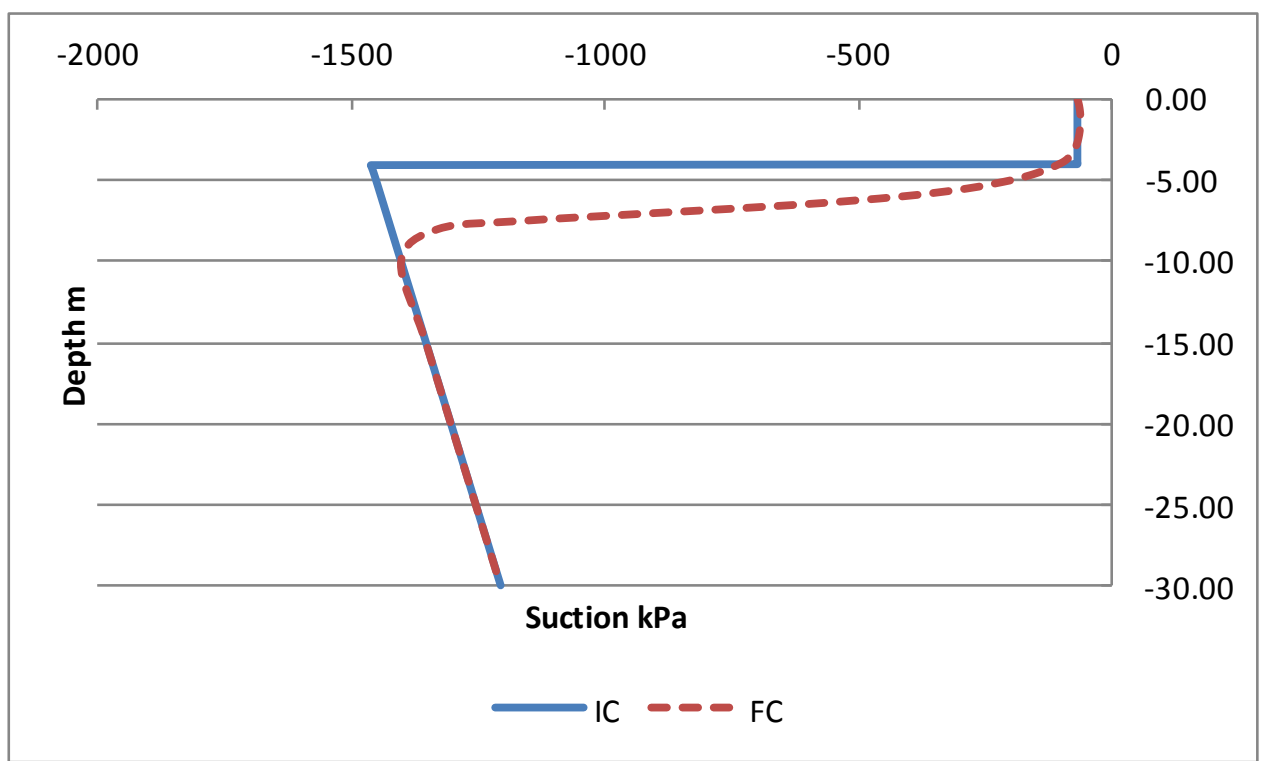

Figure C.66. Vertical suction profile at $8 \mathrm{~m}$ 


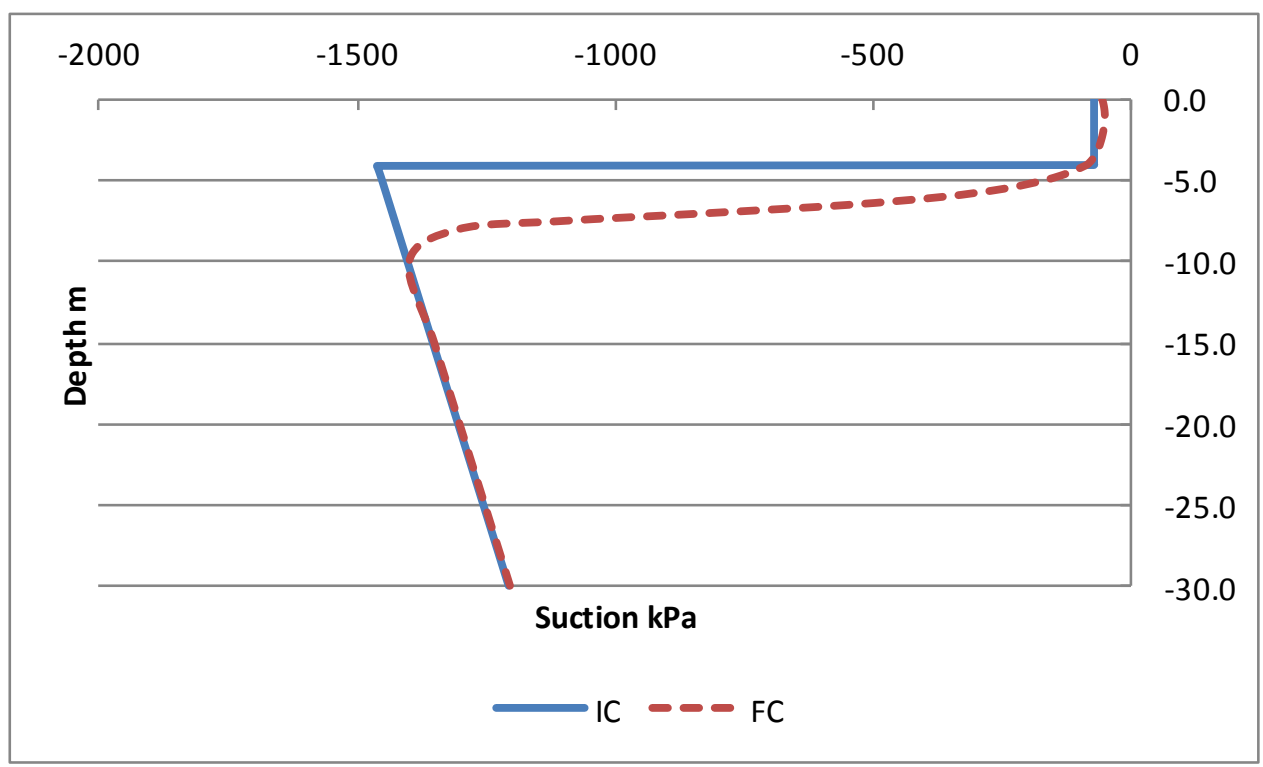

Figure C.67. Vertical suction profile at $9 \mathrm{~m}$

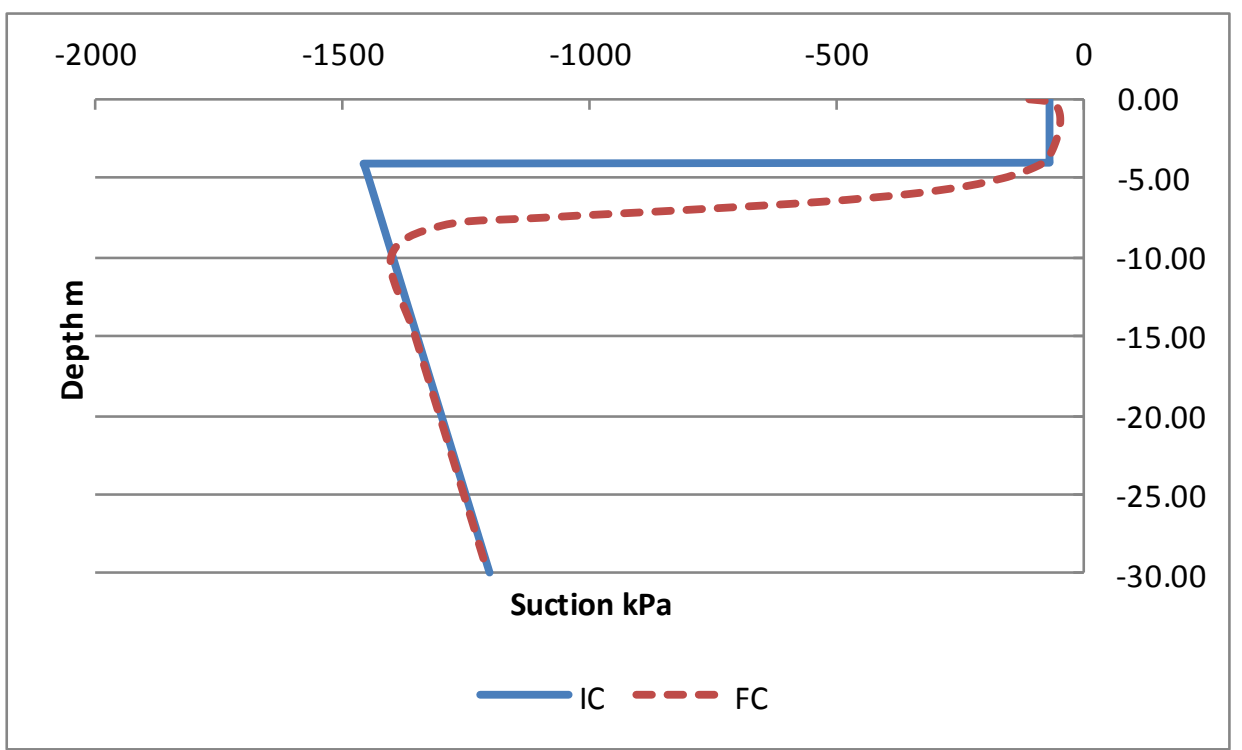

Figure C.68. Vertical suction profile at $10 \mathrm{~m}$ 


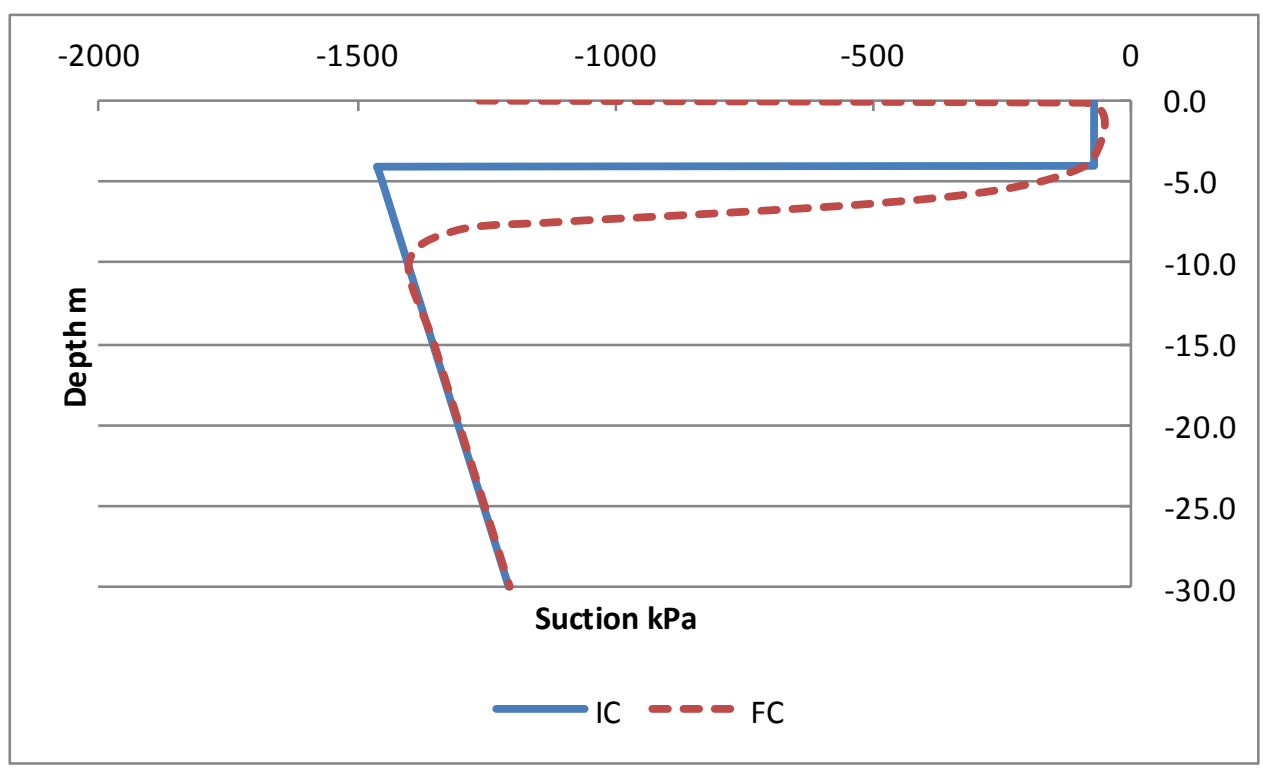

Figure C.69. Vertical suction profile at $11 \mathrm{~m}$

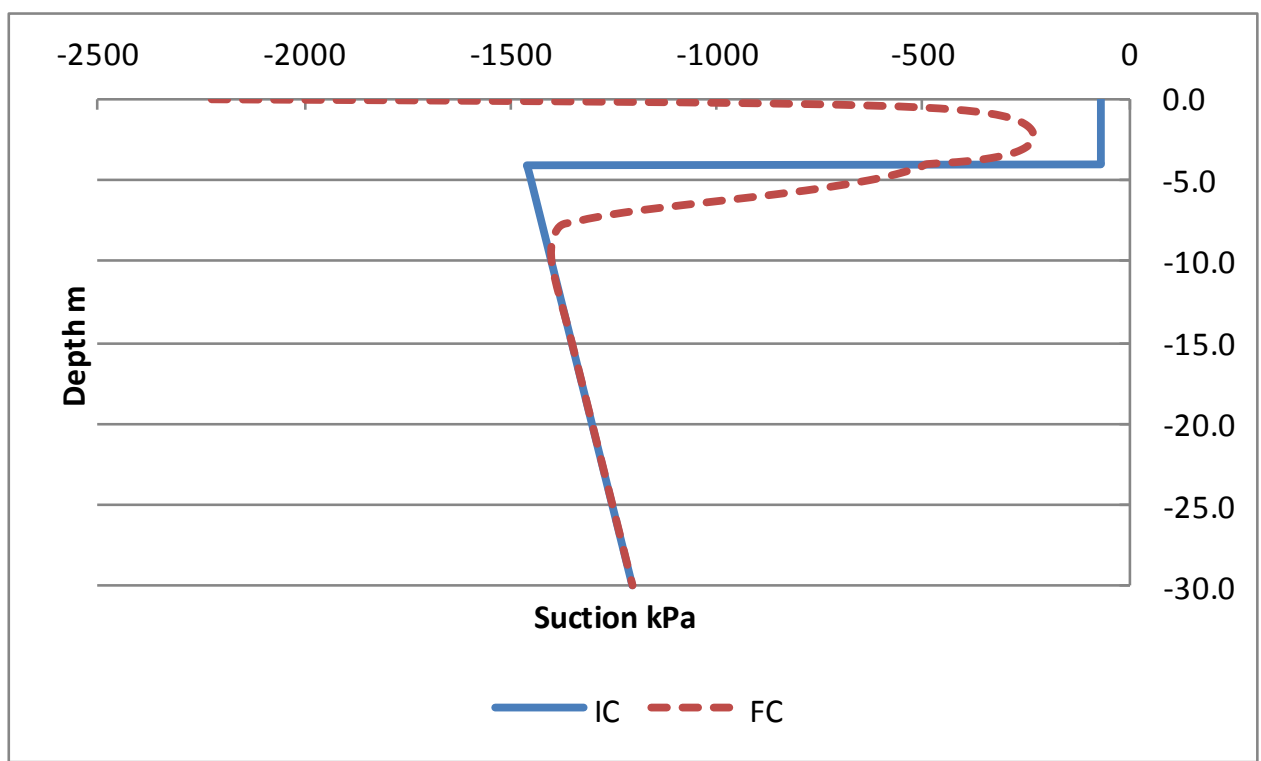

Figure C.70. Vertical suction profile at $19 \mathrm{~m}$ 


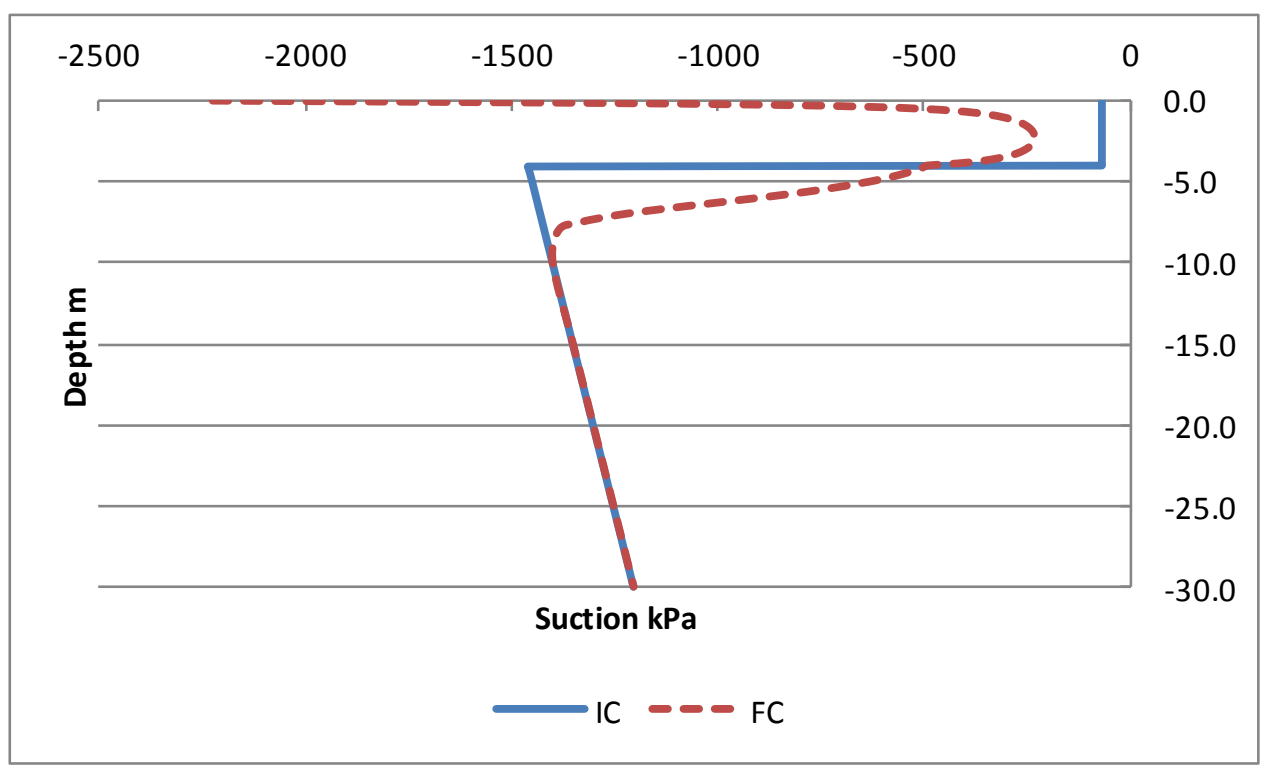

Figure C.71. Vertical suction profile at $27 \mathrm{~m}$

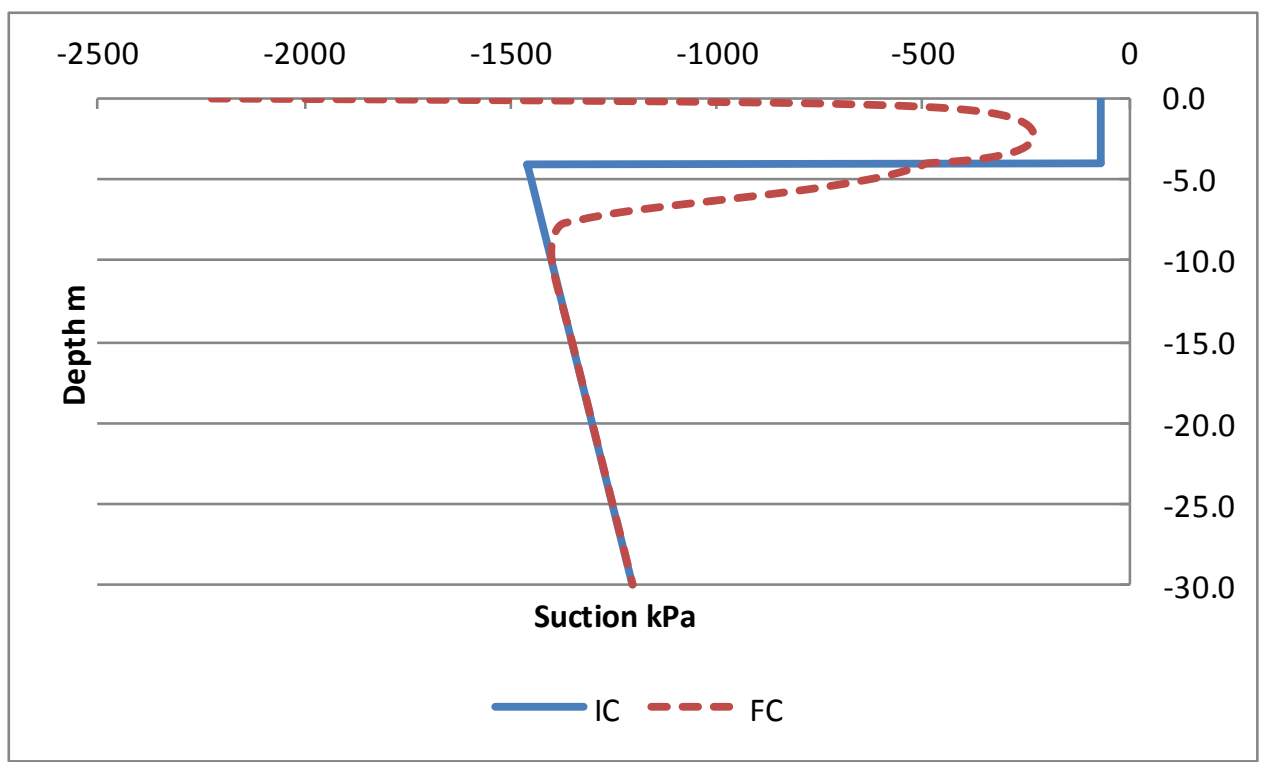

Figure C.72. Vertical suction profile at $35 \mathrm{~m}$ 


\section{C.2 Turf Landscape Boundary Conditions Case}

The suction plots included in this section are for the vertical sections of the soil profile as shown in the sketch below. The plots shown below are for all the replacement cases and no replacement case.

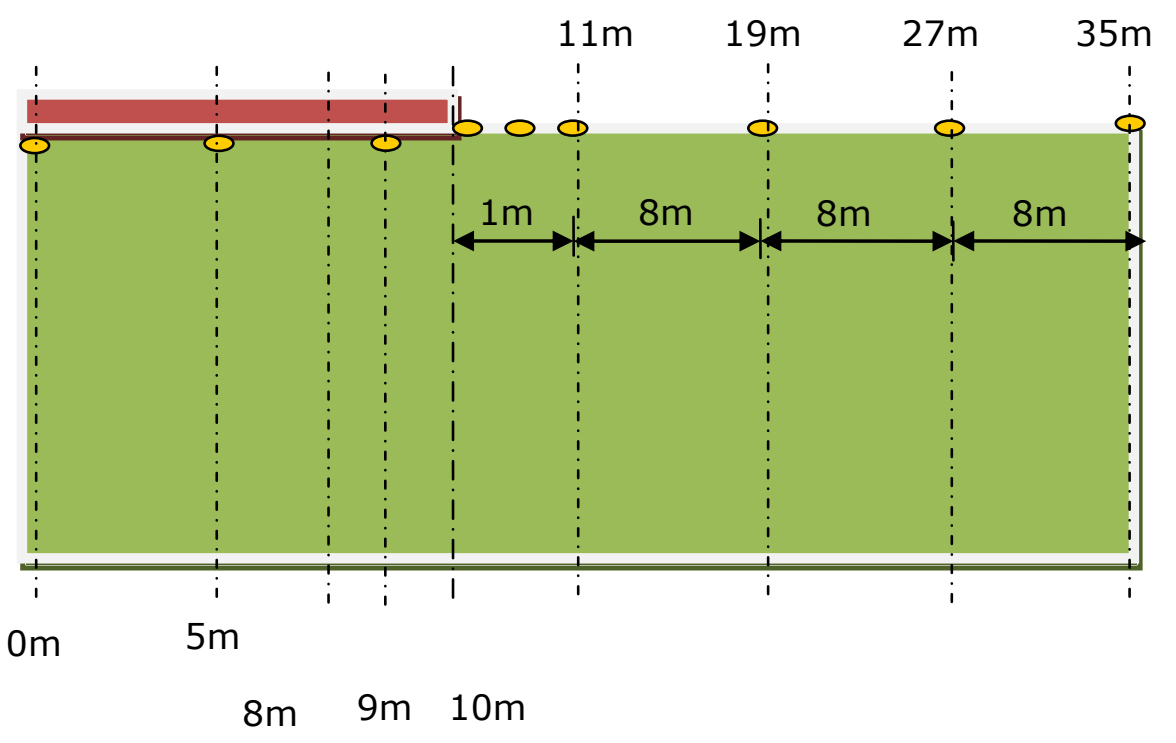




\section{C.2.1 IC and FC PWP Plots for No Replacement Expansive Clay Case}

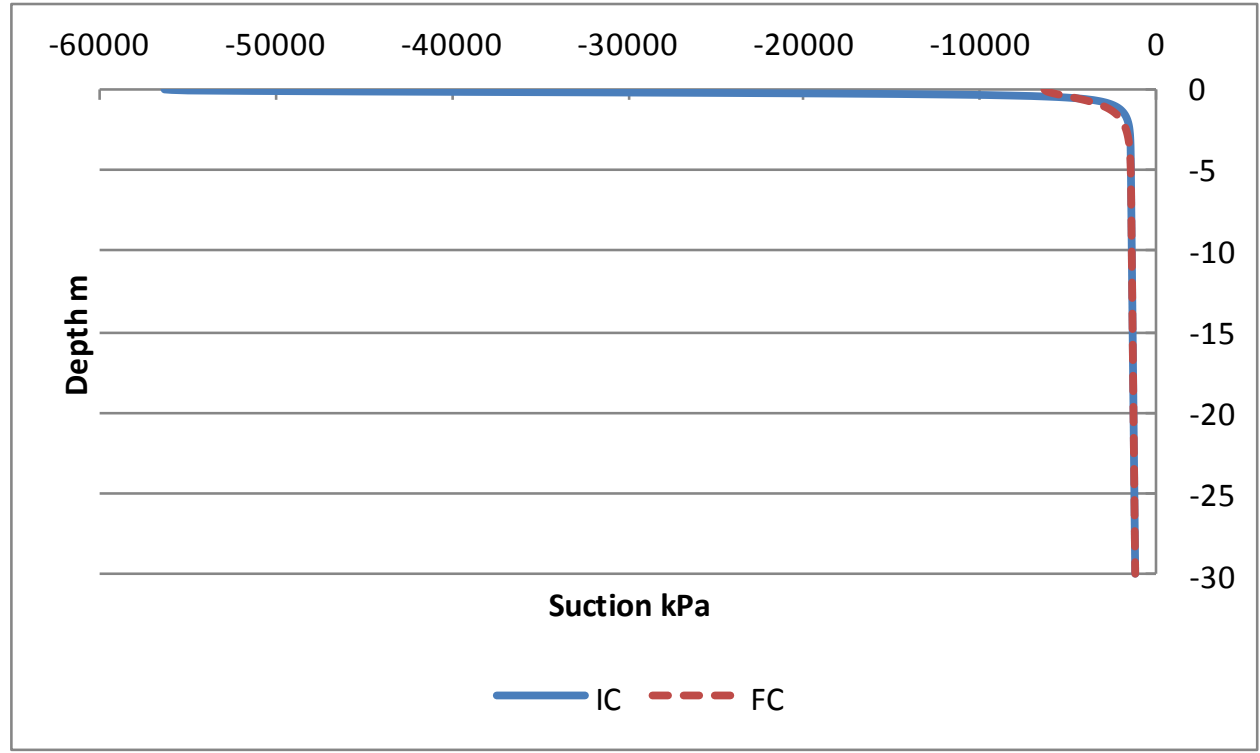

Figure C.73. Vertical suction profile at $0 \mathrm{~m}$

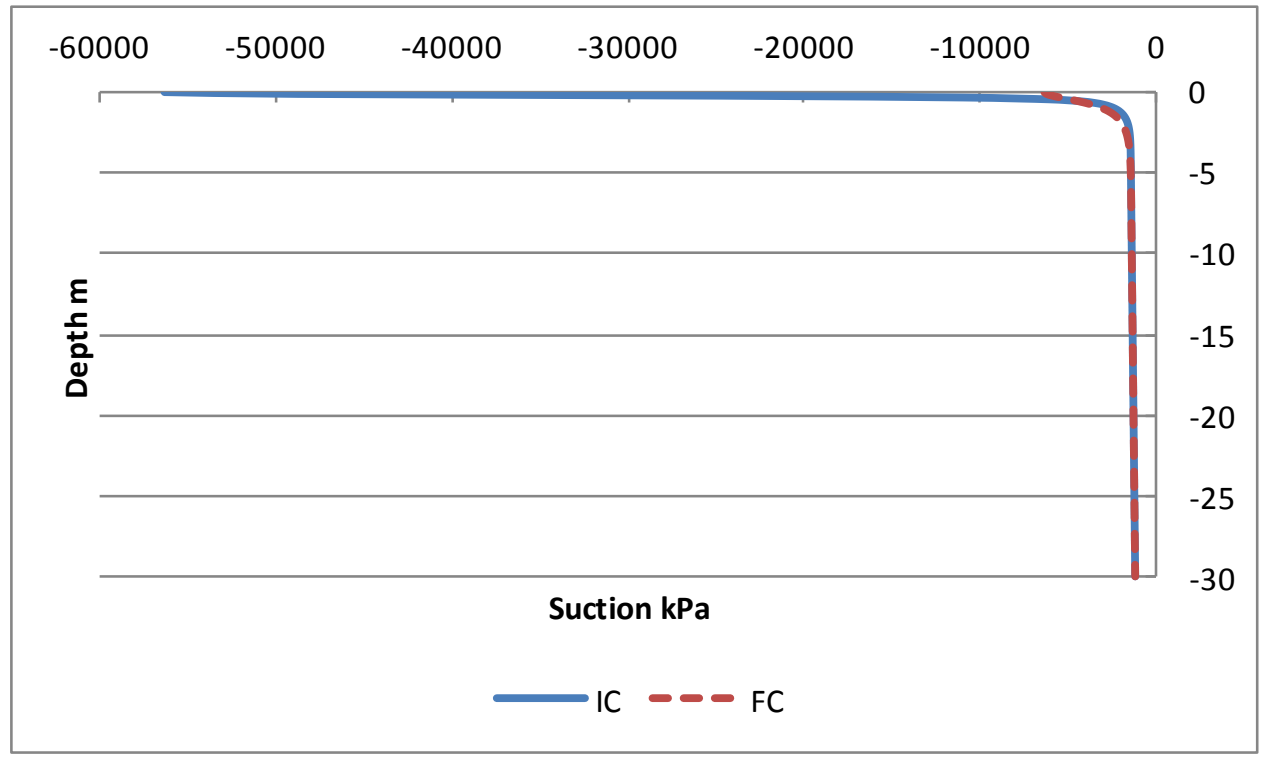

Figure C.74. Vertical suction profile at $5 \mathrm{~m}$ 


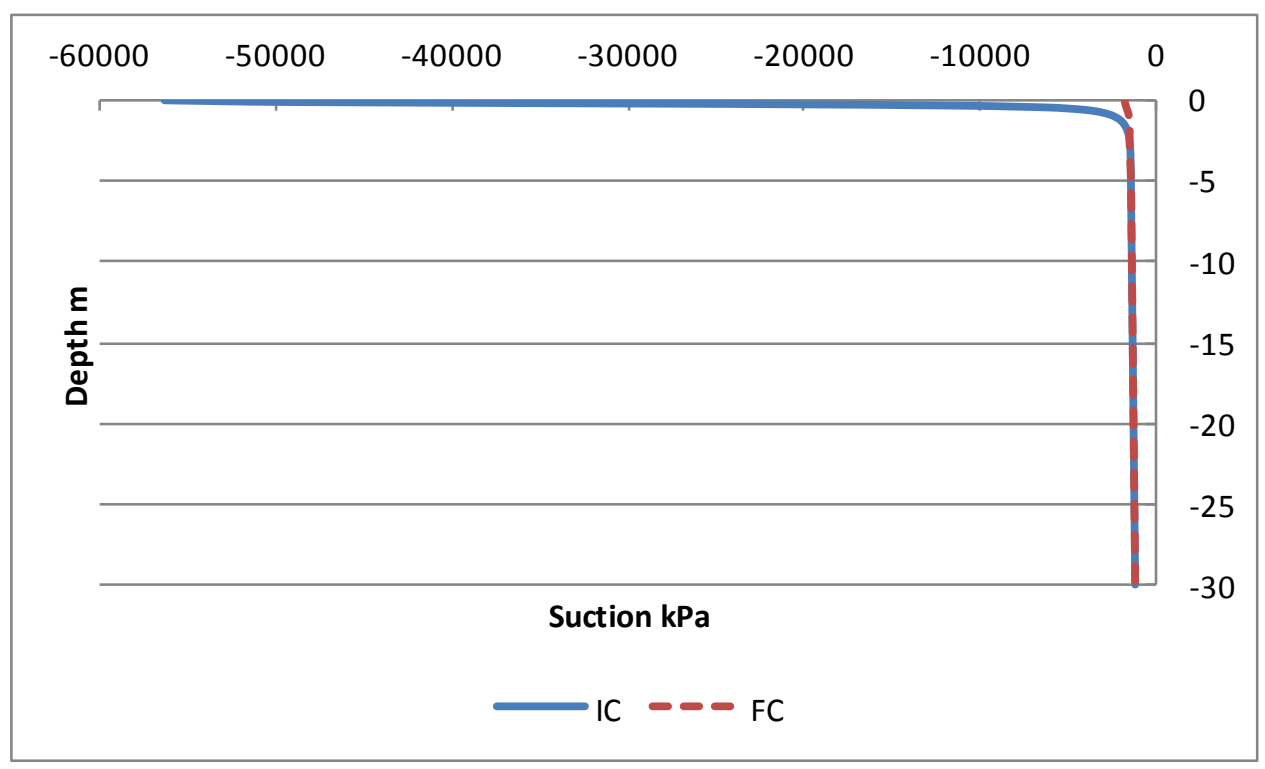

Figure C.75. Vertical suction profile at $8 \mathrm{~m}$

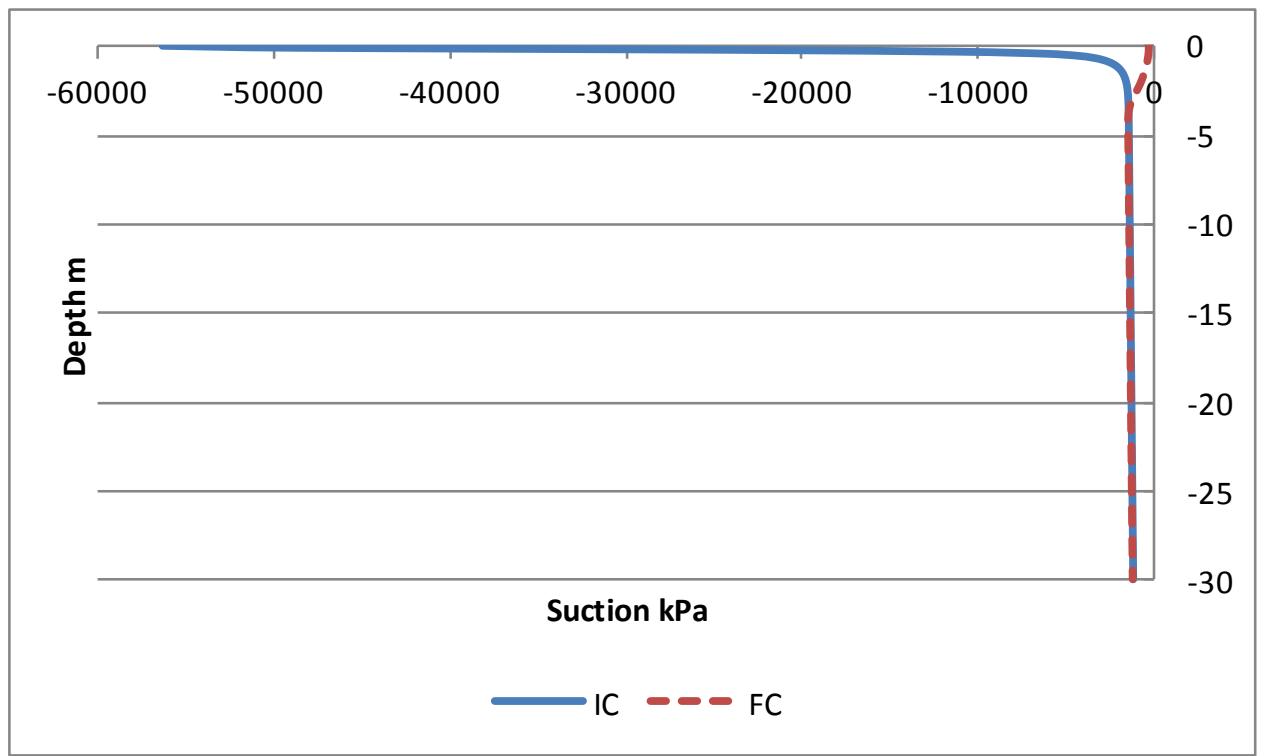

Figure C.76. Vertical suction profile at 9m 


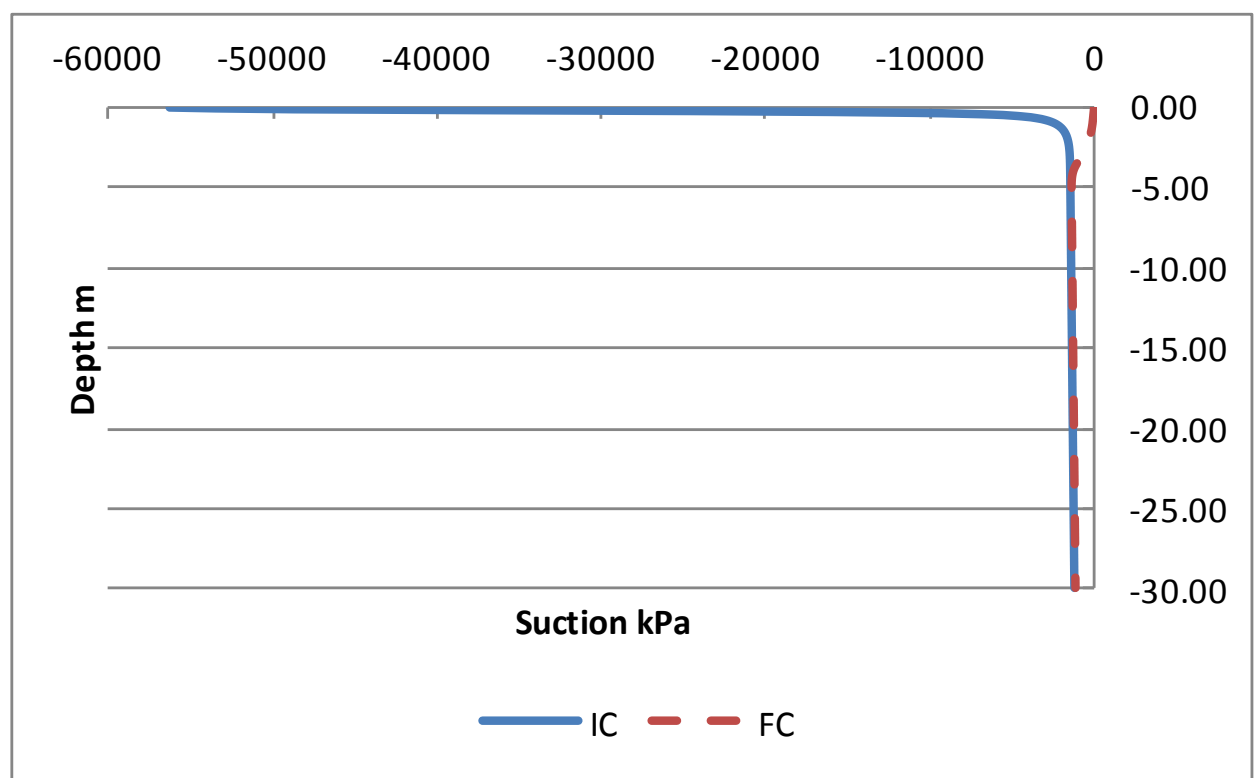

Figure C.77.Vertical suction profile at $10 \mathrm{~m}$

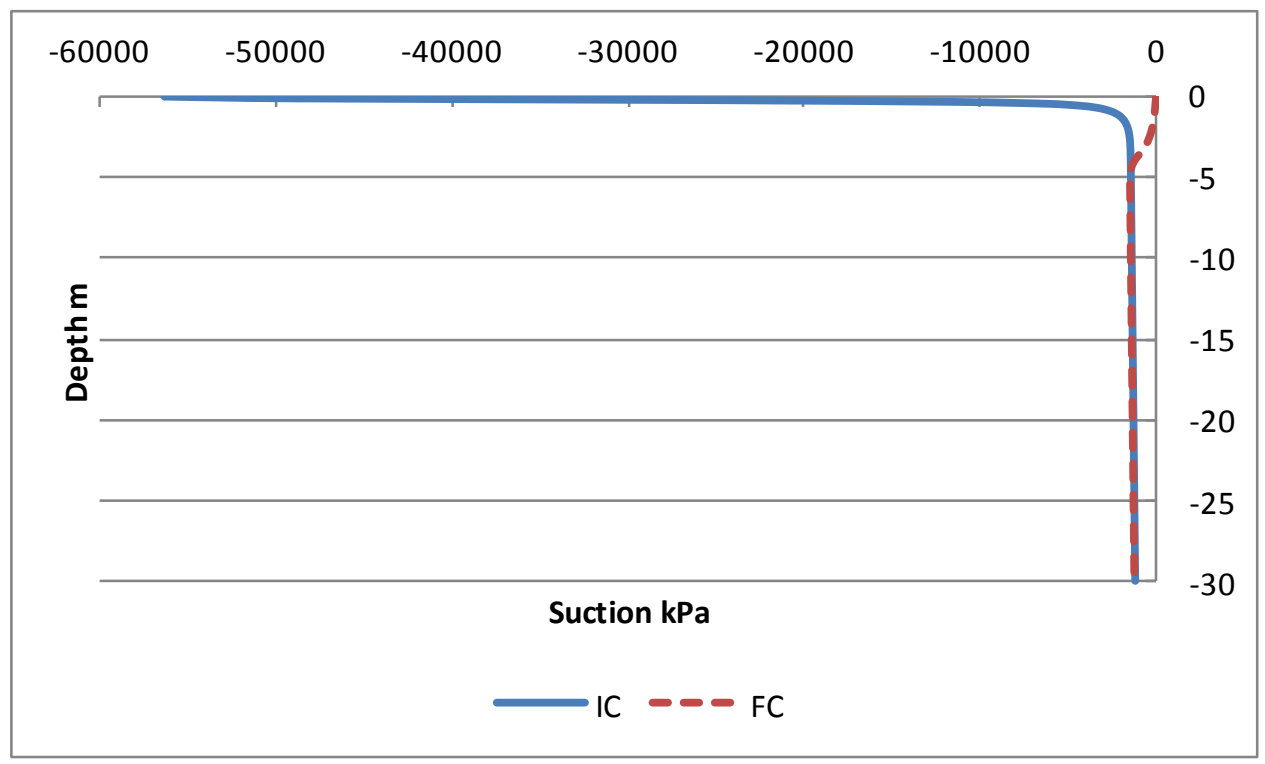

Figure C.78. Vertical suction profile at $11 \mathrm{~m}$ 


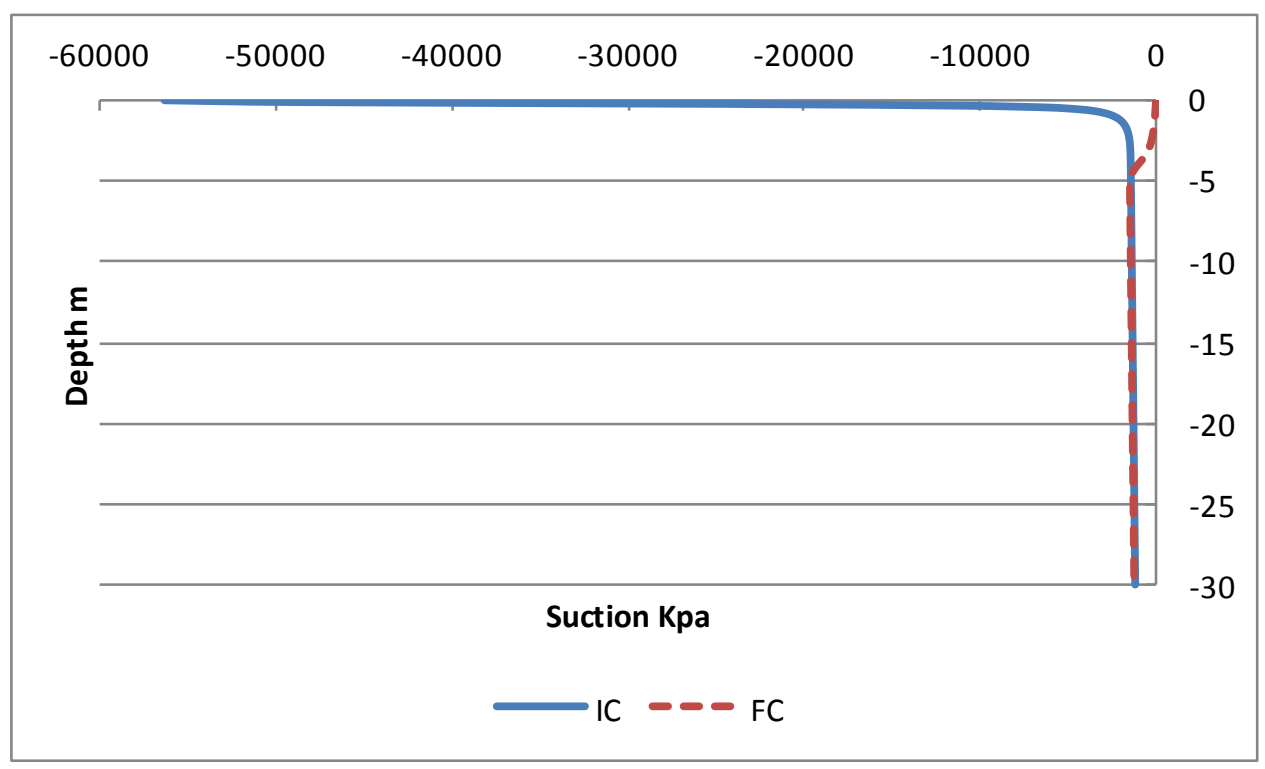

Figure C.79. Vertical suction profile at $19 \mathrm{~m}$

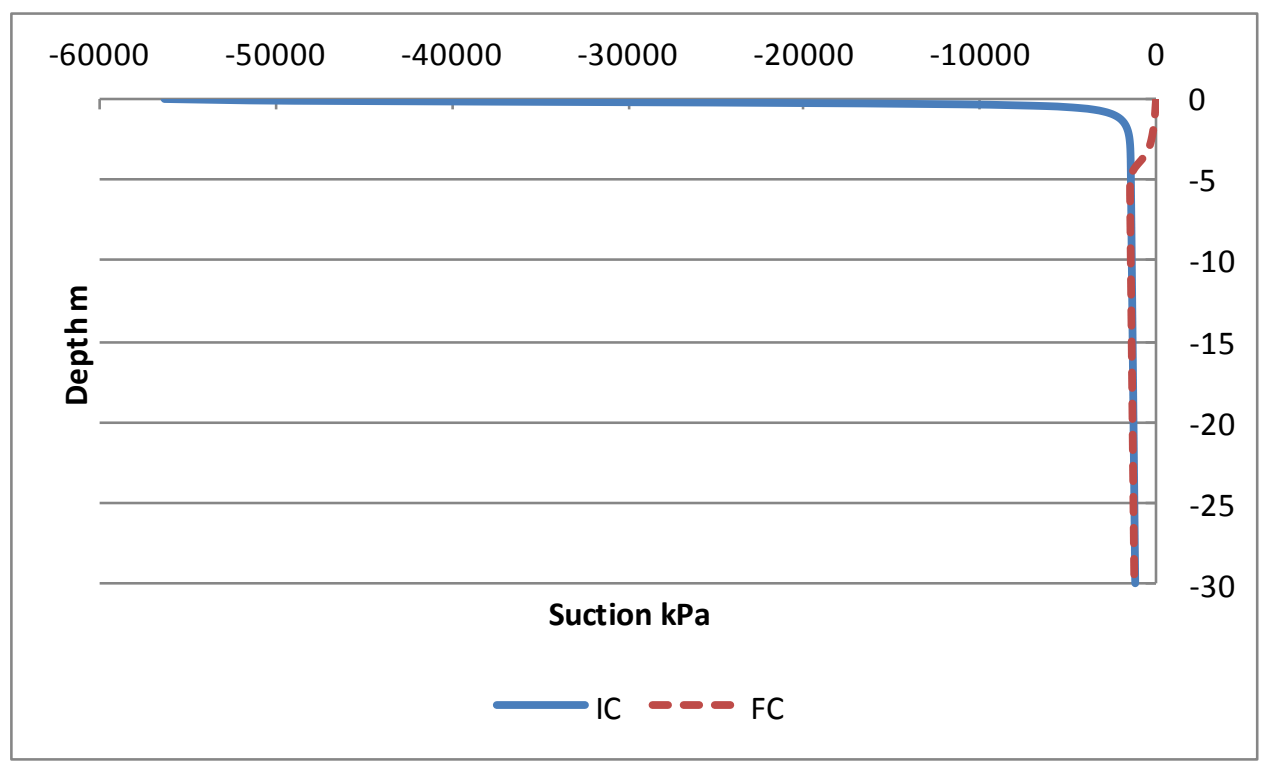

Figure C. 80 . Vertical suction profile at $27 \mathrm{~m}$ 


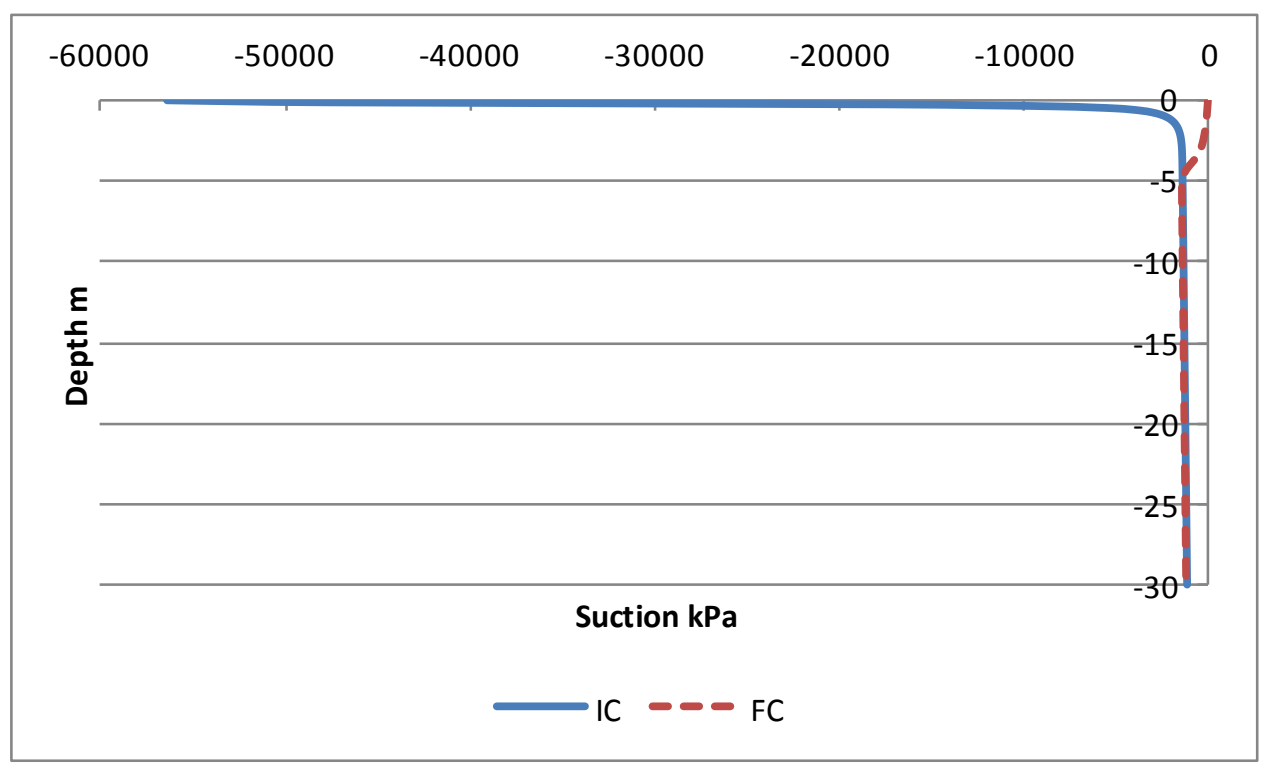

Figure C.81. Vertical suction profile at $35 \mathrm{~m}$

\section{C.2.2 IC and FC Suction Plots $\mathbf{0 . 5 m}$ Lower $\mathbf{K}_{\text {sat }}$ Replacement Layer Case}

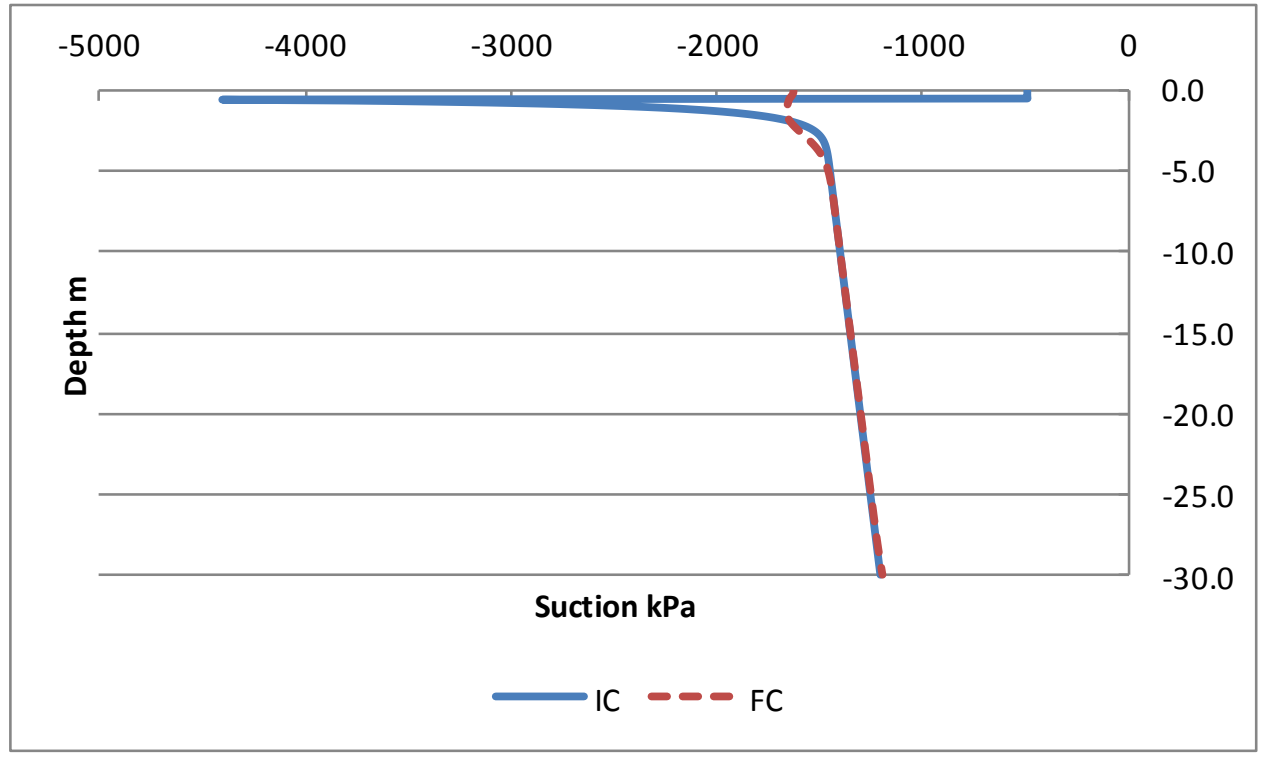

Figure C.82. Vertical suction profile at $0 \mathrm{~m}$ 


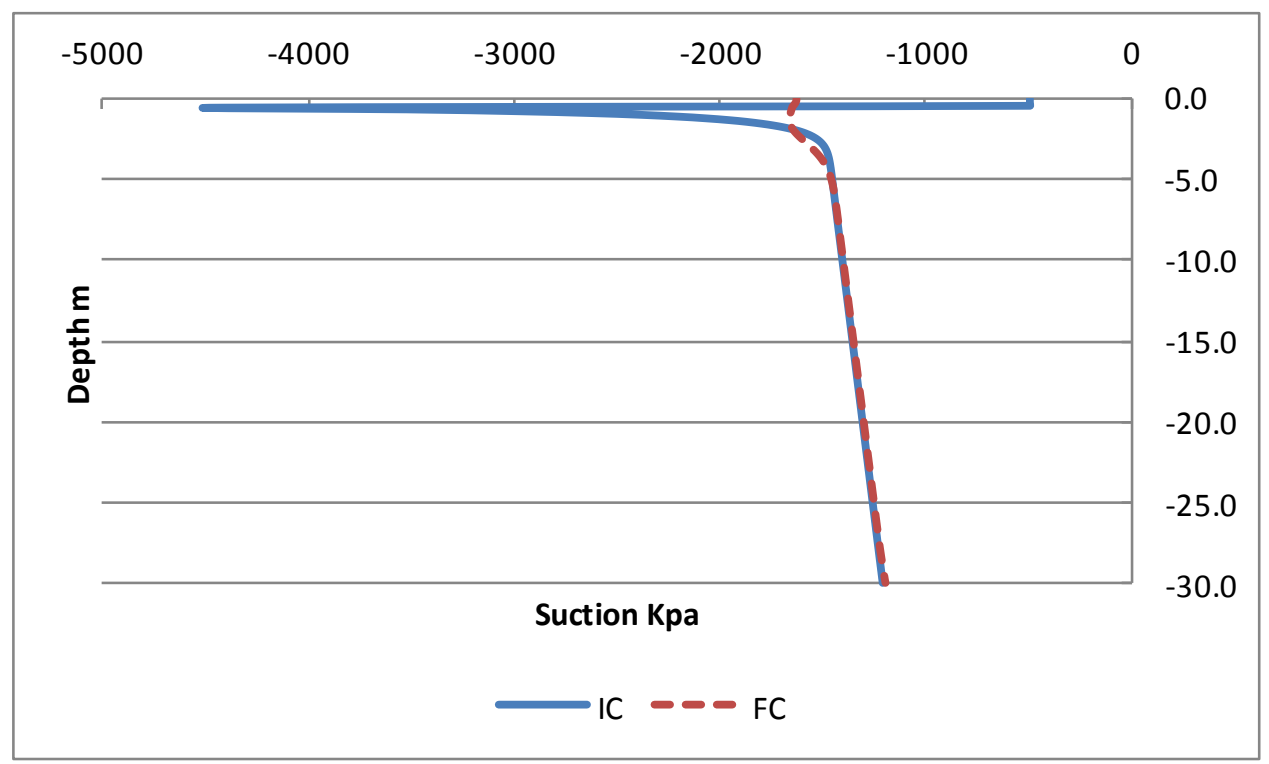

Figure C.83. Vertical suction profile at $5 \mathrm{~m}$

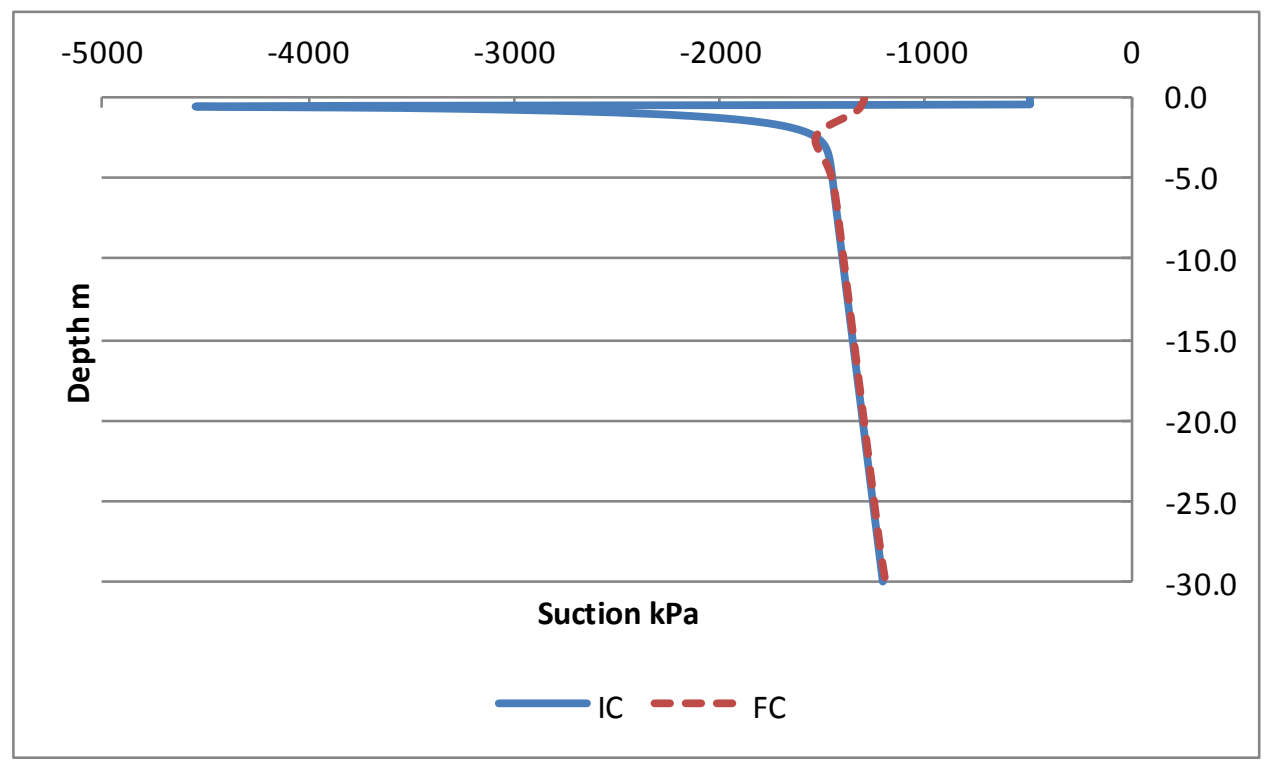

Figure C.84. Vertical suction profile at $8 \mathrm{~m}$ 


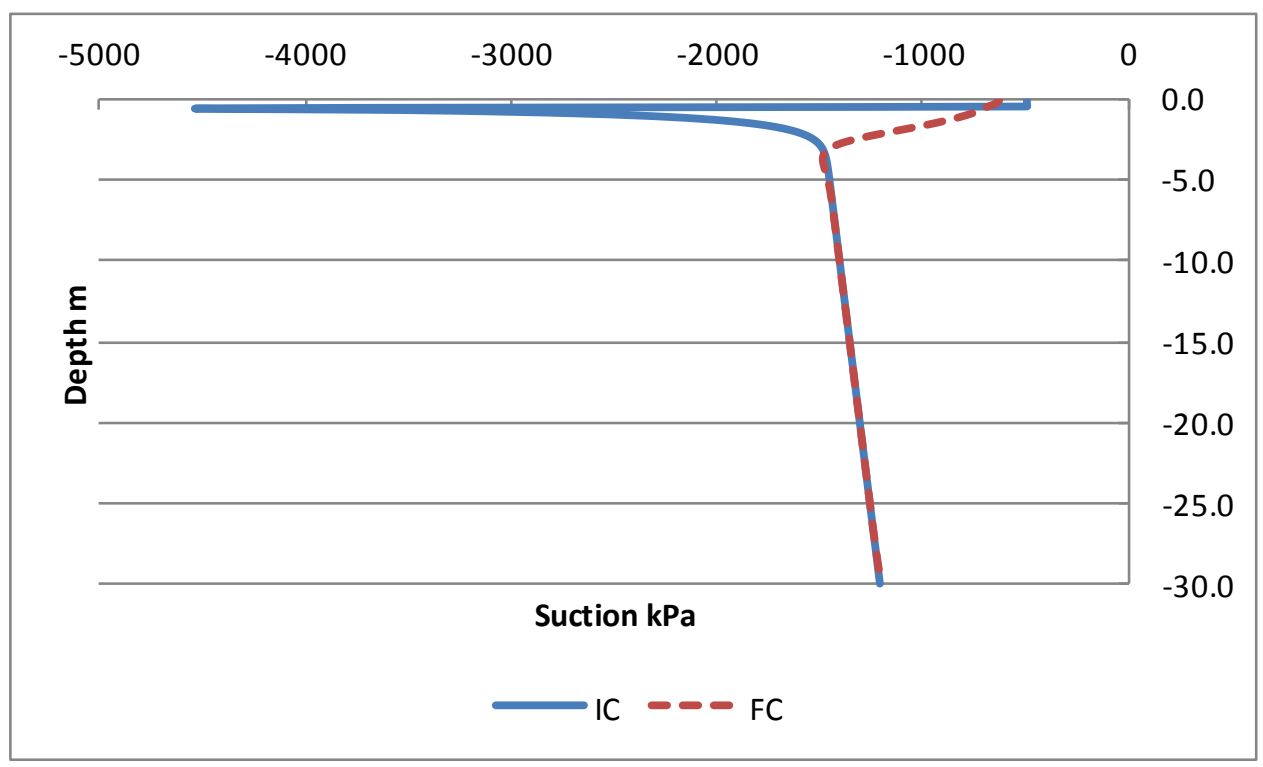

Figure C.85. Vertical suction profile at $9 \mathrm{~m}$

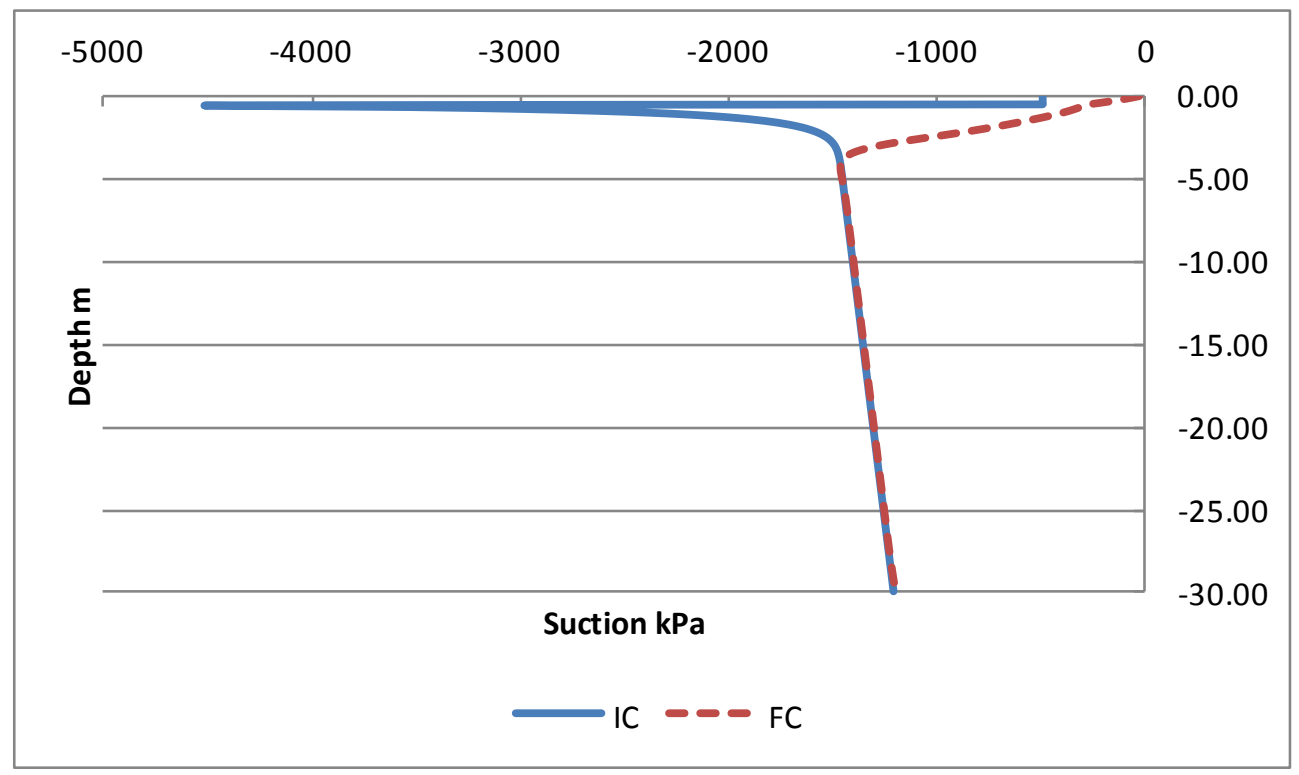

Figure C.86. Vertical suction profile at $10 \mathrm{~m}$ 


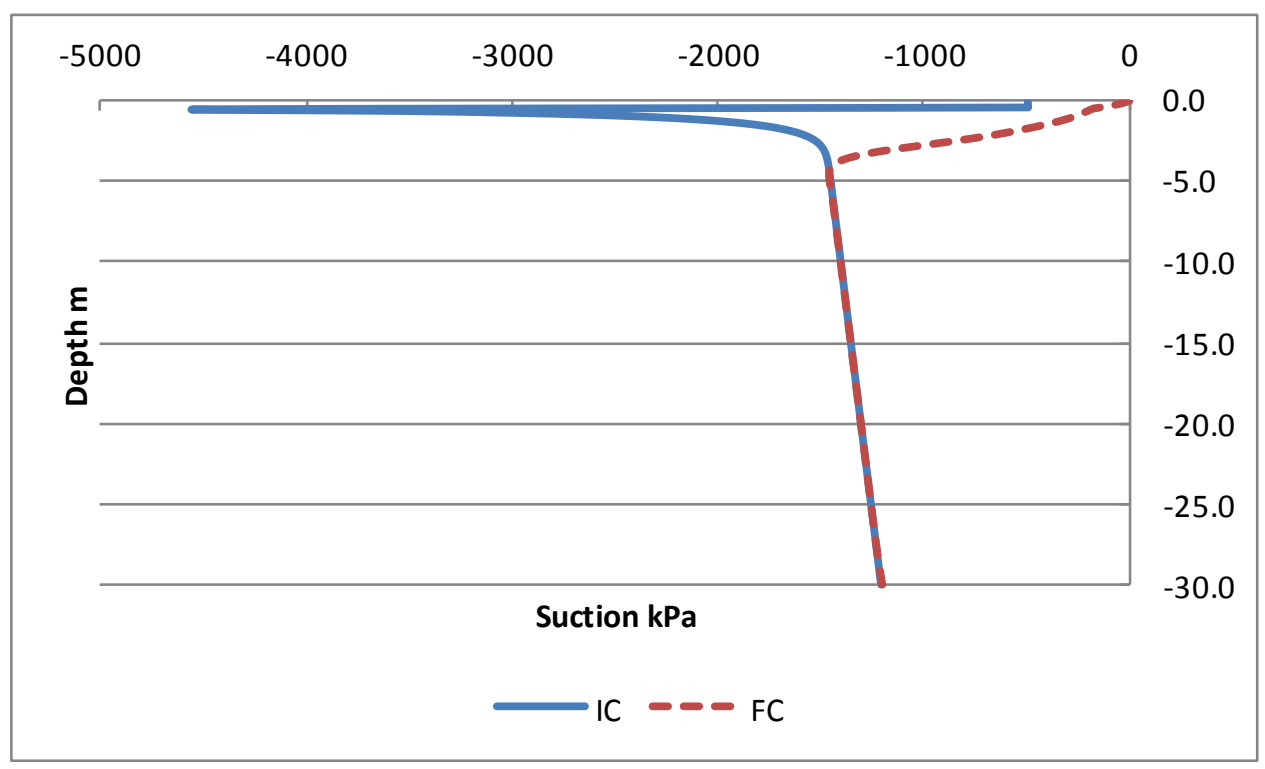

Figure C.87. Vertical suction profile at $11 \mathrm{~m}$

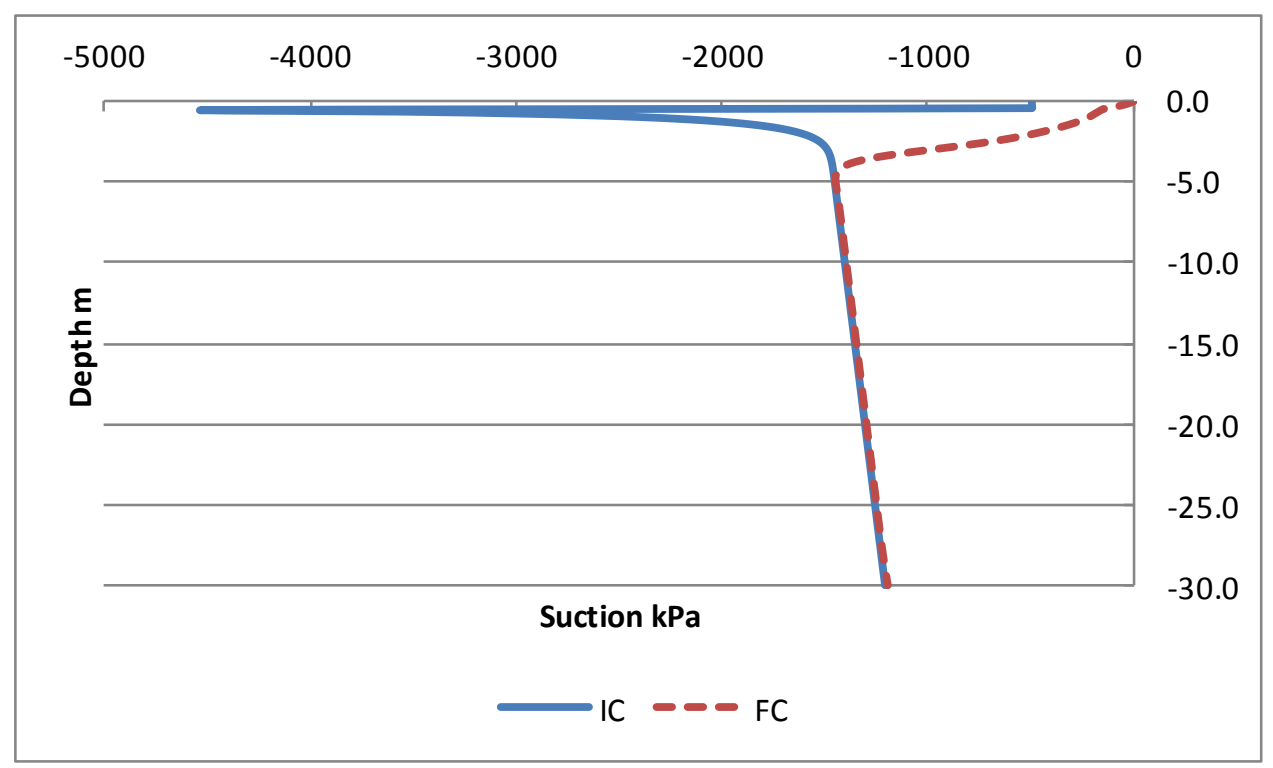

Figure C.88. Vertical suction profile at $19 \mathrm{~m}$ 


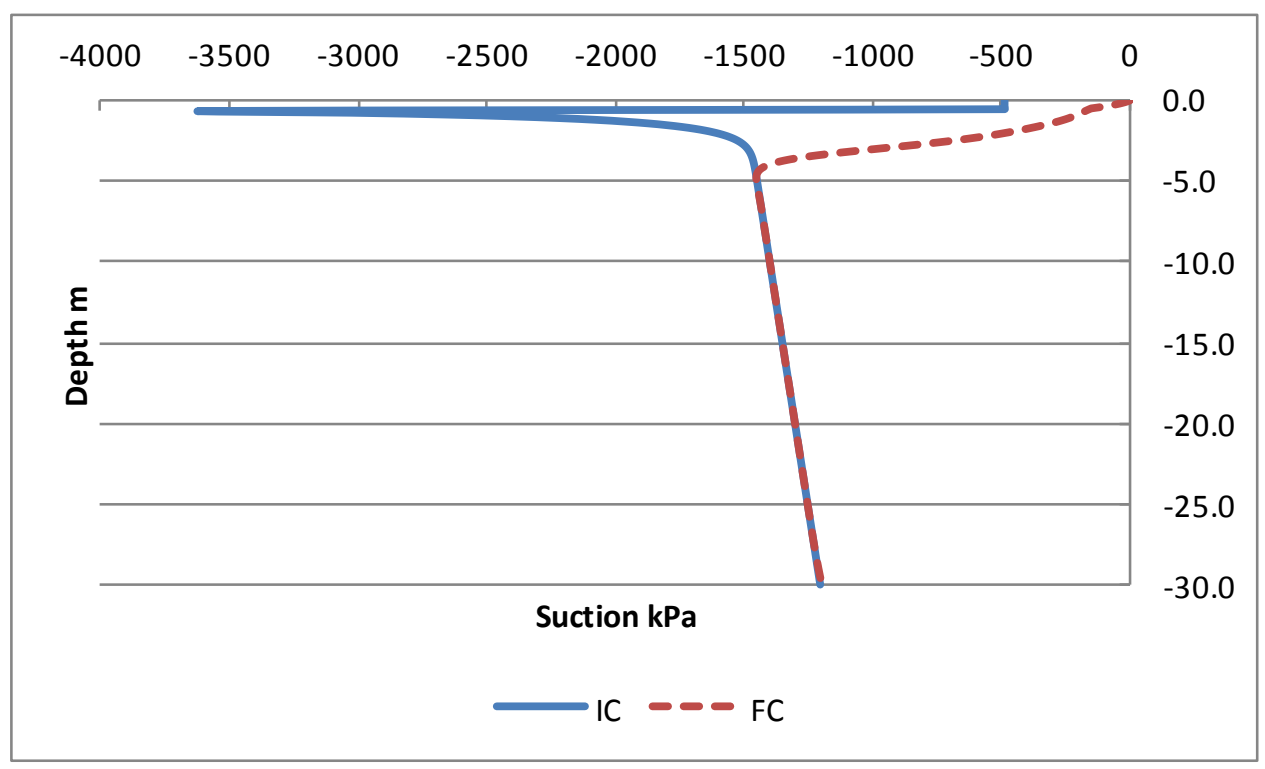

Figure C.89. Vertical suction profile at $27 \mathrm{~m}$

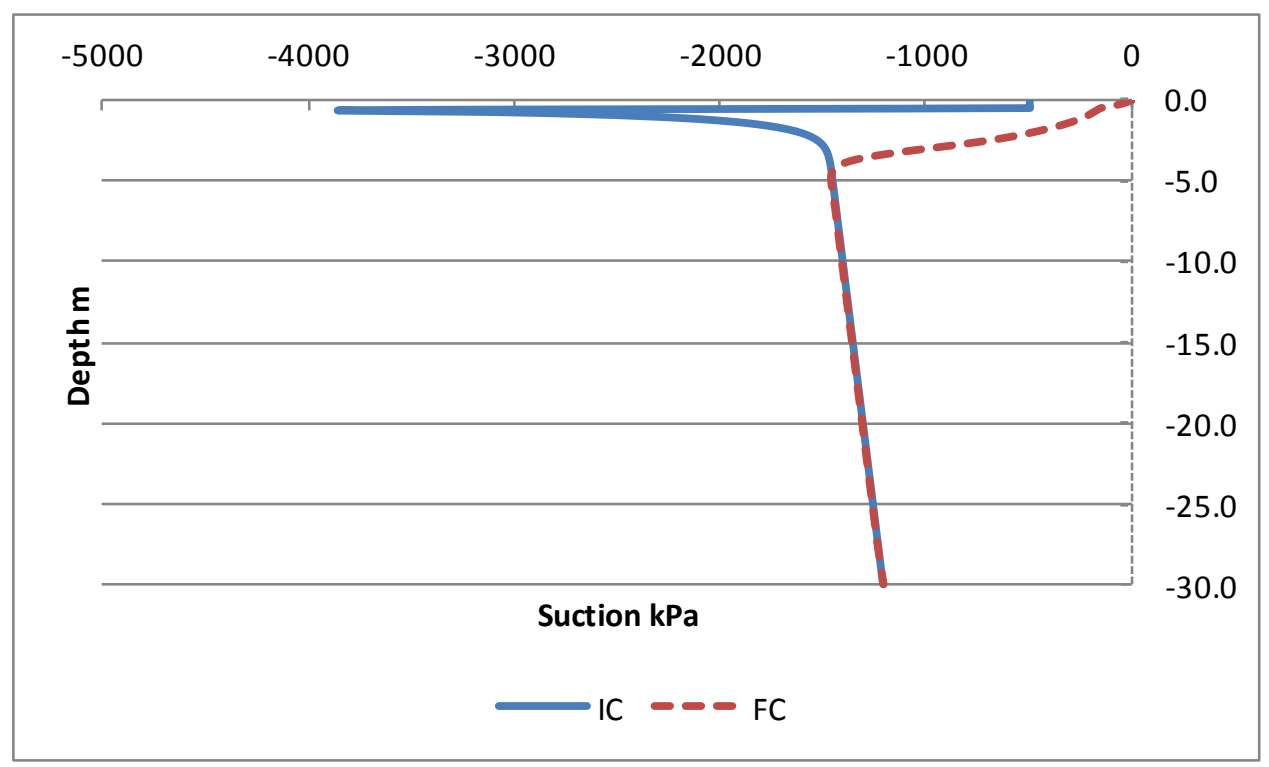

Figure C.90. Vertical suction profile at $35 \mathrm{~m}$ 


\section{C.2.3 IC and FC Suction Plots $2 \mathrm{~m}$ Same $\mathbf{K}_{\text {sat }}$ Replacement Layer Case}

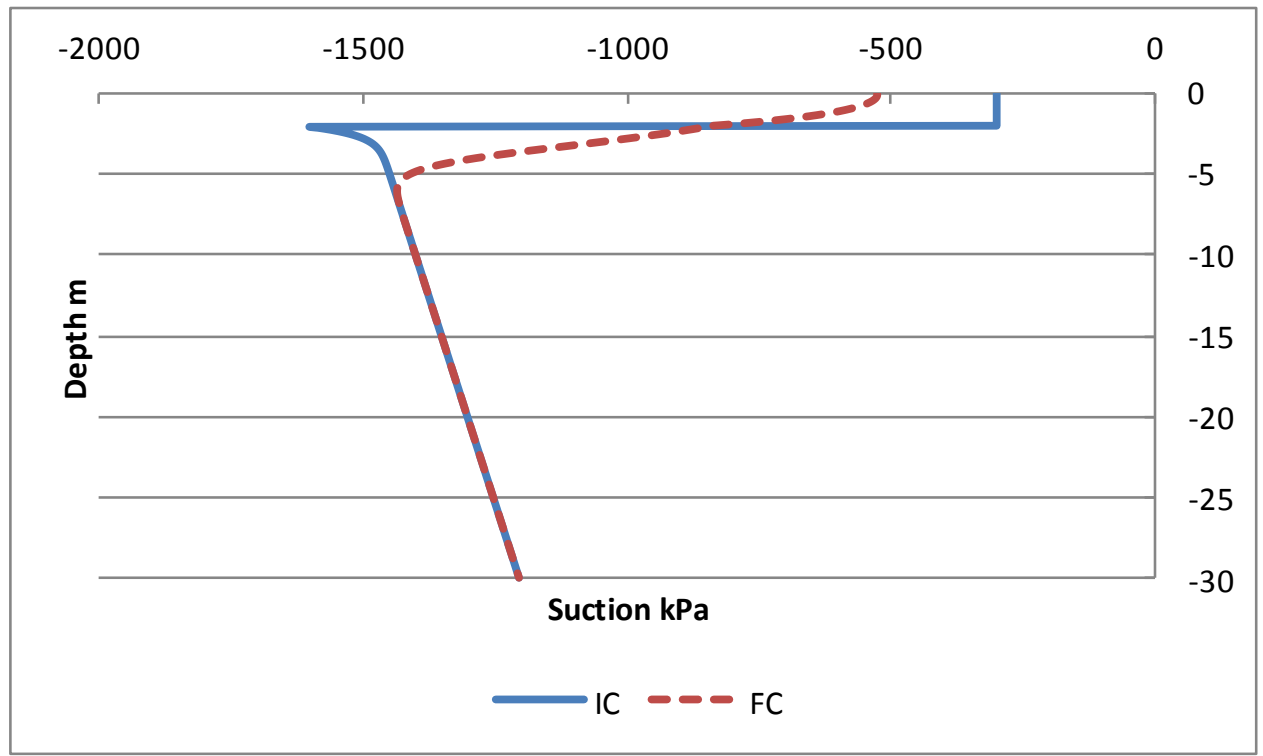

Figure C.91. Vertical suction profile at $0 \mathrm{~m}$

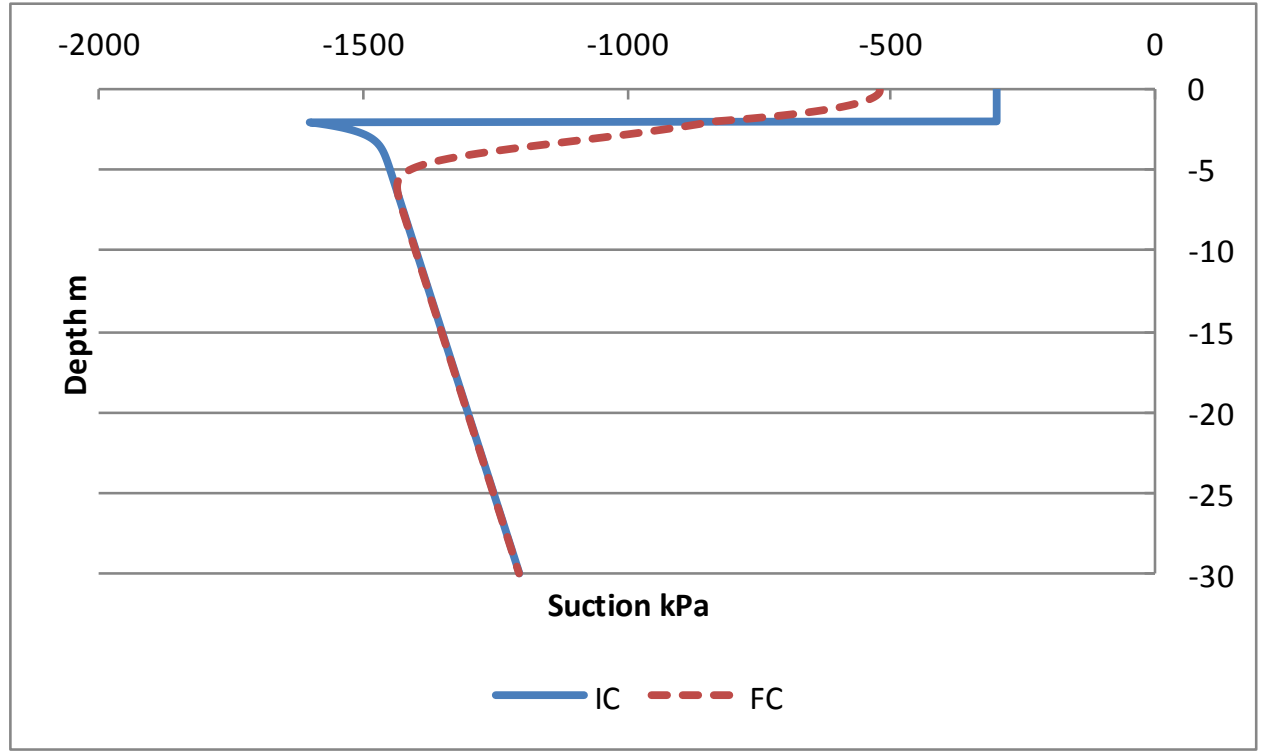

Figure C.92. Vertical suction profile at $5 \mathrm{~m}$ 


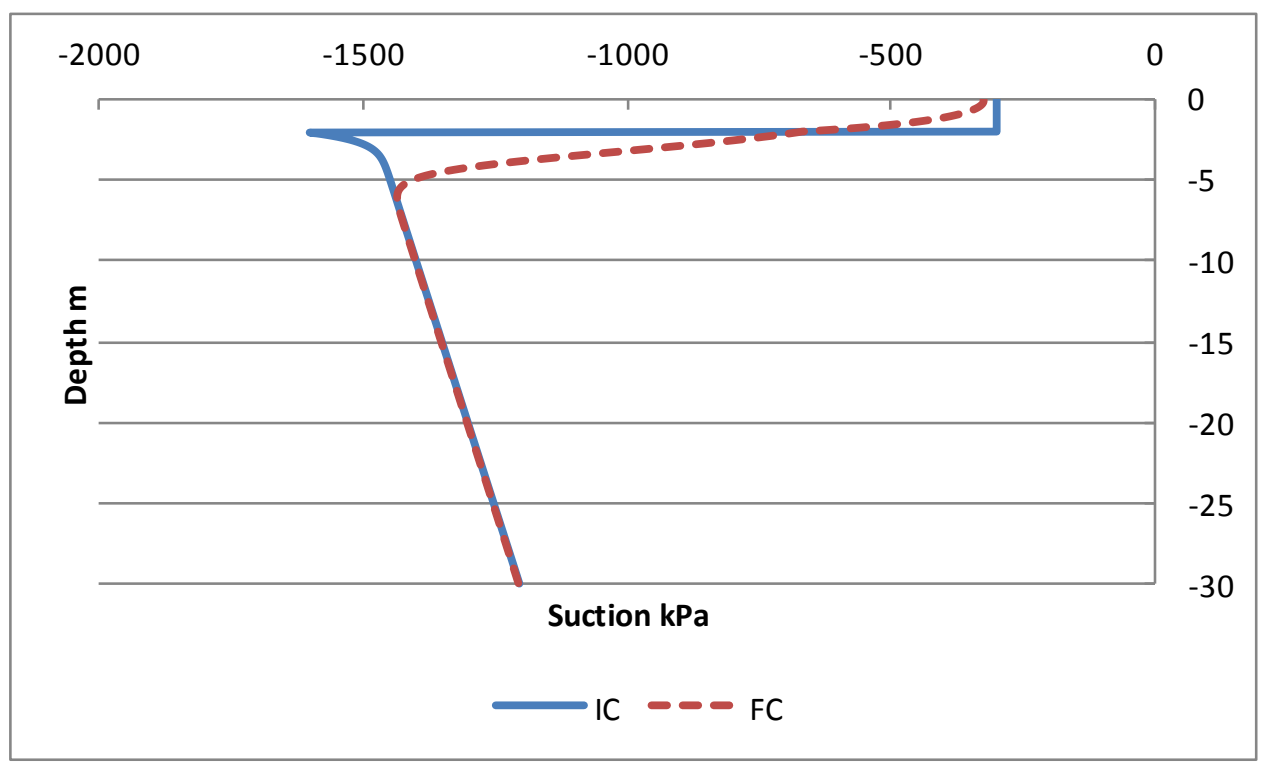

Figure C.93. Vertical suction profile at $8 \mathrm{~m}$

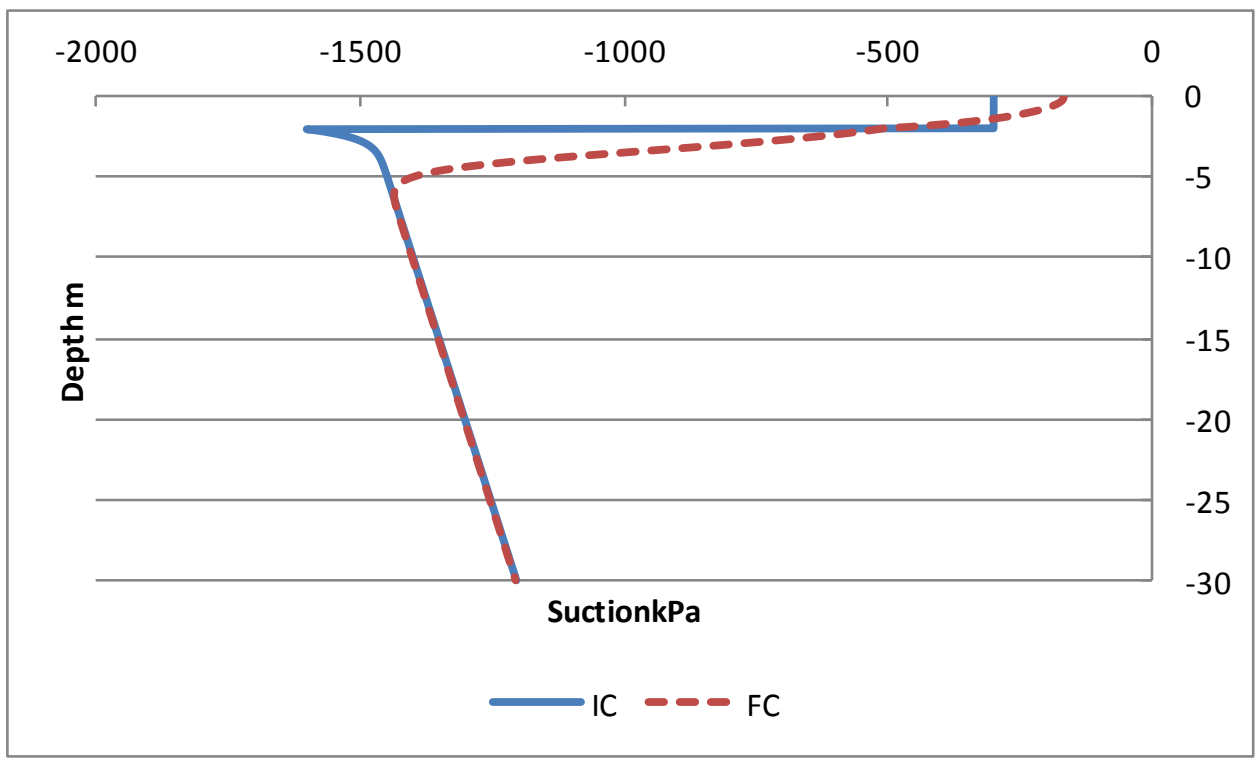

Figure C.94. Vertical suction profile at $9 \mathrm{~m}$ 


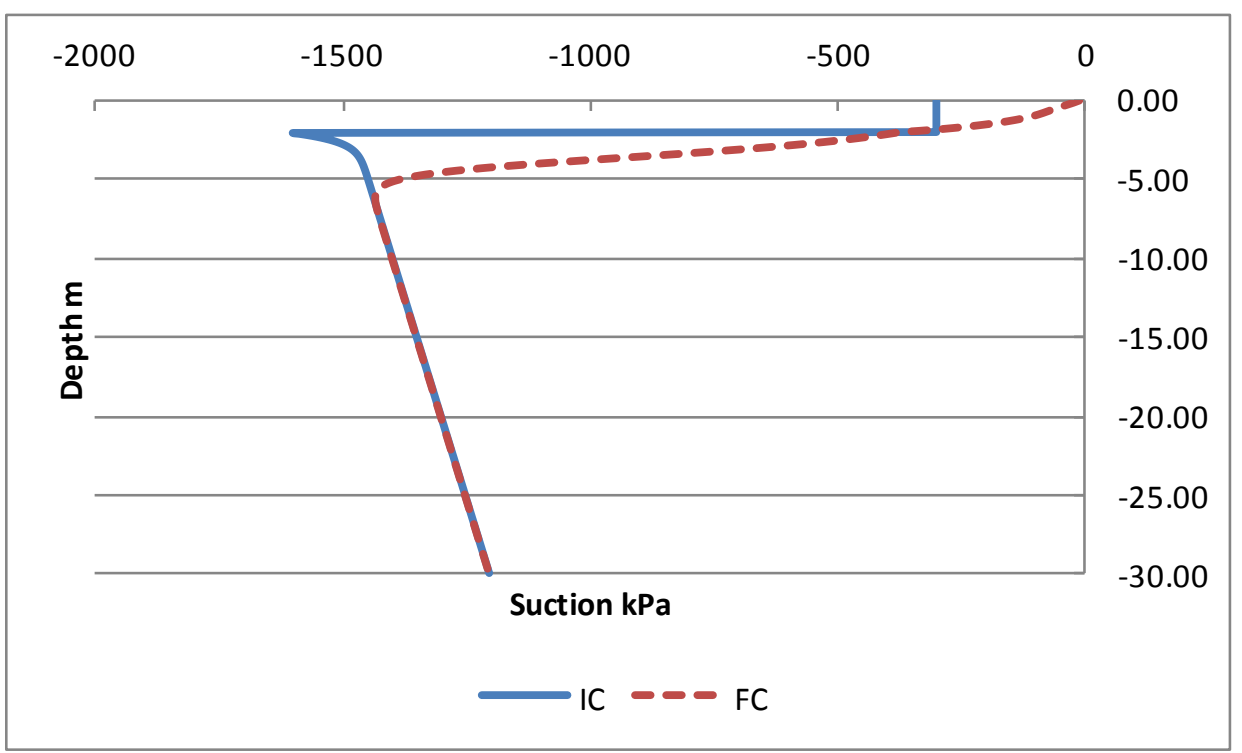

Figure C.95. Vertical suction profile at $10 \mathrm{~m}$

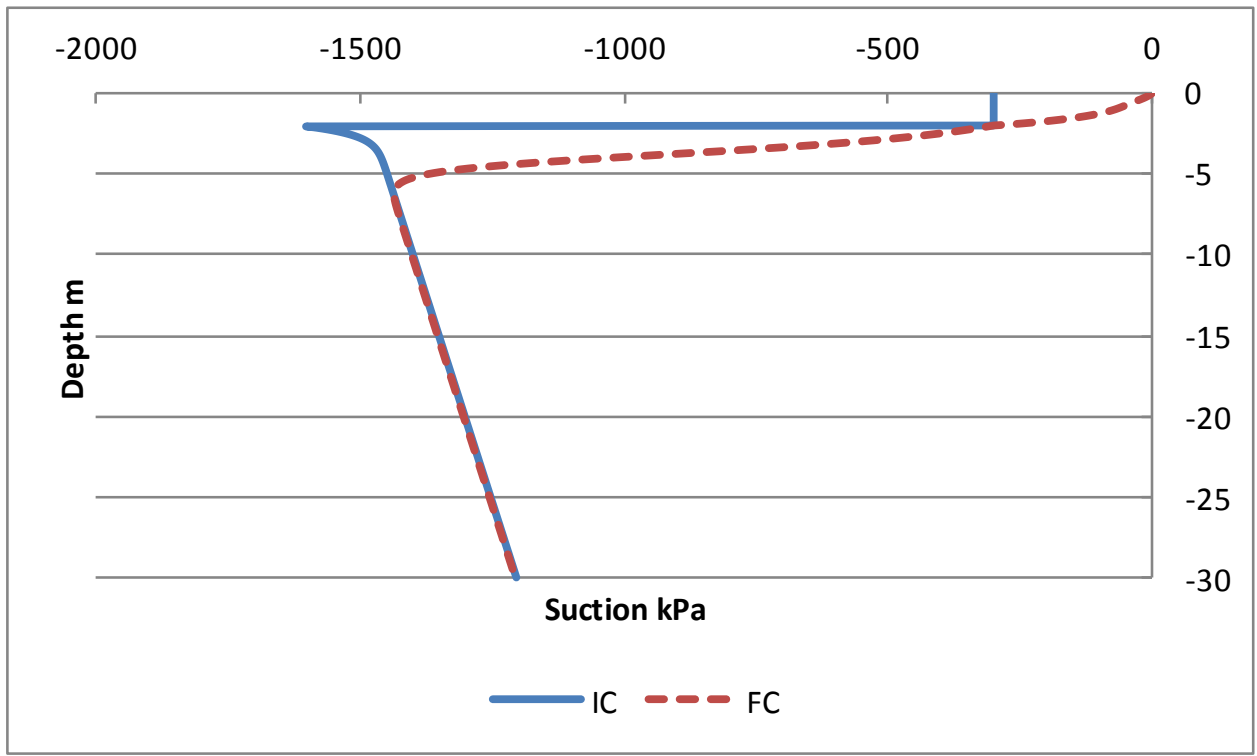

Figure C.96. Vertical suction profile at $11 \mathrm{~m}$ 


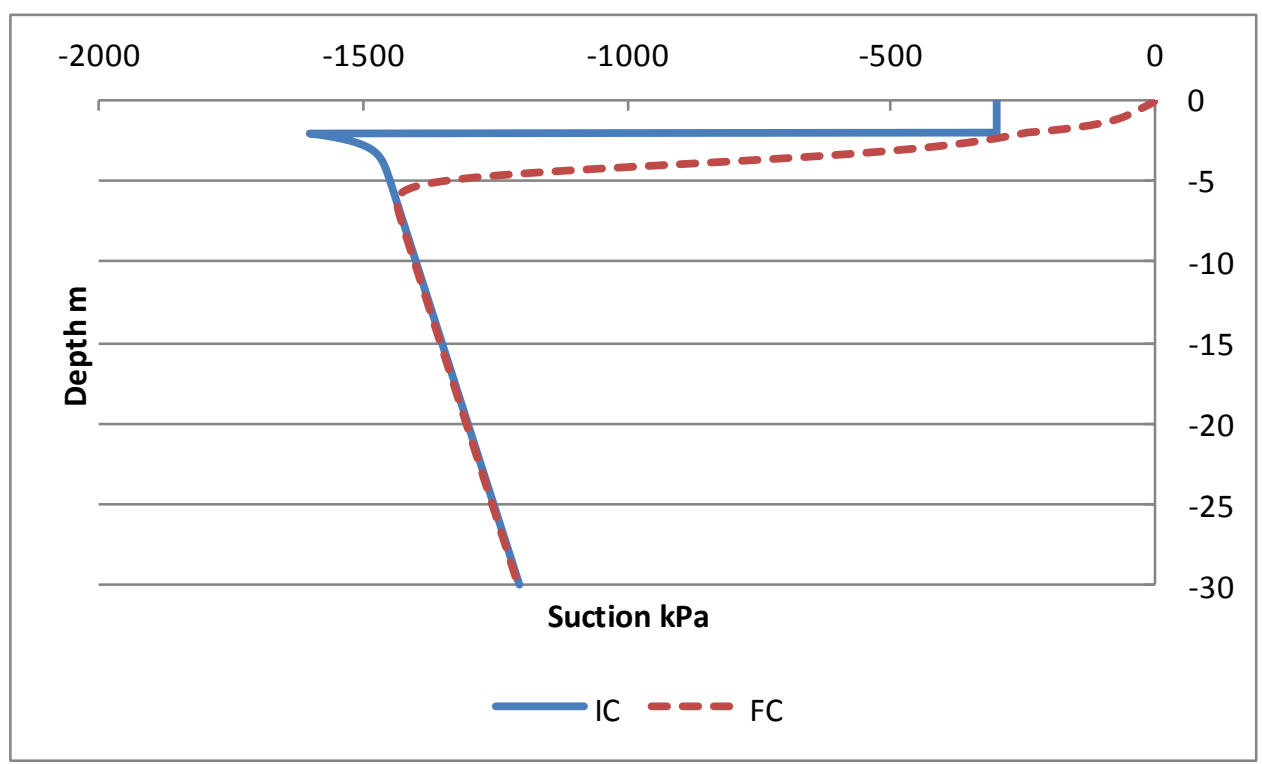

Figure C.97. Vertical suction profile at $19 \mathrm{~m}$

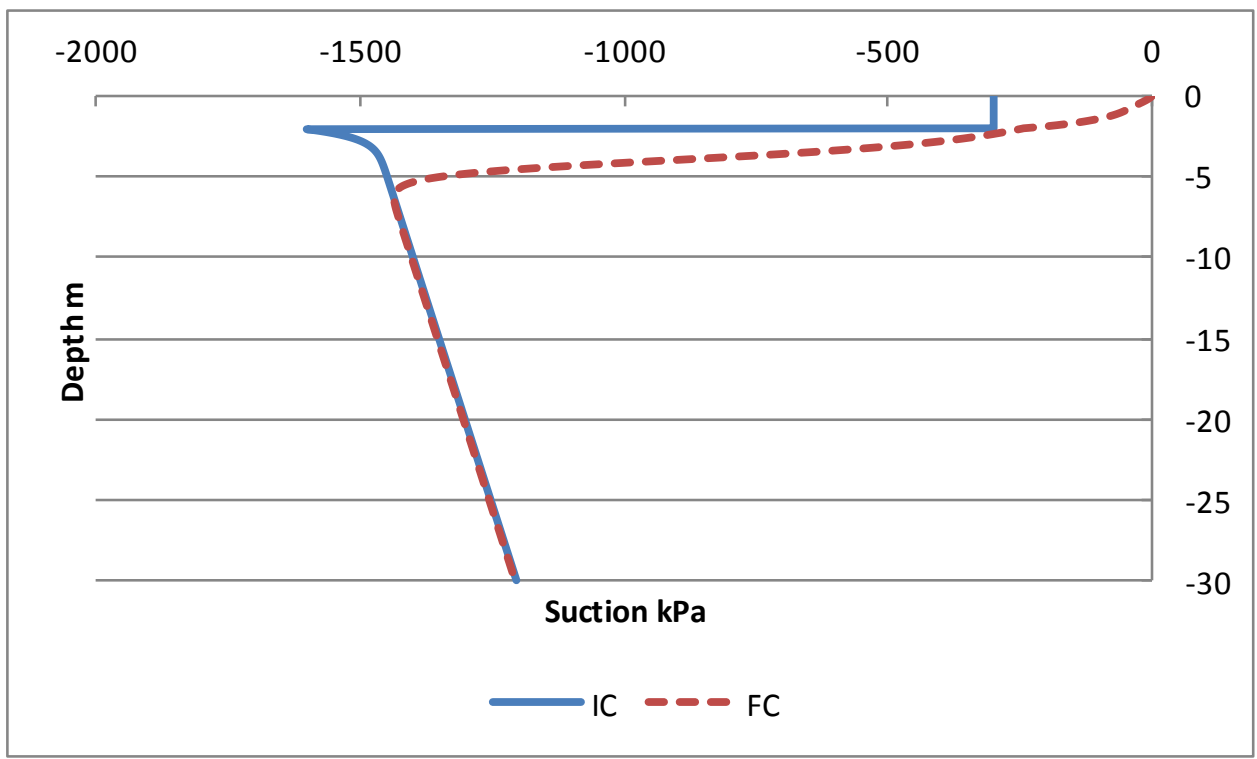

Figure C.98. Vertical suction profile at $27 \mathrm{~m}$ 


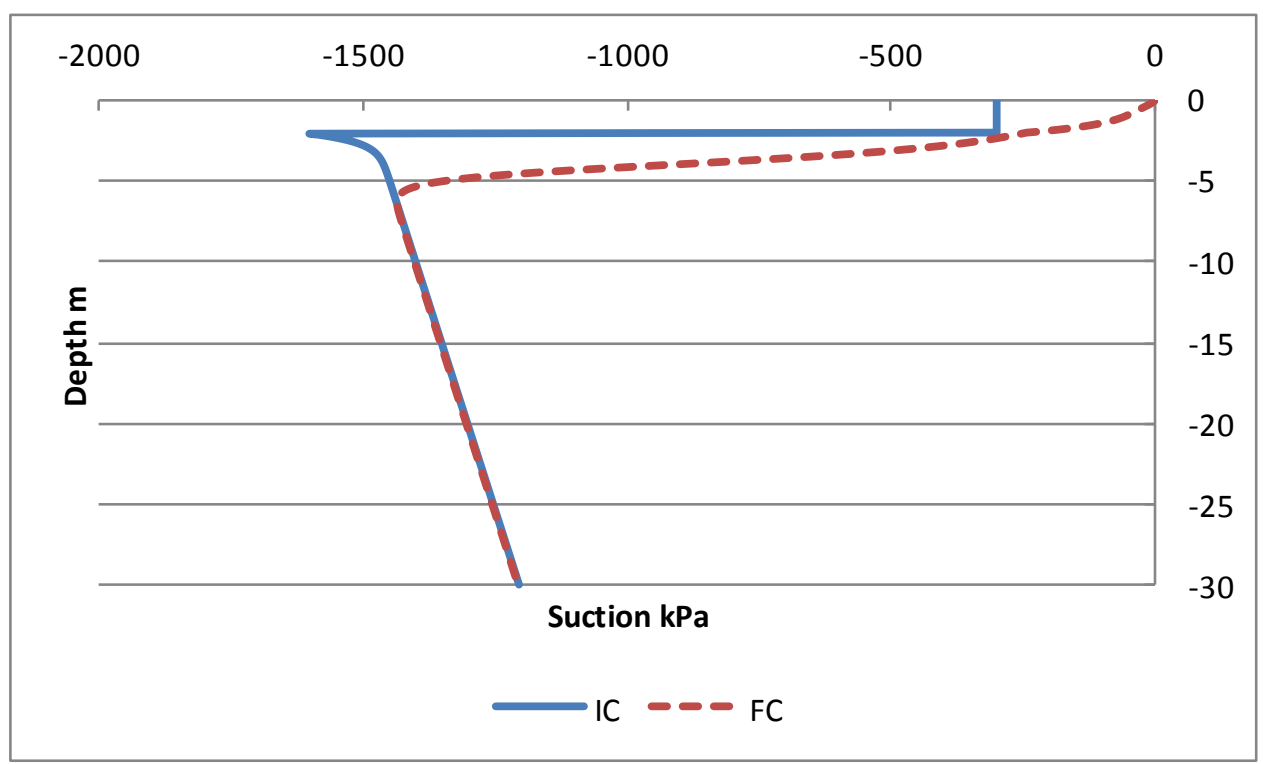

Figure C.99. Vertical suction profile at $35 \mathrm{~m}$ 


\section{APPENDIX D}

$1^{\text {ST }}$ PANAM CONFERENCE: EFFECT OF SOIL REPLACEMENT OPTION ON SURFACE DEFLECTIONS FOR EXPANSIVE CLAY PROFILES 


\title{
Effect of Soil Replacement Option on Surface Deflections for Expansive Clay Profiles
}

\author{
A. Bharadwaj, S.L. Houston, W.N. Houston \& B. Welfert \\ Arizona State University, Tempe, AZ, USA \\ K.D. Walsh \\ San Diego State University, San Diego, CA, USA
}

\begin{abstract}
In this paper the results of a stress-deformation parametric analysis are presented to show the effect of an artificial non-expansive replacement layer over an intact expansive soil on the heave at the surface. Finite element code SV Flux and SV Solid are used to perform the stress-deformation analysis. Climatic boundary conditions for a semi arid region are used. Significant decreases in the heave amount were noted, depending on the thickness and soil type of the replacement soil.
\end{abstract}

\section{INTRODUCTION}

Expansive soils are associated with shrink and swell behavior and may cause serious damage to structures. Residential foundations such as slab-on ground are generally built on unsaturated soils including expansive soils and are subject to deformations associated with changes in matric suction/ moisture content in the soil. The problem of expansive soils is more pronounced in arid regions where changes in soil suction as a result of development can be much greater than in humid regions. Expansive soils are also called moisture sensitive soils because when subjected to wetting, they undergo substantial volume changes associated with the swelling process.

Various methods are available and practiced to reduce swelling in soils at the ground surface to prevent the damage caused to structures. Mitigation measures may be broadly defined as any actions or designs that lessen or solve moisture sensitive soil problems (Houston et al. 2001).

Among the various techniques for expansive soil mitigation, the removal and replacement technique (remove-and-replace) is very popular for lightly loaded structures and shallow foundations. The heave reducing effect of replacement of expansive soil with a non expansive layer has been studied by various authors (Katti 1979, Walsh et al 2009, Murthy \& Praveen 2008) in the past. A large volume of intact soil when replaced with non expansive soil can attenuate the surface heave feature. The mechanisms for reduction of heave are: (1) removal of expansive soil with non-expansive soil results in a zone of no-heave where the expansive soils are replaced, thereby reducing surface heave, (2) the replacement soil may change the degree and depth of wetting in the native expansive clay profile by increasing, decreasing, or having only minimal effect on the amount of surface and near-surface water that infiltrates into the soil, (3) the placement of a non-expansive soil layer pushes the seat of movement deeper into the profile, thereby reducing the differential movements at the ground surface, and (4) the non-expansive soil layer may provide 
increased confinement for any expansive soil that does get wet, thereby reducing volume change

In general, the non-expansive soil layer could have a saturated hydraulic conductivity the same as, higher than, or lower than the underlying expansive soil. As a part of an on-going study at Arizona State University, the full range of hydraulic properties of the replacement layer is being evaluated. In this paper, preliminary findings are presented for the case of remove-and-replace mitigation where the replacement layer has a higher hydraulic conductivity than the underlying clay. This represents, for example replacement of expansive soil with a non-expansive granular fill.

\section{ANALYSIS OF SLAB-ON-GROUND FOUNDATION ON EXPANSIVE CLAY PROFILE WITH REMOVE-AND- REPLACEMENT MITIGATION}

The problem that was analyzed is described schematically in figure 1 . In these analyses the problem is analyzed as a two-dimensional (2D) problem for both fluid flow and deformation. The soil properties of clay typical of highly plastic clays in the Phoenix, Arizona, region were used. The clay is classified as $\mathrm{CH}$, has a LL of 85 and a PI of 53 and a swell pressure of $700 \mathrm{kPa}$.

The basic soil properties of the expansive clay are tabulated below in Table 1. In the simulation performed, roof runoff from the residential house falls directly on the edge of the foundation of the house. A pond of $150 \mathrm{~mm}$ (6 inches) depth is allowed to occur a during rain event, and any additional roof runoff is allowed to run off of the site. The surface flux conditions outside of the region of ponding correspond to natural climatic conditions. The surface flux simulates desert landscaping conditions with some degree of ponding of rain water next to the structure. This has been observed to be a fairly common condition for residential structures in the Phoenix, AZ area (Dye 2008). The concentration of water next to the structure can cause differential heave which can damage the structure.

The position of the domain boundaries (depth and width of the modeled soil profile) was determined iteratively by moving the boundaries for various SV Flux runs until position of boundaries had negligible effect on pore pressure and saturation variations in the vicinity of the slab-on-ground region. A separate analysis was performed to determine the optimum grid size (dx) and time step (dt) to obtain numerically stable results for this problem. A smaller $\mathrm{dx}$ was chosen for the upper layers since changes in soil moisture content are concentrated in the upper region of the profile. Deep down in the profile a larger grid size was used. The $\mathrm{dx}$ used for the expansive clay profile was $0.5 \mathrm{~m}$ globally. For the replaced soil profile a $\mathrm{dx}$ of $0.25 \mathrm{~m}$ was applied at the top (near surface) and the rest is kept at $0.5 \mathrm{~m}$. These are preliminary runs and more investigation is ongoing with even smaller grid size. The maximum time increment (dt) used for the analyses was 0.5 days.

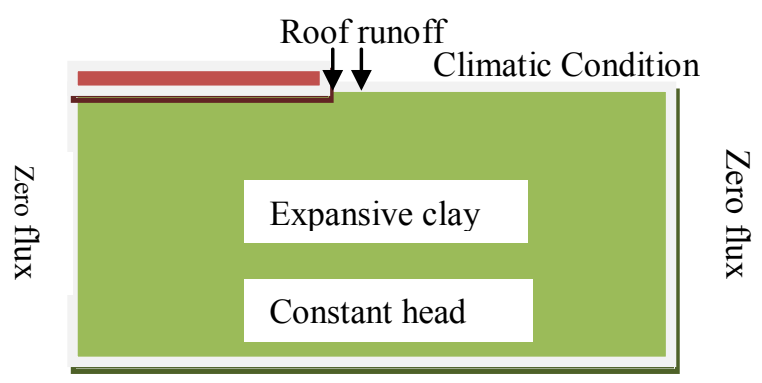

Figure 1. Schematics of the Example Problem

Table 1. Soil Properties for Expansive and Replacement soil

\begin{tabular}{lll}
\hline Soil Property & Higher Ksat & Expansive Clay \\
\hline Dry Density & $1770 \mathrm{~kg} / \mathrm{m}^{3}$ & $1360 \mathrm{~kg} / \mathrm{m}^{3}$ \\
Total unit weight & $20.6 \mathrm{kN} / \mathrm{m}^{3}$ & $18.41 \mathrm{kN} / \mathrm{m}^{3}$ \\
Sat. VWC & 0.33 & 0.512 \\
Ksat & $7.2 \times 10^{-2} \mathrm{~m} /$ day & $2.09 \times 10^{-4} \mathrm{~m} /$ day \\
Gs & 2.64 & 2.8 \\
\hline
\end{tabular}

\section{PROBLEM SETUP}

Seepage deformation analyses can be performed using either a coupled or uncoupled approach. For these analyses an uncoupled approach was used wherein unsaturated flow was modeled separately from stress-deformation (heave) analyses. The results from the SV Flux flow analyses were used as input to the heave analyses performed using SV Solid. Initial (preconstruction) soil suction profiles were determined through a simulated $30 \mathrm{yr}$ period of 
application of a surface flux condition corresponding to Phoenix, AZ, climatic conditions as determined by Dye (2008). A steady state run was done to obtain the initial condition for stress-deformation analyses. Once the initial suction profile was determined for the natural expansive clay profile, a replacement layer of a certain depth (Figure. 2) is placed, and surface flux conditions associated with the roof runoff condition are applied. After several years of simulation of ponding of roof runoff next to the structure, the final (post construction) suction profile is obtained. The initial (preconstruction) and final (post construction) soil suction profiles are used as input into the stress-deformation analyses performed using SV Solid. Three different depths of top native expansive clay are removed and replaced with non expansive soil having a hydraulic conductivity two orders of magnitude higher than the native clay.

The different replacement depths are shown in Figure 2.

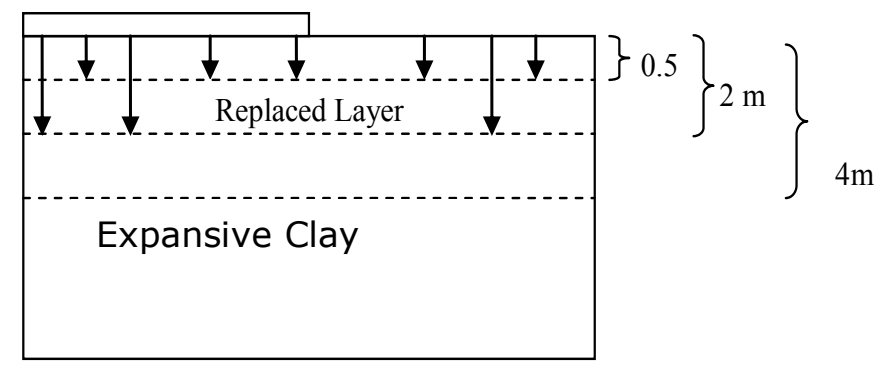

Figure 2. Replaced soil Profile

A mixed formulation (Celia 1990) of the seepage equation was used for the SV Flux analyses:

$$
\begin{aligned}
& \frac{\partial}{\partial x}\left[\left(k_{x}^{w}(\theta)+k^{v d}(\theta)\right) \frac{\partial h}{\partial x}\right]+ \\
& \frac{\partial}{\partial y}\left[\left(k_{y}^{w}(\theta)+k^{\nu d}(\theta)\right) \frac{\partial h}{\partial y}-k^{v d}(\theta)\right]=\frac{\partial \theta}{\partial t}
\end{aligned}
$$

The SWCC for the soil in this problem is defined by using the Fredlund and Xing fit (1994) which is given by the equation below:

$$
\begin{aligned}
& \theta_{w}=\theta_{s} C(\psi)\left[\frac{1}{\ln \left(e+\left(\frac{\psi}{a}\right)^{n}\right)}\right]^{m} \\
& C(\psi)=1-\frac{\ln \left(1+\frac{\psi}{h_{r}}\right)}{\ln \left(1+\frac{1000000}{h_{r}}\right)}
\end{aligned}
$$

where $\theta \mathrm{w}=$ volumetric water content at soil suction $\Psi ; \theta$ s $=$ saturated volumetric water content; $\mathrm{a}=\mathrm{a}$ material parameter which is primarily a function of air entry value of the soil in $\mathrm{kPa} ; \mathrm{n}=\mathrm{a}$ material parameter which is primarily a function of rate of water extraction from the soil once the air entry value has been exceeded; $\mathrm{m}=\mathrm{a}$ material parameter which is primarily a function of the residual water content; $\mathrm{hr}=$ suction at which residual water content occurs, $\mathrm{kPa} ; \Psi=$ soil suction

The SWCC curves for the native soil and replacement soil are shown in Figure 3.

A Leong and Rahardjo fit (1997) is used to describe the unsaturated hydraulic conductivity for this problem. The hydraulic conductivity curves (Fig 4) show a cross-over effect (Shackelford \& Nelson 1996).

$k_{(\psi)}=k_{s}\left[\ln \left(e+\left(\frac{\psi}{a}\right)^{n}\right)\right]^{-p m}$

where $\mathrm{n}=$ controls the slope at the inflection point; $\mathrm{m}=$ residual water content in the soil; $\mathrm{p}=$ different constant soil parameters; Ks $=$ saturated hydraulic conductivity

Wilson's limiting equation (1997) was used to obtain the actual evaporation. In order to avoid instability due to high spikes in evaporation from occurring, a gradient limit was applied.

$A E=P E\left[\frac{u_{v}^{\text {soil }}-u_{v}^{\text {air }}}{u_{v o}^{\text {soil }}-u_{v}^{\text {air }}}\right]$ 
where $\mathrm{u}_{\mathrm{v}}^{\text {soil }}$ is the actual vapor pressure at the soil surface, $\mathrm{kPa}$; $\mathrm{u}_{\mathrm{vo}}^{\text {soil }}$ is the saturated vapor pressure in the soil at the ground surface, $\mathrm{kPa} ; \mathrm{u}_{\mathrm{v}}^{\text {air }}$ is the vapor pressure in the air above the soil surface, $\mathrm{kPa}$.

\section{HEAVE ANALYSIS}

The soil heave was modeled using a suction volume change index. The equation showing the relationship

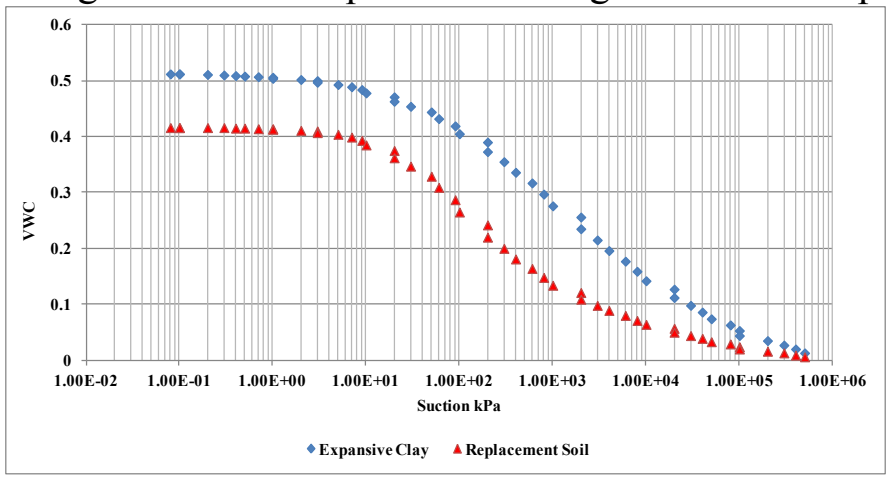

Figure 3. SWCC for Expansive and replacement soil

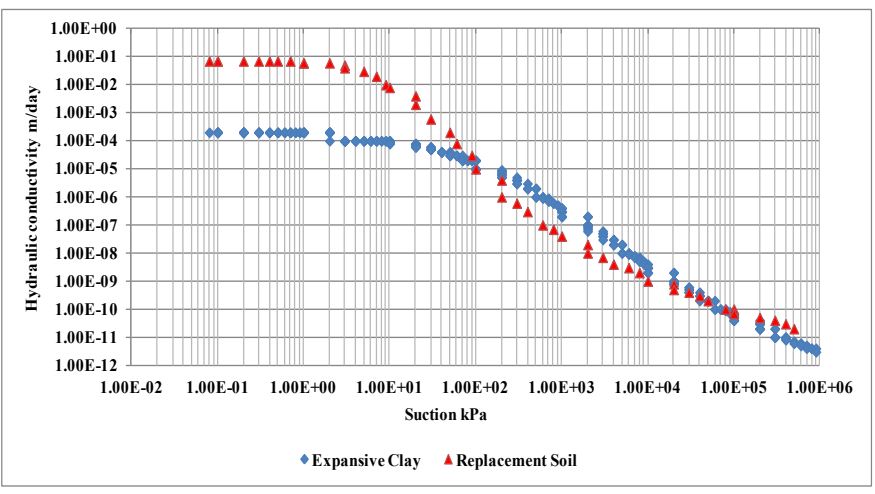

Figure 4. $\mathrm{K}_{\mathrm{unsat}}$ curves for Expansive and replacement soil

between volumetric heave and the suction volume change index follows (Fredlund \& Rahardjo 1993).

$\partial \varepsilon_{v}=m_{1}^{s} d\left(\sigma_{\text {mean }}-u_{a}\right)+m_{2}^{s} d\left(u_{a}-u_{w}\right)$

where $\sigma$ mean is the mean net normal stress $(\sigma 1+$ $\sigma 2+\sigma 3$ ) / 3; (ua-uw ) is the matric suction; $\mathrm{m} 1 \mathrm{~s}, \mathrm{~m} 2 \mathrm{~s}$ are volume change coefficients with respect to change in net normal stress and matric suction respectively. Similarly, the volume change can be obtained by associating the volume change indices with void ratio surface for different loading conditions, given by (Fredlund \& Rahardjo 1993)

$d e=C_{s} d \log \left(\sigma-u_{a}\right)+C_{m} d \log \left(u_{a}-u_{w}\right)$

The matric suction volume change index was input as a function of depth. As can be seen from Figure 5 where $\mathrm{Cm}$ (Volume change index with respect to matric suction) goes down with depth. This reduction in $\mathrm{Cm}$ with depth is due to reduced expansion potential as the confining stress approaches the swell pressure of the clay.

For the upper layer (low confinement), the swelling index for the expansive clay is 0.13 and the swelling index for the replacement layer is 0.05 (negligible since non expansive).A value of 0 cannot be used due to numerical instability in the results.

Table 2- Swelling Soil Properties for Expansive and Replacement soil

\begin{tabular}{llll}
\hline Soil & Poisson's ratio & $\mathrm{Cs}$ & $\mathrm{e}_{0}$ \\
\hline Higher $\mathrm{K}_{\text {sat }}$ & 0.35 & 0.05 & 0.99 \\
Expansive clay & 0.35 & 0.3 & 0.5 \\
\hline
\end{tabular}

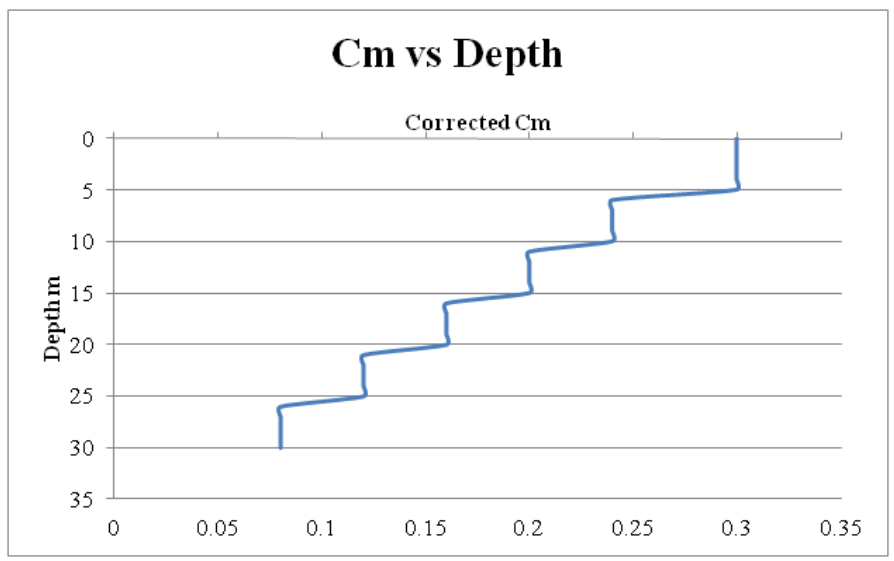

Figure 5. Variation of $\mathrm{C}_{\mathrm{m}}$ with depth for the natural expansive clay profile

For a 2D plane strain loading, the governing deformation Equations 8 and 9 are given by Hung \& Fredlund (2000). These PDE's are solved in SV Solid to obtain the final deformations in a stress deformation analyses. 


$$
\begin{gathered}
\frac{\partial}{\partial x}\left(c_{11} \frac{\partial u}{\partial x}+c_{12} \frac{\partial v}{\partial y}\right)+c_{33} \frac{\partial}{\partial y}\left(\frac{\partial u}{\partial y}+\frac{\partial v}{\partial x}\right) \\
-d_{s} \frac{\partial\left(u_{a}-u_{w}\right)}{\partial x}+b_{x}=0 \\
c_{33} \frac{\partial}{\partial x}\left(\frac{\partial u}{\partial y}+\frac{\partial v}{\partial x}\right)+\frac{\partial}{\partial y}\left(c_{12} \frac{\partial u}{\partial x}+c_{22} \frac{\partial v}{\partial y}\right) \\
-d_{s} \frac{\partial\left(u_{a}-u_{w}\right)}{\partial x}+b_{x}=0
\end{gathered}
$$

where bx and by are body forces in the $x$ - and $y$ directions respectively.

$c_{11}=c_{22}=\frac{(1-\mu) E}{(1+\mu)(1-2 \mu)}$

$c_{12}=\frac{\mu E}{(1+\mu)(1-2 \mu)}$

$c_{33}=\frac{E}{2(1+\mu)}$

$d_{s}=\frac{E}{(1-2 \mu) H}$

where $\mathrm{E}$ is the elasticity parameter for the soil structure with respect to a change in net normal stress; $\mathrm{H}$ is an elasticity parameter for the soil structure with respect to a change in matric suction; and $\mu$ is the Poisson's ratio for the soil structure.

\section{RESULTS}

The pore pressure (Figure. 6) and saturation (Figure. 7) results show that in arid regions the soil remains on the dry side even after a wetting event. . The higher conductivity replacement layer retard water infiltration by storing it during wetting and evaporating it during drying event.

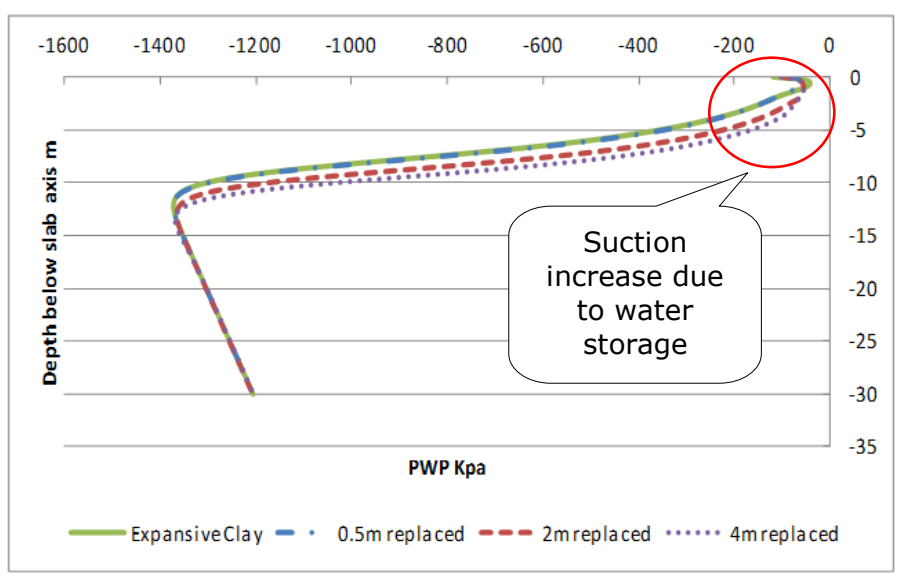

Figure 6. Pore pressure variation below slab edge

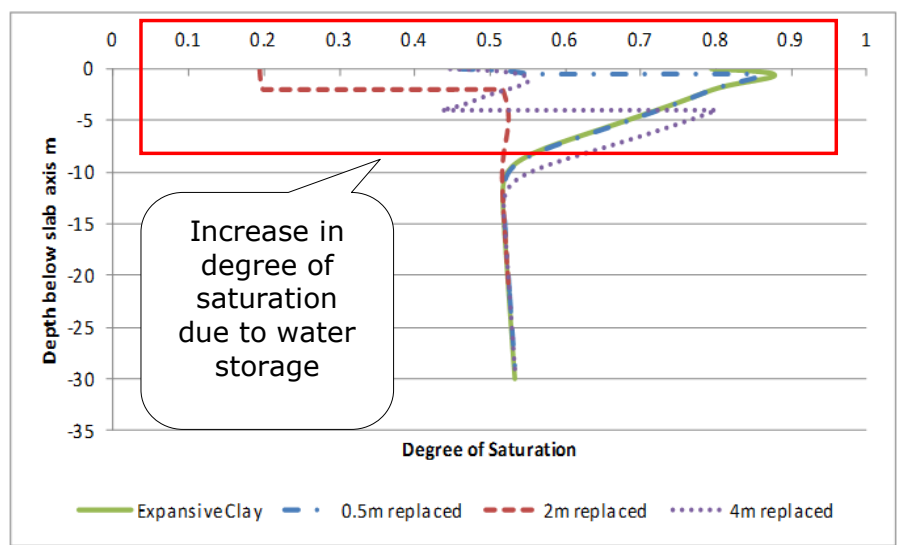

Figure 7. Saturation variation below slab edge

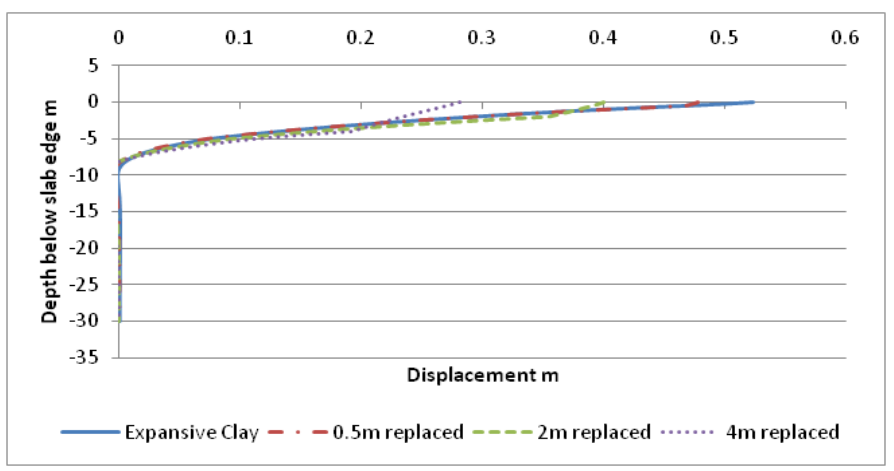

Figure 8. Displacement below slab edge 


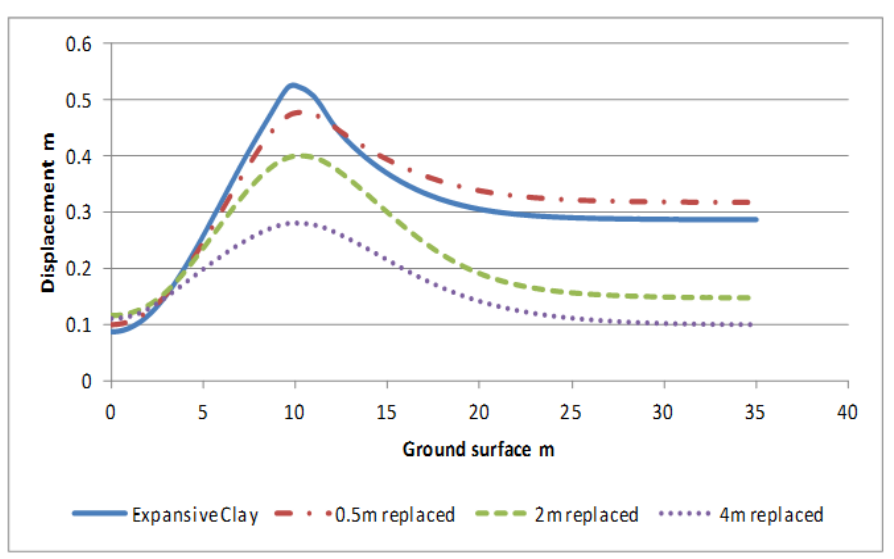

Figure 9. Heave at ground surface

\section{CONCLUSIONS}

It is evident from the displacement plots that there is a substantial decrease in heave at the surface (Figure. 8) with increases in the thickness of the upper portion of the soil profile replaced with a higher conductivity, less expansive soil. There is a significant reduction in the heave occurring on the ground and at the surface right next to the slab edge (Figure. 9) with increasing thickness of the replacement layer. This can lead to reduced differential movement and therefore less cracking and damage to the foundations of the structure. The higher conductivity layer at the top of the natural expansive clay is behaving like a sponge, due to its relatively high storage capacity, to hold onto water applied during rainfall events until it can be evaporated out from the replacement layer. The "sponge effect" of the non expansive layer traps the water while it is infiltrating and stores it for future evaporation during long non-rain periods. The function of the replacement layer can be compared to evapotranspirative (ET) covers used for landfills. The purpose of putting covers on landfills is to keep off water from infiltrating so that there is minimal leachate generation. The same principle applies to this case. The swelling is reduced in expansive soils because the surface layer can act to resist deep movement of water into the underlying clay profile for certain conditions of storage capacity, conductivity of replacement layer, and surface flux conditions.
In the case of arid and semi-arid climates, ET covers are superior to other cover systems. The typical thickness of ET covers used for landfill is $1.2 \mathrm{~m}$ to $1.8 \mathrm{~m}$. Typical values of saturated hydraulic conductivity for the storage layer of an ET cover are 1x10-4 and 1x10-5 cm/s (Kavazanjian Jr 2001). Sandy silt and silty sand have been found to be optimal soils for ET covers. Clayey soil however, does not give up water easily but it is also difficult for water to get into the tiny pores of clay material. Studies at Yucaipa landfill and Gaffey street landfill have shown that ET covers perform better than prescriptive covers for landfills (Evans et al. 2000).

The higher conductivity replacement appears to be a good option to reduce heave in arid regions. As mentioned before that this is an ongoing project, further cases are being studied. A comparative study is being done with different types of replacement soil options to obtain the optimal soil type. The best choice for replacement materials is expected to be site-specific, and dependent on climatic and irrigation conditions, as a minimum.

\section{ACKNOWLEDGEMENT}

This study was supported, in part, by the National Science Foundation (NSF) under grant number CMMI-0825089. The opinions, conclusions, and interpretations expressed in this paper are those of the authors, and not necessarily of NSF.

\section{REFERENCES}

Celia, M.A. \& Bouloutas, E.T. 1990. A General MassConservative Numerical Solution for the Unsaturated Flow Equation. Water Resources Research Vol. 26(7): 14831496.

Dye, H., Moisture Movement through Expansive Soil and Impact on Performance of Residential Structures, PhD Dissertation, Arizona State University, 2008.

Evans, T.M., Meyers, D.K., Gharios, K.M., Hadj-Hamou, H. \& Kavazanjian Jr, E. The use of a capillary barrier final cover for reclamation of a closed municipal solid waste landfill. Proceedings of the 3rd annual arid climate symposium, SWANA, New Mexico Chapter, 12-14 April 2000 Albuquerque.

Fredlund, D.G, \& Xing, A., (1994), Equations for the soilwater characteristics curve, Canadian Geotechnical Journal 31 (3): 521-532. 
Houston, S.L., Houston, W.N., Zapata, C.E. \& Lawrence, C. 2001. Geotechnical engineering practice for collapsible soils, Department of Civil and Environmental Engineering, Arizona State University, Tempe, Arizona, 85287-5306.

Katti, R.K. 1979. Search for solutions to problems in black cotton soils. First Indian Geotechnical Society Annual Lecture, Indian Geotechnical Journal 9-1: 1-88.

Kavazanjian Jr, K. Design and Performance of evapotranspirative cover systems for arid region landfills. $36^{\text {th }}$ Annual Western States Engineering Geology and Geotechnical Engineering Symposium, 28-30 March 2001 pp. 11-261, University of Nevada, Las Vegas: Nevada.

Leong, E.C. \& Rahardjo, H. 1997, Permeability Functions for unsaturated soils. Journal of Geotechnical and Geoenvironmental Engineering. ASCE 1118-1126.

Murthy, V.R. \& Praveen, G.V. 2008. Use of chemically stabilized soil as cushion material below light weight structures founded on expansive soil. Journal of materials in civil and materials, ASCE, May, Vol. ASCE08991561(2008)20:5(392).

Shackelford, C.D \& Chiu, T.F. The influence of the capillary barrier effect on the use of sand underdrains in waste disposal practice. R.N.Young and H.R. Thomas, Thomas Telford (ed.), Geoenvironmental engineering, contaminated ground: Fate of pollutants and remediation 357-364. London.

SoilVision Systems Ltd. 2008. SVFlux User's Manual. SoilVision Systems Ltd., Saskatoon: SK.

Vu, H.Q. \& Fredlund D.G. 2000. Implementation of soil Property Functions in Volume Change Analysis in Unsaturated Soils.

Walsh, K. D., Houston, S. L. \& Harraz, A. M. Finite Element Evaluation of Deep-Seated Swell. Proceedings, 4th AsiaPacific Conference on Unsaturated Soils, Nov. 2009 23-25. Newcastle: Australia.

Wilson, G.W., Fredlund, D.G., Barbour, S.L., 1997. The effect of soil suction on evaporative fluxes from soil surfaces, Canadian Geotechnical Journal 34(4): 145-155. 